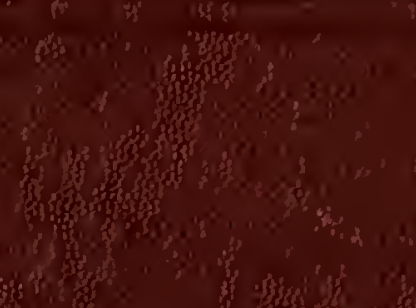

- 嗖

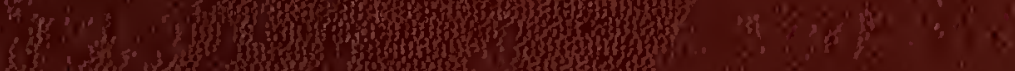

4 , s.

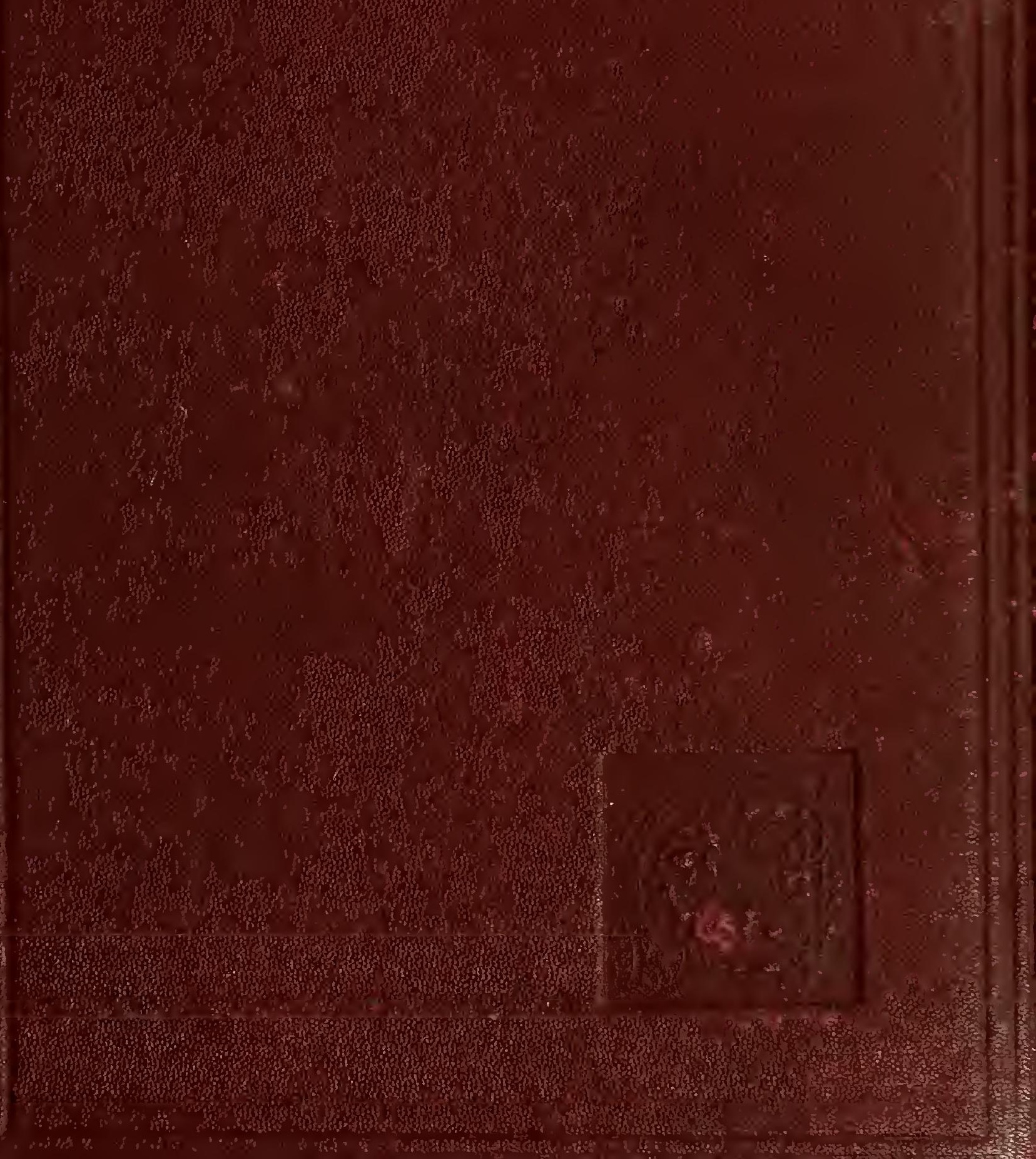





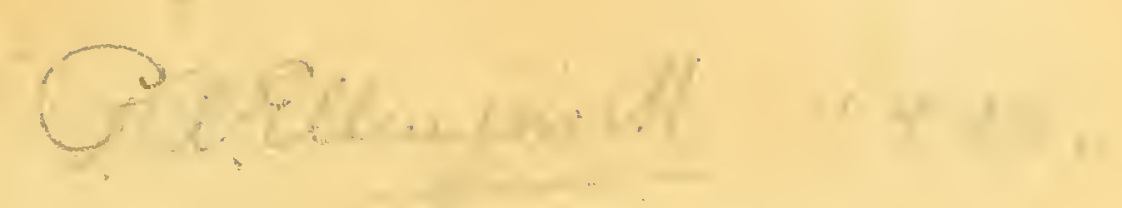





\section{ETHNOGRAPHY AND CONDITION OF SOUTH AFRICA \\ BEFORE A.D. 1505}






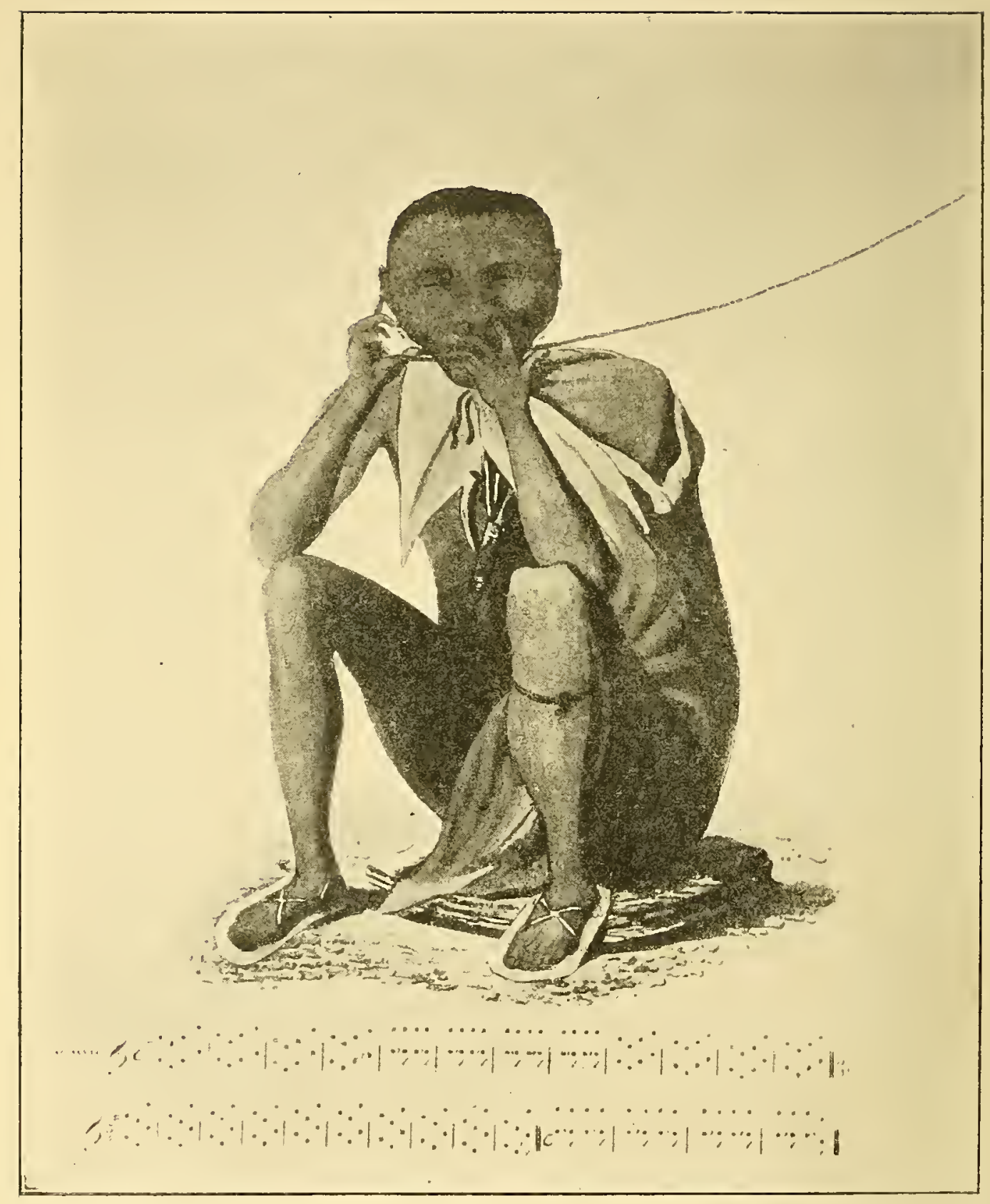

PORTRAIT OF A BUSHMAN PLAYING ON THE GORAH.

(From a Portrait by Witliam J. Burchell, Esqre.) 


\section{MAA \\ ETHNOGRAPHY AND \\ CONDITION OF SOUTH AFRICA}

BEFORE A.D. 1505

BEING A DESCRIPTION OF THE INHABITANTS OF THE COUNTRY SOUTH OF THE ZAMBESI AND KUNENE RIVERS IN A.D. I 505

TOGETHER WITH ALL THAT CAN BE LEARNED FROM ANCIENT BOOKS AND MODERN RESEARCH OF THE CONDITION OF SOUTH AFRICA FROM THE EARLIEST TIME UNTIL ITS DISCOVERY BY EUROPEANS

BY

GEORGE McCALL THEAL, Litt.D., LL.D.

SECOND EDITION IN THE PRESENT FORM (ILLUSTRATED), ENLARGED AND IMPROVED

SMITHSONIAN

AUG 021985

LIBRARIES

LONDON

GEORGE ALLEN AND UNWIN, LTD. RUSKIN HOUSE, 4O, MUSEUM STREET, W.C. 


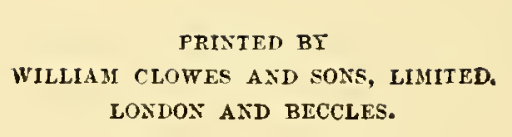




\section{PREFACE.}

THIs volume is a necessary preliminary to my detailed History of South Africa from 1505 to 1884, and indeed may be regarded as the nearest approach that is possible to a history of the country before 1505. Discoveries may yet be made which will throw a stronger light upon the distant past, but at present nothing more can be ascertained than is here placed on record. The book is the result of many years' close application to the study of the subject it deals with.

GEO. M. THEAL.

WYNBERG, SOUTH AFrica,

October, 1918. 



\title{
CONTENTS.
}

\author{
CHAPTER I. \\ The Bushilen or Aborigines of South Africa.
}

Recent discoveries concerning man in early times.-Antiquity of man in South Africa.-Great shell mound at East London.The Ancicnt Shellmound Men.-Positions in which ancient stone implements arc found.-Slow progress in knowledge of man in a savage state.-Physical features of South Africa.Civilising effects of hunger, diseasc, and war.-Conjectures as to the primeval home of the Bushmen.--Similarity of the Bushmen to the palæolithic pigmies of ancient Europe-Evi. dence of their wall paintings.-Points of resemblance between the Bushmen and the Semang.-Probablc cause of their difference in eolour.-Occupation of the African continent by the Bushmen.-Usc made of a Bushman by an ancient Egyptian king.-Mention of the Bushmen by the Greek historian Hero. dotus.-Discovery of engravings on rock in Northern Africa by Dr. Barth and others. - Migration of various races into Africa. -Extermination of the Bushmen in the greater part of the continent.-Doubtful existence of other people in Africa beforc the Bushmen.-Notes on treatises on stonc implements.Note upon the glacial period in Enrope . . . . .

\section{CHAPTER II.}

The Bushuen (continuel).

Condition of primitive inan.-Negleet of the study of the Bushmen by the first European eolonists.-Information concerning the Bushmen given in official records and by various individuals.Language of the Bushmen.-Researches by Drs. W. H. I. Bleek and L. C. Lloyd.-Causc of the loss of their language by the 
surviving Bushmen.-Territory occupied by the Bushmen before the invasion of the Hottentots and the Bantu.-Skull measurements of these people.-Territory occupied by the Bushmen after the invasion.-Constant war between the different peoples. - Adoption of Bushman girls by the invaders

\section{CHAPTER III.}

\section{The Bushuen (continued).}

Habitations of the Bushmen.-Food.-Weapons.-Use of poison.Stone implements.-Clothing.-Modes of attacking enemies.Cause of their being feared by the Bantu.-Ornaments used by the Bushmen.-Method of procuring fire.-Formation of little independent communities.-Prolific nature of the Bushmen.Character of individuals.-Physical characteristics.- Want of govermment.-Domestic life.-Nusical instruments.-Fondness for dancing. - Games. - Ordinary life. - Manufactures. - Superstitions.-Intense credulity.-Mythological ideas.-Mode of interment of the dead.-Power of mimicry.-Personal conceit.Artistic powers.-Engravings on rock.-Sense of locality.Animal happiness.-Specimens of traditional stories.-Incapacity of adopting European civilisation.-Failure of efforts made to improve the Bushmen.-Almost utter extinction of the race.Description of the Katia.-Degradation of these people .

\section{CHAPTER IV.}

The Hottentots or hïhoikhor, termed by the Bantu of the

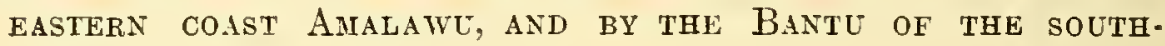
WESTERN COAST OVASERANDU.

Arrival of Hottentot immigrants in South Africa.-Researches of Dr. Bleek and of the reverend Mr. Adamson in the Hottentot language.-Discoveries by Mr. G. W. Stow.-Probable early home of the Hottentots.-Line of migration followed by them. -Conflicts with Bushmen on the way.-Incorporation of Bushman girls by the Hottentot horde.-Formation of Hottentot tribes independent of each other.-Extermination of the Bush. men who lived on the proceeds of the sea.-Migration along the southern coast.-Mode of settlement of the Hottentots.- 
Constant war with the Bushmen.-Differences in appearance between Hottentots and Bushmen.-Language of the Hotten. tots.-Its gradual extinction.-Mode of formation of the titles of different tribes.- War between the tribes.-Form of government of the tribes.-Domestic cattle of the Hottentots.-Food of the Hottentots.-Clothing.-Personal ornaments.-Habitations.- Weapons of war and the chase.-Earthenware utensils .

\section{CHAPTER V.}

The Hotтentots or Кногног (continued).

Impoverished Hottentots living on the coast as beachrangers.Their methods of catching fish.-Contents of the modern shell mounds.-Particulars concerning the people so living.-Modern shell heaps made by Bushmen.-Mixture of Bushman blood in the poorest Hottentots.-Superstitions of the Hottentots.Their dread of ghosts.-Their religion.-Tales of Heitsi-eibib. - The graves of Heitsi-eibib.-Disposition of the Hottentots.Their fondness for dancing by moonlight.-Musical instru. ments.-Division of labour between men and women.-Filthi. ness of the Hottentots.-Their good qualities.-Apparent cruelty to helpless persons.-Domestic life.-Marriage customs. -Information obtained by Captain Alexander.-Credulity of the Hottentots.-Position of their women.-Evidence of Dr. Theophilus Hahn.-Strange custom of some clans of initiating boys into manhood.-Power of imagination of the Hottentots. -Their evening amusements.-Favourite game.-Comparative happiness.-Capability of adopting European civilisation.Fondness for intoxicating drink.-Mixture of blood with other peoples.

\section{CHAPTER VI.}

\section{Specinens of Hottentot Folklore.}

The Animals and the Dam of Water.-The Iion that took a Woman's shape.-Story of the Hare.-The Lion and the Jackal.-The Ram, the Tiger, and the Jackal.-The Lion's Defeat.-The Dove and the Heron.-The Elephant and the Tortoise.-The Flying Lion . . . . . . 


\section{CHAPTER VII.}

The Dafk-Skinked People termed by Europeans the Banto.

Feason of the importance of a study of the Bantu.-Origin of the people so called.-Cause of the great variation betwcen different tribes.-Principal line of advance of the Bantu.-Commerce on the Indian ocean in early times.-Articles of value to be obtained in Eastern Africa in olden times.-Traffic of the Islaelites and the Phœnicians on the Indian ocean.-Lack of information from Phcenician sources.-Destruction of Tyre and rise of Alexandria.-Knowledge of black people possessed by the Greeks in the Homeric age.-References by Homer to the pygmies.-Reverence of the Greeks for the Homeric poems.Knowledge of black people possessed by Herodotus.-Improbability of the circumnavigation of Africa by the Phœnicians.-Exploration of the western coast a long way down by a Carthaginian fleet under Hanno.- Knowledge of Africa possessed by Aristotle.-Commerce on the Indian ocean in the time of Alexander the Great.-Exploration in the time of Ptolemy Philadelphus.-Information supplied by Strabo.-Extension of commerce on the Indian ocean by Europeans.Innowledge of the monsoons acquired by Hippalus . . .

\section{CHAPTEF VIII.}

\section{The Bantu (continued).}

Information given in the Periplus of the Erythrian sea.- Know. ledge of Africa possessed by Pliny the elder.-Information given by the astronomer and geographer Ptolemy.-Arab and Persian settlements along the eastern coast of Africa.-The work of Abou Zeyd Hassan.-The great work of Abou'l Haçan Ali el Masoudi.-Origin of the name Delagoa Bay.-Articles of barter obtained from the Bantu.-Extension of the Bantu as far south as Sofala.-Cause of the inigration.--Occupation of the country south and west by Bushmen only.-The work of Abi l'Cassem Abdallah Ebn Haukal.-The great work of Abou Abdallah Mohamed el Edrisi.-Exportation of iron and gold from Sofala.-The work of Aboulfeda.-The work of Abou Abdallah Nohamed, commonly known as lbn Batuta.-Descrip. tion of Kilwa and its ruler. . . . . . . . 
CHAPTER IX.

Setthement of Bantu Tribes sooth of the Zambesi and

KunENE RIVERS.

PAGE

Extent of the territory of Sofala.-Arrival of the ancestors of the Bakalahari and the Balala of our day.-Mode of settlement of these people.-Origin of the Masarwa.-Arrival of the Leghoyas.-Conduct of the Leghoyas towards the earlier immigrants.-Arrival of the Batlapin and Barolong.-Puelentless warfare with the Bushmen.-Changes in the climate.-Arrival of the Bakwena.-Wars between the different tribes.-Arrival of the Bavenda.-Subsequent career of the Bavenda.-Arrival of the Bakwebo.-Migration of the Bataung to the Vet river. - Settlement of many Bakwena clans along the upper Caledon. -Breaking up of the Karanga tribe.-Arrival of the Barotsi.Arrival of the Batonga.-Arrival of the ancestors of the coast tribes below Natal.-Arrival of the Amazimba and Abambo hordes.-Settlement of the Abambo in Natal.Particulars concerning the Amazizi.-Breaking up of the Abambo horde into numerous tribes.-Information obtained from the Portuguese.-Account of the Umtetwa.-Destruction of the farthest advanced Hottentot tribes by the Bantu. -Extermination of the Bushmen in the territory occupied by the Bantu.-Account of the Berg Damaras.-Arrival of the Ovaherero in Damaraland.-Conflict between the Ovaherero and the Hottentots.-Subdivisions of the Ovaherero.-Account of the Avare or Ovambo group.-Treatment of the Bushmen by these people.-Origin of the title Bantu.-Effect of the hlonipa custom. - Differences between the tribes.-Their classification in three groups.-Note on Sir Harry Johnston's account of the devastations in the sixteenth century . .

\section{CHAPTER X.}

General Description, Form of Governient, and Religion of THE Bantu.

Information obtained from the Portuguese.-Cause of the differences between the tribes.-Effect of atavism.-Characteristics of the Bantu in general.-Personal appearance.-Disposition of the men.-Robust constitution of the people.-Prolific nature of the people.-Rates of increase according to census returns.- 
Form of government of the tribes.-Military despotism.Patriarchal rule.-Position of the members of ruling families. -Position of the common people.-Checks upon arbitrary rule.-Law of succession to the chieftainship.-Manner of formation of new tribes.-Position of the chief in the life of the people.-Standard of virtue of the Bantu.-Form of oath.- Revenue of the chiefs.-Charges upon the government.Ancestral spirit worship.-Sacrifices to the spirits of the dead.-Vague nature of this belief.-Ideas conceming death.Form of burial of chiefs.-Funeral customs of the Ovaherero. -Slaughter of attcndants on the death of a great military ruler.-Xosa belief in Qamata.-Reason for certain animals being regarded as sacred.-Meaning of the word siboko.-Cause of some tribes having more than one siboko.-Mode of formation of many tribal titles.-Belief in hobgoblins and water spirits.-Belief in wise people living under the water.-Regard paid by some of the tribes to fire.-Views regarding the origin of life and death.-Unlucky days.-Rejoicing over the appearance of a new moon.-Ceremony after the gathering of crops.Duties of the tribal priests.-Influence of religion on the government.-Belief in witchcraft.-Demented seers.-Phallic charms.-Note on brother-sister marriage . . . . .

\section{CHAPTER XI.}

Superstitions and Customs of the Banto.

Profession of Rainmakers.-Herbalists.-Method of drawing blood.Surgical operations.-Use of charms.-Divination attended by revolting cruelty.-Superstitious customs of the interior tribes. - Superstitious use of a skull.-Hereditary belief in witchcraft. - System of common law and tribunals of justice.-Communal responsibility.-Form of lawsuits.-Modes of punishment.Trials for dealing in witchcraft.-Trials by ordeal.-Mode of reckoning time.-Preservation of traditions.-Official praisers. -Dynastic titles.-Mode of naming individuals.-Circumcision of lads.-Corresponding rite for girls.-Form of marriage.Position of women.-Marriage festivities.-Preliminary arrangements for a marriage.-Restrictions as to the females a man of the coast tribes might marry.-Greater liberty of men of the interior tribes.-Marriages of the Ovaherero.-Revolting custom of the Malkaranga.-Custom of a childless woman.-Custom 
regarding divorces.-Cause of numerous lawsuits.-Authority of the oldest maternal uncle over children.-Lack of chastity among the Bantu.-Advice given by Motlomi to Moshesh .

\section{CHAPTER XII.}

Description of the Bantu (continued).

Productions of Bantu gardens.-Manufacture of millet and honey beer.-Use of dacha.-Rapid spread of tobacco.-Modes of preserving millet.-Lack of frugality among the Bantu.--Extensive use of wild plants.-Use of flosh and fermented milk.-Limited use of fish.-Method of hunting.-Usc of locusts as food.Practice of cannibalism.-System of land tenure.-Law of trespass.-Destruction of trees.-Position of kraals.-Style of habitations.-Training of oxen.-Law of inheritance.-Advantages of polygamy to a people like the Bantu.-Weapons of war. - Military organisation. - Clothing of the people.-Ornaments of the person.-Attention paid to the hair.-Manufactures of wood, iron, and copper.-Doubtful knowledge of bronze.-Other industries.-Preparation of skins for clothing.-Manufacture of earthenware, baskets, mats, and grass bags.-Use of stone.Habits of the men.-Persistency in begging.-Comparison of the interior tribes with those on the coast.-Lack of veracity.Power of deception.-Institution of slavery.-Chcerfulness of the women.-Ordinary life of the women.-Evening amusements. - Games of children.-Toys of children.-Forms of greeting .

\section{CHAPTER XIII.}

Description of the Bantu (continued).

Language of the Bantu.-Specimens of Xosa proverbs.-Mention of poetry and musical instruments.-Mental capacity of the Bantu. -Evidence of numerous qualified individuals on this subject

\section{CHAPTER XIV.}

\section{Specimens of Bantu Folislore.}

Actors in Bantu stories.-Nature of the stories.-Great age of some of the stories.-Story of Long Snake.-Story of Little Red Stomach.-Story of Five Heads. - A more complete story of 
Five Heads. - Story of the Bird that made milk. - Serolong version of this story. - Story of the girl that disregarded the custom of ntonjane. - Story of Simbukumbukwana. - Story of Sikulume.-Story of the Cannibal's wonderful bird.-Story of the cannibal mother and her children.-Story of Mbulukazi

\section{CHAPTEP XV.}

Specimens of Bantu Folklore (continued).

Story of Hlakanyana.-Story of Ironside and his Sister.-Story of the Glutton.-Story of Tangalimlibo.-Story of the Runaway Children or the Wonderful Feather.-Story of Kenkebe.Another story of Kenkebe.-Story of the Great Chief of the Animals.-Story of Demane and Demazana.-Story of the Girl and the Mbulu. -Cause of a change of phraseology in folklore tales.-Story of the unreasonable Child to whom the Dog gave its Desert; a Herere tale corresponding to an incident in the Story of Hlakanyana.-Probable origin of these tales .

\section{CHAPTER XVI.}

\section{RAPID INCREASE OF THE Bantu IN NUMBer.}

Condition of the Bantu tribes when first met by Europeans.-Remarks upon slavery.-Prolific nature of the slaves in America. -Increase of the Balala in Betshuanaland.-Condition of the slaves exported from the West African coast.-Sir H. Johnston's theory as to the time of the extension of the Bantu.Dr. Bleek's researches.-Mr. J. F. van Oordt's work.-Evidence of the Bantu religion.-Disappearance in other countries of the uncivilised inhabitants in presence of European colonists.-Effects of the introduction of small-pox and consump. tion.-Cause of the enjoyment of good health by the Bantu. -Removal of all the checks upon rapid increase in number. Amazing rate of increase of the Bantu.-Comparisons with the people of other countries.-Replies to questions put to officials and others in the territories occupied by the Bantu.-Spread of disease in recent year's.-Greater intensity in the struggle for existence at the present time.-Loss by the Bantu of nearly all their cattle from rinderpest and other diseases.Necessary substitution of new kinds of food.-Effect upon the people.-Diminution in the rate of increase. 


\section{CHAPTER XVII.}

Other Inhabitants of South-Eastern Africa than Bushmen, Hottentots, and Bantu Before 1505.

Temporary occupation in remote times of part of South Africa PAGE by people well advanced in civilisation.- Extensive gold. mining operations carried on by them.-Relics of their skill.Construction of enormous stone buildings by them.-Description of Great Zimbabwe.-Entire disappearance of the miners and builders.-Reoccupation of the same territory after a long interval by other partly civilised people.-Great difference between their culture and that of the earlier occupants.Their industry along the Inyanga range.-Investigations of ruins by archæologists.-Mysterious disappearance of the strange people.-Total absence of any influence exerted by these people upon the Bushmen or the Hottentots.-Possible effect of their work upon some of the interior Bantu.-Extent in 1505 of the Bantu occupation.-Mohamedans in South Africa. -Condition of these people.-Particulars concerning them.Classes of inhabitants south of the Zambesi in 1505 



\section{LIST OF ILLUSTRATIONS.}

Bushmen playing on the Gorah . . . . Frontispiece

From a Portrait by William J. Burchell, Esqre.

Bushman Digging Stick . . . . . . . . Page 24

Engravings by Bushmen on Boulders near Lydenburg

From Photographs kindly sent to me by Dr. Pyper, of Lydenburg.

Picture of an Eland . . . . . . . . . $\quad " \quad 25$

One of the best Bushman pictures. From a cavern in the Kathlamba mountains.

Photograph of a Bushiman Girl • • . • • ,

Engraving of a Zebra on a Rock in the District of

VRYBURG • . • . • . • • •

From a Photograph of a cast in the South African Museum in Capetown. The original is thirteen inehes in length.

Portrait of a Male Adult of the Katia

Taken by Miss D. Bleek in the Kalahari, and very kindly supplied to me by her for publication in this volume.

Portrait of a Hottentot . . . . . . . •

Copy of Le Taillant's Portrait of his faithful Klaas.

The headdress and the strings of beads are European additions to the costume, otherwise the portrait is an excellent one.

\section{A Hottentot Hut}

From a Drawing by William J. Burehell, Esqre.

Hottentot Weapons of TVar and the Chase . . .

From a Drawing by William .J. Burchell, Esqre.

Portrait of the famous Hottentot chiff Jan Jonker

Afrikaner, in European Dress . . . .

From a Photograph in the South African Public Library.

Portrait of a Hottentot Woman, the wife of Jan JoNkER AFrikaner, SHOWING Strong traCES OF Bushman Blood, in European Dress . . . From a Photograph in the South Afriean Public Library. 
Group of Xosa Children . • • • • . . . Page 182

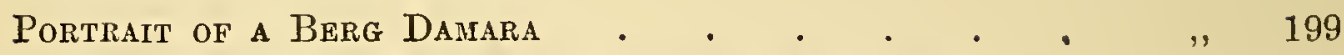

From a Photograph in the South African Public Library.

Portrait of Moshesh, the Founder of the present Basuto Tribe, in European Dress . . . . " "

From a Photograph in the South African Public Library.

Moshesh was the most intelligent Bantu chief ever known in South Africa.

Bantu Girl of High Rank. . . . . . . " , 208

Tembu Woman axd Girl • • • • • . . " " 238

Abakweta or Boys recently Circumcised . . . " " 251

Xosa Girl in Dancing Costume. . . . . . . " 255

From a Photograph in the South African Public Library.

Bamajgwato Battle Axes . • . . . . . „ " 266

Hut of the Bantu of the Interior . • . . " 275

From a Drawing by Hilliam J. Burchell, Esqre.

Herero Women in Full Dress . . . . . . " 281

From a Photograph in the South African Public Library.

Jar manufactured by a Bapedi Woman • • . . , 290

Woman of the Basuto Tribe • • • • . • " 299

Part of the outer Wall of Great Zimbabwe . . " " 415

The Cone in Great Zimbabife • . • . . . " 421 


\title{
ETHNOGRAPHY OF SOUTH AFRICA
}

\author{
CHAPTER I.
}

Early Inhabitants of South Africa, termed by Europeans Bushmen, by Hottentots Sana, by Bantu of the EAstern COAST ABatwa, of the Western coast Oratwa, of the interior Baroa.

Since the commencement of the twentieth century a great advance in our knowledge concerning the early savage inhabitants of South Africa as well as of Europe has been made through discoveries of their implements and other handiwork, coupled with remains of their skeletons found where they were buried. In Europe the successive advances and retreats of the great sheet of ice that once covered the whole of the northern and central parts of that continent, as Greenland is covered to-day, afford means for classifying in order of time the various races that once lived there, and the implements they used furnish proofs of the different stages of knowledge they had reached. South Africa, owing to its geographical position, has not been covered with ice since man first made his appearance here, or in other words since the pliocene or termination of the tertiary period as termed by geologists. There must have been great variations of climate, but these were insufficient to compel man to remove altogether from any locality to another far distant. We have here therefore a more unbroken chain of race, not as in Europe one race disappearing and another quite different taking its place, or possibly two very dissimilar races existing near each other at the same time.

It is not possible to state in years, or in centuries, or even in millenniums, the length of time that man has existed 
in South Africa, nor is it possible to determine with any degree of accuracy whether he has lived in this part of the world as long as in Europe, though the most primitive of stone implements, the one which Professor Sollas has named the boucher, is found in abundance here, and indeed all over Africa, as well as there.* By the word man is meant a being capable of communicating his thoughts by speech, understanding the use of fire, and able to make implements, however crude, of wood or stone. That such a being roamed over South Africa from an exceedingly remote period is absolutely certain from the situations in which many of his implements are found, and the crust termed the patina which has formed upon them.

The ancient mounds of shells along the seacoast are usually regarded as furnishing one proof of this fact. The first of these that was examined carefully was a heap formerly to be seen in a cave at Mossel Bay, which was for some years regarded as a curiosity more than as a record of the existence there of man at some distant period. It was even held by some amateur investigators that the shells had been brought there by seabirds. More recently many other mounds have been discovered, among them one on the left

* This implement was at first made of oval or egg-shaped waterworn stone of any size from six or seven to nine or ten centimetres in diameter, by striking or chipping off one side diagonally, so as to producc a cutting edge. The round end opposite the edge could then be held in the hand, when the stone could be used as a cleaver or hacker, possibly as a weapon of offence or defence, or for various other purposes, such as extracting bulbs from the ground, cutting notches in trees to assist in climbing, or breaking into beehives. Very little skill was required to form such an implement, which it is generally believed was the first and for a very long period the only tool for every purpose used by man. It is found in all parts of the habitable world except Australia. Professor Sollas named it the boucher after Boucher de Perthes, who was the first to call attention to the implement. In course of time it was improved until it assumed the shape of an almond, and the best specimens were trimmed by chipping on both sides. At this stage it was frequently made of a piece of stone broken off a rock, 
bank of a tributary of the Buffalo river at East London. Its discovery was dus to the opening of a way to a quarry, for it had the semblance of a natural hill, being covered with a deep layer of vegetable soil, in which trees and shrubs were growing; and this appearance it had presented as far back as could be traced. Upon examination-which was very thorough, as over thirty-two thousand cubic metres of it were removed to fill a lagoon-it was found to consist of a mass 45.72 metres or one hundred and fifty English feet long and 12.19 metres or forty feet deep, composed of oyster, mussel, cockle, periwinkle, and other shells, mixed with bones of animals of various kinds, ashes, and pieces of coarse pottery. A very few stone implements were found in it, but stones showing the action of fire were common.

This mass of shells must have been collected by a small community, for a large number of people could not have existed at the same time upon the food obtainable within walking distance. It must have been abandoned several hundred years at the lowest estimate, to allow time for dust and sand to be blown over it, and plants to grow and decay, until at length vegetable mould half a metre in depth was formed, sufficient to support large shrubs and trees. Some pestilence may have destroyed the whole of the people who obtained subsistence there, or they may have been attacked and killed by men of their own race who lived by hunting wild animals, or they may have existed until the arrival of Hottentot immigrants some time about the year 1400 of our era, when they would certainly have been exterminated. The cause of the abandonment of the mound is thus conjectural, and all that can be asserted concerning it is that it cannot have been more recently than A.D. 1400, and may have been many centuries earlier. Of the length of time required for the collection of such a vast mass of shells no estimate whatever can be made.

The other mounds composed of shells and refuse that have been discovered along the South African coast are exactly similar to the one at East London in character, 
though not usually so large. It is only by accident that they are found, for on the surface of the undulating soil there is no indication of their existence. They are turned to account by farmers at the present day, who use their contents as fertilisers for cultivated ground. In Europe, notably along the coast of Denmark, similar mounds have been exposed, and are there termed kitchen middens, a name that might also be used here. It would be convenient if the people who lived so largely upon shellfish had a distinctive name given to them, for the word strandloopers (beachrangers), applied to them by some recent writers, causes much confusion. That word was used in the middle of the seventeenth century by the first Dutch settlers in South Africa to denote a very different class of people, an impoverished people of mixed Hottentot and Bushman blood, speaking the Hottentot language and whenever possible following Hottentot customs, who from dire necessity were reduced at times to eke out a miserable existence in the same manner as the far more ancient men of the shell mounds, and it has since been commonly used in history to signify them alone. The others-those alluded to in this paragraph-were beachrangers, it is true, but that was their normal mode of existence, and to distinguish them from the very different beachrangers of recent times I propose to term them the Ancient Shellmound Men.

The mounds referred to, however, may have had their origin at a time not exceedingly remote, for those who have examined them carefully have found no apparent change in the physical features of the country since the earliest deposit was made. The shore was then where it is to-day, though the rocks along it may have undergone some slight alteration of form from the action of winds and waves. Much older are various stone implements shaped by human hands, which have been found in situations where they must have lain undisturbed for an incalculable length of time. For instance, they have been picked up in gravel washed by $\Omega$ stream into a recess when its bed was more than twelve 
metres higher than it is at present; in localities where considerable changes in the contour of the surface must have taken place since they were deposited; and at great depths in æolian rock, where bones of animals and shells are also found.*

How long the boucher continued to be used cannot be ascertained, but at length better implements were formed. Possibly the first inhabitants had evolved by themselves something superior, or another section of people, having made an advance in knowledge somewhere else, migrated slowly to South Africa, and established new industries here. From this time forward the implements were formed, not of oval water-worn stones, but of pieces broken off a rock and then chipped into the required shapes. It might be a spearhead that was needed, or a scraper, or a chopper, or something to serve as a knife, all these could now be made. The arrowhead can hardly date back as far, for it implies a knowledge of the bow, an implement which must have been the product of much thought. But if the advance is due to immigration, not to native growth of knowledge, the bow may have been brought here by the newcomers, and the stone arrowheads found in great abundance be as ancient in South Africa as the knife or the unhafted axe.

* See the paper on The Antiquity of Man in South Africa, by George R. Mackay, Esqre., in the pamphlet No. 2 of Belangrijke Historische Dokumenten, published by me in Capetown in 1896. See also the numerous proofs given by Mr. G. W. Stow in his volume on The Native Races of South Africa, edited by me, and published in London in 1905. The most important volume on the subject yet published is The Stonc Agc of South Africa as represented in the Collection of the South African Museum, by L. Peringuey, D.Sc., Director of the Museum, a book of two hundred and eighteen pages 1.78 by 102 millimetres in size, with many inset plates and twenty-eight pages containing two hundred and eleven illustrations, published in London and Capetown in 1911. It was prepared by a man thoroughly qualified for writing it, one who has brought the anthropological section of the museum to its present high standard of usefulness. Dr. Peringuey is of opinion that the sarages who made and used the earliest known stone implements had their first home in Africa and spread thence into Europe. 
None of them were ground or polished, as chipping comprised all the labour that was bestowed upon them. They were the products of the skill of man still in a very low stage of his existence. Workshops where they were manufactured have been discovered in various places, and to some of these the raw material, or unchipped stone, must have been brought from a considerable distance. The artisans may have lived there permanently, or, what is more probable, some superstition may have been connected with the localities. At these factories a quantity of stone from which flakes have been struck, some raw material, a very few finished articles, and a great many broken ones usually lie wholly or partially hidden by drift sand or mould, and it is generally by accident that they are discovered. They prove that already man had learned the lesson of the value of a division of labour, for it can be taken for certain that every one was not his own manufacturer, but that only the most skilful were employed in making the best-formed tools.

The implements used at this stage of man's residence in South Africa were almost as well fashioned as those of the people termed by us Bushmen were found to be when Europeans first visited the country, so that it is reasonable to assume that the race was continuous, especially as no indications can be found of any subsequent intrusions until the arrival of the Hottentots and Bantu only a few centuries ago. Several improvements, though with one exception trifling, are observable, but no race, however backward, can continue to exist for an enormously long period of time without making some progress in lnowledge and in manufactures. The stone implements therefore became gradually more varied and a few of them were more nicely finished, bone came into use for some purposes, and the spherical perforated stone, which shows the greatest advance of all, and which is not found with any of the early tools, was invented. Thus there was progress, though exceedingly slow, during the countless centuries that passed away. 
In the earliest stages of man's development three principal causes must have operated in forcing him to think: hunger, disease, and war. These were the elementary factors of civilisation. In favourable localities in other parts of the world commerce, as a powerful factor, came at a later period, but in South Africa that stage was not easily arrived at.

This is apparent if the physical condition of the country be considered. The land rises from the ocean level in terraces or steps, until a vast interior plain is reached. Deep gorges have been worn by the action of water, in some places internal forces have caused elevations, in other places depressions, and everywhere along the margins of the terraces distortions may be seen. There are no navigable rivers, and the coast is bold and unbroken. The steep fronts of the terraces, which from the lower side appear to be mountain ranges, and the absence of running water in dry seasons over large surfaces, tended likewise to prevent intercourse between the different parts of the country. The rude people of each section were left to themselves, without that stimulus to improvement which contact with strangers gives. There was very little necessity to exert the mind to provide clothing or habitations, for since the close of the ice period in Europe and the corresponding fluctuations of temperature in the southern hemisphere the climate has been uniformly mild, and even on the elevated interior plain snow never lies long on the ground. Like the wild animals, man on occasions of severe weather could find some temporary shelter. In this respect a savage is far more callous than a civilised man.

Hunger must have forced him to think, to plan the destruction of game, to search for edible plants, and to reject those that were noxious; but after becoming acquainted with the flora in his locality and with the use of poison in the chase, that factor would lose much of its potency. The cultivation of the ground or the domestication of animals could no more enter the mind of a savage in the palrolithic stage than into that of a child learning to walk. Disease would compel him to think, but only in an exceedingly 
slight degree when compared with a modern European, for his ailments were few and were in general attributed to witcheraft. War, whether against his fellows or the powerful carnivora, would be a more important factor in obliging hirn to exercise his mind, and to it was probably due the gradual though tardy improvement in his weapons by the selection of harder stone* and by fashioning them more carefully. But slow indeed was the progress in cultivation from the hunter who used the stone weapons of early times to the Bushman who shot his bone-tipped arrow at an antelope at the beginning of the nineteenth century.

Where the race of savages who occupied this country so long, the race now termed the Bushmen, had its origin can only be conjectured, and the highest authorities are not agreed as to the locality. That it once spread over the whole of Africa, a portion at least of Southern Europe, and SouthEastern Asia appears to be absolutely certain, but where did it have its birth and its early childhood? That is the doubtful question.

Dr. Peringuey believes in Africa, and he gives reasons for his conclusion that members of it nigrated to Europe at a time so remote that there was a passage by dry land over the centre of what is now the Mediterranean sea. He does not allude to the section of the race in South-Eastern Asia, but confines himself to Europe and Africa.

Professor Sollas, on the contrary, holds that the migration was from Europe to Africa, and assigns it to the same remote period as Dr. Peringuey. $\dagger$ He gives a graphic description

* Flint is not found in South Africa, and the earlier implements here were made of indurated shale, the later of quartzite or other hard stone.

$\dagger$ See Ancient Hunters and their Modern Representatives, by W. J. Sollas, D.S. Cambridge, LL.D. Dublin, M.A. Oxford, Ph.D. Christiania, F.R.S., Fellow of University College, and Professor of Geology and Palæontology in the University of Oxford. An illustrated volume of four hundred and thirty-two pages 170 by 98 millimetres in size, published in London in 1911. This book describes man at a time when he used only rough stone implements and had not yet learned to till 
of the Bushmen in Southern Europe, who lived there in what is termed the Aurignacian period, nearly in the middle of the palæolithic or rough stone age. They were negroids of small size, with short twisted hair. Their faces were almost vertical down to the bottom of the nose, and they had prognathous or projecting jaws and retreating chins, exactly similar to the Bushmen of South Africa. This is ascertained from two of their skeletons found in the Grimaldi caves at Mentone.

Their weapons and tools were the same in form and size, so much so that if a handful of Bushman arrowheads and scrapers were thrown into a heap of similar implements say in the museum at Brussels, they could not be separated again except by some one with a thorough knowledge of the composition of the rocks from which they were taken.

Engravings on pieces of ivory of the mammoth, now long extinct, made by these people, similar in character to Bushman engravings on stone, are familiar to students in the great museums of Europe. Many paintings on the walls and roofs of caverns, their work also, have been found during recent years in France and Spain. They are of exactly the same style as those of the Bushmen of South Africa, but of course represent different animals.

The best of these paintings yet discovered in Europe is a herd of bisons on the roof of the cavern of Altamira in Spain, in which various colours were used. Equal as a work of art, if not superior to it, is a hunting scene from a cavern in the mountains bordering Griqualand East in South Africa. Two stone slabs became detached from the roof of this cavern, and fell upon a heap of dust and débris,

the ground. One chapter of thirty-six pages is devoted to the Bushmen of South Africa, and there are several other references to them in the volume. For the discovery of the skeletons see also Ancient Types of Man, by Arthur Keith, M.D., LL.D. Aberdeen, Conservator of Museum and Hunterian Professor, Royal College of Surgeons, England. An illustrated volume of one hundred and seventy pages 125 by 75 millimetres in size, published in London and New York in 1911. Chapter VI, The Grimaldi or Negroid Type in Europe. 
which preserved the painting perfectly until the slabs were discovered and removed to the South African museum in Capetown, where they can now be seen. When pieced together, the painting is 2.39 metres in length by 92 centimetres in width, and represents seventeen elands, the largest thirty-two centimetres in length, beautifully drawn and shaded in colour, with grotesque figures of hunters using their weapons. Some of the elands are foaming at the mouth from exhaustion, and from the nostrils of one, which is in the attitude of falling, blood is actually dropping. One hunter is hamstringing an eland with a battle-axe, which together with iron-headed arrows, shows that the picture cannot be very old, as it must have been painted after the intrusion of the Bantu into that part of the country, not three centuries ago. An opinion held by most investigators that the older pictures are better as works of art than the more recent ones is thus proved to be incorrect. At all times there must have been a few individuals who excelled as painters and sculptors, while there were many who could only produce daubs.

No figures of human beings have yet been discovered among the paintings of the Europeans, but statuettes made by them have been found at Mentone and other places, which represent the Bushman type of body, with its steatopogy or very protuberant buttocks of adipose matter. There can hardly be a question therefore of the identity of race, the only difference-though a very important one if the measurements can be relied on-observable between them being that the skulls of the European branch were a little longer in proportion to their breadth (horizontal cephalic index 68 or 69 ), and the cranial capacity or size of the brain was much greater.

What became of the negroid inhabitants of Southern -Europe no one can say. They were there before the close of the great ice age, and then they disappeared as other races had done before them. This was in Professor Sollas's mind when he conjectured that they migrated into Africa; 
but they might have been exterminated entirely, or partly absorbed and partly exterminated by an invasion of a stronger race. This has ever been the law: progress in knowledge and skill and become invincible, or perish. And they were the least progressive of all mankind. Ages later this was the fate of their kinsmen in South Africa, who continued to exist so long solely because of their perfect seclusion.

In South-Eastern Asia there are people living to-day, such as some of the inhabitants of the Philippine islands, the Andamanese, and the Semang in the Malay peninsula, who are so like the Bushmen that it is almost certain they are of the same stock. The type must have been fixed in their common primeval home in some far remote time, and the changes in each that have since taken place. have been so small that the close relationship may still be seen. Mentally especially this is the case. Their power of thought on sub. jects of any nature outside of their ordinary occupations is not greater than that of a European child six or seven years of age, and they have all the credulity of such a child. There are no means of ascertaining whether this was the case with the section of the race in Europe, but the probability is very strong that it was.

The points of resemblance between the Bushmen and the Semang are so numerous that they cannot be accidental.* The average height of Semang men is 1491 millimetres, of Bushmen of South Africa 1444 millimetres, and of pygmies of Central Africa 1400 to 1450 millimetres. The average horizontal cephalic index of the Semang is 78.9 (of their women $81 \cdot 1$ ), but this index is variable. T'his hardly differs from that of Bushmen. The cranial capacity of the Semang is 1348 cubic centimetres, which is greater than that of Bushmen, but still very low. The noses of the Semang are remarkably broad and flat, and the root is depressed; the chin is feebly developed. The cheek bones are broad, the

* The characteristics of the Semang are taken from The Pagan Races of the Malay Peninsula, by Walter William Skeat, M.A., and Charies Otto Blagden, M.A., published in London in 1906. 
ears are small, and very few of the men have any beard. The hair is spirally curled, the mouth is large, and the jaws are prognathous. They do not practise circumcision, nor do they tattoo their bodies.

They are nomads, use rock shelters or screens of leaves for habitations, coil themselves up to sleep on a heap of leaves without a pillow, make baskets and mats, eat anything and everything edible, sometimes consume raw flesh, produce fire by the friction of two pieces of wood, and cook their food in the most primitive manner. Their implements of stone are not ground or polished. They do not make canoes or rafts, but harpoon fish, and use baskets as nets.

Their marriage rites are of the slightest kind, they bury their dead entire, there is no trace of an actual cult among them, they make traps, pitfalls, and snares to catch game, their only domestic animal is the dog, they have no words for any numeral higher than three or four, and yet they are decorative artists. On ornaments for the heads of their women and on their quivers they trace geometrical patterns, outlines of animals, and figures believed to be charms.

Every assertion in these paragraphs applies to the Bushmen, and though there are some characteristics mentioned in addition to these, which are not applicable to those people, they are such as might have easily arisen from their different environments. These are that the Semang have round bright eyes, straight and far apart; their foreheads are low and rounded, and their cheeks are full; their heads are covered with frizzled hair more closely than those of Bushmen. They do not use skins or feathers for clothing, but make bark cloth, and wear girdles of fungus peel; their women wear magic combs, with patterns engraved on them. They do not make pottery; their musical instruments are all formed of bamboo; they use bedsteads made by lashing half a dozen thick bamboo poles together, and raising this platform on supports. They have no great fear of ghosts; and they have a dim belief in mythological personages, of whom Kari is their highest god, and is obeyed by Tuhan and Ple. 
The chief difference is that the skin of the Semang is of a dark copper colour, or chocolate brown to shiny black. The skin of the Bushmen is yellowish brown, darker or lighter according to the locality frequented by them. In every case the shade of the skin seems to denote that it was acquired for a purpose of the greatest utility.

The Semang, living in forest gloom, required a very dark skin in order to conceal themselves. Their remote ancestors may have been of quite a different tint. The Bushmen on the arid plains and bare mountain sides of South Africa were of the colour that was most advantageous to them, for they were almost invisible at a short distance, so closely did the tint of their skin resemble that of the dried-up soil. Even their scantily covered scalps were of advantage to them in this respect. After rains when high grass sprang up, through which they could creep covered with a few tufts, or in a bushy country where they could adopt disguises, their colour would be a matter of little importance, but on the plains of South Africa it meant much, for it enabled them, by keeping to leeward and making use of anthills or boulders or shrubs, to stalk their prey until within reach of their arrows.

Is it not reasonable to suppose that the same guiding mind which coloured so many of the lower animals in accordance with their environment should have exerted its beneficent power in aid of savage man in the same way? In the far distant time when the ancestors of the Bushmen made their first appearance in South Africa, they may not have been of the same colour as they were when Europeans first saw them. In the early years of the nineteenth century the traveller Burchell observed that the Bushmen north of the Orange were differently coloured from those south of that river; though each section had the tint best suited to its surroundings. Many others have noticed this peculiarity since Burchell wrote, though no such accurate records were made as could be desired. This cannot be accidental. Of course when clothing came to be worn by primitive man such changes were useless, and consequently ceased to take place. 
It is certain that the whole of the continent of Africa at a remote period was occupied solely by people of the Bushman race. In the gloomy forest west of the Albert Nyanza they are found by European travellers of the present day, and the descriptions of them given by Schweinfurth, Junker, Stanley, Casati, Von Wissmann, and many others could be applied with perfect accuracy to the Bushmen of the southern extremity of the continent.* They could not have migrated to that locality through a country inhabited by stalwart negroes, by whom they were always regarded as noxious animals, and as such destroyed, nor could the section of their race south of the Zambesi have moved down through Bantu tribes. They must have occupied the country alone for countless generations, before invaders of greater strength destroyed or absorbed all of their kindred except

* Some cthnographers are of a different opinion. For instance Deniker, in The Races of Man: an Outline of Anthropology and Ethnography, by J. Deniker, Sc.D., Chief Librarian of the Museum of Natural History, Paris, a crown octavo volume of 611 pages, says: "Several authors confound in one group of Pigmies the Negrilloes and the Bushmen. Nothing, however, justifies their unification. The colour of the skin in Bushmen is a fawn yellow, while in Negrilloes it is of a chocolate tablet or of coffee slightly roasted; the hair of the former is black and tufted, while the hair of the latter is like extended fleece and often of a more or less light brown. The face of the Bushman is lozengeshaped, the cheeks are prominent, and the eyes are often narrowed and oblique, which traits are not met with at all in Pigmies. Steatopogy, a special trait of the Bushman race, has not been noted among Negrilloes except in individual cases among the women, and to a less degree than among Bushmen. At the same time the profile of the sub-nasal space, always convex in the Akkas according to Stuhimann, is often to be observed among Bushmen. Thus, therefore, a slight degree of steatopogy in individual cases and the profile of the sub-nasal space would be the sole characters connecting the two races." It is well to take the differences into consideration, but let any one who is at all acquainted with Bushmen read the account of Blasiyo by Mrs. Ruth B. Fisher in her volume On the Borders of Pigmy Land (demi octavo, 215 pagcs), and I feel sure that doubt will be dispelled. See further the marked steatopogy in the photographs reproduced in James J. Harrison's Life among the Pygmies of the Ituri Forest, Congo Frec State, 
the puny remnant that was forced into the deptlis of the forest where they could not be pursued. Just so, at a later date, they were exterminated or absorbed all the way down to the Zambesi, except possibly a very ferv who made their escape across that river.

Of their existence far north in the continent there is ample proof, but only after other races had settled along the Mediterranean shore and peopled the valley of the Nile as far up as Abyssinia. As they could not have migrated there after the arrival of those races, they must have preceded them as inhabitants. There are references to them in the earliest histories that were written, though the dates were modern compared with the memorials of their existence that their stone implements supply in the southern part of the continent. The first of these in order of time shows us a long-established kingdom of Egypt, with a people far advanced in civilisation, and a form of hieroglyphic writing in extensive use. Nubia too had then a settled population. - Many inscriptions in hieroglyphic characters have been translated into English,* and among them is more than one record of expeditions being sent southward to obtain Bushmen or pygmies to amuse the king by dancing before him.

Thus one official in the time of the fifth dynasty has placed his services on record. He states among other notable occurrences that he was sent to the land of ghosts, that is to the unknown country beyond the farthest part explored, to bring back a pygmy for the purpose indicated, and that he went by the way of Nubia to Punt, where he managed to secure one. How realistic this appears to South Africans who can remember the habits of the people living on the inland plateau in the middle of the nineteenth century. One of the commonest ways of many a farmer there to amuse his

* See Egypt in the Neolithic and Archaic Periods, continued as A History of Egypt from the End of the Neolithic Period to the Death of Cleopatra VII, B.C. 30, by E. A. Wallis Budge, M. A., Litt.D., Keeper of the Egyptian and Assyrian Antiquities in the British Museum. Eight crown octavo volumes, published in London in 1902. 
guests and himself was to gret one of his Bushman herdsmen to dance or caper before them, with a promise of a big glass of brandy or a long piece of roll tobacco, of both of which every individual of his race was immoderately fond, if he did it well. On being told to dance springbok, he would bound into the air again and again with as much ease apparently as one of those animals, without quivering his body or seemingly bending his limbs. Then he would be told to dance baboon, when at once every joint of his body was in motion. The agility of the little imp, the elasticity of his limbs, the wonderful contortions that he was capable of displaying, gave as much delight to the South African farmer as a similar performance by another individual of the same race gave to Pharaoh, lord of Egypt, so many thousand years ago.

Statuettes of Bushmen, with the steatopygous protuberances well marked, have been found in ancient Egyptian tombs, a conclusive proof that individuals of that race were known to the artists.

The historian Herodotus, ${ }^{*}$ writing about 440 before Christ, mentions the pygmies, but they were then. no longer to be found in the valley of the Nile below Senaar, nor had they been seen there probably for a very long time. Evidently more stalwart people had occupied the valley, and the little hunters had either been exterminated or compelled to retire from the field. They were reported to be south of the desert, and though Herodotus never saw one, he obtained information that enabled him to give a most graphic description of them. He described them as dwellers in caves or caverns, as eating serpents, lizards, and other reptiles, as being the fleetest of foot of any people he had ever heard of, and whose language was like the squeaking of bats. It would

* See History of Herodotus : a new English Version, edited with copious Notes and Appendices, illustrating the History and Geography of Herodotus, from the most recent sources of information, by George Rawlinson, M.A., Canon of Canterbury and Camden Professor of Ancient History in the University of Oxford. Four thick royal octavo volumes, published in London in 1880. 
be hardly possible to express in fewer words a description of the Bushman race.

But that is not all he related of the pygmies. He had been informed that five young Nasamonians, actuated by a spirit of inquiry and adventure, had set out on a journey of exploration from the coast of the country now called Tripoli, and having travelled first to the south and then to the west through the inhabited parts and the desert, reached a territory where they were made prisoners by men of small stature. These conducted them through extensive marshes to the bank of a great river flowing from west to east, in which were crocodiles. All the people they saw were pygmies, black in colour, addicted to magic, and speaking a language unintelligible to the Nasamonians. How the travellers escaped we are not told, but they succeeded in retracing their steps, and reached their homes again in safety. Probably the river which was the terminus of their journey was the Niger, a stream which baffled the curiosity of Europeans down to 1830 , when it was traced to its mouth by the brothers Richard and John Lander. Herodotus believed it to be the upper course of the Nile, which he thought must flow for a great distance from west to east, as otherwise he could not account for the great volume of water in it.

In 1849 the traveller Barth on his way southward from Tripoli discovered many ancient engravings on rocks in a valley near Ilurzuk in Fezzan, approximate latitude $26^{\circ}$ north, longitude $14^{\circ}$ east of Greenwich. He has given copies of three of these, though they cannot be regarded as absolutely correct, as two are from sketches and the other from memory only. But they are unmistakably of the same class as Bushman engravings, the oxen represented being fairly well outlined, but without feet, as in South Africa, and the men having the heads of animals. Barth noticed that there were no engravings of camels, beasts of burden unknown there until long after the introduction of the $\mathrm{ox}$, from which it may be assumed that these engravings were made at a time 
when the country was partly occupied by pastoral Hamitic tribes, but before the arrival of Arabs. The outlines of the figures were cut very deep into the rock.*

In Southern Algeria many engravings of animals on rocks have recently been discovered by Mr. G. B. Flamand, of the geological survey department, among others some of an extinct buffalo, whose bones are found in that region. These and some others must be of very great age. Mr. F. Foureau found similar engravings on the faces of masses of granite in the Sahara, all of a style and degree of art exactly corresponding to those in South Africa, and all made by punching holes or lines with sharp pieces of hard stone. $\dagger$

From what has been stated it seems certain that at some very remote period not only the whole of Africa, but at least parts of Europe and Asia were inhabited by a race of savages identical with the Bushmen, though differing in colour and some other features in different localities. There must have been some particular locality from which they all spread out, but, as has already been stated, that locality cannot be ascertained with certainty. Dr. Peringuey believes it was in Africa, Professor Sollas thinks it was in Europe, and Monsieur A. de Quatrefages, the eminent French savant, holds that it was in Asia. This seems to me the most

* See Travels and Discoveries in North and Central Africa: being a Journal of an Expedition undertaken under the Auspices of His Britannic Majesty's Government in the years 1849 to 1855, by Henry Barth, Ph.D., D.C.L. Five demi octave volumes, published in London in 1857 and 1858. The account of the discovery is given in chapter $i x$, volume $i$, and the pictures are on pages 197, 200, and 201.

i See the paper on Rock Engravings of Animals and the Human Figure, the Work of South African Aborigines, and their relation to similar ones found in Northern Africa, by Dr. L. Peringuey, in the Transactions of the South African Philosophical Society for 1906.

I See The Pygmies, by A. de Quatrefages, late Professor of Anthropology at the Museum of Natural History, Paris. I have only the English translation, an illustrated crown octavo volume of two hundred and sixty-five pages, published in London and New York in 1895. It contains seventy-fire pages on the African pygmies. 
likely, because it is more central in position, and from it waves of human migrations could more easily be thrown out westward to Europe, south-westward to Africa, and southeastward to the Malayan peninsula and thence to Japan.

They may have extended over a much larger surface even than this, but they were not the only people then living. Other races were in existence in Europe and Asia, races more capable of improvement, though originally starting from the same low level. A struggle for the possession of the fairest tracts of country took place, and the more intelligent and consequently the stronger races were the victors. It was for the good of all the world that it should be so. It seems to be God's law that man must raise himself constantly higher, and he who cannot as well as he who will not conform to that law must pass out of existence. And these Aurignacians, Bushmen, and pygmies of the north, though gifted with artistic tastes, were an almost unimprovable race : already, in those far off times, they had attained the highest point of their progress, and had then become inert and stagnant. What progress has the little remnant that still remains made during the countless centuries that have since passed away? They have learned how to drill a hole through a stone, that is nearly all, and that is not sufficient to satisfy God's law of progress.

And so at some time, which cannot be ascertained, but must have been many thousands of years ago, a stronger and better equipped race entered the north-eastern extremity of the continent, and gradually spread along the Mediterranean coast and up the valley of the Nile, exterminating the earlier inhabitants, or possibly taking the young females and killing all the others. This went on until the country as far south as the great desert was filled with the people now usually termed Hamites, who were a little darker in colour than modern Europeans, and who had long black hair. The purest descendants of these people at the present day are believed by many ethnographers to be the Guanches in the Canary islands and the Basques in Spain, the Copts in 
Egypt and the Berbers in Nortli-West Africa having a much larger mixture of alien blood in their veins.

After this, how long there are no means of ascertaining, negroes came into the continent, in all probability by way of the straits of Bab-el-Mandeb, and spread out south of the desert and along the Atlantic coast. Wherever they went the Bushmen disappeared, the girls being absorbed, and all the others being destroyed.

Then other races invaded the continent, Arabs, various tribes of more distant Asiatics, among whom were the progenitors of the modern Bantu, some of whom settled in the north-east, and others pushed their way southward. All were deadly foes of the Bushmen, sparing only the young females, and so it came to pass that by the year 1500 of our era there were none of the ancient inhabitants left north of the Zambesi, except the few wretched little bands that had managed to take refuge in places so difficult of access that they could exist there almost undisturbed.

A question now arises whether there were any people whatever in Africa before the Bushmen. If there were, they must have been of even a lower type, or they would not have been displaced. Recent discoveries have made it certain that there were earlier races in Europe than the Aurignacian, and so it is possible that there may have been in South Africa. From the primeval home of man, wherever it was, successive waves may have been thrown off, and the Bushman wave was not necessarily the first. It may have been to a preceding one what succeeding ones were to it, that is it may have entirely destroyed or absorbed the other.

The evidence in favour of the existence of such a race may be stated. First and strongest is the abundance of primitive bouchers that have been found, implements cruder than those used by Aurignacians and probably by Bushmen of the same age.

Next there are frequent references by Bushmen in their folklore tales and legends to an older race, but this cannot be accepted as conclusive evidence, because no tradition can 
have passed down the enormous length of time that they certainly occupied the country. They probably did not migrate from the north in one horde, but in successive bodies, possibly with a long interval of time between the journeyings of each other, and in such a case the latest arrivals would regard those they found here as an older race. In this way the existence of the Ancient Shellmound Men can be easily accounted for. They were simply driven to the margin of the ocean, and compelled to live mainly upon the produce of the shore, by others of their own race who took possession of their former hunting grounds.

Another evidence, and of much greater weight, is the Bushman language, which possesses a verb of such marvellous power that it must be a very long way removed from primitive speech.

It is even possible that remnants of an earlier race than the Bushmen existed in South Africa until a very recent date.

There is a tradition among the people of a Bantu tribe in the Transvaal province that when their ancestors arrived on the banks of the Limpopo eight generations ago they found some savages there who were unacquainted with the use of fire and were without other weapons than natural stones and sticks.

The traveller and explorer Andrew A. Anderson thus describes some savages whom he saw in 1872 in the Kalahari desert :*

"At Narukus, on the Nosop river, I came upon a family of Bushmen, ten in number, of a different type to those $I$ had in my service, evidently a lower caste. They have 110 forehead; the wool on their heads comes close down to the eyes, and the head falling back like a baboon; projecting

* See Twenty-five Years in a Waggon, Sport and Travel in South Africa, by Andrew A. Anderson. An illustrated demi octavo rolume (second edition) of four hundred and twenty-three pages, published in London in 1888. The extraets given here will be found on pages 216 and 218. They are not to be depended upon too closely, as he may have mistaken Katea for Bushmen. 
mouth, small nose, a sort of hair or wool all over the chest, arms, and legs; their eyes are small and restless, watching every movement that is going on; the tallest man did not exceed four feet four; their skin was of a reddish brown. A few old skins, broken ostrich eggs, and bows and arrows, seemed all they possessed of worldly goods.

"They would have decamped and hid in the bush, but I sent some of my Bushmen and brought them back. I asked my own boys if they were their brothers, meaning of the same raee; they repudiated the idea, and said they were monkeys not men, and told me there were very few ever seen, it was very seldom they ever eame upon any; they eat carrion. They are evidently a distinet race from the Masara Bushmen * who are largely distributed over the desert. One of the women had a baby not much larger than a half-grown kitten; all of them were destitute of elothing.

"I find there are four types of Bushmen in this desert; the lowest is the one already described with no forehead and half wool and hair on their bodies and legs. The seeond is the wild Bushmen, who live in the mountains near the Orange river, who war on all men, but they are of good form, without hair. The third is the Masara Bush family, also of good proportions and of gentle dispositions, inoffensive and harmless, ready to help or do anything, and they make good servants. It was this tribe I had with me in my wanderings. The two girls I took in eharge made good cooks, washed the elothes, and mended them. The fourth is mueh taller and well formed, great rascals, who cannot be trusted with anything; they inhabit the eastern portion of the desert and down by Langberg."

The possession of bows and arrows by the degraded creatures here mentioned would seem to prevent their classification as members of an earlier race than the Bushmen, unless they had adopted these weapons from others.

This I believe is all the evidence to hand as yet for or against a race preceding the Bushmen in South Africa. It leaves the question uncertain, and any conjecture regarding

* The Masarwa are of mixed Bantu and Bushman blood, the latter preponderating. They are numerous on the eastern border of the Kalahari desert. 
it would be worse than useless, for more than likely it would be incorrect.

Note 1.-Mr. E. J. Dunn, an accomplished geologist, during many years of search in South Africa made a very large collection of stonc implements, which he was good enough to allow me to inspect on several occasions. I was unable to detect any difference betwecn the most ancient of these implements and the magnificent cxhibits of chipped stones which I saw afterwards in the museums of London and Brussels, but of course I was unable to compare them side by side. MIr. Dunn was convinced that thcy were all of Bushman manufacture, and that some of them had lain undisturbed since the bcginning, or nearly the beginning, of the present geological period, but he had found none in the later tertiary deposits. Most of the tiny pcrforated stones found by him were irregular in shape, and he could not ascertain to what use they had bcen put, though an old Bushwoman showed him how they were drilled, as well as how to attach a stone head to an arrow. A very interesting paper on The Stonc Implements of South Africa, by Mr. Dunn, is to be found in the Transactions of the Philosophical Society during 1880.

Note 2.-Two short papers entitled Stone Implements in South Africa, with a shect of illustrations, by Sir Langham Dale, Superintendent General of Education in the Cape Colony, were prbiished in the Cape Monthly Magazine of October and Dccember 1870.

Note 3.-A short paper entitled Notes in connection with Stone Imple. ments from Natal, by John Sanderson, Esqre., of Durban, Natal, is to be found in the Journal of the Anthropological Institute for August 1878.

Note 4.-A lengthy paper on The Stone Age of South Africa was read by $W$. G. Gooch, Esqre., C.E., M.A.I., before the Anthropological Institute on the 11th of January 1881, and is published in Volume XI of the Journal. It is illustrated with numerous plates.

Note 5.-A very interesting volume on The Stone Implements of South Africa, with 258 illustrations, by J. P. Johnson, crown quarto, fifty-three pages, was published in London in 1907.

Note. 6.-In a very interesting diary of a Tour through Bushmanland by the geologist Mr. E. J. Dunn, published in the Cape Monthly Magazine in December 1872, the following paragraph occurs: "July 11th.-Process. fontein.-Let us examine the river bank close by. On the top, thickly sprinkled through the loose red sand, are black stonc implements. They continue through the undcrlying clay, through a layer of hard carbonate of lime and sand, through a soft calcareous bed, and below this mixed with gravel formed from shale and resting on the bottom of shale and trap; that is to say. through a total depth of from ninc to twelve feet of stratified 
deposits. The ancient character of these stone implements is made forcibly apparent by many of the older ones being quite honeycombed, rough, and grey, from sheer old age. There could be no better place than this for exemplifying the antiquity of the human race in this part of the world."

Note 7.-According to Penck and Brïckner the glacial period in Europe covered from half a million to a million and a half years, and was the age of palæolithic implements, painting, and sculpture. There were four intensely cold, with three interglacial period, the last of which was of about one hundred thousand years duration, and in it the loess hunters lived. The carvings of late pleistocene fauna belong to this time, but man was in existence in the second interglacial period, as bouchers, the crudest form of stone implements, hare been found in débris of that date. Penck maintains that pottery first appears in the neolithic period, which followed the melting away of the last sheet of ice. The writers upon this subject are very numerous, but nothing that can absolutely be relied on as incontrovertible has yet been established. Some, for instance, maintain that there were as many as six interglacial periods, others that there was only one. Penck's statement that pottery is first found in neolithic deposits does not apply to South Africa, for here, though in a very crude state, it is associated with palæolithic implements. As to the cause of an ice age, the theory of Croll, worked out by the eminent astronomer Sir Robert Ball, that it was due to greater eccentricity of the earth's orbit, once generally accepted, is now as generally discarded, though nothing as plausible has been substituted for it.

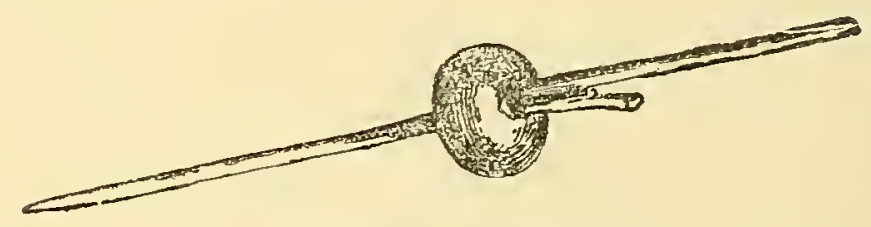

BUSHMAN DIGGIYG STICE. 

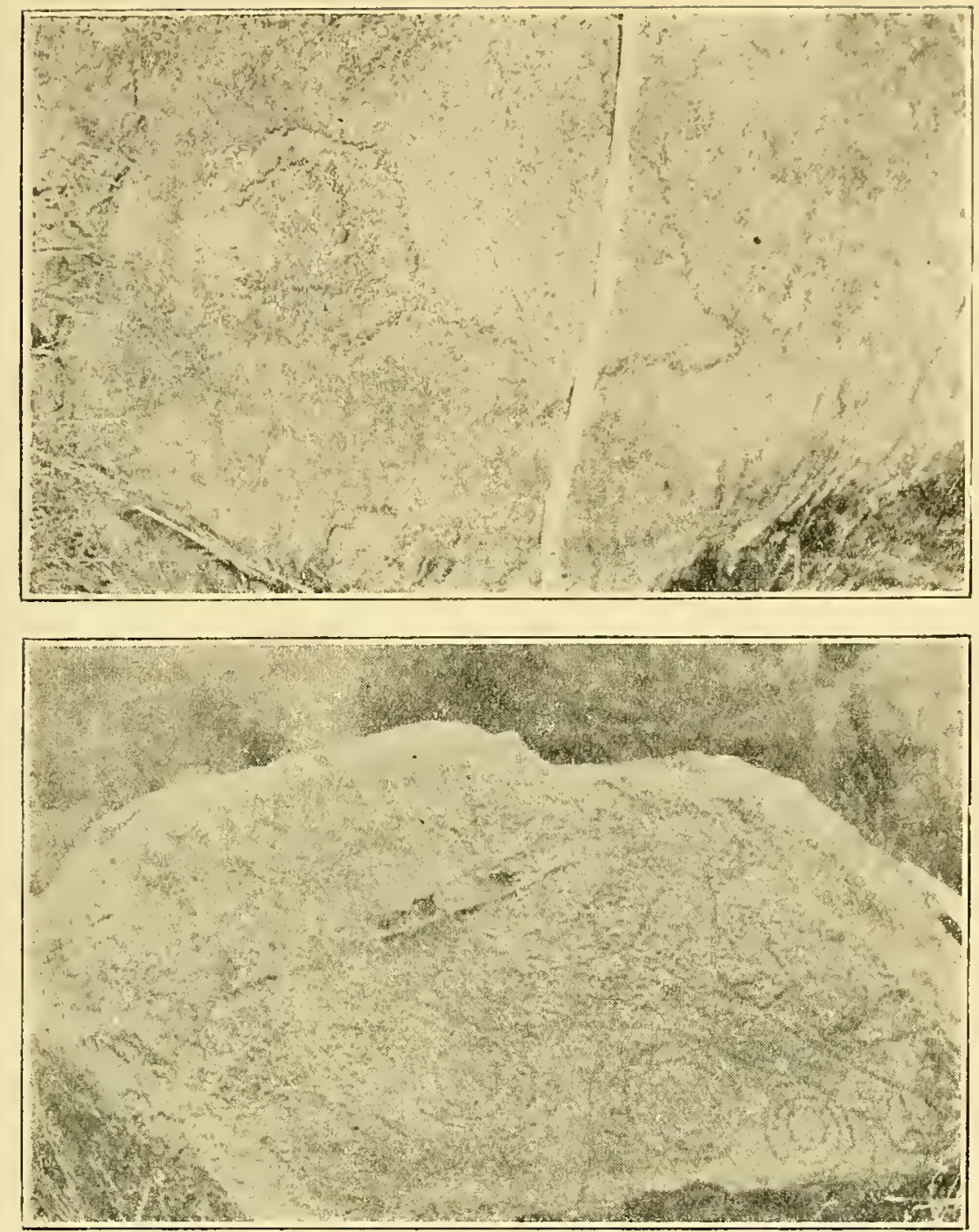

EXgRAVINGS BY BUSHMEN OY BOULDERS TEAR LYDENBURG. (From photographs kindly sent to me by Dr. Pyper, of Lydenburg.)

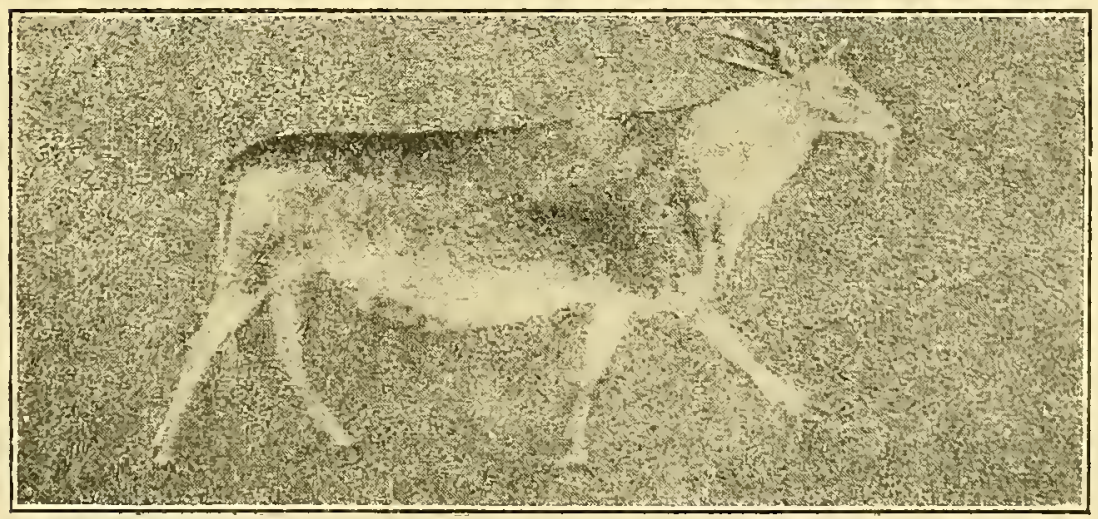

PICTURI OF AN ERATD

(One of the best Bushman pictures. From a cavern in the Listhlamba mountains.) 


\section{CHAPTER II.}

\section{The Bushmen (continued).}

Is one of the ancient palæolithic cave dwellers of Europe could make his appearance there again in flesh and blood, what an interest would be taken in him! He would be regarded as being able to throw a flood of light upon the early existence of man on the earth, and from all sides students and members of scientific societies would gather round him to learn all that he could teach. In point of fact he could tell them nothing, even if they could understand his speech. He could not explain the dim religious thoughts, or rather apprehensions of fear from something vague outside himself, that passed through his brain, nor give reliable information of any kind upon the past of his race, where they came from or when or how they had their origin. Of such subjects he knew nothing, and accepted the fact of his own existence and that of his associates without bothering himself about any inquiry into the matter. His conversation would be limited to narratives of the game he had killed, or the girl he had won by sending an arrow through a rival's heart as he lay sleeping, or how his brother had been bewitched by an enemy and had died, or how somebody had been turned into a wild animal and was still spell-bound and only to be seen in his proper form by those whose eyes had been cleansed by charms.

Only in the evening when he was surfeited with the flesh of some animal he had slain, and when weary of the dance he reclined by the fire and admired the patterns made with ochre and soot and grease on his otherwise naked body, he would tell some story of insects or birds or beasts that he had heard from 
his mother when he was a child, and though he did not know this, had really been as it were stereotyped long centuries before, and was even in those ancient days told in almost identically the same words by people living far away towards the morning dawn and others as far away towards the setting sun. The students and savants would listen, and wonder how a full-grown man, though a pygmy, with a fairly well shaped head but for the great prognathism of the jaws, could delight in such absurd stories and really believe in the truth of many of them. They would soon realise that he could tell them nothing of what they wanted to know, that though he was not an idiot, his reasoning power and his credulity were those of a little child. They would observe that his passions were those of an adult, that his physical strength was great, that he could distinguish objects clearly at a distance that they could only see with a good field-glass, that he could outrun with ease the fleetest of their athletes, and yet that his thoughts were no more lofty than those of the dullest peasant's infant boy.

But the palæolithic savage restored to life, though he could tell nothing of importance concerning the history or origin or religion of his race, would still be an object of exceeding interest. He could be studied as a workman engaged in the manufacture of timepieces studies the mechanism of a clock, and a very great deal relating to the history of man could be learned in this manner from him. He could not explain the structure of his language, but his words, or the uncouth sounds that issued from his throat and teeth and lips which correspond to words among civilised men, could be taken down and analysed, their meaning could be gradually gathered, the grammatical form in which they were put together to represent ideas could be solved, and a link in the chain of language from its origin to that of the most cultured individual of the present day would be obtained. For this painted savage, disgusting in his habits, almost hideous in his appearance, represented a stage of human existence through which our own ancestors must at one time have passed. That time may have been exceedingly remote, but we cannot get rid of the fact that this repulsive being, who ate and enjoyed the taste of carrion, 
and never cleansed even the intestine of an animal before devouring it, was a blood relative of our own, and that we ought to take more interest in him than in any of the brute creation.

The Europeans who settled in South Africa after the middle of the seventeenth century had the palæolithic man, just as he roamed over Earope in times long preceding the dawn of history, living in flesh and blood before their eyes. They were indeed far more familiar with his presence than they desired to be, for he was not at all a respectable neighbour. He belonged to an unimprovable race, incapable of adopting the habits of other people much higher in culture than itself, though, as now known, it could amalgamate with those only slightly in advance. Before the arrival of the Hottentots and Bantu in parts of South Africa, it was not in contact with any other branches of the human species, and hence it remained at its own low level, the level of palæolithic man in Europe, without making much advance of any lind during the long long time it occupied the secluded extremity of the continent. When the Europeans arrived therefore, an opportunity was afforded of becoming intimately acquainted with the condition and language of one of the lowest, if not the very lowest, of all the races on the face of the earth, and of making the information gained known to the civilised part of mankind.

That opportunity was not taken advantage of. The white settlers were entirely occupied with making a living, and regarded the Bushmen simply as robbers, just as the Hottentots and Bantu did. Then down to our own times the savage wanderers were generally considered to be outcast Hottentots, even Dr. Bleek himself when he began his researches believing that they had separated from a common ancestral stock only a few centuries back. There were exceptions to this statement, notably Dr. Henry Lichtenstein, * but they were few in number. Further,

* "Equally untrue is the assertion that the nation of the Bosjesmans is composed of fugitive slaves and Hottentots. They are, and ever have been, a distinct people, having their own peculiar language, and their own peculiar customs, if the terms language and customs can be applied to people upon the very lowest step in the order of civilisation, as the Bosjesmans may certainly be esteemed : one might almost call this extraordinary race without customs 
there were no men of sufficient education and inclination wealthy enough to afford the time requisite to conduct the necessary researches. When at length, under the auspices of the late Sir Bartle Frere, a philosophical association came into existence, its pecuniary resources were too limited to render any aid, and it was obliged to confine its attention to other subjects. These are the reasons why long and close research regarding the inner life of the Bushmen was not commenced until the nineteenth century was far advanced.

Scattered about in the early records of the Cape Colony there are many references to the Bushmen besides those relating to war with them, and though these are of considerable value, none of them give all the particulars that a student would like to know. Thus in the journal of Commander Simon van der Stel's expedition to Namaqualand in $\mathbf{1 6 8 5}$ it is related that on a certain occasion five Bushmen were met, to whom a sheep was presented, which they killed and ate, rejecting nothing but the gall and four little pieces from the thighs. Beyond stating that they gave as a reason for not eating these little pieces that it was their custom to reject them, no information is given, or probably was obtained, concerning the matter. Recent research by Dr. Bleek and Miss Lloyd fills in this gap, however. The wild people believed that animals and men could change their forms, and that these particular pieces remained part of the human body.

Many travellers and missionaries have also given accounts of the habits and mode of life of the Bushmen, but none of them remained in contact with the savages long enough to learn their language or penetrate into their innermost minds.

The reverend J. J. Kicherer, a missionary of the London Society, was the first to attempt to establish a station purely for the benefit of Bushmen. With a party of assistants, including

and without language. No Hottentot understands a word of the Bosjesman language; and the nation was hated by all others on account of its habits of plunder and disregard of the rights of property, long before the Europeans settled in South Africa."-Travels in Southern Africa in the Years 1803, 1804, 1805, and 1806, by Henry Lichtenstein. Translated from the German by Anne Plumptre. Two quarto volumes, published at London in 1812 and 1815. 
a half-breed Hottentot and his wife, who were born in the territory near the southern bank of the Orange river, and who spoke both the Dutch and the Bushman languages, so that they were useful as interpreters, on the 6th of July 1799 he took up his residence at a place which he named Blijde Vooruitzigt, or Joyful Prospect, on the bank of the Zak river. Being provided with a good stock of tobacco and a considerable number of oxen and sheep, presented to the mission by religious farmers, he was able to induce a large party of the wild people to listen to his teaching, and they remained with him as long as his stores lasted. In 1800, after he had been with them several months, he wrote of them as follows : *

"Although they are not idolaters, the doctrine of a Supreme Being was to them entirely unknown. . . Their manner of living is very horrible. Their dwelling and resting place is between the rocks, where they dig a round den of about three feet deep, in which they lie, with their whole family. This den is sometimes covered with a few reeds, to shelter them from the wind and rain, which, however, seldom answers the design, as they are generally soaked through by the first shower. They mostly lie down and sleep, except when hunger greatly torments them; then they go a-hunting; but they live many days without any food. When they find no wild beast, then they make shift with a sort of small wild onions and wild potatoes, which the women seek, but never the men. They are content to eat snakes and mice.

"Their language is so very difficult to learn that no one can spell or write the same. It consists mostly of a clicking with the tongue.

"They are total strangers to domestic happiness. The men have several wives, but conjugal affection is little known. They take no great care of their children, and never correct them except in a fit of rage, when they almost kill them by severe usage. In a quarrel between father and mother, or the several wives of a husband, the defeated party wreaks his or her revenge on the child of the conqueror, which in general loses its life. Tame Hottentots

* Transactions of the Missionary Society quoted in The History of the London Missionary Society, 1795-1895, by Richard Lovett, M.A. Two demi octaro volumes, published at London in 1899. 
seldom destroy their offspring, except in a fit of passion; but the Bushmen will kill their children without remorse on various occasions, as when they are ill-shaped, when they are in want of food, when the father of a child has forsaken its mother, or when obliged to flee from the farmers or others; in which case they will strangle them, smother them, cast them away in the desert, or bury them alive.

"The Bushmen frequently forsake their aged relations when removing from place to place for the sake of hunting. In this case they leave the old person with a piece of meat, and an ostrich egg-shell full of water: as soon as this little stock is exhausted, the poor deserted creature must perish by hunger, or become the prey of wild beasts. Many of these wild Hottentots live by plunder and murder, and are guilty of the most horrid and atrocious actions."

Dr. Henry Lichtenstein was the first to attempt to gather a number of words used by them and to place them against words with the same meanings used by Korana Hottentots, thus showing the great difference between the two languages. His information was obtained in 1804 and 1805 from Bushmen living on the great plain south of the Orange river, and he had a competent interpreter and was himself well qualified for the work. But he used no symbols except figures to denote the clicks, and did not distinguish the differences between several of these sounds. No attempt was made by him to ascertain the mode of structure of the sentences, and therefore his list of words is of little or no use to a philologist compared with what the addition of a few phrases would have made it. His general remarks upon the language are:

"Among all the Hottentot dialects, none is so rough and wild, and differs so much from the rest, as that of the Bosjesmans, so that it is scarcely understood by any of the other tribes. It is, in the first place, much poorer in sounds: many sounds, which may be expressed by our letters, in the Gonaqua, the Coran (i.e. the Korana), and the Namaqua languages, are either totally wanting among them, or very rarely occur. Pure vowels are seldom to be heard; but the cluck and the diphthongs are much more frequent. The cluck, in particular, seems the most completely at home among them : scarcely a word occurs without it. The gurgling in the throat 
is much decper, and hence ensue the most disagrecable nasal tones. The speech ends with a sort of singing sound, which dies away by degrees, and is often some seconds before it wholly ceases."

The reverend Thomas Arbousset, of the French mission in Basutoland, has also given a vocabulary, seven pages in length, but unfortunately he confused Hottentots with Bushmen, and his list contains many words adopted even from Sesuto. It was prepared about the year 1837. In his vocabulary he did not attempt to introduce any symbols whatever to represent the clicks, so that to the philological student it is valueless. His remarks upon the language, as he heard it spoken, are, however, to the point. He says :

"Their language is harsh, broken, full of monosyllables, which are uttered with strong aspirations from the chest, and a guttural articulation as disagreeable as it is difficult. . . . It is not without reason that it has been said of them that they cluck like turkeys. . . . The clucks are especially found at the recurrence of a letter which is of a harsh guttural pronunciation. . . . As this horrible aspiration recurs incessantly in the mouth of the Bushmen, one is inclined to say that they bark rather than speak."

In 1862 the late Dr. W. H. I. Bleek, a man of great learning, patience, and industry, was appointed custodian of the Grey Library in Capetown. In that capacity he had much to do, but he found time out of office hours to carry on the philological studies for which he had been specially trained, and in which pursuit he was an enthusiast, though his judgment was clear and even cold. At first his only opportunity of acquiring any knowledge of the Bushman language was by visiting Robben Island and picking up words and short phrases from prisoners there, but after a time the government allowed him to take to his home two decrepit men of that race whose terms of imprisonment had nearly expired, and when they were liberated two others were

* Narrative of an Exploratory Tour to the North-East of the Colony of the Cape of Good Hope, by the revs. T. Arbousset and F. Daumas. Translated from the original French, and published in a foolscap octavo volume in Irondon in 1852 . 
obtained in the same manner. These induced some of their relations to join them, and presently a whole Bushman family was living on his ground. From time to time as one party left another arrived, so that the material to work with was always abundant.

To his surprise Dr. Bleek soon found that he was in contact; not with degraded Hottentots or even with people closely allied to Hottentots, but with representatives of an actually primitive race. From that moment he devoted his attention almost entirely to the study of the habits, folklore, and particularly the language of the Bushmen, for their race in South Africa in its purity was almost extinct, and he realised that in a very few years such researches would be no longer possible. In this study he was warmly assisted by his sister-in-law, Miss L. C. Lloyd, who was fortunate in possessing a very sharp ear, and who was soon able to distinguish the different clicks, smacking of the lips, and guttural sounds that form so large a portion of Bushman speech.

A mass of material was collected, but was not ready for publication when, to the great loss of students throughout the world, the death of Dr. Bleek on the 17th of August 1875 put an end to his devoted and most useful labour. His Comparative Grammar of South African Languages is, and must always remain, a standard work, though it too was left incomplete and contains very little upon the Bushman tongue.

Miss Lloyd was then engaged to take charge of the Grey Library until a competent successor to Dr. Bleek could be obtained, and she resolved to continue the Bushman researches out of office hours and gather as much material as she could, before arranging for publication. In all South Africa there was no one so well qualified for the task as she. Not a few European children on farms had in earlier times learned to utter the strange sounds which constitute Bushman speech, and could converse freely with the savages, but none of these had ever been able to commit their knowledge to writing and it had died with them. Miss Lloyd was acquainted with two dialects, was accustomed to take down the sentences as they came from the lips of the speakers, 
and was therefore familiar with the various symbols used to represent the different sounds, and had the great advantage of having been trained to the work by so able a teacher as her deceased brother-in-law.

In addition to what was in manuscript when Dr. Bleek died, she collected materials upon the mythology, legends, fables, poetry, customs, and superstitions of the Bushmen, in two dialects, and then proceeded to Europe with a view of obtaining competent assistance in preparing the work of her brother-in-law and herself for the press. Some of it she had already translated into English. But unfortunately her health broke down so completely that it was only as a confirmed invalid she was able to write - a little, and so the result of the labour of her brother-in-law and herself remained unavailable for the use of others until 1910, when one volume of Bushman text with English translations appeared. This is of great interest, for the language of the Bushmen is already almost entirely lost, and it would not be possible now to collect the material used in it. The few individuals of the race that remain south of the Zambesi and the Kunene have either adopted the language of their neighbours, as those in Central Africa seem to have done, or they have been compelled to use so many foreign words and phrases that the idiom is too corrupt to be of any scientific value as far as the vocabulary goes. A knowledge of the mode of putting words together to express ideas, or the grammatical structure, is of even greater importance than a knowledge of the words themselves used singly, and it would be with great difficulty that this could be obtained now from individuals still living, but it can be acquired with ease from Miss (later Dr.) Lloyd's book.

To show how cautiously Dr. Bleek proceeded in his researches, and how he at length came to realise that he was dealing with the speech of a race either identical with or at the same stage of culture, as the palæolithic negroids in Europe, some extracts from his writings are given here. In 1857 he wrote in the Cape Monthly Magazine: 
"It is curious to notice that the Bushman tongue apparently agrees most, of all the Hottentot dialects, with that of the Cape, and next to it, with that of the Koranas, the lattcr being, in many respects, the connecting link between the Cape dialect and that of the Namaquas, in which the fullest and most original form of the Hottentot language has been prescrved. But we must not forget here, that what materials for a knowledge of the Bushman tongue are at hand are as yet limited to vocabularies of one dialect, namely that of the district of the Winterveld, from the vicinity of Colesberg and Burghersdorp. Other Bushman dialects may be widely different, nor is it impossible that many so-called Bushmen are of quite different origin. However this may be, these Bushmen from the Winterveld have decidedly been distinct from the Hottentots, as a nation, for many centuries; for their language presents more than dialectical differences from that of the Hottentots. There are, indeed, many Bushman words similar to those in use among the Hottentots, and in the general features of their structure both languages agree together. But the grammatical forms which my vocabularies of the Bushman tongue contain are peculiar, and also the construction of sentences appears to be different from that of the Hottentot language."

Before 1869 a great stride forward in knowledge was made, for in a volume termed The Cape and its People, published in that year, an article appeared from Dr. Bleek's pen dealing with the Bushman language from a scientific point of view. He wrote:

"The additional information which I have been able to collect (unsatisfactory as it is in extent) has impressed upon my mind this truth, that the Bushmen have been separate from their neighlbours, the Hottentots, for at least many thousands of years. . . The task of taking down as exactly as possible the sounds of this language was, of course, a great difficulty, for as many as six different clicks, formed either by the tongue or the lips, can at the least be distinguished here. When endeavouring to give the right mark for each click, I have no doubt frequently erred, as my ear is not very acute nor accustomed to distinguish these sounds; but as the clicks and other different sounds are not contained in the grammatical portions of the words, my observations on the structure of the language are not affected by this deficiency. 
"To show that the Bushman language, as far as we are acquaintcd with it, is entirely different from the other tongues of South Africa, we will briefly glance at the structure of them all. The South African languages, with the exception of the Bushman, all belong to one of two families. One of these great families of language is that called the Bantu, which contains Kaffir, Setshuana, etc. The other family-that of sex-denoting languages-is represented in South Africa by one member only, the Hottentot, the dialects of which do not differ essentially from each other.

"The Hottentot and Bantu languages have one very essential feature of their structure in common. In both, as a rule, each noun originally consists of two portions, one of which we will call the stem, and the other the representative element. The latter is a part of the noun which is also used to represent the whole noun, and in this manner either appears as a pronoun, or combines with other parts of speech, which are thereby referred to the noun. For example ...

"These examples are sufficient to show the peculiar structure of the Zulu language, in which the nouns are divided into thirteen classes, by being formed with thirteen distinct prefixes, which are also used to represent their respective nouns. The structure of all South African languages, excepting Hottentot and Bushman, is essentially the same as that of Kaffir and Zulu, with regard to the concord and the classification of the nouns. The Hottentot language also possesses the same method of representing a whole noun by one of its parts; but in Hottentot the representative portion is not at the beginning of the noun (as prefix), but at the end (as suffix).

"There are in this manner eight different representative elements in Hottentot, as there are thirteen in Kaffir, and sixteen in some of the languages akin to Kaffir. . . We have not been able to discover any trace in Bushman of such a system of representation of the nouns; and we cannot but conclude that it does not exist in this language. This may be explained in two different ways. Either the Bushman language never possessed the faculty of thus representing a noun by one of its parts, or, at least, had not a regular set of representative elements or pronouns, and has not developed a classification of the nouns dependent upon their forms of concord. If so (and there is no certain proof against such an assumption), the Bushman would belong to a very low order of 
language, - a stage in which no true pronouns (i.e. representatives of the nouns) were developed. But it may also be that Bushman, like many other languages descended from those in which the nouns were originally divided on the basis of this system of representing a noun by one of its parts, has lost this characteristic entirely.... It may have descended from a language possessing a rich system of concords based upon the representation of each noun by one of its parts. Such a system may have dwindled away (a process of which we have so many examples), and all traces of its existence may thus have disappeared. This is possible, but primâ facie not so probable as the reverse proposition, that the Bushman language belongs to a lower stage of development, in which neither true pronouns, nor grammatical classes (or genders) of nouns, had any existence.

"The only instances which I have met with of anything like forms of concord in Bushman are the adjectives small and large, which, in this language, have different forms for the singular and plural respectively. Thus |eri is the singular of the adjective indicating small, and | $\breve{e} n$ the plural; tuiya is the singular of the word for large, and tuita the plural ; ||kuken e !oai gan |eri one veldschoen is small, \|ku\|ku e !u gan |ĕn the two veldschoens are small, \|kuka gan $\| \mathrm{u} \ddagger$ uiya the veldschoen is large, $\|\mathrm{ku}\| \mathrm{ku}$ e ! $\mathrm{u}$ gan $\| \mathrm{u}$ tuita the two veldschoens are large, tnuî̀ yan țiya the seacow is large, țnû e toaya yan $\| \mathrm{u}$ fuita the many seacows are large. . . . We should lay more stress upon this grammatical peculiarity, and conclude that we could discern in it the remnant of a former system of concords, if it were not that, as yet, it has only been observed in the sentences taken down from the mouth of one informant, who was not a pure Bushman. Yet it is difficult to see how he could have introduced this grammatical feature into the language, as the Hottentot construction is by no means identical in this instance.*

"Many nouns in Bushman vary in their terminations according to their position or use. Thus veldschoen may be \|kuki, \|kuka, or |kkuken. Our knowledge of the language is not yet sufficiently advanced to enable us to discern the exact value of these endings; but it does not appear that they have anything to do with the concord, or even clearly with the distinction of singular and plural. . . .

* At a later date Dr. Bleek ascertained that other adjectives referring to size, as short, long, etc., have in the plural a form different from the singular. All other adjectives have the same form in both numbers. 
As the Bushman nouns do not appear to possess any representatire parts, the singular and plural cannot, of course, be distinguished by the mutual correspondence of such parts. The mode in which singular and plural are distinguished from each other in the Bushman language is far more primitive, viz. by reduplication of the first portion of each noun. Thus $\mid$ num is beard, and |nũ|nüm beards, |nũ ear, |nñu||nũntu ears, ||nõa foot, ||nõa||nõa feet, tũ mouth, tũtũ mouths, \|kun wing, \|ko\|kun wings, ku arm, kukun arms, †tkoa leg, koatkoaken legs. In some of the latter nouns it appears as if the ending $\mathrm{n}$, or en, or ken were, besides the reduplication, a distinguishing mark of the plural; but as this ending sometimes certainly also occurs in the singular, it would be rash to consider it as the indicator of the plural. The reduplication, on the contrary, has as yet only been observed in the plural of nouns. This particular employment of the process of reduplication for the purpose of forming plurals is, as far as I am aware, peculiar to the Bushman language. . . .

"Next to the plural, the feature as yet most clearly perceived with regard to Bushman nouns is the formation of the genitive. . . . In Bushman the genitive particle is suffixed to the noun, but as there is no sort of concord by which the noun in the genitive can be referred by a representative element to the noun which it defines, the noun in the genitive can only precede the other noun. The suffixed genitive particle is perfectly different in Bushman and Hottentot, the Bushman particle being $\mathrm{ka}$, ga, ya, or a; e.g. \|kã is lion, and |kã ga ãn lion's flesh, sa ga ãn eland's flesh, |kña ga !nu lion's foot, i.e. lion's traces. This Bushman genitive particle may, like the corresponding one in Hottentot, be also totally omitted. In fact, the cases of such omission appear to be more frequent than those in which the genitive particle is employed, e.g. \|kã †kui lion tail, koro tkui jackal tail, toi \$kui ostrich tail. The difference in the form of the suffixed genitive particle in Hottentot and Bushman is as significant as the difference in the use of the prefixed genitive particles of in English and de in French. Although the former is identical in meaning with the French particle, the difference in its form shows at what a distance English grammar stands, genealogically speaking, from that of the Romance languages.

"One other point of great and conclusive dissimilarity between Bushman and other South African languages is discernible in the forms of the so-called personal pronouns. They are, as far as we 
know them, n $I$, a thou, ha he, she, il, i we, u you. Of the numcrals, the second, !ku or !ú, at least offers no resemblance either to the same numeral in the Bantu languages, or in Hottentot; and beyond two every higher number is toaya many, although the Bushman may indicate with his fingers to some extent the exact number, e.g. łoaya, showing four fingers, i.e. as many as four, will indicate four, and łoaya, showing seven fingers, seven.

"In this deficiency of higher numerals the Bushman race appears to be even more primitive than the Australian tribes, which generally have distinct names for the numerals as far as three or four. But the exceedingly ancient character of the Bushman language appears to be in no way better indicated than by their very curious phonetic system. It is customary to class Hottentot and Bushman together under the category of clicking languages; and, to a certain extent, this is correct. But in the frequency of these strange sounds, in the number of their varieties, and in the range of organs which are employed in their pronunciation, the Bushman tongue by far exceeds the Hottentot language. In Bushman, clicks are not merely produced by the tongue, but also by the lips. There can be no question that. among the sounds of human language clicks are those which it requires the greatest effort to produce. The study of the history of language shows us that the further the speech of a people develops, the more it throws off such sounds as impede the pronunciation or render it more difficult. Those languages, therefore, in which the sounds are easiest of utterance are the farthest removed from the primitive phonetic systems of human speech, whilst those which abound in uncouth and almost unpronounceable sounds must be presumed to have better retained their ancient phonetic features."

As late as September 1873 Dr. Bleek intimated in an article in the Cape Monthly Magazine that he had not even then completely acquired all the information that he needed. His words were: " the present attempt thoroughly to master the Bushman language has been dictated by purely scientific motives." And in classifying the languages of South Africa, he said:

"Three kinds of native languages are spoken within the borders of this colony:-1, Kaffir, belonging to the great family of prefixpronominal languages, which fill almost the whole of South Africa, 
and extend to the north-west at least as far as Sierra Leonc: 2, Hottentot, the only known South African member of the very extensive sex-denoting family which has spread itself over South Africa, Europe, and a great part of Asia; 3, Bushman, relationship unknown as yet, presenting outward features of the so-called genderless (or as Max Muller calls it, Turanian) class, if related to Hottentot, so exceedingly metamorphosed as to be more different from it than English is from Latin; yet very primitive in its uncouth sounds and in certain structural features, while many others are evidently the result of processes of contraction, and of strong grammatical and phonetical changes, the explanation of which leads us back far into the former history of this original language."

It might be thought that human organs of sound would be incapable of producing a greater variety of clicks and guttural aspirations than those used by Bushmen in ordinary conversation, but it was not so. They put language into the mouths of various animals, and in doing so gave to each variety of beast and bird a peculiar lisp, or grunt, or hiss, or bleat, usually an imitation of the natural sound produced by it, which they introduced in every word. No adult European could ever hope to imitate these sounds, and Dr. Bleek's widow informed the writer that her husband abandoned the attempt in despair. They were not needed, however, for an analytical study of the language, and therefore nothing was lost through not being able to imitate them. To the ordinary clicks a European ear soon becomes accustomed, and they are not then unpleasant, as men find after being long in contact with the Xosas or the Namaqua Hottentots, who, however, use them far more sparingly than did the Bushmen; but the deep guttural sounds proceeding from the throats of the pygmy savages remained always very disagreeable. A Bushman on a hillside calling to another at a distance, for instance, might be said to croak rather than to speak.*

* I state this from my own experience, having heard such unpleasant sounds more than half a century ago. 
A remarkable circumstance in connection with the Bushman language is its possession of a verb of such wonderful power, conjugated by means of particles, that any action that can be expressed in English can be expressed with equal precision in it. In the infancy of the language it is evident that the verb became more highly developed than the other parts of speech, as it may have been more necessary to meet the wants of the people. Stand, run, eat, stood, ran, ate, shall stand, could run, have eaten, for instance, might be more useful words for a savage to know than the names or qualities of the objects around him.

The roots of many Bushman words are apparently poly. syllabic, thus marking a great difference from Hottentot, all of whose roots are monosyllabic. But it is possible that upon very close analysis some of those polysyllables might prove to be really composites.

In counting, besides the method of showing the fingers described by Dr. Bleek, some Bushmen used the expression two two for four, two two one for five, two two two for six, and so on up to ten, beyond which none of them could proceed. The dialects differed from each other as widely as German from English, if not much more so, and it is possible that in some of those now extinct the means for expressing numbers may have been more perfect than in those that are known, in none of which has any word for a numeral higher than three been discovered. They could, however, easily make their friends acquainted with the exact number say of five elands over a ridge by describing them as two lying down, one looking towards the water, and two looking towards a particular hill.

The principal cause of the Bushmen who still survive having lost the use of their ancestral tongue was the extreme facility with which they learned other languages. In this respect their minds were like those of little children, who acquire a foreign tongue, when brought into contact with those who speak it, far more readily than their parents do. A young Bushman on a farm in the interior of the Cape Colony 
in the early years of the nineteenth century, after five or six months' residence, could usually speak Dutch quite fluently. But this acquirement of a new language did not affect his way of thinking or his conduct in any high degree: he remained as he was before, a savage.

The Bushmen occupied the whole of South Africa, except the district bordering on the Indian ocean between the Zambesi and Sabi rivers, until a century or two before the discovery of the Cape of Good Hope by Europeans, * when they were deprived of a considerable portion of it by the people known to us as Hottentots and Bantu, who came down from the north. Being better armed and disciplined than the aboriginal savages, the invaders had little difficulty in exterminating them or driving them into the barren parts.

The variations between the three classes of human beings occupying the country after that event were very marked. In order to bring them clearly before the reader they are given here in consecutive paragraphs, though this chapter deals particularly with the primitive inhabitants only.

Bushmen: frame dwarfish, $\dagger$ colour yellowish brown, face triangular or fox-like in outline, eyes small and deeply sunk, root of nose low, and the whole organ extremely broad, jaws very protuberant, but upper part of face almost vertical, head dotted over with little knots of twisted wiry hair not much larger than peppercorns, in general no beard whatever, ears without lobes, chest particularly well developed, stomach protuberant, back exceedingly hollow, buttocks-especially of. adult females-of very large dimensions, limbs slender, hands

* The time cannot be given more closely than this. That it could not have been longer than a very few centuries will be shown in the chapters upon the Hottentots and the Bantu.

$\uparrow$ Occasionally among the Masarwa in the Betshuana country individuals over one hundred and sixty-seven centimetres or five English feet and a half are found, but these are mixed breeds. They show Bantu blood in their darker colour as well as in their general form and size. On account of their habits they are termed Bushmen by Europeans, but their descent from mixed parentage is known to themselves and to their pure Betshuana neighbours. 
and feet diminutive, arms very long, skin looser than that of other races, so that in times of scarcity or old age it was not only deeply wrinkled, but often formed folds; weapons chiefly bow and poisoned arrow; pursuits those of a hunter; government none but parental and leadership in war and the chase; habitations caverns, rock shelters, holes scooped in the ground, or mats spread over slight frames made of branches of trees; only domestic animal the dog; demeanour that of perfect independence; language abounding in clicks and in deep guttural sounds.

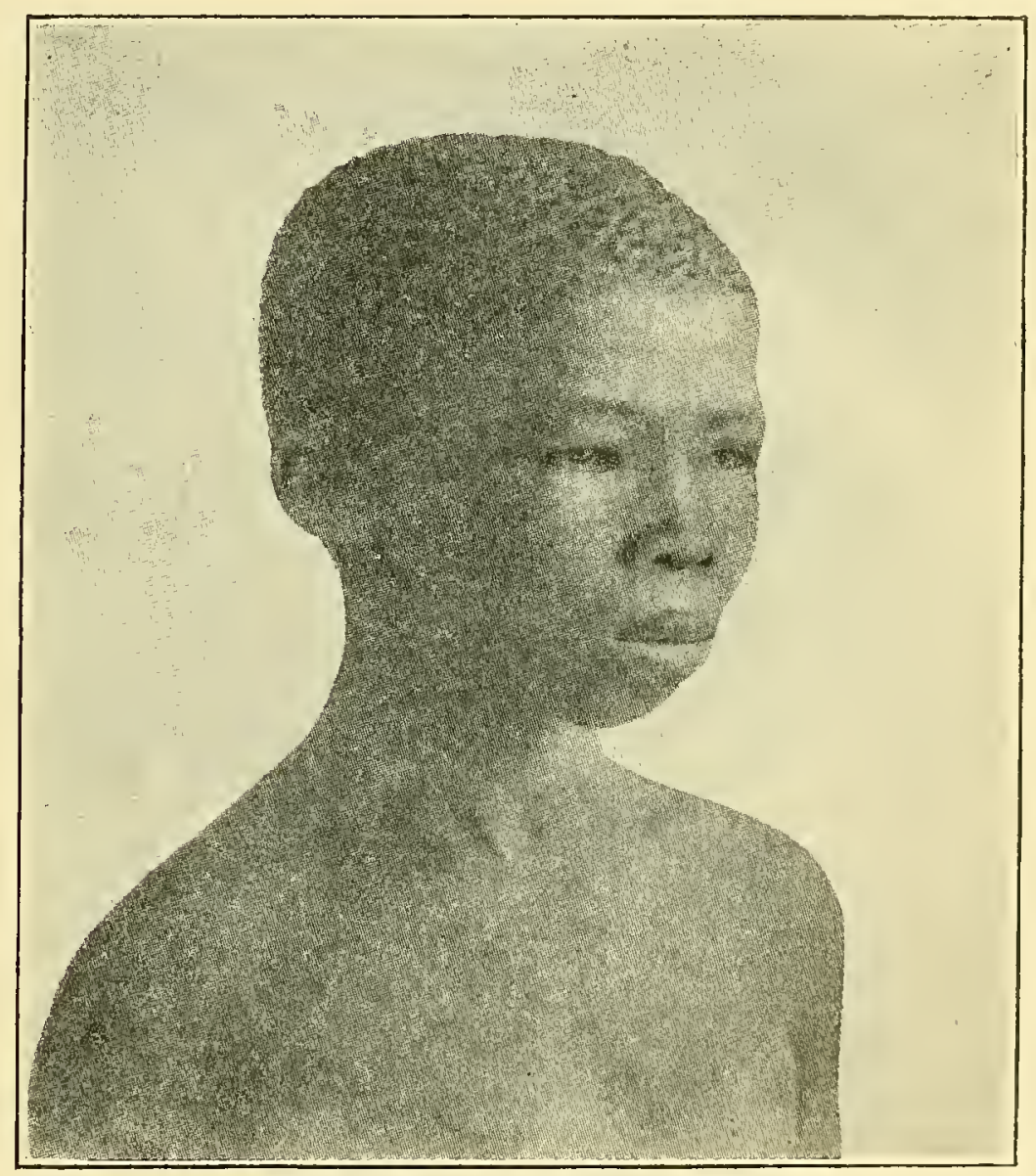

PHOTOGRAPH OF A BUSHMAN GIRL.

Hottentots : frame slight but sometimes tall, better formed than Bushmen, but back hollow, buttocks of the females often protuberant but generally less so than those of Bushmen, 
head scantily covered with little tufts of short crisped hair, occasional marks of beard, cheeks hollow, nose flat, eyes far apart and often to appearance set obliquely, hands and feet small, colour light yellow to olive; weapons assagai, knobkerie, bow and arrow, shield; pursuits pastoral and to a very limited extent metallurgic; government feeble; habitations slender frames of wood covered with reed mats; domestic animals ox, sheep, and dog; demeanour inconstant, marked by levity; language abounding in clicks, but less so than that of the Bushmen, and without the croaking sounds of the wild people.

Bantu: great variety of form and feature in the different tribes, but, generally speaking, frame of those on the coast robust and as well formed as that of Europeans, of those in the interior somewhat weaker, head covered closely with crispy hair, frequently bearded, cheeks full, nose usually flat but occasionally prominent, hands and feet large, colour different tints of brown to deep black; weapons assagai, knobkerie, shield, and among the northern and interior tribes battle-axe and bow and arrow; pursuits agricultural, pastoral, and metallurgic; government firmly constituted with perfect system of laws; habitations strong framework of wood covered with thatch; domestic animals ox, goat, sheep, dog, barnyard poultry; demeanour ceremonious, grave, respectful to superiors in rank; language musical, words abounding in vowels and inflected to produce harmony in sound.

The skull measurements show great differences in the three classes, though the number-especially of Hottentot skulls-carefully examined by competent men is as yet too small for an average to be laid down with precision.

What is termed the horizontal cephalic index, that is the proportion of the breadth of a skull to its length, is given by Professor Sir William Flower, conservator of the museum of the Royal College of Surgeons of England, from thirteen Bantu specimens as 73 to 100 . The highest in this series is $76 \cdot 8$, and the lowest 68.4. Dr. Gustaf Fritsch, from thirteen specimens, gives the average as 72 to 100 . The highest in 
this series is 78, and the lowest 64:3. M. Paul Broca, the French authority, gives the average of his measurements as 72. Thus the Bantu are dolichocephali, that is people whose skulls average in breadth less than three-fourths of their length. The average horizontal cepnalic index of white people is $78 \cdot 7$.

Of Hottentots, only four that are certainly genuine specimens are given in Professor Flower's volume. The average horizontal cephalic index of these is $72 \cdot 7$, the highest being 75 , and the lowest 70.3. Dr. Fritsch had also only four skulls which were certainly those of Hottentots. The average horizontal cephalic index of these he found to be 72.6 , the highest being 77, and the lowest 65.9 . M. Broca gives this index from his measurements as 72. The Hottentots are thus certainly true dolichocephali. But even in those that are regarded as pure Hottentot there may have been a mixture of Bushman blood, from causes that will be explained in the next chapter, so that the skull measurements are not altogether to be depended upon. This, however, would have raised the average, not lowered it.

Of genuine Bushman skulls, Professor Flower gives the measurements of five. The average horizontal cephalic index is $76 \cdot 6$, the highest being $78 \cdot 4$, and the lowest $75 \cdot 7$. The late Dr. George Rolleston, professor of anatomy in the university of Oxford, in an appendix to Oates' Matabeleland, gives the measurements of six Bushman skulls in the museum of the university. The average horizontal cephalic index was $75 \cdot 7$, the highest being 81 , and the lowest 70. Dr. Fritsch measured five Bushman skulls, and found the average horizontal cephalic index $74 \cdot 2$, the highest being $78 \cdot 5$, and the lowest 69.5. M. Broca found the average of his measurements as low as 72 , but it is doubtful whether his specimens were not Hottentot skulls. It would appear that the Bushmen are on the border line separating the dolichocephalie from the mesaticephalic races, the breadth of skulls of the latter averaging between three-fourths and four-fifths of the length. 
The cranial capacity, or size of the brain of each, is given by Professor Flower as: Bantu 1485, Hottentot 1407, and Bushman 1288 cubic centimetres. The average brain of a European is 1497 cubic centimetres in size. Dr. Rolleston found the average cranial capacity of his six Bushman specimens as low as 1195 cubic centimetres, and all other recorded measurements place these people among the extreme microcephalic or small-skulled races. The Hottentots in this classification are mesocephali, a name applied to races whose average cranial capacity is between 1350 and 1450 cubic centimetres, and the Bantu, like Europeans, are megacephali or large skulled.

The alveolar index, index of prognathism, or the slope of a line from the suture at the top of the forehead to the point in the upper jaw between the insertion of the front teeth, is an important characteristic. According to the angle which this line makes with the horizontal plane of the skull, races are classified as orthognathous, mesognathous, or prognathous. In this classification the Bushman comes nearest the European, his face above the upper jaw being much more vertical than that of either of the others. Between the Hottentots and the Bantu there is scarcely any difference.*

A marked feature of the Bushman skull is the smallness of the lower jaw and the want of prominence of the chin. The upper jaw does not overlap the lower as much as in the generality of other races. $\uparrow$ The teeth of the Bushmen did not become loose and fall out, as with us, but they wore down with age, until in extreme cases they were almost level with the jaw. There is wanting in the frame of the Bushman jaw in many instanses the means for firm attachment of the

* Measurements of Bushman, Hottentot, and Bantu crania of high scientific value are given by Mr. Frank C. Shrubsall in a paper forty-four pages in length, entitled Notes on some Bushman Crania and Bones from the South African Museum, Capetown, published in London in 1907 in Volume $V$ of the Annals of the South African Museum.

$\dagger$ A dentist with a very large practice informs me that there are occasional instances of the upper and lower teeth in Europeans meeting, though they are rare. With Bushmen it seems to be constant. 
muscles that move the tongue.* In this respect he is among the least advanced of all races. The lower jaw of the Hottentot is much better formed, but is not by any means as massive as that of a member of the Bantu family or a European. The skulls of the three classes of people described also differ from each other and from those of Europeans in many particulars which are only intelligible to professional anatomists. The subject can be studied in special works, and it is not necessary therefore to enter more deeply into it here. $\dagger$

The pygmy hunters, who were the primitive inhabitants of South Africa, having no word of their own to distinguish themselves from other races, received from the first European colonists the name of Bushmen, on account of their preference for places abounding in bushes or shrubs, where they had a wonderful faculty of concealing themselves, partly owing to the colour of their skins being almost the same as that of the soil.

After the advent of the Hottentots and Bantu the Bushmen lost the ground adjoining the coast that the invaders chose to occupy, but they managed to keep possession for a long time of the mountains and even the lower country between the widely separated kraals of the recent immigrants. Constant war was carried on against them, but they fought with the utmost determination, and could not be expelled as long as a dozen men in any locality remained capable of

* This was pointed out to me many years ago by Dr. Waterston when we were comparing some Hottentot and Bushman skulls in the South Aírican Museum.

$\uparrow$ It is perhaps presumptuous for one who knows nothing of anatomy to venture to make observations upon skull measurements, but it strikes me forcibly that in some particulars at least the form of the cranium might be slightly changed by the food ordinarily consumed by the people. Take, for instance, the Ancient Shellmound Men living for numberless generations on the seacoast of South Africa, and consuming food easily masticated, the muscles that move the lower jaw would not be so powerful as those of people of the same race living upon tough flesh and hard roots. This might in time cause modifications, though maybe very slight, in the bones of the skull. 
making resistance. They never thought of submitting and becoming the slaves of the invaders, but like the lions and leopards whose habits they knew so well, when brought to bay they did all the harm they could to their opponents, and died breathing defiance. The struggle was not over when Europeans arrived on the scene, and the Bushmen at that time still held sole possession of almost the entire interior plain from the Limpopo river southward to the second range of mountains from the sea, of the larger portion of the Kalahari desert and the land bordering on it, and of many parts of the first two steps upwards from the ocean, west, south, and east.

Though regarded and spoken of by the Hottentots and the Bantu as wild animals of a noxious kind that should be exterminated, in one particular this opinion was not acted upon. Bushman girls when captured were generally kept as concubines by the destroyers of their families, and thus a mixture of blood was gradually taking place. Captured girls, unless they could make their escape at once, were detained without difficulty, because if after a time they returned to their own people they were put to death by them as renegades, though under compulsion. Some of the Betshuana indeed, in the early days of their migration southward when they were few in number and weak, endeavoured to fraternise with the Bushmen, and obtained girls without force, from which alliances the people now known as the Masarwa sprang; but as soon as the invaders increased in number and became strong they acted towards the wild hunters as implacable foes, just as all other Bantu did. There never was any intercourse between Bushmen males and Bantu or Hottentot females, as these would have looked with horror upon such a degradation. 


\section{CHAPTER III.}

\section{The Bushmen (continued).}

A CAVE with its front protected from the wind and stormy weather by a few branches of trees, or the centre of a small circle of bushes over which mats or skins of wild animals were stretched, was the best dwelling that they aspired to possess. Failing either of these, they scooped a hole in the ground, placed a few stones round it or bent a few sticks over it, and spread a mat or skin above to serve as a roof. A little grass at the bottom of the hole formed a bed, and though it was not much larger than the nest of an ostrich, an individual by bending the body into a curve could lie down in it. Each person, male or female, except young children, in such circumstances thus required a separate reposing place. Of furniture or implements of any kind except ostrich egg shells for holding water, digging sticks, and bows and arrows with quivers, their abodes were absolutely destitute.

The ordinary food of these people consisted of roots, berries, wild plants, grass seed, locusts, larvæ of ants-now commonly called Bushman rice by European colonists,-honey, gum, fish, reptiles, birds, and mammalia of all kinds. Those who lived on the sea shore gathered oysters, mussels, cockles, and salt water fish for their subsistence. They did not know how to make any kind of boat or raft that could be used on the sea, but gathered all the small fish left in pools among rocks when the tide was low. No chance of plundering the intruding tribes of domestic cattle was allowed to escape them. They were capable of remaining a long time without food,* and could then devour immense

* Dr. Alfred Hillier, who made a special study of these people, was of opinion that this is at least partly due to the great quantity of adipose matter stored up in their protuberant buttocks, which is most observable when they have abundance of food. 
quantities of meat without any ill effects. They were careless of the future, and were happy if the wants of the moment were supplied. Thus, when a large animal was hilled, no trouble was taken to preserve a portion of its flesh, but the time was spent in alternate gorging, sleeping, and dancing, until not a particle of carrion was left. When a drove of domestic cattle was stolen, several were slaughtered at once and their carcases shared with birds of prey, while if their recapture was considered possible, every animal was hamstrung or killed.

Such wanton destruction, more than any other circumstance, caused the wild people to be detested by the Hottentots and the Bantu, as well as by the European colonists at a later date. From their point of view, however, they regarded any injury they could inflict upon members of other races as justifiable. Those races were intruders into the land that had been solely possessed by their ancestors from the earliest times, the game, which was their cattle, was killed without scruple by the invaders of their domains, their fountains and streams were appropriated without their consent, only the deserts were left to them; why then should they not retaliate, and do as much harm as they possibly could to those who had done such grievous wrong to them?

In some parts of the country the Bushmen made long walls by piling up stones, for the purpose of capturing game. These walls were constructed in the form of the sides of an isosceles triangle, with a narrow open space at the apex. Just beyond this was a deep pit carefully covered over, into which the animals that were driven forward fell without chance of escape. The construction of these walls required much labour, but the hunters were not deficient in energy when the capture of game was the end in view, and the embankments were probably only gradually lengthened and increased in height as the utility of the device became more apparent. They made pits for entrapping the elephant and the hippopotamus at the approaches to rivers, and poisoned pools of water, so that any animal which drank perished, Those who lived in the vicinity of streams containing fish used long baskets shaped like scoop nets made of reeds for the purpose 
of capturing the smaller kinds, and speared the huge barbels and yellow fish with harpoons of bone.

Honey was obtained in many localities in large quantities. The bees frequently make their hives in crevices in the faces of precipices, but it was a very lofty precipice that a Bushman would not scale or be lowered down from above to secure the spoil. A peg driven into a crack in the rock or any little projecting ledge gave him a foothold, and no baboon would venture where he feared to go. The comb was used for food, but most of the honey was fermented and consumed as an intoxicant. The Bushmen were inveterate smokers of dacha or wild hemp, a plant widely distributed in South Africa, and which possesses great intoxicating properties.

Their principal weapons were bows and arrows, but when hard pressed by an enemy and in the chase they used anything that came to hand, stones for throwing, sticks, darts, stone-headed spears, or anything else that could be improvised. The bows were nothing more than pieces of saplings or branches of trees scraped down a little and strung with a cord formed by twisting together the sinews of animals. It was thus almost useless in wet weather, as the cord when damp was liable to relax, so at such times the Bushmen never went abroad. The arrows were made of reeds, pointed generally with bone, but sometimes with chipped stone flakes. The arrowhead and the lashing by which it was secured to the reed were coated with a deadly poison, so that the slightest wound caused death. The arrows were carried in a quiver usually made of the bark of a species of euphorbia, which is still called by Europeans in South Africa the kokerboom or quiver tree. They were formidable chiefly on account of the poison, as they could not be projected with accuracy to a distance of over fifty metres, and from their frailty had in general little penetrating power. The most expert Bushmen were able to discharge arrows in very rapid succession and at short distances with a fairly accurate aim.

They-or at least some of them-were acquainted with antidotes to the poisons which they used, but were very careful not to inflict wounds upon themselves or even to allow the deadly 
substance to come in contact with any part of their bodies. The poisons were obtained from snakes, some kinds of caterpillars, and different shrubs.

With the flora in his neighbourhood the Bushman was much better acquainted than Europeans who are not botanists in general are. He knew the qualities of every plant, could at once select those that were edible and reject those that were noxious, and could even make use of those with medicinal properties in case of illness. In this branch of knowledge he had been educated by his mother, when as a little child he went with her daily to seek for food.

The Bushmen used stone flakes for various purposes, but took no trouble to polish them or give them a neat appearance. Many implements were commonly made of horn or bone. There was a stone implement, however, upon which a large amount of care and labour was bestowed in general use among these people when Europeans first became acquainted with them, though it was unknown in very remote times. It was a little spherical boulder, from nine to fourteen centimetres or $3 \frac{1}{2}$ to $5 \frac{1}{2}$ inches in diameter, such as may be picked up in abundance in many parts of the country, through the centre of which the Bushman drilled a hole large enough to receive a digging-stick, to which it gave weight. With the tools at his disposal, this must have required much time and patience, so that in his eyes a stone when drilled undoubtedly had a very high value. On it he depended for food in seasons of drought, when all the game had fled from his part of the country. Drilled stones of smaller size have occasionally been found in places once the favourite abodes of Bushmen, but from which those savages have long since disappeared. None not large enough to give weight to a digging-stick have been seen in use by any European who has put his observations on record, but from Bushman paintings it is known that moderately sized ones were employed as heads of fighting sticks, and it is conjectured that the very small ones were intended as amulets.

It is not safe, however, for a European to make any surmise regarding the use of a stone implement which he has never seen used, because he cannot analyse the working of the mind of 
a savage. Flat circular stones with a hole drilled through the centre have been found in different parts of the country, but until quite recently no one could conceive any use that could be made of them. They were not adapted for digging-sticks, as they were not more than three or four centimetres in thickness, and the surface was too large for such a purpose. What could they have been designed for ?

Not long ago a farmer was digging a pit in his ground near Kimberley, and at some depth below the surface he came across some ostrich eggshells. Still deeper he found a flat stone firmly fixed on the surface of a stratum of rock or very hard ground, and on examination the stone was seen to have a hole in it, which was carefully plugged. When the plug was removed, a little stream of water flowed out, which explained the whole matter. The Bushmen who occupied that part of the country until the beginning of the nineteenth century had desired to conceal the water, in order either to preserve it for themselves alone, or to compel the game to resort to poisoned pools, and therefore had closed the eye of the spring in such a manner that neither animals nor men, except themselves, could have access to it. A European would never have imagined that a stone of this kind was intended for such a purpose, if he had found it by accident somewhere else.*

Mr. Stow mentions various implements of stone which were manufactured by Bushmen with much labour and skill, but these were only produced after their contact with other races, and were confined to small localities. None of them surpassed the common spherical weight as a work of labour or art.

There is no record of a European having ever seen a Bushman manufacturing other stone implements than knives and arrow. heads, and no one except Mr. Stow appears to have made inquiry into the matter until it was impossible to derive any information from the people themselves. Even he commenced his investiga. tions at least half a century too late to gain full knowledge of the

* For this information I am indebted to Miss Wilman, the talented lady who is in charge of the museum at Kimberley, and who takes the keenest interest in researches of this nature. 
matter. But as the various crude unpolished implements found in all parts of South Africa were in use by the Bushmen when white men first came in contact with those savages, there can be no doubt that they fashioned them.

In many other parts of the world perforated stones are plentiful, but most of them differ in some respects from those drilled by the Bushmen, which were all of one type. In the Antiquarian Museum at Edinburgh there is a very fine collection of such stones found in Scotland. There are small ones evidently used in comparatively recent times as weights for nets and in spinning, there are enormously large ones also of not very ancient manufacture, and there are many of the usual size of the Bushman implement. Some are elegantly ornamented, showing the use of tools of metal. Others have holes the same size throughout, leading to a similar conclusion. Those that have holes narrowing from both sides towards the centre, like all the Bushman stones, are usually flat at top and bottom, not globular in form. The Bushman for some unknown reason preferred an approximate sphere, thus any observant eye with a series of each in view would at once detect that they were made by different classes of workmen.

People in a low condition of society do not use clothing for purposes of modesty, but to protect themselves against inclement weather. And as the Bushmen were hardly affected by any degree of either heat or cold that is experienced in South Africa, whether on the plains in midsummer or on the mountains in midwinter, the raiment of the males was usually scanty, and in the chase was thrown entirely aside. At the best it consisted merely of the skin of an animal wrapped round the person. Adult females wore a little apron, and fastened a skin over their shoulders. Both sexes used belts, which in times of scarcity they tightened to assuage the pangs of hunger, and on festive occasions they rubbed their bodies with grease and coloured clays or soot, sometimes pordered with aromatic plants such as buchu, which made them even more ugly than they were by nature.

When the men expected to meet an enemy, they fastened their arrows in an erect position round their heads, in order to appear as formidable as possible. But they never exposed 
themselves unnecessarily to danger, and tried always to attack from an ambush or a place that would give them the advantage of striking the first blow before their adversaries were aware of their presence. A poisoned arrow, shot from a little scrub in which a Bushman was lying concealed, often ended the career of an unwary Hottentot traveller.

This habit caused them to be feared by Hottentots and Bantu alike. There is an excellent representation of the feeling of the Bantu towards the primitive people, given by a Zulu to the reverend Canon Callaway, and published by him in his Nursery Tales, Traditions, and Histories of the Zulus. It reads as follows:

\section{"The Dreadfuliness of the Abatwa.}

"They are dreaded by men; they are not dreadful for the greatness of their bodies, nor for appearing to be men; no, there is no appearance of manliness; and greatness there is none; they are little things, which go under the grass. And a man goes looking in front of him, thinking, 'If there come a man or a wild beast, I shall see.' And, forsooth, an Umutwa is there under the grass ; and the man feels when he is already pierced by an arrow; he looks, but does not see the man who shot it. It is this, then, that takes away the strength; for they will die without seeing the man with whom they will fight. On that account, then, the country of the Abatwa is dreadful; for men do not see the man with whom they are going to fight. The Abatwa are fleas, which are unseen whence they come; yet they teaze a man; they rule over him, they exalt themselves over him, until he is unable to sleep, being unable to lie down, and unable to quiet his heart; for the flea is small; the hand of a man is large; it is necessary that it should lay hold of something which can be felt. Just so are the Abatwa; their strength is like that of the fleas, which have the mastery in the night, and the Abatwa have the mastery through high grass, for it conceals them; they are not seen. That then is the power with which the Abatwa conquer men, concealment, they laying wait for men; they see them for their part, but they are not seen.

"The bow with which they shoot beast or man does not lill by itself alone; it kills because the point of their arrow is smearcd with poison, in order that as soon as it enters, it may cause much blood to flow; blood runs from the whole body, and the man dies 
forthwith. But that poison of theirs, many kinds of it are known to hunters of the elephant. That then is the dreadfulness of the Abatwa, on account of which they are dreaded."

The Bushmen wore few ornaments; not because they were careless about decorating their persons, but because it was difficult to obtain anything for the purpose. They were without metals of any kind, and in the vast interior, as they knew nothing of commerce, they could not obtain sea-shells. The best they could aspire to was to cut little circular disks of tortoise and ostrich eggshell, drill holes in them, and string them on thongs. It requires some reflection to realise the amount of patient labour expended upon a single ornament of this kind, manufactured with stone and bone implements. In other cases they made grooves round the teeth of animals, and then strung a number together. These ornaments were worn on the forehead, and round the neck, arms, waist, and legs. Sometimes a cord of sinew was passed through the nose and ostrich egg-shell disks were strung on each side, which then hung over the cheeks.

A consideration of how much value such a simple implement as a tinder-box would have had to these people may aid in enabling a European to comprehend the life that they led. They knew how to obtain fire by twirling a piece of wood round rapidly in the socket of another piece, but the preparation of the apparatus took much time, and a considerable amount of labour was needed to produce a flame. Under these circumstances it was a task of the women to preserve a fire when once made, and as they moved their habitations to a large animal when it was killed, instead of trying to carry the meat away, this was often a difficult matter. Sometimes it necessitated carrying a burning stick for four or five hours, or, when it was nearly consumed, kindling a fire for the sole purpose of getting another brand to go on with. No small amount of labour would therefore have been saved by the possession of a flint and a piece of steel.

These wild people lived in little communities; often consisting of only a few families. It was impossible for a large number, such as would constitute an important tribe, to gain a subsistence 
solely from the chase and the natural products of the earth in any part of South Africa at any time, and more especially after the Hottentots and the Bantu had taken possession of the choicest sections. When a Bushman tribe is spoken of therefore, the term implies only a puny horde never exceeding two or three hundred souls at most. Such a band claimed the right to a fairly well defined tract of country, and any aggression beyond its borders would naturally be resented by the occupants of the next section. If a mountain intervened, the probabilities would be that the dialects of the language spoken on the different sides would vary so greatly as to prevent intercourse, had there been no other cause to keep each little band within its own bounds. Mr. Stow ascertained that these groups called themselves by the names of the animals that were depicted on the walls of their principal caves or engraved on the rocks at their principal residences, thus one band would be the people of the ostrich, another the people of the python, another the people of the eland, and so on.

The early Dutch colonists observed that they were amazingly prolific, a circumstance that is not surprising if one reflects that they were much less subject to disease than Europeans, and that every woman without exception bore children. Their numbers must therefore in remote times have been kept down by war or violence among themselves, just as they were kept down by constant strife in the territory bordering on that occupied by the Hottentots and Bantu after the intrusion of those people. In such a condition of society there could never have been peace for any length of time, for with a rapid growth of population the only alternatives would have been aggression or death from famine.

There was a difference in the disposition of individual Bushmen, though not to the same extent as is seen in civilised people. Towards the invaders that despoiled them of their game and their hunting grounds it was but natural that they should show rindictiveness and relentless cruelty ; but they were fierce and passionate in their dealings with each other. Human life, even that of their nearest kindred, was sacrificed on very slight provocation. 
They did not understand what quarter in battle meant, and as they never spared an enemy who was in their power, when themselves surrounded so that all hope of escape was gone, they fought till their last man fell. Yet after the colonisation of the country Europeans often observed that many of those who lived temporarily on farms at a distance from their former abodes were not insensible to acts of kindness, and were even capable of feeling gratitude. In this respect they were like those wild animals that in a state of restraint show attachment to their keepers. A pleasing trait in their character was fidelity in positions of trust. At the beginning of the nineteenth century many colonial farmers were in the habit of entrusting herds of cattle to the care of Bushmen in their neighbourhood, supplying them with food and tobacco in return, and seldom found them unfaithful. Another favourable feature was that no distress was so great as to induce them to devour human flesh, as so many Bantu were in the habit of doing.

Their manner of living was such as to develop only qualities essential to hunters. In keenness of vision and fleetness of foot they were surpassed by no people on earth, they could travel immense distances without taking rest, they could scale mountains and steep rocks with the agility of baboons, and yet their frames were so feeble as to be incapable of protracted labour. Their sense of smell was so dull that they experienced no discomfort from remaining for days together close to carrion, and their cave dwellings were disgustingly filthy. The stench from their persons was excessive, owing chiefly to their uncleanly habits and to their use of rancid grease when painting themselves for any festivity.

They possessed an intense love of liberty and of their wild animal way of life. Given only an abundance of food, especially of the flesh of game, and they were cheerful and merry in the highest degree. Mr. Stow states that before the intrusion of the stronger races they were governed by hereditary chiefs, and even down to our own times there have been claimants to such positions. But these chiefs were mere leaders in war and hunting exploits, and their rule did not extend to the exercise of judicial control. Far more than is the case among people possessing domestic eattle, 
each man was independent of every other. Even parental authority was commonly disregarded by a youth as soon as he could provide for his own wants.

Mr. Stow states that polygamy was common among the Bushmen in the days of their undisputed possession of the country. Kicherer, as already stated, affirms that they were polygamists. And Barrow asserts that at Kruger's farm at the Sneeuwberg he saw a Bushman with two wives and a little child. The same writer also, after coming by surprise upon a Bushman horde, remarks that it appeared customary for the elderly men to have two wives, one old and past childbearing and the other young. On this occasion he noticed that all the men had the cartilage of their noses bored, through which they wore a piece of wood or a porcupine's quill.*

The reverend John Campbell, too, when travelling in the country north of the Orange river in 1813, came by surprise upon a party of Bushmen, and states that their leader, whom he called Makoon, had two wives, each only about four feet in height. $\dagger$ The same traveller in 1820 was at a farm just beyond the mountains a short distance north of Beaufort West, where about fifty individuals, men, women, and children, of the Bushman race were living. Mr. Smit, the owner of the farm, spoke their language fluently. He gave Mr. Campbell much information upon them, and stated: "they make use of no form or ceremony at their marriages, if marriages they can be called. The men have frequently four or five wives, and often exchange wives with each other." +

* Travels into the Interior of Southern Africa, in which are described the character and the condition of the Dutch Colonists of the Cape of Good Hope and of the several tribes of natives beyond its limits, \&c., \&c., \&c. By John Barrow. Two quarto volumes, published at London in 1801-1.

$\dagger$ Travels in South Africa undertaken at the request of the Missionary Society, by John Campbell, Minister of Kingsland Chapel. Demi octavo, 400 pages, London, 1815. The incident referred to is mentioned on pages 235 and 236 .

\pm Travels in South Africa undertaken at the request of the London Missionary Society, being a Narrative of a Second Journey in the Interior of that Country. By the Rev. John Campbell. Two octavo volumes, London, 182\%. The statement transcribed above is on page 30 of the first rolume. 
With all this evidence to the contrary, it would be rash to assert that the Bushmen were strict monogamists. Circumstances would appear to have governed them in this respect. If the number of females in any locality was much greater than that of males, polygamy would be the natural result, for of course the men would have no qualms of conscience about the practice. But when the sexes were equal, or nearly equal, monogamy was the rule.

It is certain that in modern days the instances of a man living with more than one woman at a time have been exceedingly rare. Niss Lloyd, after long inquiry, could learn of but one such case, and Mr. Dunn and other investigators could hear of none whatever. That is not to say that one male and one female attached themselves to each other for life, though this may often have occurred; but that as long as they lived together a second man or a second woman was not admitted as a member of the family. Their passionate tempers prevented the presence of rivals in the same abode. Chastity, however, was unknown and uncared for, and any disagreement was sufficient to cause the separation of the man and woman, when new connections could immediately be formed by both. In general there was no marriage ceremony, the mere consent of both parties being all that was needed, but in some of the communities a youth who desired to take to himself a girl was obliged to prove himself a man by fighting with others for her and wimning her by victory.

The Bushmen possessed several musical instruments, but all of the crudest kind. The most common was a bow, with a piece of quill attached in the cord, with which by blowing and inhaling the breath a noise agreeable to their ears was produced. Pieces of reed of different lengths were used as flutes, and a drum was formed by stretching a dried antelope skin over any hollow article. To their persons when dancing they attached rattles, made of hollow globes of dried hide containing pebbles, which added to the noise of the rude chant and the stamping of the feet.

They were fond of dancing by moonlight, after abundance of flesh had been obtained by the slaughter of some large animal. 
There were various kinds of dances, each of which had its appropriate chant, but nearly all consisted of contortions of the body rather than of movements from place to place. Some of them were lascivious to the last degree, for the savages were devoid of all feeling of shame. Others, which perhaps must be considered the highest in order, were imitations of the actions of different animals. These dances caused much excitement, one especially, which was attended with great exertion of the body, frequently causing blood to flow from the noses of some of the performers and ending in the utter exhaustion of others.

The games that they practised were chiefly imitation hunts; in which some or all of them were disguised and represented animals. In this pastime they displayed much cleverness, whether they acted as men, or as baboons, or as lions in pursuit of antelopes. But it was not often that they engaged in play, for the effort to sustain existence was with them severe and almost constant.

At early dawn the Bushman rose from his bed of grass, and scanned the country around in search of game. If any living thing was within range of his far-seeing eye, he grasped his bow and quiver of arrows, and with his dog set off in pursuit. His wife and children followed, carrying fire and collecting bulbs and anything else that was edible on the way. They could pursue his track unerringly by indications that would escape the keenest European eye : a broken twig, a freshly turned stone, or bent blades of grass being sufficient to guide them aright. At nightfall, if they were fortunate, they collected about the body of an antelope, and there they remained till nothing that could be consumed was left. Or if a small animal was lilled early in the day, it might be carried to the cave where they and others had their chief abode, to be generously shared with all the occupants, for in this respect the wild people were unselfish to the last degree. Such in general was their mode of existence, varied occasionally by either a great feast with boisterous revelry or a dire famine and tightened hunger belts. And so from day to day and year to year life passed on, without anything of an intellectual nature to ennoble it. 
If the stone, hom, and bone implements, the weapons of the chase, the crude musical instruments, and the shell beads already mentioned be excluded, the Bushmen had little know. ledge of manufactures. They had not advanced beyond the stage of making a coarse kind of pottery, and even this was extremely limited in use. But as they were artists, occasionally they attempted to decorate a jar by making a circle of lines or notches round it, which really had a neat effect. Add to this industry the plaiting of rush mats and net bags of fibres, in which their women carried ostrich egg-shells filled with water, and the list is exhausted.

They were firm believers in charms and witchcraft, and were always in dread of violating some custom-as for instance avoiding casting a shadow upon dying game-which they believed would cause disaster. A Bushman would not make a hole in the sandy bed of a river in order to obtain water, without first offering a little piece of meat, or some larvæ of ants, or an arrow if he had nothing else, to propitiate the spirit of the stream, that was imagined by him to have the figure of a man hideous in aspect, and capable of making himself visible or invisible at will. And so with every act of his life, something had to be done or avoided to avert evil, to bring game within reach of his arrows, or to make the wild plants appear.

Their reasoning power was very low. They understood the habits of wild animals better than anything else, yet they believed the different species of game could converse with each other, and that there were animals and human beings who could exchange their forms at will, for instance that there were girls who could change themselves into lions, and baboons that could put on the appearance of men. The moon, according to the ideas of some of them, was a living thing, according to the notions of others it was a piece of hide which a man threw into the sky. In the same way the stars were once human beings, or they were pieces of food hurled into the air. As well might one attempt to get reasons for their fancies from European children six or seven years of age as from Bushmen: the reflective faculties of one were as fully developed as of the other. 
Drs. Bleek and Lloyd obtained from several individuals prayers to the moon and stars, but everything connected with their religion - that is their dread of something outside of and more powerful than themselves-was vague and uncertain. They could give no explanation whatever about it, and they did not all hold the same opinions on the subject. Some of them spoke indeed of a powerful being termed 'Kaang or 'Cagn, but when questioned about him, their replies showed that they held him to be a man like themselves, though possessing charms of great power. Many are supposed to have had a vague belief in immortality, because they buried a dead man's weapons with him and laid the corpse with its face towards the rising sun, and their custom of cutting off a joint of the little finger was imagined to be due to a belief that by doing so they would secure an abundance of food in the future life; 'but probably very few of them ever gave a thought to such a matter. The wants of the present were sufficient to occupy their attention.

They buried their dead in shallow graves, over which they piled stones to prevent wild animals scraping the bodies up. In a cavity scooped out of the western wall of the grave the corpse was placed on its side, bent in a curve such as when sleeping it formed in life, ${ }^{*}$ with its face turned towards the east. The bones were not broken, as by some Bantu, and as well as can be ascertained, all adult human bodies were interred. It is remarkable that the Bushmen should have performed the labour of making graves and raising cairns over them, when the Hottentots, who were so much superior to them in civilisation, looked for an anteater's den or some natural cavity in which to lay their dead, and many tribes of Bantu, so much higher still, did not bury the corpses of common people at all, but left them exposed in solitary places to be devoured by beasts of prey.

It is difficult to conceive of a human being in a more degraded condition than that of a Bushman. In some

* Dr. Peringuey informs me that all the Bushman skeletons found by his correspondents had the knees drawn up to the chins. 
respects, however, he showed considerable ability, and there. was certainly an enormous gulf between him and the highest of the brute creation. He possessed extraordinary powers of mimicry. Enclosed in a framework covered with the skin and plumage of an ostrich, he was in the habit of stalking game, and by carefully keeping his prey to windward, was able to approach within shooting distance, when the poison of his arrow completed the task. This, though the commonest disguise of a hunter, was but one of many, which varied according to circumstances. He could imitate the peculiarities of individuals of other races with whom he came in contact, and was fond of creating mirth by exhibiting them in the drollest manner.

In recent times travellers have noticed that the Bushmen are fond of showing their superiority to the large black men whenever they can do so. Thus in rainy weather when a number of Bakwena are endeavouring in vain to kindle a fire in the open air, a Bushman will look on with a smile of contempt until they desist, when he will produce his fire sticks and accomplish what they could not do. Or if they fail to find water on the border of the desert, he will wait till they are almost speechless from thirst, and then apparently by some instinct lead the way to a place where a little may be obtained by digging. In such cases he exhibits great satisfaction and pride.

And what is most remarkable in a being whose ordinary habits were not much more elevated than those of animals, he was an artist. In caverns, on the walls of caves, and on the sheltered sides of great rocks he drew pictures in profile of the animals with which he was acquainted, and then painted the spaces outlined. The tints were made with different kinds of ochre having considerable capability of withstanding the decay of time, and they were mixed with grease, so that they penetrated the rock more or less deeply according to its porousness. There are caves on the margins of rivers containing paintings which have been exposed to the action of water during occasional floods for at least a hundred 
and fifty years, and the colours are yet unfaded where the rock has not crumbled away.*

In point of artistic merit, however, the paintings were seldom superior to the drawings on slates made by European children eight or nine years of age, though there were occasional instances of game being delineated not only in a fairly correct but in a graceful manner, showing that some of the workmen possessed more skill than others. In none of them was any knowledge of perspective, and in only one or two of the very best any attempt at shading displayed. Two or more colours were sometimes used, for instance, the head or legs of an animal might be white, and the remainder of the body brown, but-with extremely rare exceptions-each colour was evenly laid on as far as it went. In short, the paintings might be mistaken for the work of children, but for the high positions of many of them on the rocks, and the scenes being chiefly those of the chase. A peculiarity in them is that the human form is almost invariably grotesquely outlined. The lion also is never represented perfectly, probably from a superstitious fear of offending the formidable animal that often furnished food by leaving parts of the large antelopes uneaten, and that could when provoked do so much harm. In only a few of the paintings are the feet of the animals shown. Sometimes disguises are represented, usually a man's body with an animal's head, though these are rare. $\uparrow$

In some places, where the rock was very smooth and hard, the Bushman drew an outline of a figure, and then

* I have seen pictures made by Bushmen on the banks of the Keiskama which in 1878 looked as fresh as if painted the day before. The Xosa chief Rarabe crossed the Kei about 1745, and shortly afterwards destroyed all the Bushmen along the Keiskana, so that the paintings must have been made before that date. But that is only a short time compared with the age of those recently discovered by Mr. R. N. Hall in Rhodesia, which must be over a thousand years old.

$\uparrow$ Copies of many of these paintings have been published in different books. In 1909 a large volume entitled Bushman Paintings, collected by Miss Helen Tongue and Miss Dorothy Bleek, was published at Oxford. 
chipped away the surface within it or the lines along it. The labour required for such a task, without metallic implements, must have been great, and the workman was undoubtedly possessed of much patience. He was a sculptor in the elementary stage of the art. Mr. Stow believed that the engravers and painters were distinct branches of the race, and

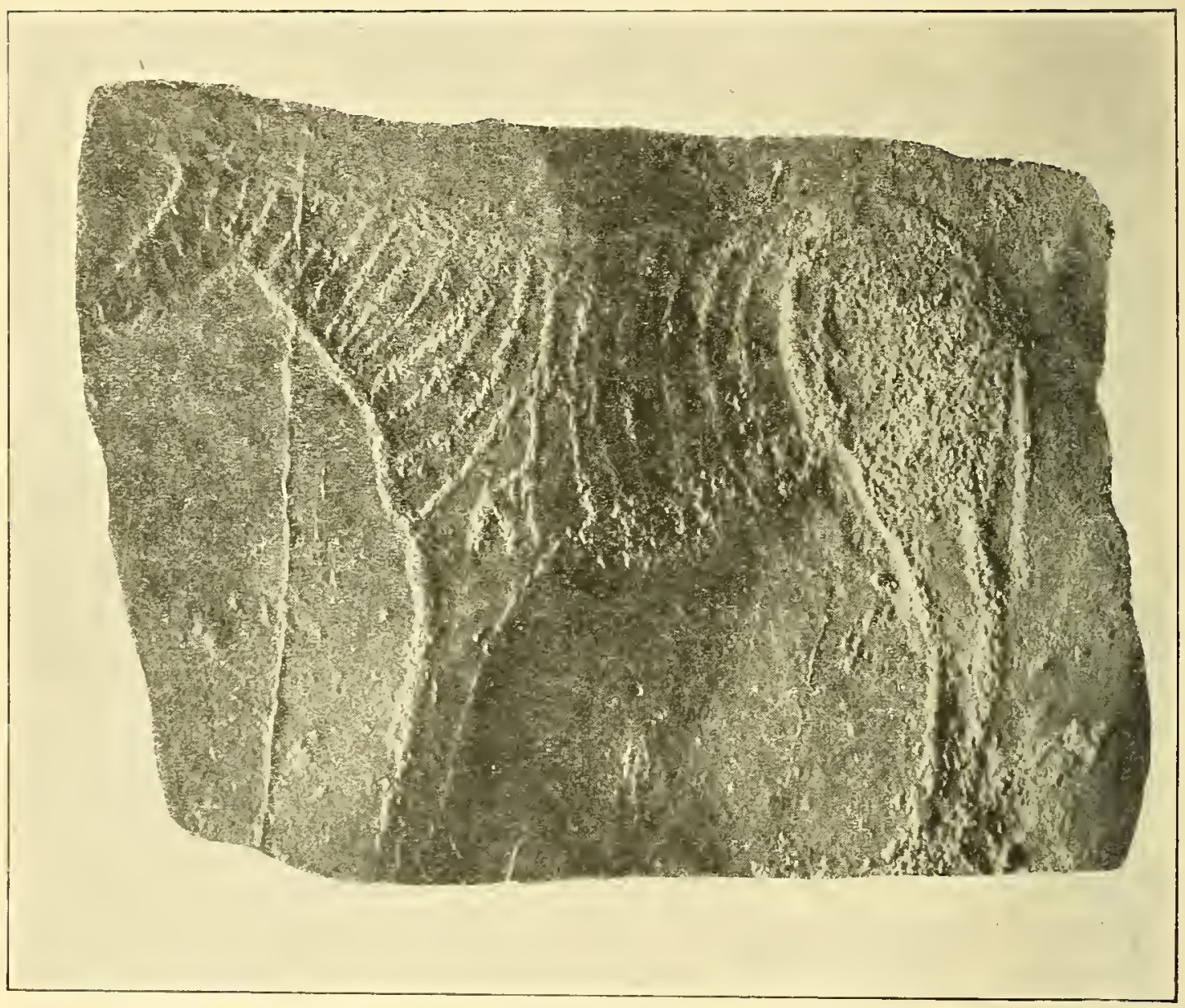

EXGRAVING OF A ZEBRA ON A ROCK IN THE DISTRICT OF VRYBURG. (From a Photograph of a cast in the South African Museum in Capetown. The original is thirteen inches in length.)

in his work he classified them as such. Dr. Lloyd, however, was of opinion that the method of delineating the figures depended merely upon the condition of the locality, the artists being the same, and with this view Messrs. Bain, Dumn, and other investigators agree.

The late Mr. R. N. Hall, the well-known archæologist, who made very extensive explorations in Rhodesia, and who 
discovered a great number of Bushman paintings and engravings, asserted that the oldest he found there are superior as works of art to the more modern. All of them were executed before the arrival of Bantu in the country, for there is not a single instance of individuals of that race or of their weapons being represented, and the Bushmen were entirely exterminated by the Bantu invaders.* These paintings and engravings must therefore be at least over a thousand years of age. The engravings are not easily discovered, as the rocks upon which they were made have completely resumed their original colour. Some of the paintings were executed over others that had become faded. from long exposure, and there are even instances where this has taken place three or four times. Who can say when the earliest of them was executed?

Mr. Hall compares the pictures and engravings of the Aurignacian negroids in Europe with those of the Bushmen in Rhodesia, and shows them to be similar in almost every respect. This extends even to the peculiar attitudes that some of the artists must have placed themselves in. $\mathrm{H}_{\ominus}$ states that "some must have painted while lying prone on their chests or sideways, and on their backs inside narrow or low fissures; an average sized European could not have painted some of the pictures which are in difficult positions. Many are ten and sixteen feet above ground level."

In addition to artistic instincts, the wild people possessed a faculty - it might almost be termed an additional sense-of which Europeans are destitute. They could make their way in a straight line to any place where they had been before. Even a child nine or ten years of age, removed from its parents to a distance of several days' journey, and without opportunity of carefully observing the features of the country traversed, could months later return unerringly. They could give no explanation of the means by which they accomplished a task seemingly so difficult. Many of the inferior

* See Antiquity of the Bushman Occupation of Rhodesia, a paper read before the Rhodesia Scientific Association, and published with plates, in a demi octavo pamphlet of fifteen pages at Bulawayo in June 1912. 
animals, however, have this faculty, as notably the dove, so that it is not surprising to find the lowest type of man in possession of it.

The life led by these savages was in truth a wretched one, judged from a European standard. They had no contact with people beyond their own little communities, except in war, for they carried on no commerce. If a pestilence had swept them all from the face of the earth, nothing more would have been left to mark where they had once been than the drilled stones, rudely shaped arrowheads, rough pottery, rock paintings, and crude sculptures. Their pleasures were hardly superior to those of dumb animals. But it is not correct to look at them from this standpoint, or to compare them with white people reduced to the same level of poverty. They knew of nothing better, they were all in the same condition and shared alike, so that envy was not felt, their cares were very few, and serious illness was hardly known among them. They probably enjoyed, therefore, more real happiness in life than the destitute class in any European city.

They had a rich stock of traditionary stories, which old women told to little children by evening fires, when food was plentiful and the able-bodied were enjoying themselves in other ways In Drs. Bleek and L. C. Lloyd's book a number of these folklore tales can be found, and it must be remembered that even the grown-up people believed them to be true narratives, for they were as credulous in such matters as infants could be. But judging from the manner in which Bantu women tell such stories, a great deal of their interest is lost when they are read in print. A Xosa woman when narrating one of them displays all kinds of gestures, alters her voice in the dialogues, and sings the parts capable of such treatment, in short, puts life into the tale. It may be taken for certain that a Bushwoman did the same, and so even the endless repetitions of the same thing would not be wearisome, especially to children. The following are literal translations of two such stories, taken down by Miss Lloyd from the dictation of a Bushman named |hanłkass'o, and published by her in the Folklore Journal of May 1880 : 


\section{"The Son of the Wind.}

"The wind (the narrator explains the Son of the Wind is here meant) was formerly still. And he rolled (a ball) to !ná-ka-ti. He exclaimed, 'Oh !ná-ka-ti there it goes.' And !ná-ka-ti exclaimed, 'Oh comrade! there it goes!' because !ná-ka-ti did not know his (the other one's) name. Therefore !ná-ka-ti said, 'Oh comrade! there it goes!' He who was the wind, he was the one who said, 'Oh! !ná-ka-ti ! there it goes.'

"Therefore !ná-ka-ti went to question his mother about the other one's name. He exclaimed, 'Oh! our mother! utter for me yonder comrade's name; for com ade utters my name; I do not utter comrade's name. I would also utter comrade's name when I am rolling (a ball) to him. For I do not utter comrade's name; I would also utter his name when I roll a ball to him.' Therefore his mother exclaimed, 'I will not utter to thee comrade's name. For thou shalt wait, that father may first strongly shelter the hut ; and then I will utter for thee comrade's name. And thou shalt, when I have uttered for thee comrade's name, thou must, when I am the one who has uttered for thee comrade's name, thou must scamper away, thou must run home, that thou mayest come into the hut, whilst thou feelest that the wind would blow thee away.'

"Therefore the child went away; they (the two children) went to roll (the ball) there. Therefore he (!na-ka-ti) again went to his mother, he again went to question his mother about the other one's name. And his mother exclaimed, |érriten-!kuan-!kuan it is ; !gau-!gaubu-ti it is. He is |erriten-!kuan-!kuan; he is !gau-!gaubu-ti, he is |erriten-!kuan-!kuan.'

"Therefore !ná-ka-ti went away. He went to roll (the ball) there, while he did not utter the other one's name, because he felt that his mother was the one who had thus spoken to him. She said, 'Thou must not, at first, utter comrade's name. Thou must, at first, be silent, even if comrade be the one who is uttering thy name. Therefore thou shalt, when thou hast uttered comrade's name, thou must run home, whilst thou feelest that the wind rould blow thee away.'

"Therefore !ná-ka-ti went away. They went to roll (the ball) there, while the other was the one who uttered his (!na-ka-ti's) name; while he felt that he (!ná-ka-ti) intended that his father 
might first finish sheltering the hut, and (when) he beheld that his father sat down, then he would, afterwards, utter the other one's name, when he saw that his father had finished sheltering the hut.

"Therefore, when he beheld thst his father finished sheltering the hut, then he exclaimed, 'There it goes! Oh |érriten-!kuan!kuan! there it goes! Oh !gau-!gaubu-ti! there it goes!' And he scampered away, he ran home; while the other one began to lean over, and the other one fell down. He lay kicking (violently) upon the flat ground. Therefore the people's huts vanished away; the wind blew away their (sheltering) bushes, together with the huts, while the people could not see for the dust. Therefore, his (the wind's) mother came out of the hut (i.e. of the wind's hut); his mother came to raise him up; his mother grasping (him), set him on his feet. And he was unwilling, (and) wanted to lie still. His mother, taking hold (of him), set him upright. Therefore, the wind became still; while the wind had, at first, while it lay, made the dust rise.

"Therefore, we who are Bushmen, we are wont to say, "The wind seems to have lain down, for it does not gently blow = it blows very strongly).' For, when it stands (upright), then it is wont to be still, if it stands; for it seems to have lain down, when it feels like this. Its knee is that which makes a noise, if it lies down, for its knee does make a noise."

\section{"The Wind.}

"The wind was formerly a person. He became a feathered thing (i.e. a bird). And he flew, while he no longer walked as formerly; for he flew, and he dwelt in the mountains (that is, in a mountain hole). Therefore he flew. He was formerly a person. Therefore he formerly rolled (a ball); he shot; while he felt that he was a person. He became a feathered thing; and then he flew, and he inhabited a mountain hole. And he was coming out of it, he flew about, and he returns home to it. And he comes to sleep in it; and he early awakes (and) goes out of it; he flies away; again he flies away. And he again returns home, while he feels that he has sought food. And he eats, about, about, about, about, he again returns home. And he, again, comes to sleep in it (that is, in his hole)."

The third story given here was taken down by Joseph M. Orpen, Esqre., British resident in Griqualand East, from the lips 
of a Bushman named Qing, who lived in the Maluti mountains. It was published by Mr. Orpen, with other tales and descriptive matter, in the Cape Monthly Magazine for July 1874, under the title of A Glimpse into the Mythology of the Maluti Bushmen. Nr. Orpen does not use the usual signs for the clicks in the Bushman words, but the letters which in the Xosa dialect are employed to represent three of them.

\section{"Story of Cagn.}

"Cagn sent Cogaz (his eldest son) to cut sticks to make bows. When Cogaz came to the bush, the baboons (co'gn) caught him. They called all the other baboons together to hear him, and they asked him who sent him there. He said his father sent him to cut sticks to make bows. So they said, "your father thinks himself more clever than we are; he wants those bows to kill us, so we'll kill you,' and they killed Cogaz, and tied him up in the top of a tree, and they danced round the tree, singing (an intranscribable baboon song), with a chorus saying 'Cagn thinks he is clever.' Cagn was asleep when Cogaz was killed, but when he awoke he told Coti (his wife) to give him his charms, and he put some on his nose, and said the baboons have hung Cogaz. So he went to where the baboons were, and when they saw him coming close by, they changed their song so as to omit the words about Cagn, but a little baboon girl said, 'don't sing that way, sing the way you were singing before.' And Cagn said, 'sing as the little girl wishes,' and they sang and danced away as before. And Cagn said, 'that is the song I heard, that is what I wanted, go on dancing till I return ;' and he went and fetched a basket full of pegs, and he went behind each of them as they were dancing and making a great dust, and he drove a peg into each one's back, and gave it a crack, and sent them off to the mountains to live on roots, beetles, and scorpions, as a punishment. Before that baboons were men, but since that they have tails, and their tails hang crooked. Then Cagn took Cogaz down, and gave him canna, and made him live again."

The following story is taken from the volume Bushman Folklore by Drs. Bleek and Lloyd. Absurd as it may seem to European readers, the narrator believed that the events recorded were actual facts. 


\section{The Mantis assumes the form of a Hartebeest.}

The Mantis is one who cheated the children, by becoming a hartebeest, by resembling a dead hartebeest. He feigning death lay in front of the children, when the children went to seek plants, because he thought (wished) that the children should cut him up with a stone knife, as these children did not possess metal knives.

The children perceived him, when he had laid himself stretched out, while his horns were turned backwards. The children then said to each other: "It is a hartebeest that yonder lies; it is dead." The children jumped for joy (saying): "Our hartebeest! we shall eat great meat." They broke off stone lnnives by striking, they skinned the Mantis. The skin of the Mantis snatched itself quickly out of the children's hands. They say to each other: "Hold thou strongly fast for me the hartebeest skin!" Another child said: "The hartebeest skin pulled at me."

Her elder sister said: "It does seem that the hartebeest has not a wound from the people who shot it, for the hartebeest appears to have died of itself. Although the hartebeest is fat, the hartebeest has no shooting wound."

Her elder sister cut off a shoulder of the hartebeest, and put it down (on a bush). The hartebeest's shoulder arose by itself, it sat down nicely (on the other side of the bush) while it placed itself nicely. She (then) cut off a thigh of the hartebeest, and put it down (on a bush); it placed itself nicely on the bush. She cut off another shoulder of the hartebeest, and put it upon (another) bush. It arose, and sat upon a soft (portion of the) bush; as it felt that the bush (upon which the child had laid it) pricked it.

Another elder sister cut off the other thigh of the hartebeest. They spoke thus: "This hartebeest's flesh does move; that must be why it shrinks away."

They arrange their burdens; one says to the other: "Cut and break off the hartebeest's neck, so that thy younger sister may carry the hartebeest's head, for (thy) yonder sitting elder sister, she shall carry the hartebeest's back, she who is a big girl. For we must carrying return (home), for we came (and) 
cut up this hartebeest. Its flesh moves, its flesh snatches itself out of our hand. If of itself places itself nicely."

They take up the flesh of the mantis; they say to the child : "Carry the hartebeest's head, that father may put it to roast for you." The child slung on the hartebeest's head, she called to her sisters: "Taking hold, help me up; this hartebeest's head is not light." Her sisters taking hold of her holp her up.

They go away, they return (home). The hartebeest's head slips downwards, because the mantis's head wishes to stand on the ground. The child lifts it up (with her shoulders), the hartebeest's head (by turning a little) removes the thong from the hartebeest's eye. The hartebeest's head was whispering, it whispering said to the child: " $\mathrm{O}$ child! the thong is standing in front of my eye. Take away for me the thong; the thong is shutting my eye." The child looked behind her; the mantis winked at the child. The child whimpered; her elder sister looked back at her. Her elder sister called to her: "Come forward quickly; we return (home)."

The child exclaimed: "This hartebeest's head is able to speak." Her elder sister scolded her: "Lying come forward; we go. Art thou not coming deceiving (us) about the hartebeest's head?"

The child said to her elder sister: "The hartebeest has winked at me with the hartebeest's eye; the hartebeest desired that I should take away the thong from his eye. Thus it was that the hartebeest's head lay looking behind my back." The child looked back at the hartebeest's head, the hartebeest opened and shut its eyes. The child said to her elder sister: "The hartebeest's head must be alive, for it is opening and shutting its eyes."

The child, walking on, unloosened the thong; the child let fall the hartebeest's head. The mantis scolded the child, he complained about his head. He scolded the child: "Oh! oh! my head! Oh! bad little person! hurting me in my head."

Her sisters let fall the flesh of the mantis. The flesh of the mantis sprang together, it quickly joined itself to the lower part of the mantis's back. The head of the mantis quickly joined (itself) upon the top of the neck of the mantis. The 
neck of the mantis quickly joined (itself) upon the upper part of the mantis's spine. The upper part of the mantis's spine joined itself to the mantis's back. The thigh of the mantis sprang forward, it joined itself to the mantis's back. His other thigh ran forward, racing it joined itself to the other side of the mantis's back. The chest of the mantis ran forward, it joined itself to the front side of the upper part of the mantis's spine. The shoulder blade of the mantis ran forward, it joined itself on to the ribs of the mantis. The other shoulder blade of the mantis ran forward, while it felt that the ribs of the mantis had joined themselves on, when they raced.

The children still ran on; he (the mantis) arose from the ground and ran, while he chased the children,-he being whole, his head being round, - while he felt that he was a man. Therefore he was stepping along with (his) shoes, while he jogged with his shoulder blade. He saw that the children had reached home; he quickly turned about, he, jogging with his shoulder blade, descended to the river. He went along the river bed, making a noise as he stepped in the soft sand, he yonder went quickly out of the river bed. He returned, coming out at a different side of the house; he returned, passing in front of the house.

The children said: "We have been (and) seen a hartebeest which was dead. That hartebeest, it was the one which we cut up with stone knives; its flesh quivered. The hartebeest's flesh quickly snatched itself out of our hands. It by itself was placing itself nicely upon bushes which were comfortable; while the hartebeest felt that the hartebeest's head would go along whispering. While the child who sits there carried it, it talking stood behind the child's back."

The child said to her father: "O father! dost thou seem to think that the hartebeest's head did not talk to me? For the hartebeest's head felt that it would be looking at the hole above the nape of my neck, as I went along; and then it was that the hartebeest's head told me that I should take away for him the thong from his eye. For the thong lay in front of his eye."

Her father said to them: "Have you been and cut up the old man, the mantis, while he lay pretending to be dead in front of you?" 
The children said: "We thought that the hartebeest's horns were there, the hartebeest had hair. The hartebecst was one which had not an arrow's wound; while the hartebeest felt that the hartebeest would talk. Therefore the hartebeest came and chased us, when we had put down the hartebeest's flesh. The hartebeest's flesh jumped together, while it springing gathered (itself) together, that it might mend, that it might mending hold together to the hartebeest's back. The hartebeest's back also joined on. Therefore the hartebeest ran forward, while his body was red, when he had no hair (that coat of hair in which he had been lying down) as he ran, swinging his arm like a man. And when he saw that we reached the house, he whisked round. He ran, kicking up his heels (showing the white soles of his shoes), while he running went before the wind, while the sun shone upon his feet's face (soles), while he ran with all his might into the little river (bed), that he might pass behind the back of the hill lying yonder."

Their parents said to the children: "You are those who went and cut up the old man. He, there behind, was one who gently came from out the place there behind."

The children said to their fathers: "He has gone round, he ran fast. He always seems as if he would come over the little hill lying yonder when he sees that we are just reaching home. While this little daughter, she was the one to whom the hartebeest's head, going along, talked, and then she told us. Therefore we let fall the hartebeest's flesh; wo laid our karosses on our shoulders, that we might run very fast. While its flesh running came together on its back, it finished mending itself. He arose and ran forward, he, quickly moving his arms, chased us. Therefore we did thus, we became tired from it, on account of the running with which he had chased us, while he did verily move his arms fast. Then he descended into the small river, while he thought that he would, moving his arms fast, run along the small river. Then he thus did, he, picking up wood, came out; while we sat, feeling the fatigue, because he had been deceiving. While he felt that all the people saw him, when we came carrying his thighs, when he went to die lying in front of us; while he wished that we should feel this fatigue, while this child here, it carried his head, he looked up with fixed eyes. He was as if he was 
dead; he was (afterwards) opening and shutting his eyes; he afar lay talking. He talked while he mended his body; his head talked while he mended his body. His head talking reached his back; it came to join upon the top of his neck. He ran forward; he yonder will sit deceiving while we did cut him up with stone knives. He went feigning death to lie in front of us, that we might do so, we ran. This fatigue, it is that which we are feeling, and our hearts burnt on account of it. Therefore we shall not hunt (for food), for we shall altogether remain at home."

It can now be asserted in positive language that the Bushmen were incapable of adopting European civilisation. During the first half of the nineteenth century agents of various missionary societies made strenuous efforts for their improvement, and often believed they had in some cases succeeded and in others were in a fair way towards success. Men more devoted to their work than many of these missionaries have never existed, and it would be unjust to accuse them of wilfully misstating the results of their teaching, but the very excess of their zeal and their dwelling constantly upon the expression that the whole human family is of one blood, without reflecting that different branches of it even in Europe are incapable of thinking alike, led them to distort what they saw and heard, so that their reports are commonly misleading. In these reports Bushmen were represented as having become civilised and Christian. But no one else ever saw those transformed savages, and no trace of them exists at the present day. The wild people in the missionary writings are described as offshoots of a higher stock, degraded by oppression or neglect, and needing only instruction and gentle treatment to elevate them again. Some of the reasoning in favour of this theory is highly acute, but it is not borne out by the deeper investigations of our day.

Apart from missionary teaching also many persons tried during long years to induce families of Bushmen to abandon their savage habits, and there were even experiments in providing groups of them with domestic cattle, in order to 
encourage a pastoral life, but all were without success. To this day there has not been a single instance of a Bushman of pure blood having permanently adopted the habits of a white man, though a few mixed breeds from Hottentol and Bantu fathers are to be found among the least skilful class of labourers in some parts of the country. Even these are generally too feeble in body to endure anything like severe toil, and unless they intermingle with blacks quickly decrease in number. Those of unmixed blood who were not destroyed as noxious animals by the invaders of their hunting grounds could not exist in presence of a high civilisation, but dwindled away rapidly, and have now nearly died out altogether. It would seem that for them progress was possible in no other way than by exceedingly slow development and blending their blood in successive stages with races always a little more advanced.

\section{The Katia.}

A small community of savages calling themselves kãi, known to other Bushmen as Xatia, and to Europeans as the Katia (Kat-ee-ah), is found in Betshuanaland, with a little offshoot on the banks of the Nosop nullah in the Kalahari desert. Much interest has been attached to these people, owing to the circumstance that their origin was long regarded as shrouded in mystery, and it was even supposed by some persons that they were earlier inhabitants of South Africa than the Bushmen. That mystery has now been entirely cleared away, mainly through the investigations of a daughter of the late Dr. Bleek, who is diligently pursuing the researches of her father and her aunt Dr. Lloyd.

The Katia are of mixed blood, being descended from Bushmen and Bantu women taken captive in war only four or five generations ago. In appearance they differ greatly from the Masarwa, who are also of mixed Bushman and Bantu blood, but this arises from their different manner of living. The male progenitors of the Masarwa were Bantu, who 
took some care of their offspring, those of the Katia were Bushmen, who cared nothing at all for the children or their

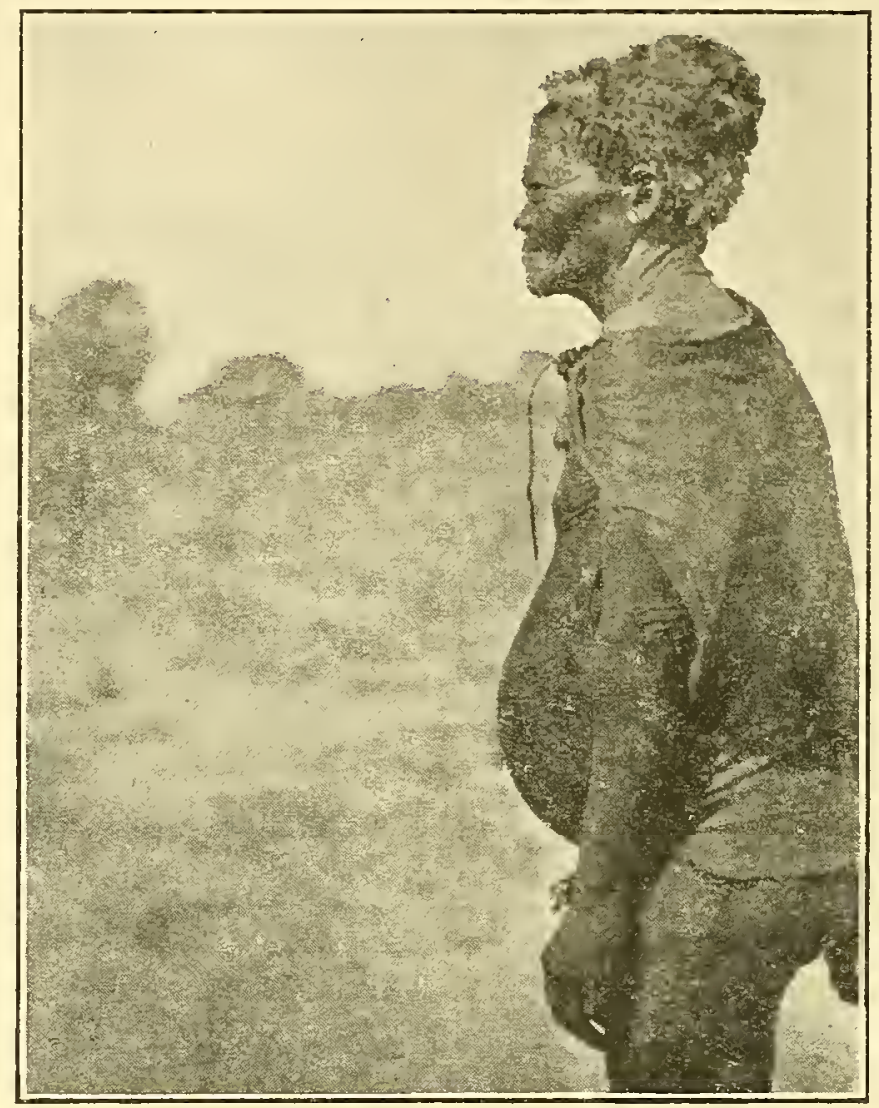

PORTRAIT OF A MALE ADULT OF THE KATIA.

(Taken by Miss D. Bleek in the Kalahari, and very kindly supplied to me by her for publication in this volume.)

mothers. In their habits they are even more degiaded than ordinary Bushmen, perhaps from being regarded and treated as outcasts by each of the races from which they sprang. Those along the Nosop hardly knew the use of water, for there was none in that locality, and depended entirely upon wild melons for the means of quenching thirst. Their food consisted of bulbs and roots containing little nourishment, with rarely flesh of any animal, it mattered not of what kind or whether fresh or putrid. It causes no surprise to learn that they were almost inconceivably stupid, living in such 
a manner they could not have been otherwise. Their skins were darker than those of ordinary Bushmen, but not as black as those of Bantu. Their jaws were not so prognathous, and their chins were better developed than in Bushmen of pure blood.

The average height of the adult males was under 152.4 centimetres or five English feet, but one, whose portrait is given here, was 167 centimetres or nearly five feet six inches in height. They dispensed with clothing, and if by chance one of them came into possession of an article of European attire it was invariably misplaced. (See the piece of calico on the back of the man whose portrait is given.) Therr language was a dialect of Bushrnan, with some words derived from the Bakwena and the Ovambo. Miss Bleek had no difficulty in taking down a number of words sufficient to form a comparative vocabulary with five other Bushman dialects, many of the words being identical or nearly so. 


\section{CHAPTER IV.}

The Hottentots, termed by the Bantu of the eastern coast Amalawu, and by the Bantu of the SOUTH-WESTERN COAST OVASERANDU.

THE next section of the human species that claims the attention of a student of South African history is the people known to us as Hottentots. Long considered and termed aborigines by many writers, the not very remote ancestors of these people are now known to have been colonists in the same sense that the Dutch and English are, that is they came from another country and settled in those parts where they were found by the first European visitors, which localities had previously been occupied by earlier inhabitants. That this circumstance long remained unknown is a matter easy of explanation. Neither the Portuguese, nor the Dutch, nor the early English settlers took any trouble to make the necessary investigations, they were wholly occupied with other affairs, they found the Hottentots in the country, and that seemed sufficient for them to know.

Then, long before any real research was commenced, the Hottentots in those parts occupied by Europeans lost their own language and customs, and the blood of most of them became mixed with that of other races. Their traditions were forgotten, and no information of any value was to be obtained from them. At length the eminent philologist Dr. Bleek, by comparing the language of those who lived in secluded localities and retained their ancestral tongue, with the speech of sections of the inhabitants of Northern Africa, pronounced them to have close affinities. Already, in 1851, the reverend Dr. James Adamson had reported to the Syro-Egyptian Society a discovery he had made, that " the signs of gender were almost identical in the Namaqua and 


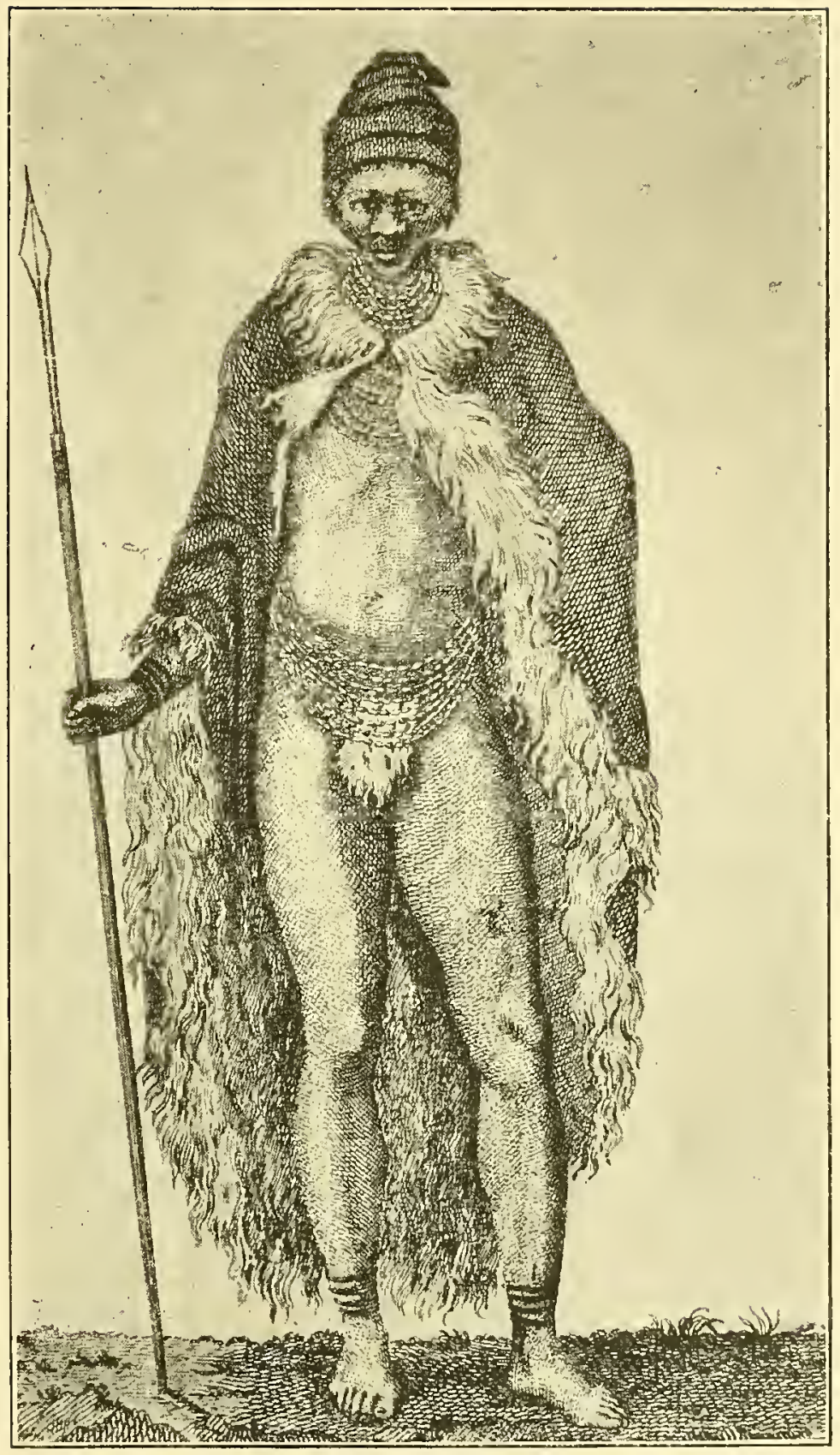

PORTRAIT OF A HOTTENTOT.

(Copy of Le Vaillant's Portrait of his faithful Klaas.)

The headdress and the strings of beads are European additions to the eostume, otherwise the portrait is an exeellent one. 
the Egyptian, and the feminine affix might be considered the same in the Namaqua, Galla, and Old Egyptian." * This was not known to Dr. Bleek, however, before he made the same discovery and others of a similar nature that placed beyond question the fact that the little group of Hottentots living on the western and southern shores of South Africa must have descended from men who once resided on or near the other extremity of the continent, though now the whole space between is filled by people the structure of whose speech is entirely different.

The question then arose how could the Hottentots, who differ almost as much from the present black inhabitants of Central Africa as they do from Europeans, have found their way to the south? Various answers were suggested, but as every one who attempted to solve this question regarded the black race as having occupied the whole of Central Africa from remote times, through whom migration would have been impossible, none were conclusive or satisfactory. $\dagger$ The mystery remained unsolved, like that which veils from our knowledge the cause and the manner of the early migrations of our own race.

A satisfactory answer has now, however, been given at least to part of what is implied in the question. Mr. George

* The reverend James Adamson, D.D., first clergyman of the pres. byterian church in Capetown, and for many years professor of mathematics in the South African college, was a man of great ability and of high education. Among the subjects to which he devoted much attention was philology, though he published nothing upon that subject except his addresses at the meetings of literary associations. After a residence of twenty-two years in Capetown, he removed to the United States in 1850 , but ten years later returned to South Africa, and remained here until his death on the 16th of July 1875, at the age of seventy-nine years.

$\dagger$ For instance, among the theories put forward in sober earnest to aceount for their origin is one that a party of light-coloured men may have been left behind on the South African coast by an ancient circumnavigating expedition; but in that case how did the horned cattle and sheep get here? 
W. Stow, a geologist of good repute in the government service, who spent many years in research among the Korana clans, the purest Hottentots now existing-if some small sections of the Namaqua be excepted,-and who was aided in his investigations by missionaries and other inquirers, learned from the traditions of those clans that their ancestors had indeed moved down from the north, and that too at no very remote time. These traditions, collected in different localities and from individuals who could have had no intercourse with each other, carried back the history of the Hottentots to a period when they were residing in a region somewhere in the centre of the continent, from which they were driven by more powerful people, of a black colour, who came down from the north or north-east. They do not go beyond that point, and are so dim that they merely state the fact of a migration from a particular direction and its cause, being in this respect even less complete than the traditions of the Bantu concerning their coming down from the north. This is owing to the Hottentot migration being of an earlier date than that of the Bantu. Mr. Stow was of opinion that the particular Bantu who drove the Hottentots to the south were the ancestors of the very Betshuana with whom the Koranas in his time were at war, and this is highly probable.

His discovery of the migration, however, does not take the people here dealt with to the still distant north, where their language indicates that they once lived. But there is strong reason to believe that the race had its origin in the country now termed Somaliland, and was formed there by the intercourse of men of a light-coloured stock with women of Bushman blood.*

* Some recent writers believe the Hottentots to have sprung from a cross between Bantu and Bushmen, but that cannot be the case. The Masarwa are of this origin, and they bear no resemblance to Hottentots. The language difficulty is also sufficient to disprore it. The Hottentots are lighter skinned than Bushmen, some females of pure blood among them have even a tinge of red in their cheeks. 
Herodotus mentions that a large band of Egyptian soldiers, said by him to be two hundred and forty thousand in number, deserted and marched into Ethiopia at a date corresponding to about 650 before Christ, and were settled by the Ethiopian king as far beyond Meroë as Meroë was beyond Elephantine. These people he termed the Automoli or Deserters, but by succeeding writers they are called the Sembritæ or Sebritæ. The locality assigned to them was in about $13^{\circ}$ to $14^{\circ}$ north latitude, Meroë being not far above the junction of the Atbara with the Nile, or in latitude $17^{\circ}$ north. This may not be correct, * and certainly, if there was any foundation for the statement, the number of the deserters must be enormously exaggerated, but it shows that such migrations were not deemed impossible at that time.

It is therefore not unlikely that at a much earlier date a small body of men, perhaps soldiers, did make their way from Egypt to Somaliland, and took to themselves there women of the Bushman race, there being no other females for them to associate with. All the difficulties of the problem are solved by this supposition, and to support it there are the following facts :-

1. The Egyptian picture of the queen of Punt is seen to be a correct portrait.

2. The Hottentot language, in its structure North African, and yet containing the four Bushman clicks most easily pronounced, is at once accounted for.

3. The possession by the Hottentots of horned cattle and Syrian sheep covered with hair and having very large tails is immediately explained.

4. The peculiarly shaped drilled stones found recently in considerable numbers by Germans in Somaliland, and now to be seen in the museum at Berlin, which are exactly similar to those used by Hottentots in South Africa and to one in the British museum found in Central Africa, also support this view.

The original Hottentots were therefore mixed breeds, but judging by analogy, there must have been a second intrusion of

* There is no mention of the Automoli in Egyptian history, nor any trace in the hieroglyphic inscriptions so far deciphered of the desertion of such an army. But nations do not usually record their own disasters. 
males, who took consorts from the first cross and so obtained a preponderance of blood, or the newly formed race would not long have remained fertile. They must have been like the Griquas of modern times, who were originally half Hottentots, and who die out speedily if they intermarry only among themselves, but who have often large families if they take consorts of either of the races from which they have sprung.

How long these mixed breeds remained in Somaliland, and what caused them at length to leave that locality cannot be stated, but in all probability they were driven out by the arrival there of people more powerful than themselves. The date of their removal must have been earlier than the occupation of Central Africa by Bantu tribes, for they could not have passed through a region inhabited by any other people than Bushmen, especially as they had horned cattle and sheep with them. Their route was south-westward to the region of the great lakes, but whether they tarried at any place or places on the way, there are no means of ascertaining. Nor can it be even conjectured how long they remained at this new home, though probably it was a period of many centuries.

While they were there the Bantu tribes were increasing in the north and pushing their way down the continent, until they too reached the lake region, and then the Hottentots were compelled to move again. They were acquainted with the use of copper and iron, and were better armed than the Bushmen in advance of them, but they were too few in number to hold their own against the stalwart black men who had now come in contact with them. They had not the energy and alertness of the Bushmen either, for their mode of existence as herdsmen did not need the exercise of those qualities. Thus it is not likely that their resistance was protracted, if indeed they made any resistance at all. Before them the country was open, that is it had no other inhabitants than the pygmy aborigines, so they set out in quest of a place where they could live in safety. It is this point of their history that tradition reaches back to.

They turned their faces to the south-west. Eastward they could not go, because in that direction the Bantu were pressing 
down the coast, and probably were already far beyond the latitude they were in. Northward their way was blocked by the enemy they were endeavouring to escape from. Their choice of a route was thus limited, and even in the country apparently open to them, it was only to the south-west that they could proceed in safety. In migrations such as this, the line of least resistance is of course followed, but in the present instance that had to be determined by more than the usual considerations. It was not only the absence of enemies more powerful than themselves, and the physical features of the country to be traversed, its mountains and rivers, that the Hottentot fugitives had to take into account. The question was complicated to them by the existence of the tsetse fly in a broad belt of land to the south, which barred their retreat with cattle in that direction. That insect alone, whose sting is fatal to domestic animals, would have prevented them from crossing the Zambesi until they had travelled very far to the westward. The Bushmen could not oppose them with any chance of success, or they could not have journeyed with their women and children, much less have driven their flocks and herds, through the country, for no right is recognised by savages and barbarians but the right of the strong, even as men observe it to be among the lower animals.

Naturally, all details of the long journey have been lost, the only circumstance preserved by tradition being the point from which it commenced. That it must have been very slow after the danger of immediate pursuit was over, seems certain, however. Cows and sheep cannot be transferred hastily from one kind of pasture to another without heavy loss, and there could have been no motive for hurrying on when only Bushmen were in the neighbourhood. Probably many years were spent at each favourable halting place, though the design of a continued advance, once initiated, was never entirely lost sight of.

At length the shore of the Atlantic was reached, and then the wave of migration turned to the south. In some parts of this course, after the twentieth parallel of latitude is passed, the pasture is better at a distance inland than on the margin of the sea. The rainfall along the coast, owing to the prevailing 
winds being offshore, is trifling compared with that of the thunderstorms in the interior, and the sandy soil does not long retain moisture. It is an arid, sterile belt of land, destitute of running streams and fountains, where in places the sand hills blown about by the wind are constantly changing their form. It is traversed with difficulty even by those who are acquainted with the localities where scanty pasture and a little water are to be found. Here therefore the migrating horde, which must have been broken up into small parties, moving on slowly at long intervals, turned inland for a short distance and then liept on towards the south, but as soon as possible it moved westward again and pursued its course along the terrace nearest the ocean. Did the wanderers expect that the shore would somewhere turn and lead them to a fairer land, where they could rest at last? No one can tell. Perhaps they themselves did not know of an object in view, but were merely impelled onward by a ruling desire for change. They were not now driven forward by enemies stronger than themselves, but still they advanced. Leaving a section behind in the territory now termed Great Namaqualand, they crossed the Orange river and entered the present Cape province.

During their march they must have had constant conflicts with the Bushmen, the only earlier inhabitants of the land, who could not look on unmoved while the country was thus invaded. These puny savages were capable of causing much mischief, though they could not prevent the strangers from either advancing or taking possession of the choicest pastures along the shore. The Hottentots did not regard them as human beings having rights, but simply as noxious animals to be got rid of as quickly as possible. In one respect, however, this was not the case. Young girls of Bushman blood, when captured, were detained and incorporated as inferior members of the families of those who slew their kindred without the slightest feeling of remorse. In this manner, probably from the first contact of the two peoples, a mixture of blood took place, which, though slight in the beginning of the journey from the centre of the continent, was considerable by the time the intruding horde reached the Cape promontory. On the other hand, there was no intercourse between Bushmen 
and Hottentot women, either before or after this period. Their arrival at the southern shore of Africa must have preceded that of the first Portuguese explorers by only a very few centuries, certainly not more than two or three at most, and probably even less.

At different stages between the mouth of the Orange river and Table Bay sections of the horde were left behind, each of which took a tribal name, and thereafter carried on war with its nearest neighbours on its own account. As the majority of the Bushmen who had lived at these localities were either exterminated or forced to retreat farther inland, the incorporation of girls necessarily almost ceased, so that each tribe of Hottentots from north to south was of purer blood than the next in advance. Nearly all of the former dwellers on the coast, the people who raised the great shell heaps that cannot now be distinguished from natural mounds unless the materials of which they are composed are discovered by accident, must have been cut off at this time. A few only may have survived in situations favourable for concealment, and at a distance from localities where the invaders settled. All the others disappeared, and then dust and sand accumulated on the mounds, and plants began to grow upon them, and when centuries went by all traces of them were lost to view.

When the southern point of the continent was reached, the migratory movement did not end, but, turning eastward, a portion of the horde continued its march, still keeping close to the shore of the sea. At no point except the one mentioned on the long journey, which may have occupied several centuries, was any attempt made to penetrate the interior country. Yet these people did not possess the skill to make even a rough canoe, and only when they were without cattle resorted to catching fish for food. It was therefore not from any attachment to the ocean or from any benefit derived directly from it that they continued their course along its margin, but from the pastures, owing to the greater rainfall, being more luxuriant in its neighbourhood than farther inland.

The character of the country had now entirely changed. The south-east wind sweeping over the Indian ocean reached the land 
laden with moisture, which was deposited in abundance on the lowest terrace, in decreasing quantities on each succeeding plateau, and least of all on the vast plain in the interior. The farther to the north-east one proceeds the more is this perceptible, until the rich vegetation of the shore forms a striking contrast to the desert belt in the same latitudes on the Atlantic side.

As band after band was thrown off along the southern and south-eastern coast, and Bush girls were continually incorporated, the most advanced party at length probably contained more Bushman than pure Hottentot blood. It was so gradually absorbed, however, that it was assimilated, for these little tribes preserved the Hottentot customs and mode of living, and carried on hostilities with the Bushmen just as if they were wholly unconnected with those savages. Along this coast the Hottentots were never so numerous as along the shore of the Atlantic south of the Orange river. There were wide gaps between the various tribes or distinct bands, which were occupied solely by the aboriginal hunters. At the beginning of the sixteenth century of our era the Hottentots extended thus in a thin line, or rather a series of dots at varying distances from each other, from Walfish Bay on the western coast round to the mouth of the Umtamvuna river on the south-eastern, beyond which there is no indication that they ever advanced.

The cause of their being so thinly scattered along this line was their depending almost entirely upon milk for subsistence. They needed a large number of cows and ewes, and consequently a great extent of pasture for each separate community, as the cattle belonging to all the families composing it were herded together for reasons of safety, and were driven from place to place according to the state of the grass. As soon as a community became so large that this was impossible or even inconvenient, a swarm was of necessity thrown off, and moved to a distance in order to acquire a new pasture of sufficient extent for its use. The offshoot might for a time consider itself a dependency of the parent band, or a clan of the tribe, but the tendency would soon be towards perfect independence. There was no other way of extension, for a party moving needed to be strong enough to 
protect itself and its cattle from Bushmen and ravenous animals. For a single family, or even two or three families together, to settle separately on the pasture of a tribe and to keep up connection with the main body was not possible. Each Hottentot community was thus compact, but limited in number to a few hundred or at most to a couple of thousand souls. It occupied a single village, or kraal as now generally termed.

From the neighbourbood of the kraal the Bushmen were cleared off as far as possible, but in many instances they still occupied the mountains and seized every opportunity to plunder cattle from the intruders and to put any stray individual of either sex to death. The feeling between the two peoples was in general one of intense animosity, though there were occasional instances of a compact between a Hottentot tribe and the Bushmen in its neighbourhood, under which the former provided food in times of great distress, and the latter acted as scouts and gave warning of any approaching danger: This was only the case, however, when the Bushmen were so reduced in number as to be incapable of carrying on war.

The great interior of the country was undisturbed by the intruders, but it did not always offer an asylum to the dispossessed people. Each little band of Bushmen had there its own hunting grounds, and resented intrusion upon them as much by individuals of kindred blood as by strangers. Then they were strongly attached to the localities in which they had lived from childhood, and in many instances preferred to die rather than abandon them. Still there were some who, under exceptional circumstances, made their way to localities far distant from the tracts they had lost, and established themselves anew on a wild mountain or an arid plain, dispossessing previous occupants as they had themselves been dispossessed of their former abode.

Such was the manner of the occupation of the South African coast by the Hottentots, and such were the effects of the invasion upon the earlier inhabitants.

The Hottentots termed themselves Khoikhoi, men of men, as they prided themselves upon their superiority over tle savage bunters, and in fact they were considerably more advanced 
towards civilisation than the Bushmen, though a stranger at first sight might not have seen much difference in personal appearance between the two. A little observation, however, would have shown that the Bushmen were not only smaller and uglier, but that their faces were broader, their eves not nearly as full and bright, their lobeless ears rounder in shape, and their chins less prominent. Their wild expression also was not observed in the Hottentot face.

The investigations of the late Dr. Bleek have shown that the languages of the two races were not only different in the words, except in such as were adopted by Hottentots from captive Bushman girls, but that they varied in construction. That of the Hottentots was of a high order, being of the same class as our own, and following grammatical rules as strictly as English does. Its vocabulary, however, was of a low type, as threefourths of the syllabic elements began with clicks, though these sounds were not so extensively used as by Bushmen and did not vary so much, being only four in number. Further it was almost free of deep guttural or croaking sounds, except where there had been a large infusion of Bushman blood. Some words were com. posites, but most were monosyllables, as were all the roots, which invariably ended with a vowel. The sound of the liquid consonant $l$ was wanting. In many instances the same word had different significations, according as it was pronounced. Thus !kaib pronounced in the lowest tone meant obscurity, pronounced in a medium tone meant a district or locality, and pronounced. in the highest tone meant a particular article of clothing.*

* I am personally entirely unacquainted with the Hottentot language, and have taken the information upon it given here from Dr. Bleek's Comparative Grammar of South African Languages, Eléments de la Grammaire Hottentote by H. de Charencey, and A Grammar and Vocabulary of the Namaqua-Hottentot Language by the reverend Henry Tindall, Wesleyan missionary, a demi octavo volume published at Capetown in 1857. The first chapter of Dr. Theophilus Hahn's Tsuni-\|Goam, the Supreme Being of the Khoi-Khoi, is exceedingly interesting in this respect, and his conclusions drawn from the structure of the language and its vocabulary fit in most accurately with the origin of the race and its migration from North-Eastern Africa as given in the preceding pages. 
The nouns were divided into eight classes, three masculine in the singular, dual, and plural numbers, two feminine in the singular and plural numbers, and three common in the singular, dual, and plural numbers. The masculine denoted not only living creatures of the male sex, but whatever was large or prominent. The class was indicated by a suffixed letter, thus masculine khoip a man, feminine khois a woman, common khoi a person of either sex. There were three case forms: nominative, objective, and vocative, thus taras, a woman, was declined as follows :

$\begin{array}{lccl} & \text { Singular } & \text { Dual } & \text { Plural } \\ \text { Nominative } & \text { taras } & \text { tarara } & \text { tarati } \\ \text { Objective } & \text { tarasa } & \text { tarara } & \text { tarati } \\ \text { Vocative } & \text { tarasi } & \text { tararo } & \text { taraso }\end{array}$

The genitive or possessive and the dative were not formed by changes at the end of the noun itself, but by words corresponding to our prepositions, which, however, were placed after the noun, as the language did not admit of prefixes even of this kind.

The adjectives were as simple as in modern English, for they were not inflected to signify either gender, number, or case. They had the defect of not being changed in form to express degrees of comparison, and this had to be done in a roundabout way by the addition of other words less expressive than our more, most, less, least.

The system of notation was decimal, and was perfect at least up to a hundred, though it does not follow that every individual could count to high numbers. It was based upon counting by fingers, as is shown by the word for five meaning also the palm or full hand.

The personal pronouns were inflected for number and case; and except the first, $I$, for gender also.

The verb was as perfect as in any of the languages of Europe. Its root was the second person singular of the imperative mood, and its tenses were formed by means of an auxiliary. It had more forms than the English verb, as is shown by the following example : ordinary $m u$ to see, relative muba to see for, reflective- 
musin to see oneself, causative mukei to cause to see, reciprocal muku to see one another, diminutive muro to see a little, negative mudama not to see; passive voice muké to be seen. It had all our moods and tenses. It was not inflected to express number or person, which were indicated by the noun or pronoun with which it was connected, just as in our common Cape Dutch.

Now here is a sex-denoting language of the same class as the languages of Europe and North Africa, and yet full of those primitive sounds called clicks. It forms a strong contrast to the speech of the Bantu in the same continent, though that is of a high order too. How can it have arisen? There is only one way in which this can be satisfactorily explained, and that is by men of a light-coloured North African race consorting with women of Bushman blood. There is reason to believe that the men were more numerous than the women, as will be pointed out elsewhere, and therefore the form of their language was retained, while many Bushman words and the four Bushman clicks least difficult to pronounce were incorporated in it. In exactly the same manner, when the Amaxosa took modern Hottentot women to live with them, many Hottentot words and three of the Hottentot clicks were adopted, but the structure of the Xosa language underwent no change whatever. The new words were simply made to fall in grammatical line with those previously in use.

There were almost as many dialects as there were tribes, but these varied less than the forms of English spoken in different counties before the general diffusion of education from books. Towards the close of the seventeenth century an interpreter belonging to a tribe in the neighbourhood of the Cape peninsula, when accompanying Dutch trading parties, conversed without difficulty with even the most distant from his own home. This is a proof that the occupation of the country by these people and their spreading out along the coast must have been very recent. Unwritten languages change rapidly, especially in the vowel sounds, and tribes having no communication with each other, as for instance the Namaqua and the Gonaqua, in the course of only eight or ten generations would have developed differences greater than were found to exist. Another proof of their recent 
arrival is their acknowledgment down to the middle of the nineteenth century of the head of the Geillkhauas as superior to all the other chiefs in rank, on account of his being the lineal representative of their ruling family when they crossed the Kunene river on their way southward.*

No difficulty has been experienced by European missionaries in reducing the Hottentot language to writing, and some religious literature has been printed in it. Words to express abstract ideas unknown before were formed from the roots of verbs and adjectives, and were at once understood by every one, just as meekness and meekly would be understood by any Englishman who had only heard the word meek used before. The reverend Mr. Waudres, Rhenish missionary in Great Namaqualand, was kind enough to write to me how this is done. He says to the root of the verb or the adjective nothing more is necessary than to add the gender suffixes, and the word is at once understood. Thus, to the verb gowa to talk, if the masculine suffix $b$ is added, the word gowab is obtained, which means language. If to the adjective ama, true, the same suffix is added, amab the truth is obtained.

The Hottentot language is now rapidly dying out, as the descendents of the people who once used it have long since learned Dutch, and nearly all have forgotten their ancestral speech. A large admixture of blood-European, Asiatic, and particularly negro-that took place during the eighteenth and nineteenth centuries, contributed to this result, as well as the state of servitude to which many of these people were reduced. At the present day the language is only in use by some of the Korana clans along the Hart river, and by some of the clans in Great Namaqualand, and even they are year by year employing it less and less.

* The Gei||khauas claim to be the oldest of the Hottentot tribes, and to be in a sense paramount over all the others. Dr. Theophilus Hahn asserts that this claim is well founded, and that it was recognised by a clan of the Koranas not many years ago. The Gei||khauas were living only two days' journey from Capetown at the close of the seventeenth century, but about I8Il as many of them as were left removed to Great Namaqualand. They are the people who lived at Gobabis under the chief Amraal until his death in 1865, and later under the chief Andries Lambert. 
The manner in which the various Hottentot tribes were formed has already been explained. They usually took their distinctive titles from the name of the chief under whose guidance they commenced to lead a separate existence, by adding to it the suffix qua, which signified those of or the people of, thus the Cochoqua were the people of Cocho, the Gonaqua the peopre of Gona. Sometimes, however, they called themselves after some animal, as the springbucks, the scorpions, or from some accidental circumstance, as the honey eaters, the sandal wearers. Many of the tribes consisted of several clans, more or less loosely joined together, though all tending to become independent in course of time. The tribes were almost constantly at war with each other, the object being to obtain possession of the cattle and girls of the opponent, and often the weaker ones were reduced to great poverty and distress. New combinations would then be formed, and the victors of one year frequently became the vanquished of the next. These internecine quarrels were not attended with much loss of life. There was never a slaughter of the whole of the conquered people, as was the case when a band of Bushmen was surrounded and overpowered.

Every tribe had its own hereditary chief, whose authority, however, was very limited, as his subjects were impatient of control. The succession was from father to son, and in the absence of a son to brother or nephew. The heads of clans not long formed recognised the supremacy in rank of the head of the community from which they had branched off, who was accounted the paramount chief, but unless he happened to be a man of more force of character than the others, he exercised no real power over them. The petty rulers, or heads of clans, were commonly jealous of each other, and only united their strength in cases of extreme danger to all. The government was thus particularly frail, and a very slight shock was sufficient to break any combination of the people into fragments. The powerful religious sentiment which binds the people of a Bantu tribe so strongly to their ruler was altogether wanting in a Hottentot community. The chief was not regarded as a divinity or the descendant of a divinity, but as a mere man like any of his 
followers. Riches commanded more respect than rank, and a man possessed of many cattle exercised as much influence as the nominal ruler, for the right of individuals to hold property apart from the community was recognised.

There were customs which had the same force as laws in civilised societies, and any one breaking them was subject to punishment. In such cases the whole of the adult males of the kraal discussed the matter and decided what was to be done, the chief, unless he happened to be a man of unusual strength of character, having little more to say than any one else. The moral code and the proportion of criminality ascribed to misdeeds were naturally very different from those of Europeans.

The principal property of the Hottentots consisted of horned cattle and sheep, of, which large numbers were possessed by some of the wealthiest tribes. They had great skill in training oxen to obey certain calls, as well as to carry burdens, and bulls were taught not only to assist in guarding the herds from robbers and beasts of prey, but to aid in war by charging the enemy on the field of battle. Under their training in short these animals were brought to recognise without fail the voices and even the gestures of their own masters, and to display almost as much intelligence as dogs. But the power to do this was not possessed by every one, it was only individuals of infinite patience who could educate cattle to this extent, and they were obliged to begin with very young calves.

Although capable of being thus highly trained, the ox of the Hottentot was an inferior animal to that of Europe. He was a gaunt, bony creature, with immense horns and long legs, but he was hardy and well adapted to supply the wants of his owner. He served instead of a horse for carrying burdens and for riding purposes, being guided by a bridle composed of a riem or thong of raw hide attached to a piece of wood passed through the cartilage of his nose, which served as a bit. Instead of a saddle a sheep skin was thrown over the back of the animal and was fastened by a 
riem drawn tight round the body. There were no stirrups, and from the skin of the ox being much looser than that of the horse, as firm a seat was not possible. Still both sexes rode these animals with ease, having been accustomed to do so from childhood.

The sheep possessed by the Hottentots were covered with hair instead of wool, were of various colours, and had long lapping ears and tails four or five kilogrammes in weight. The tails were composed almost entirely of fat, which could be melted as easily as tallow, and which was relished as a dainty, just as it is to-day by many Europeans, who prefer it to butter. It was also largely used by the Hottentots to rub their bodies with, and to make their skin karosses flexible. Animals possessing such appendages were of course hardier than European sheep, and could exist much longer on seanty herbage in seasons of drought. The milk as well as the flesh was used for food. Children were taught to suck the ewes, and often derived their whole sustenance from this source.

The only other domestic animal was the dog. He was an ugly creature, his body being shaped like that of a jackal, and the hair on his spine being turned forward; but he was a faithful, serviceable animal of his kind.

The milk of their cows was the chief article of the diet of the Hottentots. It was preserved either in skin bags or in vessels made by hollowing a block of wood, and after coagulation formed healthy and nutritious food. It was drunk either by using a tortoise shell as a basin or by sucking a little swab that had been dipped into it. The bags and vessels used were commonly in a filthy state, as indeed was everything else in and about the huts, for in this respect the Hottentots were only slightly superior to Bushmen. Though so fond of flesh that they devoured seals and dead whales that washed ashore, even in a putrid state, they did not kill horned cattle for food, except on occasions of revelry and feasting, but they ate all that died a natural death. 
Their usual method of preparing meat for food was to cut it in long narrow strips, which were laid upon embers and heated through rather than cooked, then one end was taken into the mouth, and a piece was cut off with a knife or an assagai close to the lips. The intestines of animals, after hardly any cleansing, were consumed in the same - manner. Sometimes, however, flesh was boiled in earthenware pots, though it was not much relished in that way.

Salt was not used to flavour food or to preserve flesh or fish, though the Hottentots relished it by itself just as Europeans do sugar. They obtained it without difficulty from the numerous saltpans in the country. They rolled their meat when grilled in the ashes of wood, which European travellers who have tried it assert to be a fairly good substitute for salt.

In additior to milk and the flesh of oxen and sheep, of which they rejected no part except the gall, the food of the Hottentots consisted of the flesh of birds and wild animals of every kind, great and small, obtained in the chase, locusts, tortoises, and various descriptions of wild plants and fruits. A variety of articles of diet consumed at the same time, such as civilised people consider necessary for their comfort, is not by any means essential to the enjoyment of barbarians. The Hottentots often lived for months together upon milk alone, without ever becoming weary of it. When flesh was to be had, it was consumed without any accompaniment. Agriculture, even in its simplest forms, was unknown to them, so that they had neither grain of any kind to make bread with nor garden produce.

Like the Bushmen, they knew how to make an intoxicating drink of honey, of which large quantities were to be had in the season of flowers, and this they used to excess while it lasted. Like those savages also they were acquainted with that powerful intoxicant dacha or wild hemp, and whenever it was procurable they smoked it with a pipe made of the horn of an antelope. That its effects were pernicious was recognised by themselves, still they could not refrain from 


\section{The Hottentots.}

making use of it. A few puffs of the smoke produced great exhilaration and pleasant sensations, which were shortly followed by stupor. It was fortunate for them that they were too careless to preserve a quantity of it for use at a future time, or it would have destroyed them altogether, so that as far as the use of dacha was concerned, it was well that they lived only for the day, and thought not of the morrow.

When they rose in the morning and the cows and ewes were milked and driven out to pasture they partook of focd, after which they usually laid down again for an hour or two, as their ideal of happiness was a state of repose. If they had only a sufficient number of cattle to provide them with milk to live upon, there was nothing to impel them to labour, and no reason why they should exert themselves. The hours passed by in idleness, and at sunset the principal meal of the day was taken, when the men ate first and the women and children afterwards. The men were prohibited by custom from the use of several articles of diet, for instance, they would not eat hares' flesh or drink sheep's milk, but the women and children-including the boys before being initiated into the state of manhood-could use both. On the other hand the men were at liberty to eat moles, which the women were not. They could give no reasons for these restrictions of diet to the different sexes, except that the custom had come down to them from their forefathers.

Their women were more fully clothed than those of the Bushmen, but the men were usually satisfied with very little covering, and had no sense of shame in appearing altogether naked. The dress of both sexes was made of skins, commonly prepared with the hair on. When removed from the animal, the skin was stretched out and cleansed with scrapers of any fleshy matter adhering to it, was then dried, and was afterwards rubbed with grease and worked between the hands till it became soft and pliable. The ordinary costume of a man was merely a piece of jackal skin suspended in front and a little slip of prepared hide behind. In cold weather he wrapped himself in a kaross or mantle of furs sewed 
together with sinews. The women wore at all times a head-dress of fur, an under apron, and a wrapper or a girdle of leather strings suspended from the waist. In cold weather, or when carrying infants on their backs, they added a scanty kaross. Children wore no clothing whatever. Round their legs the females sewed strips of raw hide like rings, which, when dry, rattled against each other, and made a noise when they moved.

Both sexes ornamented their heads with copper trinkets, and hung round their necks strings of shells, leopards' teeth, or any glittering objects they could obtain. Ivory armlets were worn by the men. From earliest infancy their bodies were smeared with grease, and rubbed over with clay, soot, or powdered buchu, and to this partly may be attributed the stench of their persons. The coat of grease and clay was not intended for ornament alone. It protected them from the weather and from the vermin that infested their huts and clothing.

Their dwellings were constructed by planting long pieces of supple undressed wood in the ground, and bending the upper ends inward, where they were attached by thongs to short pieces laid horizontally, so that the whole frame resembled approximately a rough hemisphere. Withes were then twisted round the structure and tied on outside, and the whole was covered with rush mats. The huts were so low that a tall man could not stand upright inside, and they had but one small opening through which the inmates crawled. In cold weather a fire was made in a cavity in the centre. The huts of a kraal were arranged in the form of a circle, the space enclosed being used as a fold for cattle. They could be taken to pieces, placed on pack-oxen, removed to a distance, and set up again, with very little labour and no waste. The furniture within them consisted merely of mats to sleep on, skins, weapons, cooking utensils, wooden milk dishes, and ostrich egg shells used for carrying and containing water. Unlike the Bushman, who doubled himself up to sleep on a little grass, the Hottentot stretched himself at full length on a mat in his hut. 
The weapons used by the Hottentots in war and the chase were bows and arrows, sticks with clubbed heads, and assagais. Mr. Stow asserts that at the time of their arrival in South Africa they were unacquainted with the use of

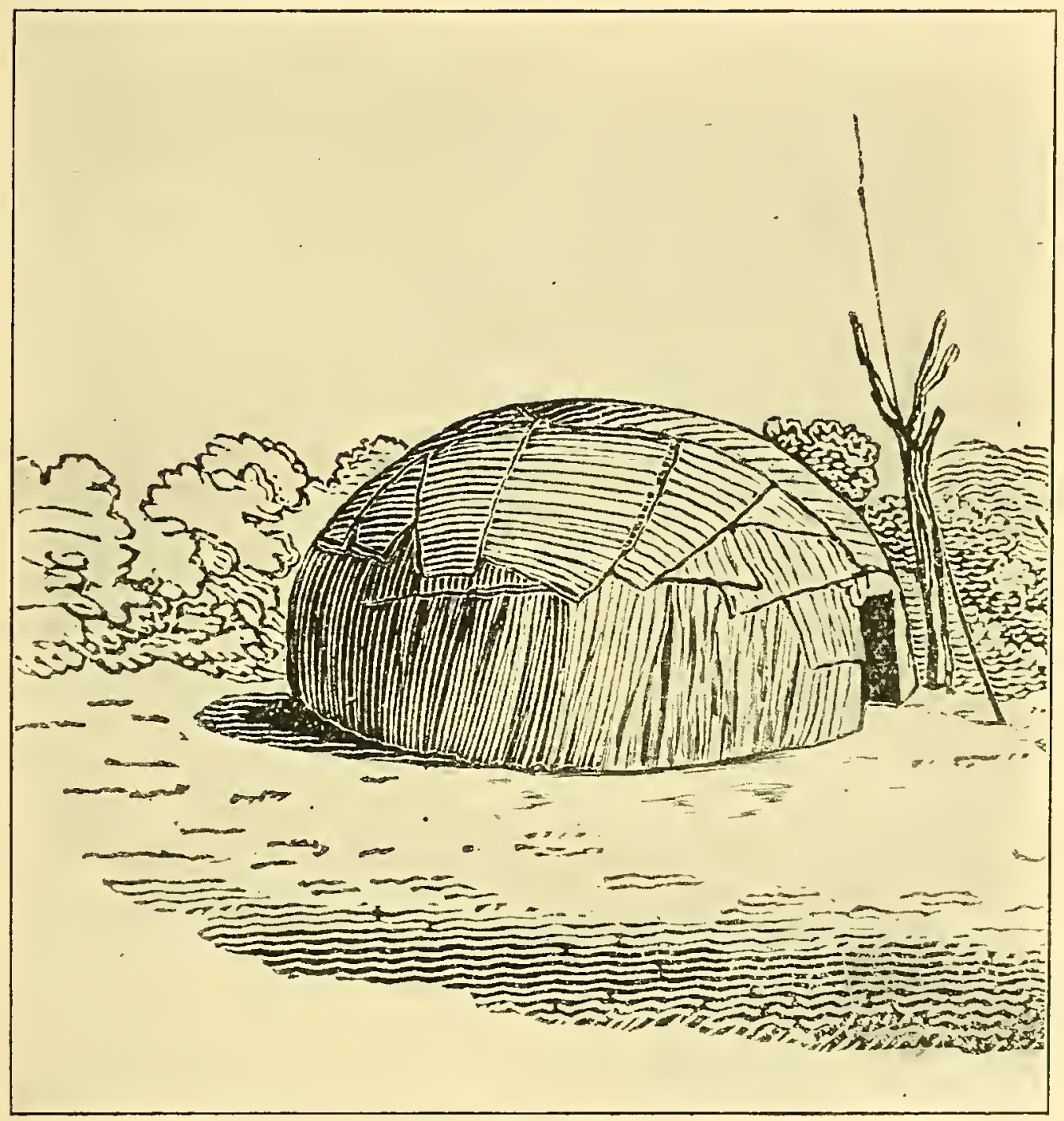

A HotTentot Hut.

(From a Drawing by William J. Burchell, Esqre.)

poison, but if that be correct they certainly acquired a knowledge of it shortly afterwards. It was not used by them so extensively, however, as by the Bushmen. The bow was larger and the arrow longer than those of the primitive inhabitants, still without poison the weapon would have been 
useless against large game. The assagai of the Hottentot was a light javelin, which could be hurled with precision to a distance of thirty or forty metres. The knobkerie, or clubbed stick, was almost as formidable a weapon. It was rather stouter than an ordinary walking cane, and had a round head six or eight centimetres in diameter. Boys were trained to throw this with so accurate an aim as to hit a bird on the wing at twenty or thirty metres distance. It was projected in such a manner as to bring the heavy knob into contact with the object aimed at, and antelopes as large as goats had their legs broken or were killed outright with it.

The Hottentots were acquainted with the art of smelting iron, but were too indolent to turn their knowledge to much account. Only a few assagai and arrow heads were made of that metal. Horn and bone were ready at hand, were easily worked, and were commonly used to point weapons. Stone was also employed by some of the tribes for this purpose, but not to any great extent, though weights for digging sticks were formed of it by them as by the Bushmen. Masses of almost solid copper were obtained in Namaqualand, and this metal was spread over the neighbouring country by means of barter and war, but was not used for any other purpose than that of making ornaments for the person.

At different places occupied by the Hottentots along the coast a very few polished stone implements have been found. They consist of arrow heads whose points have been ground, and disks like quoits with sharp edges, which are supposed to have been held in the hand and used in combat. No European has ever seen a Hottentot in possession of such implements, or ever heard them spoken of, and any remarks concerning them can only be founded on conjecture. But few as is the number of such ground stones as yet discovered, they are evidence that individuals, if not tribes, were in the neolithic stage of progress, though iron was in use at the same period.

The Hottentots manufactured earthenware pots for cooking purposes, which, though in general clumsily shaped and 
coarse in appearance, were capable of withstanding intense heat. The art was lost soon after Europeans came in contact with them and before observations upon their habits were made correctly and placed on record, so that it is only from specimens of their handiwork recently found that an opinion can be formed of the quality of such wares. Pots were useful at times, but were not much needed by people who seldom ate boiled food, nor were earthenware drinking vessels required where ox horns and ostrich egg-shells served that purpose. This may account for the small quantity and the coarse description of the utensils manufactured. Some of the pots found in recent shell heaps along the sea-shore have a number of holes neatly drilled in them, often near the bottom, probably to make them serve as strainers.

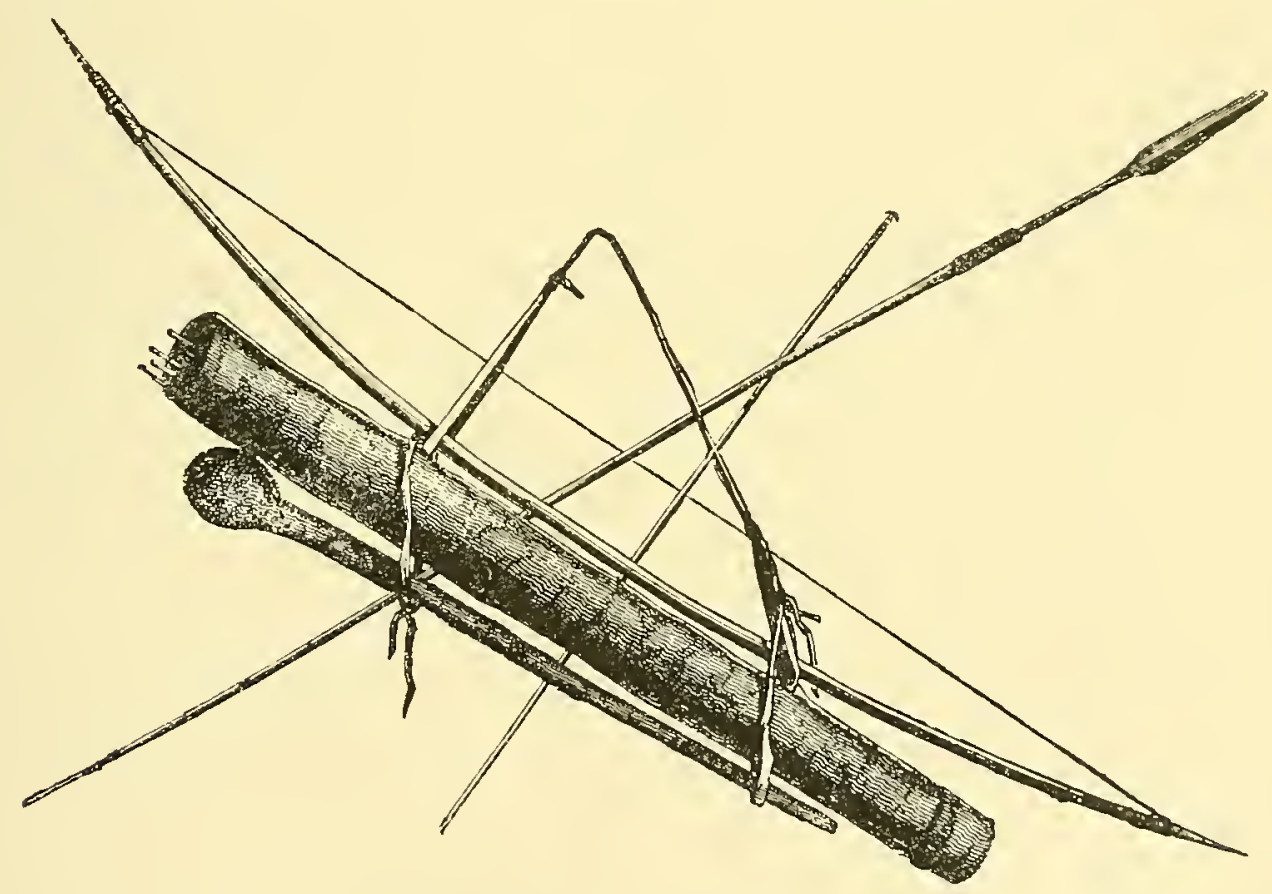

HOTTENTOT WEAPONS OF IVAR AND THE CHASE.

(From a drawing by William J. Burchell, Esqre.) 
CHAPTER V.

\section{The Hottentots or Khorkhor (continued).}

A FEW of the smallest and weakest clans of Hottentots who had lost their cattle in war or by disease, or who were the poorest members of tribes suffering from want, and had to abandon the communities to which they belonged and seek for means of existence elsewhere, lived chiefly upon the produce of the sea. They adopted from necessity the same means of obtaining a scanty supply of food as the earlier inhabitants who raised such enormous shell mounds as the one recently removed at East London had resorted to. They had neither boats nor hooks, but they managed to catch fish by throwing light assagais with lines attached to them from rocks standing out in deep water, and by making weirs in favourable situations along the shore enclosing considerable spaces which were left nearly dry at low tide. Shellfish also formed a portion of their food, and occasionally a dead whale would drift ashore and furnish them with a feast. Further, they gathered all the edible plants in their neighbourhood, and captured as many wild animals as they could. Shell and ash heaps made by these people bearing signs of being quite modern, that is dating back only two or three hundred years, are found in several places along the coast from Walfish Bay to Natal.

The heaps contain ordinary Hottentot implements, in rare instances human skeletons, and bones of animals obtained in the chase, always broken in order that the marrow might be extracted. The perforated stone weights for digging-sticks found in them are usually of the shape of compressed spheres, nearly resembling in form those of Scotland referred to on a previous page. There is a good collection of specimens of various shapes 
and sizes in the South African museum in Capetown. It is supposed that the stones perforated by Hottentots were always of a distinct type from those drilled by Bushmen, but this is not certain, though as far as is known only spherical weights are picked up in tracts of country that were exclusively occupied by the aborigines, and compressed spheres wherever the later intruders or people connected with them lived, where also a few stones have been found that have first been perforated and then chipped into a convenient shape for use.

Hottentots, or it would be more correct to say mixed-breeds largely of Bushman blood who had been brought up at Hottentot kraals, who spoke the Hottentot language, and whose ideas and normal habits were those of Hottentots, were found living in the manner here indicated when Europeans first came to the country -one small band where Capetown now stands,- and on the coast of Namaqualand there were some existing in a similar state after the middle of the nineteenth century. As far as food, clothing, and lodging were concerned, they were in no better condition than the Bushmen who lived in a similar manner, though there was always the hope before them of acquiring cattle by a successful raid, in which case they would at once revert to the ordinary mode of living of the pastoral communities.

Only a few of the recent shell heaps on the South African coast, however, were made by Hottentot-speaking people. Much the greater number were made by Bushmen, as is proved by the articles found in them and by the paintings on rocks in their neighbourhood; and these may be taken as forming a connected series with the most ancient mounds. A painting is the most positive evidence of the locality having been occupied by Bushmen, as the Hottentots did not practise that art, and the captives of the wild race living with them, being females only, could not introduce it.

The Hottentots, as observed before, did not form a continuous line of settlement, but a series of dots, frequently far apart, and between these stations Bushmen still lived, though the enmity between the two races was so strong that they were constantly seeking to destroy each other. This will account for 
shell mounds being formed by both people at the same time. But in point of fact those destitute Hottentots who lived as beachrangers, as the first European colonists termed them, in all probability had more Bushman than pure Khoikhoi blood in their veins, though they would have resented being termed Sana,* just as a mulatto prides himself upon his descent from a white man, and resents being termed a negro. In a pastoral clan the children of captive Bushman girls would be regarded as illegitimate, and would not inherit cattle from their fathers. The daughters of the next generation by Khoikhoi fathers might, and most likely did, occupy a better position, but the sons would remain paupers and dependents of some wealthy man. When fresh captives were made, their blood would become mixed with that of the half-breeds, and thus there would be men and women of only one-fourth Khoikhoi descent, and yet Khoikhoi in language, ideas, and habits.

This process having gone on for many generations, there must have been a mixture of blood in various proportions in the individual members of a clan. A raid would be made on a neighbouring tribe, and a herd of cattle would be secured, of which some of the mixed-breeds would obtain a share, when they would at once assume the position of honourable men and acquire all the rights of the purest Khoikhoi. But in the vanquished tribe there would be a similar class of mixed-breeds, and now that meat and milk had become so scarce that there was not sufficient food to keep all alive, the poorest of them would be compelled to separate from the others, and to seek subsistence along the shore until such time as chance placed an opportunity in their way of obtaining horned cattle or sheep by plunder. Their condition was more abject than that of pure Bushmen, who greatly excelled them as hunters, but as far as wild plants went, there was as great a quantity and as large a variety along the ocean shore as anywhere inland.

* Dr. Hahn explained this word, not as a proper name, but as applied by Hottentots to the Bushmen because it meant inhabitants or, as we should say, aborigines. The Hottentots often used opprobrious epithets when speaking of the wild people, but commonly called them by this name Sana. 
The Hottentots were a superstitious people who placed great faith in the efficacy of charms to ward off evil. They even besought favours from certain pieces of root so used, and if their wishes were successful, they praised and thanked the charms. This superstition might in time have developed into idolatry, but it was arrested before it reached that stage. They believed that certain occurrences foreboded good or ill luck, and were always on the watch for omens. Their veneration of the mantis, an insect that bears so close a resemblance either to a withered leaf or to a dry stalk of grass that its presence cannot be detected except when it is in motion, has been asserted by many writers, some of whom have even termed it the Hottentot God, but it has been called in question by others. The reason of this contradiction is that their notions regarding the insect were acquired from their Bushman female captives, who had been taught by their parents that it was endowed with the power of exchanging its form for that of any other animal, and that it could confer good or bad fortune upon human beings. Clans in which Bushman blood was strong would therefore venerate the mantis, and others would pay little or no regard to it.

They lived in dread of ghosts and evil spirits, but with no more conception of the nature of such shadowy beings, or of the mode of receiving harm, than little children have. They invoked blessings from the moon, the harbinger of their festivities, to whose praise they sang and danced when it appeared as new. In later times those who had come in contact with Bantu prayed for blessings from dead ancestors, to whose shades sacrifices were offered by priests on important occasions, but this was evidently a custom of foreign origin. Generally they implored protection and favour from a mythical hero named Tsuil|goab or Heitsi-eibib, who was believed by them to have lived on the earth and to have died and risen again many times, and whose worship consisted in throwing a branch of a tree, a bit of wood, or an additional stone upon a cairn at a place where he was supposed to have been once buried. Tales of the wonderful deeds of this Heitsi-eibib were commonly narrated by old men, and were implicitly believed by every one who heard them. 
All the actions ascribed to him were those of a man, but of one endowed with supernatural power.

Thus he was said on one occasion to have been pursued by an enemy, and with his family and his followers to have come to a large river. He said, " my grandfather's father, separate thyself that we may pass through, and close thyself afterwards." The river did so. Heitsi-eibib and his people passed through in safety, and when the enemy followed them, the river closed again and they were all drowned. This tale may seem to have had its origin in the teaching of missionaries, but it has been obtained from so many sources, some of which were never directly or indirectly under missionary influence, that it is beyond doubt original.

Another of the tales related of Heitsi-eibib is as follows: $\ddagger$ Gā $\ddagger$ gorib sat by a large hole in the ground, and when people passed by he told them to throw a stone at his forehead. When they did this, the stone rebounded and stunned them, and they fell into the hole and died. Heitsi-eibib heard of this, so he went to the place, and $\$$ Găłgorib challenged him to throw a stone. He declined to do so, and they then began to chase each other round the hole, saying " Push Heitsi-eibib down! Push $\ddagger$ Găłgorib down! Push Heitsi-eibib down! Push łGăłgorib down!" At last Heitsi-eibib was pushed down, but he said "my grandfather's father, raise up thy bottom and let me out." The hole did so, and he came out. They began to chase each other round it again, saying "Push Heitsi-eibib down! Push †Gāłgorib down! Push Heitsi-eibib down! Push †Gãłgorib down!" and Heitsi-eibib was thrown in the second time. He said "my grandfather's father, raise up thy bottom and let me out." The hole did so. This happened many times, but at last when $\ddagger$ Gãłgorib was looking on one side, Heitsi-eibib struck him behind the ear and stunned him, so that he fell into the hole and could not get out again. From that time onward the people had rest, because † Gàj gorib was conquered.

Still another of these tales is given, as it records one of the deaths of Heitsi-eibib, and of his coming to life again. It is in the words of the reverend G. Krönlein, as translated by him from the Nama original. 
When Heitsi-eibib was travelling about with his family, they came to a valley in which the raisin-tree * was ripe, and he was there attacked by a severe illness. Then his young (second) wife said, "this brave one is taken ill on account of these raisins; death is here at the place." The old man (Heitsi-eibib), however, told his son !Urisib (the whitish one), "I shall not live, I feel it; thou must, therefore, cover me when I am dead with soft stones." And he spoke further, " this is the thing which I order you to do: of the raisin-trees of this valley you shall not eat, for if you eat of them I shall infect you, and you will surely die in a similar way."

His young wife said, " he is taken ill on account of the raisins of this valley. Let us bury him quickly, and let us go."

So he died there, and was covered flatly with soft stones according as he had commanded. Then they went away.

When they had moved to another place, and were unpacking there, they heard always from the side whence they came a noise as of people eating raisins and singing. In this manner the eating and singing ran :

" 1 , father of !Urisib,

Father of this unclean one,

I, who had to eat the raisins, and died,

And dying live."

The young wife perceived that the noise came from the side where the old man's grave was, and said, " Urisib, go and look." Then the son went to the old man's grave, where he saw traces which he recognised to be his father's footmarlis, and returned home. Then the young wife said, "it is he alone, therefore act thus :

Do so to the man who ate raisins on the windward side,

Take care of the wind that thou creepest upon him from the leeward;

Then intercept him on his way to the grave,

And when thou hast caught him, do not let him go."

* A particular kind of tree in Namaqualand bearing a shrivelled wild truit, for which Mr. Krönlein could think of no more appropriate name than the raisin-tree. I am unacquainted with it. 
He did accordingly, and they came between the grave and Heitsi-eibib, who, when he saw this, jumped down from the raisintree, and ran quickly, but was caught at the grave. Then he said, "let me go, for I am a man who has been dead, that I may not infect you." But the young wife said, "keep hold of the rogue."

So they brought him home, and from that day he was fresh and hale.

Dr. Theophilus Hahn, the son of a missionary, who spent his youth among the Namaqua and learned to speak their language as soon as he did that of his parents, in his Tsuni-\|Goam, the Supreme Being of the Khoikhoi, published in London in 1881, states that the Namaqua believe Tsui-||Goab, or Heitsi-eibib as otherwise called, to be a powerful and beneficent being, who lives in the red sky. There is also a powerful evil being, named "Gaunab,* who lives in the black sky and does harm to men, who on that account fear and worship him. In a series of combats with ||Gaunab, Tsui-|Goab was repeatedly overcome, but after every struggle grew stronger, till at last he killed \|Gaunab by a blow behind the ear. He was, however, wounded in the knee, and has been lame ever since, whence his name, the wounded knee. At early dawn the Namaqua look towards the east, and implore blessings from him.

Dr. Hahn asserts his belief that this myth originated in the apparent conflict between light and darkness at dawn, and he gives the reasons that led him to this conclusion, which are mainly philological. If this be correct, the myth had an origin as lofty in ideal as that of many of the Aryans, but other inquirers are inclined to attribute it to the existence of some prominent man in olden time, whose exploits became magnified and distorted in legends. As they believe the moon dies and comes to life again, they may very easily have imagined this great man of their race to have done the same, or the deeds of different individuals at different times may have become blended under one name, as in some Bantu traditions.

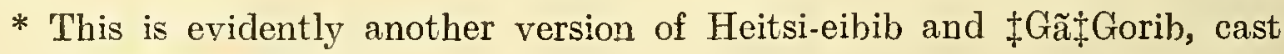
in a more poetical mould. 
Tsui-\|goab was also believed to have been the ancestor of the whole Hottentot race, and likewise to be the moon, for these people, with childlike simplicity, could not comprehend that such various suppositions were incapable of being reconciled with each other. In the corrupted form of Utixo, the first Protestant missionaries to the Bantu used the word Tsui-\|goab to signify God, and it is so employed to the present day.

Many cairns of considerable size, formed of small stones capable of being carried by one individual, have been found in various parts of South Africa, but only a few of these were raised by Hottentots at places where they supposed Heitsi-eibib to have been buried. The Bushmen erected cairns over some of their dead, and it is not unlikely that the Hottentots merely enlarged such of these as they found where they settled. Some of the Bantu also erected cairns over the bodies of their chiefs, but these are more massive and are well known, so that they cannot be confused with the graves of Heitsi-eibib. The adding a stone to such a heap, at first regarded merely as a mark of respect to the dead who lay there, might easily in course of time come to be considered as an act of worship.

The system of religion of the Hottentots could not be explained by themselves, what they understood being little more than that the customs connected with it had come down to them from their ancestors. They had not the faintest expectation of their own resurrection, or conception of a heaven or a hell. Sacred days or seasons were unknown to them, and if the graves of Heitsi-eibib be excepted, no places were set apart for worship of any kind.

A more improvident, unstable, thoughtless people never existed. Those among them who had cattle were without care or grief, and usually spent the greater part of the day in sleeping. They delighted, however, in dancing by moonlight to music, which they produced from reeds similar to those used by the Bushmen, but superior in tono and effect. Visitors of rank were also welcomed and entertained with dancing and music -if the noise produced from the reeds, sometimes accompanied by the beating of a drum made by stretching the 
dried skin of an antelope over a hollow block of wood, can be so called.* Active in this exercise and in hunting, in all other respects they were extremely indolent. The labour of collecting wild plants and most of that of building and removing huts was performed by the women.

Their filthiness of person, clothing, and habitation was

* In the early records of the Cape Colony there are several descriptions of Hottentot dances performed in honour of Europeans who visited their kraals. After the first terrible outbreak of small-pox they ceased to be practised south of the Orange river, but in the secluded district of Great Namaqualand, where the language and ancient customs were preserved inviolate, the dances of various kinds to the music of reeds were performed until the middle of the nineteenth century. Captain Alexander, who explored Great Namaqualand in 1836-7, in An Expedition of Discovery into the Interior of Africa, through the hitherto undescribed countries of the Great Namaquas, Boschmans, and Hill Damaras, performed under the auspices of Her Majesty's Government and the Royal Geographical Society, and conducted by James Edward Alexander, K.L.S., Captain in the British, Lieutenant-Colonel in the Portuguese service, F.R.G.S. and R.A.S., etc. (two demi octavo volumes, published in London in 1838), describes one that he witnessed in the following words:

"On the 20th February the chief, according to Namaqua custom, presented me with six sheep, and gave me a grand reed dance, as follows:-A dozen men assembled, and with reeds, which, closed at one end, were from one foot long to seven, like the horns, of different sizes, of the Russian horn bands, the music of which I used to hear float like that of a grand piano, over the waters of the Neva. Women and girls also came, and, throwing off their karosses, stood by. One man then blew on his reed, holding it in the left hand, and with the fingers opening and shutting to undulate the sound, while in his right hand, pressed close to his ear, he held a slight stick to clear the reed; the leader blew strongly, his head stooping forwards, and his feet stamping the ground to beat time; the others blew also to accompany their leader; wild music arose, while the musicians circled round, looking inward, stooping and beating time. The music quickened, the women sang, then sprang forward, clapping their hands, and ran round the circle of reed players, giving their bodies various odd twists, and ending by dexterously throwing up the skirt of their skin half-petticoat behind, previous to falling into their places. Sometimes the women got into the middle, and the men stamped and blew their reeds round them; and thus they continued for two or three hours, with occasional pauses, to favour me with the reed dance, which 1 had never seen or heard of before," 
disgusting to Europeans, but was unobserved by themselves. Their dwellings swarmed with vermin, which were not taken much notice of, and were only kept down by the frequent removal of the mat huts to clean ground. The greasing of their persons prevented that annoyance from vermin which to civilised people would have been unendurable, and besides from constant exposure without clothing their skins were tougher than ours.

They enjoyed eating food that would have turned the stomach of the least delicate of Europeans, for the sense of smelling with them-as with all people of a low type-was extremely dull. Thus in the accounts of early voyagers we read of their feasting upon the putrid flesh of seals, which the sailors could not venture near, and as late as 1860 some of those on the coast of Great Namaqualand were found by a party of men from one of the guano islands to be living upon a whale that had drifted ashore, and that the visitors were obliged to keep at a distance.

Still the Hottentots were not without good qualities. Their tempers were in general mild, and their hospitality to peaceable strangers as well as to individuals of their own clan was unbounded. Instances of strong affection between near relatives, such as father and daughter, before their habits became changed by contact with Europeans, are found in the early records of the Cape Colony and in the writings of missionaries. Even in the direst extremity of famine, cannibalism was never resorted to by people of their race.

They were in the habit of abandoning aged and helpless persons-even their own parents,-as well as sickly and deformed children, whom they usually left in some lonely place and allowed to die of hunger. But they regarded this as mercy, not as cruelty. In their opinion it was better for the sufferers themselves that a helpless wretch, too infirm to move about, or a cripple should give up life at once than linger on in misery. For the same reason, when a woman giving suck to an infant too young to care for itself died, the child was buried with its parent. When a woman gave 
birth to twins, if they were of different sexes the female was thrown away, if they were of the same sex the weaker of the two met that fate.

The Hottentots were polygamous in the sense that their customs admitted of a wealthy man having more wives than one, that is when his first wife became old or infirm he was allowed to take another, who was termed the young wife, but he was required to provide for the maintenance of the first, and did not discard her. Thus a rich man could have two legal wives at the same time, but the practice was by no means general. There were many kraals in which there was not a single case of polygamy. It was common with them, though not imperative, to take their wives not from their own but from a different clan, and in all cases men were prohibited from marrying any woman to whom they were related by blood, no matter how distantly.

The marriage customs required that cattle should be given by the bridegroom to the nearest relatives of the bride, but temporary unions were common, and indeed a system almost as bad as that of free love prevailed among at least some of the clans, for chastity on both sides between persons not related by blood was very lightly esteemed. One of the principal objects in their wars with each other was to take females as prisoners, who were generally treated and regarded as mere concubines, but were sometimes raised to the dignity of wives. The difference from a European point of view may seem obscure, but it involved a right over the distribution of the milk, and upon it depended the inheritance of the sons, the daughters, except in the ruling families, inheriting nothing. Female captives of Bushman blood occupied the lower position. There was no religious or moral scruple in operation against conduct of this kind, for they had no conception that it was in any way wrong. 'lo their ideas it was simply the natural right of the strong to take from the weak.

Captain Alexander, who managed to ingratiate himself with the Namaquas, obtained from a party of old men a large 


\section{The Hottentots.}

amount of information upon their customs, in reply to the following questions which he put to them:

What laws have the Namaquas?

They have none, they only listen to their chiefs.

In the old times used they to sow any grain, or had they gardens?

No; they did nothing of the sort-not before the missionaries showed them how to sow and plant.

What could the Namaquas make before the missionaries came to the Great river?

They could soften skins for their karosses, sew them together with sinews; make bows, arrows, assagais, and small axes; bambus for milk; and could weave rush mats.

What is the principal occupation of the men?

Hunting.

How are the women employed?

They put up the mat huts, soften skins, weave mats, and prepare the victuals. If they decline work they get the strap.

How is a chief chosen?

The eldest son of the last chief is selected.

How do the chiefs choose their wives?

Anyhow; from their own place, or from that of their neighbours.

How much is paid for a wife commonly?

From ten oxen to ten sheep, to the father of the girl; and if she is an orphan, her brother gets the amount of her price.

Is circumcision practised in Namaqualand?

No, not at all.

Do the people know anything of the stars?

Nothing.

Who is the greatest hunter here?

When a lion has to be killed, the chief must go out and endeavour to destroy it.

Where did the Namaquas first get iron?

We think we got it from the east before we saw white men. 
Do the Namaquas believe in lucky and unlucky days, omens, \&c. ?

They don't know anything of these things.

Are there rainmakers in the land?

None.

Do the people assemble in council or pitso, as the Betshuana do?

No, the chief merely talks with his headmen on any difficult case.

Has the captain any particular piece of the ox reserved for him?

No particular part.

Of what use have the missionaries been to the people about the Great river?

Before the missionaries came, the people knew nothing at all; they lived without any thought; they had no worship; all they cared for were their wives, children, cattle, and sheep.

What do the old Namaquas think becomes of people when they die?

They know nothing of these things; all they see is that people die and are buried, but what becomes of them they know not; and before the missionaries came to the Great river, the people had never heard of another world.

What had the Namaquas the most pleasure in, their women, tobacco, cattle, beads, or what?

(After some hesitation) They thought more of their sheep than of anything else; of tobacco they knew nothing some years ago; it was brought first from the south side of the Great river; and now, having tasted it, they prefer it to all things in the world.

What is the worst thing which could happen to a Namaqua?

The death of the sheep.

How did they use their sheep? did they milk them, did they eat them?

They milked them, and sometimes killed one or two when 
they wanted a kaross. They never killed them if they had anything else to eat.

It will be noticed that in one or two of these replies the information given is slightly different from that in previous pages of this volume, which arises from the fact that the Namaqua chiefs possessed much more power over their followers than those of the tribes south of the Great or Orange river. Captain Alexander says further of their customs:

"I never saw or heard of a people with fewer ceremonies or observances. They take wives to themselves merely by giving presents to the parents; sometimes two chiefs will have four wives between them; this is, I think, new. When a young woman attains the age of puberty, she is led round the kraal, to touch various things for good luck; thus she touches the milk bambus in the houses, the rams in the fold. When a person is sick, the doctor comes and orders a good sheep to be killed, as he can do nothing without first eating plenty of fat; he reserves a little of the fat to smear the patient with, or he scarifies the flesh over the seat of the disease. When death happens, a hole is dug with a gemsbok's horn or a stick; the body is thrust into it in a sitting posture, stones are piled over it, and the horn or stick is left upright on the heap."

The credulity of the Hottentots was that of children. Thus they really believed that there were Bushwomen who could change themselves into wild animals at will, as an instance of which the following account was given to Captain Alexander :

A certain Namaqua was travelling in company with a Bushwoman carrying a child on her back. They had proceeded some distance on their journey when a troop of wild horses appeared, and the man said to the woman: "I am hungry, and as I know you can turn yourself into a lion, do so now, and eatch us a wild horse, that we may eat."

The woman answered, "You'll be afraid."

"No, no," said the man; "I am afraid of dying of hunger, but not of you." 
Whilst he was yet speaking, hair began to appear at the back of the woman's neck, her nails began to assume the appearance of claws, and her features altered. She sat down the child.

The man, alarmed at the change, climbed a tree close by, the woman glared at him fearfully, and going to one side she threw off her skin petticoat, when a perfect lion rushed out into the plain; it bounded and crept among the bushes towards the wild horses, and springing on one of them it fell, and the lion lapped its blood. The lion then came back to where the child was crying, and the man called from the tree, "enough! enough! don't hurt me. Put off your lion's shape. I'll never ask to see this again."

The lion looked at him and growled. "I'll remain here till I die," said the man, "if you don't become a woman again." The mane and tail then began to disappear, the lion went towards the bush where the skin petticoat lay; it was slipped on, and the woman in her proper shape took up the child. The man descended, partook of the horse's flesh, but never again asked the woman to catch game for him.

It has been said that the women had to do the hardest of the work and were punished if they declined to perform it, but they occupied that position as a matter of course, and would have despised a man who intruded upon their domain. They did not interfere with him in his use of the assagai, the bow, or the club, they left the chase entirely to him, and so they would have regarded it as improper if he had set about making mats or digging bulbs from the ground. In real fact they-excepting of course such captives as have been described-were more nearly the equals of the men, and were permitted to exercise much greater freedom of speech in domestic disputes, than among most barbarians. They were mistresses within the huts. The stores of milk were under their control, not under that of their husbands, as was the case with the Bantu. The men or their sons tended the cattle, but their daughters milked the cows. 
Wherever men greatly preponderate in number over women, the females will enjoy extensive privileges, and if this is the case when a new nation is being formed, the custom

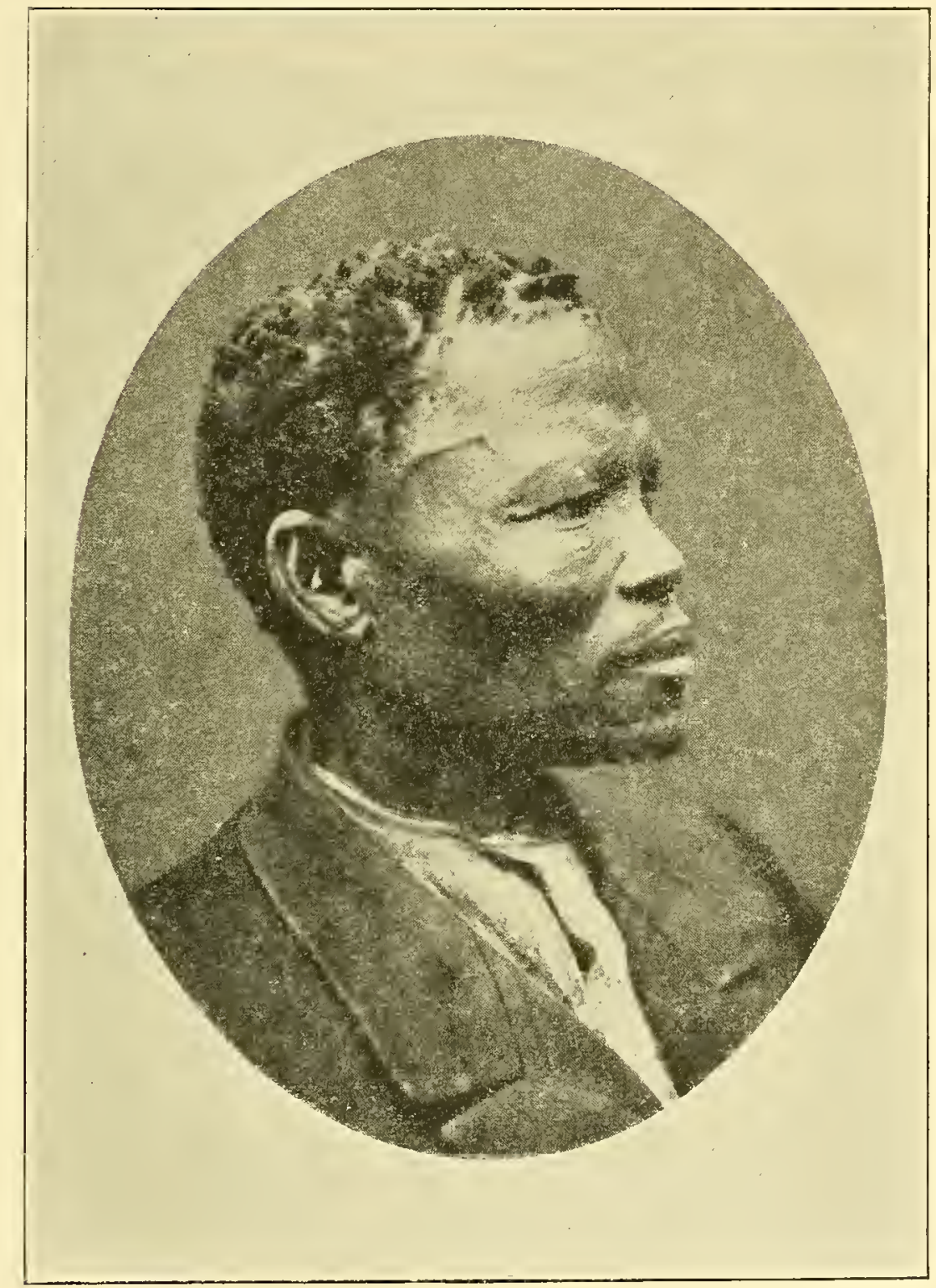

PORTRAIT OF THE FAMOUS HOTTENTOT CHIEF JAN JONKER AFRIEANER, IN EUROPEAN DRESS.

(From a Photograph in the South. African Public Library.)

regarding those privileges will become fixed. No census having ever been taken of these people in olden times, it is impossible to ascertain what the proportion of the sexes to 
each other was when Europeans first became acquainted with them; at present where the race is still comparatively pure they are believed to be about equal. Males were never destroyed in large numbers by war, as among the Bantu, so most likely after the formation of the race there was always an approximate equality between the sexes, the captive Bushman girls, who could not have been very numerous at any one time, excepted. There was no loss of human life on charges of dealing in witcheraft, or the Hottentots would have speedily died out, for they were not so prolific as white people, and very much less so than the Bushmen were or the Bantu are now.

Taking these facts into consideration, the probabilities are very great that at the time of the origin of the race the females were few in number compared with the males who entered their country and induced or forced them to become consorts. Savages as those females were, they were yet able under these circumstances to occupy a position of influence in the household, which their descendants of the same sex never lost.

Dr. Theophilus Hahn says of them: "All the Khoikhoi tribes use the expression Taras for woman. Taras is the woman, as ruler of the house, the mistress. The root $d a$ or ta means to conquer, to rule, to master, and the suffix ra expresses a custom or an intrinsic peculiarity. Taras is also a woman of rank, a lady. In every Khoikhoi's house the woman, or taras, is the supreme ruler; the husband has nothing at all to say. While in public the men take the prominent part, at home they have not so much power even as to take a mouthful of sour milk out of the tub, without the wife's permission. In the house the wife always occupies the right side of the husband and of the house.

"If a chief died, it often happened that his energetic wife became the gau-tas (contracted from gau-taras), the ruling woman-i.e. the queen of the tribe-in place of the son who was not of age. All the daughters are called after the father and all the sons after the mother. The eldest 
daughter was highly respected; to her was entirely left the milking of the cows. This was in accordance with the respect shown to the female sex in general. There is a nice charming little song illustrating this :

"My lioness !

Art thou afraid that I will bewitch thee?

Thou milkest the cow with a fleshy hand (i.e. with a soft hand).

Bite me! (i.e. kiss me !)

Pour for me (milk)!

My lioness,

Great man's daughter.

"The uncle always calls his niece, the brother's or sister's daughter, ' my lioness.'

"The highest oath a man could take, and still takes, was to swear by his eldest sister. A man can never address his own sister personally; he must speak to another person to address the sister in his name, or in the absence of anybody he says so that his sister can hear, 'I wish that somebody will tell my sister that I wish to have a drink of milk, \&c. The eldest sister can even inflict punishment on a grown-up brother if he omits the established traditionary rules of courtesy and the code of etiquette."

Among some-not all-of the Hottentot clans there was a custom which, though described by many early observers, was regarded by most writers of the nineteenth century without sufficient investigation as so utterly incredible that they did not notice it. Yet it is practised at the present day by people who are certainly not of Hottentot blood, but who must have derived their language as well as many of their customs from Hottentot conquerors in bygone times. It stands to them in the same relation that circumcision does to many Bantu clans, that is, among them a youth cannot enter the society of men or take to himself a wife until he

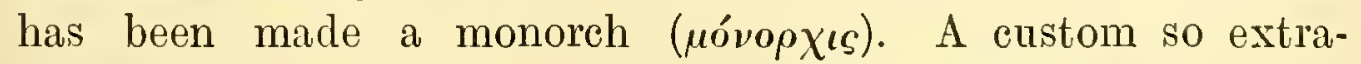
ordinary shows what force habit and superstition have among barbarians.

With all their degrading habits, the Hottentots possessed large powers of imagination. They speculated upon objects 
in nature in a way that no Bantu ever did, and their ideas on these subjects, though seemingly absurd, at least bore evidence of a disposition to think. They had names for many stars and groups of stars, which they believed were endowed with life. They were excellent story-tellers. Seated round fires of an evening, they repeated tales of the doings of men and of animals-usually the baboon or the jackal -which produced boundless mirth. These stories often contained coarse and obscene expressions, or what Europeans would regard as such, but their sense of delicacy in these matters was naturally low. Specimens will be given in the next chapter, and a sufficient number to fill several volumes might still be easily collected, for they have survived the loss of the language in which they were originally told, and have probably not undergone more alterations than were necessary to make them pass current in new surroundings.

The evening with the Hottentots, as probably with all barbarians, was the time for enjoyment. What could be more cheerful than the dance in the bright moonlight or listening to a merry tale by a fire under a starry sky? Then the young men tried their strength in wrestling matches, or in lifting others lying at full length on the ground, while the young women looked on and applauded the successful competitors. Then, too, they played games which, though apparently suited to the capacities of little children only, afforded them much amusement. The commonest of these games, very similar to one practised by the Bushmen, was adopted by the Bantu on the eastern border of the Cape province when they conquered the Hottentots there, and is performed by adults among them to-day, though the people with whom it originated have long since forgotten it.

It was played by two persons or any number exceeding two. The players sat on the ground, and each had a pebble so small that it could easily be concealed in a folded hand. If there were many players they formed themselves into sides or parties, but when they were few in number one 
played against the rest. This one concealed the pebble in either of his hands, and then threw both arms out against his opponent, at the same time calling out that he met or that he evaded. His opponent threw his arms out in the same manner, so that his right hand was opposite the first player's left, and his left opposite the first player's right. The clenched hands were then opened, and if the pebbles were found to meet, the first player won if he had called out that he met, or lost if he had called out that he evaded. When there were many players, one after another was beaten until only two were left. These two then played against each other, when the one who was beaten was laughed at and the winner was applauded. In playing, the arms were thrown out very quickly, and the words were rapidly uttered, so that a stranger might have fancied there was neither order nor rule observed. Young men and boys often spent whole nights in this childish amusement, which had the same hold upon them as dice upon many Europeans.

Probably, if intellectual enjoyment be exchuded, the Hottentots were among the happiest people in existence. They generally lived until old age without serious illness. They did not allow possible future troubles to disturb them, and a sufficiency of food was all that was needed to make them as merry and lighthearted as children at play.

They were capable of adopting the habits of Europeans, though the process required to be so gradual that the training needed two centuries and a half to complete it. They have learned to cultivate the ground, to use the same food as white people, to wear European clothing, and to act as rough handicraftsmen, but there is no instance on record of one of them having ever attained a position that required either much intellectual power or much mechanical skill. They were capable of being drilled into good soldiers, especially into light cavahymen, and in that capacity they never showed deficiency of courage in the field. For three quarters of a century a regiment of Hottentots was maintained in the Cape Colony, and on many occasions it performed excellent 
service under its European officers. The only men of this race indeed who ever attained prominence in any way did so through ability as military leaders. Willem Uithaalder, the head of the Hottentot rebels in 1850-53 in the Cape Colony, was admittedly a formidable man to have as an opponent. So was Hendrik Witbooi, who for years conducted war against the Germans in Great Namaqualand. Jan Jonker Afrikaner was another, though not so prominent as those just named, as he fought with Hereros, not with Europeans.

Their fondness for intoxicating liquor has always been an obstacle to their improvement. They are so weak-minded as readily to give way to temptation, and when once a young man or woman has tasted strong drink the power to abstain from it is lost. Brandy has been a perfect curse to them.

Since the Hottentots came in contact with Europeans of a low class and especially with African slaves, however, their blood has been so mixed that except in Great Namaqualand and along the banks of the Vaal and Orange rivers near their junction, very few of pure blood are in existence now, and every successive generation sees the number become smaller. 


\section{CHAPTER VI.}

\section{Specimens of Hottentot Folklore.}

The first of the tales given here is one which with slight variants is told by Hottentots wherever they live in South Africa. It was taken down in the corrupt Dutch used by those people and translated into English by the late $\mathrm{Mr}$. Thomas Bain, and was first published in the Folklore Journal of July 1879. The second is taken from the late Dr. Bleek's Reynard the Fox in South Africa or Hottentot Fables and Tales, published in London in 1864. It was taken down by the reverend G. Krönlein, Rhenish missionary in Great Namaqualand, from narrators in the Nama dialect, and was presented by him to the Grey Library in Capetown, where it was translated into English by Dr. Bleek. The third and fourth were collected with many others by myself from people of the Xosa tribe between 1860 and 1879. The Xosas are of mixed Bantu and Hottentot descent, and the Hottentot women who during the seventeenth and eighteenth centuries were forced to become the consorts of Bantu men must have introduced these stories, for they are not current among pure Bantu elsewhere. They have a very slight Bantu colouring but not more than sufficient to bring them into line with Xosa comprehension. The fifth is one of several taken down in Dutch by Captain Alexander in Little Namaqualand, and translated by him into English. The others are English translations by Dr. Bleek from Namaqua stories collected by the reverend $\mathrm{Mr}$. Krönlein.

\section{The Animals and the Dam of Water.}

There was a great drought in the land, and the lion called together a number of animals, that they might devise a plan for retaining water when the rains fell. The animals which attended. 
to the lion's summons were the baboon, the leopard, the hyena, the jackal, the hare, and the mountain tortoise. It was agreed that they should scratch a large hole in some suitable place to hold water; and the next day they all began to work, with the exception of the jackal, who continually hovered about in that locality, and was overheard to mutter that he was not going to scratch his nails off in making water-holes.

When the dam was finished, the rains fell, and it was soon filled with water, to the great delight of those who had worked so hard at it. The first one, however, to come and drink there was the jackal, who not only drank, but filled his clay pot with water, and then proceeded to swim in the rest of the water, making it as muddy and dirty as he could. This was brought to the knowledge of the lion, who was very angry, and ordered the baboon to guard the water the next day, armed with a huge knobkerie. The baboon was concealed in a bush close to the water; but the jackal soon became aware of his presence there, and guessed its cause. Knowing the fondness of baboons for honey, the jackal at once hit upon a plan, and marching to and fro, every now and then dipped his fingers into his clay pot, and licked them with an expression of intense relish, saying in a low voice to himself, "I don't want any of their dirty water when I have a pot full of delicious honey." This was too much for the poor baboon, whose mouth began to water. He soon began to beg the jackal to give him a little honey, as he had been watching a long time and was very hungry and tired.

After taking no notice of the baboon at first, the jackal looked round, and said in a patronising manner that he pitied such an unfortunate creature, and would give him some honey on certain conditions, viz. that the baboon should give up his knobkerie and allow himself to be bound. He foolishly agreed, and was soon tied in such a manner that he could not move hand or foot. The jackal now proceeded to drink of the water, to fill his pot, and to swim, in the sight of the baboon, from time to time telling him what a foolish fellow he had been to be so easily duped, and that he (the jackal) had no honey or anything else to give him, excepting a good blow on the head every now and then with his own knobkerie. The animals soon appeared, and found the poor baboon in this sorry plight, looking very miserable. The lion was so exasperated that he caused the baboon to be severely punished and to be denounced as a fool. 
The tortoise hereupon stepped forward and offered his services for the capture of the jackal. It was at first thought that he was merely joking, but when he explained in what manner he proposed to catch him, his plan was considered so feasible that his offer was accepted. He proposed that a thick coating of the sticky black substance found on beehives should be spread all over him, and that he should then go and stand at the entrance of the dam, on the water level, so that the jackal might tread upon him and stick fast. This was accordingly donc, and the tortoise posted there.

The next day, when the jackal came, he approached the water very cautiously, and wondered to find no one there. He then ventured to the entrance of the water, and remarked how kind they had been in placing there a large black stepping-stone for him. As soon, however, as he trod upon the supposed stone he stuck fast, and saw that he had been tricked, for the tortoise now put his head out and began to move. The jackal's hind feet being still free, he threatened to smash the tortoise with them if he did not let him go. The tortoise merely answered, "Do as you like." The jackal thereupon made a violent jump, and found with horror that his hind feet were now also fast. "Tortoise," said he, "I have still my mouth and teeth left, and will eat you alive if you do not let me go." "Do as you like," the tortoise again replied. The jackal, in his endeavours to free himself, at last made a desperate bite at the tortoise, and found himself fixed both head and feet. The tortoise, feeling proud of his successful capture, now marched quietly up to the top of the bank with the jackal on his back, so that he could easily be seen by the animals as they came to the water. They were indeed astonished to find how cleverly the crafty jackal had been caught, and the tortoise was much praised, while the unhappy baboon was again reminded of his misconduct when set to guard the water.

The jackal was at once condemned to death by the lion, and the hyena was to execute the sentence. The jackal pleaded hard for mercy, but finding this useless he made a last request to the lion (always, as he said, so fair and just in his dealings) that he should not have to suffer a lingering death. The lion inquired of him in what manner he wished to die; and he asked that his tail might be shaved and rubbed with a little fat, and that the hyena might then swing him round twice and dash his brains out upon a stone. This being considered sufficiently fair by the lion, was ordered by 
him to be carried out in his presence. When the jackal's tail had been shaved and greased, the hyena caught hold of him with great force, but before he had fairly lifted him from the ground, the cunning jackal had slipped away from his grasp and was running for his life, pursued by all the animals. The lion was the foremost pursuer, and after a great chase the jackal got under an overhanging precipice, and standing on his hind legs with his shoulders pressed against the rock, called loudly to the lion to help him, as the rock was falling and would crush them both. The lion put his shoulders to the rock, and exerted himself to the utmost. After some little time the jackal proposed that he should creep slowly out, and fetch a large pole to prop up the rock, so that the lion could get out and save his life. The jackal did creep out, and left the lion there to starve and die.

\section{The Lion that took a Woman's Shape.}

Some women, it is said, went out to seek roots and herbs and other wild food. On their way home they sat down and said, "let us taste the food of the field." Now they found that the food picked by one of them was sweet, while that of the others was bitter. The latter said to each other, "look here! this woman's herbs are sweet." Then they said to the owner of the sweet food, "throw it away and seek for other." So she threw away the food, and went to gather more. When she had collected a sufficient supply, she returned to join the other women, but could not find them. She went therefore down to the river, where the hare sat lading water, and said to him, "hare, give me some water that I may drink." But he replied, "this is the cup out of which my uncle (the lion) and I alone may drink."

She asked again: " hare, draw water for me that I may drink." But the hare made the same reply. Then she snatched the cup from him and drank, but he ran home to tell his uncle of the outrage which had been committed. The woman meanwhile replaced the cup and went away. After she departed the lion came down, and, seeing her in the distance, pursued her on the path. When she turned round and saw him coming, she sang in the following manner :

My mother, she would not let me seek herbs, Herbs of the field, food from the field. Hoo! 
When the lion at last came up with the woman, they hunted each other round a shrub. She wore many beads and armrings, and the lion said, "let me put them on." So she lent them to him, but he afterwards refused to restore them to her. Then they hunted each other again round the shrub, till the lion fell down, and the woman jumped upon him and kept him there. The lion said :

\section{"My aunt ! it is morning, and time to rise ; Pray rise from me!"}

She then rose from him, and they hunted again after each other round the shrub, till the woman fell down, and the lion jumped upon her. She then addressed him :

"My uncle! it is morning, and time to rise;

Pray rise from me!"

He rose, and they hunted each other again, till the lion fell a second time. When she jumped upon him, he said :

"My aunt! it is morning, and time to rise ;

Pray rise from me !"

They rose again and hunted after each other. The woman at last fell down. But this time, when she repeated the above conjuration, the lion said :

\section{"He kha! Is it morning, and time to rise ?"}

He then ate her, taking care, however, to leave her skin whole, which he put on, together with her dress and ornaments, so that he looked quite like a woman, and then went home to her kraal.

When this counterfeit woman arrived, her little sister, crying, said, "my sister, pour some milk out for me." She answered, "I shall not pour you out any." Then the child addressed the mother: "Nama, do pour out some for me." The mother of the kraal said, "go to your sister, and let her give it to you." The little child said again to her sister, "please pour out for me!" She, however, repeated her refusal, saying, "I will not do it." Then the mother of the kraal said to the little one, "I refused to let her (the elder sister) seek herbs in the field, and I do not know what may have happened; go therefore to the hare, and ask him to pour out for you." 
So the hare gave her some milk; but her elder sister said, "come and share it with me." The little child then went to her sister with her bamboo (cup), and they both sucked the milk out of it. Whilst they were doing this, some milk was spilt on the little one's hand, and the elder sister licked it up with her tongue, the roughness of which drew blood; this, too, the woman licked up. The little child complained to her mother: "Mama, sister pricks holes in me, and sucks the blood." The mother said, "with what lion's nature your sister went the way that I forbade her, and returned, I do not know."

Now the cows arrived, and the elder sister cleansed the pails in order to milk them. But when she approached the cows with a thong (in order to tie their fore legs), they all refused to be milked by her. The hare said, "why do you not stand before the cow ?" She replied, "hare, call your brother, and do you two stand before the cow." Her husband said, "what has come over her that the cows refuse her? these are the same cows she always milks." The mother (of the kraal) said, "what has happened this evening? These are cows which she always milks without assistance. What can have affected her that she comes home as a woman with a lion's nature?"

The elder daughter then said to her mother, "I shall not milk the cows." With these words she sat down. The mother said therefore to the hare, "bring me the bamboos that I may milk. I do not know what has come over the girl." So the mother herself milked the cows, and when she had done so, the hare brought the bamboos to the young wife's house, where her husband was, but she (the wife) did not give him (her husband) anything to eat. But when at night time she fell asleep, they saw some of the lion's hair, which was hanging out when he had slipped on the woman's skin, and they cried, "verily, this is quite another being. It is for this reason that the cows refused to be milked."

Then the people of the kraal began to break up the hut in which the lion lay asleep. When they took off the mats, they said (conjuring them), "if thou art favourably inclined to me, o mat, give the sound sawa" (meaning making no noise). To the poles they said, "if thou art favourably inclined to me, o pole, thou must give the sound Igara." They addressed also the bamboos in a similar manner. 
Thus gradually and noiselessly they removed the hut and all its contents. Then they took bunches of grass, put them over the lion, and lighting them, said, "if thou art favourably inclined to me, o fire, thou must flare up, boo boo, before thou comest to the heart." So the fire flared up when it came towards the heart, and the heart of the woman jumped upon the ground. The mother (of the kraal) picked it up, and put it into a calabash. The lion, from his place in the fire, said to the mother (of the kraal), "how nicely I have eaten your daughter." The woman answered, "you have also now a comfortable place."

Now the woman took the first milk of as many cows as calved, and put it into the calabash where her daughter's heart was; the calabash increased in size, and in proportion to this the girl grew again inside it.

One day, when the mother (of the kraal) went out to fetch wood, she said to the hare, "by the time that I come back you must have everything nice and clean." But during her mother's absence, the girl crept out of the calabash, and put the hut in good order, as she had been used to do in former days, and said to the hare, "when mother comes back and asks who has done these things, you must say, I, the hare, did them." After she had done all, she hid herself.

When the mother (of the kraal) came home, she said, "hare, who has done these things? they look just as they used to when my daughter did them." The hare said, "I did the things." But the mother would not believe it, and looked at the calabash. Seeing it was empty, she searched and found her daughter. Then she embraced and kissed her, and from that day the girl stayed with her mother, and did everything as she was wont in former times; but she now remained unmarried.

\section{STORY OF THE HARE.}

Once upon a time the animals made a kraal and put some fat in it. They agreed that one of their number should remain to be the keeper of the gate. The first one that was appointed was the coney. He agreed to take charge, and all the others went away. In a short time the coney fell asleep, when the inkalimeva (a fabulous animal) went in and ate all the fat. After doing this, he threw a little stone at the coney. 
The coney started up and cried out: "the fat belonging to all the animals has been eaten by the inkalimeva." It repeated this cry several times, calling out very loudly. The animals at a distance heard it, they ran to the kraal, and when they saw that the fat was gone they killed the coney.

They put fat in the kraal a second time, and appointed the muishond to keep the gate. The muishond consented, and the animals went away as before. After a little time the inkalimeva came to the kraal, bringing some honey with it. It invited the keeper of the gate to eat honey, and while the muishond was enjoying himself the inkalimeva went in and stole all the fat. It threw a stone at the muishond, which made him look up. The muishond cried out: "the fat belonging to all the animals has been eaten by the inkalimeva." As soon as the animals heard the cry, they ran to the kraal and killed the muishond.

They put fat in the kraal a third time, and appointed the duiker to be the keeper of the gate. The duiker agreed, and the others went away. In a short time the inkalimeva made its appearance. It proposed to the duiker that they should play at hide and seek. The duiker agreed to this. Then the inkalimeva hid itself, and the duiker looked for it till he was so tired that he lay down and went to sleep. When the duiker was asleep, the inkalimeva ate up all the fat. Then it threw a stone at the duiker, which caused him to jump up and cry out: "the fat belonging to all the animals has been eaten by the inkalimeva." The animals, when they heard the cry, ran to the kraal and killed the duiker.

They put fat in the kraal the fourth time, and appointed the bluebuck to be the keeper of the gate. When the animals went away, the inkalimeva came as before. It said: "what are you doing by yourself ?" The bluebuck answered: "I am watching the fat belonging to all the animals." The inkalimeva said: "I will be your companion, come, let us sit down and scratch each other's heads." The bluebuck agreed to this. The inkalimeva.sat down; it scratched the head of the other till he went to sleep. Then it arose and ate all the fat. When it had finished, it threw a stone at the bluebuck and awoke him. The bluebuck saw what had happened, and cried out: "the fat belonging to all the animals has been eaten by the inkalimeva." Then the animals ran up and killed the bluebuck also. 
They put fat in the kraal the fifth time, and appointed the porcupine to be the keeper of the gate. The animals went away, and the inkalimeva came as before. It said to the porcupine : "let us run a race against each other." It let the porcupine beat in this race. Then it said: "I did not think you could run so fast, but let us try again." They ran again, and it allowed the porcupine to beat the second time. They ran till the porcupine was so tired that he said : "let us rest now." They sat down to rest, and the porcupine went to sleep. Then the inkalimeva rose up and ate all the fat. When it had finished eating, it threw a stone at the porcupine, which caused him to jump up. He called out with a loud voice: "the fat belonging to all the animals has been eaten by the inkalimeva." Then the animals came running up, and put the porcupine to death.

They put fat in the kraal the sixth time, and selected the hare to be the keeper of the gate. At first the hare would not consent. He said : "the coney is dead, and the muishond is dead, and the duiker is dead, and the bluebuck is dead, and the porcupine is dead, and you will kill me also." They promised him that they would not kill him, and after a good deal of persuasion he at last agreed to keep the gate.

When the animals were gone he laid himself down, but he only pretended to be asleep. In a short time the inkalimeva went in, and was just going to take the fat when the hare cried out: "let the fat alone." The inkalimeva said: "please let me have this little bit only." The hare answered, mocking: "please let me have this little bit only."

After that they became companions. The hare proposed that they should fasten each other's tails, and the inkalimeva agreed. The inkalimeva fastened the tail of the hare first. The hare said : "don't tie my tail so tight." Then the hare fastened the tail of the inkalimeva. The inkalimeva said: "don't tie my tail so tight;" but the hare made no answer. After tying the tail of the inkalimeva very fast, the hare took his club and killed it. The hare took the tail of the inkalimeva and ate it, all except a little piece which he hid in the fence. Then he callea out: "the fat belonging to all the animals has been eaten by the inkalimeva."

The animals came running back, and when they saw that the inkalimeva was dead they rejoiced greatly. They asked the hare 
for the tail, which should be kept for the chief. The hare replied: " the one I killed had no tail." They said: "how can an inkalimeva be without a tail ?" They began to search, and at length they found a piece of the tail in the fence. They told the chief that the hare had eaten the tail. He said: "bring him to me." All the animals ran after the hare, but he fled, and they could not catch him. The hare ran into a hole, at the mouth of which the animals set a snare, and then went away. The hare remained in the hole many days, but at length he managed to get out without being caught.

He went to a place where he found a bushbuck building a hut. There was a pot on the fire with meat in it. He said to the bushbuck: "can I take this little piece of meat?" The bushbuck answered: "you must not do it." But he took the meat and atc it all. After that he whistled a particular tune, and there fell a storm of hail which killed the bushbuck. Then he took the skin of the bushbuck, and made for himself a mantle.

After this the hare went into the forest to get for himself some weapons to fight with. While he was cutting a stick the monkeys threw leaves upon him. He called to them to come down and beat him. They came down, but he killed them all with his weapons.

\section{The Lion aNd THE JaCKaL.}

Little Jackal one day went out hunting, when he met a Lion. The lion proposed that they should hunt together, on condition that if a small antelope was killed it was to be the jackal's, and if a large one was killed it was to be the lion's. The jackal agreed to this. The first animal killed was a large eland. The lion was very glad, and said to the jackal: "I will continue hunting while you go to my house and call my children to carry the meat home." The jackal replied: "yes, I agree to that." The lion went away to hunt. When he had gone, the jackal went to his own house and called his own children to carry away the meat. He said: "lion takes me for a fool if he thinks I will call his children while my own are dying with hunger." So the jackal's children carried the meat to their home on the top of a high rock. The only way to get to their house was by means of a rope.

The lion caught nothing more, and after a time he went home and asked his wife where the meat was. She told him there was no 


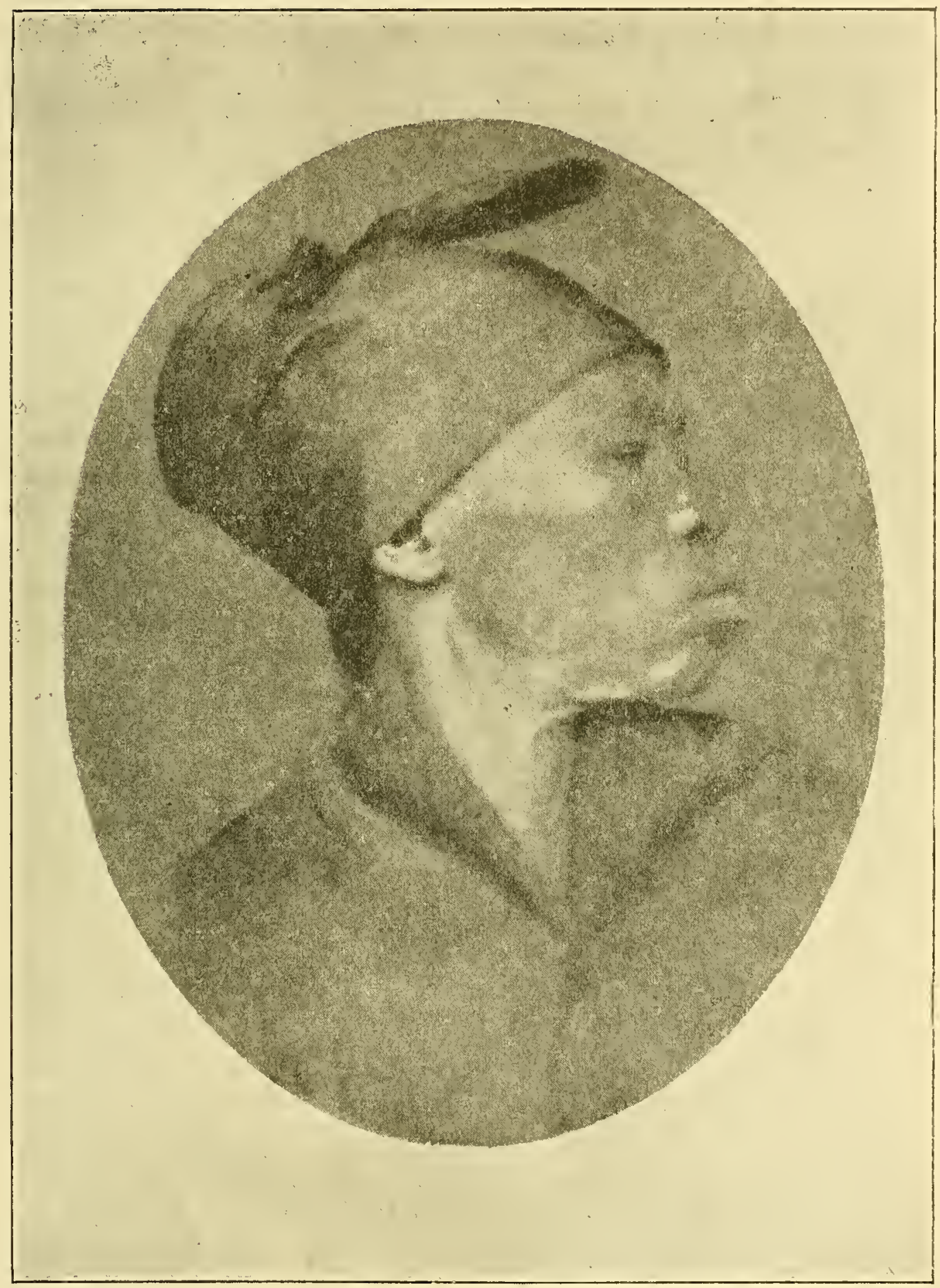

PORTRAIT OF A HOTTENTOT WOMAN, THE WIFE OF JAN JONKER AFRIKANER, SHOWING STRONG TRACES OF BUSHMAN BLOOD, IN EUROPEAN DRESS.

(From a Photograph in the South Africin Public Library.) 
meat. He said: "did not Little Jackal bring a message to my children to carry meat?" His wife replied: "no, he has not been here. We are still dying with hunger."

The lion then went to the jackal's house, but he could not get up the rock to it, so he sat down by the water and waited. After a time the jackal came to get water. He was close to the water when he saw the lion. He at once ran away, and the lion ran after him. He ran into a hole under a tree, but the lion caught his tail before he got far in. He said to him : "that is not my tail you have hold of, it is a root of the tree. If you do not believe me, take a stone and strike it, and see if any blood comes." The lion let go the tail, and went for a stone to prove what it was. While he was gone for the stone, Little Jackal went far into the hole. When the lion returned, he could not be found, so the lion lay down by the hole and waited. After a long time Little Jackal wanted to come out. He went to the entrance and looked round, but he could not see the lion. To make sure, he said: "ho! I see you, my master, although you are in hiding." The lion did not move from the place where he lay concealed. Then Little Jackal went out, and the lion pursued him, but he got away.

The lion watched for him, and one day, when the jackal was out hunting, he came upon him in a place where he could not escape. The lion was just about to spring upon him, when Little Jackal said softly: "hush! do you not see that bushbuck on the other side of the rock? I am glad you have come to help me. Just remain here while I run round and drive him towards you." The lion did so, and the jackal made his escape.

At another time there was a meeting of the animals, and the lion was the chief at the meeting. Little Jackal wanted to go too, but there was a law made that no one should be present unless he had horns. So Little Jackal took wax out of a nest of bees, and made horns for himself with it. He fastened the horns on his head, and went to the meeting. The lion did not know him on account of the horns. But he sat near the fire and went to sleep, when the horns melted. The lion looked at him and saw who it was. He immediately tried to catch him, but the jackal was quick and sprang away. He ran under an overhanging rock and sang out: "help, help, this rock is falling upon me!" The lion went for a pole to prop up the rock, that he might get at the jackal. While he was away Little Jackal escaped. 
After that they became companions again, and went hunting another time. They killed an ox. The lion said : "I will watch it while you carry the pieces away." The lion gave him the breast, and said, "take this to my wife." Little Jackal took it to his own wife. When he returned, the lion gave him a shin, and said : "take this to your wife." Little Jackal took the shin to the lion's house. The lion's wife said: "I cannot take this, because it should not come here." Little Jackal thereupon struck the lion's wife in the face, and went back to the place where the ox was killed. The lion gave him a large piece of meat, and said: "take this to my wife." Little Jackal took it to his own wife. This continued till the ox was finished. Then they both went home.

When the lion arrived at his house he found there was weeping in his family. His wife said: " is it you who sent the jackal to beat me and my children, and is it you who sent this shin? Did I ever eat a shin?" When the lion heard that, he was very angry, and at once went to the jackal's house. When he reached the rock, Little Jackal looked down and said: "who are you, and what is your name, and whose son are you, and where are you from, and where are you going to, and whom do you want, and what do you want him for?" The lion replied: "I have merely come to see you. I wish you would let the rope down." Little Jackal let down a rope made of mouse skins, and when the lion climbed a little way up, the rope broke, and he fell and was hurt. He then went home.

\section{The Ran, the Tiger, and the Jackal.}

A tiger (leopard) was returning home from hunting on one occasion, when he lighted on the kraal of a ram. Now the tiger had never seen a ram before, and accordingly, approaching submissively, he said, "Good day, friend! what may your name be?"

The other, in his gruff voice, and striking his breast with his fore foot, said, "I am a ram. Who are you?"

"A tiger," answered the other, more dead than alive; and then, taking leave of the ram, he ran home as fast as he could.

A jackal lived at the same place as the tiger did, and the latter, going to him, said, "Fricnd jackal, I am quite out of 
breath, and am half dead with fright, for I havc just seen a terrible looking fellow, with a large and a thick head, and on my asking him what his name was, he answered roughly, "I am a ram.',

"What a foolish tiger you are!" cried the jackal, "to let such a nice piece of flesh stand! Why did you do so? but we shall go to-morrow, and eat it together."

Next day the two set off for the kraal of the ram, and as they appeared over a hill, the ram, who had turned out to look about him, and was calculating where he should that day crop a tender salad, saw them, and he immediately went to his wife and said, "I fear this is our last day, for the jackal and tiger are both coming against us. What shall we do?"

"Don't be afraid," said the wife, "but take up the child in your arms, go out with it, and pinch it, to make it cry as. if it were hungry." The ram did so, as the confederates came on.

No sooner did the tiger cast his eyes upon the ram than fear again took possession of him, and he wished to turn back. The jackal had provided against this and made the tiger fast to himself with a leathern thong, and said, "come on!" when the ram cried in a loud voice, and pinching his child at the same time, "You have done well, friend jackal, to have brought us the tiger to eat, for you hear how my child is crying for food!"

On these dreadful words the tiger, notwithstanding the entreaties of the jackal to let him go, to let him loose, set off in the greatest alarm, dragged the jackal after him over hill and valley, through bushes and over rocks, and never stopped to look behind him, till he brought back himself and the half-dead jackal to his place. again. And so the ram escaped.

\section{The Lion's Defeat.}

The wild animals, it is said, were once assembled at the lion's. When the lion was asleep the jackal persuaded the little fox to twist a rope of ostrich sinews in order to play the lion a trick. They took ostrich sinews, twisted them, and fastened the rope to the lion's tail and the other end of the 
rope they tied to a shrub. When the lion awoke and saw that he was tied up, he became angry and called the animals together. When they had assembled, he said (using this form of conjuration)-

"What child of his mother and father's love,

Whose mother and father's love has tied me?"

Then answered the animal to whom the question was first put :

" $I$, child of my mother and father's love,

I, mother and father's love, I have not done it."

All answered the same; but when he asked the little fox the little fox said :

"I, child of my mother and father's love,

I, mother and father's love, have tied thee."

Then the lion tore the rope made of sinews, and ran after the little fox. But the jackal said:

"My boy, thou son of the lean Mrs. Fox, thou wilt never be caught."

Truly the lion was thus beaten in running by the little fox.

\section{The Dove and the Heron.}

The jackal, it is said, came once to the dove, who lived on the top of a rock, and said, "give me one of your little children." The dove answered, "I shall not do anything of the kind." The jackal said, "give it to me at once, otherwise I shall fly up to you." Then she threw one down to him.

He came back another day, and demanded another little child, and she gave it to him. After the jackal had gone, the heron came, and asked, "dove, why do you cry?" The dove answered him, "the jackal has taken away my little children; it is for this that I cry." He asked her, "in what manner can he take them?" She answered him, "when he asked me I refused him; but when he said, "I shall at once fly up, therefore give it to me,' I threw it down to him." The heron said, "are you such a fool as to give your children to the jackal, who cannot fly?" Then, with the admonition to give no more, he went away.

The jackal came again, and said, "dove, give me a little child." The dove refused, and told him that the heron had 
told her that he could not fly up. The jackal said, "I shall catch him."

So when the heron came to the bank of the water, the fackal asked him: "brother heron, when the wind comes from this side, how will you stand?" He turned his neck towards him, and said, "I stand thus, bending my neck on one side." The jackal asked him again, "when a storm comes, and when it rains, how do you stand?" He said to him, "I stand thus, indeed, bending my neck down." Then the jackal beat him on his neck, and broke his neck in the middle.

Since that day the heron's neck is bent.

\section{The Elephant and the Tortoise.}

Two things, the elephant and the rain, had a dispute. The elephant said, "if you say that you nourish me, in what way is it that you do so?" The rain answered, "if you say that I do not nourish you, when I go away will you not die?" And the rain then departed.

The elephant said, "vulture! cast lots to make rain for me." The vulture said, "I will not cast lots."

Then the elephant said to the crow, "cast lots," who answered, "give the things with which I may cast lots." The crow cast lots, and rain fell. It rained at the lagoons, but they dried up, and only one lagoon remained.

The elephant went a-hunting. There was, however, the tortoise, to whom the elephant said, "tortoise, remain at the water." Thus the tortoise was left behind when the elephant went a-hunting.

There came the giraffe, and said to the tortoise, "give me water." The tortoise answered, "the water belongs to the elephant."

There came the zebra, who said to the tortoise, "give me water." The tortoise answered, "the water belongs to the elephant."

There came the gemsbok, who said to the tortoise, "give me water." The tortoise answered, "the water belongs to the elephant."

There came the wildebeest, and said, "give me water." The tortoise said, "the water belongs to the elephant." 
There came the roodebok, and said to the tortoise, "give me water." The tortoise answered, "the water belongs to the elephant."

There came the springbok, and said to the tortoise, "give me water." The tortoise said, "the water belongs to the elephant."

There came the jackal, and said to the tortoise, "give me water." The tortoise said, "the water belongs to the elephant."

There came the lion, and said, "little tortoise, give me water." When the little tortoise was about to say something, the lion got hold of it and beat it; the lion drank of the water, and since that time the animals drink water.

When the elephant came back from the hunting, he said, "little tortoise, is there water?" The tortoise answered, "the animals have drunk the water." The elephant asked, "little tortoise, shall I chew you or swallow you down?" The little tortoise said, "swallow me, if you please," and the elephant swallowed it whole.

After the elephant had swallowed the little tortoise, and it had entered his body, it tore off his liver, heart, and kidneys. The elephant said, "little tortoise, you kill me."

So the elephant died; but the little tortoise came out of his dead body, and went wherever it liked.

\section{The Flying Lion.}

The lion, it is said, used once to fly, and at that time nothing could live before him. As he was unwilling that the bones of what he caught should be broken into pieces, he made a pair of white crows watch the bones, leaving them behind at the kraal while he went a-hunting. But one day the great frog came there, broke the bones in pieces, and said, "why can men and animals live no longer?" And he added these words, "when he comes, tell him that I live at yonder pool; if he wishes to see me he must come there."

The lion, lying in wait (for game), wanted to fly up, but found he could not fly. Then he got angry, thinking that at the kraal something was wrong, and returned home. When he arrived, he asked, "what have you done that I cannot fly?" Then they answered and said, "some one came here, 
broke the bones into pieces, and said, 'if he wants me he must look for me at yonder pool." "The lion went, and arrived while the frog was sitting at the water's edge, and he tried to creep stealthily upon him. When he was about to get hold of him, the frog said, "ho!" and diving went to the other side of the pool, and sat there. The lion pursued him, but as he could not catch him he returned home.

From that day, it is said, the lion walked on his feet, and also began to creep upon (his game); and the white crows became entirely dumb since the day that they said, "nothing can be said of that matter."

It will be observed that these tales are of a different class from those of the Bushmen. They differ also greatly in style from those of the Bantu, as can be seen by comparing them with the tales given in succeeding chapters. They show the power of the Hottentot mind, but are not of the great value that the Bantu tales are in tracing the migrations of these people. 


\section{CHAPTER VII.}

\section{The Dark-shinned People termed by Europeans Bantu.}

FAR more important to a student of South African history than information upon either the Bushmen or the Hottentots is a knowledge of the people termed by us the Bantu, because the former are nearly extinct, while the latter to-day outnumber by more than threefold all the other inhabitants of the country put together, and are still increasing at a marvellous rate. The Bantu tribes of Africa south of the Zambesi vary so greatly in appearance, in speech, in customs, and in intellect, that it is evident they do not form one homogeneous race, still the manner of construction of the various dialects in use by them being the same, and one ruling tenet in the religion of them all being identical, they can be classed as a family group by themselves. Of late years a flood of light has been thrown upon the condition of their kindred in Central Africa, and by applying the knowledge thus gained to occurrences which have taken place since the settlement of Europeans in the southern part of the continent, the history of the Bantu family can be traced backward in general terms, though not in a detailed form.

There is only one way of accounting for the existence of the tribes as they are seen to-day all over Africa south of the equator and even some distance north of it. At some time not exceedingly remote a band of people speaking the parent language of the various dialects now in use, and having ancestor worship as their religion, must have entered North-Eastern Africa, as so many bands had done before. The hamitic family had long possessed the land from the valley of the Nile to the Atlantic ocean, and from the Mediterranean sea to the Sahara, negroes bad entered the continent, perhaps not very long before, and 
had spread along the southern border of the desert, various lighter coloured communities of Asiatic blood had settled southwest of the Red sea, and Bushmen occupied the remainder of the continent, except perhaps where a little horde of Hottentots tended their flocks somewhere between the gulf of Aden and Lake Tanganyika, and maybe highly skilled people, Arab and Indian, were delving for gold in the Rhodesia of our day. This is no sketch of fancy, but what must have been, or the condition of Africa past and present is altogether unexplainable.

The band of immigrants conquered a section of the earlier inhabitants, and incorporated its girls, possibly some of its boys also, but destroyed all the others. Then, after a time, it separated into two or more tribes, each of which pursued a distinct career of conquest, one incorporating Asiatic girls, another negro girls, still another girls of Bushman blood. The tribes increased, and fought with each other, some were destroyed, others grew stronger and stronger, and pushed their way ever southward, where there were no other people than Bushmen to oppose them. The principal line of migration was down the eastern coast, and so when a tribe moving down the centre of the continent reached the region of the great lakes, the Hottentots were obliged to flee to the south-west. In that direction the advance of the Bantu was much slower than on the other side of the continent, for there is every indication that the lower bank of the Zambesi was reached long before the valley of the Congo was occupied.

It is possible that Arabic or Indian documents may some day be discovered which will throw light upon the migration of the Bantu down the eastern coast. At present much information from books concerning any part of the continent south of the Sahara, or of the people occupying it in ancient times, cannot be obtained. The following is all that the author of this volume has been able to gather:

Dr. Budge, in his valuable work on Egypt already mentioned, gives an account of the raising of an army of black men in the valley of the Nile above Nubia 3233 years before the commencement of the Christian era, but whether those black men had, or had not, any connection with the Bantu there are no means of 
ascertaining. In 2466 в.c. Nulia was conquered by Egypt, and again in 2433 and 2333. The Nubians, however, were certainly not near relatives of the Bantu.

There can be very little doubt that the eastern coast of Africa as far down perhaps as Cape Correntes was known to the inhabitants of Southern Arabia several thousand years ago. That they carried on commerce with India by sea is certain from various passages in the old testament, and it is most unlikely that they would expend all their energy on voyaging eastward and neglect at least to examine another coast quite as easy of access.*

They brought the spices to Egypt that were used in embalming the dead, and the great city of Thebes owed its grandeur largely to its being the distributing centre for Indian products brought in ships to the shore of the Red sea and thence conveyed overland by caravans of camels. In the very earliest times of this commerce probably a complete land route was followed, but people so far advanced as to carry on such traffic would speedily see the advantage of ocean transport, and creeping along the coast for short distances at first, they would soon learn to make use of the monsoons and steer boldly over from shore to shore. There is no other sea in the world that offers such facilities for safe navigation by small and crudely built vessels, nor one where facilities are so apparent to the people living on its shores. A single accident, such as a vessel being blown out to sea before the monsoon, would make the coast of Africa known to the people of India, and many accidents of this kind must have occurred. So it may be taken for certain that long before the dawn of written history Indians and Southern Arabians were well acquainted with the East African coast.

That there was little to be obtained in trade on that coast below the tenth degree of north latitude, compared with the products of India, is true, and there may have been nothing at all, for it is in the highest degree improbable that a race more advanced than Bushmen then inhabited the adjoining part of the continent. But if there was no trade, there was ivory to be

* A list of Indian spices that can only have been conveyed by them across the ocean is given in the thirtieth chapter of Exodus. 
collected, and timber-an article of necessity to the Arabians, which their own country did not furnish-to be cut, and possibly gold to be gathered in the territory that now bears the name Rhodesia. There is no record of any kind in existence, however, from which information can be obtained concerning the inhabitants of Eastern Africa in those far-off times, and mere conjecture is valueless.

About the year 992 before Christ an event of importance took place. Solomon, ruler of Israel, had extended his kingdom southward, was in possession of Idumea and the isthmus of Suez, and had established a naval station at Ezion-geber on the gulf of Akaba at the head of the Red sea. He must have known of the existence of an extensive traffic on the shores of what we term the Indian ocean, and have resolved to secure a share of it, or he would not have done this. But his subjects were unused to the sea, and so he had recourse to his ally, Hiram, king of the great commercial city of Tyre, then the wealthiest community in the known world, whose riches were gained by water traffic with many distant peoples.

The Phœnicians may have kept up an uninterrupted trade on the Indian ocean from the time when their ancestors removed from its shore to that of the Mediterranean, though it would appear that in the tenth century before Christ they purchased most, if not all, of the eastern produce that they needed from Sabean merchants, conveyed it in vessels up the Red sea, and then transported it on camels to Tyre. But in whatever manner they acquired their knowledge, some of the subjects of Hiram certainly were acquainted with the sea to the south, and they went as officers just as they would have done in a fleet entirely their own, while sailors were engaged wherever fishermen could be found or recruits could be hired or purchased. This was the manner in which the commerce of Tyre was carried on, just as in modern times the army of the Netherlands East India Company consisted of Dutch officers and foreign soldiers.

So with the aid of Hiram, who had a large share of the profit and who was unable to carry on the trade alone on account of Solomon's possession of Idumea, fleets were built at Ezion-geber, 
of which every particle of the material must have been conveyed overland from the Mediterranean shore, and then they sailed southward to carry on commerce on a very large scale. Of this enterprise the following account is given in the ninth and tenth chapters of the first book of Kings :

"And king Solomon made a navy of ships in Ezion-geber, which is beside Eloth, on the shore of the Red sea, in the land of Edom. And Hiram sent in the navy his servants, shipmen that had knowledge of the sea, with the servants of Solomon. And they came to Ophir, and fetched from thence gold, four hundred and twenty talents, and brought it to king Solomon."

"And the navy also of Hiram, that brought gold from Ophir, brought in from Ophir great plenty of almug trees, and precious stones."

"Now the weight of gold that came to Solomon in one year was six hundred three score and six talents of gold, (equal to $£ 3,646,350$ ), beside that he had of the merchantmen, and of the traffic of the spice merchants, and of all the kings of Arabia, and of the governors of the country."

"For the king had at sea a navy of Tharshish with the navy of Hiram : once in three years came the navy of Tharshish, bringing gold, and silver, ivory, and apes, and peacocks."

Those Phœnicians must have known a great deal about Eastern Africa and its people, but they left absolutely nothing on record, and it is only from their brief connection with the kingdom of Israel that the information given in the sacred writ. ings is obtained. They kept all their geographical knowledge carefully to themselves, for they did not wish to bring commercial rivalry into existence. And so the ships of Tharshish, which may be taken to mean the largest and best equipped vessels for long voyages then known, went up and down the coast ploughing the waters of the Indian sea, perhaps keeping the shore always in sight, or perhaps, like the South Arabian vessels, making direct courses from point to point with the sun and the stars for their guide, while the wisest men in Europe were ignorant of 
the existence of such a vast sheet of water or of the mass of land that closed it in on the western side.

Upon the death of Solomon his kingdom was divided into two sections, each too weak to carry on such great enterprises as he had engaged in, and though on one occasion subsequently the rulers of the separate states united to fit out and despatch a fleet from Ezion-geber, the attempt ended in failure and was never again repeated.

The extensive commerce of Tyre continued to be carried on, but whether she still maintained fleets in the Red sea is doubtful, for she may have needed foreign assistance to be able to do that. In the twenty-seventh chapter of Ezekiel, written about 588 years before Christ, there is a graphic account of her enormous trade, and from the twenty-second verse it would appear that her Indian wares were furnished by the merchants of Southern Arabia.

The splendid city was taken and destroyed after a siege of thirteen years by Nebuchadnezzar, king of Babylon, in the year 573 before Christ, but was soon afterwards rebuilt on an island close to the mainland, and partly recovered its commercial importance. It was taken again in 332 B.c. by Alexander the Great, of Macedon, after a siege of eight months, when its celebrity ceased for ever, as Alexandria, at the mouth of the western outlet of the Nile, took its place as the greatest commercial city of the world.

The Israelites and the Phœnicians not having supplied any information concerning the dark-skinned people of Africa, we turn now to the Greeks to ascertain whether they perchance knew and placed on record anything about them.

In the Homeric age, which is believed to have been somewhere between 1200 and 850 before Christ, the Greeks were aware that such people lived somewhere to the south, but of them, beyond their existence, they knew nothing. They considered the inhabited world to be a circular plane, with a great stream flowing round it, and farther away than the renowned city of Thebes in Egypt, on the border of this ocean stream, the Ethiopians were stated in the Iliad to dwell. The name Ethiopian was of 
course not that by which the people called themselves, but was that applied to them by the Greeks, and meant (aitio $\psi$ ) sunburned, swarthy. They were described by Homer as a "blameless people, whom the gods themselves visit, and partake of their feasts." In the Odyssey they are mentioned further as divided into two sections, the most distant of men, some living where the sun sets and some where he rises.

It is evident from this that the Greeks had a dim knowledge that black men were occupying the valley of the Nile above Egypt, but whether the remote ancestors of the Bantu were among them it is utterly impossible even to make a conjecture. There is, however, reference to another race in the upper valley of the Nile, which, if it stood alone, would be regarded with justice as mythical, but as from this time onward for many centuries it was constantly repeated, must be considered as having a foundation in fact. The Greeks had heard vague rumours of pygmies living in the same part of the world as the Ethiopians, and the poet introduced them in his immortal work as veritable tomthumbs, "men no bigger than your fist," whose mortal enemies were the cranes.

Probably no Greek of that age had ever seen a black man or a pygmy, and the vague knowledge that they had of the existence of such people must have been derived from Phœnician traders, who brought ivory among other things to them for sale; and who could have told them a great deal about Africa and its people, if they had not chosen to keep their knowledge to themselves and give fabulous accounts of everything beyond the immediate ken of those who listened to them. In this matter of the pygmies; we have the earliest reference by any European to the Bushman race, that must then have occupied wholly or partly all Africa south of the confines of Nubia.

The Homeric poems for many centuries were regarded by the Greeks as the repositories of all knowledge, and it was considered sinful to question the accuracy of Homer in such a matter as the locality of an island or the direction of a river. To so great a length did this reverence extend that even after the true form of the earth was known and its size approximately ascertained 
by Eratosthenes and others, the inhabited part was believed to be surrounded by an ocean stream, and Strabo, the most competent of all the ancient geographers, zealously maintained the authority of Homer.

In one matter only was it generally admitted that he had used the license of a poet, and that was in his description of the pygmies, who are pictured by later writers not as tom-thumbs but merely as men under the ordinary size.

The historian Herodotus, who was born in the year 484 before Christ, tells all that was known by the Greeks of his day of the people of Africa. With Egypt he was familiar, and his description of the Nile and its valley up to the first cataract is correct. From Elephantine just below the first cataract to Meroë, the principal town of the Ethiopians, the country is described from verbal information that he obtained and from traditions concerning the intrusion of an Egyptian army thus far.

Herodotus follows Homer in dividing the Ethiopians into two sections, but he is very much better acquainted with them than Homer was. The Eastern Ethiopians he placed along the southern coast of Asia, in a satrapy of Persia, extending from the mouth of the Indus to the entrance of the Persian gulf. And there to the present day a dark-skinned people extremely low in civilisation is to be found.

The Western Ethiopians he placed in the valley of the Nile south of Egypt. Above the first cataract there was an island inhabited partly by Egyptians and partly by Ethiopians, and beyond that were Ethiopians only, except the Automoli or Deserters settled farther south. Whether the Ethiopians in the valley of the Nile at this time were one people or whether they were composed of tribes of different origin, among whom were the progenitors of the Bantu, cannot be ascertained from any information that Herodotus gives. Not a word of the language or languages used by them has been transmitted to us, not an observation upon religion or peculiar customs that might lead to identification has been supplied.

Herodotus had no conception of the great extent of the 
African continent to the southward; and holding the generally received opinion of the Greeks that it was bounded by the ocean stream not far from the land of the Automoli, he could not account for the volume of water in the Nile except by assuming that it flowed for a great distance from the west and then turned sharply to the north.

He had heard that Pharaoh Necho, who reigned in Egypt from 610 to 594 before Christ, had despatched a Phœnician fleet that sailed round Africa from the head of the Red sea through the pillars of Hercules or strait of Gibraltar to the mouth of the Nile, but of the particulars of the voyage he had obtained no account except that it occupied three years and that the voyagers during part of the passage had the sun on the north. The last statement is commonly regarded as a proof that such a voyage was really made, but it does not seem to be of much weight. It was then well known that only a short distance south of Elephantine on the Nile the sun was seen in the north for several days every year, and the natural inference could not be avoided that on the ocean stream farther south the duration would be longer.

The exact words of the statement are: "As for Libya; we know it to be washed on all sides by the sea; except where it is attached to Asia. This discovery was first made by Necôs, the Egyptian king, who on desisting from the canal which he had begun between the Nile and the Arabian Gulf, sent to sea a number of ships manned by Phœnicians, with orders to make for the Pillars of Hercules, and return to Egypt through them, and by the Mediterranean. The Phœnicians took their departure from Egypt by way of the Erythrean Sea, and so sailed into the southern ocean. When autumn came, they went ashore, wherever they might happen to be, and having sown a tract of land with corn, waited until the grain was fit to cut. Having reaped it, they again set sail; and thus it came to pass that two whole years went by, and it was not till the third year that they doubled the Pillars of Hercules, and made good their voyage home. On their return they declared-I for my part do not believe them; but perhaps others may-that in sailing round Libya they had 
the sun upon their right hand. In this way was the extent of Libya first discovered." *

The Phœnicians were competent at that time to make voyages of considerable length, and they must have been acquainted by tradition at least with the East African coast a great distance down, but they never made their knowledge available for others. From them, if Africa had been circumnavigated, the Greeks would have heard nothing of it. But it was said to have been accomplished in the service of Necho, a king who favoured commerce, and who caused docks to be constructed at the head of the Red sea for the use of trading vessels. Is it possible that such a wonderful event as the discovery of a vast area of land previously unknown could have taken place without any record of it being preserved in Egypt, or is it not much more likely to have been just an idle tale told by people who believed the ocean stream to run round all the continents, and the Erythrean sea opening into it to provide a connection with the Atlantic far north of the equator? That this body of water was navigable was a matter of course, that it had been navigated from one side of Africa to the other was told of several expeditions beside this of the Phœnicians, and with as little probability of truth in any one instance as in any other.

Before the time that Herodotus wrote the West African coast had been explored a long way down, but he knew nothing of it. The voyage of discovery was made by a Carthaginian officer named Hanno, whose object was to plant trading stations and inspect the seaboard as far as he could. Hanno sailed with a feet of sixty ships from Carthage some time between 520 and 470 E.C., and after passing the strait now called Gibraltar, kept close to the shore and made himself acquainted with as many particulars concerning it as possible. At a distance of several days' sail from the strait he landed and learned from some Libyan shepherds that the interior was occupied by people who lived in

* The extent of Libya, or the African continent, was not known, or even conjectured, by either the Egyptians or the Greeks in the time of Herodotus. If such a voyage had been made, there would certainly have been some mention of it in the Egyptian records. 
caves and holes in the mountains, were of strange appearance, and swifter of foot than horses. Along the coast several trading stations were established, the last on the little island of Cerne, in a deep bay at the mouth of the river Do Ouro, in latiturle $23^{\circ} 50^{\prime}$ north.

From Cerne the explorer, now relieved of his passengers, and probably of his storeships, proceeded southward along the coast until he reached the mouth of the river Senegal. There something happened of which we have no information, that obliged the fleet to put back to Cerne, but setting out the second time Hanno kept on to Cape Verde, which he observed carefully and described accurately. South of that cape grass fires were seen; which terrified the crews, for the whole land seemed to be ablaze, just as it and other parts of the African coast are sometimes seen by modern voyagers at night. Still the fleet proceeded onward, until it reached Sherboro Sound; in latitude $7^{\circ} 45^{\prime}$ north. Herc some great apes resembling human beings were seen, and three of the females were killed, the skins of two of which were taken back to Carthage as curiosities. The explorers called them gorillas, and that name is now applied to the largest of the manlike apes found in Western Africa, though it is probable that the animals discovered by the Carthaginians were chimpanzees, as the males are stated to have taken to flight.

Sherboro Island was the farthest point reached by the expedition under Hanno. Here the coast trends to the south-east, but at no great distance turns abruptly to the east and forms the deep indentation known now as the gulf of Guinea. The general course from the strait of Gibraltar had been towards the south, but the old inaccuracy in the delineation of the African continent by the Greeks was not corrected after the discoveries made by Hanno were known. The Carthaginians were very careful not to impart useful knowledge to others, but an account of this voyage was inscribed on a tablet and placed in the temple of Moloch in their city, where it was copied, probably without the consent of the authorities. It was translated into Greek; and is known to have been extant in that language in the third century before Christ. But as Hanno kept no other reckoning 
than days' sail, and as anything resembling a compass was then unknown, though he distinctly stated that his course outward was towards the south, the Greek geographers, in their belief that the continent was bounded by the ocean stream far north of the equator, assumed that he must really have steered to the east, and marked his discoveries in that direction. The Portuguese explorers of the fifteenth century made known the true form and size of Africa, and only then was it possible to lay down the route of Hanno correctly and to fix with precision the places that he visited, which fortunately could be done from his accurate description of them.

Of the people of the African continent practically no information whatever is to be derived from the account of this expedition, but the event is a very interesting one.

The renowned scientist Aristotle, the tutor of Alexander the Great, who lived from 384 to 321 B.c., in his writings throws no light upon the subject of this inquiry. He believed that in the southern hemisphere there was a temperate belt corresponding to the one in the northern, but he expressed no opinion as to whether it was inhabited or not. Between these belts he held that there was a zone uninhabitable and impassable on account of intense heat. Whether it was partly land and partly sea, or wholly sea, he did not express an opinion. He knew of the existence of the pygmies in what we would term Northern Africa to-day, and described them as men under the middle height and with black complexions, but of any people corresponding to the Bantu he was quite ignorant.

That commerce on the Indian ocean was extensively carried on at this time is known from the various histories of the conquest of a large part of Asia by Alexander the Great. Having overrun the Punjab and made it the frontier of his dominions, Alexander prepared to descend the Indus to the sea, and for that purpose he collected a great fleet of vessels, some of which were decked and drew as much as 2.74 metres or nine English feet of water. Some he caused to be 
built, others he purchased, and possibly others he seized. The circumstance that impresses one most strongly is the existence of so many ships-about two thousand in allat one time in one part of the East. Certainly many of them were nothing more than river boats, but many were also sea-going ships, fitted for trading up and down the coast of Hindostan and the island of Ceylon.

In this fleet Alexander embarked his cavalry, his stores, provisions, and some of his infantry, and commenced to drop down the great river, the remainder of his infantry, in two divisions, marching down the banks on each side. He had over one hundred and twenty thousand men with him. From Pattala, at the head of the delta of the Indus, the ocean-going ships, eight hundred in number, were sent along the coast to the Euphrates, while Alexander with the army marched overland to Susa. The fleet sailed from the Indus in October 326 B.c., and reached its destination safely after a passage of one hundred and thirty-two days. It was commanded by a military officer named Nearchus, and had as chief pilot or sailing master a Greek mariner named Onesicritus. This, the first fleet directed by Europeans that ever sailed on the Indian sea, was manned partly by Greek, Phœnician, and Syrian sailors, who accompanied Alexander in his expedition, but chiefly by Indian lascars, who could be hired then as they can be to-day. But think what all this meant!

Alexander was well aware of the paramount importance of supremacy on the sea, but his chief object in sending Nearchus on this expedition was to prepare the way for opening a direct trade by the Greeks between India and Europe. And so he was greatly pleased with the safe arrival of Nearchus, and after some delay and a series of feasts directed him to proceed with the fleet round the coast of Arabia to the head of the Red sea. Thence goods could be conveyed on camels and in boats to Alexandria, which would become the distributing centre for Europe. Nearchus had actually embarked to carry out these instructions, when the death of Alexander at an early age put an end to the 
grand project. His vast empire was broken up, and Ptolemy, one of his generals, who succeeded in getting possession of Egypt, took no steps to carry it out in its entirety. Thereafter the Arabs and Indians conducted the trade between India and Aden, where the Greek merchants of Alexandria made their purchases, and then conveyed the goods the remainder of the distance.

So far we have actually nothing about Africa, except Egypt, in the account of the deeds of Alexander and Nearchus. We cannot be far wrong, however, in supposing that with so much shipping in use the East African coast had been explored a long distance down, though the extent of the continent cannot have been known or even conjectured. According to common belief it was just such a peninsula as Arabia, only broader and extending somewhat farther to the south. If therefore Arab or Indian seamen reported that they had been many weeks' sail beyond the entrance to the gulf of Aden, the conclusion that would be come to by those who pondered over the matter would be that they had sailed westward along the coast, just as they believed Hanno had really sailed eastward.

Plutarch, in his Life of Alexander, states that the monarch had resolved to open a route wholly by sea between India and Europe. Alexander, he asserts, was so pleased with the report of Nearchus that he was desirous of sailing in person with a great fleet from the Euphrates, and coasting round Arabia and Africa enter the Mediterranean sea through the pillars of Hercules, the present strait of Gibraltar. For this purpose he had a great number of ships built, and sent to all parts for sailors, masters, and pilots. But his subjects, reflecting on the difficulties and dangers he had already gone through, became apprehensive that if he sailed on this expedition he would never return,* so he abandoned the idea.

* See Plutarch's Lives of the Noble Grecians and Romans, translated into English by Sir Thomas North in the year 1579. Published in small quarto in London in 1895. The information here given is to be found on page 376 of volume iv. I am indebted to Dr. F. Engelenburg, 
In the time of Ptolemy Philadelphus, 285 to 247 B.c., the Greeks of Egypt must have known a great deal about the interior of Africa and its people, but they have left nothing on record that can lead to identification of the Bantu. That monarch founded a station named Myos-Hormus on the western shore of the Red sea, in about latitude $27^{\circ}$ north, in order to carry on commerce in Indian products. Goods purchased by Greek merchants from Arabs at Aden, Saba, and other emporiums were conveyed by water to MyosHormus, and then transported overland to Koptos on the Nile, a distance of about three hundred and twenty kilometres or two hundred English miles by the road. Far down the Red sea other stations were founded, from which elephant hunters went inland to capture young animals, that were taken to Egypt and trained to serve in war. That some of those hunters went a considerable distance inland south and south-west of Abyssinia is almost certain, but the information obtained from them is of elephants captured, not of tribes encountered.

In the year 30 B.c. Egypt became a Roman province, and nine years later-in 21 B.c.-an army under Petronius entered Abyssinia, where such success awaited it that Kandákè, the queen of that country, was obliged to become a tributary. At that time it is evident that no Bantu were living so far north, but beyond this nothing is to be learned regarding them.

Passing by writers of less importance, we come now to the great geographer Strabo, of Amasia, in Pontus, who died about the year of our Lord 21, and in whose work the highest knowledge of the Greeks and Romans concerning the earth and its inhabitants at the commencement of the Christian era is to be found.*

of Pretoria, for very kindly directing my attention to the above proof of the existence of so much shipping in the Indian ocean in the fourth century before Christ.

* See The Geography of Strabo, literally translated, with notes, by H. C. Hamilton, Esq., and W. Falconer, M.A. Three crown octaro 
Strabo resided for some time at Alexandria, where he had access to everything on the subject that had previously been written, and he travelled up the Nile as far as Syene, close to the first cataract, nearly under the northern tropic, where three Roman cohorts were then stationed. His idea of the form of the earth and of its division into five zones-one torrid, two temperate, and two frigid-was that of the present day; but he was the most orthodox of all the devotees of Homer, and everything in his geography is made to fit in with the expressions of the poet. So the Africa of Strabo is a continent bounded on the north by the sea now called the Mediterranean, on the east by the Arabian gulf or as we term it the Red sea, and on the south by the ocean stream which washed its coast first westward and then northwestward from Cape Noti Keras, or Guardafui as now termed, to the pillars of Hercules, the modern strait of Gibraltar. His Africa is made the smallest of the three continents, and might be represented by the body of a plough, of which the share was formed by the promontory ending in Cape Noti Keras.

The Sembritæ he regarded as the most distant inhabitants of Africa, living on the border of the ocean. How wide that ocean was he could not even conjecture, but whether land or sea, adjoining the equator was a belt so hot that it could not be occupied or traversed, just as at the poles there were tracts that were uninhabitable on account of the cold. Strabo believed it possible that beyond the known part of the sea in the north temperate zone there might be habitable land, so that a vessel sailing westward from the coast of Europe might reach it. Of the south temperate zone he thought

volumes, published in London and New York in 1889-1893. Also History of Ancient Geography among the Greels and Romans from the Earliest Ages to the Fall of the Roman Empire, by E. H. Bunbury, F.R.G.S. Second edition, two thick demi octavo volumes, published in London in 1883. A History of Ancient Geography, by H. F. Tozer. M.A., F.R.G.S., chiefly drawn from the work last named, was published in a small crown octavo volume at Cambridge in 1897. 
it most probable that it was inhabited, "but not by the same race of men as dwell with us, and it must therefore be regarded as another habitable earth."

It seems strange to us who live in a time when communication is so rapid and easy, and when information is so widely scattered by means of printed books, that Strabo was entirely ignorant of the eastern coast of Africa below Cape Guardafui. Something about it must have been known by an occasional ship-captain that sailed beyond the gulf of Aden. The commerce between the ports on the Red sea and Arabia had greatly increased since the occupation of Egypt by the Romans, and a direct trade with the coast of Malabar was now carried on by the Greeks of Alexandria as well. Strabo says that "the traffic of the Alexandrian merchants whose vessels pass up the Nile and the Arabian gulf to India has rendered us much better acquainted with these countries than our predecessors were. I was with Gallus at the time he was prefect of Egypt and accompanied him as far as Syene and the frontiers of Ethiopia, and I found that about one hundred and twenty ships sail from Myos-Hormus to India, although in the time of the Ptolemies scarcely any one would venture on this voyage and the commerce with the Indies." And yet the present Somali coast was entirely unknown to him.

Strabo's description of Ethiopia and the Ethiopians can be given in his own words as translated into English:

"But Egypt it (the Nile) traverses both alone and entirely, and in a straight line, from the lesser cataract above Syene and Elephantina (which are the boundaries of Egypt and Ethiopia), to the mouths by which it discharges itself into the sea. The Ethiopians at present lead for the most part a wandering life, and are destitute of the means of subsistence, on account of the barrenness of the soil, the disadvantages of climate, and their great distance from us."

"For formerly not even twenty vessels ventured to navigate the Arabian gulf, or advance to the smallest distance beyond the straits at its mouth; but now large fleets are despatched as far 
as India and the extremities of Ethiopia, from which places the most valuable freights arc brought to Egypt, and are thence exported to other parts."

"For the mode of life of the Ethiopians is wretched; they are for the most part naked, and wander from place to place with their flocks. Their flocks and herds are small in size, whether sheep, goats, or oxen; the dogs also, though fierce and quarrelsome, are small. It was perhaps from the diminutive size of these people that the story of the pygmies originated, whom no person, worthy of credit, has asserted that he himself has seen.

"They live on millet and barley, from which also a drink is prepared. They have no oil, but use butter and fat instead. There are no fruits, except the produce of trees in the royal gardens. Some feed even upon grass, the tender twigs of trees, the lotus, or the roots of reeds. They live also upon the flesh and blood of animals, milk, and cheese. They reverence their kings as gods, who are for the most part shut up in their palaces.

"Their largest royal seat is the city of Meroë, of the same name as the island. . . . The inhabitants of the island are nomades, who are partly hunters and partly husbandmen. There are also mines of copper, iron, gold, and various kinds of precious stones

"The houses in the cities are formed by interweaving split pieces of palm wood or of bricks. . . They hunt elephants, lions, and panthers.

"Above Meroë is Psebo, a large lake, containing a wellinhabited island. As the Libyans occupy the western bank of the Nile, and the Ethiopians the country on the other side of the river, they thus dispute by turns the possession of the islands and the banks of the river, one party repulsing the other, or yielding to the superiority of its opponents.

"The Ethiopians use bows of wood four cubits iong, and hardened in the fire. The women also are armed, most of whom wear in the upper lip a copper ring. They wear sheep-skins without wool, for the sheep have hair like goats. Some go naked, or wear small skins or girdles of well-woven hair round the loins.

"They regard as God one being who is immortal, the cause, of all things; another who is mortal, a being without a name, whose nature is not clearly understood.

" In general they consider as gods benefactors and royal persons, some of whom are their kings, the common saviours and guardians 
of all; others are private persons, esteemed as gods by those who have individually reccived benefits from them.

"Of those who inhabit the torrid region, some are even supposed not to acknowledge any god, and are supposed to abhor even the sun, and to apply opprobrious names to him, when they behold him rising, bccause he scorches and tortures them with his heat; these people take refuge in the marshes.

"Some tribes throw the dead into the river; others keep them in the house, enclosed in hyalus. Some bury them around the temples in coffins of baked clay. They swear an oath by them, which is reverenced as more sacred than all others.

"The following custom exists among the Ethiopians. If a king is mutilated in any part of the body, those who are most attached to his person, as attendants, mutilate themselves in the same manner, and even die with him. Hence the king is guarded with the utmost care."

Among the customs here mentioned are several that seem decidedly characteristic of Bantu, but by Strabo they were regarded as common to all the inhabitants of the Nile valley above Syene, and it is impossible from his account to determine whether there were or were not distinct races of men among them. Some must have been Nubians, others Abyssinians, and it is just possible that some of the most distant may have been Bantu, but beyond this supposition all is vague and uncertain. The pygmies, it will be observed, have so entirely disappeared that their earlier existence even was doubtful.

Within three-quarters of a century from the time of Strabo a very great advance was made in the knowledge by the Greeks and Romans of the eastern coast of Africa. Exactly the same thing had happened as when the Portuguese appeared in the Indian sea more than fourteen centuries later: the Europeans, that is the Egyptian Greeks under Roman dominion, had almost driven the Arabs from the ocean and monopolised the eastern trade. About the year of our Lord 47 a pilot named Hippalus became acquainted with the fact that the wind blew steadily from one quarter 
during certain months, and just as steadily from the opposite quarter during another season of the year. How it happened that the discovery of the monsoons was not made by the Greeks long before seems very strange, but so it was. They had not now to make a circuit along the coast of Asia, but could steer straight across the ocean, and without difficulty could visit any land that the Arabs had frequented before. Their ships were stronger than those of the Arabs, and in war they were superior to their naval rivals.

A few years after the discovery of Hippalus, which had such momentous consequences, the Arab emporium at Aden was destroyed by order of the emperor Claudius, though it was shortly afterwards occupied by the conquerors, and by them was termed the Roman port. The commerce of India with the dominion of the sea was then lost by those who had enjoyed it so long. Some of the coasting trade in small vessels appears to have been left to them for a time, but at length that too was taken from them, their commercial settlements on the African coast were abandoned, and for several centuries they were confined to their own country and to such trade as could be carried on by caravans. As the Roman power declined, however, the Arabs recovered some of the ocean commerce, and at length under the influence of a new religion they bounded into activity again, and with amazing vigour and energy brought into subjection a very large portion of the known world. The conquest of Alexandria by Amrou in the twentieth year of the Hegira, the year 640 of the Christian era, carried with it the absolute destruction of the Greek trade in the Indian sea, and the Arabs had once more a monopoly of intercourse with Hindostan and Eastern Africa. 


\section{CHAPTER VIII.}

The Bantu (continued).

Just before the Egyptian Greeks acquired the full dominion of the Indian sea, much light was thrown upon the condition of the eastern coast of Africa. About the year 80 of our era appeared a treatise on navigation termed The Periplus of the Erythrian Sea, ${ }^{*}$ which is believed to have been written by a Greek of Alexandria, who visited the greater part of the shores he described. It contains a wonderful amount of information, and was the first treatise to make known to Europeans generally the extent of the African coast visited by the Arabs.

In it the coast is described from Myos-Hormus down to an island termed Menuthias, which Dr. Vincent thought was the Zanzibar of our day, but which other investigators believe to be Pemba, as better answering the description of a low wooded island forty-eight kilometres from the coast. The distance named is too great, but for a conjecture without measurement it is not very inaccurate. Fither Pemba, Zanzibar, or Mafia it must have been, and it is most unlikely to have been the last. Two days' sail south of Menuthias was the commercial station of Rhapta, the last of the kind on the seaboard of Azania. Dr. Vincent believed this place to be where Kilwa was afterwards built, but if Menuthias was Pemba, Rhapta must have been on or near the site of the present station of Bagamoyo. What the Arabs or the African inhabitants termed the place is not mentioned, Rhapta (from $\rho a ́ \pi \tau \omega$, to sew) being the Greek name given to it

* See The Commerce and Navigation of the Ancients in the Indian Ocean, by William Vincent, D.D., Dean of Westminster. Two large quarto volumes, published in London in 1807. The second volume is devoted to the Periplus of the Erythrian sea. 
on account of the vessels sewed together with coir which frequented the port.

The exports of Rhapta are mentioned as ivory, rhinoceros horns, tortoise shells, and shells for ornaments. It, as well as a few other commercial stations farther up the coast, was inhabited by Africans, but the Arabs had established fortified factories, by means of which they controlled the populace. Each station was absolutely independent of all others as far as government was concerned. Rhapta itself was subject, in virtue of old-established right, to the ruler of a district in Yemen, from whom the merchants of Muza on the south-eastern shore of the Red sea rented it, and they carried on a regular trade to it with their own ships. The traders spoke the language of the inhabitants, and were in the habit of forming alliances with their females.

The Arabs change not, as they were three thousand years ago, so they are to-day. The picture of the East African coast in the periplus is an almost exact counterpart of the same coast when the Portuguese discovered it at the close of the fifteenth century, except that real settlements, not mere trading stations, came into existence during the second period. That there were Indians mixed with the Arabs can hardly be doubted, as they would naturally be employed in carrying on the trade. And these foreigners, who must have numbered at least several hundreds, were mingling their blood with that of the Bantu inhabitants in the first century of the Christian era, how long before no one can say. It is unfortunate that no description of the inhabitants is given in the periplus, but there is one word of great significance to be found in it. The country along the coast to Rhapta from about latitude $5^{\circ}$ north is termed Azania. This is to a certainty a Greek form of the Arabic name, and we are therefore justified in assuming that this territory was then occupied by Bantu tribes, and was regarded by the Arabs as the country of the Zendj.

The old theory of a zone uninhabitable on account of heat was now proved to be incorrect, for Greeks had advanced without difficulty to latitude $7^{\circ}$ south. So far Bantu occupied 
the coast; but whether they extended farther at that time it is impossible to say. If they did, the question may reasonably be asked why the Arabs who had been there so long had not formed trading stations farther south? and to this no reply can be given. That they had explored the coast farther down cannot be doubted, but there may have been reasons, unconnected with the existence or non-existence of inhabitants so far civilised as to carry on commerce, for their not caring to fix themselves beyond Rhapta.

The information contained in the Periplus of the Erythrean Sea must have been quite new to learned men in all parts of the Roman empire except Egypt, for Pliny the elder was entirely unacquainted with Eastern Africa. Caius Plinius Secundus, who was born in A.D. 23, published in 77, two years before his death in the great eruption of Vesuvius which destroyed Herculaneum and Pompeii, an exceedingly comprehensive work, that can now be read in English as well as in the original Latin. The edition in our language is entitled The Natural History of Pliny, translated, with copious notes and illustrations, by the late John Bostock, M.D., F.R.S., and H. T. Riley, Esq., B.A., Late Scholar of Clare Hall, Cambridge. It is in six crown octavo volumes, published at London in 1855 to 1858.

Pliny believed Africa to be much the smallest of the three continents. His account of the Ethiopians is not only fabulous, but utterly absurd, such as a child might laugh at. He speaks of pygmies in different countries, among others some in India only twenty-seven inches $(68.58$ centimetres) in height. Of those in Africa his only remark is: "Some writers have also stated that there is a nation of Pygmies, which dwells among the marshes in which the river Nile takes its rise." The value of his work, as far as the subject of this inquiry is concerned, is purely negative, showing that Africa beyond Abyssinia was absolutely unknown to the most learned man of his day in Rome.

The next source of information that is available is the work of the renowned astronomer and geographer Ptolemy. Claudius Ptolemæus, of whose personal history nothing is known except that he was a native of Egypt, wrote at Alexandria about the 
middle of the second century of our era. The system which he introduced of laying down places on maps according to their latitude and longitude is the one still in use, and his map of the world is an enormous improvement upon all that preceded it, but as the position of very few places indeed was then accurately known from astronomical observations, he was obliged to have recourse to the crudest means for ascertaining the distance and direction of all other points, many of which it is evident he laid down by guesswork.

This is certainly the case with regard to the territory in Africa termed Agysimba, which he placed in the centre of the continent, on the parallel of $16^{\circ}$ south of the equator. Two Roman officers, Septimius Flaccus and Julius Maternus, had been engaged in expeditions to the south, Flaccus from Cyrene and Maternus from Leptis. Flaccus reported that the Ethiopians of Agysimba were three months' journey south of the Garamantes, and Maternus stated that when he and the king of the Garamantes set out from Garama to attack the Ethiopians of Agysimba, they marched four months to the south. Rhinoceroses abounded in Agysimba. A preceding writer had stretched these distances to a fabulous length, and Ptolemy with these data and nothing more reduced the estimate of Marinus and fixed the position, giving as his reason that as black men and rhinoceroses were not found north of Meroë, Agysimba was probably the same distance south of the equator. The best commentators are now disposed to believe that Agysimba was in the Soudan, not far from the Sahara.

Of the eastern coast Ptolemy gave information similar to that of the periplus of the Erythrean sea, and stated that from Rhapta southward to Cape Prasum a gulf or shoaly sea extended, the shore of which was occupied by Ethiopians who were cannibals. It is conjectured that Cape Prasum is the Cape Delgado of our day. The Bantu are thus brought down to the tenth degree of south latitude, for there can be no doubt that the Ethiopian anthropophagi were of their family. Some terrible commotion must have taken place among them, and they had been compelled to resort temporarily to cannibalism and probably 
to migrate southward, as has more than once been the case in modern times. Ptolemy assigned latitude $15^{\circ}$ south to Cape Prasum, but that is no guide to its position, as it was mere conjecture on his part.

But in one respect he made a wonderfully correct supposition with regard to Africa. The Greek traders who had supplanted the Arabs at Rhapta were in the habit of sending mixed breeds inland to collect ivory, and these men reported the existence of two large lakes and of mountains covered with snow in the lands that they visited. This information was communicated to Ptolemy, and though it was vague, he at once concluded that the lakes must be the sources of the Nile, and that the melting of the snow on the mountains was the cause of the periodical rising of the great river. In his map he laid down the lakes very nearly in their true position, and thus gained credit with many modern writers for knowledge which he did not really possess.

That he had no actual information concerning any part of Africa distant from the coast and south of Cape Prasum, whereever that was, is proved by the fact that he laid down the continent as making a sudden turn to the east just below his Mountains of the Moon at the sources of the Nile, and extending in that direction until it joined Asia beyond the Malay peninsula, thus making the Indian ocean, like the Mediterranean, an inland sea. From him therefore, great as was his merit in other respects, no knowledge concerning the Bantu can be derived beyond that which is here given.

From the time of Mohamed to that of Vasco da Gama the Arabs and Persians were the only traders on the Indian ocean, and they must have been well acquainted with the inhabitants of Eastern Africa even before they founded a chain of settlements from Magadosho down to Sofala.* There

* Indians were largely employed in this trade, but usually, if not always, in a subordinate capacity. Some of the vessels that plied between Hindostan and the African coast were exclusively manned by them, and much of the inland bartering was carried on through their agency. Mohamedan Indians had extensive privileges, and it is possible 
may be Arabic documents in existence which would throw light upon the migrations of the tribes, but not much information is given by the authors of books in that language which have been translated and published in European speech. The following have been consulted by the author of this volume, and all the information they give concerning the East African coast is the following.

Abou-Zeyd-Hassan, a native of Syraf, a town on the Persian gulf, about the year 880 of our era wrote a book upon India and China from accounts given by travelling merchants, principally by one named Soleyman. A copy of this work, transcribed in 1199, was translated into French and published, with the Arabic original, in two small volumes in Paris in 1845. It is entitled Relation des Voyages faits par les Arabes et les Persans dans l'Inde et à la Chine dans lc IXe siecle de l'ere chretienne. Avec une traduction française par M. Reinaud, membre de l'Institut.

This author says of the country of the Zendj or Bantu that it is of great extent, but he does not mention its boundaries. The principal article of diet of the people was millet, and he gives sweet cane also as one of the productions. The people were governed by many chiefs, who were usually at war with each other. The Arabs were highly respected by them. The great influence upon the people of selfconstituted seers or prophets, who were clad in skins of wild cats and monkeys, is recorded. No other article of commerce is referred to than the skins of carnivora, which were regarded as very beautiful, and were highly prized. This information, given more than a thousand years ago, is perfectly correct, and the only fault to be found with it is that it is so scanty.

Aboul Haçan Ali el Masoudi was born at Bagdad towards the close of the third century after the hegira. In early

that some of them may have traded in Africa on their own account, but those who did not profess the creed of Islam were not permitted to do so. 
manhood he was fond of travelling, and visited India and many parts of the East, as well as the island of Kanbalou* and the African coast somewhere north of the equator. In later life he resided for a time at Antioch and at Bassorah, and died at Old Cairo in the year of our Lord 956 . In 943 he completed a great work, which has been translated into French by Messrs. C. Barbier de Maynard and Pavet de Courtaille, and was published in Paris for the Asiatic Society of France. The translation is entitled Les Prairies d'Or, and was issued with the original Arabic text in nine demi octavo volumes in the years 1861 to 1877 .

This great work contains more information upon the Bantu than all the other Arabic volumes yet translated put together. 'Masoudi describes them as having full eyes, projecting lips, and flat broad noses. Their perceptions were vague, and there was an absence of acts of intelligence on their part.

He says he had seen in Ptolemy's geography a plan representing the Nile issuing from the foot of the mountain elKomr. Its waters, which burst forth at first from twelve sources, flowed into two lakes; they united when issuing thence, and flowed through sandy and mountainous regions. The Nile pursued its course through that part of the Soudan which adjoined the country of the Zendj, and from it issued a branch which flowed into the Indian sea. This sea washed the island of Kanbalou, an island well cultivated, and inhabited by Mohamedans who spoke the language of the Zendj. They made themselves masters of the island by taking captive all the Zendj population, at the time of the conquest of the island of Crete in the Mediterranean by the Mohamedans (i.e. A.D. 823).

Concerning the branch of the Nile which flowed into the Indian ocean, this he described as a channel which issued

* The French translators of Masoudi's work were of opinion that the island of Kanbalou was the one now known as Madagascar, but they were not certain of it. It seems just as likely to have been Zanzibar or one of the Comoro islands, though there are as great difficulties in fixing upon one of these as upon Madagascar. 
from the great basin of the Zendj, and separated that country from the frontiers inhabited by the Abyssinian races. Had it not been for this channel, the great deserts, and the drifting sands, the turbulent and innumerable hordes of the Zendj would have driven the Abyssinians from the land of their birth.

The Indian sea formed upon the borders of Abyssinia a channel which projected into the country of Berbera, a part of the territory inhabited by the Zendjes and the Abyssinians. The pilots of Oman sailed down this channel (now termed the gulf of Aden) to reach the island of Kanbalou, which was in the sea of Zanguebar, and was inhabited by a mixed population of Mohamedans and of pagan Zendjes. The termination of their voyages was the island of Kanbalou and the country of Sofala and of the Wakwaks* or Bushmen.

Masoudi states that the country of the Zendj furnished skins of tawny panthers; the inhabitants used them to clothe themselves, or exported them to a Mohamedan country. They were the largest panther slins and the most beautiful to make saddles of. Tortoise shells were also exported, of which combs were made, in the same way as horn was used.

The Zendj proceeded along the channel which flowed from the larger stream of the Nile and emptied itself into the Indian sea. They established themselves in this country, and spread out to Sofala, which was the most distant frontier of the territory and the terminus of the navigation of the vessels of Oman and of Siraf on the western side of the Indian sea. The country of Sofala and of the Wakwak produced gold in abundance and other wonderful things. The climate was hot, and the land was fertile. It was there that the Zendj built their capital, and afterwards they chose

* Wakwak is the word used by some Bantu tribes and by the Arab writers to denote the Bushmen and also baboons, that are always classed together. It is the nearest approach that can be made by the human voice to the grunting sounds of baboons. See Mr. R. N. Hall's The Bushmen, the First Human Occupiers of Rhodesia. 
a king whom they termed Waklimi.* This name had always been that of their sovereigns. The Waklimi had as dependants all the other Zendjian rulers, and had command of three hundred thousand fighting men.

The Zendj employed the ox as a beast of burden, because in their country there were neither horses, nor mules, nor camels, and they were even ignorant of the existence of such animals. Snow and hail were unknown to them. Among them were some tribes who had their teeth very sharp and who were cannibals. The country of the Zendj commenced at the channel which was derived from the upper Nile, and extended to the country of Sofala and of the Wakwak. Their habitations were spread out over an area of about seven hundred parasangs $\uparrow$ in length and in breadth.

This country was formed of valleys, mountains, and sandy deserts; it contained many wild elephants, but not even one tame one was found there. The Zendj did not employ them in war or for other purposes, and they hunted them only to kill them. When they wished to eapture them, they threw into water the leaves, the bark, and the branches of a tree which grew in their country, then they placed themselves in ambuscade until the elephants came to drink. The water burned and intoxicated them, they fell down, and could not rise again, their legs being deprived of movement. The Zendj then attacked them, armed. with long darts, and killed them in order to take their tusks. It was their country which furnished those tusks of ivory which were usually taken to Oman, and then sent to China and India. That

* M. Gabriel Ferraud, the eminent scholar who has done so much to throw light upon the history of India, and especially of Madagascar, by his researches in Arabic documents, writes to me from Paris: "Waklimi is a clerical error of Masoudi's text. The Arabic spelling is mfalīmī $=$ mfalēme $=$ mfalme, meaning sovereign ruler. Mlany errors of that kind can be found in translations of Arabic words. They can be very easily corrected by one who knows the country and has studied Bantu languages."

$\dagger$ A parasang was a measure of length equal to abont five kilometres and a half. 
was the course which they followed, and if they were not so forwarded, ivory would be very abundant in the Mohamedan country.

The Zendj, although constantly occupied in hunting elephants and collecting ivory, did not employ this material for domestic purposes. Instead of gold and silver they used iron for making ornaments for their persons, just as they used oxen as beasts of burden or for war, instead of camels or horses. They gave to God the name of Maklandjalou,* which meant the sovereign master.

The Zendj expressed themselves with elegance, and there were orators among them. Frequently a devout person of the country (i.e. a pretended seer or prophet) standing in the middle of a numerous concourse of people, addressed an exhortation to his audience in which he called upon them to do that which was pleasing to God (i.e. the spirit of the greatest of the dead chiefs), and to be submissive to his commands. He represented to them the chastisements they would make themselves liable to by disobedience, and rited the example of their ancestors and their ancient chiefs. $\uparrow$ These people had no religious code ; their chiefs followed custom, and in governing they conformed to certain political rules.

The principal articles of diet of the Zendj were millet and a plant called kalari, which was drawn from the ground.

* This word may not be correctly given in the French translation. See M. Ferraud's remarks in a preceding note. The language of all the tribes must have changed somewhat since Masoudi wrote, but there does not seem to be any root for this word. Mkulunkulu or one of its many variants, meaning the great great one, that is the most powerful spirit of the dead chiefs, would be the word used to-day.

$\dagger$ This is an accurate picture of a pretended prophet, such as Makana, Umlanjeni, or Umblakaza in recent times when instigating the Xosas to war against the Cape Colony, appealing to his hearers to be obedient to the dictates of the spirits and to conform to ancient customs. If Kanbalou was the present Zanzibar, Masoudi may liave been an eye witness of such a scene, if not, his informants were certainly very well acquainted with the Bantu.

\$ I have bcen unable to ascertain what this plant is. All sections of the Bantu that I am acquainted with use many varieties of wild plants 
It was found in abundance at Aden and in the district of Yemen, it resembled the colocasie of Egypt and Syria. They consumed also honey and flesh.

In the foregoing account of Masoudi, it will have been noticed that an arm of the Nile emptying into the Indian ocean is more than once mentioned, and that the Zendj or Bantu are asserted to have migrated to the south along it. This geographical feature was for centuries regarded as correct, though at the time of the entrance of the Portuguese into the Indian sea it was believed that the stream did not issue from the Nile itself, but from one of the two lakes which were the common source of it and the Nile. A little later it was supposed that there were several lakes connected with each other in the centre of the continent, and every stream of importance that empties itself along the eastern coast was regarded as issuing from one or the other of them. We have in the name Delagoa Bay a result of this belief. The name da lagoa was first given by the Portuguese to the river on which the town of Lourenço Marques is now built, because it was held to flow from the great lake, and by the English

for food, and are much more expert in finding them than Europeans are. I once asked a Xosa youth who was out in the veld with me if he knew what a nongwe (hypozis, p. 385 Harvey's Gen. S. A. Plants) was. I wanted to know, because the word occurred in a tale I had recently heard. He stooped down, and drew one from the ground, observing " if I had not eaten so much maizc this morning I would be eating them now." They were to be found at our very feet and all around us, but I was quite ignorant of that. In his Lake Regions of Central Equatorial Africa, London, 1860, Captain (afterwards Sir Richard) Burton mentions among the vegetables of $\mathrm{Ujiji}$ the roots of a white arum, somewhat resembling the Jerusalem artichoke, but almost without flavour. Dr. Livingstone, in his Narrative of an Expedition to the Zambesi and its Tributaries: London, 1865, says: "As we ascended (the Shirc), we passed a deep stream about thirty yards wide, flowing in from a body of open water several miles broad. Numbers of men were busy at different parts of it, filling their canoes with the lotus root, called nyika, which, when boiled or roasted, rescmbles our chestnuts, and is extensively used in Africa as food." These wild plants do not contain as much nutriment as cultivated ones. 
and the Dutch, but not by the Portuguese, the name was transferred to the bay.

Masoudi terms that part of the Indian ocean adjoining the African coast the sea of Zendj, because the Bantu lived along it. $\mathrm{He}$ estimated it at seven hundred parasangs or thirty-five degrees of latitude in length from the gulf of Aden to Sofala, which is very nearly correct, though his numbers such as three hundred thousand fighting men at the disposal of the ruler of Sofala or the same number of men killed in one battle near Bassorah, are utterly fabalous.

The use by the Bantu of the ox as an animal of burden, the method of hunting and killing elephants for their tusks, the use of iron instead of gold or silver for ornaments, and the clothing made from skins are all correctly described. The account of the barter with the Arabs of ivory, skins of carnivora, and tortoise shells is an item of interest.

But far more important is the information that Bantu were then living as far south as Sofala, though what is stated of the position and power of the chief there must be rejected as a wild flight of imagination, perhaps not of Masoudi himself, but of his informants, for he never was there. How they crossed the Zambesi and settled in what is now the northern part of Mashonaland and the territory between it and the coast is not related, still the cause of the migration can be conjectured almost to a certainty. There was a constant pressure southward, and there was never ceasing war among the tribes along the coast. The people who had inhabited the country adjoining the ancient trading station of Rhapta, and who had the blood of Arabs and Persians, of Indians and even of Greeks, mixed with that of Bantu in their veins, had been compelled to leave their former home, and had by some means managed to make their way so far and to place a great unfordable river between them and their foes. Their superior intelligence, due to their better blood, had enabled them to do this. They knew the value of gold for trading purposes, though they made no use of that metal themselves, 
and so they collected it in their new settlement, and the Arabs followed them by sea to obtain it from them by barter, as Masoudi states.

The general appearance of this section of the Bantu is different from that of any other branch of the family, owing to the large admixture of superior blood. Owing to the same cause the vocabulary varies widely from that of all other Bantu dialects, though the structure of the sentences is the same. These Makaranga, as they term themselves, were the first Bantu to settle in Africa south of the Zambesi, and the time of their arrival must have been a little earlier than A.D. 900. They have at present of course no traditions extending so far back. A missionary lady, Mrs. J. M. Springer, who had resided several years among them and afterwards removed to Katanga, informed the author of this volume that on the bank of the lower Congo she found people speaking a variant of Tshikaranga. There seems no other way of accounting for this than the ejection westward in some great convulsion of a section of the tribe that subsequently migrated to its present home on the other side of the continent. There are very strong reasons for believing that the lower Congo basin was not occupied by Bantu until long after the arrival of the Makaranga (assuming that these were the people mentioned by Masoudi) in the Rhodesia of to-day, so they probably remained for several centuries in some other locality.

From the territory south of the Zambesi in which the Makaranga settled the Bushmen were of course expelled, but the area could not have been large, for centuries later they had not crossed the Sabi, and they did not extend their occupation into what is now known as Matabeleland. Masoudi does not define their border, he merely says that the Wakwak or Bushmen adjoined them, and indeed he could not have ascertained more.

Abi l'Cassem Abdallah Ebn Haukal, a native of Khorasan, wrote an account of the world as known to him between the years of our era 902 and 968 , probably completed about 
A.D. 950. The original Arabic was translated into Persian, and it is from the latter text that the edition in English has been obtained. This was published in a quarto volume in London in 1800, and is entitled The Oriental Geography of Ebn Hautial, an Arabian Traveller of the Tenth Century. Translated from a Manuscript in his own Possession, collated with one preserved in the Library of Eton College, by Sir William Ousely, Knt., LL.D.

Possibly the reason why the Mohamedan writers give so little information upon the Bantu was not their ignorance, but their scorn. Ebn Haukal, at any rate, asserts this to be the case with him. He says: "As for the land of blacks, in the west (Africa), and the Zingians, Ethiopians, and such tribes, I make but slight mention of them in this book, because, naturally loving wisdom, ingenuity, religion, justice, and regular government, how could I notice such people as these, or exalt them by inserting an account of their countries?" And all he said of Eastern Africa was that leopard and other spotted skins that were brought to Yemen came from that country, and that the inhabitants were at war with the Mohamedans.

The greatest of the Arab geographers was Abou Abdallah Mohamed el Edrisi, a native of Spain, who lived from A.D. 1100 to 1154 , and who wrote his valuable book under the patronage of Roger, Christian king of Sicily, the most enlightened monarch of his age. There is a translation into French of part of this work by R. Dozy and M. J. de Goeje, published in Leyden in 1S66, but it does not contain the sections relating to Eastern Africa. The complete work, however, though not well executed, exists in French in two quarto volumes, in which the translation - the original Arabic text is not given-occupies one thousand and fifty-one pages. These volumes were published in Paris in 1836 and 1840, at the expense of the French government, and are entitled Géografie d'Edrisi traduite de l'Arabe en Français d'après deux manuscrits de la Bibliothèke du Roi, et accompagnée de Notcs, par P. Amédée Jaubert, Professeur de Turk a 
l'ecole royale et spéciale des langues orientales vivantes, etc., etc., etc.*

Using caution when proper names occur in this translation, a good deal of information can be obtained from it. like all other Mohamedan literary productions, it contains a shade of glamour resembling that which pervades the Arabian Nights Entertainment, for their author's really believed in witchcraft and magic and enchantments of all kinds. Thus we find in Edrisi an account of a mountain projecting into the sea on the East African coast, one end of which was iron and the other end a powerful magnet that drew ships to their destruction, which the sailors were careful to keep at a great distance.

Edrisi followed Ptolemy in the belief that South Africa curved round like a horn to the eastward, and projected very far in that direction, so that the Indian ocean was really an inland sea; but of that part he professed to know nothing. $\mathrm{He}$ divided the earth into climatic zones, not into zones measured by degrees from the equator as ours are.

He termed the Bantu Zendj, and also Kaffirs, because they were people whom he believed to be without a faith. In this he was decidedly wrong, but so were all other writers down to very recent times, including even the first Christian missionaries who laboured among them. These Kaffirs knew how to extract iron from the ore found in the country and how to make implements and weapons of it. It was exported to India, where it was regarded as of very superior quality, being soft and not brittle. They hunted carnivora for the sake of their skins, and had powerful dogs,

* M. Ferraud, who has taken up the work which I was reluctantly obliged to relinquish in 1904, writes to me: "Generally the Arabic writings have not been translated by men who had a personal knowledge of East Africa, and none of them knew any Bantu language. The translation of Edrisi by Jaubert is absolutely valueless; nine proper names out of ten are incorrect. Fortunately we have in the National Library two good manuscripts of Edrisi, so that I can compare the pseudo translation with them. A good many other translations from Arabic texts are nearly valueless to non-Arabic scholars." 
which they used in the chase. Horses were unknown to them.

On the border of the country of the Zendj was Sofala, the land of gold, where iron and furs were also obtained. Zanzibar, Mombasa, and Melinde were the principal ports for exportation on the coast of the country occupied by the Zendj. Ships from Oman and India visited those ports, but the Zendj had no vessels of their own. The slave trade was carried on, and children were kidnapped and taken from the mainland to Zanzibar. The ruler of an island off the coast of Arabia also was in the habit of sending military expeditions against the Zendj, when many of them were made captives.

In all the country of Sofala gold was found in abundance and of excellent quality, notwithstanding which the inhabitants preferred copper, and they made their ornaments of the last-named metal. The gold exceeded in quantity and in size of the nuggets that of other countries. It was smelted by means of fire made of cowdung, without which it would have been necessary to have recourse to quicksilver, as was done in Western Africa, for the inhabitants of the latter country collected particles of gold, mixed quicksilver with them, fused the mixture by means of charcoal fire, so that the quicksilver evaporated and nothing remained but the mass of pure gold. The gold of Sofala did not need to be treated in this manner, but was smelted without any contrivance that altered it.

Sofala bordered on the country of the Wakwak, who were hideous in appearance, with ill-favoured dispositions, and whose language was a kind of whistling. They roamed about absolutely naked, and were seldom visited by strangers. Neither gold, nor commerce, nor ship, nor beast of burden was found there.

The geographer known in Europe as Aboulfeda was born at Damascus in the year of the hegira 672, or A.D. 1273, and died at Hamat in October 1331. The name given to him when he was circumcised was Ismaël, and on arriving at the age of manhood he took the surname Emad-eddin. 
He became prince of Hamat, when the sultan of Egypt gave him the title Almalek-almovayyad, so that Aboulfeda is only a nickname. He travelled through Egypt, Northern Arabia, Syria, and the territory eastward to the Euphrates, but the information he gives upon other countries consists of quotations from earlier authors. His work was translated into French, and was published in Paris in two quarto volumes in 1848 at the expense of the government. The translation is entitled Geografie d'Aboulfeda traduite de l'Arabe en Français et accompagnée de Notes et d'Eclaircissements par M. Renaud, membre de l'Institut de France, Professor d'Arabe, etc.

Upon South-Eastern Africa no information that is of any value is given in this work, and the positions that he assigns to the places he names are absurdly incorrect. He too mentions the mountain which projected into the sea and acted as a magnet, and he placed it in Sofala, which was the farthest inhabited country towards the south of the continent.

Abou Abdallah Mohamed ibn Abdallah el Lawãti, commonly known as Ibn Batuta, a native of Tangier, born in February 1304, travelled over the known world from the Atlantic coast to China during the twenty-four years from A.D. 1325 to A.D. 1349 , and from A.D. 1351 to 1354 he was engaged in exploring the Soudan. He went down the East African coast as far as Kilwa. His account of the countries he visited was translated into French, and was published in four octavo volumes in Paris by the Asiatic Society from 1853 to 1858. It is entitled Voyages d'Ibn Batoutah, texte Arabe, accompagné d'une Traduction par C. Defrémery et le Dr. B. R. Sanguinette.*

Of the Bantu very little information is given in these volumes, but there are descriptions of two of the Mohamedan

* There is no complete translation in English, but there is a quarto volume of two hundred and forty-three pages, published in London in 1829, entitled The Travels of Ibn Batuta, translated from the abridged Arabic manuscript copies in the public library of Cambridge by the Rev. sâmuel Lee, B.D., Professor of Arabic in the University of Cambridge. 
towns on the East African coast. Ibn Batuta embarked at Magadosho in a vessel bound southward, and touched first at Mombasa, at a distance of two days' journey from the land of the Swahil. The island had no dependency on the mainland, and therefore agriculture was not carried on, but grain was imported from the Swahil. The fruits grown were lemons, citrons, bananas, and jambas. Fish in abundance was caught. The inhabitants were religious, chaste, and virtuous. Their mosques were constructed very solidly of wood.

From Mombasa he proceeded to Kilwa, where he found the inhabitants of the coast to be Bantu of an extremely black colour, marked with incisions. Kilwa was a handsome town, with well-built houses of wood roofed with thatch. Rain was plentiful there. The inhabitants were devoted to the holy war, for they occupied a place contiguous to the country of the infidel Zendj.

A merchant at Kilwa informed the traveller that the town of Sofala, where the gold of the country was collected, was at a distance of half a month's journey. Ibn Batuta concludes the account of his visit to Kilwa with praises of its sultan, who was renowned for his generosity and humility. He made frequent incursions into the country of the Zendj, attacked them, and took booty from them, of which he set aside the fifth part to be disposed of in the manner fixed by the koran. Several Arabs of note were found at Kilwa as visitors to the sultan.

The work of Hassan el Ouazzan ibn Mohamed, of Grenada, born about 1491, who was named John Leo Africanus by Pope Leo $\mathrm{X}$, when he professed to abandon the creed of Islam, being written after the entrance of the Portuguese into the Indian sea, need not be referred to here beyond giving the title of the French edition, which is Description de l'Afrique, tierce partie du Monde, escrite par Jean Leo African premièrement en langue Arabesque, puis en Toscane et à present mise en Francais. The new edition, with notes by $\mathrm{Ch}$. Schefer, is in three quarto volumes, and was published in Paris in 1896, 1897, and 1898. 


\section{CHAPTER IX.}

Settlement of Bantu tribes south of the Zambest and Kunene Rivers.

As has been seen, the territory of Sofala was occupied by Bantu in the ninth century of our era, but how far south that territory extended cannot be ascertained with precision. It is certain; however, that it did not pass the Sabi river, and beyond it the only inhabitants were Bushmen, the Wakwak of the Arab writers. Westward its limit was short of the Mashonaland of our day, for down to much more recent times Bushmen alone occupied that border. Whether the tribe mentioned by Masoudi was the modern Karanga is uncertain, though in all probability it was, still it is possible that the first immigrants may have been conquered and exterminated by later intruders.

These Bantu of Sofala were the first of their family to occupy land south of the Zambesi. When they arrived it is most improbable that on the opposite coast the Hottentots had reached the Kunene.

Some centuries must have elapsed before they were followed by others of their kin. The centre and the western portion of the continent was being gradually occupied, and at length either pressure or war forced other bands to cross the Zambesi and make their way south. These people were the ancestors of the Bakalahari and Balala of our day, and they settled somewhere about the head waters of the Molopo river, which was then a much larger stream than it is now. From the time of their arrival until the middle of the eighteenth century of our era bands frequently came down from the north, but. even now, though they have multiplied at an amazing rate since they have been under the protection of Europeans, the whole number 


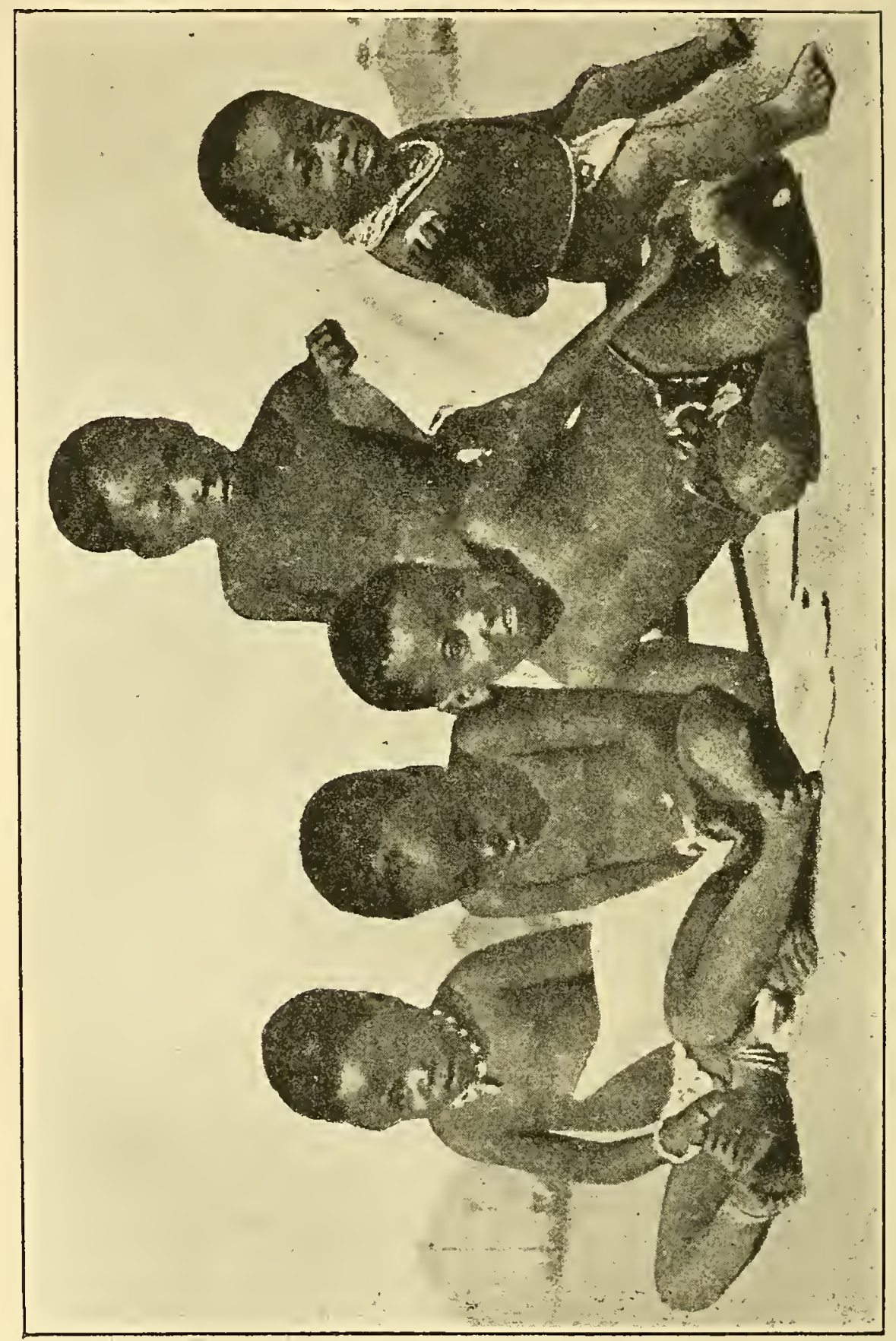

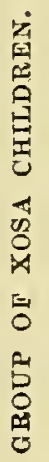


south of the Zambesi and the Kunene does not exceed seven millions, who represent all the offshoots from the great mass of Bantu in the central zone of the continent.

If tradition can be relied upon, the first immigrants who settled in the territory now called Betshuanaland had large herds of cattle in their possession. They formed a number of little bands independent of each other, who came down in succession. These pioneer parties, being small and weak, tried to fraternise with the Bushmen, and were not molested to any serious extent by those savages. Their quarrels were principally with each other. They built kraals at distances far apart, and cultivated the ground about them, leaving the aborigines in undisturbed possession of the open spaces between. With these they to some extent mixed their blood, and numbers of Masarwa or Betshuana-Bushmen came into existence.

After a time another horde came down from the north. These were the ancestors of the people known to early European visitors, from the name of one of their chiefs, as the Leghoyas, of whom the Bataung living in Basutoland are the present representatives. They were more numerous and better armed than the pioneer bands, upon whom they had no scruple in falling, with the object of seizing their cattle and garden produce. Many of the little communities were broken up and dispersed, some seeking refuge in the desert, where they have since been known as Bakalahari, others remaining as slaves, who were termed Balala or the paupers. The Leghoyas then settled in the country, built villages, and made gardens, just as the pioneers had done.

The hordes migrated slowly, often remaining for two or three years at favourable localities on the way. Some of these stations are mentioned in their traditions, others can be recognised by the materials found on their sites. The Bataung, for instance, used stone for building their huts to a much greater extent than any of the other tribes, and Mr. R. N. Hall has recently discovered close to Bulawayo the ruins of a station of those people that must have been occupied for many years. When the next body of invaders made its appearance, if it was stronger the preceding horde was obliged to move on, but 
sometimes it migrated from pure love of change, as many of the Betshuana clans have done down to our own times.

The next to make their appearance in Southern Betshuanaland were the Batlapin, closely followed by the much more powerful Barolong, who settled for a couple of generations on the northern bank of the Molopo. The antiquaries of this tribe state that their ancestors, in the time of a chief, whose name and lineage from father to son to the present day are preserved, left a country on the border of a great lake where at one time of the year shadows were cast towards the north, and gradually migrated southward.* About the middle of the eighteenth century the Barolong crossed the Molopo and dispersed the Leghoyas or Bataung, who, however, were able to retreat to the eastward with their cattle, and then the newcomers settled in the country, where some of their descendants are still living. They made their principal kraal at first on the Setlagoli river, but after a few years moved much farther on, and occupied the bank of the Hart, where their chief Tao (Lion) established his head quarters at the place ever since called after him Taung, that is the place or residence of Tao. This was the commencement of a feud between the Leghoyas and the Barolong, which was carried on without intermission until after the middle of the nineteenth century, and which was one of the leading difficulties of the government of the Orange Piver Sovereignty, when Molitsane on the one side and Moroko on the other could not be brought to observe peace.

These Batlapin and Barolong completed the destruction of the pioneer bands, those who had escaped the attacks of the Leghoyas being now compelled to become Bakalahari or Balala, and to live after the manner of Bushmen. They were in the most miserable condition to which human beings can be reduced, they could not even own a jackal's skin, and their lives were regarded by their tyrants as of no more value than the

* I had a unique opportunity of learning particulars concerning this tribe when investigating rival claims to land made by one of its chiefs and the chief of another tribe for the high commissioner, Lord Loch. In this case facts were brought out which would not otherwise have been made known. 
lives of dogs. Whether they were originally less intelligent than other Betshuana, or whether they became stupid and spiritless from oppression and degradation, is uncertain ; but when Europeans first visited these wretched people they were found to be the most abject of all the dwellers in South Africa.

There was now no attempt to conciliate the Bushmen, for the newcomers were too strong to fear their hostility. Girls of that race were taken by the Batlapin in the same manner as by the Hottentots, but against all others relentless warfare was waged. The Betshuana were armed with strong bows, and soon learned to poison their arrows; they used also the assagai and battle-axe, and protected their bodies with a diminutive shield. In a fight on the open plain the aboriginal savages had no chance whatever, though when attacked on a mountain or among rocks they often managed to beat off their assailants. Still the country was so large, the Bantu invaders were as yet so few in number, and their settlements were so far apart, that the Bushmen could not be entirely exterminated. At the beginning of the nineteenth century they were still numerous in the territory that then began to be known as Betshuanaland, and there are still a few to be found in the desert.

In the fifteenth, sixteenth, and seventeenth centuries, when these events were taking place, the climate of the country north of the Orange and east of the Kalahari was moister than it is at present. For some unknown reason it has gradually become drier since Europeans became acquainted with it, and the process must have been going on long before the first white man made his appearance there. The traditions of the Betshuana are not needed to confirm this fact: the dry beds of ancient rivers and the remains of a luxuriant vegetation are ample evidence. It is very possible indeed that the Betshuana, by frequently burning the grass and destroying the great forests of camelthorn trees they found in the territory, hastened the process of desiccation.

After the Barolong other tribes of the same family came down, notably the Bakwena, whose branches in course of time spread over the whole country south of the Waterberg and the 
Olifants' river eastward to the Kathlamba and down nearly to the Orange. These people, whose siboko is the crocodile and who in former times venerated that reptile because they believed that the spirits of their ancestors appeared to them in its form, constitute the largest section of the Bantu family in South Africa at the present day. The majority of the Basuto tribe of our time are Bakwena, so are the Bahurutsi, the Bangwaketse, the Bamangwato, and very many others. The present Bakwena tribe is merely a small section of this great family, and took its name not from that circumstance, but from its chief at the time of its formation as an independent body being named Kwena. At the close of the sixteenth century there were Bakwena living north of the Zambesi, but whether they were the pioneers of that branch of the Bantu family, or stragglers left behind on the march southward, cannot now be ascertained. The Dominican friar Dos Santos, ${ }^{*}$ who was living on the Zambesi at that time, gives the following particulars:

"Below these mountains of Lupata, close to the river on the eastern side facing the lands of Mongas, is a fine lake, three leagues in circumference and very deep, in the middle of which is an island very lofty and craggy, about a thousand yards in circumference.... The Kaffirs call this lake Rufumba. It is of fresh water, abounds with good fish, hippopotami, and very large crocodiles. On its edge is a grove called by the Kaffirs Tshipanga, thickly wooded with shady trees. The Kaffirs who live in the vicinity of this grove bury their dead there, and it is looked upon by all as a very sacred place, the principal reason of this being that the crocodiles of the Rufumba stretch themselves in the sun on its borders according to their custom, and the Kaffirs imagine that the souls of their dead go into the crocodiles and frequent this lake, for which reason they frequently throw food to them on the borders of the grove."

The various tribes who settled in the country along the eastern border of the Kalahari were constantly at war, plundering one another of cattle, yet they increased in number at a

* See the Ethiopia Oriental of João dos Santos, the whole Portuguese text of which with my English translation is to be found in the seventh volume of the Records of South-Eastern Africa printed for the Cape government. The extract given above is from the sixth chapter. 
marvellous rate. Their battles were not attended with much loss of life, and every female on arriving at the age of womanhood began to bear children. Each tribe lived by itself in a town of from five to fifteen thousand inhabitants, around which extended to a great distance gardens of millet, beans, watermelons, and sweet cane. Beyond these their horned cattle, sheep, and goats were herded, many of which were also kept at distant stations and brought in as needed. The towns required to be removed frequently. The garden ground would become less productive after three or four crops had been taken from it, and owing to the want of even the simplest sanitary arrangements the town itself would become offensive. Then another site would be selected, and on a fixed day the whole population would march to it and begin to erect huts and enclosures, each family taking its position in the new village exactly as in the place abandoned.

After the Bakwena the next to come down along the central plateau were the Bavenda group of tribes, who arrived on the southern bank of the Limpopo about the close of the seventeenth or the beginning of the eighteenth century. According to their own traditions they migrated from the lower basin of the Congo, but there is sufficient evidence in their language and their customs to prove that they do not belong to the western branch of the Bantu family. Their affinities with the Bakwena group are in many respects so close that they must have separated from them at no very remote time, and it is impossible to doubt that they were first driven to the lower Congo basin from some region far to the east. The scattering of the remnants of tribes in the destructive wars towards the close of the sixteenth century, as related in the records of the Portuguese on the Zambesi, must have been in every direction, east, west, north, and south, just as in the dispersions caused by Tshaka.

It is not improbable that these people were the same as those termed by the Portuguese Cabires, who laid waste the territory between the Zambesi and the Limpopo soon after the Abambo and some of the Amazimba passed southward through it. This is mere conjecture, however, for there are no means of tracing 
either the origin or the fate of those Cabires who were so destructive to the Makaranga. If they and the Bavenda were the same, they must have roamed about the southern portion of what is now Mashonaland for many years before crossing the Limpopo. According to their traditions, the Makaranga were subject to the greatest of their chiefs, which seems to point in that direction.

Before the wars of Tshaka the Bavenda occupied the whole of what is now the district of Zoutpansberg. In those wars they were dispersed, but after the emigrant farmers from the Cape Colony drove Moselekatse to the north, the fugitives who survived began to collect together again under the chief Mpofu and others, and settled once more in parts of the district from which they had fled. On the death of Mpofu, his sons Ramovana and Ramapulana fought for the chieftainship. The emigrant farmers assisted Ramapulana, and secured the position for him, but as their vassal. That section of the Bavenda then became known as the Baramapulana, but it was of hardly any importance until the accession in 1864 of Magadu, son of Ramapulana, to the chieftainship.

Among many other sections of less note of this branch of the Bantu family are the tribes which have as their chiefs men with the dynastic titles of Pafuri and Tshivasa, and which also occupy land in the Zoutpansberg district.*

The reverend Mr. Hofmeyr, a missionary for twenty years among these people, states in his volume issued in 1890 that they are able to make out the meaning of an address in Sesuto, and that he has seen among them wooden images, such as are

* I am personaliy. unacquainted with this section of the Bantu family, and am therefore entirely indebted to other authors for the information here given concerning the Bavenda, or Batsethla as sometimes termed. $\mathrm{My}$ principal authorities are: Twintig jaren in Zoutpansberg: een verhaal van twintig jarigen arbeid onder de heidenen in de Transvaal, door den eerwaarden Stefanus Hofmeyr, zendeling der Nederduitsch gereformeerde kerk; a volume of 322 pages, published at Capetown in 1890; History of the Native Tribes of the Transvaal, a bluebook of 67 pages, published by the Transvaal government in 1905; and The Bavenda of the Spelonken, by R. Wessmann, a crown octavo volume of 154 pages, published in London in 1908. 
found in use by some of the Betshuana. This establishes their affinity with the Bakwena, and proves them to be of East African origin. But he has also ascertained that they venerate sticks stuck in the ground, such as those used by the Ovaherero to represent their ancestors, which seems to prove that their traditions of having migrated from the lower basin of the Congo are correct. Their religion is ancestral spirit worship, like that of all other Bantu, but sacrifices to the shades of the dead are more frequent, and food is commonly placed upon graves. Some other differences exist between these people and the Bakwena, but none of much importance.

The last to move down from the distant north to the territory below the Limpopo was the little tribe termed the Bakwebo, which arrived, it is supposed from the lower Congo basin, shortly after the middle of the eighteenth century. This is the tribe governed in our time by the chieftainess Madjaji, about whom there was supposed to be much mystery, as she was kept care. fully concealed from strangers. There is no special difference, however, between these people and their neighbours, and their language is merely a link between Tshevenda and Sesuto.

The eighteenth century was far advanced before the $\mathrm{Be}$ tshuana crossed the Vaal river. The Bataung, who had been compelled to flee from the Barolong, set their faces south-east. ward from their former home on the Setlagoli, crossed the Hart and the Vaal, and took up their residence along the upper course of the Vet river. In their new settlement they were attacked by some offshoots of the Bakwena, by whom they were robbed of many of their cattle. These enemies passed onward, however, without completely destroying them, and settled along the upper banks of the Caledon, where they were joined at a later date by many others.

In 1505, when the Portuguese formed their first settlement on the south-eastern coast, the Makaranga tribe occupied the territory now termed Mashonaland and the seaboard between the Zambesi and Sabi rivers. Before the commencement of the eighteenth century that tribe was broken up by war, and about that time a considerable immigration began to set in from the 
north. The immigrants, who were the ancestors of most of the people now called by Europeans Mashona, came down from some locality west of Lake Tanganyika in little parties, not in one great horde. The first to arrive was a clan under a chief named Sakavunza, who settled at a place near the present town of Salisbury.

The details of this immigration were not placed on record by any of the Portuguese in the country, who merely noticed that there was a constant swirl of barbarians, plundering, destroying, and replacing one another; and when recent investigators, like Mr. R. N. Hall, of Zimbabwe, and Mr. W. S. Taberer, the government commissioner, endeavoured to gather the particulars from the descendants of the immigrants, it was found impossible to obtain more accurate information from them concerning the events of distant times than the general fact that their ancestors came down from the north about two centuries ago. Messrs. Hall, Taberer, and other inquirers state that their proper designation is Baroswi, or Barotsi, and that they constitute a very large proportion of the population of what is termed Mashonaland at the present day.

The larger number settled in the territory now termed Matabeleland, where they remained until 1834, when Moselekatse began to send raiding parties in their direction. Then all those nearest the Matabele kraals, without waiting to be attacked, fled eastward, those farther north, that is the section now under Lewanika, having already been conquered by the Makololo under Sebetoane, who had taken part in the murderous career of the Mantati horde, and subsequently forced their way up from the Bakwena country. The unfortunate Makaranga, who had suffered terribly under the iron rod of the Angoni and the Matshangana, were then still further crushed until they and the Baroswi alike were brought under subjection by the Matabele.

After their arrival in the territory south of the Zambesi the Baroswi not only carried on war against the earlier inhabitants, but among themselves one clan was constantly pillaging another, so that discord and strife were perpetual. There was no paramount power over all, every chief who was strong enough to 
hold his own being absolutely independent of every other. In this turmoil the aborigines almost completely disappeared, for the Bantu, at variance with each other concerning other matters, were united in endeavouring to exterminate them.

Clans of the Baroswi family continued to migrate from the distant north into the territory that is now Rhodesia until the close of the eighteenth century. In some respects, though not in any matters of importance, they differed from the earlier Bantu immigrants. Thus their custom was to dry the dead bodies of men of note before enclosing them in hides for burial, which made the corpses appear like mummies. Girls, when mere infants, were contracted in marriage, though the husband could not claim them until they were capable of bearing children.

Some other customs which are commonly considered as peculiar to them are observed by many other Bantu in South Africa. Such, for instance, is the putting to death of twin children, through fear that if they were allowed to live they would try to displace the chief, and of girls who cut their upper teeth first, under the belief that if they were permitted to grow up any man marrying them would immediately die. Their law of inheritance also, which provides that when a man dies his principal son takes all of the widows except the one who bore him, is common to many other of the interior tribes. So is their skill in weaving loin cloths of wild cotton or making them of bark, and in carving wood, as well as their knowledge of building rough walls of unhewn stone.

They differ from the Makaranga in personal appearance, having coarser features and being blacker in colour and somewhat stouter in build. There is no other tribe in South Africa which has so many individuals bearing traces of Arab, Persian, and Indian blood as the Makaranga, which is due to the long continuance of Asiatic intercourse with them in past times. All who have dealings with them state that, though now spiritless and degraded from constant strife and oppression during more than two centuries, they possess greater latent power of advancement, especially in mechanical arts, than any other Bantu in the country. 
On the eastern coast, south of the Makaranga and extending now even farther than the Fish river, are to be found the sturdiest and most warlike of all the Bantu in South Africa. The numerous tribes into which they have been divided since Europeans became acquainted with them are so closely related to each other in language and customs that they must have formed a community by themselves at no very distant date, and as some of them crossed the Zambesi only a little before the close of the sixteenth century, the others cannot have long preceded them. This section of the Bantu came from some locality on or near the western coast, so that its route of migration crossed that of the Betshuana like that of the letter X.

It is not only from the traditions of these people that it is known they came down from the country beyond the Zambesi in recent times. Tradition can never be entirely depended upon in such matters, and from it no dates could be obtained, five hundred years or three hundred years would be indistinguishable from each other. It is exceedingly vague also, and no antiquary among the tribes is able to give any particulars whatever concerning events during the migration. They can give the names of chiefs for a period of perhaps three hundred years, but are quite ignorant of what the earlier ones did or where they lived and died. In short, any occurrence that they give an account of dating back longer than a century and a half must be regarded as doubtful, unless supported by other evidence, and even their relations of more recent events must be carefully looked into and compared with those from rival tribes.

Fortunately other evidence is available in this case. In 1498 the first Portuguese fleet that crossed the Indian sea touched at the mouth of the Limpopo river, and on board one of the ships was a man, Martin Affonso by name, who could speak several dialects of the tribes on the western coast. This man was able to make himself understood by some of the people on shore, who, as the chronicler Damião de Goes states, must have been strangers from some part of Guinea.*

* " que se entẽdeo cõ algũs delles ( $\tilde{q}$ deuião ser estrãgeiros das partes de Guinê):"-Chronica do Felecissimo Rei Dom Emanuel, por Damião de 
Recent immigrants they certainly must have been, and they must have come from the western coast, or a man understanding only dialects in use there could not have conversed with them. They were Batonga, and on their way across the continent they dropped sections behind, particularly on the southern bank of the Zambesi, where the descendants of those offshoots are to be found to-day. That is all the information obtainable now upon the first billow of Bantu invaders that rolled over the continent from north-west to south-east, and that subsided on the shore of the Indian sea between the Sabi river and Delagoa Bay. What set that billow in motion, what havoc it wrought on its way, what time it took on its course, are all among the unknown particulars of the past. Nothing more can be said with certainty than that the Batonga of the Zambesi valley and of the eastern coast arrived there some time during the fifteenth century.

The whole number of these immigrants was very small, but they were strong enough to exterminate or drive away the aborigines from the localities where they settled. They practised agriculture, though not so extensively as the Betshuana, depending for sustenance more upon their cows and goats than upon vegetable food. They smelted iron, which they wrought into implements such as assagai heads, axes, knives, and hoes, coarser and clumsier than those made by the Makaranga and Betshuana tribes.

Of the next Bantu to make their appearance on the eastern coast very little definite information can be given. As they spoke the same dialect, however, as those that arrived towards the close of the sixteenth century, as their siboko was the same, and as all their leading customs were similar, they must have been members of the same community proceeding in advance

Goes. Primeira Parte, Capitulo XXXVI. Castanheda also says that Martin Affonso understood the language. "Martim Afonso porque entendia a lingoa foy aq̃la noyte á pouoação deste senhor." - Descobrimento e Conquista da India pelos Portuguezes, por Fernão Lopez de Castanheda. Livro Primeiro, Capitulo IV. For particulars of this event see my Records of South-Eastern Africa, in which the Portuguese text and English translations are given. 
of the main body. Such migrations can only be accomplished slowly, as halts are made for years at convenient places along the line of march. Then a party coming on behind arrives, and the one in advance is obliged to move on. At last the shore of the ocean is reached, and as progress in the previous direction is now barred, the future line of advance must be either up or down the coast. When the ancestors of the Xosas, Tembus, and Pondos reached the sea, the coast to the north was already occupied by the Batonga, so they turned to the south, and entered the territory now known as Natal. Vestiges of their sojourn in that region could be found there after the middle of the nineteenth century.*

They had scattered themselves thinly along the coast as far south as the mouth of the Umzimvubu river when, towards the close of the sixteenth century their numbers were greatly increased, and an impetus was given to the movement southward by an irruption from the far distant north-west into the lower valley of the Zambesi of devastating bands that pillaged and destroyed all the weaker clans in their line of march. When other food could not be procured, these invaders resorted to cannibalism, and at length became so accustomed to eat human flesh that they consumed it as an ordinary article of diet. One of the largest of these bands was termed the Amazimba, and to this day the word zim with the southern Bantu denotes a cannibal. It enters largely into folklore tales, and is commonly used to frighten disobedient children. This band drove before it a horde of fugitives composed of the remnants of numberless tribes

* The first account of the southward migration of the Zulu, Tembu, and Xosa tribes that I am acquainted with is that given by the reverend J. $L$. Döhne in the introduction to his Zulu-Kafir Dictionary, published at Capetown in 1857. In 1852 he found a small section of the Amaxosa, that had been left behind, still living in Natal. He believed these tribes to have come from the Mozambique coast, but of course he knew nothing of the invasion from the north-west and the terribly destructive wars towards the close of the sixteenth century, of which the Portuguese on the Zambesi have left accounts. Those narratives picture the events to which all the dim traditions of the tribes along the south-eastern coast point, and solve questions that could not be answered before they were published in accessible form. 
plundered and partly destroyed on the way from the Atlantic shore, and that collectively was known as the Abambo.

Just as with the Mantati horde and the Amangwane two centuries and a quarter later, the Abambo and the Amazimba were partly destroyed by starvation and partly by incessant war, but some remnants forced their way in murderous marches through the earlier settlements to distant localities, where they remained and built permanent kraals. A considerable remnant of the Abambo horde in this manner cut its way through the western part of the territory occupied by the Makaranga, and finally settled in the valley of the Tugela and in the territory farther south. On its march it had incorporated a large number of Karanga girls, and probably of boys also, so that at least one section of it was largely affected by this mixture of blood. To the present day this section-the Amazizi-show abundant signs of Karanga ancestry, and are as a rule more intelligent than any of their neighbours. By other tribes they were even often termed Amalanga on this account. The occupation of Natal by the Abambo compelled the pioneers of their family to move farther along the coast, and very likely these were joined. by many little offshoots from the main body. The Xosas, Tembus, and Pondos still term Natal Embo, that is the country of the Abambo.

Some time after its settlement in Natal the horde broke up into many communities independent of each other, between which rivalries and feuds broke out just as everywhere else among the Bantu. These new tribes were probably the remnants of older ones that had been broken up and pressed into the horde on its long journey across the continent, but which still retained their former titles and regarded their separate existence as a matter of common usage and right.

The Portuguese, who occupied stations at Sofala, Sena; and Tete at this time, give no direct information upon the occupation of Natal by the Abambo. Very likely they knew nothing of what was going on at a distance from their forts, just as the Cape government and colonists knew nothing at the time of the career of the Mantati horde or of Sotshangana or Moselekatse. 
Or if rumours of terrible destruction being caused inland by a horde of ferocious invaders ever reached them, they were too much taken up with their own disasters to pay attention to them. Even of the section which they termed the Cabires, that gave them much trouble, they placed very little information on record. It is from them, however, we learn that in 1570 the Abambo horde made its first appearance on the northern bank of the Zambesi above Tete, that there were then very few Bantu inhabitants south of the Umvolosi river, and that after 1600 Natal had a considerable population. The traditions of all the tribes that they came down from the north may not count for much, but they cannot be altogether passed over. A much stronger proof of the recent occupation by Bantu of the country south of the Sabi river is the fact that the Arabs never attempted to form a station there. They were among the very keenest traders in the world, but south of the Sabi were only Wakwak or Bushmen, so nothing was to be bought or sold there. In 1505 the Portuguese wrested Sofala from them, but they never thought of sending a trading party south of Delagoa Bay before the irruption of the Abambo, and then the days of their enterprise and vigour were gone for ever.

The remaining tribes on the south-eastern coast, that is those between Natal and Delagoa Bay, may have occupied that territory at the same time as the Abambo settled in Natal, or they may have arrived there at a little later date. They are the same in language and generally in customs, and there is nothing unlikely in the supposition that they were part of the same horde that had lagged somewhat behind. But it is possible that they were connected with the Amazimba, who, though pursuing the Abambo, were themselves fugitives from some stronger power in the locality from which they set out on their murderous career. Before the time of Tshaka the Abatetwa were the most prominent people in that part of South Africa, and at the beginning of the nineteenth century they were under a chief of note named Dingiswayo.

A man who claimed to be a grandson of Dingiswayo by one of his inferior wives, and who had received sufficient 


\section{The Bantu.}

education to be able to write English fluently, in 1883 drew up an account of this tribe, which was forwarded to the author of this volume by a friend interested in South African history. It assigns to the Abatetwa a position of greater importance than they really filled, inasmuch as it claims paramountey for them from the time of their arrival in Zululand over every other tribe in South-Eastern Africa, including even the sections of the Abambo. But this is in perfect keeping with all narratives of the kind from Bantu antiquaries, who invariably represent their own chiefs as more glorious than any others, and it need not be taken into consideration.

The writer of the account says that the Abatetwa were driven across the Zambesi from some place far away in the north or north-west by their neighbours the Komanti and the Ashongwa, and he puts their arrival in Zululand in the time of the greatgrandfather of Dingiswayo. Of the earlier history of the tribe, or even the names of its remote chiefs, his own ancestors, he had been unable to obtain any information that he could depend upon. Of its career on the march he says nothing, but pictures it as conquering all around it upon its arrival in Zululand, which country he is therefore of opinion ought to be regarded as rightly belonging to it. Such a narrative, however, is not to be strictly depended upon, and in some of the particulars given, such as, for instance, the date of the arrival of the Abatetwa, it is certainly erroneous; but it corroborates the general tradition of a not very remote migration of the tribes now living in Zululand from some far distant locality.

When the pioneers of the Bantu crossed the Umtamvuna they encountered the earlier Hottentot occupants, who were themselves recent immigrants, and who had largely mixed their blood with that of the aboriginal Bushmen. These were too feeble to resist the advancing wave from the north, and therefore met with the fate of the weaker everywhere in Africa. The males were exterminated, and the females were incorporated with the conquerors. Through this amalgamation the language of the tribes in advance was greatly affected, three of the Hottentot clicks being introduced-chiefly in words pertaining to the 
occupations of women,-and even the character and appearance of the people underwent a change. It is this mixture of Hottentot and Bushman blood that makes the difference between the Xosa or Tembu and the Hlubi of our day. Originally they were in every respect identical.

Along the coast the Bantu settlements were denser than in the interior, but south of the Tugela river in general only the terrace adjoining the sea and the one next to it were occupied. From these the Bushmen were entirely driven, but in advance of the migrating Bantu they massed in as great numbers as could obtain food, and held their own until the beginning of the eighteenth century, some indeed until nearly a hundred years later. They were numerous in the territory between the Kei and the Keiskama when Rarabe (pron. Khàkhábăy), a chief who was well known to the Europeans on the eastern frontier of the Cape Colony, entered that district. They stole and killed his favourite racing ox; which so incensed him that he gave orders for their destruction, and was not appeased until none were left. On the plateau adjoining the Kathlamba from the Tugela to the Fish river they were not disturbed, except by occasional parties of men sent to punish them for committing robberies in the lowlands, and there they remained until long after the British conquest of the Cape Colony.

On the western coast the Bantu occupation is still more recent than on the south-eastern. The first small horde that appeared there was subdued by the Hottentots, and forced to adopt the language and customs of its conquerors. These are the people now called Berg Damaras by Europeans and Ghou Damara (masculine, singular, nominative, Damup) by the Namaquas-Haukoin they term themselves,-who are Bantu or possibly negro by blood, but Hottentot by speech, religion, and many customs, and live like Bushmen almost entirely on game, insects, reptiles, and wild plants. They hardly ever attempt to cultivate the ground, and when they do, it is only to plant watermelons of the wild variety and dacha for smoking, which they use to great excess. Their habitations are made of a few branches of trees or shrubs, not always covered with 


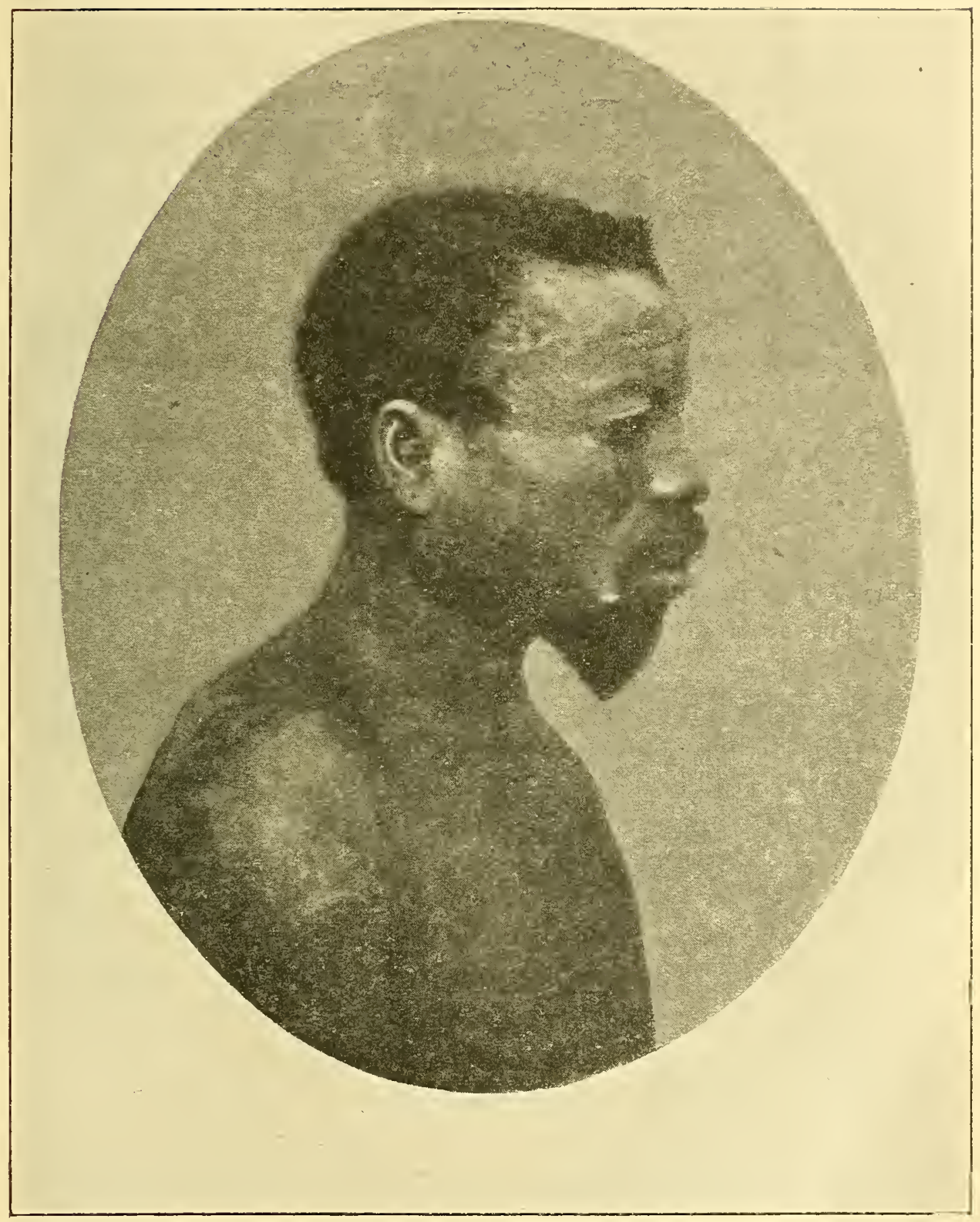

PORTRAIT OF A BERG DAMARA.

(From a Photograph in the South African Public Library.) 
mats, and their weapons and implements are of the crudest kind.

At length the Hottentots moved farther southward, and left them behind. They were then attacked by the Ovaherero, a purely pastoral and nomadic tribe, who came down from the north, drove them into the mountains of what is now Southern Damaraland, and occupied the plains themselves. The reverend C. Hugo Hahn, of the Rhenish missionary society, who was for many years a resident with the Ovaherero and collected their traditions, states that they can only with certainty be traced back to a locality somewhere in the neighbourhood of the Zambesi below the Victoria falls. From that locality they migrated westward with great herds of cattle and flocks of sheep, and then turned to the south, crossing the Kunene a little before the middle of the eighteenth century. After passing the Kaoko, they met the Haukoin or Ghou Damara, who fled from them to the mountains. They next encountered clans of the Namaqua Hottentots, whom they fought with and gradually drove far to the southward.

This war with the Hottentots lasted many years, and occasionally the Ovaherero would be beaten and driven back for a time, as was found to be the case in 1792 by the expedition from the Cape Colony which penetrated the country in that year. But occasional reverses were followed by successes until Oasib, chief of the Hottentot tribe called the red nation, applied to Jonker Afrikaner for assistance. Jonker was the son of that Jager Afrikaner who was a widely dreaded freebooter at the beginning of the nineteenth century, and who was more widely known at a later date as having in his old age become a convert to Christianity. Jonker followed the career of his father very closely. At this time he was living on the bank of the Orange river, but as soon as the request of Oasib reached him, he and his followers set out to join in the fray. The tide of fortune then turned, and the Ovaherero were speedily driven back to the Zwakop, which river bed was afterwards regarded as the boundary between the two peoples. This was the condition of things when in 1814 the reverend H. Schmelen, of the London 
missionary society, arrived in the country and commenced work there among the Namaquas.

After they crossed the Kunene the Ovaherero threw off a section, which took the name Ovambanderu and became quite independent, and from both of the tribes numbers of individuals who were without property of any kind moved away to seek food like Bushmen. These destitute persons are called Ovatyimba, and form distinct communities. Of all the inhabitants of South Africa, the Ovaherero and their offshoots have the reputation of being the most heartless and unfeeling towards each other, hence the condition of the Ovatyimba. These people differ in many respects from the Bantu of the interior and the eastern coast, though they are of the same family and speak a dialect of the same language. They do not practise agriculture, but depend for sustenance upon wild plants and their horned cattle and sheep. Some of their peculiar customs will be described farther on, which will show them to be less advanced than the othier members of their family.

The Ovaherero were preceded by the Avare group, of which the Ovambo tribe is the best known. This group consists of eleven distinct tribes, who occupy a small tract of land south of the Kunene river some distance from the coast. These people are industrious agriculturists, breeders of cattle, and workers in iron. They sink wells, sometimes thirty metres in depth, manufacture many useful articles, and are altogether far in advance of their southern neighbours. They are believed to have migrated from the valley of the Congo river, but the exact locality is unknown. Their dialect differs considerably from that of the Ovaherero, though there are strong reasons for supposing that the last-named people migrated from the same valley to the neighbourhood of the Zambesi some time before their removal to their present home. North of the Avare group the tribes need not be mentioned, as they live beyond the territory to which these pages are limited.

Along the western coast, north of the Zwakop river, the Ovaherero, like all the other invaders, attempted to exterminate or drive out the Bushmen. Pastoral communities and 
wild hunters could not exist side by side. But they did not entirely succeed, for the nature of the country is such that escape to almost waterless parts was easy. The Kalahari desert lay on the east, into which the weaker party could retreat, and so it happens that Bushmen are still to be found there, though not in any considerable number.

The invasion of the Bantu did not at first affect the Hottentots, except at the extremities of the thin line they occupied along the coast, for nowhere else did they come in contact.

All of the tribes and people dealt with in this chapter, together with their kindred who possess a vast extent of Africa north of the Kunene and Zambesi rivers, are now usually termed the Bantu, in accordance with a proposal of the late Dr. Bleek. They had no word except tribal names to distinguish themselves from other races, $n t u$ * in their language meaning a human being or person of any colour or country; but ethnologists felt the want of a specific designation for them, and adopted this as a convenient one. In the division of mankind thus naized are included all those Africans who use a language which is inflected principally by means of prefixes, and which in the construction of sentences follows certain rules depending upon harmony of sound. $\dagger$

* In the dialect of the Tembu, Pondo, Zulu, and other coast tribes : um-ntu a person, plural $a b a-n t u$ people; diminutive um-ntwana a child, plural $a b a$ ntwana children; abstract derivative $u b u-n t u$ the qualities of human beings, diminutive ubu-ntwana the qualities of children. In the Herero dialect: omu-ndu a person, plural ova-ndu people. In the dialect of the Basuto: mo-tho a person, plural ba-tho persons. The pronunciation, however, is nearly the same, the $h$ in batho being sounded only as an aspirate, and the $o$ as $o o$, baat-hoo.

$\dagger$ This definition is of course only a general one, and must be subject to exceptions, because people cannot be grouped by means of language alone. Thus the people called Berg Damaras, who have already been referred to, are Bantu or perhaps negro by blood, though they speak a Hottentot dialect, and resemble Bushmen in their habits. After their subjugation they were forced to adopt the language of their conquerors. This may also have been the case with tribes in the northern part of the continent, as it certainly was with females. 


\section{The Bantu.}

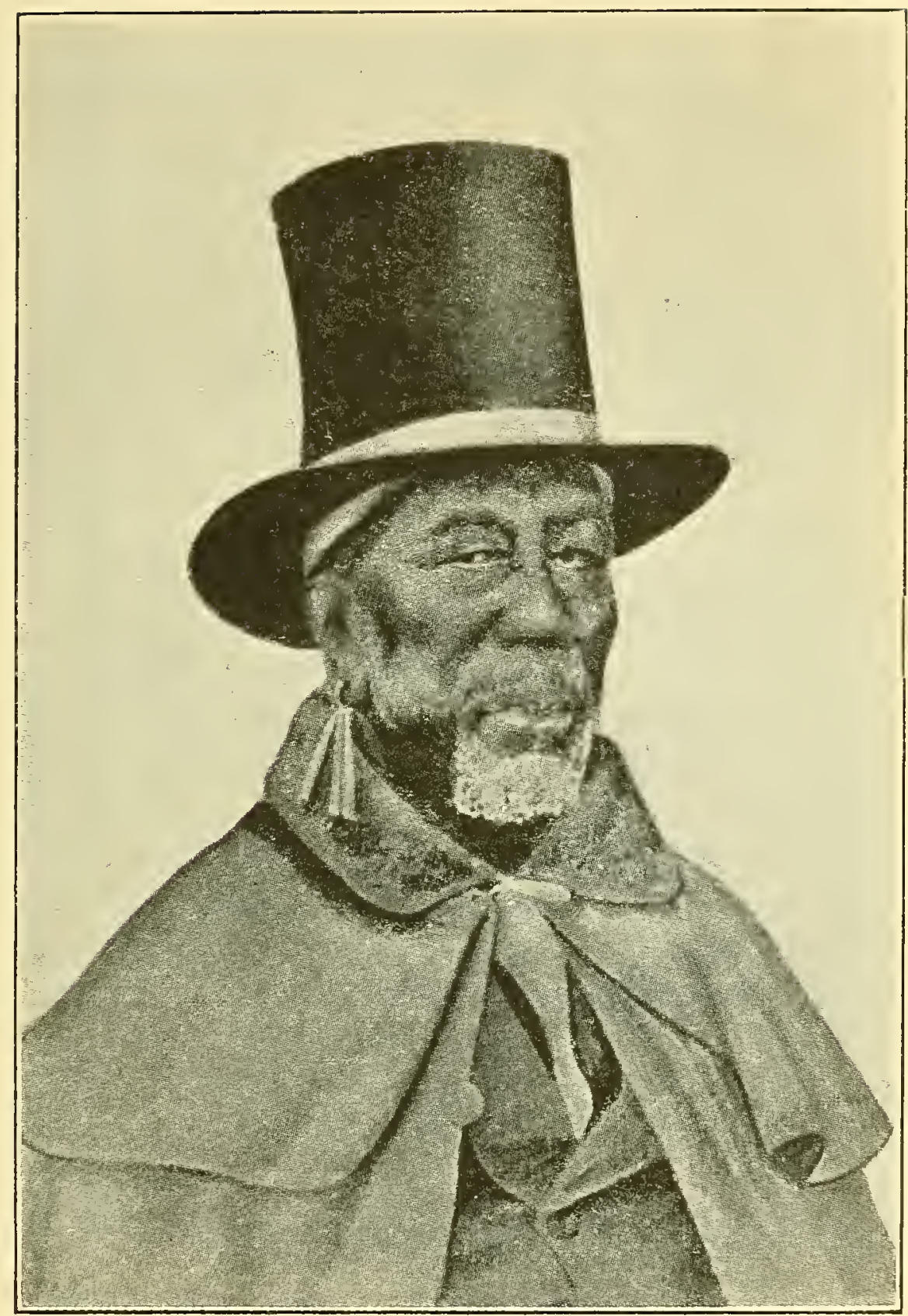

PORTRAIT OF MOSHESH, THE FOUNDER OF THE PRESENT BASUTO TRIBE, IN EUROPEAN DRESS.

(From a Photograph in the South African Public Library.)

Moshesh was the most intelligent Bantu Chief ever known in South Africa. 
Before the Bantu tribes migrated to Africa south of the Zambesi great differences existed between them, and there was a tendency for these differences to increase after their settlement where Europeans found them. Intercourse between the different sections was restricted, as in general each tribe regarded its neighbour with jealousy, and each group of tribes of recent common origin looked upon every other such group as enemies. Besides the change which takes place in all unwritten languages in the course of even a few generations, there was a habit with some of these tribes which hastened the variation, and therefore made intercourse more difficult. This was the hlonipa custom, by which women were obliged constantly to invent new words, so that each dialect changed in a different manner from all others. The structure of the dialects remained the same, but the words used by a Tembu, for instance, could not be understood by a Morolong or an Omuherero. An educated European can at once see that the great majority of the roots in all the dialects is the same, and that there is consequently but one language; but the people who used those dialects were unable to detect this.

A change of speech was followed, though much more slowly, by change of customs and ceremonies, and even by dissimilar modifications of religious belief. Leng intercourse with Arabs, Persians, and Indians resulted in a great advance in the mental condition of the eastern tribes over those of the west.

For general purposes the tribes can be classified in the three groups already mentioned as migrating to the southern portion of the continent by separate routes-from the coast of Guinea south-eastward, from the region of the great lakes southwestward, and from the Congo basin southward,- - though there are many trifling differences between the various branches of each of these. In the first group can be placed those along the eastern coast south of the Sabi river, and those which in recent times have made their way from that part of the country into the highlands of the interior. The best known of these are the Amaxosa, the Abatembu, the Amampondo, the Amabaca, the Amamfengu or Fingos, the whole of the tribes in Natal, the 
Amazulu, the Amaswazi, the Amatonga, the Magwamba, the Matshangana, and the Matabele. This group can be termed the eastern coast tribes, though some members of it are now far from the sea.

The second group can include the tribes that at the beginning of the nineteenth century occupied the greater part of the interior plain north of the twenty-ninth parallel of latitude, and came down to the ocean between the Zambesi and Sabi rivers. It will include among many others the Batlapin, the Batlaro, the Bakatla, the Barolong, the Bahurutsi, the Bangwaketse, the Bakwena, the Bamangwato, the Batawana, the Bavenda, the Bapedi, the Makaranga, the Baroswi, and the Basuto. This group can be termed the interior tribes.

The third will comprise the Bantu living between the western part of the Kalahari desert and the Atlantic ocean, who may be termed the western coast tribes. These are very recent immigrants, and before the beginning of the twentieth century had no influence upon South African history. They differ in many respects from their eastern kindred, being blacker in colour, coarser in appearance, and duller in intellect than the others, if an average be taken. The dialects spoken by them are also more primitive. It will not be necessary to describe the people of this section as fully as the others, but the principal points of difference will be given for comparison.

Noтw.-Sir Harry Johnston in his Survey of the Ethnography of Africa and the Former Racial and Tribal Migrations in that Continent says of the horde that made its way from the western coast to the eastern in the sixteenth century, and that left an important impression upon South Africa, as the most warlike of the tribes that Europeans have had to deal with here are its descendants: "Early in the sixteenth century a cannibal people of Bantu speech, but with little or none of the Bushonga or Luba civilization about them, suddenly boiled over, and devastated much of Western Congoland and Angola, of Central Zambezia, and of East Africa. These were the Jagga and the Ba-zimba of the Portuguese. Their devastations on the north almost overwhelmed and exterminated the semi-civilized kingdom of the Congo, which had already come under Portuguese influence. They occupied much of Angola, and after swarming across the Zambezi-Congo water-parting, they surged 
down the valley of the Luangwa until they came to the northern bank of the Zambezi opposite Tete. Here they fought for years with the Portuguese, who eventually got the better of them, though they practically wrecked Portuguese Zambezia for half a century." But there must have been an carlier eruption than the one here referred to, for the Batonga had reached the eastern coast and settled there before the close of the fifteenth century, being found by the Portuguese north of Delagoa Bay in 1497. These Batonga and the Abambo were very closely related, and must have come from the same locality, as they are hardly to be distinguished from each other even now, and their folklore tales are identical. These folklore tales are of the greatest value in determining such a question as this, and when they and the siboko are the same, there can be no reason to doubt that tribes now independent of each other had a common origin. Language is less reliable as evidence, for there are instances of tribes bcing compelled to adopt that of others. But the Hottentot tales now told by Xosa women prove that folklore survives the loss of language, and hardly changes its original form. 


\section{CHAPTER X.}

General Description, Form of Government, and Religion of the Bantu.

Observations made during the sixteenth century by Portuguese missionaries and travellers in South Africa throw much light upon the origin of several customs which to other, though more recent, observers of Bantu habits, were involved in obscurity. With the Hottentots or the Bushmen the Portuguese rarely came in contact, and of these people they give no information of any value. But with sections of the Bantu they lived in as close intimacy as Dutchmen or Englishmen have ever done, they learned the language of these people, studied their customs, and several of the best informed recorded what they observed. They tell of no golden age of peace and happiness disturbed by the intrusion of white men, but of almost constant strife and cruelty and misery. From them we learn that long before the time of Tshaka despots as clever and as ruthless as he spread desolation over wide tracts of land, that cannibalism as practised in Basutoland and in Natal during the early years of the nineteenth century was no new custom with sections of the Bantu family, that the military organisation and mode of attack employed by Dingiswayo and Tshaka were not inventions of those chiefs, but were known long before their time. Much besides can be learned from their writings, so that since the translation and publication of many of those documents any description of the dark-skinned tribes south of the Zambesi previously written can be considerably amplified.

The various sections of the Bantu, while they have much in common, have also many differences. There can be no doubt that these differences arise from their descent from females of 


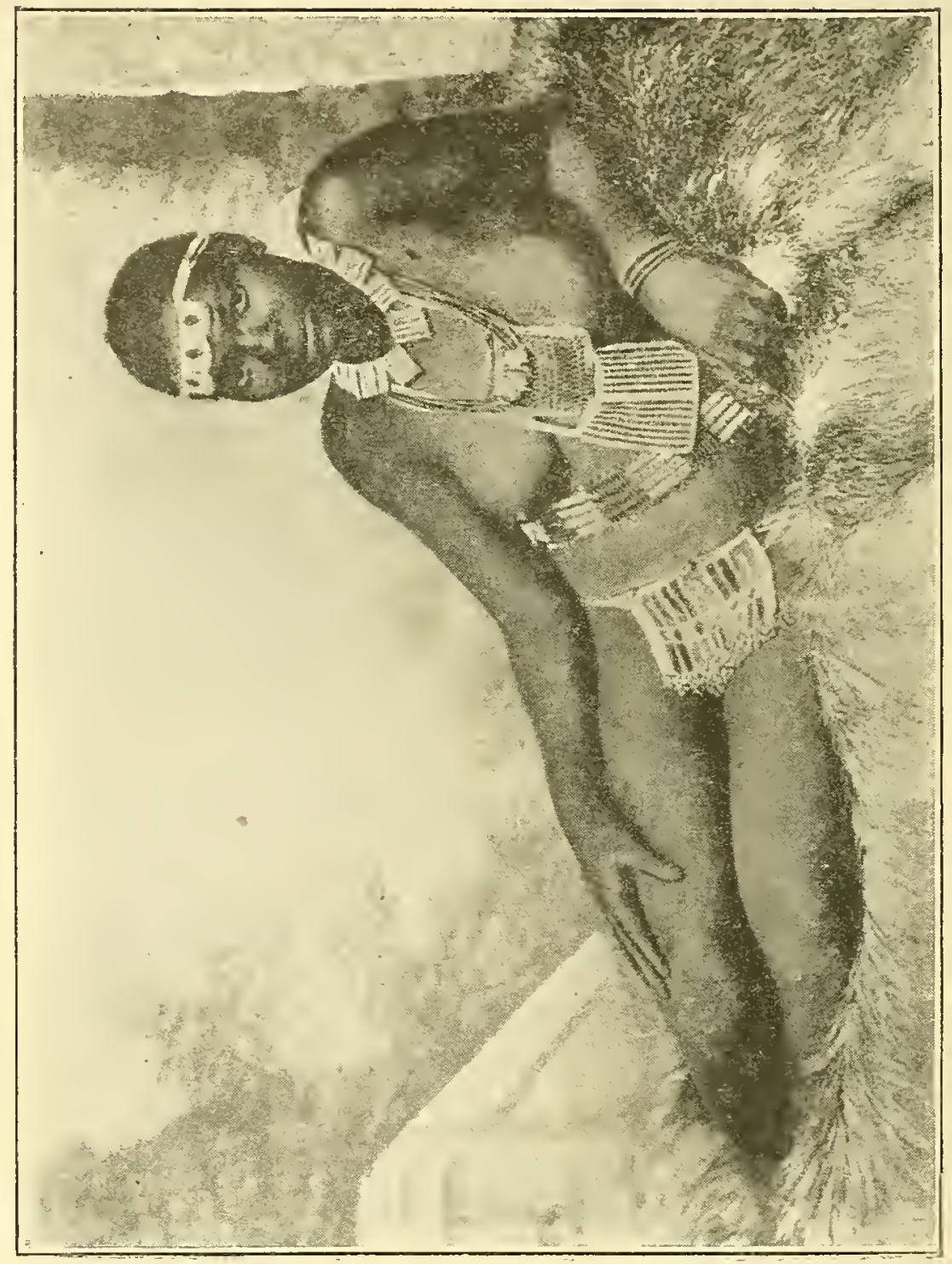

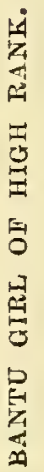


blood varying as greatly as hamitic from negro or from Bushman, and from the intercourse of large numbers of Arab, Persian, and Indian males with the eastern tribes in bygone times. If an extreme example be taken, such as that of a Damara with thick projecting lips, a broad flat nose, a narrow forehead, a square chin, a massive pelvis, and great splay feet with projecting heels, and on the other side a Karanga with features almost resembling those of a European, with an oval chin, light pelvis, and well formed feet, any one would say that they did not belong to the same race, and in truth race is not a correct word to use in connection with the Bantu. But it is not necessary to compare men of such different tribes to show their different descent: this can be seen in the same tribe, often even in the same family. Atavism sometimes produces two full brothers with hardly a point of resemblance to each other. This is especially the case mentally, and the instances are very rare of a highly intelligent man among them having equally able sons.

In general it can be said of them that they have great power of imitating, but very little of inventing, so that they are highly conservative in character. But they are emotional and impulsive, so that they seldom continue long in the same pursuit. They can learn strange languages much more quickly than most Europeans, and they have very retentive memories.

The Bantu vary in colour from chocolate brown to deep black. Those who occupy the land along the south-eastern coast are in general large without being corpulent, strong, muscular, erect in bearing, and with all their limbs in perfect symmetry. Many of them are haughty in demeanour, and possess a large amount of vanity. The men are usually handsomer than the women, owing to the girls being often stunted in growth and hardened in limb by carrying burdens on their heads and toiling in gardens at an early age. The people of the interior are in general somewhat smaller than those of the coast, though they are far from being diminutive specimens of the human species.

In some respects a description of the Bantu in South Africa as they are to-day would not be a correct representation of them as they were when Europeans first became acquainted with them, 
or even as they were in the middle of the nineteenth century. Their government by white men, missionary teaching, commerce, and particularly their employment in large numbers in mines and on farms, have tended to alter their habits and even their ideas, though there are very few of them who would not gladly have remained as their ancestors were. With some tribes this is the case to a much greater extent than with others, but as all are more or less affected, the description that follows will be of them before European influence had brought about any change.

Though at times the Bantu presented the appearance of a peaceable, good-natured, indolent people, they were subject to outbursts of great excitement, when the most savage passions had free play. The man who spent a great part of his life gossiping in idleness, not knowing what it was to toil for bread, was hardly recognisable when, plumed and adorned with military trappings, he had worked himself into frenzy with the war dance. The period of excitement was, however, short. In the same way their outbursts of grief were violent, but were soon succeeded by cheerfulness.

They were subject to few diseases, and were capable of undergoing without harm privations and sufferings which the hardiest Europeans would have sunk under. Occasionally there were seasons of famine caused by prolonged drought, when whole tribes were reduced to exist upon nothing else than wild roots, bulbs, mimosa gum, and whatever else unaided nature provided. At such times they became emaciated, but as long as they could procure even the most wretched food they did not actually die, as white people would have done under similar circumstances. Nor did pestilence follow want of sustenance to the same extent as with us.

One cause of their being a strong healthy people was that no weak or deformed children were allowed to live long. There was no law which required an end to be put to the existence of such infants, but it always happened that they died when very young, and public opinion was opposed to any inquiry into the mode of their death. Every one, even the parents, believed that it was better they should not live, and so they perished from 
neglect. But owing to the prevalence of this custom in preceding generations, the number of weaklings born was very small indeed. For some reason an exception was occasionally made in the case of albinos, who, though regarded as monstrosities, were not always destroyed in childhood. These hideous individuals, with features like others of their kindred, were of a pale sickly colour, and had weak pinkish eyes and hair almost white. Very few, however, were to be seen in any tribe, and in some none at all.

Under natural conditions the Bantu were a longer-lived people than Europeans. The friar Dos Santos found several women at Sofala who perfectly remembered events that had taken place eighty years before, and modern observers in other parts of the country have noticed the same circumstance. A man of this race placed beside a white colonist of the same age invariably looks the younger of the two, and wherever they reside individuals can be found with personal knowledge extending over the ordinary span of life in Europe or America.

They were probably the most prolific people on the face of the earth. All the females were married at an early age, very few women were childless, and in most of the tribes provision was even made by custom for widows to add to the families of their dead husbands. In some parts the brothers of the deceased took them, in others male companions were selected for them by their late husband's friends, in each case the children born thereafter being regarded as those of the dead man. In the Makaranga and most of the tribes whose remnants now form the Basuto, the principal son inherited his own father's widows for whom the full bohadi had been paid, except the one who bore him, but it was a custom with them to lend their superfluous wives to their retainers or to men who were in their service temporarily. The object of all was to have as many children as possible, to lose no productive power whatever.

The census of the Cape Colony in 1904 compared with that of 1891 shows an increase of Bantu, excluding those in the territory annexed between those dates, from 838,136 to 1,158,980, or at the rate of $25 \cdot 24$ per thousand yearly. According to these 
census returns they double in number in a little less than twentyeight years. But there were circumstances in operation in 1904 which tended to reduce the rate of increase much below that of the middle of the nineteenth century, when the people of tribes that were not at war were doubling in number in less than twenty-five years.

The form of government varied from that of a pure despotism established by a successful military ruler, to a patriarchal system of a simple order. In the former everything centred in the person of one individual, at whose word the lives of any of his subjects were instantly sacrificed, who was the owner of all the property of the tribe, and who appointed officials at his pleasure. He was served by attendants in the most abject attitudes, could only be approached by a subject unarmed and crouching, and arrogated to himself a form of address due to a deity. He was absolute in every respect, and by his will alone his subjects were guided, though to retain such power for any length of time it was necessary for him not to counteract any strong desire of the warriors of his tribe. This purely despotic form of government was rarely found among the people of the interior, who were in general more peaceably disposed than those of the coast. It ended as a rule when great reverses were sustained, or when a man of feeble intellect succeeded in the direct line of the one who established it.

The more common system, the one indeed that may be termed normal except when interfered with by a chief possessing great military genius, was of a milder character. Under it a tribe was composed of a number of sections which may be termed clans, each under its own chief, but all acknowledging the supreme rank and to some extent the authority of one particular individual. Sometimes the heads of the clans were members of the family of the paramount chief, more or less distantly connected with him by blood, in which case, unless there was a quarrel between brothers or between uncles and nephews, the tribe was a compact body, every individual in it having a common interest with every other; but it often happened that clans broken in war, though retaining their own chiefs, were adopted as vassals by 
a powerful ruler, and in these cases the cohesion of the different sections, owing to the object of their worship being different, to jealousy, and to rival views, was much less firm.

Among the interior tribes, owing to the misconduct or incompetency of individual chiefs, this system sometimes broke down, when a condition of greater freedom resulted. Here the common people acquired sufficient power to make their wishes respected to some extent, and nothing of importance was undertaken without a general assembly of the men of the tribe being first held, when each one was at liberty to express his views. But even in these cases the opinion of a member of the ruling family was regarded as of vastly greater weight than that of a commoner. Merit was of small account against privilege of blood in the estimation of any branch of the Bantu family.

Among the tribes under the normal system of government the rule of the paramount chief in times of peace was hardly felt beyond his own kraal. Each clan possessed all the machinery of administration, and in general it was only in cases of serious quarrels between them or of appeals from judicial decisions that the tribal head used his authority. In war, however, he issued commands to all, and on important occasions he summoned the minor chiefs to aid him with advice.

The members of the ruling families, even to the most distant branches, were of aristocratic rank, and enjoyed many privileges. Their persons were inviolable, and an indignity offered to one of them was considered a crime of the gravest nature. Even the customs of the people were set aside in favour of the chiefs of highest rank. A common man of the coast tribes, for instance, could not marry certain relatives by blood, no matter how distant, but a great chief could, though connections nearer than fourth or fifth cousins were very rare. Such a marriage was strictly forbidden to a commoner, but was allowed in the chief's case, in order to obtain a woman of suitable birth to be the mother of the heir in the great line.

Portuguese writers relate that the principal chiefs in the territory between the Sabi and Zambesi rivers took their own sisters and daughters as their wives of highest rank, but perhaps 
this statement arose from their attaching the European meaning to the words sister and daughter, which when used by people of the Bantu family applied equally to cousins and nieces on the father's side. No marriages with sisters or daughters in the European sense is permitted at the present day, but with cousins - sisters in the Bantu sense-they are common among the interior tribes.*

With regard to the common people, the theory of the universal Bantu law was that they were the property of the rulers, consequently an offence against any of their persons was atoned for by a fine to the chief. Murder and assaults were punished in this manner. When a man died, his nearest relative was required to report the circumstance to the head of the clan, and to take a present of some kind with hirn as consolation for the loss sustained.

But while the government of all the tribes was thus in theory despotic, the power of the chiefs in those which were not under military rule was usually more or less restrained. In each clan there was a body of counsellors-commonly hereditary-whose

* The following words in the Xosa dialect will further illustrate the difference between European and Bantu ideas as to relationship. Bawo is the word used in addressing father, father's brother, or father's half-brother. Little children say Tata. But there are three different words for father, according as a person is speaking of his own father or uncle, of the father or uncle of the person he is speaking to, or of the father or uncle of the person he is speaking of. Speaking of my father, bawo is the word used; of your father, uyihlo; of his father, uyise. $M a$ is the word used in addressing mother, any wife of father, or the sister of any of these. The one we should term mother can only be distinguished from the others, when speaking of her, by describing her as uma wam kanye, i.e. my real mother ; or uma onaizalayo, i.e. the mother who bore me. Spcaking of my mother, ma is the word used; of your mother, unyoko; of his or her mother, unina. Malume is the brother of any one called mother. A paternal aunt is addressed as dadebobawo, i.e. sister of my father, showing a distinction between relatives on the patemal and maternal side. Mnakwetu is the word used by females in addressing a brother, half-brother, or male cousin. Males when addressing any of these relations older than themselves, use the word mkuluwa; and when addressing one younger than themselves, say mninawe. A sister and a female cousin are alike termed odade wetu, our sister-the pronoun being always used in the plural form; - though sometimes the word $m z a$, an abbreviation of umzaluana, i.e. of our family, is applied to a cousin on the mother's side by females older than the one addressed. Mtakama is an endearing form of expression, meaning child of my mother. 
advice could not always be disregarded. A great deal depended upon the personal character of the chief. If he was a man of resolute will, the counsellors were powerless; if he was weak they possessed not only influence, but often real authority. Then there was a custom that a fugitive from one clan was entitled to protection by the chief of another with which he took refuge, so that an arbitrary or unpopular ruler was in constant danger of losing his followers, although they remained in the same tribe, for no misconduct on the part of a paramount chief could weaken the religious tie that bound his people to him. This custom was an effectual check upon gross and unrestrained tyranny by the minor chiefs or heads of clans.

The law of succession to the government favoured the formation of new tribes. The first wives of a paramount chief were usually the daughters of some of his father's principal retainers, but as he grew older and increased in power his alliance was courted by great families, and thus it generally happened that his consort of highest rank was taken when he was of advanced age. Usually she was the daughter of a neighbouring ruler, and was selected for him by the counsellors of the tribe, who provided the cattle required by her relatives. She was termed the great wife, and her eldest son was the principal heir.

Another of his wives was invested at an earlier period of his life, by the advice of his counsellors and friends, with the title of wife of the right hand, and to her eldest son some of his father's retainers were given, with whom he formed a new clan. The government of this was entrusted to him as soon as he was full grown, so that while his brother was still a child he had opportunities of increasing his power. If he was the abler ruler of the two, a quarrel between them arose almost to a certainty as soon as the great heir reached manhood and was also invested with a separate command. If peace was maintained, upon the death of his father the son of the right hand acknowledged his brother as superior in rank, but neither paid him tribute nor admitted his right to interfere in the internal government of the new clan.

In some of the tribes three sons of every chief divided their father's adherents among them. In the latter case the third 
heir was termed the representative of the ancients or the son of the left hand.

In this manner new tribes, entirely independent of the old ones from which they sprang, were frequently formed. This was especially the case when the adjacent territory was thinly occupied by a weak people like the Bushmen, affording means for the ruler of lower rank without difficulty to remove to a distance from his brother. The disintegrating process was to some extent checked by frequent tribal wars and feuds, which forced chiefs of the same family to make common cause with each other, but whenever there was comparative peace it was in active operation, and so a steady and rapid expansion of the Bantu communities was effected.

Sometimes it was necessary to set aside the heir to a chieftainship, as in cases of insanity, weakness of character, gross misconduct, or other cause that made him unfit for the duties of a ruler. This was considered a matter of such weight that the chief could not act upon his own authority, though he might, and usually did, initiate the proceedings. The whole tribe assembled, and the matter was discussed, often for days together, before a final conclusion was arrived at. When a great son was in this manner set aside, the next in the line of descent was invariably chosen to fill his place. It sometimes happened that a chief died without having married a great wife, and consequently without leaving a recognised principal heir. In such a case the counsellors and leading men met and decided which of the widows should hold that position, when her eldest son became the head of the tribe. If a chief died leaving a great wife childless, and the woman bore a son even years afterwards, the boy was regarded as the legitimate heir, though he usually had some trouble in displacing rivals who were actual sons of the dead man. Among some of the tribes in the Zambesi valley the chiefs were succeeded not by their own sons, but by the sons of their eldest sisters, a custom unknown farther south.

With the limitations that have been mentioned, in the life of the people the chief was everything, his wishes were the guide of their conduct, his orders were implicitly obeyed, the best of 
all they had was at his disposal. To every one else they could tell the grossest falsehoods without disgrace, but to him they told the simple truth, and that in language which could not bear two meanings. They could not even partake of the crops in their own gardens until he gave them leave to do so. In this case, when the millet was ripe the chief appointed a day for a general assembly of the people at his residence, that was known as the great place; he then went through certain rites, among which was the offering of a small quantity of the fresh grain to the spirits of his ancestors, either by laying it on their graves or by casting it into a stream, after which ceremony he gave the people permission to gather and eat.

Every people has its own standard of virtue, which if it does not live up to, it at least respects. The Bantu had theirs, which consisted in fidelity to the chief. A man might be a thorough scoundrel according to European ideas, cruel, lascivious, intemperate, mean : all this mattered nothing if he was devoted to his chief, in which case in the estimation of his tribe he was virtuous. There was a reason for this, as will presently be seen.

The most solemn oath that a man could take was by either some great legendary ruler or the one then living, though he did not regard even that as binding if he believed that by speaking falsely the interest of the chief would be advanced. Portuguese writers state that the people near the Zambesi swore by Mambo, which was rather one of the titles of the head of a great tribe than his proper name, but the individual or his line of ancestors was meant. At present the form of oath varies slightly in different places, the most common expression being I call to witness or I point to, as $K i$ supa ka Mokatshane, the usual oath of a Mosuto, I point to Mokatshane.

The amount of taxes paid by the people for the maintenance of government was not fixed, as it is in European states. The ordinary revenue of a chief was derived from confiscations of property, fines, and presents, besides which his gardens, that were usually large, were cultivated by the labour of his people. The right of the ruler to the personal service of his subjects was everywhere recognised, and it extended even to his requiring 
thern to serve others for his benefit. The Portuguese engaged carriers from a chief, who took a considerable portion of their earnings, just as the tribal heads at present señd their young men to a distance to work for them. Men who would not think of assisting in the cultivation of their own gardens went willingly, when called upon to do so, to labour in those of their chief. The breast of every animal killed, which was regarded as the choicest meat, was sent to him as his right, and certain furs were his alone. When he felt so disposed, he made a tour through his tribe, when each kraal visited provided food for him and his attendants, and if he was in need, made him a present of cattle. The oxen, often from fifty to a hundred, needed to procure his principal wife-who was to be the mother of the future ruler -were contributed by his retainers.

In some of the tribes the chief might be said to be the owner of everything. Cattle taken in war were his property, and though the cows were distributed among the people, who had the use of the milk, he could demand their restoration at any time. All trade with strangers passed through his hands, and he kept as much of the gains as he chose. Though this system was confined to the military tribes, even in those less highly organised it was usual for the chiefs to exact heavy dues upon commercial transactions between their subjects and others. When, for instance, the first fairs were established by the British authorities on the Xosa border, the chiefs fixed the quantity of beads or other merchandise to be received for every ox or tusk of ivory, and commonly took about half for themselves, without. the people raising any objection.

The charges upon the government, except in the case of the military tribes, were limited to the cost of entertainment of attendants and visitors, and of presents to favourites or for services performed. There were no salaries to be paid, and no public works to be provided for. In all the country from the Zambesi to the utmost limit of the Bantu border there was not so much as a road, nothing better than a footpath, which, though leading towards a fixed point, wound round every obstacle in the way, great or small, for no one cared to remove even a 
puny boulder to obtain a more direct line. Many of these footpaths were worn deep by constant use for years, but they were never repaired. The simplest bridge over a stream was unknown, nor was there any other public work, if barricades of stones in the approaches to hill tops are excepted.

The religion of the Bantu was based upon the supposition of the existence of spirits that could interfere with the affairs of this world. These spirits were those of their ancestors and their deceased chiefs, the greatest of whom had control over lightning. When the spirits became offended or hungry they sent a plague or disaster until sacrifices were offered and their wrath or hunger was appeased. The head of a family of commoners on such an occasion killed an animal, and all ate of the meat, as the hungry ghost was supposed to be satisfied with the smell. In case of the chief or the community at large being affected, the sacrifice was performed with much ceremony by the tribal priest, an individual of great influence, who had as other duties to ward off from the ruler the malevolent attacks of wizards and to prepare charms or administer medicine that would make the warriors who conducted themselves properly and bravely invulnerable in battle.

An instance may be given to illustrate the operation of this religion. Upon the death of Gwanya, a chief of great celebrity in the Pondomsi tribe, he was buried in a deep pool of the Tina river. The body was fastened to a log of wood, which was sunk in the water and then covered with stones. The sixth in the direct line of descent from this chief, Umhlonhlo by name, to save himself from destruction by an enemy became a British subject at his own request, but in October 1880 his clan treacherously murdered three English officials, and went into rebellion, which resulted in his being obliged afterwards to take shelter in Basutoland.* In 1891 one of Umhlonhlo's sons

* After eluding capture for twenty-three years, Umhlonhlo was at length arrested, though he made a desperate resistance. In 1904 he was put upon his trial for murder, but was acquitted, as it could not be proved, though it was morally certain, that he had personally taken part in the crime. In the interim through the agency of a Roman catholic missionary he had become a convert to Christianity. During his confinement and when on his trial ho 
ventured into the district where his father had lived, and there committed an assault, for which he was arrested and sent before a colonial court to be tried. It was a time of intense heat and severe drought, which the tribe declared were caused by the spirit of Gwanya, who in this manner was expressing displeasure at the treatment accorded to his descendant. As a peaceoffering therefore, cattle were killed on the banks of the pool containing his grave, and the flesh was thrown into the water, together with new dishes full of beer. The prisoner was sentenced to pay a fine, which was at once collected by the people for him. A few days later rain fell in copious showers, which of course confirmed the belief of the tribe that what was right had been done, and that the spirit of Gwanya was appeased.

In all such cases the conception of the spirit was that it manifested its power by doing harm, and must therefore be propitiated. The idea of a God of love was foreign to the Bantu mind until introduced by the teaching of Christian missionaries, and even then the converts were very prone to reflect more on the anathemas than on the invitations contained in holy writ. It was a peculiar turn of mind, which was not quickly diverted to an opposite direction.

The Bantu had no idea of reward or punishment in a world to come for acts committed in this life, and thus there was no other restraint of religion upon their actions than was connected with loyalty to their chiefs dead and living. Except when compelled by circumstances to do so, they thought as little as possible of their own after fate, and seldom allowed reflection of any kind to disturb them.

A belief in the existence of spirits would seem to have as its consequence a belief in some special place where they resided, but the Bantu power of reasoning in such matters did not extend so far. Their minds in this respect were like those of little children, who are content to credit marvellous things told to them, without attempting to investigate any of the particulars.

conducted himself with such dignity as to win the admiration of every one, a feature of character, however, that most Bantu chiefs would display under similar circumstances. 
It is only since European ideas have been disseminated among them that such a question has arisen, and that one has said the spirits resided in the sky, another that their place of abode was a cavern under the earth. They acted as if the ghosts of the dead remained at or near their habitations when in life, and they were constantly fearful of meeting them at night. In all parts of the country there were localities, usually wild or secluded glens, which had the reputation of being haunted, and where no one would venture to appear alone after dusk. This might be said, however, of almost every part of Europe as well, so that in it the Bantu did not differ from the most highly civilised section of mankind.

No man among them, upon being told of the existence of a single supreme God, ever denies the assertion, and among many of the tribes there is even a name for such a Being, as, for instance, the word Mukuru used by some, or Unkulunkulu the Great Great One, used by the Hlubis and others. From this it has been assumed by some investigators that the Bantu are really monotheists, and that the spirits of their ancestors are regarded merely as mediators or intercessors. But such a conclusion is incorrect. The Great Great One was once a man, they all assert, and before our conception of a deity became known to them, he was the most powerful of the ancient chiefs, to whom tradition assigned supernatural knowledge and skill.

When a person was killed by lightning no lamentation was made, as it would have been considered rebellion to mourn for one whom the great chief had sent for. In cases of death within a kraal the relatives and friends of the deceased often exhibited the most passionate symptoms of grief, which, however, seldom lasted long, though they generally shaved their heads as a sign of mourning. There was an idea that something connected with death attached to the personal effects of the deceased, on which account whatever had belonged to him that could not be placed in the grave, his clothing, mats, head rest, \&c., was destroyed by fire. The hut in which he had lived was also burned, and no other was allowed to be built on the spot. If 
he had been the chief, the whole kraal was removed to another site. Those who touched the corpse or any of the dead man's effects were obliged to go through certain ceremonies, and then to bathe in running water before associating again with their companions. Except in cases of persons of rank, however, very few deaths occurred within kraals. As soon as it was seen that any one's end was near, the invalid was carried to a distance and left to die alone, in order to avert the danger of the presence of the dreaded something that could not be explained.

If it happened that a common person died within a kraal, the corpse was dragged to a distance, and there left to be devoured by beasts of prey; but chiefs and great men were interred with much ceremony. A grave was dug, in which the body was placed in a sitting posture, and by it were laid the weapons of war and ornaments used in life. When the grave was closed, such expressions as these were used: "Remember us from the place where you are, you have gone to a high abode, cause us to prosper." To prevent desecration of any kind, watchers were then appointed to guard the grave, who for many months never left its neighbourhood. In some instances it was enclosed with a fence large enough to form a fold, within which selected oxen were confined at night. These cattle were thenceforward regarded as sacred, were well cared for, and allowed to die a natural death. The watchers of the grave were also privileged men ever afterwards.

The funeral customs of the Ovaherero were somewhat different from those of the other tribes. The backbone of a dead man was broken, to prevent his spirit from practising mischief, and the body was then doubled up and buried in a deep grave with the face towards the north, the home of his ancestors. These people believed that the eyes of the spirit of a dead man were in the back of the head. They slaughtered the favourite oxen of the deceased, in order that the shades of these might accompany him to the spirit world, but they did not eat the flesh of the dead animals, as was the practice with other Bantu. In such cases the Ovaherero killed the oxen by shedding their blood, whereas cattle killed by them on all other 
occasions were bound fast and suffocated, with their faces turned towards the north.

Before the interment of the paramount chief of a powerful tribe, especially of a great military ruler, a number of his attendants were killed, and their bodies were placed around his in the grave in such a way as to keep it from contact with the earth. The object was to provide him with servants in the spirit world. His principal wives either took poison voluntarily or were killed, to serve him as companions. If he had a favourite dog, ox, or other animal, that was also slaughtered, to give him pleasure. It does not follow that such animals were regarded as immortal, but there was something unexplainable connected with them that the dead chief could enjoy, just as there was with his assagais and his metal braceiets. Afterwards, especially when drought occurred or any disaster overtook the people, sacrifices were offered at the grave, and prayers were made to him for assistance. When a number of chiefs had thus been interred, a tacit selection was made of the one who had been the wisest and most powerful in his day, and the others were neglected and gradually forgotten except by the antiquaries who preserved their names.

The custom of slaughtering wives and attendants upon the death of a great chief was not observed by the less important tribes, nor upon the death of mere chiefs of clans or of other individuals of position; but a practice carried out to the present day shows that it must at one time have been general. When a man of what may be termed aristocratic rank died his widows betook themselves to forests or lonely places, where they lived in seclusion as best they could for a month or longer, according to the time of mourning customary among their people. During this period no one even spoke to them, and when, as sometimes - but not always-happened, they were supplied with food, it was done by leaving a little millet in a place near their haunts where they would-probably find it. Death from exposure and starvation was frequently the result of this custom. At the end of the time of mourning the emaciated creatures returned to their kraals, when ceremonies of purification were observed, 
their clothing and ornaments were burned, and their relatives supplied them with the new articles that they needed. This method of mourning must have been developed from the practice of slaughtering such wives of a man of rank as could not make their escape when he died, in order that they might accompany him to the land of spirits.

The slaughter of attendants upon the death of a chief proves a belief in the continued existence of his spirit, but the burial of the weapons and ornaments of a warrior with his corpse is by no means such conclusive evidence. The fear of the mysterious power death was such that every one dreaded to come in contact with the personal effects of the individual smitten down, lest these also should partake of the infection. Whatever could be deposited in a grave was therefore disposed of in this manner, and the hut, mats, clothing, and everything else belonging to the deceased were destroyed by fire. To keep anything whatever as a memento of a departed relative or friend was an idea utterly foreign to the Bantu mind.

The tribes farthest in advance on the south-east had a dim belief in the existence of a powerful being, whom they termed Qamata, and to whom they sometimes prayed, though they never offered sacrifices to him. In a time of danger one of them would exclaim: "O Qamata help me," and when the danger was over he would attribute his deliverance to the same being. But of Qamata nothing more was known than that he was high and mighty, and that though at times he helped individuals, in general he did not interfere with the destinies of men. Recent investigations have shown that this belief did not extend far among the Bantu tribes, and it is now known to have been acquired from the Hottentots. Not that the Hottentots venerated a deity thus designated, but that a knowledge of some other object of worship than their own ancestral shades having been obtained through Hottentot females whom they took to themselves, this name was given to the unknown divinity.

To obtain information upon the religion of any barbarous people long observation is necessary, and nothing that can be depended upon is ever obtained by direct questions to 
comparative strangers. The relationship of the author of this volume to a Gaika clan was, however, once of such a nature that knowledge possessed by its members was freely communicated, and in a discussion upon religion with a group of old men, their opinions were given, though negatively rather than positively.

Question. Was Qamata once a chief, such as Xosa or Tshawe?

Reply. No.

Q. Was he the first man, the father of the nations, the one whom some of the old Fingos call Unkulunkulu?

$R$. No, not at all; Qamata was never a man.

Q. Was he the creator of all things that we see, the mountains, and the sun, and the stars?

$R$. Perhaps he was, we don't know.

Q. Where is he?

R. Everywhere.

Q. Does he see all things?

$R$. We think he does.

Q. Does he help people?

$R$. We ask him to sometimes, and we believe he does.

Q. Is he altogether good, or altogether bad, or partly good and partly bad?

$R$. We don't know about that; but we think he is altogether good.

Q. Are there any others like him?

$R$. No, he is all alone.

Q. Is there any other name for him?

$R$. In the olden times that was the only name, but now he is called by some u-Tixo (a name for God introduced by missionaries).

In various parts of the Xosa and Tembu country there are artificial heaps of stones, and a man, when travelling, may often be seen adding one to the number. He repeats no words, but merely picks up a stone and throws it on the heap. Why does he do it? That good fortune may attend him, that he may not be carried away by the river spirit when crossing a stream, that he may find food prepared for him where he is to rest, that he 
may be successful in the business he is engaged in, or something of the kind he is thinking of at the time. It is an act of superstition. The old men said "it was for Qamata." How? They did not know; but their ancestors had done the same thing and said it was for Qamata, and so they did it too.

Here then is an instance of a foreign belief adopted by a section of the people, for the above is simply the worship of Heitsi-eibib, and must have been introduced by the Hottentot women who were incorporated in the Xosa and Tembu tribes when they were advancing south-westward. But it was further modified by the percolation of missionary teaching, as is shown by the answers of the old men, though not one of them was a professed Christian.

The Bantu believed that the spirits of the dead visited their friends and descendants in the form of animals. Each tribe regarded some particular animal as the one selected by the ghosts of its kindred, and therefore looked upon-it as sacred. The lion was thus held in veneration by one tribe, the crocodile by another, the python by a third, the bluebuck by a fourth, and so on. When a division of a tribe took place, each section retained the same ancestral animal, and thus a simple method is afforded of ascertaining the wide dispersion of various communities of former times. For instance, at the present day a species of snake is held by people as far south as the mouth of the Fish river and by others near the Zambesi to be the form in which their dead appear.

This belief caused even such destructive animals as the lion and the crocodile to be protected from harm in certain parts of the country. It was not indeed believed that every lion or every crocodile was a disguised spirit, but then any one might be, and so none were molested unless under peculiar circumstances, when it was clearly apparent that the animal was an aggressor and therefore not related to the tribe. Even then, if it could be driven away it was not killed. A Xosa of the present time will leave his hut if an ancestral snake enters it, permitting the reptile to keep possession, and will shudder at the thought of any one hurting it. The animal thus respected by 
one tribe was, however, disregarded and killed without scruple by all others.

The great majority of the people of the interior have now lost the ancient belief, but they still hold in veneration the animal that their ancestors regarded as a possible embodied spirit. Most of them take their tribal titles from it, thus the Bakwena are the crocodiles, the Bataung the lions, the Baputi the little blue antelopes. Each terms the animal whose name it bears its siboko, and not only will not kill it or eat its flesh, but will not touch its skin or come in contact with it in any way if that can be avoided. When one stranger meets another and desires to know something about him, he asks "to what do you dance?" and the name of the animal is given in reply. Dos Santos, a Portuguese writer who had excellent opportunities of observation, states that on certain occasions, which must have been frequent, men imitated the actions of their siboko; but that custom has now almost died out, at least among the southern tribes.

Frequently two or more different animals were held in veneration by a tribe. This circumstance arose in some instances from the community being composed of fragments of others blended together, in a few instances from the name of its founder having been that of an animal. Thus from the crocodiles a section might separate and become independent under a chief named the baboon. The people would then in all probability venerate the baboon as well as the crocodile, for the twofold purpose of honouring their founder and giving themselves a distinctive title. Occasionally in recent times an inanimate object has been venerated, thus the Barolong have iron as their siboko, the Bamorara the wild vine. The sun, the sky, rain, etc. are thus used as the siboko of different tribes that have long since lost all knowledge of the belief of their remote ancestors. Owing to the many terrible convulsions these people have gone through, only a glimmering remembrance of the faith and practice of the distant past has remained to some sections of them.

The tribes along the south-eastern coast, though separated into distinct communities absolutely independent of each other 
since the beginning of the seventeenth century, as far back as their tradition reaches, are of common stock. They all regard the same species of snake as the form in which their ancestral shades appear. Further, their tribal titles, with few exceptions, are derived from the chief who left the parent stock, thus the Amahlubi are the people of Hlubi, the Abatembu the people of Tembu, the Amaxosa the people of Xosa, Hlubi, Tembu, and Xosa being the chiefs under whom they acquired independence. The exceptions are derived from some peculiarity of the people, but in these cases the titles were originally nicknames given by strangers and afterwards adopted by the tribes themselves.

Nearer than the spirits of deceased chiefs or of their own ancestors was a whole host of hobgoblins, water spirits, and malevolent demons, who met the Bantu turn which way they would. There was no beautiful fairyland for them, for all the beings who haunted the mountains, the plains, and the rivers were ministers of evil. The most feared of these was a large bird that made love to women and incited those who returned its affection to cause the death of those who did not, and a little mischievous imp who was also amorously inclined. Many instances could be gathered from the records of magistrates' courts in recent years of demented women having admitted their acquaintance with these fabulous creatures, as well as of whole communities living in terror of them.

The water spirits were believed to be addicted to claiming human victims, though they were sometimes willing to accept an ox as a ransom. How this belief works practically may be illustrated by facts which have come under the writer's cognisance.

In the summer of 1875 a party of girls went to bathe in a tributary of the Keiskama river. There was a deep hole in the stream, into which one of them got, and she was drowned. The others ran home as fast as they could, and there related that their companion had been lured from their side by a spirit calling her. She was with them, they said, in a shallow part, when suddenly she stood upright and exclaimed, "It is calling." She then walked straight into the deep place, and would not 
allow any of them to touch her. One of them heard her saying "Go and tell my father and my mother that it took me." Upon this, the father collected his cattle as quickly as possible, and went to the stream. The animals were driven into the water, and the man stood on the bank imploring the spirit to take the choicest of them and restore his daughter.

On another occasion a man was trying to cross one of the fords of a river when it was in flood. He was carried away by the current, but succeeded in getting safely to land some three or four hundred metres farther down. Eight or ten stout fellows saw him carried off his feet, but not one made the slightest effort to help him. On the contrary, they all rushed away frantically shouting to the herd boys on the hillsides to drive down the cattle. The escape of the man from the power of the spirit was afterwards attributed to his being in possession of a powerful charm.

Besides these spirits, according to the belief of the Bantu, there are people living under the water, pretty much as those do who are in the upper air. They have houses and furniture, and even cattle, all of their domestic animals being, however, of a dark colour. They are wiser than other people, and from them the witchfinders are supposed to obtain the knowledge of their art. This is not a fancy of children, but the implicit belief of grown-up men and women at the present day. As an instance, in July 1881 a woman came to the author of this volume, who was then acting as magistrate of a district in the Cape Colony inhabited by Bantu, and asked for assistance. A child had died in her kraal, and the witchfinder had pointed her out as the person who had caused its death. Her husband was absent, and the result of her being smelt out was that no one would enter her hut, or so much as speak to her. If she was in a path every one fled out of her way, and even her own children avoided her. Being under British jurisdiction she could not be otherwise punished, but such treatment as this would of itself, in course of time, have made her insane. She denied most emphatically having been concerned in the death of the child, though she did not doubt that some one had caused 
it by witcheraft. The witchfinder was sent for, and, as the * matter was considered an important one, a larger number of people than usual appeared at the investigation. On putting the ordinary tests to the witchfinder he failed to meet them, and when he was compelled, reluctantly, to admit that he had never held converse with the people under the water, it was easy to convince the bystanders that he was only an impostor.

By some of the Bantu tribes great regard was paid to fire. The Makaranga when first visited by Europeans four centuries ago were in the habit of extinguishing all the fires throughout their country on a certain day named by the chief, and lighting them again from a flame produced at his residence by friction of two pieces of wood, which obserrvance was attended with much ceremony. The Ovaherero keep a fire constantly burning at the place where cattle are sacrificed to the spirits of the dead at the principal ruler's kraal, which flame is considered sacred, and is guarded by the eldest unmarried daughter of the chief. When the kraal is removed the sacred fire is put out, and is lit afresh at the new place of settlement with much ceremony, when pieces of wood to represent their ancestors are set up. Symbolic figures of their ancestors are kept in their huts and are held in veneration by some of the Betshuana also, but the sacred fire, if ever it existed among them, has long since died out.

Of the origin of life or of the visible universe the Bantu never thought, nor had any one of them ever formed a theory upon the subject. There was indeed a story told in all the tribes of the cause of death, but it is in itself an apt illustration of their want of reasoning power in such matters. The chameleon, so the tale was told, was sent to say that men were to live for ever. After he had gone a long time the little lizard was sent to say that men were to die. The lizard, being fleet of foot, arrived first at his journey's end, and thus death was introduced. But in whom lay the power of forming these decisions, and of sending the animals with the messages, they did not trouble themselves to inquire, nor did it strike them that the narrative 
was incomplete without this information until Europeans questioned them concerning it.

Some of the eastern Bantu had a legend that men and animals formerly existed in caverns in the bowels of the earth, but at length found their way to the surface through an opening in a marsh overgrown with reeds. They always pointed to the north as the direction in which this marsh lay. The Bantu of the interior believed that men and animals first made their appearance from a fissure in a large rock far away in the north. Wizards had power to cause this rock to open and shut at will, but whether it was the entrance to a cavern, or merely itself hollow, no one could say. The legends collected in different parts vary greatly in detail as to the manner in which the men and animals made their appearance, the special gifts bestowed on each-by whom is never stated,-and the mode of their dispersion subsequently. The Bushmen in these tales are not included in human beings, they were already in existence when the men and cattle appeared.

The Ovaherero and their kindred believe that the first man and woman came out of a tree similar to a particular species found in the country they now inhabit. From this couple were born the ancestors of the Hottentot and Bantu tribes, but not of the Bushmen, the Berg Damaras, or the baboons, classifying the three latter as equal. Cattle also and game animals first came from the same tree, but emerged from it in herds, not in couples. They pay such respect to every tree of this species that they will not even lop a twig from it, but when passing by one make an offering to it by throwing a bunch of grass or some sticks at its foot. For this reason it is now commonly called by the Europeans in the country the Damara mother tree, Damara being the Hottentot name of all the black people living north of Walfish Bay, who are distinguished merely as Cattle Damaras, that is Ovaherero, and Berg Damaras, or those who live like Bushmen.

This belief of the Ovaherero is possibly of Hottentot origin; for the people that hold it have strangely mixed up the worship of Heitsi-Eibib with that of their own ancestral shades. Wherever 
barbarous races intermingle, even as enemies as in this instance, each derives something from the beliefs of the other. Mr. Stow gives a legend of some of the Bushmen near the mouth of the Orange river, that men and animals first came forth from a hole in the ground at the foot of a great tree, which may also have had a Hottentot origin.

Dos Santos states that the people of his time in the Zambesi basin observed certain fixed days as holy, and abstained from labour upon them; but this custom was certainly not universal, and very likely the friar was mistaken in the object of doing no work on particular days. At any rate modern observers in that part of the country as well as in the south have noticed that no days or seasons are regarded as more sacred than others, though there are times marked by particular events when it is considered unlucky to undertake any enterprise, and even movements in war are delayed on such occasions.

For instance the actual day of new moon, when that luminary is not visible either in the morning or the evening, is regarded by many tribes as an unlucky day on which to commence any undertaking or to go upon a journey, and consequently no one does any work that can be avoided. It is called the dark day, the day when the moon is dead, but it would not be correct to term it a sacred day any more than it would be correct to say that many English sailors in the middle of the nineteenth century regarded Friday as a sacred day because they objected to sail from port on it. The dark day was simply an unlucky day, nothing more. Of the cause of the moon's not being vis.ble the Bantu did not attempt to give an explanation, for they had not the gift of imagination which the Hottentots possessed.

Still it must be observed that, though no days were considered holier than others, or were specially dedicated to religious observances, with the Bantu, as probably with all uncivilised people, the time of the first appearance of a new moon was one of special rejoicing. Next to the apparent 
course of the sun through the sky, the changes of the moon are those which to every one are most striking. This is particularly so in a country like South Africa, where a moonlit evening, when the winds are lulled and the air is deliciously fresh and cool, is to Europeans the pleasantest part of the twenty-four hours, far more so to people who know of no other artificial light than that of burning wood. It is no wonder therefore that the new moon was hailed with shouts of joy, that its praises were chanted in set words, and that among some of the tribes dances and other ceremonies took place in its honour. With all this, however, the moon was not regarded as a deity, nor was the evening of rejoicing considered more holy than any other.

After the crops were gathered, many of the tribes were accustomed to offer special sacrifices to the spirits of their dead ancestors, especially of their deceased chiefs of note, though there was no fixed day in every year set apart for the purpose, and indeed they did not even know how to reckon time as we do. A chief who considered that his people, male or female, needed rest, might issue an order that no work was to be done on a particular day, but that did not cause it to be regarded as holy.

Each ruling family had an individual connected with it, one of whose duties can correctly be described as that of a priest, for it was he who in times of calamity sacrificed cattle for the tribe to the spirits of its dead chiefs. Another of his duties was by means of charms and incantations to ward off evil influence of every kind from the existing chief and his family. When a community was broken in war and compelled to become a vassal clan of some other tribe, it retained its priest and therefore its own particular object of worship until by time or circumstances a thorough incorporation took place. That was a process, however, not usually completed until several generations had passed away.

As a factor in the government of a Bantu tribe religion was more powerful than in any European state, for the fear of offending the spirits of the deceased chiefs, and so bringing 
evil upon themselves, liept the clans loyal to their head. He was the representative, the descendant in the great line, of those whose wrath they appeased by sacrifices. A tribe all of whose clans were governed by offshoots of the family of the paramount chief was thus immensely stronger in war than one of equal size made up of clans brought together by chance. In the one case the religious head was the same as the political, in the other they were separate.

The belief in witcheraft was deep-seated and universal. The theory was that certain evil-disposed persons obtained power from the demons to bewitch others, and so to cause sickness, death, or disaster of some kind. They were believed often to use snakes, baboons, and other animals as their agents and messengers. They could only be discovered by individuals who went through a very severe novitiate, and to whom the necessary knowledge was imparted by people who lived under water. Undoubtedly some of the witchfinders were impostors; but many of them were really monomaniacs, and had the firmest conviction in their ability to do what they professed.

Occasionally a person believed that he had received revelations from the spirit world. If his statements were credited, his power at once became enormous, and his commands were implicitly obeyed by all classes of the people. Crafty chiefs sometimes made use of such deranged beings for the purpose of exciting the people to war, or of inducing them to approve of measures which would otherwise have been unpopular.

Among tribes varying from each other in blood as much as the different Bantu communities south of the Zambesi and the Kunene, it might be expected that there would be great differences in religious belief, and this was really so. Ancestral wor hip was common to them all, and so was fetishism, or a trust in certain charms to ward off evil or to bring about good. But fetishism was much more prevalent with some tribes than with others, so that it is only in general terms that the religion of these people can be described. To go more closely into detail would need 
the treatment of each section separately, which would lead more to confusion than to enlightenment.

The large number of stone phalli found in the ruins of great buildings in Rhodesia has caused some persons to suppose that phallic worship may once have prevailed among a section of the Bantu. But the ruins and the phalli found at the bottom of the rubbish in them were there before a tribe of this family crossed the Zambesi, and there is not a trace of such worship existing at present, or having ever existed, among the dark coloured people in any part of the country, unless the occasional use of imitation phalli as charms by individuals belonging to some of the interior tribes can be regarded in that light. Among the Basuto and some of the Betshuana a childless woman procures charms from a man professing to be a doctor, which she carries about with her in hope that through their efficacy she may become a mother. These are sometimes, but not always or even commonly, imitations of phalli, such as the neck of a calabash elaborately adorned with beads. But in no case are they regarded in any other light than as charms to be employed for a particular purpose, and among most of the tribes this species of charm is quite unknown.

Perhaps João dos Santos and other early Portuguese writers were correct when they stated that the monomotapa married his sistere and daughters, or as we should say nieces, in order to secure an heir of the highest rank. From the Makaranga of the present day no information whatever on such a subject is to be obtained, because all knowledge of what transpired in the period of their greatness was crushed out of them by the terrible oppression they went through for more than two centuries before they became subject to the rulc of the British Soutli Africa Chartered Company. Broken up into little communities always at variance with each other, in a chronic state of semi-starvation, seeking shelter on the summits of rugged hills, and continually on the watch against the approach of foes, they forgot everything except the needs of the present moment. The following paragraph, taken from Dr. C. G. Seligmann's Some Aspects of the Hamitic Problem in the Anglo-Egyptian Sudan came to my knowledge too late to be made use of when my account of the Makaranga was printed. That tribe had its original 
home not very far from those mentioned by Dr. Scligmann, and may have had the same custom, abhorrent to us indeed, but approved of by the ancient Hebrews. "I may herc refer to a fcature of the social organization of the ancient Egyptians and certain African peoples of mixed Hamitic and Negro descent which there is every reason to believe is connected with matrilineal descent and which is probably a legacy of an old Hamitic practice, namely, the custom of brother-sister marriage in the royal family. It is so well established that this occurred in Egypt that it does not seem necessary to cite specific instances. But it cannot be said that the fact that such unions occur among the powerful lacustrine tribes of Central Africa has received the attention that its importance warrants. These tribes, namely, the Bahima, the Banyoro, and the Baganda, are all totemic and observe the ordinary rules of clan exogamy, yet the Bahima marry their sisters and even have intercourse with their sisters married to others. . . The Baganda also trace their descent in the male line, except in the case of the royal children, who take their mother's totem as well as certain totems claimed by every prince and princess. Clan exogamy was strictly observed except in the case of the ruling prince, who on his becoming king, was ceremonially married to one of his half-sisters, who shared with him the coronation ceremonies and the official mourning for his predecessors." 


\section{CHAPTEP XI.}

Superstitions and Customs of the Bantu.

Among all the sections of the Bantu there were individuals who professed to be able to make rain, and whose services were frequently called into use when any part of the country suffered from drought. If it happened that rain fell soon afterwards they received credit for it, and were amply rewarded, while if the drought continued they asserted that some unknown powerful wizard was working against them, a statement that was in most cases believed. Sometimes, however, the chief and people lost faith in them, when they were pronounced guilty of imposture, and were tied hand and foot and thrown over a precipice or into a stream.

This belief in the power of certain individuals to cause or to prevent rain was universal, and in our own times has been shown to exist even among people who were supposed to have made long strides towards European civilisation. As an instance, a few years ago the Cape government, under the guidance of the right honourable Cecil J. Rhodes, caused a large area of land at Glen Grey to be surveyed into small farms, and allotted to Tembus who were believed to be so far advanced as to be able to appreciate the advantages of individual tenure. After a time it was found that some of the stone boundary beacons had been thrown down, and upon inquiry it was ascertained that the owners of the farms had been directed by a rainmaker to plant poles in the ground when they wanted rain and take them out when they desired it to cease. They thought the stone beacons would have the same effect, and consequently broke them down to prevent floods. 


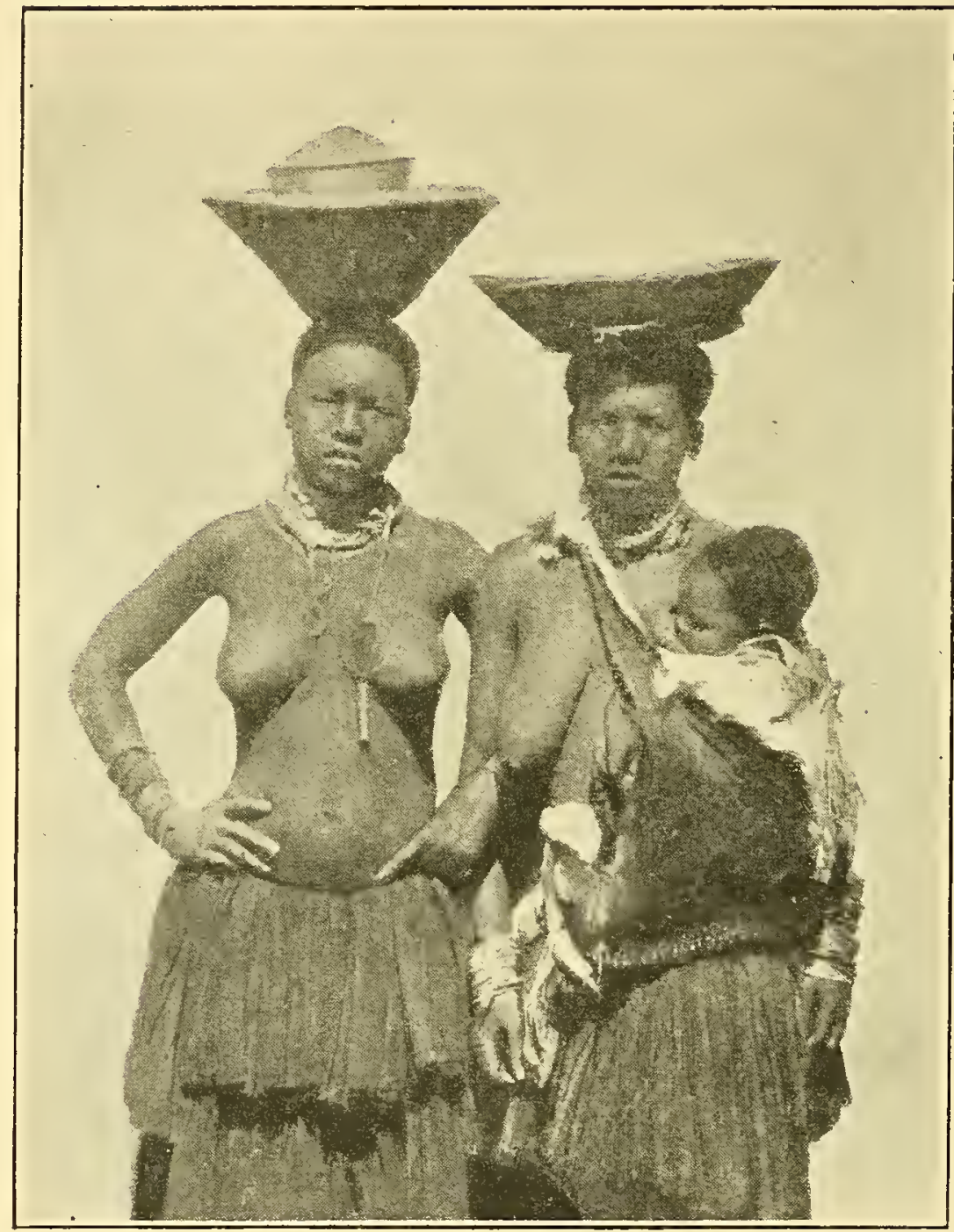

TEMIBU WOMIAN AND GIRL. 
There were also among them persons who were skilful in the use of herbs as remedies for diseases, and who were well acquainted with different kinds of poison. This knowledge was transmitted in certain families from father to son, and was kept profoundly secret from the mass of the people. Some of their medicines were beyond doubt of great efficacy, such as those used for the cure of dysentery, for causing virulent sores to heal, and to counteract snake bites.* But with these, and classified as of equal value, they professed to have medicines that would cause love from a woman, favour from a chief, etc. The writer of this was once so fortunate as to come into possession of the whole stock in trade of a famous Xosa herbalist. Each article in it was afterwards submitted to different practitioners, under exceptionally favourable circumstances for eliciting information, when most of them were at once recognised and their uses pronounced. Some were cures for various diseases, one was a love philter, and one was a piece of wood which was to be burned and the smoke inhaled, when the person using it would find favour in the eyes of his superior. But there were several whose use no one would divulge, their properties being regarded as secrets upon the strictest maintenance of which the fortunes of the herbalist families depended. In every case, in addition to the medicine, charms were made use of, and the one was as much relied upon as the other by the people at large.

The remedies used by these people would have been more

* A valuable pamphlet, in which the botanical, Xosa, and colonial names, and the uses of a great many of these medicinal plants are given, was some years ago prepared and published by the late Andrew Smith, Escre., M.A., for many years a teacher in the higher depart. ment of the Lovedale Missionary Institution, who expended a great deal of time and thought in the investigation of the subject. My late friend, the reverend Dr. W. A. Soga, a medical missionary with the Bomvanas in the district of Elliotdale, informed me that a remedy for one form of cancer was certainly known to some herbalists of his acquaintance, but though he had long been endeavouring to acquire their secret, he had been unable to do so. 
efficacious if they had understood how to prepare them in proper doses, but this was never considered as of importance, nor had they the knowledge necessary to repeat the doses at regular intervals. Very often when a man of good position was ill, instead of taking the medicine himself he would require one of his attendants to swallow it, in the full belief that if it was taken by some one about him it would answer the purpose as well as if taken by himself. Of course in such cases faith, or the influence of the mind upon the body, was the real healer.

A common practice with Bantu medical practitioners was to draw blood from their patients, and to pretend that with the blood they drew out some deleterious matter that caused the disease. The horn of an ox with the solid end cut off so as to leave only a small aperture was used for this purpose. The base of the horn, that was smoothed so as not to cut or scratch, was pressed over a spot on the limb or other part affected, or where pain was felt, which was first scarified, and the practitioner then applied his mouth to the other end and drew out the air. This instrument, though simple, was most efficacious. By some sleight of hand a foreign substance, even as large as a young lizard, was often produced with the blood, and the patient was told and really believed that it had been extracted from his body. In such a case wilful deception was certainly practised, but in most instances the person operated upon declared that he or she felt immediate relief.

None of the practitioners knew anything at all of anatomy, and no surgical operation except of the very simplest kind could be performed by them. A man with a broken limb or a wound, or any other injury that he could understand the cause of, was a perfect stoic, and endured pain without complaint, but an attack of rheumatism, for instance, the nature of which he could not comprehend, at once prostrated him and made him terrified in the belief that he was a victim of witchcraft. Wounds with these people, owing to their simple diet and their living so much in the open air, 
healed more easily and rapidly than with Europeans before the present mode of treatment was discovered.

If often happened that the three offices of witchfinder, rainmaker, and herbalist were combined in the same person, but this was not always the case, and the occupations were distinct. When practising, these individuals attired themselves fantastically, being painted in various colours, and having the tails and claws of wild animals suspended around them.

Charms were largely depended upon to preserve the wearers against accident or to produce good luck. They were merely teeth of animals or bits of wood or bone, or pieces of glittering mineral, which were hung about the neck, and were regarded just as lucky pennies and fortunate days are by some silly Europeans. But the belief was firm in charms and medicines which would give to an assagai the property of hitting the mark, to an individual the property of winning favour, and such like.

The issue of warlike operations was divined by revolting cruelties practised upon animals. At the commencement of hostilities, and often before an engagement, two bulls were selected to represent the opposing parties. These were then skinned alive, and success was foretold to the combatant represented by the one that lived longest. By some means, however, each band of warriors was made to believe that the result denoted victory to iț side. While this was taking place pieces of flesh were cut from other living bulls, which the warriors devoured raw, in the supposition that by this means their courage in battle would be increased. Cruelty of so dreadful a kind shocked no heart among the spectators, for the Bantu in general were utterly indifferent to the sufferings of animals, except favourites such as a man's pet dog or his fleet racing ox on which he prided himself.

As a general rule the Bantu of the interior were more superstitious than those of the eastern coast, as they were guided in nearly all their actions by the position in which some pieces of bone or wood of the character of dice fell when they were east on the ground by their owner. The largest 
made of wood were oblong tablets, about fifteen centimetres in length, five centimetres in width, and a centimetre and a half in thickness, but usually those of wood, and almost invariably those of bone, were smaller, the commonest being about six centimetres long, two centimetres and a half wide, and a third of a centimetre in thickness. On each tablet a different pattern was carved, and each had a signification different from the others. Sometimes instead of tablets pieces of bone or of ivory carved in various shapes were used, in the manufacture of which a great deal of patient labour was expended. The usual number employed was five, but more were sometimes found in a set. If an ox strayed the daula was thrown to ascertain in what direction it had gone, if a hunt was to take place it was consulted to indicate in what quarter game was most readily to be found, in short it was resorted to in every case of doubt. Each individual carried with him a set of these mystic articles strung on a thong, to be used whenever required. This superstitious practice, just as it was described more than three hundred years ago by the friar Dos Santos, is still prevalent and firmly believed in.

With many of the tribes there was a custom upon the accession of a chief to kill the commoner with the largest head among the people, in order that his skull might be used by the priest as a receptacle for the charms against witchcraft employed in the protection of the ruler. Such a receptacle was regarded as requisite for that particular purpose. Only a generation ago a man was killed with this object by a section of the Xosa tribe that was not then under British rule, but that had been to some extent for many years under European influence. The writer has heard his grandchildren speak of the event without the slightest feeling of horror, with as much indifference, in fact, as if they were relating any ordinary occurrence.

The belief in witcheraft was a part of the very nature of these people, and to the present time in very few instances has it been eradicated by the adoption of Christianity. Instances have come under the observation of the author of this volume of young men who were not only professing Christians themselves, but whose parents and even grandparents were also 
Christians, on some emergency showing that the old ideas were still in full force. One bright, cheerful, intelligent youth of eighteen years of age in particular may be mentioned. He was giving promise of a life of usefulness, when suddenly on a slight attack of illness he became morose, and persisted in declaring that " the river had bit him."

In a pamphlet issued in February 1910 * a teacher at Lovedale says :

"But it is not so generally recognised that up to the present Christian teaching and our educational systems have failed to dislodge this terrible enemy to progress and happiness. When I first went to Lovedale nothing impressed me more forcibly with the futility of much of the educational work than the sight of boys in the senior classes learning Latin and reading Shakespeare while their minds were steeped in the crudest superstitions. There was one boy in particular whose name I may mention. He was in the matriculation class, a Christian, and a member of the Christian Association, in connection with which he used to go out to preach on Sundays to the 'red' Kaffirs in the surrounding kraals. Through overwork his health broke down, and seeing no ostensible cause of his illness he immediately thought he was bewitched, a belief shared by all his friends at the Institution. He consulted a native witchdoctor in the district, who advised him that he was being bewitched by an enemy in Basutoland, and a few days later he left the school to seek out his would-be murderer. In Christian congregations, in Christian villages, people still attribute sickness to the work of some witch, generally a neighbour, whose life is often rendered unbearable because of social or other persecution."

The Bantu had a system of common law and perfectly organised tribunals of justice, which, however, were sometimes set aside by the great military tribes. Their laws came down from a time to which even tradition did not reach, and those which related to ordinary matters were so well known to every

* Native Higher Education. The proposed inter-colonial Native College. An address delivered at Durban before a meeting of the Natal Native Affairs Reform Committee. By K. A. Hobart Houghton, M.A., of Lovedale. 
member of the community that trials were mere investigations into statements and proofs of occurrences. When complicated cases arose, precedents were sought for, antiquaries were referred to, and celebrated jurists even in other tribes were consulted. If all these means of ascertaining the law failed, and the chief before whom the case was being tried was not a man of generally recognised ability, it often happened that no judgment was given, for fear of establishing a faulty precedent. From the decisions of the minor chiefs there was a right of appeal to the head of the tribe.

The law held every one accused of crime guilty, unless he could prove himself innocent. It made the head of a family responsible for the conduct of all its branches, the kraal collectively in the same manner for each resident in it, and the clan for each of its sub-divisions. Thus if the skin of a stolen ox was found in a kraal, or if the footmarks of the animal were traced to it, the whole of the residents were liable to be fined. There was no such thing as a man's professing ignorance of his neighbour's doings: the law required him to know all about them, or it made him suffer for neglecting a duty which it held he owed to the community. Every individual was not only in theory but in practice a policeman.

In general principles the law was the same in all the Bantu tribes, but in details there were almost as many variations as there were distinct communities. The law was simply the recognised custom of each, fixed by time as in a mould. Since they have come under European government, some attempts have been made to frame codes applicable to certain areas inhabited by several distinct tribes, but none have been fully successful, though a vast amount of trouble has been taken in their preparation. The same punishment for a particular offence of a man in tribe $A$, and which was regarded by his fellows as just and correct, would be resented by tribe $\mathrm{B}$ as altogether oppressive if applied to one of its members. Their standards of degrees of offences were different. Then their customs in many matters, regarded by us as trifling, were different, and each would consider itself slighted if these were disregarded. 
A lawsuit among these people was commonly attended by all the men of the kraal where it took place. Nothing was more congenial than to sit and listen to the efforts of the querists to elicit the truth, or for the ablest among them to assist in the investigation. The trial took place in the open air. The person charged with crime or the defendant in a civil suit underwent a rigorous examination, and anything like warning him against criminating himself was held to be perversion of justice.

The accuser or plaintiff or a friend prosecuted, and a friend of the individual on trial conducted the defence ; the counsellors, who acted as assessors, or any individual of recognisedlegal ability who happened to be present, put any questions they chose; and the mass of spectators observed the utmost silence and decorum. At the conclusion of the trial, the counsellors expressed their opinions, and the chief then pronounced judgment.

There were only two modes of punishment, fines and death, except in cases where an individual was charged with having dealt in witcheraft, when torture, often of a horrible kind, was practised. In this class of trials every one was actuated by fear, and was in a state of excitement, so that the formalities required on other occasions were dispensed with. The whole clan was assembled and seated in a circle, the witchfinder, who was fantastically painted and attired, went through certain incantations, and when all were worked into a state of frenzy he pointed to some individual as the one who had by bewitchment caused death or sickness among the people, murrain among cattle, blight in crops, or some other disaster. The result to the person so pointed out was confiscation of property and torture, often causing death. The number of persons who perished on charges of dealing in witcheraft was very great. The victims were usually old women, men of property, persons of eccentric habits, or individuals obnoxious to the chief. Any person in advance of his fellows was specially liable to suspicion, so that progress of any kind towards what we should term higher civilisation was made exceedingly difficult by this belief.

No one except the chief was exempt, however, from being charged with dealing in witcheraft. The cruelties practised on 
the unfortunate individuals believed to be guilty were often horrible, but a single instance, which occurred in July 1892, will be sufficient to exemplify them. A wife of the Pondo chief Sigcawu being ill, a witchfinder was directed to point out the person who caused the malady. He declared that Ma Matiwane, sister of the Pondomsi chief Umhlonhlo and widow of Sigcawu's father, was the guilty person, and that she had a lizard and a mole as her servants in the evil work. By order of Sigcawu, a number of young men then seized Ma Matiwane, stripped her naked, fastened her wrists and ankles to pegs driven in the ground, and covered her with ants irritated by pouring water over them. She suffered this torture for a long time without confessing, so they loosed her, saying that her medicines were too strong for the ants. They then lashed her arms to a pole placed along her shoulders, and taking her by the feet and the ends of the pole, they held her over a fire. Under this torture she confessed that she was guilty, but as she could not produce the lizard and the mole, she was roasted again three times within two days. No European could have survived such a burning; but she was ultimately rescued by an agent of the Cape government, and recovered. This woman had taken care of Sigcawu after the death of his own mother, yet on the mere word of a witchfinder she was thus horribly tortured. And instances of this kind were common events in the olden times.

Frequently, when a great calamity had occurred, or the life of a chief was believed to be in danger, not only the individual pointed out by the witchfinder, but his or her whole family was exterminated, and even entire kraals were sometimes wiped out of existence on such occasions. So strong was the belief in witchcraft and in the power of witchfinders to detect those guilty of practising it that instances were not rare of persons accused admitting that the charge against them must be correct and that they ought to suffer death, because some evil emana. tion over which they had no control must have gone forth from their bodies and caused the disaster, though they had done nothing directly to produce it. 
The Bantu were seen in the most favourable light at ordinary lawsuits before the chiefs and counsellors, and in the most unfavourable light at trials for the discovery of wizards and witches. In the one case men were found conducting themselves with the strictest gravity and propriety, in the other case the same people were seen as a panic-stricken horde, deaf to all reason, and ready to perform most atrocious acts of cruelty, even upon persons who just previously were their companions.

The sentences pronounced in ordinary cases were often such as would have seemed unjust to Europeans, but that was because our standard of comparative crime is not the same as theirs, and because with us there is supposed to be no difference of punishment according to the rank of the criminal. With them the ruling families in all their branches had the privilege of doing many things with impunity that commoners were severely punished for. Bribery was not unknown, but in courts as open as theirs, and where there was the utmost freedom of inquiry, it could not be practised to any great extent. When a case was talked out, every one present was usually acquainted with its minutest details.

Among the northern tribes trial by ordeal was resorted to in cases where personal or circumstantial evidence was wanting, and in appeal from decisions of witchfinders. The form of ordeal varied. In some instances the accused person was required to lick or to pick up a piece of red-hot iron, and if he was burnt he was condemned as guilty. In other cases he drank the poisonous juice of a certain herb, and if it had effect upon him he was doomed to immediate death. In others again he was forced to drink a huge basin of hot water mixed with a bitter emetic, and if he could not retain it the charge against him was regarded as proved. Yet so confident were innocent persons that no harm would come to them from the iron, the poison, or the emetic, that they accepted the ordeal with alacrity. Among the southern tribes this practice was not common, though it was well known.

The Bantu knew of no other periods in reckoning time than the day and the lunar month, and could describe events only 
as happening before or after some remarkable occurrence, such as the death of a chief, a season of famine, or an unusually heavy flood. The rising of the Pleiades shortly after sunset was regarded as indicating the planting season. To this constellation, as well as to several of the prominent stars and planets, they gave expressive names. They formed no theories concerning the nature of the heavenly bodies and their motions, and were not given to thinking of such things. In later times, if questioned by a European, they might venture to remark that the sky was smoke which had risen from fires, but in such cases it would be evident that the effort to find a solution to a query of this kind was new to them.

They had no knowledge of letters or of any signs by which ideas could be expressed. There were old men who professed to be acquainted with the deeds of the past, and who imparted their knowledge to the young, but their accounts of distant times seldom corresponded in details. They touched lightly upon defeats sustained by their own tribe, but dilated upon all its victories. In the traditions of each independent community a particular chief, usually the second or third in descent from the founder, was invariably represented as having conferred extraordinary benefits upon his people. He was the inventor of iron weapons, the one who decorated them with copper ornaments, and who taught them to use millet for food. Thus among the Barolong at the present day all this is attributed to Noto, son of Morolong; among the Amaxosa to. Tshawe, great grandson of Xosa; among the Abatetwa to Umyambosi, son of Umtetwa. Now it is absolutely certain that long before the time of Morolong, Xosa, and Umtetwa, who founded these modern tribes, iron, copper, and millet were in general use by almost all sections of the Bantu. But in praise of chiefs who probably gained some important victory, or under whose rule there was unusual prosperity, whatever the succeeding generations could think of as being great improvements was ascribed to their wisdom, and has been handed down as tribal history from one antiquary to another. Thus these narratives convey incorrect impressions, and little is beyond question except the 
genealogies of the great chiefs, which have been carefully preserved for ten or twelve generations.

Every chief of highest rank in the military tribes was attended by individuals whose duty was to act as official praisers. These persons were attired in the most fantastic costumes, thus one might have his head and every part of his body covered with the skin of a lion, another with that of a leopard, and so on. On any appearance of the chief, they shouted in a kind of chant a poem in which greatness of every kind was attributed to him, using such terms as great elephant, great despoiler, great ravisher, great conqueror, and great soothsayer. Very often at the same time drums were beaten and horns were sounded, making a din gratifying to the Bantu ear, but intolerable to that of a European. The chiefs of tribes in the ordinary condition had also official praisers, who were, however, more modest in their words, and whose chants were seldom accompanied by such a deafening noise of discordant instruments.

The heads of the independent communities along the eastern coast from the Zambesi river to Kosi Bay had dynastic names, which they assumed upon succeeding to the chieftainship, and by which they were afterwards known, just as all the rulers of ancient Egypt were termed Pharaoh. Thus the paramount chiefs of the tribe that occupied the south-eastern shore of Delagoa Bay took the name Nyaka, those of the adjoining tribe to the westward Kapela, and those of the tribe living along the lower course of the Limpopo river Manisa. Each of these dynastic names originally had a special signification, and was derived from some occurrence connected with the founder of the ruling family or one of the most distinguished of his descendants. The custom applied only to paramount chiefs. South of Kosi Bay dynastic names were not used, owing probably to the manner in which the tribes were formed and their recent origin.

The names given to children at birth were often changed at a later age, especially in the case of chiefs who performed any noteworthy act, or with a view to flattery, a custom that makes research into their history somewhat difficult. It 
frequently happened also that a chief was known to his own people by one name, and to neighbouring tribes by another very different. In our own day there are many instances of this custom. Thus a chief of a Barolong clan, Montsiwa as his own people called him, is termed Seyangkabo (meaning intruder in a bad sense) by some of his immediate neighbours, and Motshele oa Maaka (the fountain of lies) by others. Some of the names given to notable persons were very expressive, and of these also there are many instances at present. Thus Sigcawu (the great spider), the paramount Xosa chief, was so named on account of his supposed cleverness, Dalindyebo (creator of wealth, from roots uku dala to create and indyebo riches), the paramount Tembu chief, on account of his having been born during an exceedingly abundant harvest, Ngonyama (the lion), a Gaika chief, on account of his personal bravery, Uzwinye (one word, from roots izwi a word and nye one), the reverend Mr. Hargreaves, on account of his constantly recommending peace. When a woman is married, her husband's parents give her a new name, by which she is known to his family afterwards. Upon the birth of her first child, whether son or daughter, she is usually called by every one else after the name given to the infant, $\mathrm{Ma} * *$, the mother of **.

When about fifteen or sixteen years of age boys in nearly all the tribes were circumcised. The rite was purely civil. By it a youth was enabled to emerge from the society of women and children, and was admitted to the privileges of manhood. Its performance was attended with many ceremonies, some of a harmless, others to European ideas of a criminal nature. At a certain period in every year, unless it was a time of calamity or the chief had a son not ready, all the boys of a clan who were old enough were circumeised. Thereafter for a couple of months or longer they lived by themselves, and were distinguished by wearing a peculiar head-dress and a girdle of long grass about the loins, besides having their bodies covered with white clay. During this period they had license to steal freely from their relatives, provided they could do so without being caught in the act. After returning to their homes, they were 


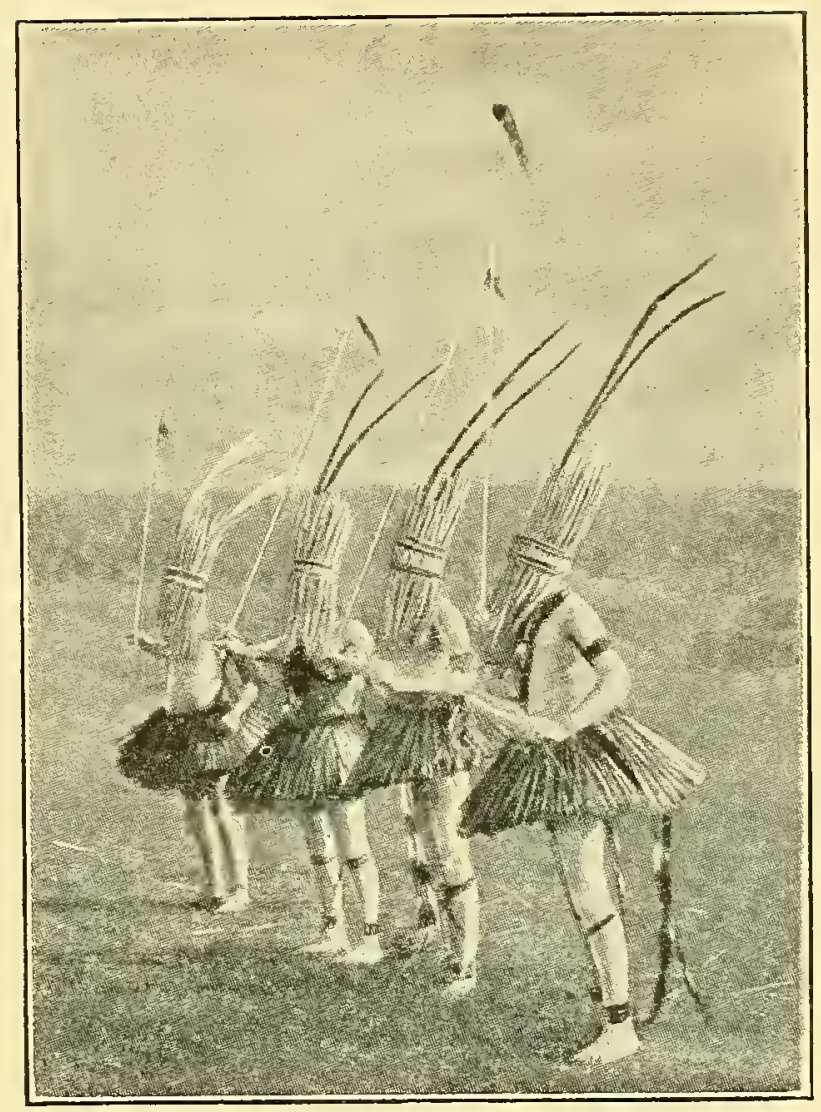

ABAKWETA OR BOYS RECENTLY CIRCUMCISED.

This plate represents the costume of the boys, whose bodies are covered or painted with white clay, during the time that they live by themselves at some distance from their usual place of residence. They are usually in high spirits, as they are about to have the privileges of men conferred upon them. The time is passed by them in practising the various dances of their people, which are different from one another, though all depend more upon quivering the body and springing up and down in perfect time with each other, than in moving from place to place. This is also a time for planning mischief and scheming cattle thefts, so that it is upon the whole about as bad a school as youths of their age could attend. 
brought before the old men of the tribe, who lectured them upon the duties and responsibilities which they had taken upon themselves. Presents of cattle and weapons were afterwards made by their friends to give them a start in life, and they could then indulge in immorality without let or hindrance from their elders.

In case a scion of the ruling house was growing up, the performance of the rite of circumcision was generally allowed to stand over for a year or two, so that he might have a large number of companions. These were all supposed to be bound to him by a very strong tie. In after years they were to be his counsellors and attendants, and in case of danger were to form his bodyguard. In modern times no instance has been known of any one who was circumcised at the same time as a chief afterwards proving unfaithful to him, but numerous instances have come under the notice of Europeans where such persons have sacrificed their lives for him.

With some-if not all-of the interior tribes at the time of circumcision the youths were formed into guilds with passwords. The members of these guilds were bound never to give evidence against each other. The rites of initiation were kept as secret as possible, but certain horrible customs connected with them were known. One of these was the infusion of courage, intelligence, and other qualities. Whenever an enemy who had acted bravely was killed, his liver, which was considered the seat of intelligence, the skin of his forehead, which was considered the seat of perseverance, and other members, each of which was supposed to be the seat of some desirable quality, were cut from his body and baked to cinders. The ashes were preserved in the horn of a bull, and during the circumcision ceremonies were mixed with other ingredients into a kind of paste and administered by the tribal priest to the youths, the idea being that the qualities which they represented were communicated to those who swallowed them. This custom, together with that of using other parts of the remains of their enemies for bewitching purposes, led them to mutilate the bodies of all who fell into their hands in war, a practice which infuriated 
those whose friends were thus treated, and often provoked retaliation of a terrible kind.

Among the Ovaherero and kindred tribes boys were generally circumcised between the ages of four and seven years, and therefore the rite had not the same signification as it had with other Bantu. From it they dated their age, naming the most important event at the time of their circumcision as their starting point in life, just as other Bantu name the most important event at the time of their birth. These people differed further from their eastern kindred by mutilating themselves in a peculiar manner. When a child was eight or ten years of age its four lower front teeth were broken out, and the corresponding upper front teeth were filed with stones into the shape of triangles with the base downwards. This was their national mark, as the mode of wearing the hair is with many other tribes.

Among the tribes along the eastern coast females who arrived at the age of puberty were introduced into the state of womanhood by peculiar ceremonies, which tended to extinguish virtuous feelings within them. Originally, however, the very worst of the observances on these occasions was a test of discipline. The object of the education of the males was to make them capable of self-restraint. They were required to control themselves so that no trace of their emotions should appear on their faces, they were not to wince when undergoing the most severe punishment. In olden times a further test was applied, which has now degenerated into the most abominable licentiousness. It will be sufficient to say that the young women who attended the revels on these occasions were allowed to select temporary companions of the other sex, and if they declined to do so, the chief distributed them at his pleasure. As the first edition of this chapter was being prepared, a chief, who was regarded as being more advanced towards civilisation than most of his people, came into legal collision with the European authorities for distributing a large number of girls in this manner in a district within the Cape Colony.

But degrading as this rite was among the Bantu of the coast, among some of those of the interior it was even more vile. All 
that the most depraved imagination could devise to rouse the lowest passions of the young females was practised. A description is impossible.

The other ceremonies observed on this occasion varied among the tribes, but an account of those of the Amaxosa at the present day will give a general idea of all. When-a girl of this tribe arrives at the age of puberty, messengers are sent by her father to all the neighbouring kraals to invite the young women to attend the "ntonjane." The girl in the meantime is kept secluded in the hut of an aunt, or other female relative, and her father does not see her. Soon parties are seen coming from all sides, singing as they march. The first that arrive halt in front of the cattle kraal, where they are joined by those who come later. When the girls are all assembled, the father selects an ox to be slaughtered, and the meat is cooked for a feast. The women then dress the girls for a dance, and when this is done they are ranged in rows in front of the cattle kraal. They are almost naked, having on only a girdle round the loins, and a little apron called cacawe, made for the occasion out of the leaves of a certain plant. In their hands they hold assagais, using them as walking sticks.

When all is ready, four of the girls step out of the front row and dance, the rest singing; and when these are tired four others step out, and so on, until all the girls present have danced. The spectators then applaud the best dancer, or if they do not at once fix upon the same person, the girls dance until all present agree. The girls then give room to the men and women that in the meantime have arrived, who form themselves in lines in the same manner, and dance until it is decided which of them surpass the others. The dancing is continued until sunset, when the men and women return home, leaving the party of girls, called the jaka, who remain overnight. Next day dancing is resumed in the same order, the guests usually arriving very early in the morning.

If the girl's father is a rich man three oxen are slaughtered, and the ntonjane is kept up for twelve days. On the thirteenth day the young woman comes out of the hut where she has all 


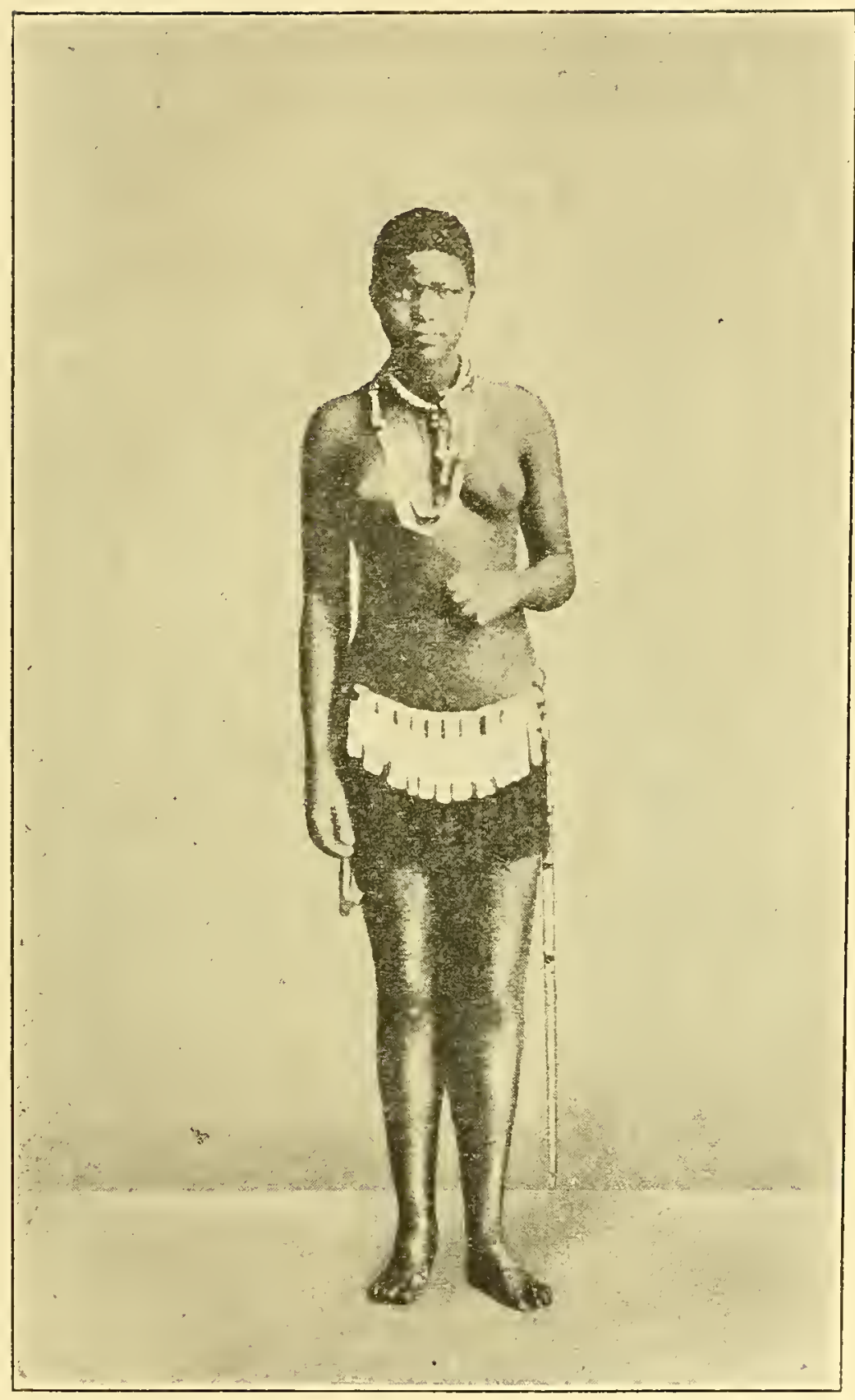

XOSA GIRL IN DANCING COSTUME.

(From a Photograph in the South African Public Library.) 
the time been living apart from her family. If the girl is a chief's daughter the ntonjane is kept up for twenty-four days. All the counsellors send oxen to be slaughtered, that there may be plenty for the guests to eat.

The following ceremony takes place on the occasion of a chief's daughter coming out of the house in which she was concealed during the twenty-four days :-

A son of her father's chief counsellor puts on his head the two wings of a blue crane (the indwe), which are regarded as an emblem of bravery only to be worn on this occasion and by veterans in time of war. He goes into the hut where she is, and when he comes out she follows him. They march towards the kraal where the dancing took place, the girl's mother, the jaka or party of young women, the girl's father, and his counsellors, forming a procession. More cattle are slaughtered for the indwe, and then dancing is renewed, after which the girl drinks milk for the first time since the day when she was concealed in the hut. Large skin bags containing milk are sent from different kraals to the place where the ntonjane is held. Some milk is put into a small vessel made of rushes, a little of it is poured on the fireplace, the aunt or other female relative in whose charge the girl was takes the first mouthful, then she gives the milk to the girl, who, after having drunk, is taken to her mother's house. The people then disperse, and the ntonjane is over.

This ceremony acts as an advertisement to people far and wide that the girl can now be applied for in marriage.

The Bantu were polygamists, and women occupied a lower position than men in their society. Marriage was an arrangement, without any religious ceremony, by which in return for a girl cattle were transferred to her relatives by the husband or his friends. It did not make of a woman a slave who could be sold from hand to hand, nor did it give her husband power to maim her. In its best aspect this method of marriage was a protection to a woman against ill usage, as well as a guarantee to the husband that she would study his interests. If he maimed her, or treated her with undue severity, she could return 
to her father or guardian, who was allowed in such cases to retain both the woman and the cattle, but if she abandoned him without sufficient cause he could reclaim the cattle he had transferred and she lost caste in the eyes of every one. In its worst aspect it permitted a parent or guardian to give a girl in marriage to the man who offered most for her, without the slightest reference to her inclinations. A woman was a drudge, upon whom the cultivation of the ground and other severe labour fell, she could inherit nothing, and she was liable to moderate castigation from her husband, such as a parent is at liberty to inflict upon a child, without protection from the law. Wealth was estimated by the number of wives and cattle that a man possessed, and the one was always made use of to increase the other. The husband was head or lord of the establishment, and the wives were required to provide all the food except meat and milk. Each had a hut of her own, which she and her children occupied, and the husband used his caprice as to which of them he associated with at any time.

Though the transfer of cattle alone made a marriage binding, it was customary to engage in festivities in connection with it. Those ordinarily observed in the Xosa tribe at the present day are fairly typical of all. Among these people the whole of the marriage ceremonies are included in the term umdudo, a word derived from the verb uku $d u d a$, which means to dance by springing up and down, as uku xentsa means to dance by moving the upper parts of the body. The dance at a marriage is considered of more importance than any of the others except the war dance, and is therefore frequently practised until skill in its performance is attained.

The marriage of a young woman is arranged by her father or guardian, and she is not legally supposed to be consulted in the choice of a husband. In point of fact, however, matches arising from mutual love are not uncommon. In such cases, if any difficulties are raised by the guardians on either side, the young people do not scruple to run away together, after which their relatives usually come to an arrangement. Yet instances 
are not wanting of girls being compelled against their wishes to marry old men, who have already perhaps five or six wives. In practice the umdudo is often deferred to a convenient season, but the woman is considered not less a wife, and her children not less legal, provided always that the transfer of cattle has taken place according to agreement.

Marriage proposals may come from the father or guardian of the young woman, or they may first be made by the man himself or the relatives of the man who wishes to take a wife. The father of a young man frequently selects a bride. for him, and intimates his wish by sending a messenger to make proposals to the girl's father or guardian. In this case the messenger takes some cattle with him, when, if the advances are favourably received, an assagai is sent back, after which the relatives of the young people discuss and finally arrange the terms of the marriage. If the proposal comes from the girl's father, he sends an assagai, which is accepted if the suit is agreeable, or returned if it is not.

When the preliminary arrangements are concluded, unless, as sometimes happens, it is considered expedient to permit the marriage at once to take place, but to postpone the festivities to a more convenient season, a bridal procession is formed at the young woman's kraal, to escort her to her future home. It consists of her relatives and all the young people of both sexes who can get away. It leaves at such a time as to arrive at its destination after dark, and tries to reach the place without attracting notice. The bridal party takes with it a cow, given by the bride's father or guardian to confer fortune upon her, and hence called the inqakwe. This cow is afterwards well taken care of by the husband. The party has also an ox. provided by the same person, as his contribution towards the marriage feast. On the following morning at daylight the ox is killed, when a portion of the meat is taken by the bride's party, and the remainder is left for the people of the kraal. The bridegroom's friends then send messengers to invite the people of the neighbourhood to the feast, and as soon as these arrive the dancing commences. 
In the dance the men stand in lines three, four, or more rows in depth, according to their number, and at a little distance behind the women stand in the same order. The men stand with their heads erect and their arms locked together. They are nearly naked, but wear ornaments of brass around their waists. The trappings of the war dance are altogether wanting. The women are, however, in full dress, for their part consists only in singing. When all are ready, a man who has been selected for the purpose commences to sing, the others immediately join in, and at a certain note the whole of the men rise together from the ground. The dance consists merely in springing straight up and coming down with a quivering of the body ; but when the men warm to it, it gives them great satisfaction. The song is very monotonous, the same note recurring at every rise from the ground. 'This dancing, with intervals of rest and feasting, continues as long as the bridegroom's relatives supply oxen for slaughter. A day suffices for a poor man, but a rich man's marriage festivities may last a week or upwards.

On the closing day the bridegroom and his friends march from one hut, while the bride and her party march from another, so as to meet in front of the entrance to the cattle kraal. The bride carries an assagai in her hand, which she throws so as to stick in the ground inside the kraal in an upright position. This is the last of the ceremonies, and the guests immediately begin to disperse, each man taking home the milk-sack which he had brought with him. In olden times ox-racing usually took place on the closing day, but this custom has of late years fallen into neglect.

There were different restrictions with regard to the females whom a man was at liberty to marry. No man of any coast tribe would marry a girl whose relationship by blood to himself on his father's side could be traced, no matter how distantly connected they might be. So scrupulous was he in this respect that he would not even marry a girl who belonged to another tribe, if she had the same family name as himself, though the relationship could not be traced. A man, for instance, whose 
family title was the Amanywabe * might belong to the Dushane clan of the Xosa tribe. Among the Tembus, the Pondos, the Zulus, and many other distinct communities, are people with this same family title. They cannot trace any relationship with each other, but wherever they are found they have ceremonies peculiar to themselves. Thus the customs observed at the birth of a child are exactly the same in every part of the country among people of the same family title, though they may never have heard of each other, while neighbours of the same clan, but of different family titles, have these customs altogether dissimilar. This indicates that the tribes and clans of the present day are combinations of others that were dispersed before their traditional history commenced. No marriage between the Amanywabe is permissible.

In some tribes, as at present in the Pondos, Tembus; and Xosas, the same rule was applied to relatives by blood on the mother's side also. Children take the family title of the father, and can thus marry those of the same family title as the mother, provided their blood relationship cannot be traced. Every man of a coast tribe regarded himself as the protector of those females whom we would call his cousins, second cousins, third cousins, and so forth, on the father's side, while some had a similar feeling towards the same relatives on the mother's side as well, and classified them all as sisters. Immorality with one of them would have been considered incestuous, something horrible, something unutterably disgraceful. Of old it was punished by the death of the male, and even now a heavy fine is inflicted upon him, while the guilt of the female must be atoned by a sacrifice performed with due ceremony by the tribal priest, or it is believed a curse will rest upon her and her issue.

Of late years this feeling has become less operative than formerly among those Bantu of the coast belt who have long

* The Amanywabe must at some distant date have been a tribe or a clan of a tribe, which was broken up, when its members were dispersed and subsequently joined different communities. The old tribal title then became a kind of family name. And so with all the other family names in every Bantu tribe, they indicate that the existing communities are formed of the fragments of others long since broken up. 
been in contact with Europeans, still immorality between persons related to each other as above described is extremely rare. It is still more so among those who have learned little or nothing from white men. Shortly after the annexation of Pondoland to the Cape Colony the principal chief of the western division of that territory instituted an inquiry into one such case, which he reported to a magistrate, and wished the usual punishment to be inflicted. The common ancestor was found on investigation to be seven generations back, still in public opinion the crime was enormous.

In contrast to this prohibition the man of the interior almost as a rule married the daughter of his father's brother, in order, as he said, to keep property from being lost to his family. This custom more than anything else created a disgust and contempt for them by the people of the coast, who term such inter-marriages the union of dogs, and attribute to them the insanity and idiocy which in recent times have become prevalent among the inland tribes.*

With the Ovaherero and their near kindred marriage was a much looser union than among other Bantu, for it could be more easily dissolved by either party. There was practically very little property at stake in the matter. Custom required that when a woman went to live with a man he should transfer to her father or guardian a large ox, a heifer, a large fat sheep, a ewe with a lamb, and a young ewe, but the most valuable of these animals were at once strangled and eaten at the feast which was the only ceremony attending the alliance. A rich man or a man of rank gave no more than a poor one.

With the Makaranga infant girls could be contracted as wives, but they remained with their parents until they attained

* Among the tribes within the Cape province at the present time the differences are as follows:-

Xosas, Tembus, and Pondos : marry no relative by blood, however distant, on either father's or mother's side.

Hlubis and others commonly called Fingos: may marry the daughter of mother's brother and other relatives on that side, but not on father's side.

Basuto, Batlaro, Batlapin, and Barolong : very frequently marry cousins on father's side, and know of no restrictions beyond actual sisters. 
the age of puberty. With these people a custom revolting to our sense of morality was common. A young man too poor to acquire a wife by the transfer of cattle would make an arrangement with the father of a girl to live with her and to serve him, when, as children do*not belong to their father until the full ikazi* has been transferred, the father of the woman had sole control over all that were born, and enriched himself by the disposal of the females.

In no section of the Bantu was there any restriction in regard to marrying a wife's blood relatives. Thus a man might marry two sisters, though not at the same time, and of course two brothers might marry two sisters. Sometimes it happened that a man and his wife could not agree, and that he could bring some substantial charge against her, when; if she had a young unmarried sister, an arrangement was usually made by which she returned to her parents and her sister took her place, on the husband's making a small addition to the cattle that had been transferred on the first occasion.

This was also the case when, as sometimes happened, a woman was childless. Such a person finds little favour in Bantu society, so that on becoming a mother a wife who has been married some time may say from the bottom of her heart, with Elizabeth of old, that "her reproach is taken away from among men." A childless woman is usually exchanged for a marriageable sister, but the husband is required first to perform a ceremony which can be illustrated by a case tried before the writer when acting as a border magistrate in 1881. A sued B

* Ikazi, Sesuto bohadi, means the cattle transferred to the father or guardian of a woman for her. When this has been delivered in full, she becomes a member of her husband's family and her children are legally his, but until that is done she is a member of her father's family and any children she may give birth to are wholly or partly under his control. An attempt to prevent the endless contention and litigation that arises from this rule was made by the colony of Natal, which provided by law that in the case of a common man the ikazi should not exceed ten head of cattle, that it should be paid in full before the marriage, and a declaration to that effect be made by the woman's father or guardian before an official witness. As no action can be brought before any court thereafter for any portion of the ikazi, litigation is prevented, but immorality of the grossest kind has greatly increased. 
to recover the value of a heifer supplied to him two years before under these circumstances. B's wife, who was distantly related to $A$, had been married over a year without bearing a child. B thereupon applied to him for a heifer, the tail hair of which was needed by the doctor of the clan to make a charm to put round the woman's neck. He had supplied one for the purpose, and now wanted payment for it. The defence was that A, being the woman's nearest relative who had cattle, was bound to furnish a heifer for the purpose. The hair of the tail was needed, the doctor had made a charm of it and hung it round the woman's neck, and she had thereafter given birth to a son. The heifer could not be returned after being so used. In this case, if the plaintiff had been so nearly related to the defendant's wife as to have participated in the benefit of the cattle given by her husband for her, he could not have justified his clajm under Bantu law; but as he was very distantly connected, he got judgment. The feeling entertained by the spectators in court in this instance was that B had acted very ungratefully towards $\mathrm{A}$, who had not even been present at the woman's marriage feast, but who had cheerfully acted in conformity with the custom which requires that a charm must be made out of the hair of the tail of a heifer belonging to a relative of a childless wife, in order to cause her to bear children.

If it happened that a woman had such a repugnance to her husband that her life with him was miserable, her father or guardian had the power of releasing her by sending back to the husband the portion of the ikazi that had been transferred, which was equivalent to a legal divorce. Such instances, however, were extremely rare.

Far the greater number of lawsuits among the Bantu arose from their marriage customs. The cattle to be transferred to the family of a woman were seldom or never fully paid until long after the union, and in the meantime if the husband died disputes were almost sure to arise as to what family the widow and her children belonged, whether she had a right to return to her parents, if so whether she could take any of her offspring with her, and so on. The nearest relative of a deceased man 
had it in his power to settle the matter at once by paying the cattle still due, but he did not always follow that course. If there were any daughters, an arrangement was possible that of the cattle to be received for them when they should marry the number due on account of the mother should be paid. But even in this case disputes were sure to arise. One party would fix the number very differently from the other, and then the case would have to be tried, when every little particular from first to last was entered into, and much patience was needed before a decision could be arrived at. Sometimes these cases depended upon the payment or non-payment of cattle three generations back, for in Bantu opinion if a grandmother had not been fully incorporated into the family of her husband, that is if the full number of cattle had not been transferred for her, the position of her descendants was doubtful, two distinct families having claims upon them. In their expressive way of speaking, such cases did not die.

In most of the tribes the eldest brother of a married woman exercised greater influence over his sister's children than any of her husband's brothers until all the cattle to be given for her had been transferred. The reason is obvious: the woman did not fully belong to her husband's family until that time, and her children were in the same position. Her eldest brother was considered their natural guardian. Except with chiefs, in whose case it was necessary that there should be no question whatever as to the family each child belonged to, it very seldom happened that the whole, or even the greater number of the cattle were transferred until many years after the marriage. It might almost be said it never happened, because at the birth of a child a claim was, made upon its father by the father or brother of its mother for an ox or a cow, and this claim was recognised as one of right. Thus it was usually the case that a woman of the commoner class was well advanced in life before the guardianship of her brother over herself and her children ceased and she and they were entirely incorporated in her husband's family. In the meantime her sons grew up, when this maternal uncle of theirs had the right of control over 
them to a considerable extent, with the corresponding duty of giving protection and assistance if necessary. Her daughters grew up and got married, when some of the cattle given for them went to this maternal uncle, who had been in a way their guardian and had kept them supplied with clothing if they needed it. With some tribes the principal malume, that is the eldest full brother of the mother of any one, had much more authority over his sister's children than with others. But with all it rested upon the principle that a woman was a member of the family of her father-provided of course that her mother had become so-until she was fully incorporated in the family of her husband. But there was a long period of her life when her position was not perfectly assured, and it was for this time, when protection was most needed, that Bantu law provided by the custom here described. It was when the position of a woman's mother, or even her grandmother, was uncertain, that complications arose which taxed the ingenuity of a court of Bantu law to clear.

Chastity in married life was exceedingly rare among the coast tribes. By custom every wife of a polygamist had a lover, and no woman sank in the esteem of her companions on this becoming publicly known. The law allowed the husband a fine from the male offender, and permitted him to chastise the woman, provided he did not maim her; but in the opinion of the females the offence was venial and was not attended with disgrace. Favoured guests had female companions-who were, however, generally widows-allotted to them. Still, chastity had a value in the estimation of the men, as was proved by the care with which the harems of a few of the most powerful chiefs were guarded. It might be thought that the framework of society would fall to pieces if domestic life were more immoral than this, but in point of fact a kraal on the coast was a scene of purity when compared with one in some parts of the interior.

There it was a common occurrence for a chief to secure the services and adherence of a young man by the loan of one of his inferior wives either temporarily or permanently. In either 
case the children belonged to the chief, who was regarded by the law as their father. Another revolting custom among them was that of polyandrous marriages. A. man who had not the requisite number of cattle to procure a wife, and whose relatives were too poor to assist him, sometimes obtained aid to do so from a wealthy individual on condition of having joint marital rights.

It is commonly stated by the Basuto that their great chief Moshesh received from Motlomi, who was regarded as the wisest man of his day, the advice to get as many wives as possible, and to secure the attachment of retainers by lending them to men of position.

All this shows a standard of morality widely different from that of Europeans, and it shows the difficulty that exists in bringing these people under civilised government. The greatest caution is needed to avoid running counter to their opinions to such an extent as to cause dissatisfaction, and at the same time a European magistrate is required to make an attempt to suppress at least the vilest of the customs, such as that connected with the ntonjane. In this field the missionaries have done excellent work, and already the effect is such that the description here given now applies only to that section of the Bantu which is most conservative in its habits.

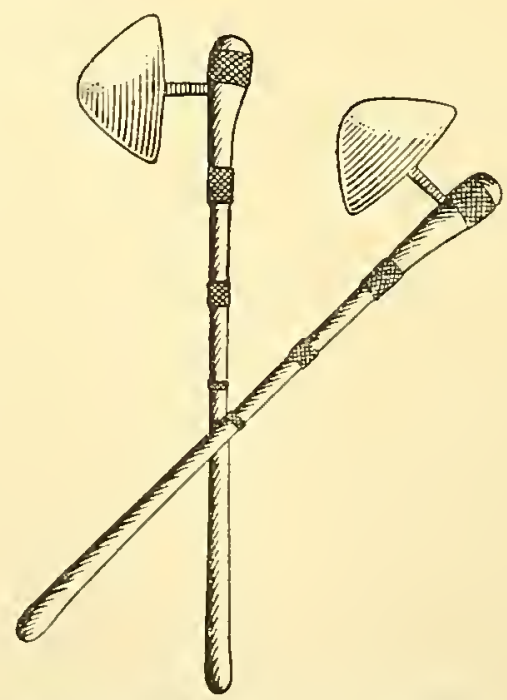

EAMANGWATO BATTLE AXES. 


\section{CHAPTER XII.}

\section{Description of the Bantu (continued).}

THE Bantu were agriculturists. Millet of several varieties, all now called by Europeans kaffir-corn, was the grain exclusively grown. They raised large quantities of this, which they used either boiled or bruised into paste from which a very insipid kind of bread was made. In good seasons rauch millet was converted into beer. It was steeped in water until it began to sprout, then dried in the sun, and afterwards partly crushed in wooden mortars made by hollowing the end of a block of wood about seventy or eighty centimetres high. Two women, standing by the mortar, stamped the contents with heavy wooden pestles, keeping time with the strokes and usually lightening their labour by chanting some meaningless words. The malt was then boiled, and leaven mixed with it to cause it to ferment. Sometimes a bitter root was added to flavour it. It could be made so weak as to form a harmless and refreshing beverage, or so strong as to be intoxicating. In the latter case unmalted corn was crushed and mixed with water, which was then boiled, and malt was added afterwards until it was almost as thick as gruel, and to a European palate would have been nauseating. Millet beer was largely consumed at feasts of all kinds. It was used as soon as it ceased fermenting, for it speedily became sour. Some women were reputed to be able to make it much better than others, and on that account their services were largely in demand. In some parts of the country an intoxicating drink was also made from honey, which was plentiful in the season of flowers.

More pernicious was the custom of smoking dried leaves of wild hemp, which had the effect of producing violent coughing, 
followed by stupefaction. The usual pipe was a horn, but sometimes the smoke was inhaled through a clay tube made on the surface of the ground, and sometimes it was drawn through a vessel partly filled with water. A number of men would sit round the smoking apparatus, and each in turn make use of it until all were helpless. Another means of intoxication was afforded by the same leaves of wild hemp, which, when dried and reduced to powder, were mixed with water and drunk. The practice, however, either of smoking or drinking bangue was necessarily limited to a few men in each community, and the baneful plant was only obtainable at certain seasons of the year. In the form of snuff the stalks as well as the leaves and fibres, dried and beaten into powder, could be preserved, and were more generally used.

The individuals, whether male or female, among the Bantu who could resist the temptation of using intoxicants to excess were so few in number, that their amazing fertility must have been checked, if the opportunities for indulging the vicious taste had not been so limited. Nature is pitiless in her mode of strengthening the will and the minds of men. Europeans would not be what they are to-day if in past times intoxication had not destroyed so many of the feeblest-willed of their race, and the Bantu have not gone through that strengthening process.

Tobacco is believed to have been introduced by the Portuguese in the sixteenth century, but there is no account extant of the importation of the plant, nor any tradition of its first appearance, as there is of maize. Wherever it came from, and at whatever time it was brought into the country, it spread among the Bantu with great rapidity, for all the tribes visited by the Dutch in the seventeenth and eighteenth centuries were found cultivating and using it.

Among the coast tribes a supply of millet was preserved from attacks of weevil by burying it in air-tight pits excavated beneath the cattle-folds. When kept for a long time in these granaries, the grain lost the power of germinating, and acquired a rank taste and smell, but it was in that condition none the less agreeable to the Bantu palate. The interior tribes preserved 
their grain either in huge earthenware crocks or in enormous baskets, which were perfectly watertight, and which could be exposed to the air without damage to their contents.

But even after the best seasons the grain rarely lasted longer than a few months, as it was recklessly wasted in making beer, which might almost be said to have been common property as long as it lasted. Frugality is not a virtue of barbarians, and the thought that a time of scarcity might arrive was not allowed to trouble their minds while the means of gratifying their appetites to excess were at hand. Thus at one season of the year a clan would be revelling in abundance, every member of it being fat and strong and happy, and six months later the same people would be stinted with hunger, dejected, and miserable.

Different kinds of gourds, a cane containing saccharine matter in large quantities, and a sort of ground nut were the other products of their gardens. In the country between the lower Zambesi and Sabi rivers rice and various foreign vegetables had been introduced by the Arabs long before the beginning of the sixteenth century, but the cultivation of these had not extended beyond that area. Everywhere wild bulbs and plants, the pith of certain shrubs, and different kinds of indigenous fruit formed no inconsiderable part of the vegetable diet of the people, being almost entirely depended upon when the millet stores were exhausted. Children at a very early age were taught to look for edible plants, and soon acquired such extensive knowledge in this respect that they were able to support themselves easily where Europeans would have perished.

As food they had also milk and occasionally flesh, though domestic cattle were seldom slaughtered except for sacrifices and feasts. The flesh of all that otherwise died was, however, eaten without hesitation. Milk was kept in skin bags, where it fermented and acquired a sharp acid taste. As it was drawn off for use by the master of the household, who was the only one permitted to touch the bag, new milk was added, for it was only in the fermented state that it was used. Amasi, or fermented milk, was exceedingly nutritious, and at the present 
day is relished by most Europeans. In warm weather, especially, it is a pleasant and wholesome beverage. The art of making butter and cheese was unknown.

Fish was consumed only by the tribes living along the large rivers in the interior and those on the eastern coast from Delagoa Bay northward. South of Delagoa Bay it was not used, except by offshoots from the northern tribes that had settled at a few places along the sea shore, possibly because in ancient times it may have been regarded as connected with the snake in whose form the ancestral spirits appeared. This, however, is mere conjecture, as the people themselves at the present day can give no other reason for not eating fish than that their fathers did not do so.

Occasionally large quantities of meat were obtained by means of the chase. The chief would select a day, and give instructions for all his people to assist in the hunt. A large tract of country would then be surrounded, and the game would be driven towards a deep pit, with a strong hedge extending some distance on each side of it. The pit was made in such a way that no animal forced into it by pressure of the herd behind could escape until it was full. By the warlike tribes the pit was often disdained as a means of capturing such game as antelopes and zebras, and they preferred gradually to contract the circle of hunters and drive the animals towards the centre, killing with their assagais all that could not break through the ring. After one of these hunts feasting was continued until not a particle of meat was left, as the palates of the people did not reject what Europeans would regard as carrion.

Very large animals, such as the elephant, the hippopotamus, and the rhinoceros, were generally captured either by means of snares that caused a heavily weighted spear to fall upon them as they passed under a tree, or by means of carefully covered pits with sharp stakes in them, made in the beaten tracks of the animals towards water. Sometimes, however, men were found sufficiently courageous to lie in ambush beside the paths and hamstring the animals as they went by, when their destruction was easy. North of the Sabi river the 
tusks of the elephant and the hippopotamus were always saleable to the Mohamedan traders along the coast, and everywhere among the Bantu ivory arm-rings were esteemed as ornaments. The flesh of all these animals was much prized, especially that of the hippopotamus.

Another occasional article of food was dried locusts. Swarms of these destructive creatures sometimes appeared, when every one engaged in capturing and preserving them, the legs, when dried, being regarded as not only nutritious, but pleasant to the taste. By the people of the interior a species of caterpillar was considered a special dainty, and the little field mouse was eagerly sought for as another. Boys before being circumcised were permitted to eat any kind of meat, even wild cats and other carnivora, but after that ceremony was performed the flesh of animals of prey was usually rejected.

Ordinarily two meals were eaten every day: a slight breakfast in the morning, and a substantial repast at sunset. Any one passing by at that time, friend or stranger, provided only that he was not inferior in rank, sat down without invitation or ceremony, and shared in the meal. So great was the hospitality of the people to equals and superiors that food could almost have been termed common property.

When reduced to great extremity of want by the ravages of enemies, sections of the Bantu sometimes resorted to cannibalism, but the horrible practice was by no means common. Portuguese writers indeed mention tribes whose habitual food was human flesh, still everything related concerning them shows that they were war-stricken hordes driven from their homes and wandering about with their hands against every man and every man's hands against them. In just the same manner in the early years of the nineteenth century parties of absolutely destitute people in Basutoland and in Natal, driven into the forests and mountains by the devastations of Tshaka, preyed upon their fellows, whom they pursued as game; but as soon as a condition of comparative peace was restored, most of them returned to their normal way of living. A few indeed, who had acquired a taste for human flesh, though they were 
held in execration by all others, continued to exist as cannibals until they died out or were exterminated. It must have been the same in olden times with the tribes along the Zambesi of whom information is given by Dos Santos and other Portuguese writers: it was the direst necessity, not by any means their own choice, that led them to adopt a mode of maintaining life so different from that of the Bantu in general. They may have continued longer in that condition than those in the south in the days of Tshaka, but it is certain that no tribe depended permanently upon human flesh for its subsistence.

The Bantu had an admirable system of land tenure for people in their condition. The chief apportioned to each head of a family sufficient ground for a garden according to his needs, and it remained in that individual's possession as long as it was cultivated. He could even remove for years, with the consent of the chief, and resume occupation upon his return. He could not lend, much less alienate it. But if he ceased to make use of it, or went away for a long time without the chief's permission, he lost his right. Under the same conditions he had possession of the ground upon which his huts stood, and of a yard about them. All other ground was common pasture, but the chief had power to direct that portions of it should be used in particular seasons only. No taxes of any kind were paid for land, air, or water.

The gardens were not enclosed by hedges or fences, and they were very irregular in outline, as were also the different cultivated plots within them, for the eyes of the women were indifferent as to straight rows of plants. If the crops were damaged by cattle at night, the owner of the cattle was required by law to make good the loss, because he should have seen that his herds were either confined in a fold or guarded on a pasture so distant that they could do no harm. But if the damage was done in the daytime there was no redress, because some member of the family of the owner of the garden was then supposed to be watching it.

Sometimes a tree was left standing at a kraal, and the men would sit in its shade during the heat of the day, but in general 
all others in the neighbourhood were ruthlessly destroyed for fuel, and not one was ever planted to take their place. The havoc wrought in a patch of natural forest by a Bantu kraal being built in its vicinity was so great that in the course of a very few centuries the whole land would have been denuded of trees, if the population had not been kept very limited by strife and slaughter for alleged dealing in witcheraft, and if European influence following so speedily after the arrival of the tribes in the localities which they now occupy had not prevented the waste. The Bantu were so thoughtless and so indifferent to the wants of future generations that such a thing as the preservation of a forest never occurred to them.

Kraals were usually built in situations commanding an extensive view of the surrounding country, and always on ground with good natural drainage. The brow of a hill, with a clear flowing stream at its base and fertile garden ground beyond, was the site most favoured. Sanitary arrangements, even of the simplest kind, were unknown and uncared for, as the sense of smell was much duller with these people than with Europeans, and an impure atmosphere did not affect their health. Their superstition too required them to remove their residences whenever a man of importance died, so that kraals seldom remained many years on the same site.

Clans exposed to sudden attack by powerful enemies had naturally little or no choice in selecting sites for kraals. They were under the necessity of constructing their habitations in the best possible defensive position, which was usually the crown of a steep hill difficult of approach. Such hills are found in different parts of the country, often with sides so precipitous that the top can be reached by only one or two paths. When these were barricaded with rough stone walls, the space above became a fortress, impregnable or nearly so. Such sites for kraals were, however, only resorted to as a last means of defence, on account of the occupants being eut off from gardens and pasture for their cattle as well as from easy access to water. Along the Zambesi some clans lived in stockaded enclosures, but these were unknown farther south. 
The huts of the tribes along the coast were shaped like domes or beehives, and were formed of strong frames, thatched with reeds or grass. They were proof against rain or wind. The largest were about seven or eight metres in diameter, and from two metres and a fifth to two and a half in height at the centre. They were entered by a low, narrow aperture, which was the only opening in the structure. A hard and smooth floor was made of antheaps mixed with oxen's blood and then kneaded with a round stone. When this had set, it was painted with a mixture of cowdung and water, which was the material used afterwards for keeping it in good order. In the centre of the floor a fireplace was made, by raising a band three or four centimetres in height and a metre or so in diameter, and slightly hollowing the enclosed space. Many women bestowed a great deal of attention upon their firecircles, often enclosing them with three bands, a large one in the centre, and a smaller one on each side of it, differently coloured, and resembling a coil of large rope lying between concentric coils of less thickness. Against the wall of the hut were ranged various utensils in common use, the space around the firecircle being reserved for sleeping on. Here in the evening mats were spread, upon which the inmates lay down to rest, each one's feet being towards the centre. Above their heads the roof was glossy with soot, and vermin swarmed on every side. It was only in cold or stormy weather that huts were occupied during the day, for the people spent the greater portion of their waking hours in the open air.

The habitations of the people of the interior were much better than those of the people of the coast. With them the hut had perpendicular walls, and consisted of a central circular room, with either a broad verandah or three or four small apartments outside, each being a segment of a circle. It was surrounded by a courtyard enclosed with a high wall of reeds or wattles, in the case of one or two of the tribes with a fairly built wall of uncut stone. Within this enclosure stood also the granary and frequently two or three subsidiary huts, and the ground was levelled and was usually kept perfectly clean. The 
The Bantu.

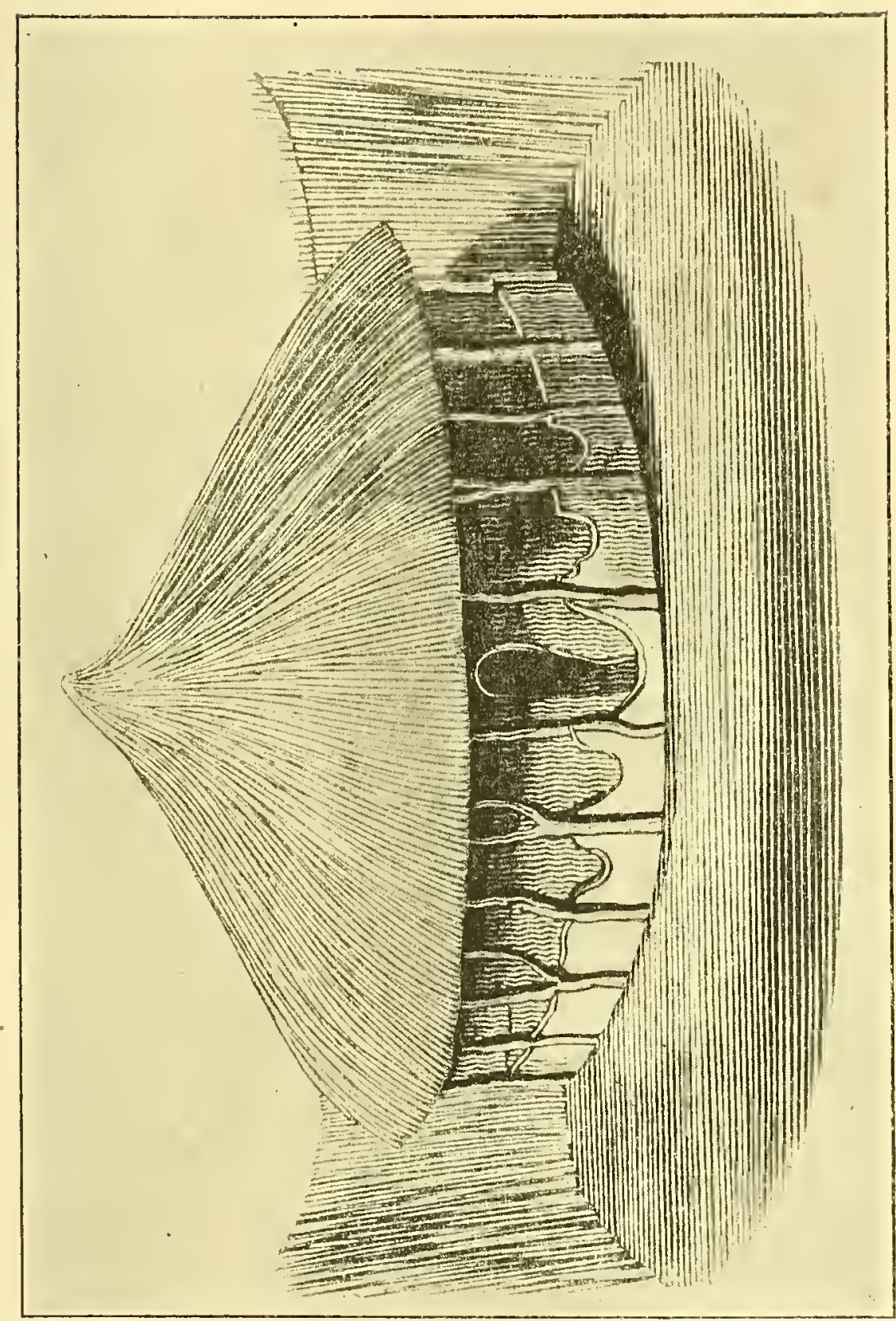

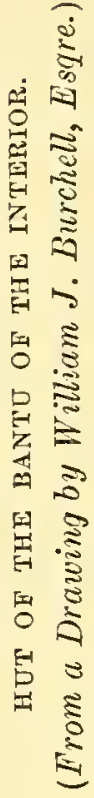


interior of the principal hut was smoothly plastered, and was often coloured red, or white, or blue, occasionally decorated with simple patterns or rude figures of animals. It was destitute of chimney or window, or as a habitation it would have been equal, if not superior, to the abodes of many European peasants. On the coast no effort was made to secure privacy.

Horned cattle constituted the principal wealth of the Bantu, and formed a convenient medium of exchange throughout the country. Great care was taken of them, and much skill was exhibited in their training. They were taught to obey signals, as, for instance, to run home upon a certain call or whistle being given. Every man of note had his racing oxen, and prided himself upon their good qualities as much as an English squire did upon his blood horses. The horns of the animals were trained into the most fantastic shapes, and were often divided into two, three, or more parts, which was effected by slitting them as soon as they appeared on the young animal. The intelligence displayed by some of these oxen was as wonderful as the patience and skill shown by their trainers. They were taught to lie down at an order, to run in a circle, or to dance in rows. Ox racing was connected with all kinds of festivities. The care of cattle was considered the most honourable employment, and fell entirely to the men. They milked the cows, took sole charge of the dairy, and would not permit a woman so much as to touch a milk-sack.

The other domestic animals were goats, dogs, and barnyard poultry everywhere, and in the north sheep of the large-tailed hair-covered breed. Eggs were never used as an article of diet, and poultry very rarely except by young children.

The descent of property was regulated in the same manner as the succession to the chieftainship, and disputes could not easily arise concerning it. Every head of cattle a man acquired was immediately assigned to a particular branch of his family, that is either to the house of his great wife, to that of his wife of the right hand, or to that of his wife of the left hand. If he had more wives than three, the remainder were in a subordinate position in one or other of these houses. When 
he died, the eldest son of each of the three principal wives inherited everything that belonged to his mother's house. But the distribution of wealth was more equal than in any European society, for each married man had a plot of garden ground, and younger brothers had a recognised claim upon the heirs of their father for assistance in setting them up in life.

The heir was in fact regarded as the representative of his dead father, and as having taken upon himself the duties and responsibilities as well as the property and privileges of the head of the establishment. Among the interior tribes this idea was carried so far that he inherited even his father's widows, except the one who bore him, though it was usual for him to distribute most of them to other men. Daughters born to them afterwards, however, no matter who their fathers were, were under his control only, and the bohadi given for them went to enrich him. Following out this principle, he was supposed to assist his brothers in raising the bohadi needed by them when they married, so that he might really be regarded as a trustee as well as an heir of his deceased father's estate. In some tribes along the coast the brothers of the dead man distributed his widows among them, but even then the heir claimed the offspring, as they were held to be the children of his deceased father.

There was thus a simple but perfect law of inheritance, which regulated the succession of three heirs or representatives at most, but usually two, the great son and the right hand son. Among common people the first wife married was usually, though not always, the great wife, which further simplified the matter. A man, however, had the right of disinheriting any of his sons for gross misconduct, but this could only be done in open court with the sanction of his chief and the counsellors of his clan, when the next in order of succession took the place of him who was dispossessed, just as if death had occurred. In case the great wife had no son, the eldest male child born in her establishment would be adopted by her, and become the heir of that branch of the family. The same was the case with the right hand wife. 
Polygamy was the cause of many evils, but it had its advantages too. Low as was the state of morality among the Bantu, it would have been infinitely lower if monogamy had been their rule, and a large number of women, who regarded it as folly to restrain their passions, had been unable to obtain the status even of inferior wife in the establishment of a rich man. Their constant feuds and wars caused the number of women to be much greater than that of men, even if the sexes were at birth nearly equal, which is doubtful. The census of the Cape Colony in 1904, when war had long ceased to have any effect upon the Bantu inhabitants, showed the number of males to be 692,728 and of females 732,059, that is for every hundred men and boys there were nearly one hundred and six women and girls. By force of circumstances, in many parts of South Africa polygamy is greatly decreasing among these people at the beginning of the twentieth century, but for their own sakes it may almost be hoped that it will not quite cease until they learn to have more command over themselves than is the rule at present.

The Bantu of the coast were more warlike in disposition and braver in the field than those of the interior. The universal weapons of offence were wooden clubs with heavy heads and assagais or javelins, and shields made of oxhide were carried, which varied in size and pattern among the tribes. The assagai was a slender wooden shaft or rod, with a long, thin, iron head, having both edges sharp, attached to it. Poising this first in his uplifted hand, and imparting to it a quivering motion, the warrior hurled it forth with great force and accuracy of aim. The club was used at close quarters, and could also be thrown to a considerable distance. Boys were trained from an early age to the use of both these weapons. To those above named the northern and central tribes added the battle-axe and bow and arrow, which, though known to, were not used by the men of the south.

In the most warlike of the Bantu communities the men were formed into regiments, and were trained to act in concert and to go through various simple military evolutions, but in 
the others the warrior knew nothing but the use of his weapons. With these a battle was a series of individual engagements, in which it sometimes happened that a man would challenge a noted adversary by name, and a duel would take place in presence of the others on both sides as mere spectators. In such cases the victor was presented by his chief with a crane's feather to be worn on his head, and he was thereafter a man of note among his people. A classification thus arose of the plumed and the unplumed in the following of a chief, though the former did not thereby become leaders or officers, that distinction being reserved exclusively for members of the ruling house and their counsellors. It was a custom for a man to be marked, usually with a scar from a gash or a brand, for every adversary slain, and warriors prided themselves relatively upon the number of these.

Among the military tribes reviews in presence of the chiefs and mock combats were of frequent occurrence. The warriors were in full dress on such occasions, with their kilts of animals' tails around them, and their ornaments on their persons. Everything was conducted with as much order and ceremony as were observed by our own ancestors in their tournaments. At the command of the chief one regiment would be pitted against another, and each would attack, retreat, skirmish, and go through all the evolutions of a real battle until the weaker side became exhausted, when the other was pronounced the conqueror. Or it might be a general skirmish of the whole army against an imaginary enemy, or an attack upon a hill supposed to be fortified, or simply a march of the regiments past the commander in chief. Sometimes oxen were brought to take part in the manœuvres and to prove the skill of their trainers. A feast and a dance invariably followed the review, but often jealousies had been roused by the events of the day which led afterwards to engagements in real earnest between different regiments.

The dress of the people between the lower Zambesi and Sabi rivers at the beginning of the sixteenth century was partly composed of skins of animals and partly of cloth either obtained 
in barter or manufactured by themselves of wild cotton or the fibres of a certain bark. The home made cloth was coarse but strong, and was woven in the simplest manner in squares large enough to be fastened round the loins. The art of weaving, though not much more difficult than mat making, was not practised by all the clans, but by certain of them who traded with their productions. At a much earlier date the Arabs and Persians had introduced Indian calico, and squares of this material, obtained in exchange for ivory and gold, were in common use in that part of the country.

Elsewhere the ordinary dress of men when the air was chilly was composed of skins of wild animals formed into a square mantle the size of a large blanket, which they wrapped about their persons. The skin of the leopard was reserved for chiefs and their principal counsellors, but any other could be used by common people. Married women wore a leather wrapper like a petticoat at all times, and big girls at least an apron of leather strings, usually much more. In warm weather men and little children commonly went quite naked.

They were fond of decorating their persons with ornaments, such as necklaces of shells and teeth of animals, arm-rings of copper and ivory, head-bands, etc. They rubbed themselves from head to foot with grease and red ochre, which made them look like polished bronze. Their clothing was greased and coloured in the same manner.

Some of the attires of the women on festive occasions were grotesque in the extreme, and to a European eye made them appear perfectly hideous. Thus the Herero women wore a headdress with three large leather ears attached to it in an upright position, and carried on their persons leather thongs and bands with pieces of iron attached to them often weighing ten or twelve kilogrammes.

Many of them worked lines and simple patterns on different parts of their bodies-chiefly the breasts, shoulders, cheeks, and stomachs-by raising the skin in little knots with a sharp iron awl and burning it, a process that to European eyes disfigured them much more than tattooing would have done, but which 


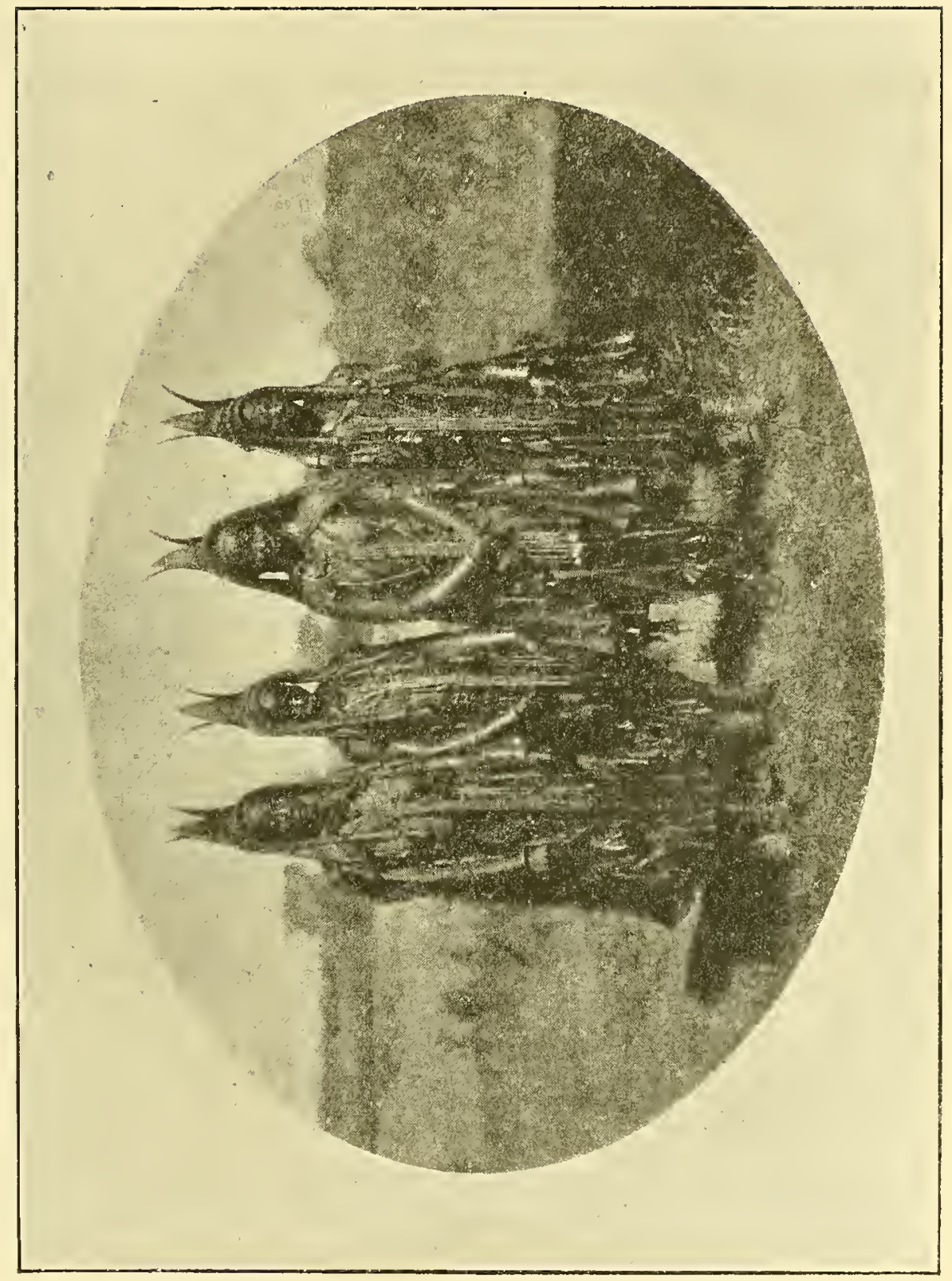

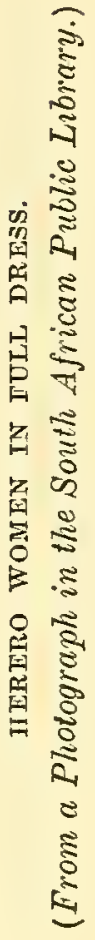


they regarded as ornainental. Each community that adhered to this custorn favoured a form of cicatrice different from that of its neighbours, but there were numerous tribes that were without such markings. So with the front teeth: some clans filed them to a point, a few removed the two upper, but most allowed them to remain in their natural state. The hideous boring and plugging the lips and cheeks, so common north of the lower Zambesi, was not practised south of that river.

More attention was bestowed upon the hair than upon any other part of the body. Each tribe had its own fashion of wearing it, so that at first sight the nationality of an individual was known. Some worked it with wax and strings into imitations of horns, others into arches, others into circles, and so on. This necessitated the use of a peculiar head rest when sleeping, to prevent the hair from becoming disordered. The rest was made of a single piece of wood, according to the fancy of its owner. Some were forty-five centimetres long, six or seven centimetres wide, and as many deep, with a slightly concave surface. Others were only fifteen or twenty centimetres long, ten to twenty centimetres high, and five to eight centimetres wide, with a deep concave surface for the head to lie in. Some of these were beautifully carved out of a block of hard wood, and were highly polished by being frequently rubbed with grease. In no other manufacture of wood was so much ingenuity displayed in designing patterns. An elaborate head rest used by a chief, for instance, might be a carved band supported by two, three, four, or even six, columns standing on an oval or oblong base, each column fluted or otherwise decorated, and the base covered with little knobs or marked with a herringbone pattern. Or it might be of almost any conceivable design between that and a plain block of wood of the requisite shape. It was never more than seven or eight centimetres wide, because it was necessary for the head to project beyond it, in order that the horms or other forms into which the woolly hair was trained might remain undisturbed.

Their manufactures, however, were not of a very high order when judged by a European standard of the present day. 
Foremost among them must be reckoned metallic wares, which included implements of war and husbandry and ornaments for the person. In many parts of the country iron ore was abundant, and this they smelted in a simple manner. Forming a furnace of clay or a boulder with a hollow surface, out of which a groove was made to allow the liquid metal to escape, and into which a hole was pierced for the purpose of introducing a current of air, they piled up a heap of charcoal and virgin ore, which they afterwards covered in such a way as to prevent the escape of heat. The bellows by which air was introduced were made of skins drawn from the animal with as little cutting as possible. These were inflated by opening the ends, which were then closed, when the air was pressed through horns of large antelopes tightly fixed at the other extremities. Two skins were worked by one man, using his hands alternately, and thus a continuous current was kept up.* The molten iron, escaping from the crude yet effective furnace, ran into clay moulds prepared to receive it, which were as nearly as possible of the same dimensions as the implements they wished to make. These were never of great size, the largest being the picks or heavy hoes required for breaking up ground for gardens.

The smith, using a boulder for an anvil and a hammer of stone, next proceeded to shape the lump of metal into an assagai head, an axe, a pick, or whatever was wanted. The occupation of the worker in iron was hereditary in certain families, and was carried on with a good deal of mystery, the common belief being that it was necessary to employ charms unknown to those not initiated. But the arts of the founder and the blacksmith had not advanced beyond the elementary stage. Instead of an opening for inserting a handle in the hoe, it terminated in a spike which was driven into a hole burnt through the knob of a heavy shaft of wood. The assagai was

* The double bellows are identical in form with those used by the Malays, Papuans, and Polynesians, which may be accidental, or it may indicate that the principal ancestral tribe of the Bantu had close affinity with those people. Standing alone, it would not have much weight, but, as will be seen farther on, there is another and stronger reason for believing that the last named alternative may be correct. 
everywhere in use, and in addition the interior tribes made crescent-shaped battle-axes, which were fastened to handles in the same manner as the hoes. On these implements of war they bestowed all their skill, and some of them really produced neatly finished articles. They worked the metal cold, and were unable to weld two pieces together.

Knives, or more properly daggers, for the ends were pointed and both edges were sharp, were also made of iron. The handles, which were of wood, bone, horn, or even occasionally of ivory, were frequently ornamented, as were also the sheaths of wood or bone in which they were carried. The amount of labour required to make one of these implements and its sheath was very considerable, so that its value relatively to other articles was high, and it was not every man who was so fortunate as to possess a knife. It was carried about by means of a thong round the neck, and lay on the chest a little lower than the charms and strings of teeth and other ornaments, so that it was always ready for use. It was not regarded as a weapon of war, and indeed was unfit for much real service in combat.

Copper was found in several parts of the country, and was distributed over it by means of barter. It was used only for making such ornaments for the person as large beads, earrings, and armlets. Much less skill was employed in working this metal than in manufacturing iron implements, the articles produced being of a very rough kind, not to be compared in point of finish with a battle-axe or an assagai. The armlet was a mere bar bent until its ends met, and the earring was of no better workmanship. The beads were nothing more than drilled lumps of metal globular in shape, and were strung with bits of wood and teeth of animals on a thong. The neater ornaments of copper and brass wire now in use, and exhibited in various museums as specimens of Bantu industry, are of modern date, made of materials obtained from Europeans.

To a people acquainted with the use of iron, bronze could not be of much importance except for making ornaments, and its use appears to have been unknown to the Bantu before the arrival of Europeans. In all the inquiries made by and for 
the writer among various tribes, no individual was ever found acquainted with the art of mixing copper and tin to make bronze, nor have implements of that metal-with possibly one exception-as yet been discovered in any other part of the country than at Zimbabwe, where those collected are certainly not of Bantu manufacture. The exception is an implement now in the South African museum, something like a spearhead with deeply indented edges, obtained in the Barotsi country and supposed to be of Barotsi manufacture, though this is doubtful. Yet there is ample evidence that some individuals in recent times acquired the knowledge of mixing copper and tin, both of which are to be obtained in different parts of South Africa, though it is evident they had been instructed by strangers how to do it. In the instance mentioned by the reverend Dr. Moffat, quoted farther on, the description of the hammer and the cold chisel proves contact with some more highly civilised people. The only other authority for the use of bronze by Bantu gives the locality as the neighbourhood of Delagoa Bay, where Portuguese had then been trading nearly a century and a half.

This authority, Jan van de Capelle, an official of the Dutch East India Company at Delagoa Bay, reported to the governor and council of policy at the Cape on the 3rd of August 1723 that some blacks had brought a quantity of copper and also of tin for barter, and that all the inhabitants there used the tin of the country as well as what they obtained from the Dutch to mix with copper for the purpose of making neck and arm rings.*

* "In laatste van 't jongst gepasseerde jaar aan la goa neegers sijn geweest, uijt de landschappen paraotte en machicos idie niet alleen koper, maar ook tin met haar bragten om aldaar te verruijken; het koper was seer mooij van couleur . . . ; het tin is meede mooij van couleur dogh wat weekelijk en ligt, gelijk uijt twee stukjes van staafjes gesien kan werden; het eene is veel harder van specie, dan het andere, gelijk sulx bij omsmelting hebbe gevonden. Dit thin seggen sij gevonden te werden in de landstreek machicosje, aan de kanten der rivier, in mandjes opgeraapt, gesuijvert van het zand, en dan door de negers tot staafjes gebragt om te verruijlen, alle de inlanders gebruijken dit thin, ook het geene zij van ons inkoopen, om onder haar kooper, tot hals en armringen te smelten: waar door 't sonder twijffel komt, dat haare ringen, sô een glans hebben, en buijgsamer zijn dan d'Comps ringen, die daar sijn geweest." In a report dated 17 th of February 1732 Mr. Van de Capelle informed the governor and council of policy that he had purchased from blacks at Delagoa Bay fifty-six bars (staven) of tin. Quite 
In 1826 the reverend Robert Moffat visited the Barolong near the Nolopo, and at Kongke, one of their kraals, he saw a Mohurutsi making bronze. He says on pages 466 to 468 of his Missionary Labours and Scenes in Southern Africa:

"Having occasion to mend the linchpin of my wagon, I inquired for a native smith, when a respectable and rather venerable man, with one eye, was pointed out. Observing, from the cut of his hair, that he was a foreigner, and inquiring where he practised his trade, I was affected to hear him reply, 'I am a Mohurutsi, from Kurrechane.' I accompanied him to his shop, in an open yard at the back of his house. The whole of his implements consisted of two small goat-skins for bellows, some small broken pots for crucibles, a few round green stone boulders for his anvil, a hammer made of a small piece of iron about three-quarters of an inch thick, and rather more than two by three inches square, with a handle in a hole in the centre, a cold chisel, two or three other shapeless tools, and a heap of charcoal. 'I am not an ironsmith,' he said ; 'I work in copper,' showing me some of his copper and brass ornaments, consisting of ear-rings, arm-rings, etc. I told him I only wanted wind and fire. He sat down between his two goat-skins, and puffed away. Instead of using his tongs, made of the bark of a tree, I went for my own. When he saw them he gazed in silent admiration; he turned them over and over; he had never seen such ingenuity, and pressed them to his chest, giving me a most expressive look, which was as intelligible as 'Will you give them to me?' My work was soon done, when he entered his hut, from which he brought a piece of flat iron, begging me to pierce it with a number of different-sized holes, for the purpose of drawing copper and brass wire. Requesting to see the old one, it was produced, accompanied by the feeling declaration, 'It is from Kurrechane.' Having examined his manner of using it, and formed a tolerable idea of the thing he

recently tin mines, worked at some former, but not very remote, period, have been discovered at and near the Rooiberg, in the district of Waterberg, south of the Limpopo river. These have been abandoned for many years, and there are no traditions among the present inhabitants concerning them. But the tribes in that part of the country settled there so recently that no information can be expected from them, and most probably it was from this locality that the tin taken to Delagoa Bay in 1732 was obtained. How Bantu acquired a knowledge of this metal, and how to smelt it, remains a mystery. 
wanted, I set to work; and finding his iron too soft for piercing holes through nearly an half-inch iron plate, I took the oldest of my two handsaw files to make a punch, which $I$ had to repair many times. After much labour, and a long time spent, I succeeded in piercing about twenty holes, from the eighth of an inch to the thickness of a thread. The moment the work was completed, he grasped it, and breaking out into exclamations of surprise, bounded over the fence like an antelope, and danced about the village like a Merry-Andrew, exhibiting his treasure to every one, and asking if they ever saw anything like it. Next day I told him, that as we were brothers of one trade, (for, among the Africans, arts, though in their infancy, have their secrets too,) he must show me the whole process of melting copper, making brass, and drawing wire. The broken pot or crucible, containing a quantity of copper and a little tin, was presently fixed in the centre of a charcoal fire. He then applied his bellows till the contents were fused. He had previously prepared a heap of sand, slightly adhesive, and by thrusting a stick about two-eighths of an inch in diameter, like the ramrod of a musket, obliquely into this heap, he made holes, into which he poured the contents of his crucible. He then fixed a round, smooth stick, about three feet high, having a split in the top, upright in the ground, when, taking out his rods of brass, he beat them out on a stone with his little hammer, till they were about the eighth of an inch square, occasionally softening them in a small flame, made by burning grass. Having reduced them all to this thickness, he laid the end of one on a stone, and rubbed it to a point with another stone, in order to introduce it through the largest hole in his iron-plate; he then opened the split in the upright stick, to hold fast the end of the wire, when he forced the plate and wire round the stick with a lever-power, frequently rubbing the wire with oil or fat. The same operation is performed each time, making the point of the wire smaller for the less hole, till it is reduced to the size wanted, which is sometimes about that of thick sewing-cotton. The wire is, of course, far inferior in colour and quality to our brass-wire. These native smiths, however, evince great dexterity in working ornaments from copper, brass, and iron."

In the manufacture of wooden articles, such as spoons, bowls, fighting sticks, mortars, etc., they were tolerably expert. Each 
article was made of a single block of wood, requiring much time and patience to complete it, and upon it was frequently carved some simple pattern or the figure of an animal. Standing on the handle of a spoon might be seen a lizard, an ox, or an elephant, though always stiff in attitude; encircling the fighting stick might be seen two or three snakes with spots burnt upon them to make them resemble the living reptiles.

The tribes bordering on some of the rivers of the interior and along the eastern coast north of Delagoa Bay were able to construct canoes out of the trunk of a single tree, and knew how to propel them with paddles, but this simple art was not practised elsewhere. No means for crossing a swollen river, other than carrying a stone under each arm if the water was not too deep, had been devised by the Bantu of the coast below Delagoa Bay, and ocean navigation was of course unthought of.

A product of some ingenuity was a little vase used for various purposes. It was made of the scrapings of skins which when soft were spread over clay moulds, and when dry became solid cases. The clay was then taken out with an isilanda or large iron pin which every man carried about with him to extract thorns from his feet, and the vessel was ready for use. Some were in the shape of animals, others of gourds, or whatever else the moulders desired. Usually while the gluey matter was still soft it was creased, or raised in riages, or pricked all over with a sharp piece of wood, which greatly improved its appearance. Some of these articles, especially those in the form of European vases or decanters, were really extremely neat and pretty.

Skins for clothing, when the fur was preserved, were prepared by scraping them carefully and then thumping them with the hand and rubbing them for a length of time with a very smooth stone, by which means they were made nearly as soft and pliable as cloth. The interior tribes excelled in the art of dressing skins, and were able to make beautiful fur robes, which they stitched with sinews by the help of an awl. When the hair was removed from skins to make wrappers for women the process of preparing them was different. They were steeped in water, scraped on both sides, then dried, and afterwards 
beaten and rubbed with grease till they were soft. Finally they were cut into shape and sewed together with sinews to the required size, when the wrapper was coloured with red ochre and was ready for use.

In one comparatively small district of South Africa,-the territory between the lower courses of the Zambesi and Sabi rivers,-men were sometimes engaged in an occupation altogether unknown to their kindred elsewhere. This was the collection of gold. The chiefs were induced by the Mohamedan traders of the coast to employ bands of their subjects in searching for the precious metal, principally by alluvial washing in the rainy season, though sometimes by extracting quartz from reefs near the surface by the aid of fire. The quartz was crushed, and the gold was then obtained by washing. As the Makaranga knew of no other artificial light than burning wood they could not mine beneath the surface, and consequently very little gold was obtained in this manner. This gold was inferior to the other in quality, and was known by a different name. According to Dos Santos the diggers were termed botonghi, which is evidently an approximation to the Tshikaranga word for gatherers, from the root uku buta, to collect or gather.

The industries above mentioned were confined to males, but in other departments the women were equally skilful. Earthenware vessels containing from a quarter of a litre to three hectolitres were constructed by them, some of which were almost as perfect in form as if they had been turned on a wheel. Though they were frequently not more than a third of a centimetre in thickness, they were so finely tempered that the most intense heat did not damage them. These vessels were used for beer pots, grain jars, and cooking utensils. The potter's art has now become nearly, if not wholly, lost by the Bantu of the coasts, owing to the cheapness of importations from abroad. The women have found by experience that with much less labour they can earn sufficient money to purchase earthenware crocks, iron pots, and wooden kegs, and so contact with European civilisation has had the effect in this respect of diminishing their former skill. 
In the interior, however, the manufacture of pots is still carried on, and some very neat articles are sometimes produced. For instance, I have before me a jar manufactured by a woman of the Bapedi tribe, and it is quite equal in appearance to one of the same size of English make. It is of the colour of terracotta, and has on it an ornamental. design in black and white, with a line of small punctured dots along the border. It holds nearly three litres, and its weight is rather over a kilogramme. The use of this jar was to contain millet beer, and it answered the purpose of a goblet for drinking. It was very kindly sent to me by Dr. Piiper, of Lydenburg.

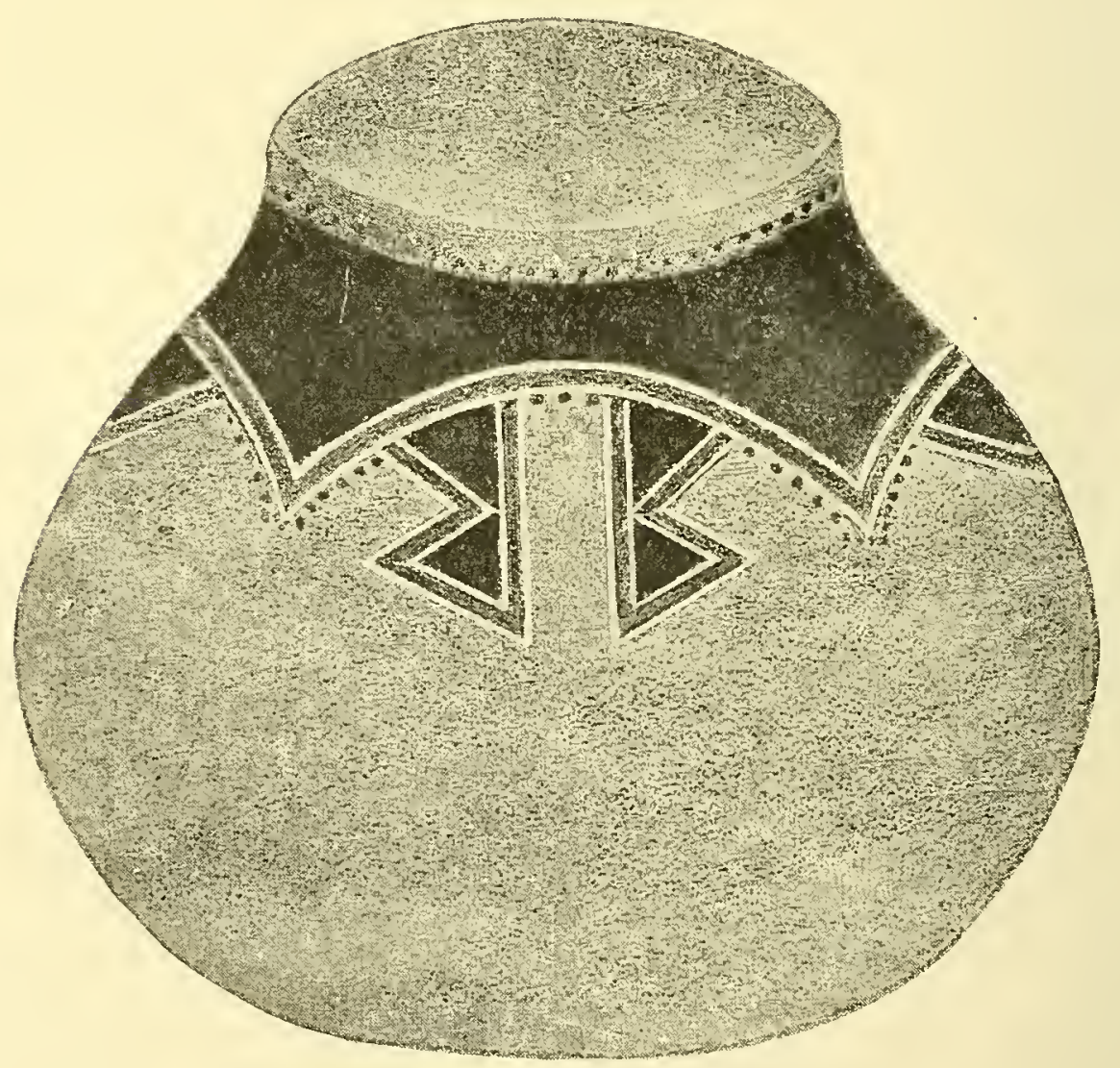


Baskets for holding corn, rush mats for sleeping on, small mats used like plates to serve food on, and grass bags were made by the women. The bags were so carefully and strongly woven that they were used to hold water or any other liquid. In general none of these articles were dyed, nor was any attempt made to ornament them, though by a few of the people of the interior simple patterns were occasionally worked in the best of their mats with materials of different colour.

Of the use of stone for building purposes, the coast tribes knew nothing, and the interior tribes very little. None of them ever dressed a block, but the cattle-folds, which along the coast were constructed of branches of trees, in parts of the interior were made of round stones roughly laid together to form a wall. A few of the enclosures of courtyards among the Betshuana were also made of rough stones, and the walls of the huts of the Bataung were usually made of that material. The quern, or handmill for grinding corn, which was in common use, consisted of untrimmed stones, one flat or hollow and the other round or oval.

When not engaged in the industries that have been mentioned, the men were habitual idlers. A great portion of their time was passed in visiting and gossip, of which they were exceedingly fond. They spent days together engaged in small talk, and were perfect masters of that kind of argument which consists in parrying a question by putting another. Though not pilferers, they were inveterate cattle thieves. According to their ideas, cattle stealing except from people of their own clan was not so much a crime as a civil offence, and no disgrace was attached to it, though if it was proved against a man the law compelled him or his connections to make ample restitution. But any one detected in the act of lifting cattle might be killed with impunity by the owner, and a chief punished with death any of his subjects whose conduct as a robber from other clans had a tendency to involve his own people in war.

A custom of the Bantu everywhere which irritated the first Europeans who came in contact with them was their persistency in begging for everything that a stranger had, no matter how 
indispensable it was to him. From the chief down to his poorest subject, the cry was nothing but give, give. Every artifice was employed to get from him whatever they saw, and among some of the most degraded of the communities he might consider himself fortunate if really violent means were not used to effect the purpose. This habit made it very difficult to explore the parts of the country that they occupied, added to which every tribe invariably represented the next in advance as dangerous to deal with, the object being to keep all gain for themselves. A very strong party could of course make its way onward without being subjected to annoyances, and a little party of perfectly destitute people, such as a band of shipwrecked sailors, might traverse the country and be assisted with food on the journey, but an ordinary traveller, unless under exceptionally favourable circumstances, had to pay a very heavy toll.

The interior tribes were the more advanced in skill in such handicrafts as were common to them all, and many of them had greater latent power of mind, owing to the large mixture of blood of higher stock in their veins. Their males sometimes aided the females in agriculture, though the hardest and most constant labour was by them also left to the women. But with these exceptions, all comparisons between the tribes must be favourable to those of the coast. The Bantu of the interior were smaller in stature and less handsome in appearance than the splendidly formed men who lived on the terraces facing the sea. In all that is comprised in the word manliness they were vastly lower.

Truth is not a virtue of barbarian life. In general if a man could extricate himself from a difficulty, escape punishment, or gain any other advantage by telling a falsehood, and did not do so, he was regarded as a fool. Many of the chiefs of the coast tribes, however, prided themselves on adhering faithfully to their promises; but the word of an interior chief was seldom worth anything.

The deceptive power of all these people was great. But there was one member which a man of the coast could not entirely control, and while with a countenance otherwise devoid 
of expression he related the grossest falsehood or the most tragic event, his lively eye often betrayed the passions he was feeling. When falsehood was brought home to him unanswerably, he cast his glances to the ground or around him, but did not meet the eye of the person he had been attempting to deceive. The man of the interior, on the contrary, had no conception whatever of shame attached to falsehood, and his comparatively listless eye was seldom allowed to betray him.

The man of the coast was brave in the field; his inland kinsman was in general an arrant coward. The one was modest when speaking of his exploits, the other was an intolerable boaster. The difference between them in this respect was great, and was shown in many ways, but a single illustration from an occurrence of the present generation will give an idea of it. Faku, son of Gungushe, chief of the Pondos, by no means the best specimen of a coast resident, once wished to show his regard for a white man who was residing with him. He collected a large herd of cattle, which he presented with this expression: "You have no food to eat, and we desire to show our good will towards you, take this basket of corn from the children of Gungushe." An inland chief about the same time presented a half-starved old goat to his guest, with the expression "Behold an ox!"*

Among the coast tribes the institution of slavery did not exist, but there could be no more heartless slave-owners in the world than some of the people of the interior. Their bondsmen were the descendants of those who had been scattered by war, and who had lost everything but life. They could not

* This was unquestionably the case when Europeans first came into contact with the different tribes and placed on record the peculiarities of each, but it is not so in all instances at the present day. The chief of our time who possesses the highest moral qualities of any in South Africa is Khama, ruler of the Bamangwato. Bathoen, chief of the Bangwaketse, and Sebele, chief of the Bakwena, are also superior to most of the other Bantu rulers. All of these are heads of interior tribes. It is not only from the observations of others, but from personal experience, that the writer of these pages is able to state that the chiefs here named are capable of acting with such generosity and good feeling as would do credit to any European. But they are exceptions to the general rule, and unfortunately few of their followers come up to their standard. 
own so much as the skin of an antelope, and upon any caprice of their masters they were put to death with as little compunction as if they were vermin.

In a state of society in which women were drudges performing all the severest labour, in which a man carrying only an assagai and a knobbed stick walked in front of his wives and daughters all bearing heavy burdens on their heads, it might be supposed that the females were unhappy. Such a supposition, however, would be erroneous. Freedom from care to anything like the extent that is common to most individuals of our own race tended to make Bantu females as well as males far happier on the whole than white people.

The women were quite as cheerful as the men, and knew as well as Europeans how to make their influence felt. In times of peace, after working in her garden a great part of the day, towards evening a woman collected a bundle of sticks, and with it on her head and a child on her back, trudged homeward. Having made a fire, she then proceeded to grind some soaked millet upon a quern, humming a monotonous tune as she worked the stone. When sufficient was ground, it was made into a roll, and placed in the hot ashes to bake. Meantime curdled milk was drawn by the head of the household from the skin bags in which it was kept, and the bags were refilled with milk just taken from the cows. The men made a hearty meal of the milk and the bread, with sometimes the flesh of game and different vegetable products, and after they had finished the women and children partook of what was left. Then the men gathered round the fire and chatted together, and the young people sat and listened to the stories told by some old woman till the time for sleep arrived. Different games were also played occasionally, but as the only artificial light was that of burning wood, they were usually carried on in the daytime.

At a very early age boys commenced trials of skill against each other in throwing knobbed sticks and imitation assagais. They enjoyed this exercise in little groups, those of the same age keeping together, for there was no greater tyrant in the world than a big lad over his younger fellows. Commencing 
with an antheap at a distance of ten or fifteen metres for a target, they gradually became so perfect that they could hit an object thirty centimetres square twice or even three times as far off. The knobbed stick and the imitation assagai were thrown in different ways, the object with the first being to inflict a heavy blow upon the mark aimed at, while that with the last was to pierce it. This exercise strengthened the muscles of the arms and gave expansion to the chest. The result was that when the boys were grown up they were able to use their weapons without any further training. When practising, they kept up a continual noise, and if an unusually successful hit was made the thrower uttered a cry of exultation.

Boys above the age of nine or ten years were fond of sham fighting with sticks. They stood in couples, each with a foot advanced to meet that of his antagonist, and with a cudgel elevated in the right hand. Each fixed his eye upon the eye of his opponent, and sought to ward off blows as well as to inflict them. In these contests pretty hard strokes were sometimes given and received with the utmost good humour.

A game of which they were very fond was an imitation hunt. In this, one of them represented a wild animal of some kind, a second acted as a hunter, and the others took the part of dogs in pursuit. A space was marked off, within which the one chased was allowed to take breath, when he was said to be in the bush. He tried to imitate as closely as possible the animal he was representing. Thus if he was an antelope he simply ran, but if he was a lion he stood and fought.

The calves of the kraal were under the care of the boys, and a good deal of time was passed in training them to run and to obey signals made by whistling. The boys mounted them when they were eighteen months or two years old, and raced about upon their backs. When the boys were engaged in any sport, one of the number was selected by lot to tend the calves. As many blades of grass as there were boys were taken, and a knot was made on the end of one of them. The biggest boy held the blades between the fingers and thumb of his closed hand, and whoever drew the blade with the knot had to act as herd. 
They had also a simple game called hide and look for; exactly like our own. As a training for the eye and hand nothing could be better than their method of playing with little round pebbles. Each boy had a certain number, which he threw into the air one after another, catching them on his hand by turns as they fell, and throwing them up again before any touched the ground. He who could keep the whole longest in the air was the winner. Or they would try who could keep the greatest number of pebbles in the air at once.

If they chanced to be disinclined for active exercise, they amused themselves by moulding clay into little images of cattle, or by making puzzles with strings. Some of them were skilful in forming knots with thongs and pieces of wood, which taxed the ingenuity of others to undo. The cleverest of them sometimes practised tricks of deception with pebbles. They were so sharp that although one was sure that he actually saw the pebble taken into the right hand, that hand when opened would be found empty, and it would be contained in the left, or perhaps it would be exhibited somewhere else.

The above comprised the common outdoor sports of boys up, to the age of fourteen or fifteen years. At that time of life they usually began to practise the different dances which they would be required to take part in when they became men. These dances differed from one another almost as much as those practised by Europeans.

The commonest indoor game of the extreme southern tribes at the present time is the iceya, but this is of Hottentot origin, so need not be described here. A game of Bantu children everywhere was the imfumba. One of the players took a pebble or any other small substance in his hands, and pretended to place it in the hands of the others, who were seated in a circle around him. He might really give it to one of them, or he might keep it himself. One after another then guessed in whose possession it was. A variation of this game was played by men in rows of holes in the ground, but it was much more complicated.

Another common indoor game of children was called cumbulele. Three or four little ones stood with their closed 
hands on top of each other, so as to form a column. They sang cumbulele, cumbulele, pangalala, and at the last la they drew their hands back sharply, each one pinching with his thumb nail the hand above.

Toys as playthings were few in number, and were almost confined to clay oxen, wooden darts, bows and arrows, and the nodiwu. This was a piece of wood about fifteen or twenty centimetres long, four or five centimetres wide, and a third or half a centimetre thick in the middle. Towards the edges it was bevelled off, so that the surface was convex, or consisted of two inclined planes. At one end it had a thong attached to it by which it was whirled rapidly round. The other end of the thong was usually fastened to a small round piece of wood used as a handle. The nodiwu, when whirled round, gave forth a noise that could be heard at a considerable distance. Besides the use which it was put to by the lads, when a little child was crying inside a hut, its mother or nurse would sometimes get a boy to make a noise with it outside, and then induce the child to be still by pretending that a monster was coming to devour it. There was a kind of superstition connected with the nodiwu, that playing with it invited a gale of wind. Men would, on that account, often prevent boys from using it when they desired calm weather for any purpose. It was much in evidence when the millet crops were ripening, and women and children were engaged from early dawn until darkness set in keeping the birds away. Little stages were then erected in the gardens, and on the appearance of a flock of finches each watcher shouted, clapped hands, whirled a nodiwu, or otherwise made as much noise as possible.

The form of greeting when people met varied greatly among the tribes. In the north clapping hands was the commonest form, accompanied by prostration of an inferior before a superior. "I see you" was the expression used by others on the coast. Among some of the interior tribes one person on meeting another asked the question "what are you eating?" and received as a conventional reply " nothing at all." In the south, on meeting a chief the salutation was " ah!" There was no general custom observed in this respect by all the branches of the Bantu family. 


\section{CHAPTER XIII.}

\section{Description of the Bantu (continued).}

THe language of the Bantu differed in construction from that of any European people. It was broken up into many dialects, which varied so much that the men of one group could not understand those of another. On analysing the words, it is seen that the roots used by the coast tribes and often the full words are the same as those of some of the dialects of Lower Guinea, which arises from their recent separation. Between the coast dialects and those of the interior the difference is not only in the words, but in some of the roots, while in the extreme case of the Tshikaranga - most of the roots vary from those of all others in the country. This follows from the ancestors of one group of tribes having taken to themselves females of a different race from those incorporated by another group. From the Arabs, Persians, and Indians who mixed their blood with that of the Bantu bordering on the eastern coast, words unknown to the peopie elsewhere were adopted. Such words would be so changed in sound as to be soon unrecognisable by those from whose language they were taken. As an instance, the Xosas call a horse ihashe, plural amahashe, which is the nearest approach to the sound of the English word that they can make, yet few Englishmen would recognise amahashe without a little thought.

But while the words, and even some of the roots, vary, the structure of the sentences is the same in all. The noun is the governing word in each sentence. There are classes of nouns, in some dialects more numerous than in others, and each class is distinguished by its prefix, whicb is changed to form the plural. Thus in the dialect of the Xosa 
The Bantu.

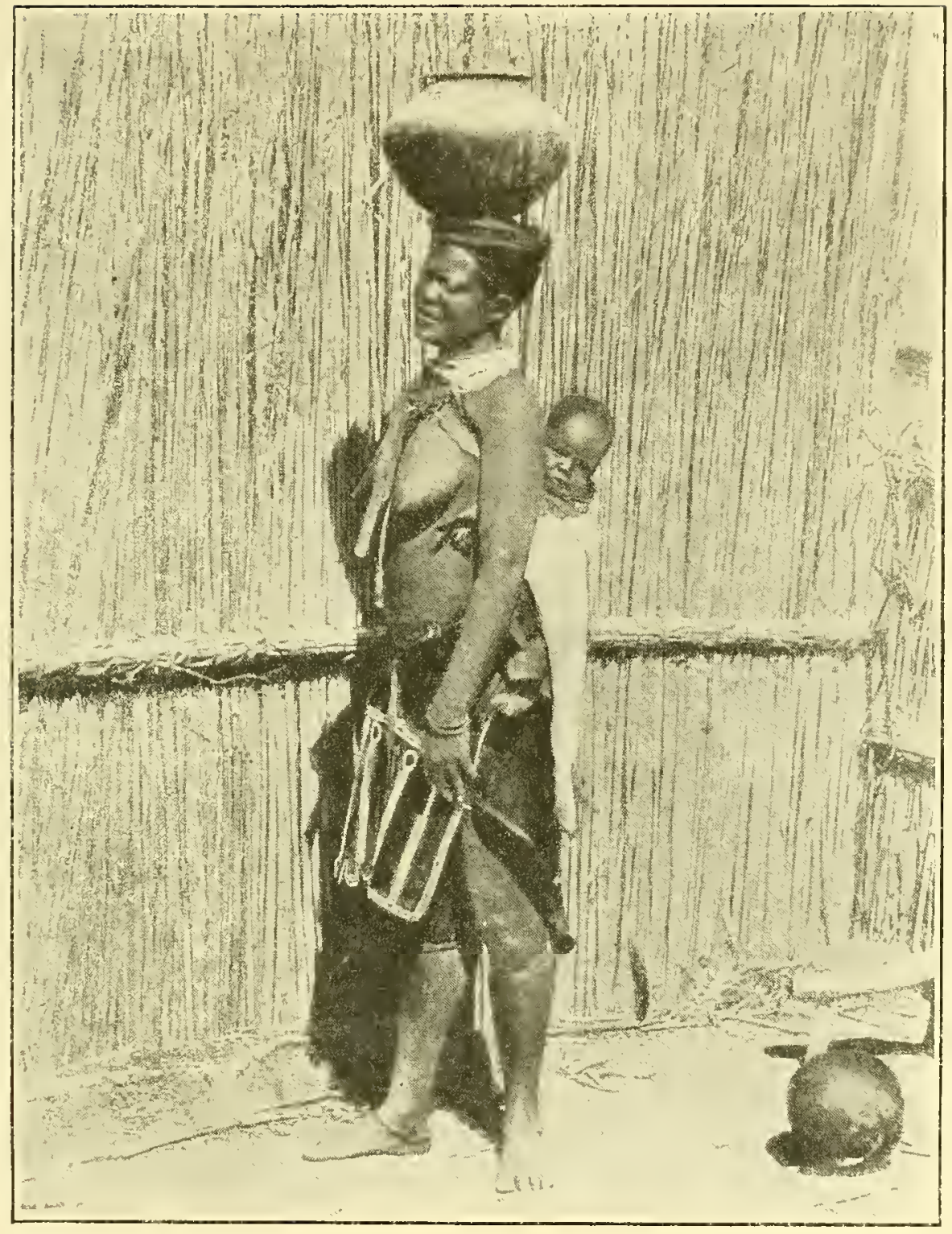

WOMAN OF THE BASUTO TRIBE. 
tribe in-doda, a man, ama-doda, men, um-fazi, a woman, aba-fazi, women, is-andla, a hand, iz-andla, hands.*

Here alone are six prefixes, and every adjective and every verb connected with one of these nouns must take before it a corresponding prefix, so that the other words in a sentence may agree with it in that syllable, as abafazi bané, women four, izandla ziné, hands four. Until this rule was discovered, a Bantu dialect could not be reduced to writing, and was regarded as formless, but now it can be studied as easily as French or German. Its system of notation is decimal, and is complete up to a very high number, but it is cumbersome for arithmetical purposes. The language has a very copious verb, and abstract nouns can be formed readily where they are not already in common use, so that any idea whatever can be expressed in it. As nearly every word ends in a vowel, and the enunciation of the people is clear and distinct, with the voice nicely modulated, the language is musical to the ear. Many individuals, especially among the chiefs and counsellors, display great ability in public speaking. In some dialects the sound of our $r$ is not heard, in others the sound of our $l$, in others again $r, l$, and $d$ are interchangeable. Dr. Bleek has pointed out that the language has close affinities with the Malayan, Papuan, and Polynesian tongues. When brought under European rule, the members of one tribe learn the dialect of another very quickly, as they do also English or Dutch, their power in that respect being like that of young white children.

Besides the change which takes place in all unwritten languages in the course of even a few generations, some of the tribes had a habit which hastened the variation, and therefore made intercourse between them more difficult. This was the

* As excellent grammars of various dialects, in which the medium of explanation is English, can be procured without difficulty, it is not necessary for me to give more than the very barest outline of the structure of the language in this chapter. Among the best of the grammars published at an early date are $A$ Grammar of the Zulu Language, by Rev. Lewis Grout, demi octavo, 432 + lii pages, London, 1859, and A Grammar of the Kaffir Language by the Rev. William J. Davis, demi octavo, 183 pages, London, 1872. Dr. Bleek's valuable Comparative Grammar of South African Languages has already been mentioned, 
hlonipa custom, by which women were obliged constantly to invent new words, in which the principal syllable of their husband's name or that of any of his male relatives in the ascending line was avoided, and as some of those words came into general use, the dialect had a tendency to change in a different manner from all others. This custom of hlonipa extended so far that if a stranger were to ask the daughter-in-law of the head of a kraal whose place it was, she was obliged to call some one else to tell him, as she could not pronounce his name herself.

There were clicks in only a few of the dialects spoken by the Bantu family. They were three in number, and were derived in the south chiefly from Hottentot, and elsewhere from Bushman sources. They were introduced by females who were spared when the hordes to which they belonged were conquered, as is evident not only from tradition, but from the words in which the clicks occur being chiefly those pertaining to the occupations of women.

The reverend J. L. Döhne, in the introduction to his ZuluKafir Dictionary, was the first to make known to English students a fact with which every one conversant with any Bantu dialect is now acquainted, that the language contains a considerable number of words whose roots are identical with those of words with the same or nearly the same meaning in other tongues. He gives a list of over forty akin to words in Hebrew, Arabic, Greek, Latin, English, Dutch, and German, though the identity of some of them is not very clear. Mr. I. Bud-M'belle, in the introduction to his excellent Kafir Scholar's Companion, published at Lovedale in 1903, gives a list of fourteen wordseleven of them verbs,--which have the same meaning and almost the same sound in Zulu as in English. Among them are ukubeta to beat, uku-kala to call (out), and uku-lala to lie (down). A gentleman long resident among the Xosas and Tembus occupied much time in making a similar list of Xosa and Latin words with the same roots, and he informed the writer that he had succeeded in obtaining over thirty. The early French missionaries in Basutoland were astonished to find the people there sacrificing to the Barimo, a word identical with Baalim, the $l$ 
in other dialects being often changed by the Basuto to $r$, and the noun requiring a vowel ending. How can these facts be explained? As to the last, the identity of words is probably accidental. The Barimo are the spirits of the dead, Baalim are forms of the sun god. The meaning is thus not the same. Then Barimo is found only in a highly specialised dialect of the Bantu language, and before any certainty can be arrived at, it will be indispensable to know what the primitive form was, that is the form in use by the original conquering band.

As for the numerous words with roots common to many languages, the only explanation that can be offered seems to be this. Taking the human species as of one origin, no matter where that origin may have been, there must have been a time, however remote, when all mankind, then a small community, used the same language. That language was probably very limited in words. Then a division of the people took place, when some migrated in one direction, some in another. Each section added new words to the old vocabulary to express new ideas, and each put the words together to form sentences in a different manner. Very soon there would be many distinct languages, varying from each other not only in the words used, but in grammatical construction. But is it not allowable to suppose that the original words common to mankind would be retained by all to express the same meanings, and that though modified and distorted, abraded in some instances, enlarged in others, many of these primitive words may have come down even to the present day in such a form that their identity can be recognised by diligent observation? Is it not possible at least that when a Zulu or a Xosa says ngena and an Englishman says enter, the on in both instances is a relic of a far-off age, when a little group of human beings, perhaps in Southern Asia, perhaps in some land now buried beneath the ocean waves, could look around in every direction without seeing others of their kind, and could claim the whole world. as their own?

Many of the proverbs in common use among all sections of the Bantu conveyed excellent practical lessons of prudence 
and wisdom. The following are a few of those collected by the writer when residing with the Xosas, and they might be extended to fill many pages :-

A brand burns him who stirs it up, equivalent to our English one Let sleeping dogs lie.

Like the marriage feast of Mapasa, used to denote anything unusually grand. The marriage festivities of one of the ancients, Mapasa by name, are said to have been carried on for a whole year.

Misfortune of soup made of shanks and feet, applied to any person who never does well, but is always getting into trouble. The kind of soup spoken of is very lightly esteemed.

One fly does not provide for another, a saying of the industrious to the idle, meaning that each should work for himself as the flies do.

Bakuba is far away, no person ever reached it. Bakuba is an ideal country. This proverb is used as a warning against undue ambition, or as advice to be content with that which is within reach. It is equivalent to our English saying It is no use building castles in the air.

They have slaughtered at Kukwane, where much meat is obtainable. According to tradition, there was once a very rich chief who lived at Kukwane, and who entertained strangers more liberally than any who went before or who came after him. This proverb is used to such persons as ask too much from others, as if to say: It was only at Kukwane that such expectations were realised.

It is not every one who is a son of Gaika. Gaika was at the beginning of the nineteenth century the most powerful chief west of the Kei. This proverb signifies that all are not equally fortunate.

I rejoice that Kolomba's mother is dead. The mother of Kolomba was, according to tradition, a very disagreeable person. This saying is used when anything that one dreads or dislikes has passed away.

You will shed tears with one eye like a monkey. A warning used to deter any one from being led into a snare of any kind. 
It is said that when a monkey is caught in a trap he cries, but that tears come out of one eye only.

It is the seed of the umya (a species of wild hemp). This saying is applied to any thing or person considered very beautiful. The seed referred to is like a small jet black bead.

$\mathrm{He}$ is ripe inside, like a water-melon. Said of any one who has come to a resolution without yet expressing it. From its appearance it cannot be said with certainty whether a watermelon is ripe or not.

You will find out what Hili of the Amambala experienced. This saying is applied as a warning to people to avoid doing wrong, lest the punishment of Hili overtake them. Hili, or Tikoloshe, is, according to the belief of the Xosas, a mischievous being who usually lives in the water, but who goes about as a human dwarf playing tricks upon people. He milks the cows when no one is watching them. He causes women to fall in love with him, for he is of a very amorous disposition towards the female sex. There are few Xosas even at the present day who doubt the existence of such a being. It is said that a long time ago there was a man of the Amambala who had good reason to suspect that his wife had fallen in love with Hili. He accordingly pretended to go upon a journey, but returned in the middle of the night and fastened his dogs at the door of his hut. $\mathrm{He}$ then went inside and kindled a fire, when, as he anticipated, he found Hili there. The man called his neighbours, who came with sticks and beat Hili till he was unable to move. They then tied him up in a bundle, fastened him to the back of the woman, and sent her away to wander wherever she liked.

A spy for both. Said of a talebearer.

The shield turned the wrong way. This saying is applied to any one who goes over from one party to another. It is a common expression for one who turns evidence against accomplices in crime.

It is a cob stripped of grain in an ashpit. Said of a worthless character.

You will prefer roasted meat. This saying is applied to any one who is boasting immoderately, as a warning that if he 
does not take care he will get into trouble, when he will be glad to take whatever comes to hand. He will prefer roasted meat because it is easily cooked, and he will have neither time nor means to boil it. This saying is also used as a threat, as if one said, I will punish you thoroughly.

Throats are all alike in swallowing. This proverb is used when one asks another for anything, and implies, if you do not give to me now, I will not give to you when I have anything that you would like a share of.

The people who rescue and kill. This saying is applied to Europeans. It first arose from the heavy demands made by Lord Charles Somerset upon the Gaikas in return for English protection, but the Xosas maintain that we have acted up to the description ever since. It is sometimes put in this form, The people who protect with one hand and kill with the other.

The coming of Nxele. This saying implies anything long expected, but which never occurs. Nxele (the lefthanded), or Makana, one of the most remarkable men that the Xosa tribe has produced, rose by his own merits from a private station to be the leader of the Ndlambe clans in the second decade of the nineteenth century. It was he who united them against the English when Lord Charles Somerset invaded their country with a view of compelling them to recognise a chief whom they detested. He led in person the attack upon Grahamstown, and only retreated after the flower of his forces was swept away. To obtain peace for his people, he voluntarily surrendered to the English troops, and was sent as a prisoner of state to Robben Island. In attempting to make his escape from the island in a boat, he was drowned. But the Xosas would not believe that Makana was dead, for they deemed him immortal. All through the wars of $1835,1846-7$, and 1851-2, they looked for his reappearance to lead them to victory. In 1872 his personal ornaments were still in preservation at a kraal near KingWilliamstown, but about that date the hope of his return was generally abandoned.

He has drunk the juice of the flower of the wild aloe. Said of a dull, sleepy person. This juice when drunk has a 
stupefying effect, and benumbs the limbs so as to make them powerless for a time.

The walls have come into collision, said of any dispute between persons of consequence.

A person who will not take advice gets knowledge when trouble overtakes him.

You have cast away your own for that which you are not sure of, equivalent to the English proverb A bird in the hand is worth two in the bush.

$\mathrm{He}$ is a buck of an endless forest, a saying applied to a shiftless person, one who never continues long in any occupation.

You are lighting a fire in the wind, said to any one who favours strangers in preference to relatives, or to their disadvantage.

There is no beast that does not roar in its den, meaning that a man recognises no superior in his own establishment. Equivalent to Every cock crows on his own dunghill.

A dog of the wind, a saying applied to any one who has no settled plan of living.

I, the adhesive grass, will stick fast to you. This proverb is used as a warning to any one to avoid a bad habit or an unworthy companion that cannot easily be got rid of.

The sun never sets without fresh news.

They are people of experience who do not sleep at a strange place, said in praise of one who is smart in going a message, or who performs any duty at a distance quickly.

The land is dead, a saying which implies that war has commenced.

One does not become great by claiming greatness, used to incite any one to the performance of noble deeds. It means that a man's actions, not his talk and boasting, are what people judge of his greatness by.

The wonderful and the impossible have come into collision. A saying applied to any intricate question.

The mist and the sun are together. A saying denoting a very great number. 
It is the foot of a baboon. A saying denoting a treacherous person.

We shall hear, we are on the side towards which the wind blows. This saying denotes, we shall soon know all that is going on.

He has gone in pursuit of the (fabulous) birds of the sea. A saying applied to one whose ambitious aspirations are not likely to be realised.

They prevent us from getting red clay from the pit, and they do not use it. This saying is used of Europeans, to derote that they act as the dog in the manger towards the Xosas. It has unfortunately become a very common expression.

You drink out of the old cup. The indebe is a drinking vessel made of rushes. The saying is used to a wealthy man, and means, you use a vessel handed down to you from your ancestors.

You are creeping on your knees to the fireplace. This saying is used as a warning to any one who is following a course that must lead to ruin. It is as if one said, you are like an infant crawling towards the fire-circle, who is sure to get burnt.

To skin a mouse. A saying which implies to do anything secretly. A mouse can be skinned without any one seeing it, but an ox can not.

It has stuck fast by one of the front legs. This saying is used when one has committed oneself to any natter of importance. An animal cannot extricate itself easily when fast by one of its front legs.

One who eats the remains of a meal without first obtaining permission. This saying is used of an uncalled-for expression of opinion.

You disturb monkeys on their way to drink. This saying is used to express uncalled-for interference.

It dies and rises like the moon. Said of any question that springs up again after it is supposed to be settled.

There is no wormwood that comes into flower and does not wither. A proverb descriptive of the life of man. 
The foot has no nose. This proverb is an exhortation to be hospitable. It is as if one said, give food to the traveller, because when you are on a journey your foot will not be able to smell out and avoid a man whom you have turned from your door, but to your shame it may carry you to his.

You have exposed yourself. This saying is applied as a warning not to give anything to an importunate person, as he would very likely be encouraged thereby to continue asking for more.

The crab has stuck fast between the stones at the entrance of its hole. Said of any one who is involved in difficulties of his own creation, or of one who raises an argument and is beaten in it.

He has fastened a dog to a shrub. This saying is used to denote a very greedy person, one who is so greedy as to fasten his dog to a shrub that the animal may not beg for food while he is eating. The shrub denoted is the very common one that is covered with yellow flowers at midsummer.

Guluwe's two of yesterday. This is a saying of any one who goes away promising to return, and does not do so. It had its origin in an event which happened six generations back. Guluwe was a hunter of great renown, who crossed the Kei with Khàkhábay, the great-grandfather of the late Sandile. No man was ever so skilful and successful in the pursuit of game as he. But when Khàkhábay took possession of the Amatola mountains, which he purchased from the Hottentot chieftainess Hoho, he found them infested by great numbers of Bushmen. One day Guluwe, who had two young men with him, killed an eland, but while he was still shouting his cry of triumph: "Tsi! ha! ha! ha! ha! the weapons of Khàkhábay!" he was surprised by a number of these inhuman abatwa. They said: "Look at the sun for the last time, you shall kill no more of our game." Guluwe offered them a large quantity of dacha for his ransom. One of the abatwa was unwilling to spare him, but all the rest agreed. They kept him with them while he pretended to send the two young men for the dacha, but privately he told them not to return. The Bushmen then commenced to eat the eland. They ate that day, and all that night, never ceasing to watch 
Guluwe. The next morning they asked him when the young men would be back with the dacha, and he replied that he did not expect them before sunset. The abatwa, gorged with meat, then lay down to sleep, all except the one who advised that Guluwe should not be spared. That one watched a little while longer, but at length he too was overcome by drowsiness. Guluwe then with his assagai put one after another to death, until, forgetting himself, he shouted his cry: "Tsi ! ha! ha! ha! ha! Izikali zika Rarabe!" This awakened the Bushman who had advised that he should be killed; he now sprang to his feet and escaped, calling out as he ran with the speed of the wind: "I said this Guluwe of the Khàkhábays should be destroyed; you who are dead have perished through not following my advice."

Of poetry the Bantu had a fairly rich store, but there was nothing particularly grand in it. It was chanted by men on special occasions, and consisted chiefly of adulation of chiefs, deeds of war, and actions of animals. Thus a favourite ox might have a chant in its praise. The war chants, in certain parts of which the whole of the men present joined, were certainly impressive, but those in ordinary use were monotonous and disagreeable to a European ear. All were distinguished by a note of sadness. These people, though their voices were rich and melodious, had no conception of such vocal music as we are accustomed to : they had neither rhymic hymn, nor song, nor glee. Their musical instruments were of the rudest kind, mostly calculated to make noise rather than melody, those in ordinary use being capable of producing only a monotonous thrumming sound. The best consisted merely of pieces of wood or iron for keys, with calabashes attached to them, arranged on stretched strings, and struck with a small round-headed cane, or of thin iron keys fastened over a gourd or hollow block of wood, and touched by the hand. Of these there were several kinds, but all were constructed on the same principle.

The description given in the preceding pages is that of the Bantu in general south of the Zambesi when Europeans first became acquainted with them at the beginning of the sixteenth 
century, and of the sections of their family when they arrived at a later date. It is also a description of a very large proportion of them as they are to-day, though the customs of many have been more or less modified by the authority or the influence of white people. With blood of such different origins in their veins, some are far more intelligent than others, but the opinion of those who have most to do with them now-four hundred years after their first contact with Caucasian civilisation-is that occasional individuals are capable of rising to a high standard, but that the great mass shows little aptitude for European culture.

In mission schools children of early age are found to keep pace with those of white parents. In some respects, indeed, they are the higher of the two. Deprived of all extraneous aid, a Bantu child is able to devise means for supporting life at a much earlier age than a European child. But while the European youth is still developing his powers, the Bantu youth in many instances is found unable to make further progress. His intellect has become sluggish, and frequently he exhibits a decided repugnance, if not an incapacity, to learn anything more. The growth of his mind, which at first promised so much, has ceased just at that stage when the mind of the European begins to display the greatest vigour.

Numerous individuals, however, have emerged from the mass, and have shown abilities of no mean order. A score of ministers of religion might now be named as earnest, intelligent, and devoted to their calling as average Europeans. Masters of primary schools, clerks, and interpreters, fairly well qualified for their duties, are by no means rare. One individual of this family has translated Bunyan's Pilgrim's Progress into the dialect of the Xosa tribe, and the translation is as faithful and expressive as any that have been made in the languages of Europe. Plaintive tunes, such as the converts at mission stations love to sing, have been composed by another for a considerable number of hymns and songs in the same dialect. Still another edits a newspaper, and shows that he has an intelligent grasp of political questions. One of the very best clerks the writer 
of this volume ever had was a Xosa who served him in that capacity when he was magistrate of a border district, and who was industrious, painstaking, and thoroughly trustworthy. But unfortunately these men are exceptions to the general rule, though it may be hoped that their number will increase as time goes on and the effect of education becomes more generally felt. As might be expected, they are very weak in everything that relates to finance, and are consequently incapable of conducting any but the simplest commercial transactions. The position of a merchant, or even of a large storekeeper, is quite beyond them, for they would not be able to calculate profit or loss.

As mechanics they do not succeed very well, though an individual here and there shows an aptitude for working with iron. No one among them has invented or improved a useful implement since white men first became acquainted with them. And the strong desire of the greater number is to live as closely like their ancestors as the altered circumstances of the country will permit, to make use of a few of the white man's simplest conveniences and of his protection against their enemies, but to avoid his habits and shut out his ideas. Compared with Europeans, their adults are commonly children in imagination and in simplicity of belief, though not unfrequently one may have the mental faculties of a full-grown man.

As this is a matter of great importance for the future of South Africa, the opinions of the most competent men in the country, as supplied by them in evidence before a committee of the parliament of the Cape Colony appointed in 1908 to investigate the question of the education of these people, are given here: *

\section{Dr. Thomas Muir, C.M.G., LL.D., M.A., F.R.S., Superintendent General of Education in the Cape Colony.}

Question. You could not express an opinion as to the theory which is often advanced about the inability of the native $\uparrow$ to go beyond a certain stage in mental development?

* Report of the Select Committee of the House of Assembly of the Cape Colony on Native Education. Demi octavo, 709 pages, Capetown, 1908.

$\dagger$ By native an individual belonging to the Bantu family is meant throughout these inquiries. 
Answer. Yes, I think I have had evidence of that. With boys who become pupil teachers it is noticeable that when they reach a certain stage of development their mental growth rather comes to a stop.

$Q$. Does that apply to girls also, or not so much?

$A$. I have not the same experience in reference to girls, but if you compare a white boy and a coloured boy from the ages of twelve onwards you will find that a white boy goes on growing mentally, whereas a coloured boy seems for a while almost to come to a stop. I believe there are physiological reasons given for it.

Q. You believe that is really the essential thing in the physiology of the native?

$A$. Yes. There are exceptions.

Q. Do you think the evidence on this point has advanced so far that we can say it is established?

$A$. If you take the case of writers on Kafirs, you will find it considered an established thing. I only notice it in connection with examinations that there is not that rapid growth over twelve years of age that you have in the early stages, and more especially in reference to anything requiring initiative-that a native has very considerable imitative powers, and those parts of his education that call upon the imitative powers make progress, whereas those requiring real fresh thought or initiative do not.

$Q$. You see no reason for thinking that the system of education is in any way responsible for that, or for thinking that some improved system might remedy that defect?

$A$. I do not think so; I think it is inherent.

Q. Going back to the opinion you expressed about the mental growth seeming to stop at the age of twelve years or thereabouts, do not you think it is to a very large extent a question of their home life and environment? Up to that age their education would consist very largely of all matters with which they have come into contact in their home life ?

A. Yes.

Q. When they begin to get beyond a certain stage they go away from questions that they come into daily contact with, and come, as it were, into a foreign world, so that they are there, as it were, with nothing that they can lay hold of. It is all a new field to them, and therefore they are at a disadvantage to European 
children, to whom that is not a foreign field, owing to their contact with it in their life?

$A$. I think that is quite possibly a partial explanation; and then it must be remembered, too, that the African who has settled in the United States of America does not show that to any appreciable extent. Whether it is the difference in the surroundings in America during these generations or not I do not know, but there are plenty of American negroes who progress in mental development steadily as a European does.

Q. Do you hold there is an inherent lack of capacity beyond that?

$A$. Not an inherent lack of capacity; I would not say that, because one cannot very well judge of that. When I said there was something inherent, I meant it was more of a physiological reason than anything else.

$Q$. Do you mean unalterable?

$A$. It would be alterable under different circumstancesdifferent surroundings.

Q. But then would it not be incorrect to say it is physiological ?

$A$. I do think it is connected with physiology.

Q. I did not quite understand you to say that they stopped in mental development, but that they were slower?

$A$. Yes, that is the point: they do not stop; they simply do not progress at the same rate.

Q. The evidence you have given as regards America would rather militate against the statement that it is dependent upon physiology, would it not?

$A$. Not quite; because I do not say if they were brought under totally different circumstances their bodily habits and so forth would not be affected to the same extent.

Q. So that if we continued our present line of education, especially in parts of the country where the natives do not continue to live in their kraals, it is quite possible that in a century or two that race might not be so backward?

$A$. That is exactly what I wanted to suggest by bringing forward the case of America.

Mr. Newton Ogitvie Thompson, Resident Magistrate of Kentani.

Q. With regard to the actual teaching and the effects of education, we have had evidence on the question whether the 
native mind is specially limited and unable to progress beyond a certain age. Have you any opinion upon that question?

A. Well, I had the idea myself that the native mind was not limited, and with proper teaching would be able to go on, and on making inquiries they lead to the confirming of those conclusions. I have often heard the question discussed, but I have never heard it conclusively proved to my own mind.

$Q$. That is just your opinion?

A. I still think so.

Q. And it is an opinion which is not only a theoretical opinion, but which squares with your experience of the natives?

$A$. Yes, as far as my experience goes.

Q. But is it not a fact that with many of the educated natives there is a want of initiative?

$A$. Yes, there is, but then of course one cannot expect that it should be otherwise. If one looks back and counts time, as you would do in the history of a people, I do not think we can expect any very great results at this day.

$Q$. You ascribe that defect to the fact that the native starts a long way behind?

$A$. Yes.

Q. Do you think the environment of native home life has a considerable effect in that way?

A. Oh yes, I do think so. Now, for instance, I think the rising generation and the next generation will lend itself more to education than the past generation, because of the parents in their home life, and the conversation and everything, and the education that they are getting will help matters.

The reverend William Charles Willoughby, Principal of the Tigerkloof Native Institution in Betshuanaland.

$Q$. You say that the Betshuana are lacking in intelligence as compared with English people. Do you think their civilisation has advanced far enough for us to be able to say that it is a radical defect or is it perhaps curable?

A. I do not think I quite said he was lacking in intelligence : I should say his intelligence is of a different order. In many cases he excels us ; in many others-and those we are apt to think most essential to civilisation-he is most distinctly our inferior. 
Q. Is that due to something ineradicable, or is it due to circumstances and surroundings?

$A$. I dare say environment has a very great deal to do with it. It is very difficult to say physiologically how much hereditary influence and environment respectively have to do with the peculiar twist of a native's mind, or of a tribal mind. I dare say if one studied it carefully one would come to the conclusion that it is more generally due to environment than anything else. At the same time, the true capacity of the native mind is just now occupying the attention of a good many scientists. Statistics are being prepared in the Soudan, and especially the age at which the fissures of the skull close up is being studied, and we may have some light on that in a few years: I do not think we have any now.

Q. As far as you have seen, does the native in the district with which you are acquainted stop developing in a remarkable way at a particular standard?

$A$. Yes; natives in school, you mean.

Q. Does he develop faster in the lower than in the higher standards?

A. Yes. I should say upon the whole the advantage is in favour of the lower standards. ... It is a fact that the lower standards are easier in proportion than the higher standards. I have not seen anything along the lines of your question to lead me to the conclusion that there is any cessation of growth in the native mind. I have watched it, as the question is being asked in a good many quarters, and I have seen nothing at all that enables me to make any dogmatic statement on the subject.

Q. Have you found them (big boys) quick to learn in these directions (building with stone, bricks, and wood)?

$A$. Of course there is considerable difference between them, as between all other boys. They are very quick to learn to a certain point, but when you get to the point needing more care and exactness a certain number are almost unable to appreciate it. About one-third seem to stick at that point. They can all do a certain 'amount of rough work, and then in anything a little finer you lose about a third of your class as far as advance is concerned.

Mr. James M'Laren, M.A., Inspector of Schools in Fingoland.

$Q$. Do you think that the natives show a capacity for advance at the higher standards as much as at the lower standards? 
A. A capacity to benefit by instruction in the higher standard ?

Q. Yes.

$A$. I have been very much surprised to find how many of my teachers were able successfully to teach Standard V and Standard VI, and how well the pupils, on the whole, were able to meet the requirements of these standards.

$Q$. It is sometimes said that the native mind is incapable of advancing beyond a certain very limited standard. Have you found that so in your experience?

$A$. No, not in the elementary school course, up to Standards IV, V, and VI, but I find that the children of the second and third generations of civilised natives are considerably more intelligent than the children of the raw natives; that is to say, the children of men who have been brought up in an atmosphere of civilisation have much less difficulty in appreciating the work of the higher standards than the ordinary native child has.

Q. From that you would be inclined to infer that any want of intelligence there may be is due to environment and circumstances quite as much as to any physiological difference?

$A$. I think it is due to heredity - that the child of the civilised parent actually acquires at birth some slightly improved mental capacity.

Q. It is heredity which only depends on the parents; it does not depend on the race? If the parents are civilised the children will be born civilised, so to speak, according to your theory?

$A$. If the parents have been educated I think the children are born with a rather better intelligence.

$Q$. So even if you take a raw native, if you educate him his child will have a better chance?

A. Certainly.

\section{Reverend James Henderson, Principal of Lovedale Missionary Institution.}

Q. Have you seen any reasons to suppose that the native is constitutionally incapable of developing beyond a certain stage, as is sometimes stated?

$A$. There is, I think, a great deal of what one might call "cant" written and spoken about natives, and one of the doctrines of this cant is about native boys and girls at the age of puberty. At the age of puberty, on general grounds, we should expect that 
pupils would show increased mental activity and greater capacity for responsibility. Now, it is impressed upon us, as if it were an established fact, that the average native at that age goes back - that that is the critical period of his development, and in the great majority of cases it is the point at which his advancement ceases. Now, this degeneration at puberty is not an established fact. Experienced men I have come in contact with do not recognise that there is this break in development at puberty. What does happen is that in European and native schools-I am not aware in native schools any more than in European schoolsthere is a small percentage of pupils who from that date do not make normal progress, but I do not think the number is any greater in native schools than in European schools. What does occur in native schools is this. When pupils-and this is a much more serious problem in the newer fields than in districts of the country which have long been under the influence of civilisation -begin school-work at the age of ten or twelve they are liable to come to a dead-stop later on, and probably more so beginning later on ; it is more marked with pupils beginning, in many cases, after puberty. In these new fields we have grown-up men and grown-up women coming for education. Now, what has repeatedly been the experience in regard to these is that when education has been pressed with these people grown beyond mere boyhood or girlhood there has been a liability to mental trouble; the pupils become saturated and incapable of mental effort, and in some cases a form of temporary insanity appears.

\section{Reverend Canon Cyril Edwin Earl Bulwer, Principal of an Institution for training Native Teachers.}

Q. Is there steady progression, or do they come to a point at which they seem to stop?

A. Individual children?

Q. Take the average.

A. It depends so much on the age. We find the young boys especially are very sharp, and go right to the end of their course without a break. If a boy comes at the age of nineteen or twenty in Standard IV or V it is very rarely that he will get beyond the first year. They seem above that age to have come to the end of their intelligence, and get very dull and heavy. We always encourage the younger boys; they seem much more successful. 
Q. What is your explanation of this?

A. It is hard to say. I think it is a natural dullness which comes to this kind of native character. They begin to think about different things more than their school work, I think. You know what they are. They think of getting marricd, and leaving school, and so on, and it seems to affect their brains in some way, so that they get very dull and heavy at that age.

Reverend David Duncan Stormont, M.A., B.D., L.C.P., LL.B., Principal of Blythswood Missionary Institution.

Q. Is there anything in the theory that a native child seems to lack capacity for development when he gets to a certain age, say about twelve or thirteen years?

A. Well, I examined that question practically many years ago, and I have not examined it recently: I find your age is wrong, but there is something in the theory. The stop in development comes later. It may come at seventeen; it may not come till twenty-one. But, speaking from my enquiries made practically a dozen years ago, I should say when the sexual feelings begin to be very powerful, especially in the men, the moral and intellectual faculties degenerate, as we would say, and if the native gives way to the sexual feeling he is gone.

Q. That would apply also to a European?

$A$. The surroundings of the European save him from collapse, and then I believe the sexual feelings, physiologically and psychologically, come later in Europeans than natives.

Q. You mean the native gives way altogether?

A. And they come earlier with him.

Reverend Richard Fraser Hornabrook, Governor of the Wesleyan Training Institution, Healdtown.

Q. Have you, in your experience, seen any reason to suppose that the native mind is incapable of advancing beyond a certain stage?

A. No.

Q. You think the opinions which are sometimes expressed with considerable confidence on this subject are not warranted, according to your experience?

$A$. I think not. 
Dr. Neil Macvicar, M.D., D.P.H., Medical Officer to the Lovedale Mission.

I should like to say that my experience does not in any way support the theory put forward by some writers that the native's mental development is arrested at pubcrty. I know that at Blantyre many of the highest boys in school were from seventecn to twenty years of age. And the same is the case in Liovedale. There are some native boys, it is true, who fall into evil habits at that age, and so injure their health. But this happens even at the best English public schools. Such boys in an institution like Lovedale are a trifling minority, perhaps five per cent of the whole number of big boys. The others, the great majority that is, at the age in question throw themselves into their lessons with increasing earnestness. At a later age, about twenty-three or twenty-four, I have noticed some native young men suffering from mental exhaustion. I attribute this partly to the long number of years some of these boys had been at school, but chiefly to the fact that they were carrying on all their studies in a difficult foreign language which even the most intelligent among them understood very imperfectly.

Reverend William Allerton Goodwin, who had been nine years Principal of the Training College, Umtata, and five years doing similar work in Natal.*

Q. Will you tell us how the Zulus compare in intelligence with the Europeans; taking the raw native at the age of twclve and educating him properly, how would he compare with the white boy?

$A$. In subjects like arithmctic, reading, or writing, he will be equal to any European, but if you put him to anything that requires abstract thought, he is absolutely beaten. Furthermore, he has no power, as far as I have known, of initiative. He is a splendid pupil, but is no good at all as a master.

Q. He does not realise, for instance, in argument, that he has been beaten?

$A$. I do not think so, in abstract matters. He is a past master in arguing concrete facts, but he has no idea of abstract reasoning.

* This gentleman's evidence was not given before the Committee on Native Education, but on the 12th of May 1904 before the Native Affairs Commission. See Report of the South African Native Affairs Commission 1903-5, with Minutes of Evidence. Five Foolscap folio volumes, together 3979 pages, Capetown, 1904-5. 


\section{CHAPTER XIV.}

\section{Specimens of Bantu Foliklore.}

Among a people without knowledge of letters, legends and traditional tales occupy the same place as books with Europeans, and thus form perfect guides as to their powers of expression and thought. The greater part of the folklore of the Bantu was neither of a moral character, nor did it convey any useful lessons. The actors in it were animals that spoke as human beings, persons who were bewitched and compelled to appear as beasts, individuals with magical powers, fantastic creatures, imps, cannibals, young chiefs, girls, \&c., \&c. There was nothing that led to elevation of thought in any of these stories, though one idea, that might easily be mistaken on a first view for a good one, pervaded many of them: the superiority of brain power to physical force. But on looking deeper it is found that brain power was always interpreted as low cunning; it was wiliness, not greatness of mind, that won in the strife against the stupid strong. Such an idea was in full accord with the life of the people, and it may have been on this account that the tales were so much liked.

Where force is directed as mercilessly as it is among brutes, the weak were compelled to scheme against the strong. The little boy, who lived in constant terror of larger ones, the woman, who was the drudge, not the companion, of her husband, the petty clan, that felt the exactions of a powerful neighbour, all were obliged to scheme, and no people on earth ever learned the art of deception more thoroughly than the Bantu. Thus these traditional tales, many of which must have been those of the original or parent band of the Bantu, as they are found with little variation among tribes using dialects that are not 
understood by each other, gave a large amount of pleasure to those among whom they passed current, though to European minds there is nothing amusing or interesting in them. Readers must bear in mind that full-grown men and women who have never been under European influence really believe many of the actors in these tales to have had an existence, so that they are not merely stories to amuse children.

The tales which follow, with two exceptions, were collected by the author of this volume from individuals of the Xosa tribe nearly forty years ago, and were revised for him by ancient dames to whose ears they were familiar. They are not indeed exact literal translations, but they are as nearly such as they could be made while at the same time they were put into English that can be easily read and understood. The original of the first one is given, as a specimen of the language.

\section{INTSOMI KA NYOKALIDE.}

Yati intombi etile yemka kowayo yaya emzini ka Nyokalide. Ifikileke kulomzi ka Nyokalide yahlala kona, kodwa engeko umninimzi. Kupela umntu okoyo kulomzi ingunina.

Kute ngokuhlwa unina ka Nyokalide wanika lentombi amazimba ukuba iwasile. Emveni kokuba iwasilile yenze isonka. Sati sakuvutwa wati unina ka Nyokalide " yisa esisonka kulandlu ka Nyokalide."

Kuteke kusemzuzwana lentombi ingene kulendlu wafika umninimzi. Yaza yamnika isonka namasi, wadlake. Bate bakugqiba ukudla baya kulala. Kute kusasa wemka u-Nyokalide, ngokuba emini uhlala endle.

Ite ke nentombi yaya kokwayo. Waza unina ka Nyokalide wayivatisa ngengubo ezinhle kakulu. Emveni kokuba ivatisiwe ite yabiza izembe yaya kuteza inkuni. Ifikileke endle ayigaulanga zinkuni, kodwa isuke yalilahla izembe yazimela yaya kowayo.

Kute kwakuba ifikele kowayo udade wayo ubuzile ukuba ezingubo zinhle uzitatepina. Udade wayo uyixelele, yati ke " nam ndiyaya kulomzi."

Uteke udade wayo, "ngaupulapule ndikuxelele isimo salomzi." Kodwake udade wake ukupendula, "andifuni ukuba undixelele nto ngokuba nawe akuzange uyalwe mhla wemka." 
Uhambile ke kwaoko waya kufika ngokuhlwa kulomzi ka Nyokalide. Kuteke isahleli unina ka Nyokalide wayinika amazimba ukuba mayiwasile yenze isonka. Site sakuvutwa wasisa endlwini ka Nyokalide. Kute ngokuhlwa wafika umninimzi, yaza intombi leyo yamnika isonka namasi. Kute bakugqiba ukudla baya kulala, kute kwakusa wemka u-Nyokalide.

Yaza intombi yaya kokwayo. Unina ubuye wayivatisa lentombi kwanjengokuba ebeyivatisile enkulu. Iteke yaboleka izembe yayakuteza inkuni. Kantike yenza iqinga lokuzimela.

Kuteke namhla indoda yabaputuma abafazi bayo, yayakufika xa litshonayo ilanga ebukweni.

Bamkwelela indlu umyeni yokulala. Kute xa adlayo abantu balomzi bafumbela izitungu zenca watshiswake nendlu umyeni. Wafake ngokunjalo.

\section{Story of Long Snake.}

Once upon a time a certain girl left her father's place and went to the village of Long Snake. Having arrived at the village of Long Snake she remained there, but the owner of the place was absent. The only person present was the mother of the owner of the place.

Then in the evening the mother of Long Snake gave that girl some millet that she might grind it. After it was ground she made bread. When it was ready the mother of Long Snake said, "bring this bread into the house of Long Snake."

A short time after that girl went into the house the owner of the place arrived. Then she gave him bread and fermented milk,* and he ate. When they had finished the food they went to sleep. Then early in the morning Long Snake went away, because in the daytime he lived in the open country.

The girl went to the house of the parents of Long Snake. The mother of Long Snake clothed her with a very beautiful robe. After she was dressed she called for an axe and went to cut firewood. Having arrived in the open fields she did not cut the firewood, but she threw away the axe and ran to her father's place.

After she arrived at her father's place her sister enquired where she had got that beautiful robe. Her sister told her, and she said "I am also going to that village."

* It is not in accordance with Bantu custom for a girl to serve out amasi or fermented milk to a man, but in this case the circumstances were exceptional, 
Her sister said, "just listen to what I tell you of the custom of that village." But her sister said in reply, "I do not want you to tell me anything because you yourself were not warned before you went."

Then at once she journeyed and went until she arrived in the evening at the village of Long Snake. When she sat down the mother of Long Snake gave her millet that she might grind it and make bread. When it was ready she took it into the house of Long Snake. Then in the evening the owner of the place arrived, and the girl gave him bread and fermented milk. When they had finished eating they went to sleep, and early in the morning Long Snake went away.

Then the girl went to the house of Long Snake's parents. His mother also clothed that girl in the same manner as she had dressed the elder one. Then she borrowed an axe and went to cut fuel. In doing so she made an excuse to run away.

On this day however the man went after his wives, and arrived at his father-in-law's place as the sun was setting.

They went out of the house that the bridegroom might sleep in it. While he was eating, the people of the village piled up bundles of grass, and the bridegroom was burned in the house. In this manner he died.*

\section{Story of Little Red Stomach.}

There was, in times of old, a certain boy by the name of Little Red Stomach. On a certain day that boy went to till the ground. While he was hoeing he became thirsty, and accordingly he went to drink water out of a pool.

Then suddenly his mother came, and said, "do not drink that water, because you do not know the owner." He said, "I will drink." Then his mother answered and said, "you will be killed by the owner of the water." "I do not care, because I will die alone," he replied. Then his mother said, "I will go away when you drink this water."

Accordingly his mother went away. Little Red Stomach then drank. "Why is it that you have drunk my water? Did

* This story is one of a class very common among the Bantu, in which a man assumes the outward form of an inferior animal, and while partaking partly of the nature of the beast, still retains the faculties of a human being. Usually the man has been bewitched by an enemy, and is ultimately restored to his human form by a kiss from a devoted maiden. 
not your mother tell you not to drink of this water ?" said the owner of the water. "I will kill you, because your mother told you that you were not to drink this water," said the owner of the water often.

After this, Little Red Stomach closed his eyes, and was swallowed by this beast. The beast then went away to the place where it lived, in a large pool of water. When the beast reached that pool of water, he remained outside of it, on account of the weight of his stomach.

When this beast had thus remained a while, a large frog came up out of the pool, and said, "did I not tell you that you must not swallow that person who drinks your water, because you will die and then we shall have no one to take charge of us?" After this frog had so spoken, he sank down there, in the pool of water.

About sunset that animal said, "I have a stomach ache." As it was so, all the animals collected at that pool of water, and he said, "pay attention to the thing that I tell you." Then all the little animals that lived in that pool of water paid attention. $\mathrm{He}$ said, "all of you are left here without a friend." Then accordingly they all went away to their friends.

After they had all gone away, this animal died. But Little Red Stomach was still alive in the stomach of the animal. He pulled out his knife, and cut open the stomach of the animal, and came out. When he had come out, he went home.

Having arrived at his home, he said to his mother, "did I not tell you that I would not die?" "I did not know, my child, that you had a plan of safety," said his mother. Then Little Red Stomach remained at the village of his parents.

\section{Story of Five Heads.}

Once upon a time two girls were going to dig wild carrots. One of them said, "I will not go." "Why is it that you are unwilling to go with me?" asked the other girl. She answered, "I want to be married to Five Heads." "As you say so, tell father," said the other girl.

Then, after that, she went away to the village of Five Heads. When she arrived, the man in charge of that village inquired where she came from? Accordingly she told where she came from, and what her business was at the village of Five Heads. Then a little old woman went away and told the mother of Five 
Heads what was said by the strange girl. When the mother of Five Heads heard that, she went and brought the girl into his house. She took a mat and spread it on the ground. Then, in the evening, Five Heads arrived from hunting.

She asked that person, "where do you come from?" His mother said, "ask of her." Accordingly Five Heads asked her where she came from. The girl told him why she had come to his village. Then said Five Heads, "before I marry you, I will send a message to your father, that you may know you are allowed by him to be married to me." That girl agreed that the message should be sent. An answer was returned that they had no objection, if the girl loved that person.

Accordingly Five Heads said to the people of his village, "are you willing that I should marry this girl?" They were willing. He gave for her twenty head of cattle. The ikazi was sent to the father of the girl. The parents were very well satisfied. There came a message to the effect that they were very well satisfied. After a while that girl was made the great wife at the village of Five Heads.*

\section{A more complete Story of Five Heads.}

There was once a man living in a certain place, who had two daughters big enough to be married. One day the man went over the river to another village, which was the residence of a great chief. The people asked him to tell them the news. He replied that there was no news in the place he came from. Then the man inquired about the news of their place. They said the news of their place was that the chief wanted a wife.

The man went home and said to his two daughters: "which of you wishes to be the wife of a chief ?" The eldest replied: "I wish to be the wife of a chief, my father." The name of that girl was Mpunzikazi. The man said: " at that village which I visited, the chief wishes for a wife; you, my daughter, shall go."

The man called all his friends, and assembled a large company to go with his daughter to the village of the chief. But the girl

* Five Heads, literally Heads Five,-Makanda Mahlanu--appears frequently in stories told by the coast tribes. He was a chief who was bewitched and obliged to assume the form of a monstrous snake with five heads, but was restored to his proper appearance by the devotion of a girl. 
would not consent that those people should go with her. She said : "I will go alone to be the wife of the chief." Her father replied: "how can you, my daughter, say such a thing? Is it not so that when a girl goes to present hersclf to her husband she should be accompanied by others? Be not foolish, my daughter." The girl still said : "I will go alone to be the wife of the chief." Then the man allowed his daughter to do as she chose.

She went alone, no bridal party accompanying her, to present herself at the village of the chief who wanted a wife. As Mpunzikazi was in the path, she met a mouse. The mouse said : "shall I show you the way?" The girl replied: "fust get away from before my eyes." The mouse answered: "if you do like this, you will not succeed." Then she met a frog. The frog said: "shall I show you the way?" Mpunzikazi replied: "you are not worthy to speak to me, as I am to be the wife of a chief." The frog said : "go on then ; you will see afterwards what will happen." When the girl got tired, she sat down under a tree to rest. A boy who was herding goats in that place came to her, he being very hungry. The boy said: "where are you going to, my eldest sister?" Mpunzikazi replied in an angry voice: "who are you that you should speak to me? Just get away from before me." The boy said: "I am very hungry; will you not give me of your food?" She answered: "get away quickly." The boy said : "you will not return if you do this."

She went on her way again, and met with an old woman sitting by a big stone. The old woman said: "I will give you advice. You will meet with trees that will laugh at you: you must not laugh in return. You will see a bag of thick milk: you must not eat of it. You will meet a man whose head is under his arm : you must not take water from him." Mpunzikazi answered: "you ugly thing! who are you that you should advise me?" The old woman continued in saying those words.

The girl went on. She came to a place where were many trees. The trees laughed at her, and she laughed at them in return. She saw a bag of thick milk, and she ate of it. She met a man carrying his head under his arm, and she took water to drink from him.

She came to the river of the village of the chief. She saw a girl there dipping water from the river. The girl said: "where 
are you going to, my sister?" Mpunzikazi replied: "who are you that you should call me sister? I am going to be the wife of a chief." The girl drawing water was the sister of the chief. She said: "wait, I will give you advice. Do not enter the village by this side." Mpunzikazi did not stand to listen, but just went on.

She reached the village of the chief. The people asked her where she came from and what she wanted. She answered: "I have come to be the wife of the chief." They said: "who ever saw a girl go without a retinue to be a bride?" They said also : "the chief is not at home; you must prepare food for him, that when he comes in the evening he may eat." They gave her millet to grind. She ground it very coarse, and made bread that was not nice to eat.

In the evening she heard the sound of a great wind. That wind was the coming of the chief. He was a big snake with five heads and large eyes. Mpunzikazi was very much frightened when she saw him. He sat down before the door and told her to bring his food. She brought the bread which she had made. Makanda Mahlanu (Five Heads) was not satisfied with that bread. He said : "you shall not be my wife," and he struck her with his tail and killed her.

Afterwards the sister of Mpunzikazi said to her father: "I also wish to be the wife of a chief." Her father replied: "it is well, my daughter ; it is right that you should wish to be a bride." The man called all his friends, and a great retinue prepared to accompany the bride. The name of the girl was Mpunzanyana.

In the way they met a mouse. The mouse said: "shall I show you the road?" Mpunzanyana replied: "if you will show me the way I shall be glad." Then the mouse pointed out the way. She came into a valley, where she saw an old woman standing by a tree. The old woman said to her: "you will come to a place where two paths branch off. You must take the little one, because if you take the big one you will not be fortunate." Mpunzanyana replied: "I will take the little path, my mother." She went on. Afterwards she met a coney. The coney said: "the village of the chief is close by. You will meet a girl by the river : you must speak nicely to her. They will give you millet to grind: you must grind it well. When you see your husband, you must not be afraid." She said : "I will do as you say, coney." 
In the river she met the chief's sister carrying water. The chief's sister said: "where are you going to?" Mpunzanyana replied: "this is the end of my journey." The chief's sister said: "what is the object of your coming to this place?" Mpunzanyana replied: "I am with a bridal party." The chief's sister said: "that is right, but will you not be afraid when you sce your husband?" Mpunzanyana answered: "I will not be afraid."

The chief's sister pointed out the hut in which she should stay. Food was given to the bridal party. The mother of the chief took millet and gave to the bride, saying: "you must prepare food for your husband. He is not here now, but he will come in the evening."

In the evening she heard a very strong wind, which made the hut shake. The poles fell, but she did not run out. Then she saw the chief Makanda Mahlanu coming. He asked for food. Mpunzanyana took the bread which she had made, and gave it to him. He was very much pleased with that food, and said: "you shall be my wife." He gave her very many ornaments.

Afterwards Makanda Mahlanu became a man, and Mpunzanyana continued to be the wife he loved best.

\section{Story of the Bird that Made Milk.}

There was once upon a time a poor man living with his wife in a certain village. They had three children, two boys and a girl. They used to get milk from a tree. That milk of the tree was got by squeezing. It was not nice as that of a cow, and the people that drank it were always thin. For this reason those people were never glossy like those who are fat.

One day the woman went to make a garden. She began by cutting the grass with a pick, * and then putting it in a big heap. That was the work of the first day, and when the sun was just

* Ikuba, a pick or hoe. Before the advent of Europeans, the largest implement that was made was this instrument for breaking up the ground. It was of nearly the same shape as a European hoe; but in platce of having an eye, into which a handle could be fastened, it was made with a top like a spike, which was driven into the large knob of a long and heavy club. It was at best a clumsy tool. Among the Bantu of the coast the work of cultivating the ground fell entirely upon the women in olden times. The introduction of the plough has caused a change in this respect, but to the present day the planting and weeding are performed by females. 
about to set she went home. When she left, there came a bird to that place, and sang this song:

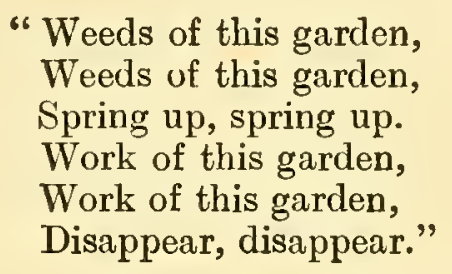

It was so. The next morning, when she returned and saw that, she wondered greatly. She again put it in order on that day, and put some sticks in the ground to mark the place. In the evening she went home and told that she had found the grass which she had cut growing just as it was before. Her husband said: "how can such a thing be? You were lazy and didn't work, and now tell me this falsehood. Just get out of my sight, or I'll beat you."

On the third day she went to her work with a sorrowful heart, remembering the words spoken by her husband. She reached the place, and found the grass growing as before. The sticks that she stuck in the ground were there still, but she saw nothing else of her labour. She wondered greatly. She said in her heart, "I will not cut the grass off again, I will just hoe the ground as it is." She commenced. Then the bird came and perched on onc of the sticks. It sang :

"Citi, citi,

Who is this cultivating the ground of my father ?

Pick, come off,

Pick handle, break,

Sods, go back to your places."

All these things happened. The woman went home and told her husband what the bird had done. Then they made a plan. They dug a deep hole in the ground, and covered it with sticks and grass. The man hid himself in the hole, and put up one of his hands. The woman commenced to hoe the ground again. Then the bird came and perched on the hand of the man, and sang :

"This is the ground of my father.

Who are you, digging my father's ground ?

Pick, break into small pieces ;

Sods, return to your places." 
It was so. Then the man tightened his fingers and caught the bird. He came up out of the place of concealment. He said to the bird: "as for you who spoil the work of this garden, you will not see the sun any more. With this sharp stone I will cut off your head."

Then the bird said to him : "I am not a bird that should be killed. I am a bird that can make milk." The man said : "make some then." The bird made some milk in his hand. The man tasted it. It was very nice milk. The man said: "make some more milk, my bird." The bird did so. The man sent his wife for a milk basket.* When she brought it, the bird filled it with milk. The man was very much pleased. He said: "this pretty bird of mine is better than a cow."

He took it home and put it in a far. After that he used to rise even in the night and tell the bird to make-milk for him. Only he and his wife drank of it. The children continued to drink of the milk of the tree. The names of the children were Gingci, the first-born son; Lonci, his brother; and Dumangashe, his sister. That man then got very fat indeed, so that his skin became shining.

The girl said to her brother Gingei: "why does father get fat and we remain so thin?" He replied: "I do not know, perhaps he eats in the night." They made a plan to watch. They saw him rise in the middle of the night. He went to the big far and took an eating mat off it. He said : "make milk, my bird." He drank much. Again he said: "make milk, my bird," and again he drank till he was very full. Then he lay down and went to sleep.

The next day the woman went to work in her garden, and the man went to visit his friend. The children remained at home, but not in the house. Their father fastened the door of the house and told them not to enter it on any account till his return. Gingci said: "to-day we will drink of the milk that makes father fat and shining; we will not drink of the milk of the euphorbia to-day." The girl said : "as for me, I also say let us drink of father's milk to-day."

They entered the house. Gingci removed the eating mat from the jar, and said to the bird: "my father's bird, make milk $\mathfrak{f}_{\text {or }}$ me." The bird said: "if I am your father's bird, put me by

* Itunga, a basket used to milk the cows in. It is woven so nicely as to be watertight. 
the fireplace, and I will make milk." The boy did so. The bird made just a little milk. The boy drank, and said: "my father's bird, make more milk." The bird said: "if I am your father's bird, put me by the door, then I will make milk." The boy did this. Then the bird made just a little milk, which the boy drank. The girl said: "my father's bird, make milk for me." The bird said: "if I am your father's bird, just put me in the sunlight, and I will make milk." The girl did so. Then the bird made a jar full of milk. After that the bird sang:

\footnotetext{
"The father of Dumangashe came, he came,

He came unnoticed by me.

He found great fault with me.

The little fellows have met together,

Gingci, the brother of Lonci.

The Umkomanzi cannot be crossed,

It is crossed by swallows

Whose wings are long."
}

When it finished its song it lifted up its wings and flew away. But the girl was still drinking milk. The children called it, and said : "return, bird of our father," but it did not come back. They said: "we shall be killed to-day." They followed the bird. They came to a tree where there were many birds. The boy caught one, and said to it: "my father's bird, make milk." It bled. They cried: "this is not our father's bird." This bird bled very much; the blood ran like a river. Then the boy released it, and it flew away. The children were seized with fear. They said to themselves : "if our father finds us, he will kill us to-day."

In the evening the man came home. When he was yet far off, he saw that the door had been opened. He said: "I did not shut the door that way." He called his children, but only Lonci replied. He asked for the others. Lonci said: "I went to the river to drink; when I returned they were gone." He searched for them, and found the girl under the ashes and the boy behind a stone. He inquired at once about his bird. They were compelled to tell the truth concerning it.

Then the man took a riem and hung those two children on a tree that projected over the river. He went away, leaving them there. Their mother besought their father, saying that they should be released, but the man refused. After he was gone, the boy tried to escape. He climbed up the riem and held on to the tree; then he went up and loosened the riem that was tied to lis 
sister. After that they climbed up the tree, and then went away from their home. They slept three times on the road.*

They came to a big rock. The boy said : "we have no father and no mother ; rock, be our house." The rock opened, and they went inside. After that they lived there in that place. They obtained food by hunting animals, - they were hunted by the boy.

When they were already in that place a long time, the girl grew to be big. There were no people in that place. A bird came one day with a child, and left it there by their house. The bird said : "so have I done to all the people."

After that a crocodile $\dagger$ came to that place. The boy was just going to kill it, but it said : "I am a crocodile, I am not to be killed, I am your friend." Then the boy went with the crocodile to the house of the crocodile, in a deep hole under the water. The crocodile had many cattle and much millet. He gave the boy ten cows and ten baskets of millet. The crocodile said to the boy "you must send your sister for the purpose of being married to me."

The boy made a fold to keep his cattle in; his sister made a garden and planted millet. The crocodile sent more cattle. The boy made a very big fold, and it was full of cattle. At this time there came a bird. The bird said: "your sister has performed the custom, and as for you, you should enter manhood (i.e. be circumcised)." The crocodile gave one of his daughters to be the wife of the young man.

The young woman went to the village of the crocodile, she went to be a bride. They said to her: "whom do you choose to be your husband?" The girl replied: "I choose crocodile." Her husband said to her: "lick my face." She did so. The crocodile cast off its skin, and arose a man of great strength and fine appearance. He said: "the enemies of my father's house did that; you, my wife, are stronger than they."

* This is equivalent to saying that they travelled for three days.

$\uparrow$ There are no crocodiles in the rivers south of Natal, but the reptile and its habits are well known to the people from traditions. It is not unlikely that their belief in a water-spirit which bas power to charm people and entice them into rivers to their destruction may have originated in the fact of their having migrated from a country where these destructive animals were common, as the spirit and the reptile have the same name. In this story it is seemingly a crocodile that appears, but very shortly we learn that it is really a man who has been bewitched and forced to assume that form. 
After this there was a great famine, and the mother of those people came to their village. She did not reeognize her children, but they knew her and gave her food. She went away, and then their father came. He did not recognize them either, but they knew him. They asked him what he wanted. He told them that his village was devoured by famine. They gave him food, and he went away. He returned again. The young man said: "you thought we would die when you hung us in the tree." He was astonished, and said: "are you indeed my child?"

Crocodile then gave them (the parents) three baskets of corn, and told them to go and build on the mountains. He (the man) did so and died there on the mountains.

\section{Serolong version of the Story of the Bird that made Mıгк.*}

It is said that there was once a great town in a certain place, which had many people living in it. They lived upon grain only. One year there was a great famine. There was in that town a poor man, by name Masilo, and his wife. One day they went to dig in their garden, and they continued digging the whole day long. $\uparrow$ In the evening, when the digging companies returned home, they returned also. Then there came a bird and stood upon the house which was beside the garden, and began to whistle, and said: "Masilo's cultivated ground, mix together." The ground did as the bird said. After that was done the bird went away.

In the morning, when Masilo and his wife went to the garden, they were in doubt, and said: "is it really the place we were digging yesterday?" They saw it was the place by the people working on each side. The people began to laugh at them, and mocked them, and said: "it is because you are very lazy."

* This story was written down for me in English by an educated grandson of the late chief Moroko of the Baseleka branch of the Barolong tribe. $\mathrm{He}$ informed me that he had often heard it told when he was a little boy, and that he believed every Morolong woman knew it by heart. Here then is a story current among people of the interior, almost identical in its principal features with one current among the coast tribes, though these two branches of the Bantu family cannot understand each other, and migrated from different parts of the continent. It must therefore be of great age.

$\uparrow$ Among the interior tribes poor men frequently assist their wives to break up rough ground for gardens. 
They continued to dig again that day, and in the erening they went home with the others. Then the bird came and did the same thing. When they went back next morning, they found their ground altogether undug. Then they believed that they were bewitched by some others.

They continued digging that day again. But in the evening when the companies returned, Masilo said to his wife: "go home; I will stay behind to watch and find the thing which eats our work." Then he went and laid himself down by the head of the garden, under the same house which the bird used always to stand upon. While he was thinking, the bird came. It was a very beautiful bird. He was looking at it and admiring it, when it began to speak.

It said: "Masilo's cultivated ground, mix together." Then he caught it, and said : "ah! is it you who eat the work of our hands?" He took out his knife from the sheath, and was going to cut the head of the bird off. Then the bird said: "please don't kill me, and I will make some milk for you to eat." Masilo answered: "you must bring back the work of my hands first." The bird said: "Masilo's cultivated ground appear," and it appeared. Then Masilo said : "make the milk now," and, behold, it immediately made thick milk, which Masilo began to eat. When he was satisfied, he took the bird home. As he approached his house, he put the bird in his bag.

When he entered his house, he said to his wife: "wash all the largest beer-pots which are in the house," but his wife was angry on account of her hunger, and she answered: "what have you to put in such large pots?" Masilo said to her: " just hear me, and do as I command you, then you will see," When she was ready with the pots, Masilo took his bird out of his bag, and said: "make milk for my children to eat." Then the bird filled all the beer-pots with milk. They commenced to eat, and when they were finished, Masilo charged his children, saying: "beware that you do not tell anybody of this, not one of your companions." They swore by him that they would not tell anybody.

Masilo and his family then lived upon this bird. The people were surprised when they saw him and his family. They said: "why are the people at Masilo's house so fat? He is so poor, but now since his garden has appeared he and his children are so 
fat!" They tried to watch and to see what he was eating, but they never could find out at all.

One morning Masilo and his wife went to work in their garden, and about the middle of the same day the children of that town met together to play. They met just before Masilo's house. While they were playing, the others said to Masilo's children: "why are you so fat while we remain so thin?" They answered: "are we then fat? We thought we were thin, just as you are." They would not tell them the cause. The others continued to press them, and said: "we won't tell anybody." Then the children of Masilo said: "there is a bird in our father's house which makes milk." The others said : "please show us the bird."

They went into the house and took it out of the secret place where their father had placed it. They ordered it as their father used to order it, and it made milk, which their companions drank, for they were very hungry. After drinking they said: "let it dance for us," and they loosened it from the place where it was tied. The bird began to dance in the house, but one said: "this place is too confined," so they took it outside of the house. While they were enjoying themselves and laughing, the bird flew away, leaving them in great dismay.

Masilo's ehildren said: "our father will this day kill us, therefore we must go after the bird." So they followed it, and continued going after it the whole day long, for when they were at a distance it would sit still for a little while, and when they approached it would fly away. When the digging companies returned from digging the people of that town cried for their children, for they did not know what had become of them. But when Masilo went into the house and could not find his bird, he knew where the children were, but he did not tell any of their parents. He was very sorry for his bird, for he knew that he had lost his food.

When evening set in, the children determined to return to their homes, but there came a storm of rain with heavy thunder, and they were very much afraid. Among them was a brave boy, named Mosemanyanamatong, who encouraged them, and said: "do not be afraid ; I can command a house to build itself." They said : "please command it." He said : "house, appear," and it appeared, and also wood for fire. Then the children entered the house and made a large fire, and began to roast some wild roots which they dug out of the ground. 
While they were roasting the roots and were merry, there came a big cannibal, and they heard his voice saying: "Mosemanyanamatong, give me some of the wild roots you have." They were afraid, and the brave boy said to the girls and to the other boys : "give me some of yours." They gave to him, and he threw the roots outside. While the cannibal was still eating, they went out and fled. He finished eating the roots, and then pursued them. When he approached they scattered some more roots upon the ground, and while he was picking them up and eating, they fled.

At length they came among mountains, where trees were growing. The girls were already very tired, so they all climbed up a tall tree. The cannibal came there, and tried to cut the tree down with his sharp and long nail. Then the brave boy said to the girls: "while I am singing you must continue saying: tree be strong, tree be strong." He sang this song:

"It is foolish,

It is foolish to be a traveller,

And to go on a journey

With the blood of girls upon one!

While we were roasting wild roots

A great darkness fell upon us.

It was not darkness,

It was awful gloom!"

While he was singing, there came a great bird and hovered over them, and said: "hold fast to me." The children held fast to the bird, and it flew away with them and took them to their own town. It was midnight when it arrived there, and it sat down at the gate of Mosemanyanamatong's mother's house. In the morning, when that woman came out of her house, she took ashes and cast upon the bird, for she said: "this bird knows where our children are." At midday the bird sent word to the chief, saying: "command all your people to spread mats in all the paths." The chief commanded them to do so. Then the bird brought all the children out, and the people were greatly delighted.

\section{Story of the Girl who disRegarded the Custom of NTONJane.}

There was once a chief's daughter who had reached the age when it was necessary for her to observe the ntonjane. She was 
therefore placed in a hut, in which she was to remain during the period of the ceremony. One day her companions persuaded her to go and bathe in a stream near at hand, though this was against the custom of the ntonjane. When they came out of the water, they saw a snake with black blotches, called the Isinyobolokondwana, near their clothes. They were very much afraid and did not know what to do at first. But by-and-by one of them commenced to sing these words :

The snake replied:

"Sinyobolokondwana,

Sin yobolokondwana, Bring my mantle!"

"Take it,

And pass on."

The companions of the chief's daughter, one after the other, asked the snake for their mantles in this manner, and obtained permission to take them. Last of all was the chief's daughter. But instead of speaking to the snake respectfully as the others had done, she said mockingly, "Ngcingcingci, ngcingcingci," * So the snake became very angry, and bit her, when she immediately became of the same hideous colour as it was. Her companions were so frightened that they left her and ran away home. They put another girl in the hut, and pretended that she was the chief's daughter. The girl, thus left alone, went to a forest close by, and climbed up a tree to hide herself.

About this time the chief was killing an ox on account of his daughter, and so he sent a young man to the forest to get pieces of wood to peg out the skin. The young man was cutting sticks, when he heard some one crying: "Man cutting sticks, tell my father and my mother that the sinyobolokondwana bit me." He heard this repeated twice, and, without looking to see what was crying, he ran home and told the chief. Two young men were then sent back with him to see what it was, one of these happening to be the girl's brother. These two were told to hide themselves and listen while the other cut the sticks. They did so, and heard the voice crying as before. Then the brother of the girl knew the voice of his sister, and they all went to the tree where she was, and took her home with them.

* Words without meaning, but used to express contempt, being merely a repetition of the sound ngci. 
The chief was very much surprised to see his daughter in that state, and was so angry with her companions for taking her to the river, and then for substituting another girl so as to deceive him, that he caused them all to be killed.

Then he sent some of his men with forty cattle to take his daughter to a distant country, where she was to remain far away from him. They did as they were told, and built huts in that place to live in. After they had been there a long time, they found that the cows which the chief sent with them were giving more milk than they could consume, so they poured what was left in a hole in the ground. To their amazement the milk rose, and rose, and rose, higher and still higher, till at last it stood up out of the ground like a great overhanging rock. They called the girl to see this wonderful thing that was happening. In her curiosity she went close to the precipice, when it fell down on her, and, as the milk ran over her, all her ugly blotched skin disappeared, and she was again beautiful as at first.

Soon afterwards a young chief who was passing by saw the girl, and fell in love with her. He thought she was the daughter of one of the men who were there to protect her, but when he made inquiries they told him she was the daughter of their chief. Then he went to her father, and some of the men went also to tell how the milk had cured the girl. The young chief had very many cattle, which he offered to her father. So the old chief agreed to let him marry the girl, and she became his great wife, and was loved by him very dearly.*

\section{Story of SimbukUmbukWana.}

There was a man whose wife had no children, so that he was much dissatisfied. At last he went to a wise woman (igqirakazi) and asked her to help him in this matter. She said: "you must bring me a fat calf that I may get its tallow to use with my medicine" (or charms-the Xosa word is imifizi). $\uparrow$ The man

* A large proportion of Bantu tales have a similar termination with many English ones: the heroine gets married to a prince. These show that a desire for worldly rank is as great in the one people as in the other. Most Bantu tales are destitute of moral teaching from our point of view. What recommendation, for instance, has the girl in this story to the favour of the young chief ?

$\uparrow$ Charms and medicines for the cure of diseases are classed together by the Bantu. Some of the women as well as of the men have really a wonderful 
went home and selccted a calf without horns or tail, which he took to the wise woman. She said: "your wife will have a son who will have no arms and no legs, as this calf has no horns and no tail." She told him further that he was not to inform any one of this.

The man returned to his home and told his friends what was to happen. Not long after this his wife bore a child, but it was a daughter and had arms and legs. The man would not own that child, he said it was not his. He beat his wife, and commanded her to take the child away and leave it to perish. Then he went to the wise woman and told her what had taken place. The wise woman said: "it was because you did not obey my command about keeping this matter to yourself, but your wife will yet have a son without arms and without legs." It was so. His wife bore another child, which was a boy without arms and without legs, therefore he was called Simbukumbukwana. He began to speak on the day of his birth. During this time the girl that was first born was growing up in the valley where her mother left her; she lived in a hole in an antheap, and ate honey, and nongwes, and gum.

One day the mother of Simbukumbukwana went to work in her garden, and left the boy at home with the door fastened. While she was away the girl came; she stood at a distance, and said: "where are the people?" There came a voice from inside which said: "here am I." She said: "who are you?" The voice replied: "I am Simbukumbukwana." She said: "open for me." He answered : "how can I open? I have no legs and no arms." She said: "my mother's Simbukumbukwana, have legs and arms." (Simbukumbukwana sikama, yiba nemilenze nemikono).

Then legs and arms came on the boy, and he arose and opened for his sister. She went in and swept the floor; then she took millet and ground it and made bread. She told her brother when his parents asked him who did these things to say that he did them himself, and if they should ask him to do them again to reply: "I have done it already." Then she said: "my mother's

knowledge of the properties of herbs and roots. They are acquainted with various vegetable poisons and with their antidotes, and not unfrequently make use of them. The Bantu are perfect slaves to charms, and hardly ever undertake any matter of importance without using them, 
Simbukumbukwana, sink legs and sink arms." (Simbukumbukwana sikama, tshona milcnze, tshona mikono). Then his legs and arms shrank up, and his sister went away.

After a time his father and his mother came home; they went in and saw the clean floor and bread ready for eating. They were surprised, and said to Simbukumbukwana: "who did this?" He replied: "I did." They said: "do so again that we may see you." He answered : "I have done it already."

The next day the woman went again to work in her garden, but the man hid himself to watch what would happen. After a time the sister of Simbukumbukwana came and said: "where are the people?" (Exactly the same conversation as before). She went in and began to smear the floor; water was wanting, so she sent Simbukumbukwana to the river for some. His joy in walking was great, so that he did not stop at the river, but put the pot down there and continued to go forward. The girl thought he ought not to be so long absent, for the river was close by, so she went to look for him. She saw him walking up a hill far away, and she called to him to return. He would not. Then she sang : "Simbukumbukwana sikama, tshona milenze, tshona mikono," and immediately his legs and arms shrank up. Then she was going away, but her father came out and caught her; he kissed her, and said she must remain with him.

Her mother was coming home, when she saw something moving on the hillside. She went to see what it was, and found her son. She said: "how did you come here?" He replied: "I came by myself." She said : "let me see you go farther." $\mathrm{He}$ answered: "I have done it already." Then she put him on her back and went home. She found her daughter there, and her husband much pleased. The girl said: Simbukumbukwana sikama, yiba nemilenze nemikono, and legs and arms came on him.

One day his sister and some other girls went to get red clay, and he followed them. When they looked behind they saw him, and his sister got angry. She said to him: "what do you want here?" He replied: "I am going for red clay for my mother." His sister compelled him to sit down; but as soon as they went on, he followed; then his sister beat him, and left him in the path.

After that there was a heavy storm of rain, but none fell where the little boy was. When the rain was over, the other girls said 
to the one who had beaten her brother: "let us go and look after the little boy." They went and saw he was quitc dry. He called to his sister : "you have beaten me," but she asked him to forgive her. Then he said : "I want my father's house to be here," and immediately it came. He said: "I want the fire of my father to be here," and there was a fire. He said to them: "now go in; although you have beaten mc, there is a house and fire for you." He said afterwards: "I want the cattle of my father to be here," and at once they were all there. That was a nice place, so they remained there ever after.

\section{Story of Sikulume.}

There was once in a certain village an old man who was very poor. He had no children, and only a few cattle. One day, when the sky was clear and the sun was bright, he sat down by the cattlefold. While he was sitting there, he noticed some birds close by which were singing very joyfully. He listened for a while, and then he stood up to observe them better. They were very beautiful to look upon, and they sang differently from other birds. They had all long tails and topknots on their heads. Then the old man went to the chief and told him what he had seen. The chief said : "how many were they?" The old man replied: "there were seven."

The chief said : "you have acted wisely in coming to tell me; you shall have seven of the fattest of my cows. I have lost seven sons in battle, and these beautiful birds shall be in the place of my seven sons. You must not sleep to-night, you must watch them, and to-morrow I will choose seven boys to catch them. Do not let them out of your sight by any means." In the morning the chief ordered all the boys of the village to be assembled at the cattle-fold, when he spoke to them of the birds. He said: "I will choose six of you, and set my son who is dumb over you, that will make seven in all. You must catch those birds. Wherever they go you must follow, and you must not see my face again without them." He gave them weapons, and instructed them that if any one opposed them they were to fight till the last of them died.

The boys set off to follow those beautiful birds. They chased them for several days, till at last the birds were exhausted, when each of the boys caught one. At the place where they caught 
the birds they remained that night. On the morning of the next day they set out on their return home. That evening they came to a hut in which they saw a fire burning, but no one was there. They went in, and lay down to sleep. In the middle of the night one of those boys was awake. He heard some one saying: "there is nice meat here; I will begin with this one, and take this one next, and that one after, and the one with small feet the last." The one with the small feet was the son of the chief. His name was Sikulume, for he had never been able to speak till he caught the bird. Then he began to talk at once.

After saying those words the voice was still. Then the boy awakened his companions, and told them what he had heard. They said: "you have been dreaming; there is no one here; how can such a thing be?" He replied: "I did not dream; I spoke the truth." Then they made a plan that one should remain awake, and if anything happened, he should pinch the one next him, and that one should pinch the next, till all were awake.

After a while the boy who was listening heard some one come in quietly. That was a cannibal. He said the same words again, and then went out for the purpose of calling his friends to come to the feast. The boy awakened his companions according to the plan agreed upon, so that they ali heard what was said. Therefore, as soon as the cannibal went out, they arose and fled from that place. The cannibal came back with his friends, and when the others saw there was no one in the hut, they killed and ate him.

As they were going on, Sikulume saw that he had left his bird behind. He stood, and said: "I must return for my bird, my beautiful bird with the long tail and topknot on its head. My father commanded that I must not see his face again unless I bring the bird." The boys said: "take one of ours. Why should you go where cannibals are?" He replied: "I must have the one that is my own." He stuck his assagai in the ground, and told them to look at it. He said: " if it stands still, you will know I am safe; if it shakes, you will know I am running; if it falls down, you will know I am dead." Then he left them to return to the hut of the cannibals.

On the way he saw an old woman sitting by a big stone. She said: "where are you going to?" He told her he was going 
for his bird. The old woman gave him some fat, and said: "if the cannibals pursue you, put some of this on a stone." He came to the hut and got his bird. The cannibals were sitting outside, a little way back. They had just finished eating the owner of the hut. When Sikulume came out with his bird they saw him and ran after him. They were close to him, when he took some of the fat and threw it on a stone. The cannibals came to the stone, and began to fight with each other. One said: "the stone is mine." Another said: "it is mine." One of them swallowed the stone. Whon the others saw that, they killed him and ate him.

Then they pursued again after Sikulume. They came close to him again, when he threw the remainder of the fat on another stone. The cannibals fought for this also. One swallowed it, and was killed by the others. They followed still, and Sikulume was almost in their hands, when he threw off his mantle. The mantle commenced to run another way, and the cannibals ran after it. It was so long before they caught it that the young chief had time to reach his companions.

They all went on their way, but very soon they saw the cannibals coming after them. Then they observed a little man sitting by a big stone. He said to them : "I can turn this stone into a hut." They replied: "do so." He turned the stone into a hut, and they all went inside, the little man with them. They played the iceya there. The cannibals came to the place and smelt. They thought the hut was still a stone, for it looked like a stone to them. They began to bite it, and bit till all their teeth were broken, when they returned to their own village.

After this, the boys and the little man came out. The boys went on. When they reached their own home they saw no people, till at length an old woman crept out of a heap of ashes. She was very much frightened, and said to them: "I thought there were no people left." Sikulume said: "where is my father?" She replied: "all the people have been swallowed by the inabulele" (a fabulous monster). He said: "where did it go to?" The old woman replied: "it went to the river."

So those boys went to the river, and Sikulume said to them: "I will go into the water, and take an assagai with me. If the water moves much, you will know I am in the stomach of the inabulele; if the water is red, you will know I have killed it." 
Then he threw himself into the water and went down. The inabulele swallowed him without tearing him or hurting him. He saw his father and his mother and many people and cattle. Then he took his assagai and picrced the inabulele from inside. The water moved till the inabulele was dead, then it became red. When the young men saw that, they cut a big hole in the side of the inabulele, and all the people and the cattle were delivered.

One day Sikulume said to another boy: "I am going to the doctor's; tell my sister to cook food for me, nice food that I may eat." This was done. He said to his sister: "bring me of the skin of the inabulele which I killed, to make a mantle." She called her companions, and they went to the side of the river. She sang this song :

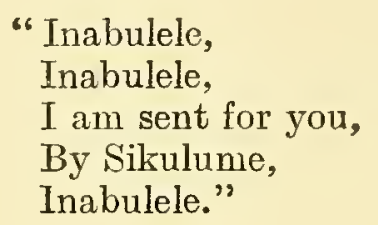

The body of the inabulele then came out. She cut two little pieces of the skin for sandals, and a large piece to make a mantle for her brother.

When he was a young man, Sikulume said to his friends: "I am going to marry the daughter of Mangangezulu." They replied : " you must not go there, for at Mangangezulu's you will be killed." He said: "I will go." Then he called those young men who were his chosen friends to accompany him. On the way they came to a place where the grass was long. A mouse came out of the grass, and asked Sikulume where he was going to. He replied : "I am going to the place of Mangangezulu." The mouse sang this song :

"Turn back, turn back, Sikulume,
No one ever leaves the place of Mangangezulu.
Turn back, turn back, O chief."

Sikulume replied: "I shall not turn back." The noouse then said: "As it is so, you must kill me and throw my skin up in the air." He did so. The skin said: "you must not enter by the front of the village; you must not eat off a new mat; you must not sleep in a hut which has nothing in it." They arrived at the village of Mangangezulu. They entered it from the wrong side, 
so that all the pcople said: "why is this?" They replied: "it is our custom." Food was brought to them on a new mat, but they said : "it is our custom to eat off old mats only." An empty hut was given to them to sleep in, but they said: "it is our custom only to sleep in a hut that has things in it."

The next day the chief said to Sikulume and his companions: "you must go and tend the cattle." They went. A storm of rain fell, when Sikulume spread out his mantle and it became a hut as hard as stone, into which they all went. In the evening they returned with the cattle. The daughter of Mangangezulu came to them. Her mother pressed her foot in the footprint of Sikulume, and he became an eland. The girl loved the young chief very much. When she saw he was turned into an eland, she made a great fire and drove him into it. Then he was burned, and became a little coal. She took the coal out and put it in a pot of water, when it became a young man again.

Afterwards they left that place. The girl took with her an egg, a milksack, a pot, and a smooth stone. The father of the girl pursued them. The girl threw down the egg, and it became a mist. Her father wandered about in the mist a long time, till at length it cleared away. Then he pursued again. She threw down the milksack, and it became a sheet of water. Her father tried to get rid of the water by dipping it up with a calabash, but he could not succeed, so he was compelled to wait till it dried up. He followed still. The girl threw down the pot, and it became thick darkness. He waited a long time till light came again, when he followed them. He could travel very quickly. He came close to them, and then the girl threw down the smooth stone. It became a rock, a big rock with one side steep like a wall. He could not climb up that rock, and so he returned to his own village.

Then Sikulume went home with his wife. He said to the people: "this is the daughter of Mangangezulu. You advised me not to go there, lest I should be killed. Here is my wife." After that he became a great chief. All the people said: "There is no chief that can do such things as Sikulume."

\section{Story of the Cannibal's Wonderful Bird.}

A number of girls once went away from their homes early in the morning for the purpose of getting red clay. Among them was 
the daughter of a chief, a very pretty girl. After they had collected the red clay, they were about to return home, when one of them proposed that they should bathe in a large pool of water that was there. To this they all agreed, and so they went into the water and played about in it for a long time. At last they dressed themselves again, and set out for home; but when they had gone some distance, the chief's daughter noticed that she had forgotten one of her ornaments, which she had taken off when they went to bathe. So she asked one of the girls to return with her to get it. The girl refused. Then she asked another girl, and another, but one and all refused to go back. She was thus obliged to return to the water alone, while the other girls went home.

On arriving at the pool, a big ugly cannibal with only one leg came up to her, caught her, and put her in his bag. She was so frightened that she lay quite still. The cannibal then took her round to the different villages and made her sing for him. $\mathrm{He}$ called her his bird. When he came to a village he asked for meat, and when it was given to him he said: "Sing, my bird." But he would never open the bag so that any one could see what sort of a bird he had.

When the girls reached home, they told the chief that his daughter had reached the age of ntonjane, and they selected one of themselves and shut her up in a hut. The chief believed that story, and so he killed a large ox and said the people must eat. That day they ate fat beef, and were very merry. The boys took meat, and went away from the village to eat it. The cannibal, who did not know that the girl's father was chief at this place, came there just at this time. He said to the boys if they would give him meat he would make his bird sing for them. So they gave him meat, and he said: "Sing, my bird." The girl's brother was among those boys, and he thought the bird sang like his sister, but he was afraid to ask the cannibal to let him see. $\mathrm{He}$ advised the cannibal to go to the village where the men were, and told him there was plenty of meat that day.

The cannibal went to the village and made his bird sing. The chief wanted very much to see the bird, but the cannibal would not open the bag. The chief offered him an ox for the bird, but the cannibal declined the offer. Then the chief made a plan. He asked the cannibal to go for some water, and said he would give him plenty of beef when he returned. The cannibal said he 
would go if they would promise not to open his bag while he was away. They all promised not to touch the bag. They gave the cannibal a leaky pot to carry the water in, so that he was gone a long time. As soon as he was out of sight the chief opened the bag and took his daughter out. At first he could not believe it was his daughter, for he thought she was observing ntonjane. But when he knew how those other girls had deceived him he said they must all die, and so they were killed. Then he put snakes and toads in the bag, and tied it up again.

When the cannibal came back he complained of the leaky pot, but they gave him plenty of meat to satisfy him, so he picked up his bag and went away. He did not know what had happened while he was absent. When he came near his own house he called to his wife: "Make ready to cook." He sent and called all the other cannibals to come to a feast, and they came expecting to get something nice. He let them wait a little to get very hungry. Then he opened his bag and thought to take the girl out, but found only snakes and toads in it. The other cannibals were so angry when they saw this, that they killed him and made their feast of him.

\section{Story of the Cannibal Mother and her Children.}

There was once a man and a woman who had two children, a son and a daughter. These children lived with their grandfather. Their mother was a cannibal, but not their father. One day they said to their grandfather: "We have been long with you, we should like very much to go and see our parents." Their grandfather said: "Ho! will you be able to come back? Don't you know your mother is a cannibal ?" After a time he consented. He said: "You must leave at such a time that you may arrive there in the evening, so that your mother may not see you, only your father." The boy's name was Hinazinci. He said: "Let us go now, my sister."

They started when the sun was set. When they arrived at their father's house, they listened outside to find out if their mother was there. They heard the voice of their father only, so they called to him. He came out, and when he saw them he was sorry, and said: "Why did you come here, my dear children? Don't you know your mother is a camnibal ?" Just then they heard a noise like thunder. It was the coming of their mother. Their 
father took them inside and put them in a dark place, where he covered them with skins.

Their mother came in with an animal and the body of a man. She stood and said: "There's something here. What a nice smell it has!" She said to her husband: "Sohinazinci, what have you to tell me about this nice smell that is in my house? You must tell me whether my children are here." Her husband answered: "What are you dreaming about? They are not here." She went to the place where they were, and took the skins away. When she saw them, she said: "My children, I am very sorry that you are here, because I must eat people." She cooked for them and their father the animal she had brought home, and the dead man for herself. After they had eaten, she went out.

Then their father said to them: "When we lie down to sleep, you must be watchful. You will hear a dancing of people, a roaring of wild beasts, and a barking of dogs in your mother's stomach. You will know by that she is sleeping, and you must then rise at once and get away." They lay down, but the man and the children only pretended to go to sleep. They were listening for those sounds. After aw while they heard a dancing of people, a roaring of wild beasts, and a barking of dogs. Then their father shook them, and said they must go while their mother was sleeping. They bade their father farewell, and crept out quietly, that their mother might not hear them.

At midnight the woman woke up, and when she found the children were gone, she took her axe and went after them. They were already a long way on their journey, when they saw her following them. They were so tired that they could not run. When she was near them, the boy said to the girl: "My sister, sing your melodious song, perhaps when she hears it she will be sorry and go home without hurting us." The girl replied: "She will not listen to anything now, because she is in want of meat." Hinazinci said: "Try, my sister, it may not be in vain." So she sang her song, and when the cannibal heard it, she ran backwards to her own house.

There she fell upon her husband, and wanted to cut him with the axe. Her husband caught hold of her arm, and said: "Ho! if you put me to death, who will be your husband?" Then she left him and ran after the children again. They were near their 
grandfather's village, and were very weak when their mother overtook them. The girl fell down, and the cannibal caught her and swallowed her. She then ran after the boy. He fell just at the entrance of his grandfather's house, and she picked him up and swallowed him also. She found only the old people and the children of the village at home, all the others being at work in the gardens. She ate all the people that were at home and also all the cattle that were there.

Towards evening she left to go to her own home. There was a deep valley in the way, and when she came to it she saw a very beautiful bird. As she approached it the bird got bigger and bigger, until at last when she was very near it, it was as big as a hut. Then the bird began to sing its song. The woman looked at it, and said to herself: "I shall take this bird home to my husband." The bird continued its song, and sang:

"I am a pretty bird of the valley,

You come to make a disturbance at my place."

The bird came slowly towards her, still singing its song. When they met, the bird took the axe from the woman, and still sang the same song. The cannibal began to be afraid. She said to the bird: "Give me my axe, I do not wish for your flesh now." The bird tore one of her arms off. She said: "I am going away now, give me what is mine." The bird would not listen to her, but continued its song.

She said again : "Give me my axe and let me go. My husband at home is very hungry, I want to go and cook food for him." The bird sang more loudly than before, and tore one of her legs off. She fell down and cried out: "My master, I am in a hurry to go home. I do not want anything that is yours." She saw that she was in danger. She said to the bird again: "You don't know how to sing your song nicely, let me go, and I will sing it for you." The bird opened its wings wide, and tore open her stomach. Many people came forth, most of them alive, but some were dead. As they came forth she caught them and swallowed them again. The two children were alive, and they ran away. At last the woman died.

There was great rejoicing in that country. The children returned to their grandfather, and the people came there and made them rulers of the country, because it was through them the 
cannibal was brought to death. The girl was afterwards married to a son of the great chicf, and Hinazinci had for his wife the daughter of that great one.

\section{Story of Mbulukazi.}

There was once a man who had two wives, one of whom had no children, and for that reason she was not loved by her husband. Her name was Numbakatali. The other wife had one daughter who was very black, and several children besides, but they were all crows. The one who had no offspring was very downcast on that account, and used to go about weeping all day. Once when she was working in her garden, and crying as usual, two doves came and perched near her. One of them said to the other: "Dove, ask the woman why she is crying." So the dove questioned her. She replied: "It is because I have no children, and my husband does not love me. His other wife's children are crows, which come and eat my corn, and she laughs at me." The dove said: "Go home, and get two earthen jars, and bring them here."

Numbakatali went and got them. Then the doves scratched her knees till the blood flowed, and put the blood in the jars. The woman gave the doves some corn to eat, after which she took the jars home to her hut, and set them carefully down in a corner. Every day the two doves came to be fed, and always told the woman to look at what was in the jars. At last, when she looked one day, she saw two children, one a boy, the other a girl, and both very handsome. She was very much delighted at the sight, but she did not tell any one.

When the children grew a little she made a snug place for them in the hut, where they were to sit all day, because she did not wish them to be seen. Always before she went to her work she charged them not to go out, and as her husband never came to see her, no one knew of the existence of these children except herself and a servant girl. But one day, when they were big, she went out, and after she was away some time, the boy said to his sister: "Come, let us help our mother by bringing water from the river."

So they went for water, but they had not reached the river when they met a company of young men with a chief's son, who was looking for a pretty girl to be his wife. The young chief was called Broad Breast, because his chest was very wide, and it was also made of a glittering metal that shone in the sun. These men 
asked for water to drink. The boy gave them all some watcr, but the young chief would only takc it from the girl. Hc was very much smitten with her beauty, and watched her when she left, so as to find out where she lived. As soon as the young chief saw the hut that the girl went to, he returned home with his party and asked his father for cattle with which to marry her. The chief, who was very rich, gave his son many fine cattle, with which the young man went to the girl's mother's husband, and said: "I want to marry your daughter."

So the girl who was very black was told to come, but the young chief said : "That is not the one I want, the one I saw was lighter in colour and much prettier." The father replied: "I have no other children but crows." But Broad Breast persisted, so the man called his wives, both of whom denied that there was such a girl. However, the servant girl went to the man and privately told him the truth. In the evening he went to his wife's hut, and to his great joy saw the boy and his sister. He was so delighted that he remained there that night, and after talking it over with his wife, he agreed to let Broad Breast marry the girl.

In the morning a mat was spread in the yard, and the young chief was asked to sit down. The two children and the servant girl who told their father about them were also called, and they all sat down on the mat. The young chief, as soon as he saw her, said : "This is the girl I meant." He stayed part of the day, and then with his attendants went to his father for more cattle, which, having obtained, he brought them to the father of the girl.

The mother of the very black girl and the crows was very jealous when she saw such a fine young chief coming with so many cattle. She wanted her daughter to be the one that was to be married, so she dressed her as finely as she could, but she had no such pretty clothes as the other girl had. Her name was Mahlunguluza, for she was called after the crows, who were the other children of her mother. The pretty girl's name was Mbulukazi, which name was given to her because her handsome dress was made of the skin of a mbulu.

The mother of Mahlunguluza spoke to the young chief about her daughter, and so he married both the girls. Tlieir father gave to each an ox, with which they went to their new home. Mbulukazi's ox was a pretty young one, and Mahlunguluza's ox 
was an old and poor one. When they arrived, Broad Breast gave to Mbulukazi a very nice new hut to live in, but to Mahlunguluza was given an old one quite in ruins. Then the very black one saw she was not loved, so she made a plan to kill her sister. One day she told her she heard their father was sick, and proposed that they should go to see him.

Mbulukazi consented, and as soon as they obtained leave from their husband they left. Their road led them along the edge of a cliff, below which was a deep pool of water. Mahlunguluza lay down on the rock, and said: "Come, see what is here in the water." Her sister lay down with her head over the edge of the rock, when Mahlunguluza jumped up quickly and pushed her over. Mbulukazi sank in the water and was drowned. Then the very black one returned home, and when her husband asked where Mbulukazi was, she said that she was still with their father.

The next day the ox of the drowned one came running to the village and walked about lowing for a while, after which it tore down the old ruined hut of Mahlunguluza with its horns. Its actions attracted the notice of the men, and they said: "Surely this ox means something, why is it doing this?" Then it went to the deep pool of water, the men following it; it smelt all over the rock, and then jumped into the water and brought out the body of Mbulukazi. The ox licked her till her life came back, and as soon as she was strong once more, she told what had happened.

They all went home rejoicing greatly, and informed Broad Breast. When the young chief heard the story he was angry with Mahlunguluza, and said to her: "Go home to your father, I never wanted you at all, it was your mother who brought you to me." So she had to go away in sorrow, and Mbulukazi remained the great wife of the chief. 


\section{CHAPTER XV.}

Specimens of Bantu Folklore (continued).

\section{Story of Hlakanyana.*}

ONCE upon a time there was a village with many women in it. All the women had children at the same time except the wife of the chief. The children grew, and again all the women gave birth to others. Only the wife of the chief had no child. Then the people said: "Let us kill an ox, perhaps the wife of the chief will then bear a child." While they were killing the ox, the woman heard a voice saying: "Bear me, mother, before the meat of my father is all finished." The woman did not pay any attention to that, thinking it was a ringing in her ears. The voice said again : "Bear me, mother, before the meat of my father is all finished."

The woman took a small piece of wood and cleaned her ears. She heard that voice again. Then she became excited. She said : "There is something in my ears ; I would like to know what it is. I have just now cleaned my ears." The voice said again : "Make haste and bear me, mother, before the meat of my father is all finished." The woman said: "What is this ? there was never a child that could speak before it was born." The voice said again : "Bear me, mother, as all my father's cattle are being finished, and I have not yet eaten anything of them." Then the woman gave birth to that child.

When she saw that to which slie had given birth, she was very much astonished. It was a boy, but in size very little, and with a face that looked like that of an old person. He said to his mother : "Mother, give me a skin robe." His mother gave him a robe.

* I have greatly reduced this story in bulk by leaving out endless repetitions of exactly the same trick, but performed upon different individuals or animals. In all other respects it is complete, The word Hlakanyana means the little deceiver. 
Then he went at once to the kraal where the ox was being killed. He asked for some meat, saying: "Father, father, give me a piece of meat."

The chief was astonished to hear this child calling him father. He said: "Oh, men, what thing is this that calls me father?" So he continued with the skinning of the ox. But Hlakanyana continued also in asking meat from him. The chief became very angry, and pushed him, and said : "Get away from this place." Hlakanyana answered : "I am your child, give me meat." The chief took a little stick, and said: "If you trouble me again, I will strike you with this." Hlakanyana replied : "Give me meat first, and I will go away;" but the chief would not answer, because he was very angry.

Hlakanyana continued asking. Then the chief threw him outside the kraal, and went on with his work. After a little time the child returned, still asking. So the chief said to the men that were with him: "What strange thing is this?" The men replied: "We don't know him at all." The chief asked of them also advice, saying: "What shall I do?" The men replied: "Give him a piece of meat." So the chief cut off a piece of meat and gave it to him. Hlakanyana ran to his mother and gave the meat to her to be cooked.

Then he returned to his father, and said again: "Father, give me some meat." The chief just took him and trampled upon him, and threw him outside of the kraal, thinking that he was dead. But he rose again and returned to his father, still saying: "Father, give me some meat." Then the chief thought to get rid of him by giving him meat again. The chief gave hirn a piece of liver. Hlakanyana threw it away. Fat was then given to him. He put it down on one side. Flesh was then given to him, and a bone with much marrow in it. Hlakanyana said: "I am a man to-day." He said : "This is the beginning of my father's cattle."

At this time the men were saying to each other: "Who will carry the meat to our huts?" Hlakanyana answered: "I will do it." They said: "How can such a thing as you are carry meat?" Hlakanyana replied: "I am stronger than you; just see if you can lift this piece of meat." The men tried, but could not lift it. Then Hlakanyana took the piece of meat and carried it out of the kraal. The men said: "That will do now, carry our 
meat for us." Hlakanyana took the meat and carried it to the house of his mother. He took blood and put it on the eating mats at the houses of the men.

The men went to their houses, and said : "Where is our meat?" They called Hlakanyana, and asked him what he had done with the meat. He replied: "Surely I put it here where the blood is. It must have been taken by the dogs. Surely the dogs have eaten it." Then those men beat the women and children because they did not watch that the dogs did not take the meat. As for Hlakanyana, he only delighted in this trick of his. He was more cunning than any of the old men.

Hlakanyana said to his mother that she must put the meat in the pot to cook, but that it must not be eaten before the next morning. It was done. In the night this cunning little fellow rose and went to the pot. His mother heard something at the pot, and struck with a stick. Hlakanyana cried like a dog. His mother said: "Surely a dog is eating the meat." Hlakanyana returned afterwards, and left nothing but bones in the pot. In the morning he asked his mother for meat. His mother went to the pot, and found nothing but bones. The cunning little fellow pretended to be astonished. He said: "Where is the meat, mother ?" His mother replied: "It has been eaten by a dog." Hlakanyana said: "As that is so, give me the bones, for you who are the wife of the chief will not eat from the same pot with a dog." His mother gave him the bones.

Hlakanyana went to sleep in the same house with the boys. The boys were unwilling to let him sleep with them. They laughed at him. They said: "Who are you? You are just a child of a few days." Hlakanyana answered: "I am older than you." He slept there that night. When the boys were asleep, he got up and went to the cattle kraal. He killed two cows and ate all their insides. He took blood and smeared it on one of the boys who was sleeping. In the morning the men found those two dead cows. They said: "Who has done this thing?" They found the boy with blood upon him, and killed him, because they thought he was the robber. Hlakanyana said within himself: "I told them that I was older than they are; to-day it is seen who is a child and who is a man."

Another day the father of Hlakanyana killed an ox. The head was put in a pot to be cooked. Then Hlakanyana considered 
in his mind how he could get that mcat. So he drove all the cattle of the rillage into a forest, a very thick forest, and tied them by their tails to the trees. After that he cut his arms and legs and breast with a sharp stone, and stood on a hill and cried out with a loud voice: "The enemy has taken our cattle; the cattle are being driven away. Come up, come up; there is an army going away with the cattle." The men ran quickly to him. He said to them: "Why are you eating meat while the enemy is going away with the cattle? I was fighting with them; just look at my body."

They saw he was covered with blood, and they believed it was as he said. So the men took their assagais and ran after the cattle, but they took the wrong way. Only one old man and Hlakanyana were left behind. Then Hlakanyana said to the old man: "I am very tired with fighting; just go to the river, grandfather, and get some water." The old man went, and as soon as he was alone Hlakanyana ate the meat which was in the pot. When the old man returned with the water he was very tired, for the river was far for an old man to go to, therefore he fell asleep. When he was sleeping, Hlakanyana took a bone and put it beside the old man. He also took some fat and put it on the mouth of the old man. Then he ran to the forest and loosened the cattle that were tied by the tails.

At this time the men were returning from seeking the enemy. Hlakanyana was coming also from the other side with the cattle. He shouted: "I have conquered the enemy." $\mathrm{He}$ also said: "The meat must be eaten now." When they opened the pot they found no meat. They found only dung, for Hlakanyana had filled the pot with dung. Then the men said: "Who has done this ?" Hlakanyana answered: "It must be the old man who is sleeping there." They looked, and saw the bone by the side of the old man and the fat on his mouth. Then they said: "This is the thief." They were intending to kill the old man because he had stolen the meat of the chief.

When the children saw that the old man was to be killed, they said that he did not eat the meat of the chief. The men said: "We saw fat on his mouth and a bone beside him." The children replied: "He did not do it." The men said : "Tell us who did it." The children answered: "Hlakanyana ate the meat and put dung in the pot. We were concealed, and we saw him do 
it." Hlakanyana denied. He said: "Let me go and ask the women; perhaps they saw who ate the meat of the chief." The men sent a young man with him to the women; but when they were a short distance away, Hlakanyana escaped.

The chief sent an army after him. The army pursued, and saw Hlakanyana sitting by a bush. They ran to catch him. When they came to the bush, only an old woman was sitting there. They said to her: "Where is Hlakanyana?" The old woman replied : "He just went across that river." See, you must make haste to follow him, for the river is rising." The army passed over the river quickly. Then that old woman turned into Hlakanyana again. He said in himself: "I will now go on a journey, for I am wiser than the counsellors of my father, I being older than they."

The little cunning fellow went to a village, where he saw an old woman sitting beside her house. He said to her: "Would you like to be made young, grandmother?" The old woman replied : "Yes, my grandchild; if you could make me young, I would be very glad." Hlakanyana said : "Take that pot, grandmother, and go for some water." The old woman replied : "I cannot walk." Hlakanyana said: "Just try, grandmother; the river is close by, and perhaps you will be able to reach it." The old woman limped along and got the water.

Then Hlakanyana took a large pot and set it on the fire, and poured the water into it. He said to the old woman: "You must cook me a little first, and then I will cook you a little." The old woman agreed to that. Hlakanyana was the first to be put in the pot. When the water began to get hot, he said: "Take me out, grandmother; I am in long enough." The old woman took him out, and went in the pot for her turn. Soon she said: "Take me out now, my grandchild; I am in long enough." Hlakanyana replied : "Not yet, grandmother, it is not yet time." So the old woman died in the pot. Hlakanyana took all the bones of the old woman and threw them away. He left only the toes and the fingers. Then he took the clothing of the old woman and put it on.

The two sons of this old woman came from hunting. They went into the hut, and said: "Whose meat is this in the pot?" Hlakanyana was lying down. He said in a voice like that of their mother: "It is yours, my sons." While they were eating, the 
younger one said : "Look at this, it is like the toe of mother." The elder one said: "How can you say such a thing? Did not mother give us this meat to eat?" Again the younger one said: "Look at this, it is like the finger of mother." Hlakanyana said : "You are speaking evil of me, my son."

Hlakanyana said in himself: "I shall be discovered; it is time for me to flee." So he slipped quietly out of the house and went on his way. When he got a little way off, he called out: "You are eating your mother. Did any one ever see people eating their mother before?" The two young men took their assagais and ran after him with their dogs. They came to the river; it was full. The cunning fellow changed himself into a little round stone. One of the young men picked up this stone, saying: "If I could see him, I would just throw this stone at him." The young man threw the stone over the river, and it turned into Hlakanyana again. He just laughed at those young men. Hlakanyana went on his way. He was singing this song :

Ndahlangana Nonothloya.

Sapekapekana,

Ndagwanya,

Wapekwa wada wavutwa.
I met with Nonothloya.

We cooked each other,

I was half cooked,

She was well cooked.

Hlakanyana met a boy tending some goats. The boy had a digging-stick * with him. Hlakanyana proposed that they should pursue after birds, and the boy agreed. They pursued birds the whole day. In the evening, when the sun set, Hlakanyana said: "It is time now to roast our birds." The place was on the bank of a river.

Hlakanyana said: "We must go under the water and see who will come out last." They went under the water, and

* This and another part of the story of Hlakanyana show Hottentot influence upon a Xosa tale. I have been informed that Arab influence is even more perceptible in many of the tales common to the Bantu in the lake regions, though the groundwork of them all is unquestionably Bantu. William Koyi, a Christian Xosa who went with the first mission party from Lovedale to Lake Nyassa, and remained there with one short interval until his death, when on a visit to his early lome informed me that after he had learned the language of the people there he was surprised to hear the stories given in this volume told nearly as he had heard them related by women of his family when he was a boy. He also found the imfumba the commonest game of the children in that part of Africa. 
Hlakanyana came out last. The cunning fellow said: "Let us try again." The boy agreed to that. They went under the water. Hlakanyana came out quickly and ate all the birds. $\mathrm{He}$ left the heads only. Then he went under the water again. The boy came out while he was still under the water. When Hlakanyana came out he said : "Let us go now and eat our birds." They found all the birds eaten. Hlakanyana said: "You have eaten them, because you came out of the water first, and you have left me the heads only." The boy denied having done so, but Hlakanyana said: "You must pay for my birds with that diggingstick." The boy gave the digging-stick, and Hlakanyana went on his way.

He saw some people making pots of clay. He said to them: "Why do you not ask me to lend you this digging-stick, instead of digging with your hands?" They said: "Lend it to us." Hlakanyana lent them the digging-stick. Just the first time they stuck it in the clay it broke. He said: "You have broken my digging-stick, the digging-stick that I received from my companion who ate my birds and left me with the heads." They gave him a pot.

Hlakanyana carried the pot till he came to some boys who were herding goats. He said to them: "You foolish boys, you only suck the goats, you don't milk them in any vessel; why don't you ask me to lend you this pot?" The boys said: "Lend it to us." Hlakanyana lent them the pot. While the boys were milking. the pot broke. Hlakanyana said: "You have broken my pot, the pot that I received from the people who make pots, the people who broke my digging-stick, the digging-stick that I received from my companion, my companion who ate my birds and left me with the heads." The boys gave him a goat.

Hlakanyana came to the keepers of calves. He said to them: "You foolish fellows, you only sit here and eat nothing. Why don't you ask me to let you suck this goat?" The keepers of calves said: "Allow us to suck this goat." Hlakanyana gave the goat into their hands. While they were sucking, the goat died. Hlakanyana said: "You have killed my goat, the goat that I received from the boys that were tending goats, the boys that broke my pot, the pot that I received from the people who make pots, the people who broke my digging-stick, the 
digging-stick that I received from my companion, my companion who ate my birds and left me with the heads." They gave him a calf.

Hlakanyana came to the keepers of cows. He said to them : "You only suck the cows without letting the calf suck first. Why don't you ask me to lend you this calf, that the cows may be induced to give their milk freely?" They said: "Lend us the calf." Hlakanyana permitted them to take the calf. While the calf was in their hands it died. Hlakanyana said: "You have killed my calf, the calf that I received from the keepers of calves, the keepers of calves that killed my goat, the goat that I received from the boys that were tending goats, the boys that broke my pot, the pot that I received from the people who make pots, the people who broke my digging-stick, the digging-stick that I received from my companion, my companion who ate my birds and left me with the heads." They gave him a cow.

Hlakanyana continued on his journey. He saw a young man going the same way. He said: "Let us be companions and travel together." The young man agreed to that. They came to a forest. Hlakanyana said: "This is the place for picking up keries." They picked up keries there. Then they reached another place, and Hlakanyana said: "This is the place for throwing away keries." They threw the keries away. Again they canre to another place, and Hlakanyana said: "This is the place for throwing away spoons." The companion of Hlakanyana threw his spoon away, but the cunning little fellow only pretended to throw his away. In fact, he concealed his spoon. They went on.

They came to another place, and Hlakanyana said: "This is the place for throwing knives away." It happened again as with the spoons. Hlakanyana concealed his knife, when his companion threw his away. They came to a certain place, and Hlakanyana said: "This is the place for throwing away izilanda" (awls used to make holes in skins when they are sewed together, and also for taking thorns out of the bare feet and legs of pedestrians). His companion threw his isilanda away, but Hlakanyana kept his.

They went on and reached a place where they had to walk on thorns. Afterwards they looked at their feet, and saw many thorns in them. Hlakanyana said: "Let us sit down and take 
out the thorns." His companion replied: "I cannot do so, because I have no isilanda." Then Hlakanyana took the thorns out of his feet, and the other was obliged to walk lame.

They came to a village. The people said to them: "Tell us the news." Hlakanyana replied: "Just give us something to eat first, look at our stomachs and behold the pinchings of hunger." The people of that village brought meat. Hlakanyana said to his companion : "Now let us eat." The companion of Hlakanyana answered: "I have no knife." Hlakanyana said: "You are just a child; I shall not lend you my knife." The people of that village brought millet and put it before them. Hlakanyana said to his companion: "Why do you not eat?" He answered, "I have no spoon." Hlakanyana said: "You are just a child; I shall not lend you my spoon." So Hlakanyana had all the meat and the millet to himself.

Hlakanyana met a girl herding some goats. He said: "Where are the boys of your village, that the goats are herded by a girl ?" The girl answered: "There are no boys in the village." $\mathrm{He}$ went to the father of the girl and said: "You must give me your daughter to be my concubine, and I will herd the goats." The father of the girl agreed to that. Then Hlakanyana went witl the goats, and every day he killed one and ate it till all were done. He scratched his body with thorns. The father of the girl said: "Where are all the goats?" Hlakanyana replied: "Can you not see how I have been fighting with the wild dogs? The wild dogs have eaten the goats. As for me, I will stay here no longer." So he went on his way.

As he was going on, he saw a trap for catching birds. There were some birds in it. Hlakanyana took the birds out and ate them. The owners of the trap were cannibals. They saw the footprints of Hlakanyana, and said: "This is a little boy that is stealing our birds." They watched for him. Hlakanyana came again to the trap and saw a bird caught in it. He was just going to take the bird out when the cannibals caught him. They made a big fire and put a pot on for the purpose of cooking him. Hlakanyana saw two oxen. One was white, the other was red. He said to the cannibals: "You can take which one of these oxen you like instead of me." The cannibals said: "We will take the white one, because it is white (i.e. fat) inside also." Then Hlakanyana went away with the red ox. The cannibals ate the white 
ox, and then pursued after Hlakanyana. They came up to him by a big stone. He jumped on the stone, and sang this song :

Ndahamba ndayakuva indaba

Zemvula ku mankazana.
I went to hear the news

About rain from the girls.

The cannibals began to dance when they heard him sing. Then he ran away, and the stone continued to sing that song.

As he was journeying, Hlakanyana came to a place where some baboons were feasting. He asked them for some food. The baboons replied: "If you will go for some water for us, we will give you food." He agreed to that. When he returned with the water, the baboons refused to give him food. Then Hlakanyana shouted loudly and said : "At my village there is a marriage of baboons to-day." When the baboons heard that they fled, old and young. So Hlakanyana remained there, and ate all the food.

As he was going along, he saw a hyena building a house, having cooked some meat. Hlakanyana asked the hyena to give him some. The hyena said: "No, I will not give you any; it is too little even for me." Hlakanyana said: "Will you not have me to assist in building?" The hyena replied: "I would have you without delay if you are intending to help me." While they were fastening the thatch, Hlakanyana sewed the hair of the tail of the hyena fast. Then he took the pot and sat down. The hyena said: "Let that pot alone, Hlakanyana." He replied: "I am going to eat now." The hyena wanted to come down, but he found his tail was fast. Hlakanyana ate all the meat, and threw the bones at the hyena. The hyena tried to frighten him by saying there were many hyenas coming quickly to devour him. He just answered: "That is false;" and continued eating till the meat was finished. Then he went on his way.

Hlakanyana came to a river. He saw an iguana that was playing on an ugwali (a simple musical instrument). Hlakanyana said to the iguana: "Lend me your ugwali for a little, please." The iguana said: "No, you will run away with my ugwali." Hlakanyana replied: "How can I run away with a thing that is not mine?"' So the iguana lent him the ugwali. When Hlakanyana saw that he could play upon the instrument nicely, he ran away with it. The iguana pursued him. Then Hlakanyana changed himself into a rush. The iguana took that rush and 
threw it across the river, saying: "If I could see him, I would throw him like this." Then the rush turned to be Hlakanyana again, and he went on his way playing on the ugwali of the iguana.

Hlakanyana came to the house of a leopardess. He proposed to take care of her children while the leopardess went to hunt animals. The leopardess agreed to that. There were four cubs. After the leopardess had gone to hunt, Hlakanyana took one of the cubs and ate it. At the time for giving food, the leopardess came back and said: "Give me my children that I may suckle them." Hlakanyana gave one. The mother said: "Give all at once." Hlakanyana replied : "It is better that one should drink and then another." The leopardess agreed to that. After three had drunk he gave the first one back the second time. Then the leopardess went to hunt again.

Hlakanyana took another of the cubs and ate it. $\mathrm{He}$ also made the door of the house very small so that the mother of the cubs could not come in, and then he made a little hole in the ground at the back so that he could go out. The next day the leopardess came to give her children suck. There were only two left now. Hlakanyana gave them both back the second time. After that the leopardess went away as before.

Hlakanyana ate another of the cubs, so that only one was left. When the mother came, he gave this one four times. When he gave it the last time the leopardess said: "Why does my child not drink to-day?" It was already full, and did not want to "drink more. Hlakanyana replied: "I think this one is sick." The mother said : "You must take good care of it." Hlakanyana promised to do so, but when the leopardess was gone he ate that one also.

The next day when the leopardess came there was no cub left to give her. She tried to get in the house, but the door was too sinall. She sat down in front to watch. Then Hlakanyana went out through the hole he had made in the ground behind. The leopardess saw him and ran after him. He went under a big rock, and cried out loudly for help, saying the rock was falling. The leopardess said: "What is that you are saying?" Hlakanyana replied: "Do you not see that the rock is falling? Just hold it up whilc I get a prop and put under it." The leopardess went to hold the rock up, and Hlakanyana did not return. He just ran away from that place. 
Hlakanyana came to the village of the animals. The animals had trees that bore fruit. There was one tree that belonged to the chief of the animals only. This tree was a very good one, bearing much fruit on it. One day when all the animals were assembled, Hlakanyana asked them the name of the tree of the chief. They did not know the name of that tree. Then Hlakanyana sent a monkey to the chief to ask the name of the tree. The chief told the monkey. As the monkey was returning, he struck his foot against a stone and fell down, which caused him to forget the name of the tree.

In the night when all were sleeping, Hlakanyana went up the tree of the chief and ate all the fruit of it. He took a branch of the tree and fastened it to one of the monkeys. In the morning when the animals awoke and found that the tree of the chief was finished in the night, they asked each other: "What became of the fruit of the chief's tree? What became of the fruit of the tree of the chief?" Hlakanyana looked at the monkey with the branch on him, and said: "It is eaten by the monkey : it is eaten by the monkey; look at the branch on him." The monkey denied, and said: "I don't know anything about it. I never ate the fruit of the tree of the chief."

Hlakanyana said: "Let us make a plan to find out who ate the fruit of the tree of the chief." All the animals agreed to this. Hlakanyana said: "Let us put a rope from one rock to another, and let all go over it. He that has eaten the fruit of the tree will fall down from that rope." One of the monkeys went over first. The next was Hlakanyana himself. He went over carefully and avoided falling. It came to the turn of that monkey with the branch on. He tried to go, but when he was in the middle he fell down. Hlakanyana said therefore: "I have told you that it is this monkey." After that he went on his way.

Hlakanyana came to the house of a jackal. He asked for food, but the jackal said there was none. Then he made a plan. He said to the jackal: "You must climb up on the house and cry out with a loud voice. "We are going to be fat to-day because Hlakanyana is dead.' " The jackal did so. All the animals came running to hear that news. They went inside the house, because the door was open. Then Hlakanyana shut the door, and the animals were caught. After that Hlakanyana killed the animals and ate. 
Hlakanyana returned to the home of his father again. He was told that his sister had gone away for some red clay. When she was returning he shouted: "Let all the black cattle which have white teeth be killed. The daughter of my father is coming who has white teeth." The chief said: "What is the matter with you, Hlakanyana?" He just repeated the same thing. The chief said : "Let a black ox be killed, but you must not break any of its bones, because it belongs to the daughter of a chief." So Hlakanyana got fat meat to eat that day.

Hlakanyana went out one day to tend the calves of his father. He met a tortoise. He said : "Where are you going to, tortoise?" The tortoise answered: "To that big stone." Hlakanyana said: "Are you not tired?" The tortoise replied: "No, I am not tired." Hlakanyana took it and put it on his back. Then he went to the house of his mother. His mother said: "What have you got there, my son?" Hlakanyana answered: "Just take it off my back, mother." The tortoise held fast to Hlakanyana, and would not be pulled off. His mother then heated some fat and poured on the tortoise. The tortoise let go quickly, and the fat fell on Hlakanyana and burnt him, so that he died. That is the end of this cunning little fellow.

\section{Story of Ironside and his Sister.}

A long time ago a woman who went to cultivate her garden took her little daughter with her, and before she began to hoe the ground she laid the child down in the shade of a tree. About midday there came two birds and flew away with the girl. They carried her across a great river, and laid her gently down in a pumpkin field on a plain. As the birds were carrying her away, she called to her mother, who took no notice of her cries, because she could not imagine her child was being carried away. In the afternoon the girl was missing, and her mother searched for her without success. She made inquiries of the neighbours, and some of them told her they had heard the child crying: "I am going away with the birds."

The plain on which the little girl was put down was near a town in which lived a nation of cannibals who had one leg much longer than the other. There she remained alone till the next day. That night the chief of the cannibals dreamed that he saw 
a very pretty girl in that place, so in the morning he sent a party of men to look for her. When the girl saw them coming she was afraid, and hid herself among the pumpkins. But the mon had already noticed where she was, so they easily found her, and took her home with them. The chief was very much pleased with her appearance. He gave her to his mother to take care of, and when she grew up he took her to be his wife.

Afterwards she had two children, one very pretty, and with two legs like her own; the other ugly, and like its father, with one leg longer than the other. The cannibals saw the advantage of having two legs of equal length, and they became jealous of the woman and her child. They told the chief it would be dangerous to allow the child to grow up, because then a nation stronger than themselves might arise. They persuaded him to consent to her being put to death, and then they rejoiced greatly, because she was very fat, and they intended to eat her; but one of them, who had more compassion than the others, told the woman what they were about to do.

After the little girl had been taken away by the birds, her mother had a son, one of whose sides was flesh like other people's, and the other side was iron. His mother told him of his sister who was lost, and when he became a man he determined to go in search of her. In his journey he came to a great river full of water. He had an iron rod in his hand, with which he struck the water, and at the same time he called out with a loud voice : "River, I. have no sister. Be empty." Then the river dried up, and he went safely across.

After this he came to the stream where the cannibals drew their water, and concealed himself among the reeds which grew on its banks. While he was there his sister came to get water, and he at once knew who she was. She, of course, did not know him, but he told her he was her brother. Then she said the cannibals would eat him if he went to their town without an introduction. So they arranged that he should smear himself with mud and go to the top of a high hill, and when he was coming down she would tell the cannibals who he was.

Ironside went on the hill, and as soon as he came in sight of the town his sister said: "There is the servant of the wife of the chief of the cannibals." These words she repeated twice. When Ironside reached the town, a mat was brought to him and spread 
in front of his sister's house; but after a time he was allowed to go inside, still covered with mud.

The next day they all went to hunt, and Ironside killed more game than the others, upon which they became envious of him. This was shortly before the cannibals agreed to kill and eat the daughter of their chief. When the one who had compassion made known what was about to be done, Ironside was present and heard what was arranged. He said to his sister that she must pluck the hair from her head and scatter it about in different directions. This she did, after which Ironside and his sister and her child left the town in haste. The cannibals came, and when they could not find the child they called her loudly by name. Then the tufts of hair all answered in her voice, and the seekers became confused.

Ironside and his companions, having two legs, could walk much quicker than the cannibals, and soon they were on the other side of the large river. The child trembled, and was very much frightened; but Ironside told her not to fear at all. After they had crossed Ironside struck the river with his iron rod, and said : "River, I have found my sister. Be full." Then the water rose very high, quite to the top of the banks.

A party of cannibals who were in pursuit came to the river after it was full, and Ironside made a long rope, and threw the end over to them. They caught hold of it, thinking that he would pull them across; but when they were in the middle of the river he let go the rope, and they were all drowned. Another party then came and asked where their companions were. Ironside said they had gone to a ford farther down; but they knew that was not true, so they returned home. Afterwards they discovered who it was that gave warning of their intentions, and they killed and ate that one.

Ironside took his sister home to her mother, who received her with the greatest joy, never having forgotten her during that long time.

\section{Story of the Glutton.}

There was once a man who quarrelled with his wife, so that she left him, and went home to her father's place. When she got home she found nobody, for all the people had been swallowed by a monster. She went into the house that used to be her father's and noticed that there were footprints of animals and spots of 
blood all orer the floor. She then got into the top of the hut and hid herself. She heard the monster coming, saying :

$$
\begin{aligned}
& \text { "Oh man, Oh man, } \\
& \text { I have eaten, } \\
& \text { And am still living." }
\end{aligned}
$$

She kept awake. Shortly the house was filled with all kinds of animals, which made a fire, cooked their food, ate it, and slept. Next morning they awoke, and all went out to search for something to eat. The woman had two children born while the animals were away. She came down from her hiding-place, and took up a stone used for raising pots above the fire (called isoko), and went again into her hiding-place.

The animals returned in the evening; and while their pots were on the fire, she threw down the stone into one of them. The animals all rushed out of the house. Outside they held a consultation, and their chief decided that those living in holes should go to the holes, that those living in forests should go to the forests, and that those living in rivers should go to the rivers. After this the woman set a trap, and succeeded in catching a buffalo, but she could not skin it. She saw a glutton (called an igongqongqo, a fabulous monster, like a man, but capable of devouring enormous quantities of food) coming, and asked him to help her. He consented. He pulled out his knife and skinned the buffalo. She gathered some wood, and kindled a fire for the purpose of roasting the liver. The glutton roasted it. She went away and picked up an empty calabash, and when she returned she found the glutton roasting the legs, having already eaten the liver. She then said: "I am going for water."

She got behind a bush, and blew the empty calabash. The glutton wondered what this was, and called her. She continued blowing, until the glutton was so frightened that he took his bag and put the remainder of the meat into it, and ran away. She followed him, still blowing, until he threw away the bag containing the meat. She still followed, blowing. The glutton stumbled, and fell into a thorny bush, where he was held fast. The woman then ceased blowing, and heard him blubbering out:

"Let me alone, lu bo bo,"
Let me alone, lu bo bo."

She blew again, and he struggled and got free. He ran away with all his might. She then took the bag home with her, made 
a fire, and cooked the meat. When it was ready she took it to her hiding-place, and lived on it till her children were able to run about outside.

One day these twins asked their mother to make bows and arrows for them. Their mother advised them not to wander away from the hut, saying to them: "The glutton will swallow you." But at a certain time they left home, and went in the direction where the monster lived. They found it asleep, and shot it with their arrows in both eyes. The boys returned home, and told their mother. Next day they went to the place, and found the glutton dead. The boys heard people talking inside the glutton. Having told their mother, she took a knife and cut it open, when people came out, and cattle, and dogs. The people asked: "Who killed the glutton?" The mother of the twins told them, and they rewarded the boys with a large number of cattle.

\section{Story of Tangalmutio.}

There was once a man who had two wives, one of whom had no children. She grieved much about that, till one day a bird came to her and gave her some little pellets. The bird said she must eat of these always before she partook of food, and then she would bear a child. She was very glad, and offered the bird some millet. But the bird said: "No, I do not want millet." The woman then offered an isidanga (an ornamental breast-band which women wear), but the bird said it had no use for that. Then she got some very fine gravel and placed before the bird, which it received at her hands.

After this the woman had a daughter. Her husband knew nothing of what had happened, because he never went to her house. He did not love her at all, for the reason that she bore no children. So she said: "I will keep my daughter in the house till my husband comes; he will surely love me when he sees that I have such a beautiful child." The name given to the girl was Tangalimlibo.

The man went always to the house of the other wife, and so it happened that Tangalimlibo was grown to be a young woman when her father first saw her. He was very muclı pleased, and said: "My dear wife, you should have told me of this before." 
The girl had never been out of the house in the daytime. Only in the night she had gone out, when people could not see her.

The man said to his wife: "You must make much beer, and invite many people to come and rejoice with me over this that has happened." The woman did so. There was a big tree in front of the kraal, and the mats were spread under it. It was a fine sunny day, and very many men came. Among them was the son of a certain chief, who fell in love with Tangalimlibo as soon as he saw her. When the young chief went home he sent a message to the father of the girl that he must send her to him to be married. The man told all his friends about that. He told them also to be ready at a certain time to conduct his daughter to the chief. So they came and took her, and the marriage feast was very great. The oxen were many which were killed that day. Tangalimlibo had a large and beautiful ox given to her by her father. It was called by her name. She took off a piece of her clothing and gave it to the ox, which ate it.

After she had been married some time, this woman had a son. She was loved very much by her husband, because she was pretty and industrious; only this thing was observed of her, that she never went out in the daytime. Therefore she received the name Sihamba Ngenyanga (the walker by moonlight).

One day her husband went to a distant place to hunt with other men. There were left at his home with this woman only her father-in-law, her mother-in-law, and a girl who nursed the little child. The-father-in-law said: "Why does she not work during the day?" He pretended to become thirsty, and sent the girl to Tangalimlibo to ask for water, saying: "I die with thirst." The woman sent water to her father-in-law, but he threw it on the ground, saying: "It is water from the river I desire." She said: "I never go to the river in the daytime." $\mathrm{He}$ continued to ask, saying again: "I die with thirst." Then she took a milkbasket and a calabash ladle, and went weeping to the river. She dipped the ladle in the water, and it was drawn out of her hand. She dipped the milk-basket in the water, and it was drawn away from her. Then she tried to take some water in her mantle, and she was drawn under the surface.

After a little time the girl was sent to look for her, but she came back, saying: "I found her not who is accustomed to draw water only in the night." 
Her father-in-law drove oxen quickly to the river. He took the big ox that was called by her name and killed it. He put all the flesh and everything else that was of that ox into the river, saying: "Let this be instead of my child." A voice was heard saying: "Go to my father and my mother and say to them that I am taken by the river."

That evening the little child of Tangalimlibo was crying very bitterly. Its father was not yet home. Its grandmother tried by every means to keep it from crying, but in vain. Then she gave it to the nurse, who fastened it on her back. Still the child continued to cry. In the middle of the night the nurse went down to the river with the child, singing this song :

\footnotetext{
"It is crying, it is crying, The child of Sihamba Ngenyanga;

It is crying, it will not be pacified."
}

Then the mother of the child came out of the river, and wailed this song :

"It is crying, it is crying, Sihamba Ngenyanga,

The child of the walker by moonlight. Sihamba Ngenyanga.

It was done intentionally by people whose names are unmentionable. Sihamba Ngenyanga.

They sent her for water during the day. Sihamba Ngenyanga.

She tried to dip with the milk-basket, and then it sank. Sihamba Ngenyanga.

Tried to dip with the ladle, and then it sank. Sihamba Ngenyanga.

Tried to dip with the mantle, and then it sank. Sihamba Ngenyanga."

Then she took her child and put it to her breast to suck. When the child had finished sucking, she gave it back to the nurse, telling her to take it home. She commanded the nurse never to say to any one that she came out of the water, and told her that when people asked where the child got food she must say she gave it berries to eat. This continued for some days. Every night the nurse took the child to the river, when its mother came out and suckled it. She always looked round to see that no one was present, and always put the same command on the girl.

After a time the father of the child returned from hunting. They told him of Tangalimlibo's going to the river and not returning. Then the nurse brought the child to him. He inquired what it ate, and was told that berries were given to it. He said: "That cannot be so ; go and get some berries, and let me see my child eat them." The girl went and brought some 
berries, but thcy were not eaten by the child. Then the father of the child beat the girl until she told him the truth. She said she went at night to the river, when the mother came out and caressed her child and gave it of her milk.

Then they made a plan that the husband of Tangalimlibo should hide himself in the reeds and try to catch his wife when she came out of the water. He took the skin of an ox and cut it into a long riem, one end of which he fastened round his waist. The other end he gave to the men of that place, telling them to hold it fast and to pull hard when they felt it being drawn from them. At night the man hid himself in the reeds. Tangalimlibo came out of the water and looked all round while she was singing her song. She asked the girl if any one was there, and when the girl replied that there was no one she took her child. Then her husband sprang upon her, clasping her very tight. She tried to pull back, but the men at the village drew-upon the riem. She was drawn away, but the river followed her, and its water turned into blood. When it came close to the village, the men who were pulling at the riem saw it, and became frightened. They let the riem go, when the river at once went back, taking Tangalimlibo with it.

After that her husband was told of the voice which came from the water, saying: "Go to my father and my mother and tell them I am taken by the river." He called his racing ox, and said: "Will you, my ox, take this message to the father and mother of Tangalimlibo?" The ox only bellowed. He called his dog, and said: "Will you, my dog, take this message to the father and mother of Tangalimlibo?" The dog only barked.

Last of all he called the cock. He said : "Will you, my cock, take this message to the father and mother of Tangalimlibo?" The cock answered : "I will do so, my master." He said : "Let me hear what you will say." The cock answered : "I will sing

"I am a cock that ought not to be killed-Cock-a-doodle-doo!

I have come to intimate about Tangalimlibo-Cock-a-doodle-doo

Tangalimlibo is dead-Cock-a-doodle-doo!

She dipped water for a person that cannot be named-Cock-a-doodle-doo !

It was tried to send an ox; it bellowed-Cock-a-doodle-doo!

It was tried to send a dog; it barked-Cock-a-doodle-doo ! ${ }^{22}$

The chief said: "That is good, my cock, go now." As the cock was going on his way, some boys who were tending calves 
saw him. One of them said to the others: "Come here, come here, boys ; there is a cock for us to kill." Then the cock stood up, and sang his song. The boys said: "Sing again, we did not hear you plainly." So he sang again: "I am a cock" \&c. (as above). Then the boys let him go on his way.

He travelled far from that place, and came to a village where the men were sitting in the kraal. He flew up on the back of the kraal to rest himself, and the men saw him. They said: "Where does this cock come from? We thought all the cocks here were killed. Make haste, boys, and kill him." The cock began to sing his song. Then the men said: "Wait, boys, we wish to hear what he says." They said to him : "Begin again, we did not hear you." The cock said : "Give me some food, for I am very hungry." The men sent a boy for some millet, and gave it to him. When he had eaten, he sang his song. The men said: "Let him go," and he went on"his way.

Then he came to the village of the father of Tangalimlibo, to the house of those he was seeking. He told the message he was sent to carry. The mother of Tangalimlibo was a woman skilful in the use of medicines. She said to her husband: "Get a fat ox to go with us." They arrived at the river, and killed the ox. Then that woman worked with her medicines while they put the meat in the water. There was a great shaking and a rising up of the river, and Tangalimlibo came out. There was great joy among those people when they took her home to her husband.

\section{The Runaway Children, or the Wonderful Feather.}

Once in a time of famine a woman left her home and went to live in a distant village, where she became a cannibal. She had one son, whose name was Magoda. She ate all the people in that village, until only herself and Magoda remained. Then she was compelled to hunt animals, but she caught people still when she could. In hunting she learned to be very swift of foot, and could run so fast that nothing she pursued could escape from her.

Her brother, who remained at home when she left, had two daughters, whom he did not treat very kindly. One day he sent them to the river for water, which they were to carry in two pots. These pots were made of clay, and were the nicest and most valuable 
in the village. One of the girls fell down on a rock and broke the pot she was carrying. Then she did not know what to do, because she was afraid to go back to her father. She sat down and cried, but that did not help, the pot would not be whole again. Then she said to her sister: "Let us go away to another place, where our father will not be able to find us." She was the younger and the cleverer of the two, and so she persuaded her sister.

They walked away in the opposite direction from their home, and for two days had nothing but gum to eat. Then they saw a fire at a distance, and went to it, where they saw a house. It was the house of their aunt, but they did not know it. They were afraid to go in, but Magoda came out and talked to them. When he heard who they were, he was sorry for them, and told them their aunt was a cannibal, giving them advice not to stay there. But just then they heard her coming, so they went into Magoda's house and hid themselves, for he lived in one house and his mother in another.

The woman came and said: "I smell something nice; what is it, my son?" Magoda said there was nothing. She replied: "Surely I smell fat children." But as she did not go in, they remained concealed that night.

The next morning the mother of Magoda went out to hunt, but she did not go far, so the children could not get away. They went into her house, where they saw a person with only one arm, one side, and one leg. The person said to them : "See, the cannibal has eaten the rest of me ; take care of yourselves."

When it was nearly dark, the mother of Magoda came home again, bringing some animals which she had killed. She smelt that children had been in the house, so she went to her son's house and looked in. She said to Magoda: "Why do you not give me some? Do I not catch animals for you?"

Then she saw the children, and was very glad. She took them to her house, and told them to sleep. They laid down, but were too frightened to close their eyes. They heard their aunt say : "Axe, be sharp ; axe, be sharp;" and to let her know that they were awake, they spoke of vermin biting them. After a while the cannibal went to sleep, when they crept out, first putting two blocks of wood in their places, and ran a way as fast as they could. When the mother of Magoda awoke, she took the axe and went to kill them, but the axe fell on the blocks of wood. 
As soon as it was day, the cannibal pursued the children. They looked behind, and saw clouds of dust which she made as she ran. There was a tall tree just in front of them, so they hastened to climb up it, and sat down among the branches. The mother of Magoda came to the tree and commenced to cut it down; but when a chip fell out, a bird (ntengu) sang :

$$
\begin{aligned}
& \text { "Ntengu, ntengu, } \\
& \text { Chips, return to your places, } \\
& \text { Chips, return to your places, } \\
& \text { Chips, be fast." }
\end{aligned}
$$

The chip then went back to its place and was fast again. This happened three times; but the mother of Magoda, who was very angry, caught the bird and swallowed it. When she put it in her mouth, one of the feathers dropped to the ground. Then she began to chop at the trce again; but as soon as a chip was loose the feather sang:

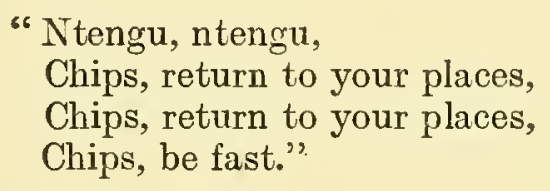

The chip then stuck fast again. The cannibal chopped till she was tired, but the feather continued to keep the tree from receiving harm. Then she tried to catch the feather, but it. flew about too quickly for her, until she sank down exhausted on the ground at the foot of the tree. The children up in the branches could see a long way off; and as they strained their eyes, they observed three dogs as big as calves, and they knew these dogs belonged to their father, who was seeking for them. So they called them by name, and the dogs came running to the tree and ate up the cannibal, who was too tired to make her escape. Thus the children were delivered, and their father was so glad to get them back again that he forgave them for breaking the pot and running away.*

* There are three or four versions of this story, but all agree in the main points. In one, it is the grandmother of the children who is the cannibal, in another, it is their mother, and in a third it is the husband of their aunt. One version makes Magoda escape with the children, and introduces a great deal of obscenity. The parts referring to the bi:d and the manner of the children's delivery are the same in all. So also is the episode of the broken pot, but the conversation between the two girls differs in some respects. The ntengu is rather larger than a swallow, and is of a bright bluish-black colour. It may often be seen on the backs of cattle, seeking for insects on which it feeds. 


\section{Story of Kenkebe.}

There was once a great famine in a certain country, and the people were obliged to eat wild plants to keep themselves alive. Their principal food during this time was nongwes (Hypoxis), which they dug out of the ground. There was living at that place a man called Kenkebe, and one day his wife said to him: "My husband, go to my father and ask him to give us some corn." The man said : "Yes, I will go." So he rose up early in the morning, and went on till he arrived at his father-in-law's village, where he was received with every mark of kindness. A very large ox was killed for his entertainment. It was so large that it was six days before it was all eaten.

His father-in-law asked of him the news. He said: "There is no news to tell to friends. All the news is this, that at my home there is not a grain to be eaten. Famine is over our heads. Will you give us some corn, for we are dying?" His father-in-law gave him seven bags (i.e., skins of animals dressed entire) full of millet, and his wife's sisters went with him to carry them. When they came to a valley close by his home, he told his sisters-in-law that they could now go back to their father. They said: "How will you manage to carry all those bags alone?" He replied: "I shall be able to carry them all now, because we are not far from my home." So those girls went back to their father.

Then he carried the bags one by one, and hid them in a cave under a great rock that was there. Afterwards he took some of the millet and ground it. When it was ground very fine he made it into cakes just like nongwes. Then he dug some real nongwes out of the ground, and went home to his wife. He said to her: "There is a great famine at your father's also. I found the people there eating themselves." He told his wife to make a fire. Then he pretended to cut a piece of meat out of his thigh, and said: "So they are doing at your father's village. Now, my wife, let us do the same." His wife cut a piece from her leg and roasted it. The piece that Kenkebe put on the fire was some that he brought home with him. Then Kenkebe's little boy said : "Why does my father's meat smell nice in roasting, and my mother's meat does not smell nice?" Kenkebe answered : "It is because it is taken from the leg of a man." 
After this he gave his wife some nongwes to roast. He took for himself some of those he had made of millet. The little boy said : "Why do my father's nongwes smell nice in roasting, and my mother's do not smell nice?" Kenkebe said : "It is because they were dug by a man." After eating, he went outside, but he had dropped one of his nongwes by the fire. When he went out the boy found that nongwe. He broke it in two and gave half to his mother. He said: "There is a difference between our nongwes and those of father." His mother said: "Yes, my child, this one is made of millet."

The next morning, just at the first beginning of dawn, Kenkebe got up and went away with a pot in his hand. The boy was awake, and saw his father go out. So he called to his mother, and said: "Mother, mother, wake, my father is going away with the pot in his hand." So she got up, and they followed after Kenkebe. They saw him go to the cave, where he took some corn out of one of the bags and began to grind it. Then they went on top of the rock, and rolled a big stone over.

When Kenkebe saw the stone coming he ran away, but it followed close behind him. He ran down the valley, the stone kept running too. He jumped into a deep hole in the river, down went the stone too. He ran up the hill, up went the stone also. He ran over the plain, but whenever he turned to look, the stone was there just behind him. So it continued all that day. At night he reached his own house, and then the stone stopped.

His wife had already come home, and had brought with her one of the bags of millet. Kenkebe came in crying. His wife said to him : "Why do you cry as if you were a child?" $\mathrm{He}$ said: "Because I am very tired and very hungry." She said: "Where are your clothes and your bag?" He replied: "I was crossing a river, and I fell down. The stream carried away my mantle, and my bag, and my keries, and everything that was mine." Then his wife gave him his mantle, which she had picked up when he was running away, and she said to him: "You are a very foolish man to do such things. There is no food for you to-night."

The next morning Kenkebe rose early and went out to hunt with his two dogs. The name of the one was Tumtumse, and the name of the other was Mbambozozele. He found an eland with a young calf, which he drove to his place. He cut an ear 
off the calf and roasted it in the fire. It was fat, and he liked it so much that he cut the other ear off and cooked it also. Then he wished to kill the calf, but he said to himself: "If I kill this calf I shall not be able to get milk from this eland." So he called his two dogs, and said to the one: "Tumtumse, my dog, if I kill this calf, will you imitate it and suck the eland for me?" The dog said: "No, I will bark like a dog." Kenkebe said: "Get out of my sight and never come near me again, you ugly, useless animal." He said to the other: "Mbambozozele, my dog, if I kill this calf, will you imitate it and suck the eland for me?" The dog said: "I will do so."

Then he killed the calf and ate it. He took the skin and put it upon Mbambozozele, so that the eland thought it was her calf that sucked before Kenkebe milked her. But one day the dog was sucking too long, and Kenkebe wanted him to leave off. He tried to drink just a few drops more, when his master got angry and struck him with a stick. Thereupon the dog began to howl, and the eland saw how she had been deceived. At once she ran after Kenkebe and tried to stick him with her horns. He ran one way and the eland ran after him, then he ran another way, and still the eland chased him. His wife came out and saw him running. She cried out to him: "Jump up quickly on the big stone." He did so, and the eland ran with such fury against that stone that it broke its head and fell down dead.

They then cut the eland up and wanted to cook it, but there was no fire. Kenkebe said to his son: "Go to the village of the cannibals that is on that hill over the valley, and ask for some fire; but do not take any meat with you, lest they should smell it." The boy went, but he hid a piece of meat and took it with him. When he got to the first house he asked for fire, but they sent him to the next. At the next they sent him farther, and so he had to go to the house that was farthest away. An old woman lived there. The boy gave her a little piece of meat, and said : "Do not cook it till I am far away with the fire."

But as soon as the boy was gone, she put it on the coals. The smell came to the noses of the cannibals, and they ran to the place and swallowed the old woman, and the meat, and the fire, and even the ashes. Then they ran after the boy. When he came near his own house, he cried out: "Hide yourselves, you that are at home." His father said: "My son is saying we must 
gather wood that will make coals." His mother said: "No, he is saying we must hide ourselves." The boy cried again: "Hide yourselves." Then his mother hid herself in a bush; an old woman that was there covered herself with ashes, and Kenkebe climbed up into a tree, with the breast of the eland in his hand. The boy slipped into a hole that was by the side of the path.

The cannibals came to the place. First they ate the eland. Then one of them said: "Search under the ashes." There they found the old woman, and they ate her. Then they said : "Search in the tree." There they found Kenkebe. He cried very much, but they would not spare him. They ate him and the breast of the eland. Then the wise one said: "Look in the bush." They looked there and found the wife of Kenkebe. They said: "We will eat her another time," and so they took her home with them. They did not look for the boy.

The woman made a plan to escape. She made beer for the cannibals, and they all came to drink. They sat together in a big house, and drank very much beer. Then she said: "Can I go out?" They said: "You can go, but come back quickly." She said: "Shall I close the entrance?" They said: "Close it." Then she took fire and put it on the house, and all those cannibals were burnt to death. So the woman escaped, and afterwards lived happily with her son.*

\section{Another Story of Kenkebe.}

At a certain time Kenkebe went to get his wife at the place of her parents. When he was on the way, he met a crow. He borrowed its eyes. Then he arrived at his wife's parents' place with the eyes of the crow. When he arrived, his wife said : "Where are your own eyes?" He replied: "My eyes have been taken away by the crows." Then his wife said: "Let us go home." When they reached home, his wife said: "Take those eyes, you silly one, to their owner, and bring back your own." Accordingly Kenkebe went for his eyes and got them back.

* In the above story Kenlsebe is represented as the personification of selfish greed. In this character his name has passed into a common proverb : Sibayeni sonke, Kenkebe, We are all bridegrooms, Kenkebe. This saying is used to any one who does not readily share food with others. It means, we are all entitled to a portion, you greedy one. A Xosa, when eating, commonly shares his food with any others who may be prosent at the time. 
Then, as he was returning, he met an ant, and exchanged stomachs with it. When he arrived at his house, his wife gave him food. After he had finished eating, he went to milk a cow. When he was gone out, his little boy went to the place where he had been sitting. He said: "Mother, this food that is spilt here, whose is it?" His mother replied: "Perhaps it has been spilt by your father. You must not eat it until your father comes." When Kenkebe came in, his wife said: "Where does this food come from?" The man replied : "My stomach has been borrowed by an ant." His wife said : "You must go and take this stomach back to-morrow." He went to do so. When he arrived at the ant's place, he demanded his stomach. His stomach was given to him, and then he went home.

\section{Story of the Great Chief of the Animals.}

There was once a woman who had occasion to leave her home for a short time, and who left her children in charge of a hare. The place where they lived was close to a path, along which droves of wild animals were accustomed to pass. Soon after the woman left, the animals appeared, and the hare at sight of them became frightened. So she ran away to a distance, and stood to watch. Among the animals was one terrible monster, which called to the hare, and demanded to know what children these were. The hare told their names, upon which the animal swallowed them entire.

When the woman returned, the hare told her what had happened. Then the woman gathered some dry wood, and sharpened two pieces of iron, which she took with her and went along the path.

Now this was the chief of the animals; therefore when she came on a hill over against him, the woman began to call out that she was looking for her children. The animal replied: "Come nearer, I cannot hear you." When she went, he swallowed her also. The woman found her children alive, and also many other people, and oxen, and dogs. The children were hungry, so the woman with her pieces of iron cut some flesh from the animal's ribs. She then made a fire and cooked the meat, and the children ate. The other people said: "We also are hungry, give us to eat." Then she cut and cooked for them also. 


\section{The Bantu.}

The animal felt uncomfortable under this treatment, and callcd his counsellors togcther for advice, but thcy could suggest no remedy. He lay down and rolled in the mud, but that did not help him, and at last he went and put his head in the kraal fence, and died. His counsellors were standing at a distance, afraid to approach him, so they sent a monkey to see how he was. The monkey returned and said: "Those whose home is on the mountains must hasten to the mountains ; those whose home is on the plains must hasten to the plains ; as for me, I go to the rocks." Then all the animals dispersed.

By this time the woman had succeeded in cutting a hole through the chief's side, and came forth, followed by her children. Then an ox came out, and said : "Bo! bo!* who helped me?" Then a dog, who said: "Ho! ho! * who helped me?" Then a man, who said: "Zo! zo!* who helped me?" Afterwards all the people and cattle came out. They agreed that the woman who helped them should be their chief.

When her children became men, they were out hunting one day, and saw a monstrous cannibal, who was sticking fast in a mud hole. They killed him, and then returned to tell the men of their village what they had done. The men went and skinned the cannibal, when a great number of people came out of him also. These joined their deliverers, and so that people became a great nation.

\section{Story of Demane and Demazana.}

Once upon a time a brother and sister, who were twins and orphans, were obliged on account of ill usage to run away from their relatives. The boy's name was Demane, the girl's Demazana. They went to live in a cave that had two holes to let in air and light, the entrance to which was protected by a very strong door, with a fastening inside. Demane went out hunting by day, and told his sister that she was not to roast any meat while he was absent, lest the cannibals should discover their retreat by the smell. The girl would have been quite safe if she had done as her brother commanded. But she was wayward, and one day she took some buffalo meat and put it on a fire to roast.

A cannibal smelt the flesh cooking, and went to the cave, but

* Imitating the voice of an ox, a dog, and a man coughing. 
found the door fastened. So he tried to imitatc Demane's voice and asked to be admitted, singing this song:

\footnotetext{
"Demazana, Demazana,

Child of my mother,

Open this cave to me.

The swallows can enter it.

It has two apertures."
}

Demazana said: "No. You are not my brother; your voice is not like his." The cannibal went away, but after a little time came back again, and spoke in another tone of voice: "Do let me in, my sister." The girl answered : "Go away, you cannibal ; your voice is hoarse, you are not my brother."

So he went away and consulted with another cannibal. He said: "What must I do to obtain my desire?" He was afraid to tell what his desire was, lest the other cannibal should want a share of the girl. His friend said: "You must burn your throat with hot iron." He did so, and then no longer spoke hoarse. Again he presented himself before the door of the cave, and sang:

\section{"Demazana, Demazana, Child of my mother, Open this cave to me. The swallows can enter it. It has two apertures."}

The girl was deceived. She believed him to be her brother come back from hunting, so she opened the door. The cannibal went in and seized her. As she was being carried away, she dropped some ashes here and there along the path. Soon after this, Demane, who had taken nothing that day but a swarm of bees, returned and found his sister gone. He guessed what had happened, and followed the path by means of the ashes until he came to Zim's dwelling. The cannibal's family were out gathering firewood, but he was at home, and had just put Demazana in a big bag, where he intended to keep her until the fire was made.

Demane said: "Give me water to drink, father." Zim replied : "I will, if you will promise not to touch my bag." Demane promised. Then Zim went to get some water; and while he was away, Demane took his sister out of the bag, and put the bees in it, after which they both concealed themselves.

When Zim came with the water, his wife and son and daughter came also with firewood. He said to his daughter: "There is 
something nice in the bag ; go and bring it." She went, but the bees stung her hand, and she called out: "It is biting." He sent his son, and afterwards his wife, but the result was the same. Then he became angry, and drove them outside, and having put a block of wood in the doorway, he opened the bag himself. The bees swarmed out and stung his head, particularly his eyes, so that he could not see. There was a little hole in the thatch, and through this he forced his way. He jumped about, howling with pain. Then he ran and fell headlong into a pond, where his head stuck fast in the mud, and he became a block of wood like the stump of a tree. The bees made their home in the stump, but no one could get their honey, because when any one tried his hand stuck fast.

Demane and Demazana then took all Zim's possessions which were very great, and they became wealthy people.

\section{Story of the Girl and the Mbulu.*}

There was once a widow woman who had one son and two daughters. On a certain day she went to her garden, taking with her one of the girls. While she was away the boy quarrelled with his sister and killed her. In the course of the day the woman sent the girl who was with her to the hut, and when she came there a fly told her what had happened. She did not believe it. Then a mouse told her the same thing, but still she did not believe it was true. Afterwards the fly told her to look in a certain place, and there she saw the head and the bones of her sister.

When the woman came home and found out what had happened, she killed her son. Then she gave the girl a stick, and told her to go to her uncle's house, saying that when she got there she must strike the ground with the stick, and all the clothes and other things that belonged to her would then rise up out of the earth. The woman said she was now all alone, and therefore intended to kill herself.

The girl was very sorry, but she did as her mother told her. When she was a little way off she looked back and saw smoke coming out of the hut, from which she knew that her mother had

* The mbulu is a fabulous creature, firmly believed in by little folks. It can assume the human form, but cannot part with its tail. One of its peculiarities is that it never speaks the truth when it is possible to tell a falsehood, 
burned herself and was no longer a person under the sun. After this she met an old woman, who called to her, but she took no heed and walked on. Next she met a mbulu at a place close by a river. The mbulu said that whoever wetted any part of the body in crossing the river must go in and bathe. The girl was standing on the bank, and the mbulu struck the water with its tail and splashed it in her face, so that she had to go in and bathe. Then the mbulu took her clothes and put them on. When the girl came out of the water she asked for her clothes, but the mbulu said : "I will give them when you are dry."

So they went on together. After a while the girl asked again, and the mbulu said : "I will give them when we get to the village." But when they arrived there the mbulu said: "You must tell the people here that you are my servant, and that I am the danghter of a chief." The poor girl was so afraid that she promised to do so. They were well received at the village, because the people believed that the mbulu was a great person. They wondered at her voice, but she told them she had been ill and her throat was not well yet.

After a time one of the men of that kraal married the mbulu, and the real girl was sent to the gardens to drive the birds away from the millet. While engaged in this occupation she used to sing about the mbulu taking her clothes and passing itself off for a person, until the women who worked in the gardens took notice of this song of hers. Then they made a plan to find out if what the girl was singing was the truth. They said: "The tail of a mbulu will want mice and fat," so they set snares to catch the mice. In the night the tail was pursuing mice, and itself got fast in a snare. The mbulu then asked the man who was married to her to go and get some medicine, as she was sick, and when the man went she took off the snare.

After this they made another plan. They said: "The tail of a mbulu will seek milk," so they dug a hole in the ground, put milk in it, and required every one in the village to jump over the hole. The mbulu was unwilling at first, but they urged her. She tried to jump quickly, but the tail could not pass the milk. When it went down the people saw that this was a mbulu, so they killed it and buried it in that hole.

After this the same man who had married the mbulu took the girl to be his wife. She had a child, and one day when it was 
playing a square gourd came out of the ground where the mbulu was buried, and tried to kill the infant. But the people ehopped the gourd in pieces, and burned it. They afterwards threw the ashes into a river, so that nothing more could come of that mbulu.

The foregoing is one of the stories in which the actors were believed half a century ago by adult Xosa females to be real beings. They did not doubt the existence of mbulus at that very time, and accounted for their not being generally recognisable by saying they were so cunning that they managed to conceal themselves, for if they could only hide their tails no one would know they were not women. They enter into many of the folklore stories, and play parts always marked by deceit. It will have been observed that the same, or nearly the same, incident occurs in different tales, so that it is possible that many of them have been formed from a single story extant in the olden time.

In a very interesting and valuable work upon the Ba. tonga, termed The Life of a South African Tribe, giving a great amount of information concerning that section of the Bantu family, the reverend Henri A. Junod, of the Swiss Romande mission, published a version of the story of the Girl and the Mbulu, almost the same as the one here given.* It is coloured by expressions derived from contact with European civilisation, and no doubt those collected by me among the Xosas over forty years ago have undergone or are undergoing similar changes. The whole life of the Bantu south of the Zambesi is different now from what it was half a century ago, and the phraseology of the olden time has given place to language that appeals better to the understanding to-day. But the groundwork of a tale remains as it was. The Batonga and the Amaxosa are not so distantly related to each other as are the Barolong and the

* See The Life of a South African Tribe, volume ii, published at Neuchatel in 1913. The story, entitled by Mr. Junod The Ogre ScalyHeart, will be found on pages 231 to 341 of the volume. 
Amaxosa, as both came from the same locality in the distant north-west, but they have been separated for at least four hundred and fifty years. This tale must therefore be of considerable age, though perhaps it is not so very ancient as the Story of the Bird that made Milk.

As far as I am aware, the only folklore tale of the $\mathrm{He}$ rero tribe that has yet been collected and published by a European, except those in the Folklore Journal, is the following. The Herero and Xosa tribes may have lived together, possibly indeed have been one people at some distant time, but for at least five hundred years they have been separated. Yet on comparing this tale with the incident in the story of Hlakanyana given on page 359 of this volume, it will be seen that they are almost identical. The Herero story was taken down by the reverend $\mathrm{e}$. Rath, of the Rhenish missionary society, and was presented by him to Sir George Grey's library in Capetown. It was translated into English, and published in 1864 in Dr. Bleek's Reynard the Fox in South Africa, from which I take it.

The Unreasonable Child to whom the Dog gave its Deserts.

There was a little girl who had an eingi (pronounced a-inghi, some kind of fruit). She said to her mother : "Mother, why is it that you do not say, My first-born, give me the eingi? Do I refuse it?"

Her mother said: "My first-born, give me the eingi." She gave it to her, and went away. Her mother ate the eingi.

When the child came back, she said, "Mother, give me my eingi," but her mother answered, "I have eaten the eingi."

The child said, "Mother, how is it that you have eaten my eingi, which I plucked from our tree?" The mother then to appease her gave her a needle.

The little girl then went away and found her father sewing thongs with thorns; so she said, "Father, how is it that you sew with thorns? Why do you not say, My first-born, give me your needle. Do I refuse ?"

So her father said, "My first-born, give me your needle." 
She gave it to him, and went away for a while. Hor fathor commenced sewing, but the necdle broke. When therefore the child came back and said, "Father, give me my necdlc," he answered, "The nccdle is broken;" but she complained about it, saying, "Father, how is it that you break my needle, which I got from Mother, who ate my eingi, which I had plucked from our tree?" Her father then gave her an axe.

Going farther on, she met the lads who were in charge of the cattle. They were busy taking out honey, and in order to get at it they were obliged to cut down the trees with stones. She addressed them, "Our sons, how is it that you use stones in order to get at the honey? Why do you not say, "Our first-born, give us the axe. Do I refuse, or what do I ?" They said, "Our first-born, give us the axe." So she gave it to them, and went away for some time. The axe broke entirely. When she came back, she asked, "Where is the axe? Please give it to me." They answered, "The. axe is broken." She then said, "How is it that you break my axe, which I had received from Father who had broken my needle, which I got from Mother who had eaten my eingi, which I had plucked from our tree?" But they gave her some honey (to comfort her).

She went her way again, and saw a little old woman eating insects, to whom she said, "Little old woman, how is it that you eat insccts? Why don't you say, My first-born, give me honey. Do I refuse or not?" Then the little old woman asked, "My first-born, give me honey." She gave it to her, and went away; but presently returning, said, "Little old woman, let me have my honey." Now the old woman had managed to eat it all during her absence, so she answered, "Oh! I have eaten the honey." So the child complained, saying, "How is it that you eat my honey, which I received from the lads of our cattle, from our children who had broken my axe, which had been given me by Father who had broken my needle, which was a present from my mother who had eaten my eingi, that I had plucked from our tree?"

The little old woman gave her food, and she went away. This time she came to the pheasants, who scratched the ground; and she said, "Pheasants! how is it that you scratch the ground? Why do not you say, First-born, give us food? 
Do I refuse, or what do I ?" They said, "First-born, give." So she gave to them, and went away. When she came back and demanded her food again, they said, "We have eaten the food." She asked, "How is it that you have caten my food, which I had received from a little old woman who had eaten my honey, that I had got from the lads of our cattle who had broken my axe, which had been given me by my father who had broken my needle, which was a present from my mother who had eaten my eingi, which I had plucked from our tree?" The pheasants, flying up, pulled out each one a feather and threw them down to the little girl.

She then, walking along, met the children who watched the sheep. They were plucking out hairs from the sheep skins. So she asked them, "How is it that you pull at these skins? Why do not you say, First-born, give us the feathers. Do I refuse, or what do I?" They said, "First-born, give us the feathers." She gave them, and went away, but all the feathers broke. When she returned and said, "Give me my feathers," they answered, "The feathers are broken." Then she complained, "Do you break my feathers which I received from the pheasants who had eaten my food, which had been given to me by a little old woman who had eaten my honey, that I had got from the lads of our cattle who had broken my axe, which had been given me by my father who had broken my needle, which was a present from my mother who had eaten my eingi, which I had plucked from our tree?" They gave her some milk.

She went again on her way, and found their own handsome dog gnawing bones. She said, "Our dog, how is it that you gnaw these bones?" The dog answered, "Give me milk." She gave it to him, and he drank it all. Then she said to the dog, "Give me back my milk." He said, "I drank it." She then repeated the same words she had spoken so often before, but the dog ran away, and when she pursued him he scampered up a tree. She climbed up after him, but the dog jumped down again on the other side. She wanted to do the same, but could not. Then she said, "Our dog, please help me down." He answered, "Why did you pursue me?" and ran away, leaving her up the tree.*

* A Tonga version of this story is given by the reverend Mr. Junod. 
At the present day no individual of the Bantu family who has not received an education in European schools could compose a tale like any of the foregoing, all of which display a large amount of ingenuity and power of thought in puttings them together. As far as my reasoning goes there is but one way of accounting for their existence. In some remote time an individual, or possibly more than one at different periods, born with a capacity beyond that of ordinary men, invented them, and they have been transmitted orally from one generation to another ever since. Such a man was Homer, and in this way the Iliad and the Odyssey were transmitted by the Greeks until the art of writing became known to them.

Among the early Bantu there must have been a man like the great Hellenic poet, though of course with an intellect inferior to bis, who knew how to tell his fellows something that appealed so strongly to their sympathies, because it represented their ordinary conduct and thoughts most faithfully, that they treasured his productions and preserved them with a feeling akin to veneration. In the terrible vicissitudes of the career of the Bantu, conquering and at times conquered, splitting up into tribes independent of each other, one tribe incorporating females of hamitic blood, another of negro blood, another again of Bushman blood, and so on, the traditional lore of necessity became altered to a large extent in different groups, but the principal features of it were preserved unchanged. In reading these tales therefore we are making ourselves acquainted with the highest power of the Bantu mind previous to contact with European civilisation, and in comparing the versions of different groups we are witnessing the strife of the distant past.

In the absence of all historical records such as every state even semi-civilised possesses, recourse must be had to anything and everything that will throw light upon events in the distant past of South Africa. In this respect folklore tales are of high importance, as from them can be 
learned the course of the migrations of the various tribes that at present occupy the country. But the collection is as yet too imperfect and is limited to so small a number of the tribes of the interior and of the western coast that it can only answer its purpose to a very limited extent. For instance, the folklore of the tribes in Angola and Benguela and of the Avare group is entirely wanting. Those who have written of these people hitherto have apparently considered it beneath their notice, or as interesting only to children, and have lost sight of its great value for historical purposes. Some day men like Bishop Callaway and the reverend Mr. Junod may find it worth the time and trouble needed to collect it, and we shall then have a much more complete base upon which to build up the details of past affinities and migrations than we have at present.

Of course it is not meant that folklore is the only subject needed in making historical researches concerning the Bantu tribes, but that it is one of the most important. In a classification of subjects it should take precedence even of language, because there are instances of tribes being compelled by conquest to adopt dialects different from the one originally spoken by them. But when the folklore is the same the affinity is beyond all question. 


\section{CHAPTER XVI.}

Rapid Increase of the Bantu in number.

Wherever the Bantu have been met with, whether on the coast of Guinea or in South or Central Africa, the tribes have been found in a state of almost constant war with each other, and putting great numbers of individuals to death on charges of dealing in witchcraft when they could not sell them into slavery to Europeans. It is believed by some persons that the tribes along the western coast were instigated by slave traders to make war with others farther inland for the express purpose of capturing prisoners for sale, but this was certainly not a common practice, though it may have been done on a few occasions. The slave traders were not as a whole such inhuman monsters. Some of them were men of benevolent dispositions, who really believed that they were aiding in the improvement of the condition of the blacks by securing to them their lives and a sufficiency of food, and removing them from a land of heathen darkness to places where they would have an opportunity of learning something of Christian light. Detestable as the system of slavery by Europeans unquestionably was, it was as unquestionably an enormous improvement upon the normal condition of the poor and helpless in every African community. This is a novel assertion to make, but it is a perfectly correct one.

It must be remembered that the worst horrors of the slave trade, the march from the interior to the coast of bands of captives manacled together or fastened one to another with wooden forks, when any who became too faint to travel were put to death as useless, when little children 
were left behind to perish while their mothers were driven on with the whip, must not be laid to the charge of Europeans, but to that of Africans of the same blood as the wretched creatures themselves, men whose hearts were hardened by the possession of absolute power and the insane belief in witchcraft. Even the fearful misery endured in the sea passage was not so appalling to the slaves in the early days of the traffic, accustomed as they were to hardships of every kind, as it became in the beginning of the nineteenth century, when the risk of capture by British cruisers caused the traders to play a desperate game by stowing the blacks between decks as closely as they could be packed. It was not worth while to make the venture without the prospect of enormous gain. Such a commerce to the enlightened eyes of Englishmen to-day was simply devilish, but it should not be painted in blacker colours, as far as Europeans are concerned, than it was really tinted with. The slaves transported to America and kept in bondage there were far more prolific than Europeans, as can be seen from the census returns of the countries that imported them. Most of them were Bantu, but some were pure negroes.

In South Africa there has been a better opportunity than in Europe to learn how one Bantu tribe can treat another weaker than itself. No one who has seen the Balala in Betshuanaland even as late as the seventh decade of the nineteenth century, or who has read attentively the accounts of early travellers concerning them, will deny that slavery to Europeans was preferable to their condition. And yet the Balala multiplied as rapidly as did their masters. With intelligence but little superior to that of terriers, without any other aim in life than to ward off the sharpest pangs of hunger, those wretched creatures increased in number at such a rate that if many of them had not been destroyed and many more died of famine they would have swarmed in the land. It must have been the same with the tribes along the western coast that supplied the barracoons with 
the ancestors of the millions of blacks who now inhabit the West India islands, Brazil, and the southern states of the American union: they were prolific in a wonderful degree, but their number was kept down by artificial means. Most of the wretched captives taken to the coast for sale to white men were individuals condemned by their own people for being sorcerers, and who, together with their families in many instances, would have been put to death if a love of gain had not induced their chiefs to dispose of them to foreign purchasers. Far the larger number of them were slaves from their birth, for that was the normal condition of existence of the bulk of most African tribes.*

These drains upon the population must have been continuous from the earliest times, and yet the Bantu increased in number until they occupied a very large portion of the African continent. This is sufficient proof of their amazing

* See any account of the wcstern coast of Africa in any European language published in carly times, of which I may mention particularly the two following in English: A Voyage to the river Sierra Leone on the Coast of Africa, containing an Account of the Trade and Productions of the Country and of the Civil and Religious Customs and Manners of the People, in a series of Letters to a Friend in England. By John Matthews, Lieutenant in the Royal Navy, during his Residence in that Country in the Years 1785, 1786, and 1787. With an additional Letter on the Subject of the African Slave Trade. An illustrated demi octavo volume of one hundred and eighty-three pages and a folding-out map, published in London in 1788. This author sums up his obscrvations in the following words: "The trade therefore which the Europeans carry on with the natives of Africa for slaves is probably permitted by Providence as a means of prescrving the lives of the many thousands who would otherwise be put to death, and are thus made useful members of society." See also Observations upon the Windward Coast of Africa, the Religion, Character, Cusioms, \&c., of the Natives, with a Sysiem upon which they may be civilised and a Knowledge attained of the Interior of this Extraordinary Quarter of the Globe, and upon the Natural and Commercial Resources of the Country, made in the Years 1805 and 1806, by Joseph Corry. With an Appendix containing a Letter to Lord Howick on the most simple and effectual Means of abolishing the Slave Trade. A demi quarto volume of one hundred and sixty-three+xiv pages, with large folding-out plates, published in London in 1807. 
fertility as compared with Europeans, for no white nation could continue to exist under similar circumstances. The length of time that has elapsed since the arrival in Africa of the parent Bantu cannot be ascertained with precision, but whether it was long or short makes no difference in calculating the rate of increase on the same scale as that of Caucasians, because 0 multiplied by 2,000 or by 20,000 remains the same.

Sir Harry $H$. Johnston in his article on the Bantu Languages in the last edition of the Encyclopedia Britannica says: "The general deduction to be drawn from a study of the Bantu languages, as they exist at the present day, is that at some period not more than three thousand years ago a powerful tribe of negroes speaking the Bantu motherlanguage, allied physically to the negroes of the southwestern Nile and southern Lake Chad basins (yet impregnated with the Caucasian Hamite), pushed themselves forcibly from the very heart of Africa (the region between the watersheds of the Shari, Congo and western Nile) into the southern half of the continent.

"Relying on linguistic evidence," he "fixed the approximate date at which the Bantu negroes left their primal home in the very heart of Africa at not much more than two thousand years ago; and the reason adduced lay in the root common to a large proportion of the Bantu lan. guages expressing the domestic forvl-7uku (nkuku, ngoko, nsusu, nguku, nku). Now the domestic fowl reached Africa first through Egypt, at the time of the Persian occupation -not before 500 to 400 B.c. It would take at that time at least a couple of hundred years before-from people to people and tribe to tribe up the Nile valley-the fowl, as a domestic bird, reached the equatorial regions of Africa. ... The Bantu people must have had the domestic fowl well established amongst themselves before they left their original home, because throughout Bantu Africa (with rare exceptions and those not among the purest Bantu tribes) the root expressing the domestic fowl recurs to the one vocable of 
kuku. Curiously enough this root kuku resembles to a marked degree several of the Persian words for fowl, and is no doubt remotely derived from the cry of the bird....

"The possession amongst its root-words of a common name for fowl seems to show conclusively that (1) the original Bantu tribe must have possessed the domestic fowl before its dispersal through the southern half of Africa began, and that (2) as it is historically certain that the fowl as a domestic bird did not reach Egypt before the Persian conquest in 525 B.c., and probably would not have been transmitted to the heart of Africa for another couple of hundred years, the Bantu exodus (at any rate to the south of the equatorial region) may safely be placed at a date not much anterior to 2100 years ago."

This argument by Sir Harry Johnston is entitled to. respectful consideration, as indeed would be anything from his pen, but it does not seem to me to be by any means conclusive as to the locality in which the Bantu had their original home, though as far as the dispersal and migration of the tribes is concerned, it is based on the same solid ground as numerous other root words could have afforded. It assumes that as a distinct people the Bantu had their birthplace and commenced their career in Central Africa, and that the domestic fowl was received by them from Egypt. That the Bantu originated in Asia and were invaders of Africa fits in with all that we see and know of their condition and their language better than Sir Harry Johnston's theory, and the parent tribe may have brought the domestic fowl with them, without going near Egypt or having any communication directly or indirectly with that country. Even the "resemblance to a marked degree of the word kuku to several of the Persian words for fowl" seems to support an Asiatic rather than an African birthplace of the Bantu.

The eminent philologist Dr. W. H. I. Bleek observed that the language of the Bantu has close affinities with the Malayan, Papuan, and Polynesian tongues, and his authority 
is of the greatest weight. This camnot be reconciled with an African origin.

Mr. J. F. van Oordt has endeavoured to show that the ancestral tribe or tribes of the Bantu were immigrants from Asia of a recent date, by comparing long lists of words in various Bantu dialects with similar lists of words having the same meanings in several Asiatic languages.* He takes no account of the structure of sentences, but confines his argument to the vocabularies, and bases his conclusion upon them alone. It has been stated in a preceding chapter that not a few Bantu words certainly have roots in common with Latin and English words, and a surmise has been made as to the cause. But that surmise fails to explain the very large number of instances given by $\mathrm{Mr}$. Van Oordt, which tend to show that the original Bantu tribe must at least have had close intercourse or connection with people in Southern Asia. It leaves the approximate number of the invaders undecided, which must necessarily be known before an accurate account of the increase to the present day can be given.

In addition to language, religion must be taken into consideration when dealing with the past history of these people. It consists of a mixture of ancestor spirit worship and fetishism, in different proportions in different tribes. The first of these elements must have been brought from Asia, for it is widely prevalent there, and it is inconceivable that it could have had its origin in Central Africa. Fetishism was developed after their arrival in this continent, particularly by the tribes that mixed their blood with that of the more degraded negroes who were here before them.

In many other countries where Europeans have settled, as for instance in the United States of America, in Canada, in Australia, and in New Zealand, the earlier uncivilised inhabitants have dwindled away, and in one-Tasmania-

* See The Origin of the Bantu, by J. F. van Oordt, B.A. A roya octavo pamphlet of ninety-seven pages, published by the government of the Cape Colony in 1907. 
have entirely died out. 'I'he chief cause of this has been the introduction of new diseases, which had spent their force upon Europeans long ago, and had consequently ceased to be very destructive to them, but which swept off the uncivilised people, who had not gone through the same hardening process, in an appalling manner. Chief among the diseases that operated in this way, and that opened vast territories to European occupation, was the small-pox. In former times, when no preventive for this scourge was known, its introduction into a new country, was followed by the almost complete extermination of the barbarous inhabitants. In South Africa in the eighteenth century its ravages were terrible. Whole tribes of Hottentots utterly disappeared before it, and even the Bantu did not entirely escape, for the section of the Tembus living between the Kei and Bashee rivers perished almost to a man. The state of constant warfare in which these people lived, however, preserved the neighbouring tribes from the same fate. They were so isolated that other tribes did not come in contact with them, especially when it was reported that they were bewitched and were dying like locusts in a storm of hail.

Then came the discovery that small-pox could be prevented by vaccination, and the Bantu were spared from the fate that had overtaken the Hottentots. The Europeans who introduced the disease into Capetown did all that was possible to prevent its spreading, and ultimately taught the Bantu tribes how to ward off danger from it. Consumption, another fell disease that has worked havoc among many barbarous nations, was almost unknown to South Africa until recent years. Europeans suffering from pulmonary complaints came to this country to be cured, and if the disease was not too far advanced they were usually restored to perfect health in its warm dry air. For a long time they did not come in close contact with Bantu, and consequently did not communicate the disease to them. The dark-skinned people, sprung from robust parents, for all the weaklings were destroyed in infancy, living on plain but substantial 
food, using little clothing, but lubricating their persons, and passing their days in the open air of a mild climate, with a moderate amount of exercise, enjoyed much more perfect health than falls to the dwellers in civilised Europe or America. Setting aside occasional cases of leprosy, it was only when they were maimed by accident, which did not very often occur, or when men were wounded in battle, that the whole inhabitants of a kraal, male and female, were not as sound in wind and limb as people can be. The only cases of sickness commonly found were in the chief's family, which arose from living on the best of everything and passing away the time in perfect indolence.

Thus after the awful destruction of human life by the wars of Tshaka, when in the fourth decade of the nineteenth century European dominion was established northward as far as the Limpopo and the surviving Bantu could emerge from the mountains and deserts and cultivate the ground and breed cattle once more, there was a people possessing greater power of increasing their number rapidly than any other on the face of the earth. The European governments removed all the checks to speedy growth that had existed in early years. They prevented the tribes from fighting with and slaughtering each other, and they would not permit the putting to death of individuals charged with dealing in witchcraft. They suppressed to some extent even in independent communities the arbitrary power of the chiefs over the lives of their people. In most localities, though not in all, they even prohibited the sale of intoxicating liquor to the barbarians. For some time the effect was hardly noticed, but at length it became so apparent that every one was forced to observe it. The locations assigned to the Bantu, more than ample in size when they were first set apart, became overcrowded, and the surplus population flowed out into places previously vacant or nearly so. The crown lands were invaded, privately owned farms were occupied by Bantu on lease, a system which, when once commenced, had a tendency to 
spread, for the neighbouring farmers were forced to do the same, or remain to be plundered, and there was a constant application to the governments for land, always more land. The great uninhabited wastes that every traveller in the fourth decade of the nineteenth century described were half a century later teeming with human life.

A comparison of the number of children under fifteen with that of females over fifteen years of age in different parts of the world in 1881 shows the surprising rate of increase of the Bantu at that time. The census of England and Wales in that year showed the proportion to be $110 \cdot 17$ to 100 , in Canada it was 124.73 to 100 , in the European population of the United States it was (census of 1880) $130 \cdot 76$ to 100 , in Australia $145 \cdot 62$ to 100 , and in New Zealand $177 \cdot 16$ to 100 . In the census returns of the Cape Colony in 1875 the proportion of Bantu children under fifteen to females over fifteen years of age is given as 169.98 to 100 , but these include all the drunkards and all the degraded residents in the town locations, so the return must be taken as of the Bantu under the least favourable circumstances at that time for increasing their number. It is certain that a census taken almost anywhere else in South-Eastern Africa would have shown a larger proportion of children under fifteen to females over that age. On every occasion where large parties have been accurately numbered,-as in instances of their removal when they were provided with food by the government in different quantities for men, women, and children of both sexes under fifteen years of age, ${ }^{*}$-this was the case. In a considerable number of such cases the lowest proportion was 195 children to 100 females over fifteen.

In the negroes of the United States the proportion of children under fifteen to females over that age was $172 \cdot 28$ to 100 . Bring-

* In the case of infants at the breast with the sanction of the government I allowed the mother a child's ration extra when the Gaikas of Ngonyama were removed by me from the frontier during the war of 1878. This was also the rule with regard to the women and children sent to Capetown during the war, and with regard to the people of Sandile and Anta who were removed to Kentani from the present district of Catheart, so that the ration returns arc safe guides. 
ing these proportions together that they may be seen in one glance, the ratio was

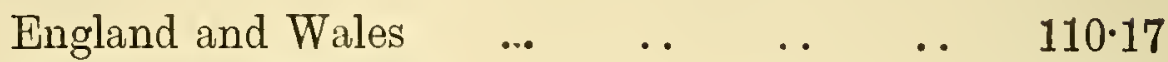

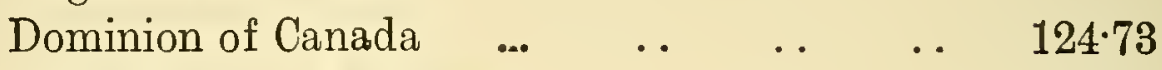

United States, European $\quad \ldots \quad \ldots \quad \ldots \quad \ldots \quad 130 \cdot 76$

$\begin{array}{lllllll}\text { Australia . . } & \text {.. } & \text {... } & \text {. . } & \text {. } & \text {.. } & 145.62\end{array}$

Bantu of South Africa under the least

favourable circumstances ... $\quad$.. $\quad \ldots \quad$... $169 \cdot 98$

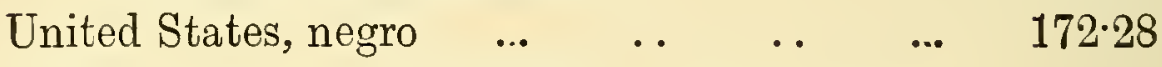

New Zealand, where all the conditions were

most favourable to the increase of the

$\begin{array}{lllllll}\text { Europeans } & \ldots & \ldots & \ldots & \ldots & \ldots & 177 \cdot 16\end{array}$

Bantu of South Africa under ordinary circum-

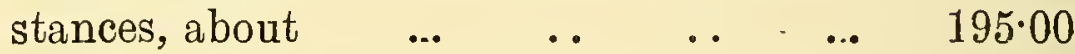

Early in 1885 a circular containing several questions having reference to this matter was issued at the request of the author of this volume by the native affairs department of the Cape government to the officers in the territories occupied by Bantu, and copies were also supplied to the missionaries and leading traders with a request that they would kindly assist in the investigation. The returns sent in were voluminous, but the substance of them all when condensed was as follows:

Question 1. To what cause or causes do you assign the great increase of the Bantu in number during recent years?

To this question the replies were almost uniform in language; and entirely uniform in effect: To the controlling power of the civilised governments.

While, except in that very small section of the people that had embraced Christianity, there was nothing to affect sensibly any of the causes that in former times tended to a rapid increase of population,--such as early marriages, polygamy which secured that no woman capable of childbearing should remain single, constitutional vigour, freedom from heritable diseases, and absence of care and anxiety as to provision for children,-the ancient checks upon overgrowth had been removed. 
(a) Tribal wars and feuds between clans, by which great numbers of people were formerly destroyed, had been prevented.

(b) The execution of people on charges of dealing in witchcraft had been suppressed.

(c) A better and surer supply of food than in ancient days was secured. The introduction of the plough had enabled the people to grow much more corn, and in seasons of drought they could procure food in return for labour or in exchange for property of any kind. The improved means of intercourse admitted of food supplies being sent to any part of the country where there was a demand for them.

Question 2. Which people attain the greatest average age, the Bantu or the European? On what calculations do you base your reply?

To this question the answers from nearly all the old and experienced magistrates, missionaries, and traders were to the effect that the average life of the black man is longer than that of the European. This opinion was based upon

(a) The very large number of blacks then living who remembered and took part in the battle of Amalinde in 1818, the flight of the Fingos from Natal in 1821 and 1822, the wars of Moselekatse and the depopulation of the territory between the Orange and Limpopo rivers, 1821 to 1830, the defeat of the Amangwane in 1828 , and other notable events of more than fifty years before 1885 .

(b) A comparison of Bantu and Europeans known to be of the same age, when the former invariably have the appearance of being the younger of the two. A black man of fifty does not look older than a European of forty.

(c) The general good health of the Bantu, in which prolonged observation shows that they greatly surpass Europeans.

Question 3. Are there any causes in operation tending to affect the future increase of the Bantu population? In the reply to this question, please state the effects of embracing Christianity, of drunkenness, of syphilis, \&c., upon the birth rate of the people under your observation. 
The answers were varied, and all given merely as expressions of opinion.

Most of the writers considered that the rate of increase of that time would not long be maintained, because the struggle for existence must become more intense with the pressure of population. The limit of food supply, both in flesh and in grain, which the country was capable of producing without such artificial aids as manuring and irrigating, must soon be reached. Then would come care and necessity for forethought, which would prevent early marriages. Already in some localities there was a tendency to postpone the marriage of girls to a later age than formerly. Fingo girls especially, when in service with Europeans and earning wages for their fathers, were frequently allowed to remain unmarried until the age of twenty.

The effects of embracing Christianity were viewed in very different lights. Some of the missionaries were of opinion that the birth rate would be increased if the deplorable immorality of the uncivilised blacks should give place to purity of life. Others thought that enforced monogamy coupled with virtuous habits would greatly decrease the number of children born. Many of the magistrates and traders referred to the increase of disease among the semi civilised natives as an indication that the birth rate would probably be less if Christianity were generally adopted. This increase of disease was attributed to

(a) Less cleanly habits. The uncivilised black bathed frequently and then rubbed grease and red clay over his body. His semi civilised brother obtained a suit of European clothing; which he seldom washed. His shirt was not once removed from his body till it was worn out. Of course there were exceptions, but this was commonly the case.

(b) Exposure to wet. The greased black man took no harm from being out in rain. His kaross was kept dry. The black man in European clothing, owing to his improvidence, seldom had a change of garments, and when he had been drenched with rain usually sat by a fire to dry himself.

(c) The cares and anxieties which even semi civilisation increased. 
(d) Less bodily exercise.

All the returns agreed in the view that the unrestrained use of intoxicating liquors would not only diminish the birth rate, but speedily destroy the people. Barbarians are incapable of resisting the temptation to use spirituous liquor to excess when it is within easy reach. But as yet drunkenness had no perceptible effect upon the birth rate among the people of the purely Bantu territories, because the sale of spirits had not been permitted by law, and the contraband trade had not been very great. It was in the colony proper that the destructive effects of drunkenness could be seen.

As to syphilis, different opinions were expressed. In the purely Bantu districts it was then prevalent only among those persons who had come into close contact with vagrant Europeans. One missionary stated that it appeared from observations he had made to be more easily eradicated from blacks than from Europeans. Two magistrates reported that some of the Bantu herbalists appeared to have remedies of their own and cured it easily. On the other hand, several missionaries regarded it as a coming evil, the deleterious consequences of which must be widely felt, owing to the immoral habits of the uncivilised Bantu.

Question 4. What is the average age at which Bantu women are married?

The replies to this question were as varied as the tribes with which the writers were residing.

There was a general agreement that marriage might take place immediately after the ceremony which girls go through upon attaining the age of puberty, usually about thirteen, and that in all the tribes it did sometimes take place shortly after. But while with some tribes such early marriages were very frequent, with others they were very rare. The Betshuana and Basuto tribes were those in which early marriages were common. With some of these the average would be as low as fourteen, with others it would be fifteen. Bantu girls along the coast as a rule were not married so early. In some of the tribes sixteen was the average age, while in others it would 
probably be as high as seventeen. There were mission stations on which it was as high as eighteen and even nineteen.

For the whole of the Bantu tribes south of the Limpopo the average would probably be between fifteen and sixteen; but this estimate could only be regarded as conjecture formed from such information as was available. The object which the father or guardian had in view in bringing about the marriage of girls before they were fully developed was variously stated to be

(a) To settle them respectably in life, for which purpose alliances were sought with influential families, the proposals being frequently made by the guardians of the females.

(b) To preserve the girls from loss of reputation, which delay in marriage would probably cause.

(c) To prevent capital from lying waste. A girl represented a certain number of cattle, the increase and milk of which took the place of interest on money invested.

(d) To perpetuate the customs of his forefathers, or in other words to do as every one else in the circle of his acquaintance was doing and as his people had done as long as memory or tradition went back.

(e) That his posterity might be numerous in the land.

Question 5. Can you give any information upon the relative number of births and deaths in places not affected by emigration or immigration?

The almost invariable replies to this query were either that owing to no records of births and deaths having been kept, or that owing to the roving habits and frequent change of residence of the Bantu, no reliable information could be given. Only five returns in all were sent in, representing five mission stations and small kraals, at which during certain stated periods the total number of births was 379 and the total number of deaths 125 .

Question 6. What is the average number of children of women married $(a)$ to monogamists, $(b)$ to polygamists? In the reply to this query, please state the number of women from whom the calculations are made. The greater the number the better, but care must of course be taken not to include women who are still 
capable of childbearing. The only reliable plan will be to question the old women, and ascertain from each one exactly how many children she has given birth to and how many wives her husband has had. If the husband was a monogamist, note whether Christianity had been embraced. The greatest possible accuracy is requisite to make the reply to this query of value.

To this question a good many carefully drawn up tables were sent in, particularly from some of the older magistrates and from several missionaries. One from Donald Strachan, Esq., merchant, of Umzimkulu, was especially valuable, from the great pains that had evidently been taken to obtain reliable information. Altogether these returns embraced 393 women, the wives or widows of monogamists, mostly professing Christians, and 591 women, the wives or widows of polygamists. In a few instances it was noted that the women might not yet have passed the age of childbearing. The 393 women, wives of monogamists, had borne 2223 children, that is on an average 5.65 children to each woman. The 591 women, wives of polygamists, had borne 3298 children, that is on an average $5 \cdot 58$ children to each woman. Thus monogamy in this respect made hardly any appreciable difference in the birth rate. Christianised Bantu girls did not marry at as early an age as the others, but the interval between the births of children in families who had embraced Christianity was usually shorter than with women in an uncivilised state, owing to a superstitious feeling of the latter which required them to live in strict seclusion from intercourse with their husbands and lovers during the period of giving suck to their children, usually from two to three years.

But the death rate of the Christian Bantu was so much higher than that of the others that the balance was more than equalised. Some of the returns merely gave the total number of children each woman named had given birth to, but others had been so carefully arranged as to give the sexes of the children born-showing that more boys than girls were brought into the world-and gave the numbers living when the information was obtained and the numbers that had died. Of the children of polygamists 73 per cent were still living, while of the children 
of monogamists only 67 per cent were alive. The larger death rate among monogamists was explained by the facts that chest diseases had become not uncommon on mission stations, and that the children were perceptibly. less robust, owing to their changed conditions of living.

The widows of polygamists continued to bear children as if their husbands were still living. In some instances a widow returned to her father or nearest male relative, and was remarried, when her children after the second marriage belonged by law to her second husband. But in most instances she remained with her dead husband's relatives, because she could not take his children away with her. In such cases either a brother of her dead husband had taken her, or she had a male companion formally allotted to her, and she had her lover. All the children she gave birth to were under any of these circumstances considered as her dead husband's.

The number of women who had never borne children was less than three per cent of the whole ; a few had borne ten and eleven each; but the great majority ranged from four to eight.

The numbers in these tables are too small for the averages here given to be considered more than approximately correct. To arrive at anything like accuracy, similar statistics must be collected for many years and by competent persons in all parts of the Bantu territories.

Question 7. Can you explain why decrepid, infirm, and half breed children are not found among the Bantu?

The answers were to the effect that owing to the robust constitutions of the people very few decrepid children were born. In olden times such children were destroyed by filling their mouths with earth. At the time these queries were replied to they were commonly neglected, or it was given out that they were lost or that some accident had happened to them. In one way or other they generally disappeared at a very early age. Still, a few were to be found, but always on mission stations or in places where European influence was prevalent. Albinos were met with occasionally, and they were suffered to live. As for half-breed children, they were seldom found except in places 
where the people had become semi-civilised, or where shipwrecked or renegade white men had been living as adopted members of a clan. There was no disgrace to which a Bantu female was subject equal in the opinion of her people to that of giving birth to a half-breed child. Abortion or infanticide would be resorted to, if the customs of the tribe had not previously been partly abandoned and those of Europeans adopted. In this respect the Bantu were the very opposite of the Hottentots, whose females had no repugnance to intercourse with white men. Owing probably to inter-marrriages with near relatives, many idiotic children were born among the branches of the Basuto.

Question 8. Have you observed what effect great difference of age between man and wife has upon the number of children among the Bantu?

The replies were uniform that it had no effect whatever. Men did not marry women older than themselves. Old men very frequently married girls, but nearly every uncivilised black woman had a lover as well as a husband. This fact could not be left out of consideration when studying the effects of polygamous marriages. It was taken as a matter of course that a woman married to a polygamist, unless he was a chief of very high rank, would form a connection with some other man. She did not sink in the slightest degree in the estimation of other women by so doing. The offence was punishable by Bantu law, the lover being subject to a fine and the woman to chastisement by her husband, but in most instances it passed unnoticed as an ancient custom of the people.

A third of a century has passed away since the returns here given were sent in, and in 1918, though it is impossible from any statistics in existence to give accurately the rate of increase of all the Bantu south of the Zambesi at the present time, it can be stated that it is certainly less than it was at the commencement of this period, though it is possibly even now as high as that of Europeans in any part of the world. Polygamy has decreased in this sense, that fewer men in proportion to the whole number have more than one wife, but there are 
as yet no old maids among the Bantu, for a few wealthy men secure the surplus females.

Disease, however, is far more rife among them than in former times. Syphilis has spread among the Betshuana to an alarming extent, and is seriously affecting the rate of increase of that branch of the Bantu family. Consumption seems to have taken a firm hold of the coast tribes, and is producing a similar effect. What can be done to prevent the ravages of these diseases is being done by the European authorities, but the habits of the people are such that it is much more difficult to deal with them thoroughly in sanitary matters than it would be to deal with white colonists in similar circumstances.

Then the struggle for existence is very much greater now than it was when the men lived an idle and contented life, and the women cultivated their gardens. In many localities the people have become too numerous for the ground, and consequently some have no gardens to work in. Tens of thousands of the men find it necessary to labour for wages in the mines, and return to their homes in many instances with their constitutions debilitated, though all possible care is taken of them. Anxieties and worries, to which in olden times they were absolute strangers, are now their lot in common with Europeans, and they find it hard to bear up against them. Youths who realise that the support of children will fall upon them do not marry at as early an age as they did when it was so easy to provide for all their simple needs.

More than all these causes together, the decrease in the rate of productiveness of the Bantu south of the Zambesi must be attributed to the loss of nearly all their horned cattle by the ravages of runderpest and other diseases since 1896. Cattle constituted their wealth, and upon fermented milk they depended for subsistence quite as much as upon the produce of their gardens. The loss of this to them was what the loss of wheaten bread would be to the people of England. They are getting cows together again, but it will be a very long time, if it ever comes, before the great herds that formerly fed on their pastures are seen there once more. Meanwhile the substitution of new 


\section{The Bantu.}

kinds of food is detrimental to their health, and children especially suffer from it. The bright happy little urchins of bygone days, playing in perfect nakedness in the sunshine, and hardly knowing what it ever was to be sick, have given place in numerous localities to pinched figures sedate beyond their years and altogether wanting in boisterous mirth. Numbers of those whose parents are under European influence wear clothing now, which does not add either to their comfort or their protection from disease. The rate of mortality among infants has become much higher than it was in earlier days, and the stamina of the adults is less. In a word, they are undergoing a great change in their diet as well as in their mode of living, and until they become habituated to the new environment in which circumstances beyond their control have placed them, they cannot increase at such an amazing rate as they did when everything was in their favour. 


\section{CHAPTER XVII.}

Other Inhabitants of South-Eastern Africa than Bushmen, Hottentots, and Bantu before 1505.

Ar some unknown period in the past the territory between the lower Zambesi river and the twenty-fifth parallel of south latitude was occupied by a people well advanced in civilisation. Their nationality is uncertain, and nearly everything connected with them is involved in mystery. They were miners, and were skilled in looking for gold-bearing reefs and working them when found. It is not impossible, though it is only a conjecture of some writers, that traders from the great commercial city of Tyre on the eastern shore of the Mediterranean sea visited this part of the African continent, and that in holy scripture an account of their visits is given. The conditions mentioned of the fleets that went down the Red sea to Ophir in the time of Solomon are not inapplicable to voyages to the mouths of the Zambesi or the Sabi, or to Sofala, and the articles-gold, silver, precious stones, almug trees, ivory, apes, and peacocks-with which they returned are all found in South-Eastern Africa, if by almug trees ebony or some other very hard wood is meant, by precious stones pearls, and by peacocks the bustards that to-day are called wilde pauwen (wild peacocks) by the Dutch colonists. The name of the bird given in the bible is said, however, to be of Tamil origin, and to be used for the peacock (pavo cristatus) at the present day in Ceylon. This appears to be the greatest impediment to the supposition that the Ophir of scripture is the Rhodesia of to-day, but as almost to a certainty there was intercourse between Eastern Africa and Southern India in those times, an African bird might have received from strangers a Dravidian name. 
The object that brought the first civilised explorers to South Africa can only be conjectured. They may have come in search of ivory, which from very early times was a valuable article of commerce, and the fact that elephants were plentiful in the country may have been ascertained either by the crews of vessels driven to the coast or by hunters pushing their way down from the north. The elephant hunters may have found gold, and then mining would have commenced. This, however, is mere surmise, and there are obstacles in the way of accepting it or any other supposition that has yet been made. For instance, it is not likely that either hunters or ivory traders would recognise the presence of the precious metal in quartz reefs in a country where alluvial gold is found only in a few localities and in small quantities. Thus it is not possible to say how, when, or by whom gold was first discovered in the Rhodesia of our day, any more than it is to say how, when, or by whom tin was first discovered in Cornwall.

What is certain is that at some time in the remote past, of which there is neither written record nor tradition now, mining operations were carried on over an immense tract of country south of the lower Zambesi. The miners were sufficiently skilful to be able to sink pits and run underground galleries along reefs, but they were obliged to cease operations when water began to flow in, as they had no means except buckets and human labour for keeping the excavations dry. The quantity of a reef that could be removed depended thus entirely upon its position, and where drainage was good, depths of over one hundred and fifty feet or $45 \cdot 72$ metres were reached.

With the appliances at the disposal of the most advanced people of that time there was only one way apparently in which this kind of mining could be carried on successfully, for a vast amount of labour was needed in excavating the gold-bearing rock, bringing it to the surface of the ground, there crushing it to powder, and then washing the dust to obtain perhaps a thirty or forty thousandth part of gold from it, though the value of that metal relatively to other articles must then have been very much greater than it is now. With a large number of slaves or Indian 
labourers compelled to work for next to nothing, some employed in extracting and crushing rock and others in raising food, it was possible to make gold-mining profitable, and it may be taken for certain that this was the condition of things at that time in the territory called Rhodesia to-day.

Among various articles manufactured by these people that have been found where they were left or lost are an ingot mould, crucibles, and beads, tacks, and thin plates of beaten gold. The thin plates in little squares of uniform size were intended to overlay wood, perhaps the ceilings and columns of grand buildings in other parts of the world, and the wedge-shaped tacks were for fastening them on. Many of these plates and tacks have been found.

Over the whole country where mining was carried on, ruins of stone buildings and walls are scattered, implying a prodigious amount of labour exerted over a long period of time. The oldest of the ruins may be of much later origin than the commencement of the mining operations, but the articles found in the debris beside them prove that some of them were strongholds and factories of miners and workers in gold. Others; however, seem to have had no connection with mining industry, but to have been fortifications constructed for purposes of defence by people subject to attack by enemies.

Here another mystery is opened up. Who could the enemies of the gold miners have been, that necessitated the erection of strongholds in the interior and a line of forts along the Sabi river down to the place of entrance on the coast of the Indian sea? Invasion must have been feared, which implies that there was more than one great seafaring power in existence at the time, and that the knowledge of the wealth of South Africa was widely spread. Little, or rather nothing at all, do we know indeed of what was transpiring when, as modern mining engineers inform us, gold to the value of over a hundred million pounds sterling of our day must have been taken out of the rocks of Rhodesia.

In the ancient structures the workmanship, though solid, was not of a graceful order. The arch was unknown, the outer 
walls, though circular or elliptical, were not perfectly regular in form; nor were they either absolutely perpendicular or of the same slope along their whole length or of equal thickness throughout. The men who planned and built them were not sufficiently refined to appreciate mathematical correctness of shape or finish. The stones used in them, taken from strata or layers of granite which could be broken off like slabs and which were consequently flat on two surfaces and of equal thickness, were trimmed at the sides, so that the courses are perfectly regular. They were laid as close to each other as it was possible to get them, and no cement or plaster was used to bind them, though excellent cement was employed in making floors and drains.

The most imposing of the ruins is that known as Great Zimbabwe (more correctly Zimbabgi), in latitude $20^{\circ} 16^{\prime} 30^{\prime \prime}$ south, longitude $31^{\circ} 10^{\prime} 10^{\prime \prime}$ east of Greenwich, $22 \cdot 4$ kilometres or fourteen miles from the present township of Victoria. The building there that has attracted most attention is elliptical in form, two hundred and ninety-two feet or eighty-nine metres in its greatest length by sixty-seven metres in greatest breadth, and was built of blocks of stone flat above and below when taken from the rock and trimmed to about double the width of ordinary bricks, but of varying lengths. The greatest height of the wall still standing is thirty-five feet or 10.68 metres, and its thickness varies from sixteen feet two inches or 4.9 metres to five feet or a metre and a half. The only ornamentation consists of two courses of stone laid in oblique positions in contrary directions along a fourth part of the wall near the top. A solid conical stone tower, seventeen metres in circumference at the base and still about nine metres high, stands within the wall of this building, and is of very superior workmanship, the stones having been accurately trimmed to meet the requirements of the different parts of the cone. Under the debris covering the cement floor of this great building numerous stone phalli have been found, indicating that the religion of the builders was a form of nature worship.

The labour required for the erection of such a building, or of another of great size on a hill close by, would be enormous 
in amount at the present day; what then must it have been when mechanical appliances such as are now in common use were unknown?

It is generally believed that the mines and ruins here referred to indicate a remote period of occupation, of great but unknown length, which can be distinguished by skilful underground excavations and by structures in which the stones are laid in regular courses like bricks and the walls are built solidly from side to side, not faced and filled in between with rubbish. In connection with these buildings carved birds of soapstone, stone phalli, and gold ornaments are found. Mr. Richard N. Hall, the gentleman who could speak with the greatest authority on this subject, was of opinion that the mouth of the Sabi river was the port used by the people who left these memorials of their skill and enterprise behind them.

This period came suddenly to an end, but neither the cause nor the time has yet been ascertained. One might form a conjecture that some great revolution in the affairs of Asia, such as the wide conquests of Alexander the Great of Macedon, or the wresting of the commerce of the Indian sea from the Arabs and Indians by the Greeks of Egypt under Roman dominion, was the cause, but there are difficulties in the way of adopting such a view, particularly as it gives no explanation of the removal of the entire body of the inhabitants then residing on the mining area. Even supposing the mines to have been worked and the buildings to have been erected by male slave labour sent from some distant country, it is difficult to believe that during the long period of occupation the higher classes were entirely unaccompanied by females, or that there were no families at all in South Africa when the abandonment took place. But if there were what became of them? The abandonment was not only complete, but sudden, for heaps of uncrushed quartz were left behind near the mouths of the pits, and the floor of the great temple Zimbabwe was thickly strewn with gold ornaments, thrown away in haste by the last of those who worshipped there. Some day light may be thrown on this subject by discoveries in Africa or in Southern Asia, and therefore it is wisest to make 
Other Inhabitants before I505. 4I5

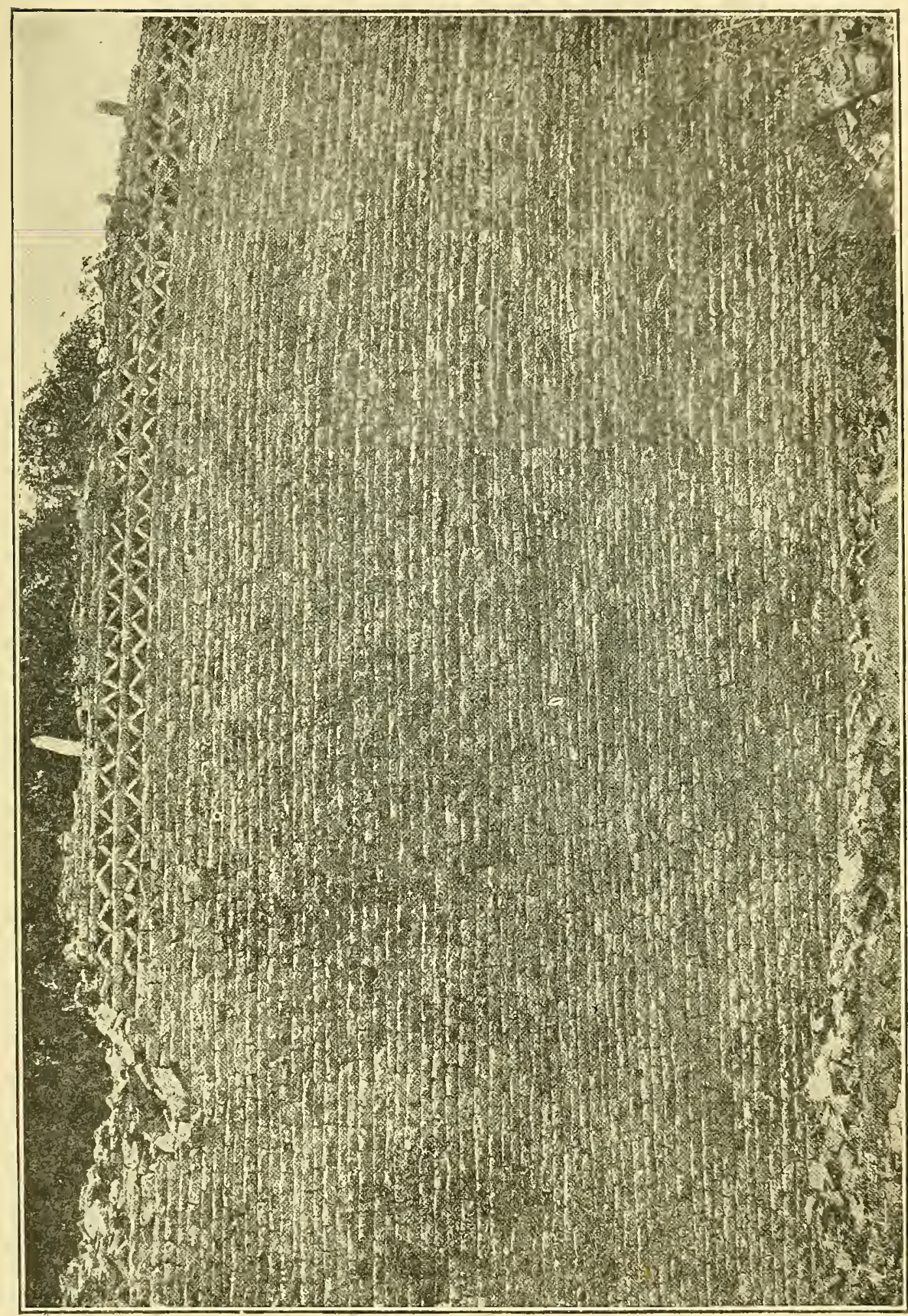

是 
no conjectures at present, but to wait until time or accident solves the mystery.

The aborigines must have disappeared entirely from the locality occupied by the miners, for there was no way by which two classes of people, so dissimilar in everything, could live together on the same soil. They may have been exterminated, or they may have retired to other parts of the country, there is no way of ascertaining what became of them. One thing only is certain, that those living outside of the mining area, and who must have known something of what was going on there, learnt absolutely nothing from the strangers, but remained as wild and as savage as they were before.

The first mining period had passed away; and then, after an interval of unknown duration, but long enough for dust and mould to accumulate on the floor of the Zimbabwe temple and conceal the stone phalli and gold trinkets and other articles lying there, came another body of strangers and settled in the country. No one knows where they came from, or even the approximate date of their arrival, but they also have left almost imperishable memorials of their existence in the land. They were not such expert miners as their predecessors, for they did not venture underground, but worked only on the outcrops of reefs and washed the soil for alluvial gold. The ancient pits may even then have been filled with silted soil, as they were at the close of the nineteenth century when great trees were growing in some of them, and so no traces of the mines may have been left to catch the eye. Nor were they such skilful builders in stone, though the ruins of their structures are almost incredible in extent. The walls that they built were of undressed though selected stone, and thickness was gained by filling up the centre with rubbish, the ends were square, not beautifully rounded as in the more ancient buildings, and no provision was made for drainage. Sometimes, as in the Zimbabwe temple itself, they added walls to the old buildings, when the inferiority of their work is at once apparent by contrasting it with the other. They did not even clear away the soil that had accumulated on the floor, but built upon it, so that the treasures it concealed were 
left undisturbed for Europeans at the close of the nineteenth century to gather.

But in one respect they surpassed the earlier occupants. Along the Inyanga range they terraced the slopes in order to cultivate them, and irrigated the ground by means of watercourses and dams as skilfully constructed as they would be by modern engineers. At first sight it might seem that to conserve water nothing more was necessary than to construct dams across the courses of streams, but so violent were the floods in the rainy season that unless the dams were immensely strong they would certainly be swept away. Under such circumstances artificial reservoirs were requisite, into which water could be led when the streams were full, and from which it could be drawn into furrows for irrigating purposes when dry weather set in. Such reservoirs required skill and much labour to construct and afterwards to preserve in order. This part of South Africa must, therefore, have presented a scene of industry that is not easy to realise by those who know it at the beginning of the twentieth century of the Christian era.

In none of the ruins of these people have gold ornaments, or stone phalli, or carved birds been found, everything connected with them is of an inferior order. But so little has yet been done by competent persons in the way of thoroughly examining any of the ruins of buildings in the vast area of Rhodesia, that next to nothing can be stated with absolute certainty regarding them. Blocked up to the depth of many feet with the kitchen middens of recent Bantu occupants and with nould in which trees and bushes are growing, it needs time and mucli labour to explore them and to sift the soil taken from and around them. But so far the only man who his spent years in this occupation - the greater portion of the time at Great Zimbabwe-is $\mathrm{Mr}$. Richard N. Hall, whose conclusions are those given in this chapter. The visits of Mr. Theodore J. Bent and Dr. D. Randall MacIver, both of whom have issued most interesting volumes on this subject, were too fleeting to enable them to make thorough investigations even of the limited number of ruins which they inspected. 
It is conjectured by some that the people who erected the structures of the second period disappeared also in some mysterious way, while others suppose that they remained until the arrival of the first Bantu immigrants, by whom the greater number were destroyed and the remainder incorporated. The last alternative seems most unlikely, however, for there is very strong proof that the country was inhabited by Bushmen when Bantu first entered it. The Bushman occupation is recorded in rock pictures, many of which remain to this day. Still another supposition is that the structures of the second period were erected after the Bantu immigration, and by the hands of Bantu under the guidance of Asiatics. But there are difficulties in the way of accepting this theory. It cannot be imagined that the Inyanga terraces and irrigation works were constructed by Bantu even under compulsion, and the absence in the sixteenth century of all traditions and knowledge concerning the erection of the buildings, with the prevalent belief of that time that they were the result of supernatural agency, would seem to overthrow it. The disappearance of the builders of the second period, as well as that of the miners and builders of the first, like their arrival, is as yet an unsolved mystery, and we can only trust to time for enlightenment.

There being nothing accessible to work with beyond what is stated here, all that is absolutely certain regarding this subject is that at some unknown periods in the past two distinct types of men, differing in culture and in creed, occupied the country between the lower Zambesi and the twenty-fifth parallel of south latitude, though probably only a portion of it at any time, and that each in turn disappeared, leaving an enormous number of structures of stone, which the Bantu who at a later date took possession of the same territory, and who can imitate, though they cannot initiate, used to some extent as models for the rough walls or rather piled up lines of stones that they still make fcr various purposes.

The reader who wishes to know the views and reasonings of archæologists on this subject may consult Mr. Richard N. Hall's Pre-Historic Rhodesia, an octavo volume of 516 pages, 
published in London in 1909. This is the latest volume relating to the ruins issued from the press, and was written to refute Professor David Randall MacIvor's theory that the stone structures were the work of Bantu, as enunciated in his beautifully illustrated Mediceval Rhodesia, a quarto volume of one hundred and six pages, published in London in 1906. Other works that may be consulted on the subject are Mr. Theodore J. Bent's The Ruined Cities of Mashonaland, a crown octavo volume of four hundred and twenty-seven pages, published in London in 1896, Messrs. R. N. Hall and W. G. Neal's The Ancient Ruins of Rhodesia, a demi octavo volume of four hundred and fifty-two pages, published in London in 1904, Mr. R. N. Hall's Great Zimbabwe,* a demi octavo volume of five hundred and three pages, published in London in 1905, and the honourable A. (now Count) Wilmot's Mononotapa (Rhodesia), its Monuments and its History from the most Ancient Times to the Present Century, a crown octavo volume of two hundred and eighty-three pages, published in London in 1896.

* The death of Mr. Hall on the 18th of November 1914 must be regarded as a great calamity by all who take an interest in attempts to discover something of the distant past of South Africa. He was a most indefatigable worker in this field, and when the death of Mr. Rhodes deprived him of the means of carrying on investigations at Great Zimbabwe, continued to make such other researches as were within his power. In his exploration of the least known parts of Rhodesia he was repeatedly prostrated by fever, but the discovery of an unknown ruin or of a Bushman picture or engraving always put new life in him again. His letters to the author of this volume showed intense enthusiasm and love of the task to which he had devoted himself. $\mathrm{He}$ had made copies of a great number of Bushman works of art, which must have been executed before the entry of Bantu into the country, and was preparing a volume on this subject for the press when he received the appointment from the Rhodesian government of curator of the ancicnt ruins, and with the glee of a schoolboy who has won a big prize he at once went back to Great Zimbabwe to reside and resume his earlier explorations. Here recurring attacks of fever so reduced his strength that he was compelled to act on medical advice to repair to the Cape peninsula for a month or two to recuperate. He reached Bulawayo on his journey, and there was carried to the hospital, only to die. 
The question remains, what effect had the occupation of a part of Africa south of the Zambesi by men advanced in culture upon any of the people with whom this volume deals? As for the Bushmen, the answer is that upon them it had no effect whatever. Those savages must have abandoned the area inhabited by the strangers, but only to return, probably many centuries later, when those strangers were there no more. What were gold mines or great stone structures to them? No more than to the jackals or the baboons that lived on the same soil. They learned nothing from them, nor did they make any use of them, but when the miners and the builders had gone away and the game entered the vacant space once more, they followed and hunted and danced and feasted where their remote ancestors had done the same long before. Perhaps they gazed with something akin to wonder upon a vast building like Great Zimbabwe, or conjured up evil spirits in the picturesque gorges between the cliffs where the Khami ruins lie, but they took no more thought of the work of human hands than of the rocks that nature had formed. They had no eye for anything but game and edible plants, and so the foreign occupation did nothing to make them more intelligent or in any way wiser than their ancestors had been. There is no indication whatever of the slightest intermixture of blood having taken place.

Upon the Hottentots, who never came within many hundred lilometres of the area of the stone buildings, and who must have been in the far distant north when the mining operations were going on, if even they were in existence at that time, the presence in South Africa of strangers could of course have had no effect at all.

Neither could it have had any effect upon the Bantu of the coast, who also never came near the area of the stone buildings except when they passed through it in their devastating march from the north-west, but it may have had upon those of the interior, who if they were not south of the Zambesi during the later period mentioned, which is doubtful, 


\section{Other Inhabitants before 1505.}

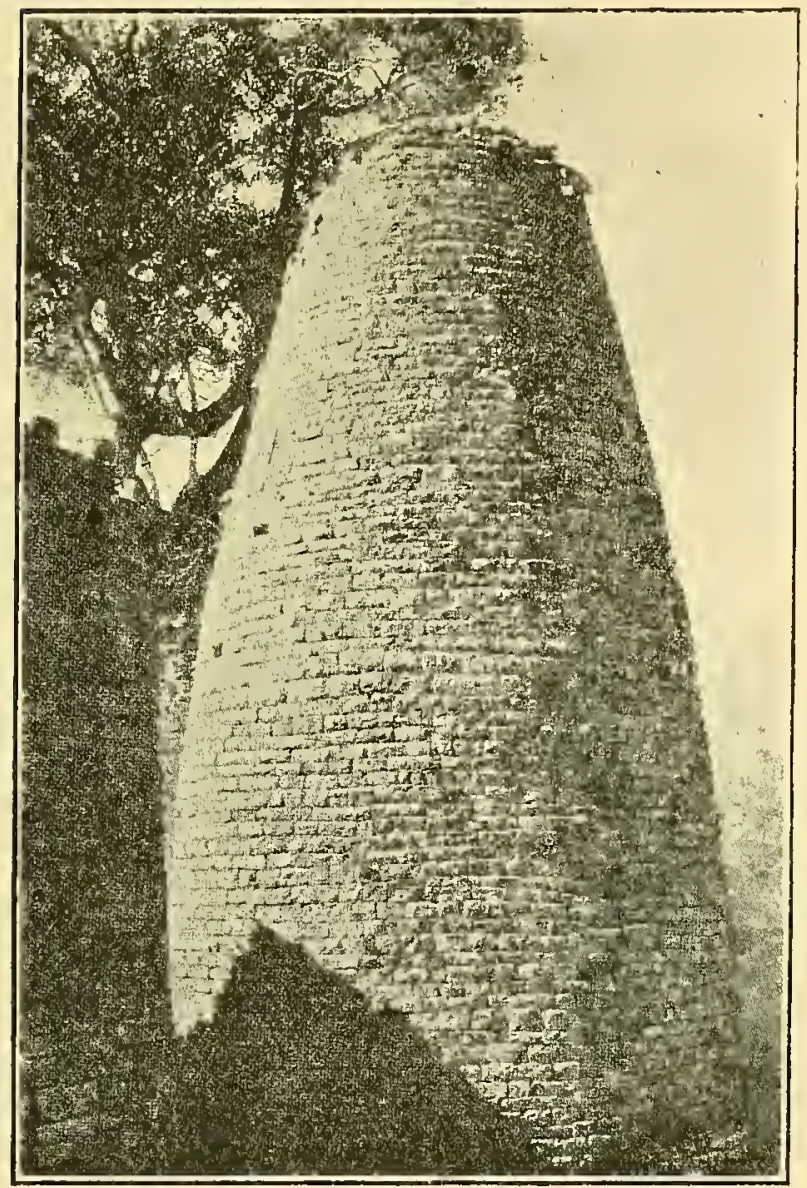

THE CONE IN GREAT ZIMBABWE.

The object of this cone is not known to a certainty, but it is generally believed to have had some connection with the religious observances of those who constructed it. It is the most neatly finished of all the ruins yet discovered in Rhodesia. The structure is solid throughout, as was ascertained on the removal of a few courses at the top, and the stones have been trimmed to fit closely together in every part of it. The courses are as regular as in the best modern brick wall. 
certainly copied some of the work done, though imperfectly, and may have had their faculties sharpened and their skill in mechanical arts increased by what they saw before them.

At the close of the fifteenth century of the Christian era, when South-Eastern Africa was first visited by Europeans, Bantu were in occupation of the coast belt as far down as Delagoa Bay and of parts of the interior as far westward as the Kalahari desert. The greater portion of the high central plateau below the Zambesi, however, was still possessed by the Bushmen, its aboriginal inhabitants. The Karanga branch of the Bantu fanily, the section most advanced in intelligence and in knowledge of mechanical arts, owned the territory between the lower Zambesi and Sabi rivers. Some clans of these people were in the habit of collecting gold-chiefly alluvial-which they disposed of in barter to Mohamedan traders, for they made no use of it themselves. A small quantity was obtained by crushing quartz on outcrops, but the labour required in this process was so great that it was only carried out to a very limited extent, and the metal so obtained, which bore the distinguishing name of matuka, was inferior in value to that acquired by washing the soil. There were no traditions extant of the working of underground mines or of the erection of the great stone buildings whose ruins were so numerous in the southern part of the territory.* These were regarded as the work of superhuman beings.

* It was not until the second decade of the twentieth century that any Bantu asserted that it was handed down to them by tradition that the buildings were erected by their ancestors as places of worship. This shows what extreme care must be taken in dealing with so-called Bantu traditions. They have recently heard that this was a European theory, and they at once adopted it, as it gave them importance. It has no other foundation, and is quite untenable. That the ancient miners and builders were one people admits of no doubt. Now the shafts and galleries in the mines could not have been made by Bantu, for this could only be done by means of portable artificial light, such as that of lamps of some kind. Even the most advanced Bantu knew nothing of such a device, simple as it appears to us. Many otlicr reasons could be given, but this onc is conclusive. 
At Sofala on the sea coast not far south of the Zambesi and at two little outstations, one where Sena now stands on the southern bank of the river and the other where Beira has recently been built at the mouth of the Pungwe, there had been living for several centuries a small community professing the Mohamedan religion. These people sent traders among the Makaranga to collect the gold obtained and the ivory of slain elephants, and the Portuguese, who termed them Moors, learned from them of the existence of extensive ruins inland, which they do not appear at any time to have visited themselves, for the descriptions given by their writers are very far from being correct.* Thus Great Zimbabwe, $\dagger$ according to their accounts, was a square building, not elliptical as it really is, and they stated that there was an inscription over one of its entrances which no Arabic scholar could decipher, whereas not only is there no such inscription now, but no indication of a stone having been removed on which one could have been displayed at any time.

The Mohamedans of Sofala and its outstations were the only traders among the Makaranga, but they did not possess any land in the country except that on which their villages stood, nor did they exercise any dominion or authority whatever over the Bantu. They were subject to their own laws, and were merely allowed to live unmolested on account of the advantages which their presence as traders afforded. They barely exceeded a thousand in number, all told.

The settlement at Sofala had no connection with the ancient Asiatic stations along the eastern coast, of which Rhapta in the first century of our era was the most southern.

* The Portuguese in course of time became well acquainted with the district of Manika and the basin of the Mazoe, a stream which rises near the present town of Salisbury and flows into the Zambesi, but they never acquired much information about the part of the country in which the principal ancient gold mines and ruins are situated.

$\dagger$ This spelling is now fixed, but properly it should be Zimbabgi, from zimba structures and babgi stones. It is a difierent word from Zimbaoe as used by the Portuguese, which denotes the residence of a chief. 
'I'hese had cutirely disappeared, and many years after the time of Mohamed others more permanent in character had been formed by Arabs and Persians, the most important of which was a town named Kilwa, that carried on commerce with Southern Asia and India. Sofala had long been a dependency of Kilwa, but just before the arrival of Vasco da Gama in the Indian sea had become an independent, though very petty state. It possessed no shipping of its own, but was frequented by vessels from other Mohamedan stations.

The Mohamedans of Sofala were of mixed blood, and many of them could not be distinguished from pure Bantu except by their dress. The original settlers were males, who had taken Karanga women as consorts, and this had gone on until there were individuals of every shade of colour from the quadroon to the black. But in many respects they were of a higher order than the other dwellers in the land. They were better clothed, for even the poorest among them was decently covered from the breast to the knee, and had on his head a silken or cotton turban. Their arms, of which they were very proud, included highly finished daggers, worn at the waist, and often scimitars of the choicest steel. Their females were not mere drudges, but were well dressed and fairly treated, and conducted themselves in a becoming manner. They had introduced the banana and the lemon, besides different garden plants, and though their habitations were not much better or more commodious than Bantu huts, they were more comfortably furnished.

Their greatest defect was their superstition. To the Bantu belief in charms they added all the wild imaginations of the Arab mind, so that they lived in mental slavery of the worst description. They would do nothing on a day deemed unlucky, they were deterred from any act by a dream or an omen regarded as unfavourable, they consulted a charm before going on a journey of a day. For prosperity they looked to powerful genii acting in their favour far more than to their own exertions. Bound in such mental chains, they were 
incapable of raising the Bantu to a higher level of civilisation, and indeed they made no attempts to do so. They were by no means fanatical, and there was not even a mosque at Sofala.

So in Africa south of the Zambesi there were in the year of our Lord 1505 four distinct classes of people

1st. The Mohamedans, who were the highest in civilisation, but who were few in number and were confined to a very limited space.

2nd. The Bantu, comprising the great Karanga tribe, the pioneers of the Betshuana tribes, and the recently arrived Batonga tribes in the Zambesi valley and on the eastern coast north of Delagoa Bay.

3rd. The Hottentots along the western and southern coasts from the Kunene river to the Umzimvubu.

4th. The Bushmen, pure savages, in all parts of the country not occupied by the others. 



\section{SYNOPTICAL INDEX.}

Авамвo horde :

account of the, 195; a section of it settles in Natal, 195

ABATEMBU, BANTU TRIBE :

mention of, 204

Abi l'Cassem Abdallah Ebn Haukal:

work of, 175 and 176

abou Abdallah Mohamed, commonly called Iba Batdta:

work of, 179 and 180

Abod Abdallah Mohamed el Edrist : important work of, 176 to 178

ABodlfeda :

work of, 178 and 179

Abod'l Haçan Ali el Masoddi:

important work of, 168 to 174

Aвod Zeyd Hassan :

work of, 168

Adamson, Rev. Dr. JAMES :

references to the researches of, 80 and 82

ADEN, PORT OF :

is occupied by the Romans, 162

AFrICA :

the true form and size of are first made known by the Portuguese explorers of the fifteenth century, 154

AgRicULTURE :

is not practised by the Hottentots, 98 ; or by the Ovaherero tribes of Bantu, 201

Agysimba, of Ptolemy :

mention of, 166

Albinos :

are found among the Bantu, 211

AleXANDER, CAPTAIN JAMES E. :

references to the work of, 112, 114, 117, and 125 
Alexander the Great :

reference to, 154

ALEXANDRIA :

takes the place of Tyre as the greatest commercial city of the world, 148

Altamira, cavern in Spain :

ancient painting on the roof of, 9

Arabaca, Bantu tribe :

mention of, 204

Amamifengu or Fingos:

mention of, 204

Amampondo, Bantu tribe:

mention of, 204

Amangwane, Banto tribe:

mention of, 195

AMASI, OR FERMENTED MILK:

is largely used as food by the Bantu, 269

Amaswazi, Banto tribe :

mention of, 205

Amatonga, Bante tribes:

mention of, 205

AMAXosa, BANTU TRIBE :

mention of, 204

AMAZniBa HORDE :

account of the, 194 and 195

Amazizi, Bantu tribe :

particulars concerning, 195

Amazuld, Bantu tribe :

mention of, 205

AmRAAL, HotTENTOT CHEF :

mention of, 94

Amosements :

of the Bushmen, 60 and 61 ; of the Hottentots, 122 and 123; of the Bantu, 294

ANCESTRaI SpIRIT Worship :

is the religion of the Bantu, 219

further mention of, 396

Ancient Gold Mines :

description of, 411

Ancient Honters and their Modern Representatites:

reference to the volume so called, 8 
ANCIENT TIPES OF $M_{A N}$ :

reference to the volume so called, 9

Anderson, ANDrew A. :

reference to the work of, 21; description of some savages of a very low type in the Kalahari, ib.

Andries Lambert, Hottentot chief:

mention of, 94

Arabla, Southern :

the inhabitants of in very remote times carry on commerce with India, 145; they are deprived by the Greeks of Alexandria of the eastern trade, 161; but completely recover it after the conquest of Alexandria by Amrou in 640 A.D., 162; from that time to the close of the fifteenth century they and the Persians are the only traders on the Indian ocean, 167; extent of their commerce in South-Eastern Africa, 195

Arab stations on the East African coast in 100 a.D.:

description of, 164

Arbousset, Rev. Thomas :

reference to the work of, 32

ARIStotim:

throws no light upon the condition of Africa in his time, 154

Assagat :

description of the, 102

Atavism:

effect of, 209

BaHURUTSI, Bantu tribe :

mention of, 205

Batn, Thomas :

reference to the researches of, 66 and 125

Bakalahari, Bantu of the DESERT:

account of, 182

Bakatla, Bantu tribe:

mention of, 205

BaKWEBo, BanTU trIbe: account of, 189

BaKWENa, Group of Bantu tribes: account of, 186; account of some north of the Zambesi in 1600, 186; some of the tribes cross the Vaal and settle along the upper Caledon, 189 ; further mention of, 205 
Balali, Bantu paupers :

account of the, 183 ; condition of, 392

Bamangwato, Bantu tribe:

mention of, 205

Bangwaketse, Bantu tribe:

mention of, 205

BANTU :

age of marriage of girls, 403

amazing increase after 1836 in the number of, 398

among some tribes girls who cut their upper teeth first are put to death, 191

among some tribes twin children are put to death, 191

among the Barotsi girls when infants are contracted in marriage, 191 are agriculturists, 267

are exceedingly hospitable, 271

are exceedingly prolific, 211

are incapable of conducting financial operations, 311

are long-lived, 211

are persistent beggars, 291

are polygamists, 256

are robust in constitution, 209

are skilful in carving wood, 191

are subject to outbursts of excitement, 209

are wanting in frugality, 269

arrival of the Abambo horde, 195

arrival of the ancestors of the Poudo, Tembu, and Xosa tribes, 194 arrival of the Avare group, 201

arrival of the Bakalahari and the Balala, 183

arrival of the Bakwebo, 189

arrival of the Bakwena, 186

arrival of the Barotsi, 190

arrival of the Batlapin and the Barolong, 184

arrival of the Batonga, 193

arrival of the Bavenda, '187

arrival of the Ovaherero, 200

arrival of the Untetwa, 197

Avare group of Bantu tribes, account of the, 201

average number of children of women, 405

believe in the efficacy of charms, 338

believe in the existence of hobgoblins, water spirits, and other demons, 228

believe in the power of rainmakers, 237

believe in unlucky days, 232 
BANTU (continued) :

believe in wise people living under the water, 229

believe in witcheraft, 234

believe that the spirits of the dead appear in the form of animals, 226

cause of differences between the tribes, 207

causes of the present diminution in the rate of increase of, 408

cause of the robustness of, 397

charges upon the government, 218

checks upon the tyranny of chiefs, 213

colour of skin, 209

comparison of rate of increase with that of people of other countries, 400

condition of, in 1918, 408

credulity of, 385

description of gardens, 272

differences between the tribes, 202

differences of religious belief among the tribes, 234

difficulty of setting aside the heir to a chieftainship, 216

disposal of the corpses of commoners, 222

division of a chief's establishment into the great house, the right

hand house, and the left hand house, 215

domestic animals, 44 and 276

employ herbalists in cases of slight sickness, 238

extent of occupation in 1505,422

folklore, remarks upon, 320 ; possible origin of, 390 ; specimens of, $320,329,336$

form of government, 212

forms of oath, 217

funeral customs of the Ovaherero, 222

habitations or huts, 44 and 274

have a system of common law and organised tribunals of justice, 243

have great deceptive powers, 292

have little respect for truth, 292

lave no holy days or seasons, 232

have no knowledge of letters, 248

have no other theories than silly legends as to the origin of life or death, 230

headrests of wood, 282

ideas of death, 221

immorality of, 407

in addition to millet, cultivate gourds, sweet canc, and ground nuts, 269

in A.D. 100 those on the eastern coast are mixing their blood with that of strangers, 164 . 
BANTU (continued) :

in A.D. 880 the tribes are represented as at war with each other, 168

in times of great pressure resort to cannibalism, 194 and 271

know of no other method of computing time than the day and the lunar month, 247

language, 36, 44, and 298

law of inleritance as regards property, 276; as regards widows, 191 ; as regards succession to the chieftainship, 215

longevity of, 401

make extensive use of charms, 240

manufacture: of baskets, 291 ; of copper trinkets, 284 ; of earthenware, 289; of glue vases, 288 ; of grass baskets, 291; of iron implements, 283; of leather and fur robes, 288; of mats, 291; of wooden articles, 282 and 287

marriage arrangements, 256

meaning of the title Bantu, 202

mental capacity, 310

method among the Barotsi of preserving the corpscs of men of note, 191

method of formation of new tribes, 216

method of naming individuals, 249

migration into Africa south of the Zambesi and Kunene rivers of. The first of their family to arrive occupy the territory back of Sofala, 183

military discipline, 278

mode of disposal of the dead, 63

mode of formation of different tribes, 144

mode of interment of chiefs, 222

musical instruments, 309

obtain flesh by hunting, 270

ordinary life of the men, 291; of the women, 294

origin of the, 143

ornaments of the person, 280

particulars of the person, 418

personal appearance, 209

personal characteristics, 44

poetry, 309 ; specimens of, in folklore, 344, 358, 372, 382

position of the chiefs in the life of the people, 216

position of common people, 213

position of members of the ruling families, 212

pound regulations, 272

power of mind, 210

practise circumcision, 250 
BANTU (continued) :

practise revolting cruelty on animals for divination purposes, 241 principal line of early migrations, 144

probable original home of, 395

prolific nature of, 391

proportion of childless women, 406

proverbs, specimens of, 379

rate of increase of, 211

rejoice at the appearance of the new moon, 232

religion, 219

replies of officials and others to questions concerning, 400

restrictions among the coast tribes with regard to the women a man may marry, 259

revenue of the chiefs, 217

situation of kraals, 273

skull measurements, 44 et seq.

slaughter of wives and attendants on the death of powerful chiefs, 223

some of the tribes pay great regard to fire, 230

some of the tribes practise trial by ordeal, 247

some of those of the interior may have been slightly affected by the presence of civilised people in South Africa in ancient times, 420

some tribes have two sibokos, 227

some tribes make loin cloths of bark, 191

some tribes make rough stone walls, 191

some tribes weave loin cloths of wild cotton, 191

south of the Untamvuna river the tribes in advance encounter

Hottentots, whom they destroy, 197

standard of morality differs greatly from that of Europeans, 266

standard of virtue, 217

system of land tenure, 272

take forcible possession of Bushman territory, 42

the chiefs use human skulls as receptacles for charms, 242

the different tribes vary greatly from each other, 143

the interior tribes are slaveholders, 293

the rate of increase is now, in 1918, diminishing, 407

the tribes along the south-eastern coast are of common stock and have the same siboko, 228

the tribes are almost constantly at war with each other, 186

those of the interior are guided in most of their actions by the position in which dice fall, 242

traditions, unreliability of, 422

treatment of dying persons, 221 
BANTU (conlinued) :

use a horn for drawing blood, 240

use as food, in addition to garden produce, milk, flesh, wild plants, 269 ; and locusts, 271

use beer miade of millet and of honey, 267 .

use torture on persons charged with dealing in witchcraft, 245

use wild hemp or dacha for smoking, 267

vastly outnumber the whole of the other inhabitants of South Africa combined, 143

weapons, 44 and 278

women occupy a lower position than men in their society, 256

BAPEDI, BANTU TRIBE :

mention of, 205

BAROLONG, BANTU TRIBE :

mention of, 184 and 205

Barotsi or Baroswi, BaNTU CLANS:

mention of, 190; mode of preserving corpses of men of note, 191 ; further mention of, 205

BARROW, SIR JOHN :

reference to, 59 ; published work of, ib.

Barth, Henry, Ph.D., D.C.L. :

discovers engravings on rocks in Northern Africa, 17; reference to the work of, 18

BASKETS :

manufacture by the Bantu of, 291

BASUTO, BANTU TRIBE :

mention of, 205

BataUNG: see Leghoyas

BATAWANA, BANTU TRIBE:

mention of, 205

BathoEN, CHIEF OF THE BANGWAKETSE:

mention of, 293

Batlapin, Bantu tribe:

mention of, 205

Batlaro, Bantu tribe :

mention of, 205

BATONGA, BANTU TRIBES:

mention of, 193 and 385

Bavenda, Bantu tribes:

mention of, 187 and 205 
BeER :

is made of millet by the Bantu, 267

BELIEE IN WATER SPIRITS:

instances of the effects of this belief, 228

Bent, Mr. Theodore J. :

references to, 47 and 419

Berg Damaras or Hadkhoi: account of, 198 and 202

Betshuanaland :

change in the climate of, 185

BetshuaNa tRIBEs :

constant war among, 186; mode of living of, 186; weapons of, 185

BIRDS CARVED IN SOAPSTONE :

are found at Great Zimbabwe, 414

Blagden, Charles Otto, M.A. :

reference to a book written by, 11

BleEk, Dr. W. H. I. :

references to the researches of, $28,29,32,33,63,68,80,82,91,125$, 202, 299, 386, 395

BleEK, Miss Dorothy :

references to the work of, 65 and 77

BIIJdE VOORUITZIGT, BUSHMAN MISSION STATION:

account of, 30

BOHADI :

meaning of the term, 262

BONE TMPLEMENTS :

mention of, 6

Bostock, JонN, M.D. :

reference to the work of, 165

BOUCHERS, PRIMITIVE STONE IMPLEMENTS :

are found in abundance in South Africa, 2 and 20

Bodndary beacons at Gien Grey :

cause of some being thrown down, 237

Broca, M. PAUL :

reference to the skull measurements madc by, 45 et seq.

Bronze :

doubtful knowledge of the Bantu of, 284

BuDGe, E. A. WAI.lis, M.A., LiTT.D. :

references to the work of, 15 and 144 
BUd-M'Belle, Mr. I. :

reference to the work of, $30 \mathrm{I}$

Bulwer, Rev. Canon:

eridence of, 317

Bunburi, E. H. :

reference to the work of, $15 \mathrm{~S}$

Burchell, W. J. :

reference to the work of, 13

Burton, Sir Richard :

mention of, 173

\section{BushMeN :}

affinities with other peoples, 11

all those along the Keiskama are destroyed by the Xosa chief Rarabe, 65

animal happiness of, 68

are alluded to by Homer, 149

are described by the historian Herodotus, 16

are destroyed in great numbers by the Hottentots, 90

are entirely unaffected by the presence of civilised people in South

Africa in ancient times, 414 and 420

are expelled from Northern Africa by the Hamites, 19

are expert botanists, 52

are incapable of adopting European civilisation, 76

are inveterate smokers of dacha, 51

are now nearly extinct, 77 and 143

are often mentioned in the early Cape records, 29

are termed Wakwak by Arab writcrs, 182

average height of, 11

before 1505 are almost exterminated in Africa north of the Zambesi, 20

belief in sorcery, 26

cause of their being so called by Europeans, 47

cause of their losing their proper language, 41

cause of the colour of the skin of, 13

characteristics of, $11,16,26$, and 27

clothing, 54

customs of, 29

dance or caper for the amusement of an ancient king of Egypt, and

do the same for the amusement of South African farmers, 16

desperate resistance to the Hottentots and the Bantu made by, 47

differ in appearance from the Hottentots, 91

disposition of, 50 and 57 
BUSHMEN (continued) :

domestic animal, 43

domestic life of, 60

elasticity of the limbs of, 16

engravings on rocks by, 66

extent of occupation in 1505,422

extermination of, 185

family life of, 30

folklore, 72 et seq.

fondness of dancing, 60 and 61

food of, 49

fruitless efforts made by Europeans for their improvement, 76

games of, 61

government of, 43

great age of paintings and engravings in Rhodesia, 67

habitations of, 30,43 , and 49

have a wonderful sense of locality, 67

have many points of resemblance to the Semang, 11

have no marriage ceremonies, 60

have no regard for chastity, 60

have no word for a numeral higher than three, 39

in Bantu legends are not regarded as human beings, 231

language, 21, 24 et seq., 30,31, 32, 34, and 43

live in very small communities, 56

manufactures, 62

rethod of obtaining fire, 56

method of sleeping, 49

methods of catching fish, 12

methods of entrapping game, 12

mode of burying the dead, 63

musical instruments, 60

never resort to cannibalism, 58

ordinary life of, 61

ornaments, $\mathbf{5 6}$

paintings on rocks by, 64; description of one of the best, 9 ; particulars concerning, 105

particulars concerning, 418

peculiarity of the teeth of, 46

personal characteristics of, 42 and 58

personal pride of, 64

possess a rich stock of traditionary stories, 68

power of mimicry of, 64

probably early home of, 8

probable lines of migration of, 21 
BushMEN (continued) :

prolific nature of, 57

reasoning power of, 62

skull measurements of, 45 et seq.

superstitions of, 62 and 63

territory occupied by in 1505,48

territory once occupied by, 14

treatment of their girls by the Hottentots and the Bantu, 48

use honey as an intoxicant, 51

use of poison by, 50 and 51

use stone implements, 52

want of government, 58

wariness of, 55

weapons, 43 and 51

Zulu description of, 55

Cabires, Bantu horde:

mention of, 187 and 196

Callaway, Reve. Canon:

reference to the work of, 55

CAMPBell, Rev. John :

reference to, 59 ; published works of, ib.

CANNibalism :

is never practised by Bushmen, 58; or by Hottentots, 113 ; in times of great pressure is resorted to by Bantu, 194

VAN DE CAPELLE, JAN :

reference to, 285

CARRION :

is enjoyed as food by Hottentots, $\mathbf{1 1 3}$

CaRthaginian VOYage of DISCOVERY : account of, 152 and 153

Casati, Major Gaetano: reference to the work of, 14

de Castanheda, Fernão Lopez: eridence of, 193

Cattile:

loss of by the Bantu from rinderpest since 1896, 408

Cattle stealing by Bantu:

mention of, 291 
Cement :

use of in ancient buildings, 413

Census of the Cape Colony in 1904:

returns showing rate of increase of Bantu, 211; other particulars concerning, 278

Cerne, Carthagintan trading station :

mention of, 153

de Charencey, H. :

reference to the work of, 91

Charms :

use of by the Bantu, 338

Chastity :

is held in no regard by the Bushmen, 60; is very lightly esteemed by the Hottentots, 114; is not a virtue among the Bantu, 265

Chiefs, Bantu :

privileges of, 247

Chuldless Bantu womei :

proceedings with regard to, 262 ; proportion of, 406

CiCATRICES :

are used by the Bantu instead of tattooing, 280

Circumcision :

is practised by the Bantu, 250; particulars concerning, ib. ; among the interior tribes is accompanied by certain revolting practices, 250 ; as practised by the Ovaherero, 253; corresponding rites for females, ib.

Circumanigation of Africa by a Phenician fleet: improbability of, 151

Civilisation :

elementary factors of, 7

Climate of Betshudnatand :

change in, 185

Climate of South Africa, 7

Clothing :

of the Bushmen, 54; of the Hottentots, 99; of the Bantu. 2S0

Commerce Among the Bantu:

dues of the chiefs on, 218

COMMERCE :

in the fourth century before the Christian era is very extensive cls the Indian ocean, 154 
Commox LAW MMONG THE BANTU:

particulars concerning, $24 t$

Communal responsibiltit AMONG the Bantu:

particulars concerning, 244

Consumption :

until recent years was almost unknown in South Africa, 397; is now, in 1918, prevalent among the coast tribes of Bantu, 408

Contrast between a Damara ANd a Karanga, 209

Copper :

is known to the Hottentots, 85 ; is used by them to make ornaments of, 102 ; is similarly used by the Bantu, 281; in A.D. 1150 is mentioned as being in use by the Bantu of Sofala, 178

CORRY, JOSEPH :

reference to the work of, 393

de Courtallle, Pavet :

mention of the work of, 169

\section{Crucibles :}

mention of some found in Rhodesia, 412

\section{DACHA OR WILD HEMP:}

is used for smoking by the Bushmen, 51 ; by the Hottentots, 98 ; also by some of the Bantu, 267; by whom it is sometimes mixed with water for drinking, and dried and powdered as snuff, 268; is used to great excess by the Haukhoi, $19 \mathrm{~S}$

DaI,e, Sir Langham:

reference to, 23

Dalindyebo, Tenibu chief :

mention of, 250

DAXCING :

is a favourite amusement of the Bushmen, 60; and of the Hottentots, 111

DAUMAS, REv. F. :

reference to the work of, 32

Davis, Rev. William J.:

mention of, 299

Defréniery, C. :

mention of the work of, 179

Delagoa Bay :

origin of the name of, 173

Deniker, Dr. J. :

reference to the work of, 14 
Dice AS USED by Bantu OF THE INTERIOR:

particulars conccrning, 242

Digging sticks Weighted by a Perforated stone:

are used by the Bushmen, 52; and by the Hottentots, 102

Dingiswayo, ChiEf of the Umtetwa:

mention of, 196 and 207

\section{Disease :}

is an elementary factor of civilisation, 7

DisPosat OF THE DEAD :

by the Bushmen, 63 ; by the Hottentots, ib.: by many of the Bantu, ib.

Divination :

is practised by Bantu by perforning revolting cruelties on animals, 241

Divorce of BANTU WOMEN :

method of obtaining, 263

Dog of the Hottentot:

description of, 97

Döhne, Rev. J. L. :

mention of, 194 and 301

Doniestic animals :

of the Hottentots, 96 and 97 ; of the Bantu, 276

Dos SANtos : see dos Santos

Double bellows of tile Bantu:

notc on, 283

Dozy, R. :

work of, 176

DRILLED STONes :

particulars concerning, 52 and 54

DunN, E. J.:

references to, 23,60 , and 66

Dysastic titles of certain Bantu Chiles:

mention of, 249

Earlier inhabitants of Africa than the Bushmien: doubtful existence of, 20 and 21

EARTHENWARE POTS :

are manufactured by the Bushmen, 62; by the Hottentots, 102: and by the Bantu, 289 
EASTERn Africh:

commerce of in 100 A.D., 164

EbN Hadkal: see Abi l'Cassem

EDRISI : see Abou Abdallah

Elephants, African :

are captured and made to scrve in war, 157; mcthod of killing by the Bantu in the tenth century, 171

Емво :

Xosa name for Natal, 195

Engelenburg, Dr. F. :

information supplied by, 156

Engravings made in Sodth Africa on rocks by Bushmen:

mention of, 66; they are found also on rocks in Northern Africa, 17 and 18 ; similar engravings are found in Europe, 9

ETHIOPIANS OR BLACK PEOPLE:

are very dimly known to the Greeks, 149 ; are described by Herodotus, 150 ; and by Strabo, 159

EUROPEAN COLONISTS :

neglect to study the Bushmen, 28

EVIDENCE TN REGARD TO THE NENTAL POWER OF BANTU YOUTHS:

given by Mr. Newton Ogilvie Thompson, 313; by the Rev. William Charles Willoughby, 314; by James McLaren, M.A., 315; by Rev. James Henderson, 316; by Rev. Canon Cyril Edwin Earl Bulwer, 317; by Rev. David Duncan Stormont, M.A., B.D., L.C.P., LL.B., 318; by Rev. Richard Fraser Hornabrook, 318; by Dr. Neil Macvicar, M.D., D.P.H., 319; by Rev. William Allerton Goodwin, 319

Fakd, Pondo Chief: mention of, 293

FALConer, W., M.A. : reference to the translation of Strabo by, 157

Fetishism among the Bantu :

particulars concerning, 234

Fivgos: see Amamfengu

FIRE :

method of obtaining by the Bushmen, 56 ; is venerated by some of the Bantu tribes, 230

FisH :

method of eatching by impoverishcd Hottentots, 104; limited use of by the Bantu, 270 
Fisher, Mrs. Rбтн B.:

reference to the work of, 14

Flamand, G. B. :

discovers ancient engravings on rocks in Southern Algeria, 18

FuINT :

is not found in South Africa, 8

FLOWER, SIR WHIIAII:

reference to the skull measurements made by, 44 et seq.

Folklore Tales of the Bdshmen:

The Son of the Wind, 69

The Wind, 70

Story of Cagn, 71

The Mantis assumes the form of a Hartebeest, 72

Folklore Tales of the Hottentots:

The Animals and the Dam of Water, 125

The Lion that took a Woman's shape, 128

Story of the Hare, 131

The Lion and the Jackal, 134

The Ram, the Tiger, and the Jackal, 137

The Lion's Defeat, 138

The Dove and the Heron, 139

The Elephant and the Tortoise, 140

The Flying Lion, 141

FolkLore, BANTU :

possible origin of, 390

Folklore Tales of the Banto:

Story of Long Snake, 322

Story of Little Red Stomach, 323

Story of Five Heads, 324

Story of the Glutton, 367

Story of the Bird that made Milk, 328

Serolong version of the Story of the Bird that made Milk, 333

Story of Simbukumbukwana, 338

Story of Tangalimlibo, 369

Story of the Girl that disregarded the Custom of Ntonjane, 336

Story of Sikulume, 341

Story of the Cannibal's Wonderful Bird, 345

Story of the Cannibal Mother and her Children, 347

Story of Mbulukazi, 350

Story of Hlakanyana, 353

Story of Ironside and his Sister, 365

Story of the Runaway Children or the Wonderful Feather, 373 
Folklore Tales of the Baxto (continued):

Story of Kenkebe, 376

Another Story of Kenkebe, 379

Story of the Great Chief of the Animals, 380

Story of Demane and Demazane, 381

Story of the Girl and the Mbulu, 383

Reference to the Tonga version of the above story, 385

Story of the unreasonable Child to whom the Dog gave its Deserts, 386

FOOTPATHS :

eondition of in Bantu territory, 218

Foreau, F. :

discovers ancient engravings on rocks in the Sahara, 18

Frere, SiR Bartle:

reference to, 29

Fritsch, Dr. GUSTaF :

reference to the skull measurements made by, 44 et seq.

Frugaitity :

is almost unknown among the Bantu, 269

FUR Robes:

manufacture by the Bantu of, 288

Games :

of the Bushmen, 61; of the Hottentots, 122; of the Bantu, 294

GaRdens of the Banto :

deseription of, 272

Gei||Khadas, Hottentot tribe :

particulars eoneerning, 94

\section{GIRLS :}

among some Bantu tribes infant females who eut their upper teeth first are put to death, 191

GLaCIAL PERIOD IN EUROPE :

theories concerning, 24

\section{Glen Grey :}

Tembu settlement at, 237

\section{Gude vases :}

manufacture by the Bantu of, 288

DE GoEje, M. J. :

mention of the work of, 176

de Goes, Damiño :

reference to, 192 
GOLD EEADS :

are found in ancient ruins in Rhodesia, 412

GoLD :

beaten into thin square plates is found in ancient ruins in Puhodesia, 412; enormous exportation of in ancient times, 412; is collectcd by the Makaranga, 423 ; is mentioned in A.D. 943 as a product of Sofala, 170 ; also in 1150, 178; mining gold at some remote time was very extensively carried on in a part of South Africa, 410; method of mining, 411 ; ornaments of this metal are found in Great Zimbabwe, 414; are only found in the most ancient ruins, 417 ; preservation of them, 414 ; tacks of gold are found in ancient ruins, 412

Gooch, W. G. :

reference to, 23

Goodwin, Rev. William Alikrton:

evidence of, 319

GRASS BAGS :

are manufactured by the Bantu, 291

Graves of Banto CHIEFs :

particulars concerning, 222

Graves of HeItsI-EIBIB :

particulars concerning, 111 ; are found in the country occupied by the

Tembu and Xosa tribes, 225

Great Zimbabwe :

description of, 413 ; further particulars concerning, 416

GreEK TRAFFIC WITH INDIA :

account of, 159; the Greeks of Alexandria drive the Arabs from the

Indian ocean and almost monopolise the eastern trade. 161

GREeting :

forms of among the Bantu, 297

Grodt, Rev. Lewis :

mention of, 299

GWanyà, Pondonsi CHIEF :

mention of, 219

HAHN, Dr. THEophiLds :

references to the work of, 91,94, 106, 109, and 120

HaHN, Rev. C. Hugo:

reference to, 200 
HiLt, Mr. RichaRd N.:

references to the work of, $65,66,67,170,183,188,190,414,417,418$, 419

Hamiton, G. C. :

reference to the translation of Strabo by, 157

\section{HaNNo :}

exploration of the western coast of Africa by, I52 and 1503

Hargreaves, Rev. MIr. :

mention of, 250

HARRISON, JAMES J. :

reference to the work of, 14

Hassan et Odazzan ebN Mohamed : mention of the work of, 180

HaUkhoi or Berg Damaras : account of, 198

Headrests :

of the Bantu, 282

Heitsi-eIBIB, HotTentot divinity :

particulars concerning, 107 et seq.; tales concerning, 108 et seg.

HeNdERSON, Rev. JAMES :

evidence of, 316

HENDRIK Witbooi, HotTEnTot LEADER:

mention of, 124

Herbalists, Bantu :

particulars concerning, 238

HERERO WOMEN :

attire of, 280

Herodotus, Greek historlan :

gives a description of the Bushmen, 16; reference to the work

of, ib.; further reference to, 84; gives an account of the Ethiopians, 150

HILliter, Dr. AlFred :

reference to researches of, 49

Hippalus, a Greek pILOT:

becomes acquainted with the monsoons in the Indian ocean, 161

HIRAM, KING OF TYRE :

assists Solomon in trading on the Indian ocean, 146

HLONIPA CUSTOM :

mention of, 204, 301 
HöbgobliNs :

belief of the Bantu in, 228

\section{HOMER :}

possesses very little knowledge of Africa, 148

\section{HONEY :}

is converted into an intoxicating drink by the Bushmen, 51: by the Hottentots, 98 ; and by the Bantu, 267

HORN FOR DRAWING BLOOD :

use of by Bantu, 240

Hornabrook, Rev. Richard Fraser:

evidence of, 318

\section{HOTTENTOTS :}

a few small clans live as beachrangers, 104

amusements of, 122

and those in the north with the Ovaherero, 200

are acquainted with the use of copper and iron, 85

are colonists in South Africa, 80

are constantly at war with the Bushmen, 87 and 90

are entirely unaffected by the presence of civilised people in South

Africa in ancient times, 420

are not so prolific as Bushmen, 120

capability of adopting European civilisation, 123

clothing, 99

comparative happiness of, 123

convert honey into an intoxicating drink, 98

courts of judicature, 96

credulity of, 117

custom corresponding to circumcision, 121

depend almost entirely upon milk for food, 89

description of their dwellings, 100

differ in appearance from Bushmen, 91

disposition of, 111

domestic animals, 44 and 96

domestic life of, 113

do not practise agriculture, 98

dread of ghosts, 107

during the eighteenth and nineteenth centuries mix their blood very

largely with that of other races, 94

esteem chastity very lightly, 114

exterminate the occupants of the shell mounds along the coast, SS filthy habits of, 97 and 112

folklore tales, 125 et seq. 
Hotrentots (continued) :

foudness of dancing by moonlight, 111

for'm of government, 95

game of, 122

good qualities of, 113

habitations of, 44

have great skill in training cattle, 96

incorporate numbers of Bushman girls, 87 and 88

labour performed by women, 112

language, $35,36,43,80,82,91,92$, and 93

make use of iron, horn, bone, and stone for manufacturing weapons, 102 manufacture earthenware pots, 102

marriage customs, 114

method of preparing food, 98

method of sleeping, 100

mixture of blood, 124

mode of burying the dead, 63

mode of formation of the titles of tribes, 95

musical instruments, 111

never resort to cannibalism, 113

on the south-eastern coast they are incorporated in Bantu tribes, 197

ordinary life of, 99

personal characteristics, 43

position of women, 114, 118, and 120

possess horned cattle and sheep, 96

power of imagination, 122

probably originated in Somaliland, 83 ; migrated thence to the region of the great lakes, 85 ; are driven from that locality by Bantu tribes coming down from the north, ib.; reasons in support of this view, 84; migrate then to South Africa, 86 and 87 ; on the route leave sections behind, which become independent communities, 87

pure Hottentots are now nearly extinct, 124

religion, 110

restrictions of diet to the different sexes, 99

skull measurements, 45 et seq.

south of the Umtamvuna river are destroyed or incorporated by

Bantu, 197

take forcible possession of Bushman territory, 42

term themselves Khoikhoi, 90

their principal food is milk, 97 ; other food of, 98

the separate communities are of necessity small, 89

the tribes are almost constantly at war with each other, 95 
Hottentots (conlinued) :

traditions of, 83

use copper for making ornaments for their persons, 102

use dacha or wild hemp for smoking, 98

use digging sticks weighted with pcrforated stones, 102

weapons of, 44 and 101

\section{HOTTENTOT DANCE :}

description of, 112

Hodghton, K. A. Hobart, M.A.:

reference to, 243

\section{HUNGER :}

is an elementary factor of civilisation, 7

HUNGER BELTS :

reference to, 54

HUNTING :

mode of conducting by the Bantu, 270

Hots :

description of those of the Hottentots, 100; of those of the Bantu, 274

IbN BatdTa: see Abou Adballah

ICE :

South Africa has not been covcred with since man first made his appearance here, 1

ICE AGE IN EUROPE:

mention of, 1

IKAZI :

meaning of the term, 262

Imigigants into AFrica:

succession of, 19

INCREASE OF THE BANTU IN NUMBER:

particulars concerning, 399

INDIANS :

are acquainted with Eastern Africa in ancient times, 145; are largely employed by the Arabs in the East African trade, 167

INGOT MOULD :

mention of one found, 412

Inhabitants of East Africa in 1505:

classes of, 425 


\section{IXHERITANCE :}

Bantu law of, 276

INYANGA RANGE :

vast amount of work along the, 417

IRON :

the use of is known by the early Hottentots, 85 ; is smelted by them to a limited extent after their arrival in South Africa, 102; use of by the Bantu, 283 ; in A.D. 943 is used by the Bantu for making ornaments, 172 ; in A.D. 1150 is mentioned as being exported from Sofala, 177

IRRIGATION WORKS ALONG THE INYANGA RANGE:

mention of, 417

IVORY :

is a product of Eastern Africa, 145; is an article of commerce in remote times, 410 ; in A.D. 943 is mentioned as an article of export from East Africa, 172; armlets of ivory are worn by the. Hottentots, 100 ; and by the Bantu, 271, 280

JAGER AFRIKaNer, HotTENTOT CHIEF : mention of, 200

JAN JoNker Afrikaner, Hottentot leader : mention of, 124

JaUbert, Professor P. AMÉDÉE : work of, 176

JoHrson, J. P. : reference to the work of, 23

JohNSTON, Sir HARry H.: reference to, 397

Jonker Afrikaner, Hottentot chief : mention of, 200

JUNKER, Dr. WILHELM : reference to the work of, 14

Junot, Rev. Henri A. : reference to, 385

\section{KAFFTRS :}

origin of the name, 177

\section{KAPELA :}

dynastic title of chiefs of a certain Bantu tribe, 249 
KATIA, THE :

particulars concerning, 77 et seq.

KeIтH, ARThUR, M.D., LL.D. :

reference to the work of, 9

Khama, chief of the Bamangwato:

mention of, 293

KHAMI RUINS :

mention of, 420

Кногкног :

mixture of Bushman blood with, 106

KiCherer, Rev. J. J. :

gives an account of the Bushmen among whom he lived, 29 and 30 ; references to, 59 and 125

KNOBKERIE :

description of, 102

KraAls of Bante:

favourite position of, 273

KRöNLEIN, Rev. G. : references to, 108 and 109

LANDER BROTHERS, EXPLORERS :

mention of, 17

LAND TENURE :

Bantu system of, 272

LANGUAGE :

of the Bushmen, 30,31,32, 34, and 43 ; of the Hottentots, 35, 44, $80,82,91,92$, and 93 ; of the Bantu, 36, 298

LawsUits among the Bantu:

mode of procedure in ordinary cases, 244 ; in charges of dealing in witcheraft, ib.

LEATHER :

manufacture by the Bantu of, 289

Lee, Rev. Samder : reference to the work of, 179

LEghoyas or BataUng:

account of the, 183 and 184 ; cross the Vaal, and settle along the upper course of the Vet river, 183

Leo Africanus: see Hassan 
LES PrAIRIES D'OR:

extracts from, 169 et seq.

\section{LETTERS :}

are unknown to the Bantu, 248

LEWANiKa, Barotsi CHIEF :

mention of, 190

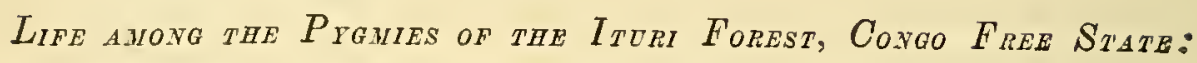
reference to, 14

Livingstone, Rev. Dr. David : reference to, 173

Lloyd, Dr. L. C. : references to the researches of, $29,23,34,60,66$, and 68

LOCH, LORD : mention of, 184

\section{Locusts :}

are used as food by the Bantu, 271

\section{LOIN CLOTHS :}

are made of bark by some tribes of Bantu, 191; and also woven of wild cotton by some, ib.

LOVETt, RichaRD :

reference to the work of, 30

MacIver, Dr. D. Randati :

references to, 319,419

Mackay, George R. :

reference to a paper on the antiquity of man in South Africa written by, 5

McLaren, Mr. James :

evidence of, 315

Macvicar, Dr. NeIL :

evidence of, 319

MIADJAJT, BakWEBo CHIEFTAINESS: mention of, 189

MAGADU, BaVENDA CHIEF : mention of, 188

Magwamba, Bantu tribe : mention of, 205

MAKANA, XOSA SEER : particulars concerning, 305 
Makaranga, the oldest Bantu tribe in Sodth Africa:

is broken up by war, 189 ; mention of, 205; personal appearance of the men, 191 ; marriage custom of, 261

Malume :

meaning of the term, 265

Ma Matiwane :

torture of, 246

MAN :

definition of the word, 2

MANISA :

dynastic title of chjefs of a certain Bantu tribe, 249

MANTATI HORDE :

mention of, 195

MANtis, The :

superstition concerning, 107

MANUFACTURES :

of the Bushmen, 62 ; of the Hottentots, 102 ; of the Bantu, 282

Marriage among Bantu :

particulars conccrning, 256; customs of the Makaranga, 261; customs of the Ovaherero, ib.

Marriage festivities among Banto:

description of, 257

Marriage LaW OF the Bantu :

complications arising from the, 263

Marriage Restrictions aMoNG THe coAst tribes of Bantu: particulars concerning, 259

Martin Affonso, a Portuguese:

is conversant with several dialects of the tribes of Lower Guinea, 192 ; in 1498 is able to converse with Bantu at the mouth of the Limpopo river, ib.

MasarWa :

are of mixed Bantu and Bushman blood, 22; particulars concerning, $42,48,83$, and 183

Mashona, THE :

account of, 190

Masoudi : see Abou'l Haçan

Matabele, the :

mention of, 205

MATERNAL UNCLE :

position of in a Bantu family, 264 
Mats :

manufacture by the Bantu of, 291

Matshangana, THE :

mention of, 205

Matthews, Liedtenant John :

reference to the work of, 393

de Maynard, C. Barbier:

work of, 169

MENTAL CAPACITY :

of the Bantu, 310; evidence upon, 311

Method of SLEePING :

of Bushmen, 100; of Hottentots, ib.

Migration OF PRIMitive MAN :

probable lines of, 18

MILK :

is the principal food of the Hottentots, 97

Millet :

in A.D. 880 is mentioned as the principal food of the Bantu, 168; is still the grain principally used, 267 ; mode of preservation of, 268

MisSIONARY TEACHING :

effect of, 266

Moffat, Rev. Dr. Robert :

reference to, 285 ; extract from the work of, 285

Mohamedans iN South Africa in 1505 :

account of, 423 ; description of, 423 ; extent of the occupation of, 423 ; plants introduced by, 424 ; superstitions of, 424

Molitsane, Chief of the Batadng:

mention of, 184

Molopo RIVER :

was formerly a much larger stream than it is at present, 182

Montsiwa, Barolong CHIEF :

mention of, 250

Monsoons :

offer great advantages for commerce, 145

MIOON, THE :

Hottentot opinion concerning: 107

Moroiso, Barolong ChiEf :

mention of, 184 
Morolong, FoUNdER OF THE BAROLONG TRIBE :

mention of, 248

Moselekatse, Matabele chief :

mention of, 190 and 195

Moshesh, Fodnder of the BasUto tribe:

mention of, $266^{\circ}$

Motlomi, ESTEEMED AS THE WISEST CHIEF OF HIS DAY : mention of, 266

Mrofu, Bavenda CHIEF :

mention of, 188

MuIr, Sir Thomas, LL.D., M.A., F.R.S.: evidence of, 311

MUKURU :

meaning ascribed by the Bantu to the word, 221

Musical instrumen'ts :

of the Bushmen, 60 ; of the Hottentots, 111 ; of the Bantu, 309

Naming individuats :

Bantu method of, 249

NATAL CODE OF LAWS FOR THE BANTU :

particulars concerning, 262

NEAL, Mr. W. G. :

reference to, 419

Nearchus, VoYage OF :

mention of, 155

New Moon :

causing rejoicing among the Bantu, 232

NGonyama, GaIKA CHIEF :

mention of, 250

NIGER, THE :

mention of, 17

North, Sir Thomas :

reference to the work of, 156

Noto, Barolong CHIEF :

mention of, 248

NTONJANG CEREMONIES :

particulars concerning, 254

NYAKA :

dynastic title of chiefs of a certain Bantu tribe, 249 
OAsib, Hottentot Chief:

mention of, 200

OFFICIAI, PRAISERS OF BANTU CHIEFS :

particulars concerning, 249

On the Borders of Pigut Lavi:

reference to, 14

VAN OORDT, Mr. J. F. :

reference to, 396

OPHIR :

mention of, 410

ORNAMENTS :

of the Bushmen, 56 ; of the Hotientots, 100 ; of the Bantu, 280

Orpen, Joseph M. :

reference to, 71

Ouseley, Sir Whliam :

reference to the work of, 176

Ovaherero, Bantu tribe :

account of, 200 ; circumcision practices of, 250 ; funeral customs of, 222 ; marriage customs of, 261; neither they nor their offshoots practise agriculture, 201 ; pay regard to sacred fire, 230

Ovambanderu, Bantu tribe :

account, of, 201

Ovambo or Avare, group of Bantu tribes :

mention of, 201

OvATYIMBA, THE :

account of, 201

$\mathrm{Ox}$, THE :

in A.D. 943 is mentioned as the only beast of burden of the Bantu,

171 and 174 ; description of the ox of the Hottentots, 96

\section{PAFURi :}

dynastic titlc of the chiefs of a certain Bantu tribe, 188

Pagan Races of the Malat Peningula:

reference to, 11

Paintings made on rocks by Bushmen:

account of, 64; similar paintings have been found in France and Spain, 9

Paleolithic Prgaies of Europe:

weapons and arts of, 9 . 


\section{PeAcocks :}

mention of, 410

Perforated stone weights : particulars concerning, 104

Peringuey, Dr. Louis, Director of the South African museum: references to, $5,8,18$, and 63

PENCK AND BRUCKNER:

reference to the work of, 24

PERIPLUS OF THE ERYTHREAN SEA :

information obtained from the, 163

Persians and Arabs :

from the time of Mohamed to that of Vasco da Gama are the only traders on the Indian ocean, 167

Phallic emblems among the Bantu :

particulars concerning, 235

Phalit, stone :

are found in abundance at Great Zimbabwe, 413

Pharaoh, KIng of Egypt :

is amused by the antics of a Bushman, 16

PHENICIANS :

carry on an extensive commerce, 146; leave no record of their geographical knowledge, ib.; further mention of, 151 and 152

Physical condition of South Africa, 7

Pliny the ELDER:

gives no information of value upon Africa, 165

Plutarch's LiFE of Alexander:

reference to, 156

Poetry of the Bantu :

particulars concerning, 309 ; specimens of, 329, 336, 344, 358, 371, 382

PoIson :

use made of by the Bushmen, 50 and 51 ; and by the Hottentots, 101

POLISHED STONE IMPLEMENTS:

very few are found in South Africa, 102

PolyandRods MARRIAGES :

mention of, 266

Polygany among the Bantu :

advantage of to them, 278 
Pondo tRIBE:

account of, 194

Portuguese Explorers of the FIFTEenth CEntury :

are the first to make known the correct form and size of Africa, 154

\section{Pontuguese :}

extent of the trade of in South-Eastern Africa, 196; information supplied by, 196 ; further reference to, 423

\section{POTTERY :}

manufacture of, 24

Podnd Regulations of the Bante:

description of, 272

Priests, Bantu :

duties of, 232

Primitive man :

destruction of, 19

Proportion of the Sexes among the Bantu, 278

\section{Proverbs :}

of the Bantu, 379; specimens of those of the Xosa tribe, 302

\section{Ptolemy Philadelphes :}

founds the station of Myos-Hormus on the shore of the Red sea, and sends elephant hunters far into the interior, 157

Ptolemy, the Geographer :

information upon Africa supplied by, 165; incorrect form of the continent given by him, 167

Prgmies in ancient Europe:

weapons and arts of, 9

Pygnites of Central Africa:

height of, 11 ; further mention of, 14

QAMATA:

belief by the Xosas and Tembus in a powerful being so called, 224; the belief is derived from Hottentot sources, ib.; the form of worship is the same as that of Heitsi-eibib, 226

DE QUATREFages, A. : reference to the work of, 18

QUERN FOR GRINDING CORN :

description of, 291 
Ruingakers among the Bantu :

particulars concerning, 237

Ruamapulana, Bavenda Chief:

mention of, 188

RARABE, XOSA CIITEF :

destroys all the Bushmen along the Keiskama, 85; further mention of, 198

RATH, Rev. J.:

reference to, 386

RawLinson, CANON G., M.A.:

reference to the work of, 16

Reasoning power :

of Bushmen, 62

REINAUD, M. :

references to the work of, 168 and 179

ReLigion :

of the Bantu, 219; is a very powerful factor in their government, 233 ; differences of belief among the tribes, 234

RHAPTA :

in A.D. 100 is the last commercial station to the southward of the Arabs on the eastern coast of Africa, 163

Rhodes, Right Hon. Cecil J. : mention of, 237,419

RILEY, H. T. :

reference to the work of, 165

Rock paintings by Bushmen : particulars concerning, 105

Rolleston, Dr. George :

reference to the skull measurements made by, 45 et seq.

Ruins of Stone BURdings in Rhodesia:

mention of, 412 ; present condition of, 417

SABI RIVER :

is the entrance to the ancient gold mining areas of South Africa, 412

SACRIFICES OF CATTLE BY THE BANTU to SPIRITS:

account of, 219

SAKAVUNZA, BAROTSI CHIEF :

mention of, 190 
SALT :

use of by Hottentots, 98

SANA :

meaning of the term, 106

Sanderson, Mr. John :

reference to, 23

Sanguinette, Dr. B. P. :

reference to the work of, 179

DOS SANTOS, JoÃo, DOMINICAN FRIAR:

references to the work of, 186, 211, 227, 231, 242, 272, 289

SCHEFER, C. :

reference to the work of, 180

SchmeleN, Rev. H. :

mention of, 200

SchweInfurth, Dr. Georg :

reference to the work of, 14

Sebele, Bakwena chief :

mention of, 293

Sebetoane, Makololo CHtEF :

mention of, 190

Semang of the Malay peninsuli:

have many points of resemblance to the Bushmen, 11

Sheep of the Hottentots:

description of, 97

Shell heap at Mossel Bay:

mention of, 2

Shell modnd at East London:

description of, 3

Shell modnds along the coAst :

the people occupying them are exterminated by Hottentot invaders, 88

SHELL MOUNDS, MODERN :

particulars concerning, 104

Shell Mounds in Europe:

mention of, 4

SHERBoro ISLAND :

is the termination of Hanno's voyage down the West African coast, 153

Shrdbsalt, F. C. :

reference to the work of, 46 
Sigcawt, Pondo chief :

mention of, 246

Sigcawo, Xosa ChIEF :

mention of, 250

SKEAT, WALter WTLLIAM, M.A. :

reference to a book written by, 11

SKINS OF CARNIVORA :

are used as clothing by the Bushmen, 54; by the Hottentots, 99 ; and by the Bantu, 279: in A.D. 880 are mentioned as being exported from East Africa, 168; also in A.D. 943, 176; and in A.D. 1150,177

SKULL, HUMAN :

is used by Bantu chiefs as a receptacle for charms, 242

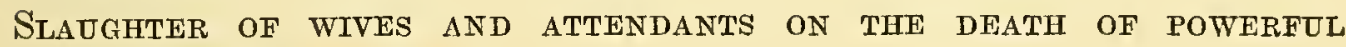
BANTU CHIEFS, 223

Slavery of Bantu :

particulars concerning, 391 ; is common among the interior tribes of Bantu, 293

Slave TRADE :

in A.D. 1150 is carried on by the Arabs on the East African coast, 178

\section{SMALL-POX :}

destructive effects of upon uncivilised people, 397

SMTtH, ANDREw, M.A. :

reference to the work of, 238

SOFALA :

in A.D. 943 is represented as occupied by Bantu, 170; and as being the terminus of navigation from the north, ib.; extent of the territory of, 182; in 1505 it is wrested from the Arabs by the Portuguese, 196 ; account of, 423 ; further mention of, 410

Soga, Rev. DR. W. A. :

mention of, 238

Sollas, Professor W. J. :

references to, $2,8,10$, and 18

SOLOMON, RULER OF ISRAEL :

fits out fleets to traverse the Indian ocean, 146

SomaLIIAND :

is probably the birthplace of the Hottentots, 84 
Somerset, Lord Chirles :

mention of, 305

SOTSHANGANA, BANTU CHIEF :

mention of, 195

\section{SOdTH Africa :}

climate of, 7 ; physical features of, ib.

\section{South African nuseun:}

valuable contents of, the, 10

\section{SPIRITS OF THE DEAD :}

are believed by the Bantu to appear in the form of animals, 226; effects of this belief, ib.; it has become lost among many of the tribes of the interior, 227

Sprivger, Mrs. J. M. :

information supplied by, 175

\section{STANLEy, Sir HENRY :}

reference to the work of, 14

STONE :

use of by the Bantu, 291

\section{Stone BUILdings in Rhodesia :}

mention of ruins of, 412 and 414 ; style of architecture of, ib.

\section{STONE IMPLEMENTS :}

are found in situations in South Africa proving their great age, 4; the most ancient are all chipped, but not ground or polished, 6; the latest invented-the perforated spherical weight-required much labour to drill, ib.; collection of by Mr. Dunn, 23; further particulars concerning, 52

STONE PHALLI:

are found in abundance at Great Zimbabwe, 416

Stormont, Rev. David Duncan :

evidence of, 318

Stow, G. W. :

references to the work of, 5,53,57,58,59,66,83, 101, and 232

STRABo :

gives a description of Africa and its people, 157

STRANDLOOPERS :

confusion caused by the use of the word, 4

SUperstitions :

of the Bushmen, 62 and 63 ; of the Hottentots, 107 ; of the Bantu, 228 
TABErer, W. S. :

reference to, 190

TAO, ChteF of the Barolong:

mention of, 184

\section{TAUNG :}

meaning of the word, 184

TEMBU TRIBE :

account of, 194

Terraces along the Inyanga range:

mention of, 417

THEBes, CITy OF :

owes its grandeur to the Indian trade, 145

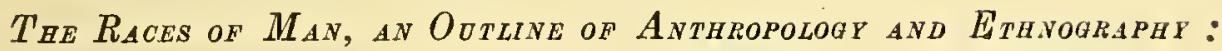
reference to, 14

Thompson, Mr. Newton Ogituie:

evidence of, 313

Trmber :

is a product of Eastern Africa, 146

TrMe :

method of computing by the Bantu, 247

TIN :

reference to the use of by Bantu, 285

Tindall, Rev. Henry :

reference to the work of, 91

ToBacco :

use of by the Bantu, 268

Tongue, Mrss Helen :

reference to the work of, 65

TORTURE OF PERSONS ChaRgED WITH DEALING IN WITCHCRAFT By THE

BaNTU :

particulars concerning, 245

TOYS OF BANTU CHILDREN :

mention of, 295

Tozer, H. F., M.A. :

reference to the work of, 158

Traditions, Bantu :

are exceedingly unreliable, 192 ; particulars concerning, 248

TreEs :

destruction of by the Bantu, 273 
TRIAL BY ORDEAL :

is practised by some Bantu tribes, 246

Tribal priests amona the Bantu:

duties of, 219

Tribal titles of Bantu tribes:

in the interior are derived from their siboko, 228 ; along the southeastern coast are derived from the names of the founders of the independent communities, 228

Tribunals of Justice, Bantu :

particulars concerning, 243

Truth :

is little respected by the Bantu, 292

Tshaka, Zulu ChiEF :

mention of, 207, 271, and 398

TShawe, Xosa CHIEF :

mention of, 248

Tshivasa :

dynastic title of the chiefs of a certain Bantu tribe, 188

TSUI||GOAB, HotTENTOT Divinity :

particulars concerning, 107 et seq.

TWIN CHILDREN :

among some Bantu tribes are put to death, 191

TYRE :

importance of the city of, 146; enormous trade of, 148; destruction of the city, ib.; further mention of, 410

Umitonhlo, Pondomsi chief :

mention of, 219 and 246

UMTETWA, FOUNDER OF A BANTU TRIBE:

mention of, 248

UMTETWA, BANTU TRIBE :

account of, 197

Umyanbosi, UMteTwa CHIEF :

mention of, 248

UNKULUNKULU :

meaning ascribed by the Bantu to the word, 221

UNI.UCKY DAYS :

are believed in by Bantu, 232 
Vincent, WIIIAM, D.D. :

- reference to the work of, 163

WAKWAK OR BUSHHEN :

are mentioned in A.D. 943 as bordering on Sofala, 170; and again in 1150,178

WATER SPIRITS :

belief of the Bantu in, 228

WATERSTON, Dr. :

mention of, 47

WAUdRes, Rev. Mr. :

information given by, 94

WAR :

is an elementary factor of civilisation, 7 and 8

WEAPONS :

of the Bushmen, 43 and 51 ; of the Hottentots, 101 ; of the Bantu, 278

IVETRS :

are made by impoverished Hottentots for catching fish, 104

WIDOWS :

disposal of by the Bantu, 211

WILD HEMP : see Dacha

WIID PLANTS :

are largely used as food by the Bantu, 269

Willem UtThaAlder, Hottentot leader:

mention of, 124

William Koyi, Christian evangeisist :

mention of, 358

Willodghby, Rev. William Charles:

evidence of, 314

WhMan, Miss :

information supplied by, 53

Von Wissmann, HERMANN :

reference to the work of, 14

WITCHCRAET :

is firmly believed in by the Bantu, 234; instances of belief in, 242; connection with slavery of the belief in, 392

WitchFinders, Banto :

particulars concerning, 234 
WOMEN :

among the Bantu occupy a lower position than men, 256; ordinary life of, $: 94$

WOOD :

manufactures by the Bantu of, 282 and 287

XOSA, FOdNDER OF the AMASOSA TRIBE: mention of, 248

XOSA TRIBE :

account of the, 194

XOSA PROVERBS :

specimens of, 302 



$$
u
$$







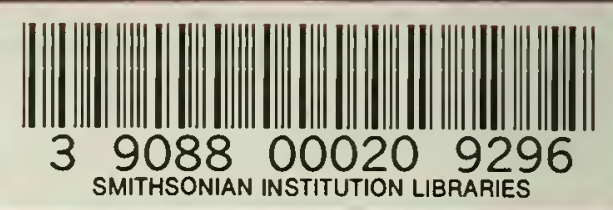

